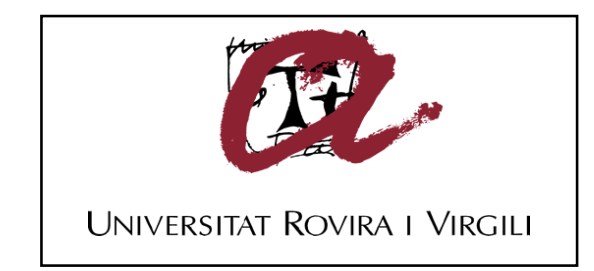

\title{
DIRECCIÓN ESCOLAR Y LIDERAZGO: ANÁLISIS DEL DESEMPEÑO DE LA FIGURA DIRECTIVA EN CENTROS DE EDUCACIÓN PRIMARIA DE TARRAGONA
}

\author{
Marta Camarero Figuerola
}

\begin{abstract}
ADVERTIMENT. L'accés als continguts d'aquesta tesi doctoral i la seva utilització ha de respectar els drets de la persona autora. Pot ser utilitzada per a consulta o estudi personal, així com en activitats o materials d'investigació i docència en els termes establerts a l'art. 32 del Text Refós de la Llei de Propietat Intel.lectual (RDL 1/1996). Per altres utilitzacions es requereix l'autorització prèvia i expressa de la persona autora. En qualsevol cas, en la utilització dels seus continguts caldrà indicar de forma clara el nom i cognoms de la persona autora i el títol de la tesi doctoral. No s'autoritza la seva reproducció o altres formes d'explotació efectuades amb finalitats de lucre ni la seva comunicació pública des d'un lloc aliè al servei TDX. Tampoc s'autoritza la presentació del seu contingut en una finestra o marc aliè a TDX (framing). Aquesta reserva de drets afecta tant als continguts de la tesi com als seus resums i índexs.
\end{abstract}

ADVERTENCIA. El acceso a los contenidos de esta tesis doctoral y su utilización debe respetar los derechos de la persona autora. Puede ser utilizada para consulta o estudio personal, así como en actividades o materiales de investigación y docencia en los términos establecidos en el art. 32 del Texto Refundido de la Ley de Propiedad Intelectual (RDL 1/1996). Para otros usos se requiere la autorización previa y expresa de la persona autora. En cualquier caso, en la utilización de sus contenidos se deberá indicar de forma clara el nombre y apellidos de la persona autora y el título de la tesis doctoral. No se autoriza su reproducción u otras formas de explotación efectuadas con fines lucrativos ni su comunicación pública desde un sitio ajeno al servicio TDR. Tampoco se autoriza la presentación de su contenido en una ventana o marco ajeno a TDR (framing). Esta reserva de derechos afecta tanto al contenido de la tesis como a sus resúmenes e índices.

WARNING. Access to the contents of this doctoral thesis and its use must respect the rights of the author. It can be used for reference or private study, as well as research and learning activities or materials in the terms established by the 32nd article of the Spanish Consolidated Copyright Act (RDL 1/1996). Express and previous authorization of the author is required for any other uses. In any case, when using its content, full name of the author and title of the thesis must be clearly indicated. Reproduction or other forms of for profit use or public communication from outside TDX service is not allowed. Presentation of its content in a window or frame external to TDX (framing) is not authorized either. These rights affect both the content of the thesis and its abstracts and indexes. 


\title{
MARTA CAMARERO FIGUEROLA
}

\section{DIRECCIÓN ESCOLAR y LIDERAZGO: Análisis del desempeño de la figura directiva en centros de Educación Primaria de Tarragona TESIS DOCTORAL}

\author{
Dirigida por: \\ Dra. CHARO BARRIOS ARÓS \\ Dra. PILAR IRANZO GARCÍA \\ Dra. JUANA Ma TIERNO GARCÍA \\ Departamento de Pedagogía
}

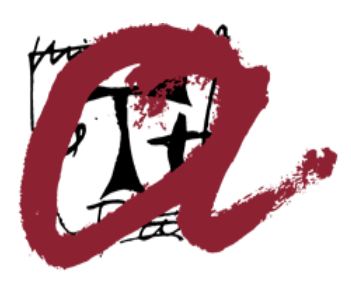

UNIVERSITAT ROVIRA I VIRGILI

Tarragona

2015 
DIRECCIÓN ESCOLAR Y LIDERAZGO

\section{PRIMARIA DE TARRAGONA}

ANÁLISIS DEL DESEMPEÑO DE LA FIGURA DIRECTIVA EN CENTROS DE EDUCACIÓN Marta Camarero Figuerola 


\section{UNIVERSITAT}

ROVIRA I VIRGILI

Departament de Pidagogia

Carretera de Valls, s/n

43007 Tarragona

Tel. 977558077
Fax 977558078

e-mail: sdpedaeurv.cat

https//pedagogia.foep.urv.cat

Charo Barrios Arós, Pilar Iranzo García y Juana $\mathrm{M}^{\mathrm{a}}$ Tierno García, profesoras del Departamento de Pedagogía de la Universitat Rovira i Virgili,

\section{HACEMOS CONSTAR:}

Que este trabajo, titulado "DIRECCIÓN ESCOLAR Y LIDERAZGO: ANÁLISIS DEL DESEMPEÑO DE LA FIGURA DIRECTIVA EN CENTROS DE EDUCACIÓN PRIMARIA DE TARRAGONA", que presenta MARTA CAMARERO FIGUEROLA para la obtención del título de Doctor, ha estado realizado bajo nuestra dirección en el Departamento de Pedagogía de esta universidad y que cumple los requisitos para poder optar a este título.

Tarragona, 9 de noviembre de 2014

Las directoras de la tesis doctoral

Dra. Charo Barrios Arós

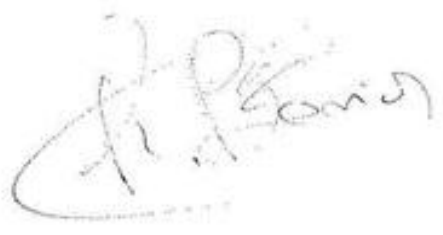

Dra. Pilar Iranzo García

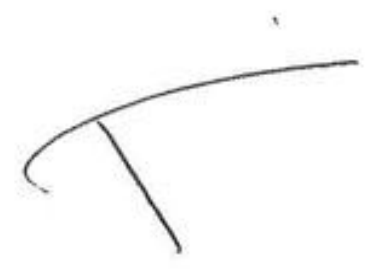

Dra. Juana $M^{\mathrm{a}}$ Tierno García

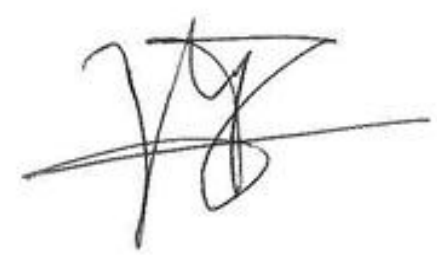


DIRECCIÓN ESCOLAR Y LIDERAZGO

\section{PRIMARIA DE TARRAGONA}

ANÁLISIS DEL DESEMPEÑO DE LA FIGURA DIRECTIVA EN CENTROS DE EDUCACIÓN Marta Camarero Figuerola 
UNIVERSITAT ROVIRA I VIRGILI

DIRECCIÓN ESCOLAR Y LIDERAZGO: ANÁLISIS DEL DESEMPEÑO DE LA FIGURA DIRECTIVA EN CENTROS DE EDUCACIÓN PRIMARIA DE TARRAGONA

Marta Camarero Figuerola

A mis padres,

por su apoyo incondicional

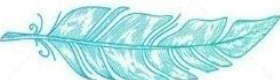
. 
DIRECCIÓN ESCOLAR Y LIDERAZGO

\section{PRIMARIA DE TARRAGONA}

ANÁLISIS DEL DESEMPEÑO DE LA FIGURA DIRECTIVA EN CENTROS DE EDUCACIÓN Marta Camarero Figuerola 


\section{AGRADECIMIENTOS}

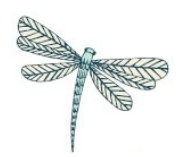

Me siento afortunada por todo lo vivido y aprendido durante estos dos años en los que he realizado mi tesis doctoral. He disfrutado al máximo de la experiencia y del aprendizaje. He estado acompañada de grandes profesionales y mejores personas. Por todo esto, quiero dar las gracias a todas y cada una de las personas que, de una manera u otra, han estado a mi lado en esta bonita y dura etapa.

A mis tres directoras, Dra. Charo Barrios, Dra. Pilar Iranzo y Dra. Joana Tierno, por dirigir el proceso de elaboración de esta tesis pero sobre todo por compartir su sabiduría, su motivación y su comprensión. Gracias por haberme enseñado tanto y por hacerme crecer personalmente y profesionalmente.

Al Departamento de Pedagogía, a Jose Miguel Jiménez por sus ánimos cada mañana. A Gabi Sánchez y Cinta Cort por cuidarme tanto. A Sergio Pasamontes por su predisposición en ayudarme siempre y su paciencia tecnológica. A todas las profesoras y profesores más "bandarres" del departamento. Gracias por hacerme sentir una más del equipo desde el primer día que llegué. A los miembros del grupo FORTE ICE del Departamento de Pedagogía.

A los directores de los centros de Educación Primaria por su participación en este estudio.

A mi familia, por su apoyo permanente y por soportar mi mal humor debido al estrés y, sobre todo, por alentarme en todo momento. En especial a mi padre y a mi madre, mis mejores maestros, por haberme transmitido sus valores y su amor, por su comprensión.

A mis compañeras de Granada, Marta Olmo y Ana Martín, por nuestras "terapias madermain” y su arte! A Cristina Castro por ser la mejor compañera y su ¡Pura Vida! A las "més guapes del planeta” por compartir cenas, risas y amistad. A Sergio García, por confiar ciegamente en mí y transmitirme tanta energía.

A mis amigos "SúperCalis" por liberarme de la presión de las tesis y robarme las sonrisas más sinceras en los momentos que más escaseaban. Mención especial a Carlos, mi mejor amigo, que a pesar de estar viviendo en Tokio siempre le he sentido cerca.

Y, especialmente, a Edu, mi confidente, mi apoyo y mi fuerza. Por su infinita paciencia, palabras y amor. Gràcies de tot cor. 
Esta tesis ha sido elaborada con el apoyo de:

- Beca Martí Franquès d'ajuts a la investigación adscrita al Departamento de Pedagogía de la Universitat Rovira i Virgili.

- Autorización de la Dirección de los Servicios Territoriales (SSTT) de Educación de Tarragona. 
En esta tesis doctoral, y con el objetivo de facilitar la lectura del texto, se utiliza el "masculino genérico" para referirse a los directores de ambos géneros. No significa connotaciones, ni lenguaje sexista.

El idioma del cuestionario utilizado en la investigación es el catalán. Por ese motivo, las citas literales de textos escritos en lengua catalana son de traducción propia. 
DIRECCIÓN ESCOLAR Y LIDERAZGO

\section{PRIMARIA DE TARRAGONA}

ANÁLISIS DEL DESEMPEÑO DE LA FIGURA DIRECTIVA EN CENTROS DE EDUCACIÓN Marta Camarero Figuerola 


\section{ÍNDICE GENERAL}

ÍNDICE DE TABLAS .........................................................................................

ÍNDICE DE GRÁFICOS .........................................................................................IV

ÍNDICE DE FIGURAS ...............................................................................................

ÍNDICE DE ILUSTRACIONES ............................................................................. VI

GLOSARIO............................................................................................................. VII

RESUMEN ...................................................................................................................... VIII

PUBLICACIONES DERIVADAS DE LA TESIS..................................................... XII

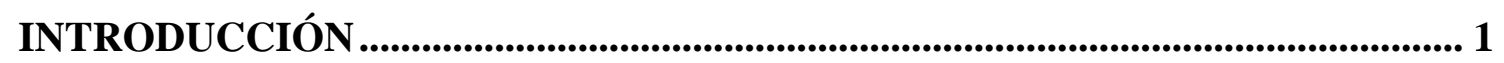

1. Problema de investigación: justificación y propósito general .................................. 2

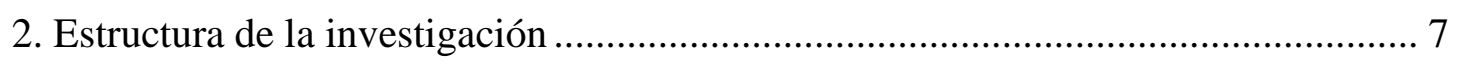

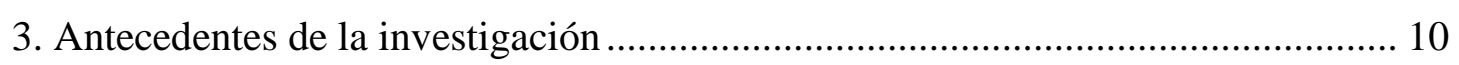

A. MARCO CONCEPTUAL................................................................................................ 15

\section{CAPÍTULO I:}

DIRECCIÓN ESCOLAR Y LIDERAZGO ................................................................ 17

1.1 Definición dirección escolar y liderazgo .............................................................. 18

1.2 Perfil de manager versus Perfil de líder............................................................ 20

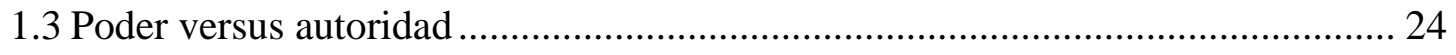

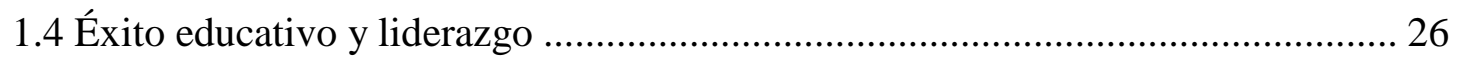

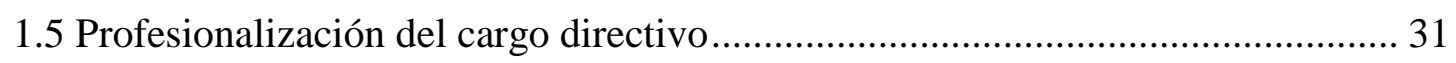

\section{CAPÍTULO II:}

MODELOS DE LIDERAZGO Y DIRECCIÓN ESCOLAR ..................................... 35

2.1 Evolución de los modelos sobre la función directiva ............................................ 36

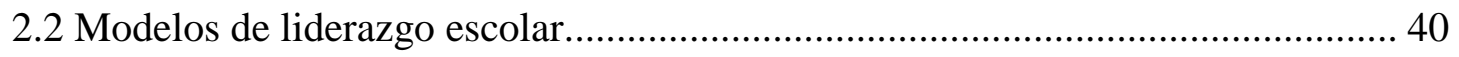

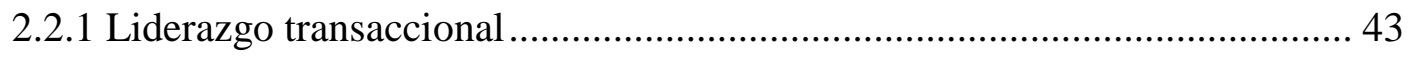

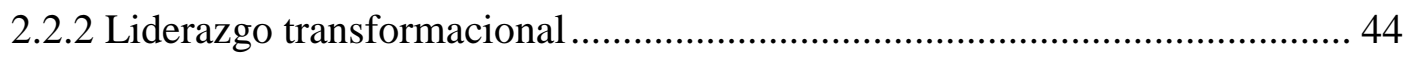

- Liderazgo Pedagógico, Instructivo o Liderazgo para el aprendizaje ................ 46

- Liderazgo distribuido, participativo o colegiado .............................................. 49

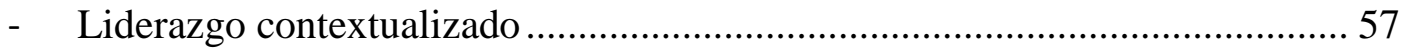




\section{CAPÍTULO III:}

\section{DIRECCIÓN ESCOLAR: DE LOS MODELOS A LA PRÁCTICA....................... 59}

3.1 Evolución legislativa Española ............................................................................ 60

3.1.1 Leyes españolas: De la L.G.E (1970) a la L.O.M.C.E (2013)....................... 60

3.1.2 Leyes Catalanas: de la L.E.C (2009) a la actualidad ...................................... 63

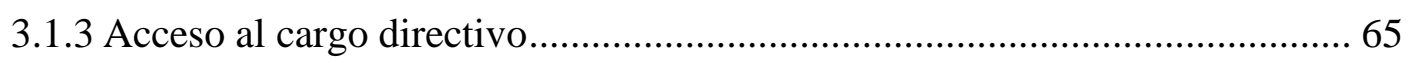

3.1.4 Funciones y tareas de la dirección ............................................................... 70

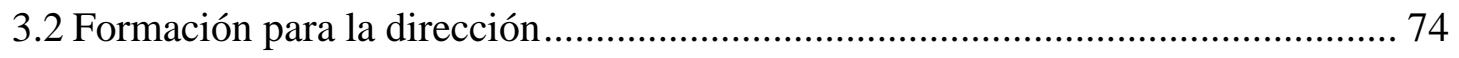

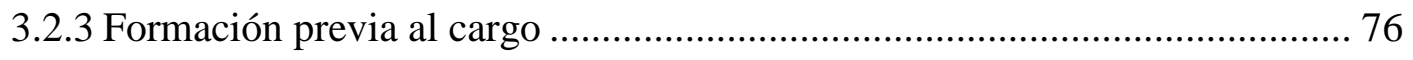

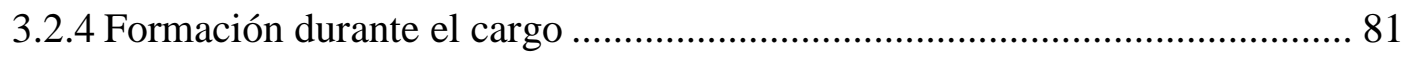

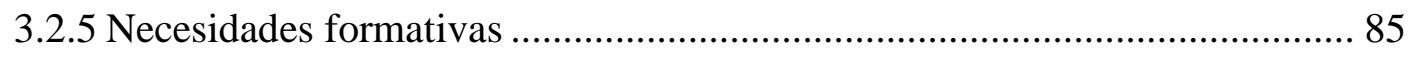

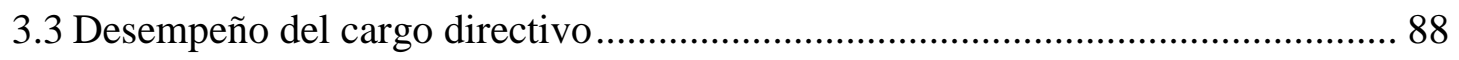

3.3.3 Competencias y características directivas ..................................................... 88

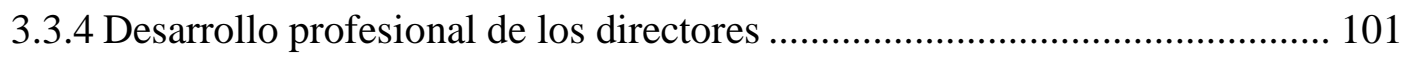

3.3.5 Género y dirección escolar ..................................................................... 106

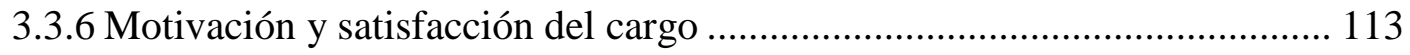

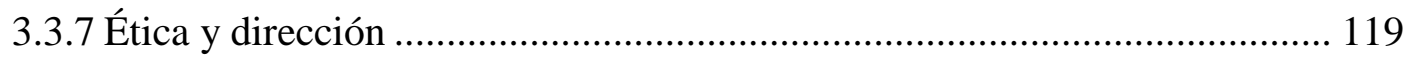

3.4 Prácticas de liderazgo eficaces para la mejora escolar .......................................... 123

B. MARCO METODOLÓGICO ...................................................................... 129

\section{CAPÍTULO IV:}

DISEÑO Y OBJETIVOS DE LA INVESTIGACIÓN ............................................ 131

4.1 Enfoques teóricos de la investigación educativa ................................................ 131

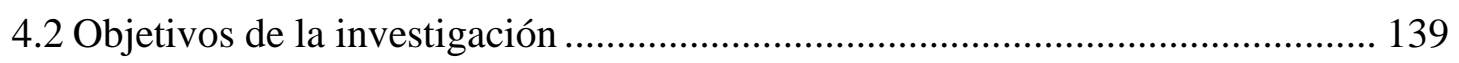

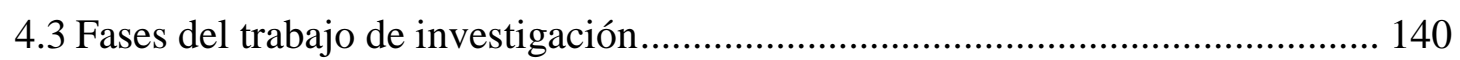

4.4 Contextualización de la investigación.............................................................. 141

4.5 Población y muestra de la investigación ............................................................ 146

4.6 Métodos y técnicas de recogida de información ................................................. 148

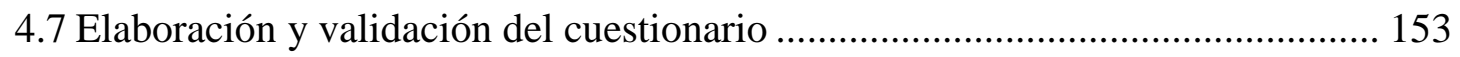

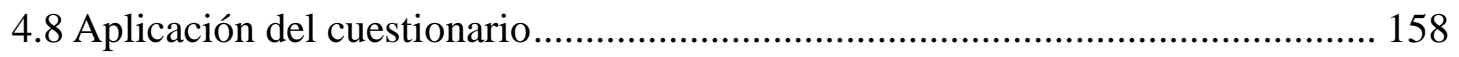

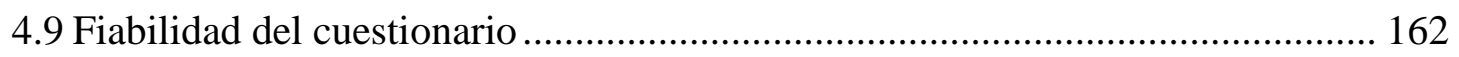

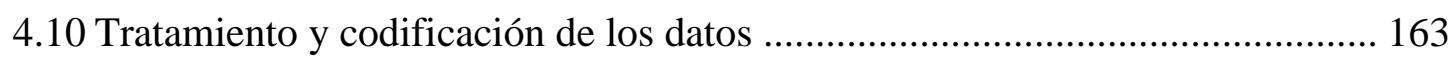




\section{CAPÍTULO V:}

ANÁLISIS RESULTADOS

5.1 Caracterización de la muestra ....................................................................... 168

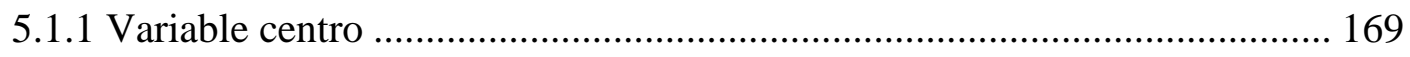

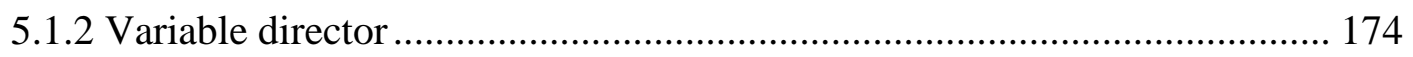

5.2 Análisis descriptivo por bloques del cuestionario ......................................... 178

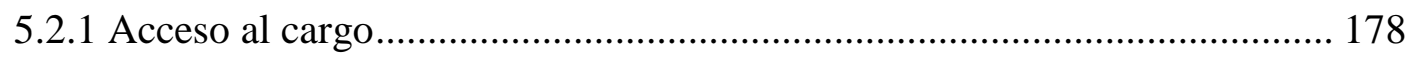

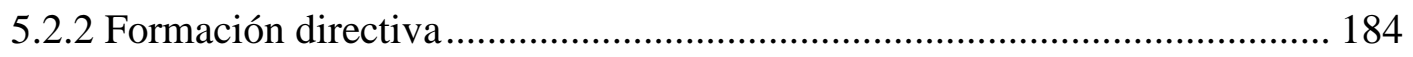

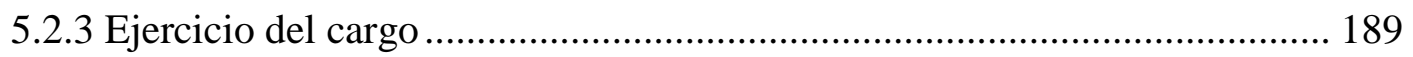

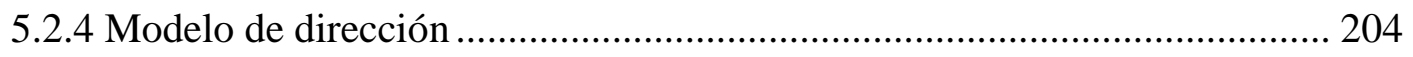

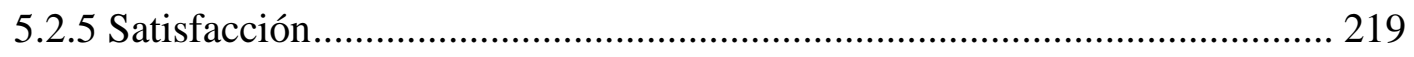

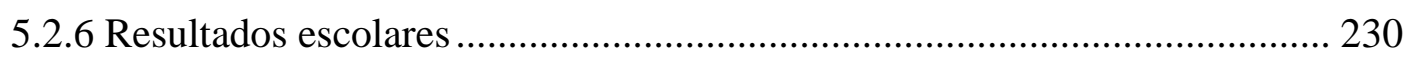

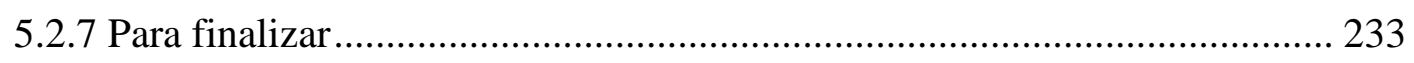

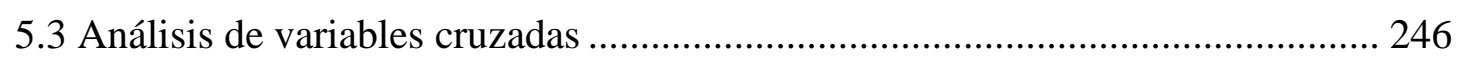

5.3.1 Acciones directivas y autopercepción del compromiso ............................. 246

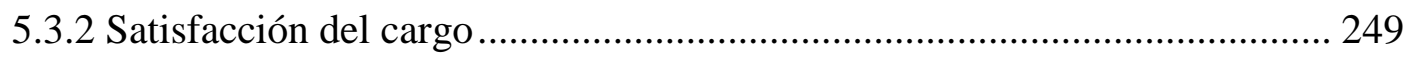

5.3.3 Situación actual e importancia del cargo directivo.................................... 250

5.3.4 Satisfacción del cargo y la situación actual del cargo directivo .................. 253

5.3.5 Satisfacción del cargo e importancia del cargo directivo ............................ 253

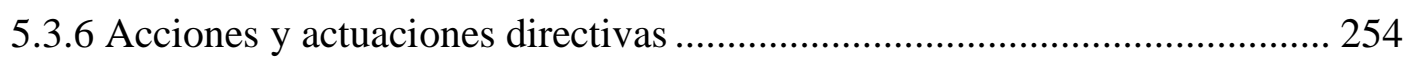

5.3.7 Acciones directivas y la autopercepción del modelo directivo .................. 257

5.3.8 Funciones directivas y las actuaciones directivas..................................... 258

5.3.9 Compromiso de la comunidad y factores del éxito escolar ....................... 259

\section{CAPÍTULO VI:}

CONCLUSIONES Y CONSIDERACIONES FINALES.................................... 264

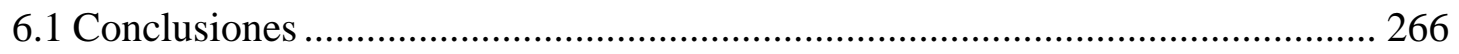

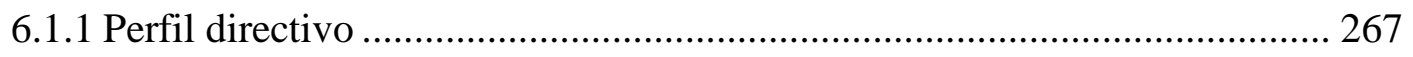

6.1.2 Concepción y situación de la dirección escolar .......................................... 273

6.1.3 Estilos de dirección y de liderazgo escolar................................................ 278

6.1.4 Acciones para potenciar el liderazgo y el éxito escolar.............................. 282

6.2 Limitaciones del estudio y futuras líneas de investigación................................. 286

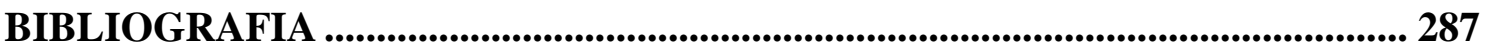

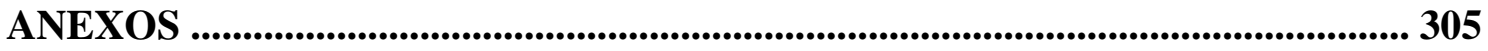

Anexo 1: Competencias directivas básicas ........................................................... 305

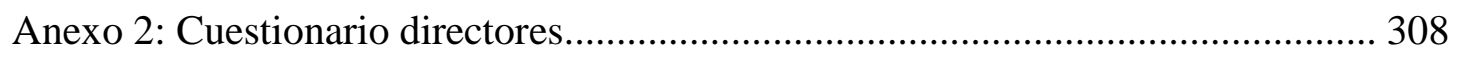


DIRECCIÓN ESCOLAR Y LIDERAZGO

\section{PRIMARIA DE TARRAGONA}

ANÁLISIS DEL DESEMPEÑO DE LA FIGURA DIRECTIVA EN CENTROS DE EDUCACIÓN Marta Camarero Figuerola 


\section{ÍNDICE DE TABLAS}

Tabla 1: Descriptores código UNESCO

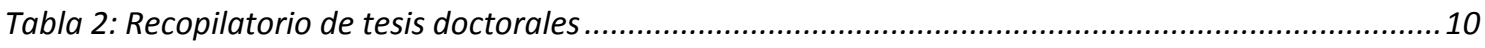

Tabla 3: Recopilación de investigaciones sobre la temática.............................................................. 13

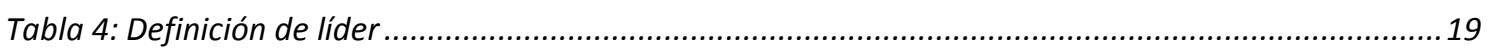

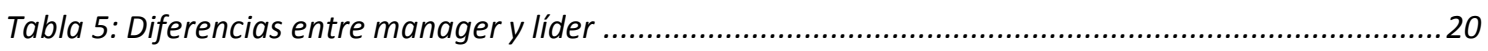

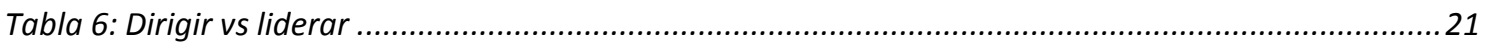

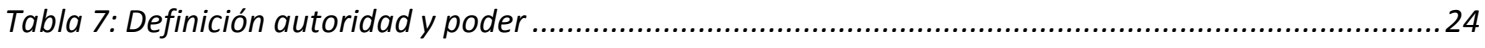

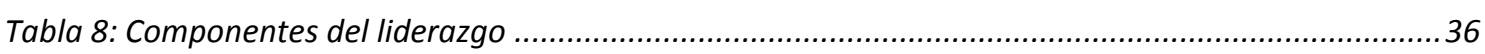

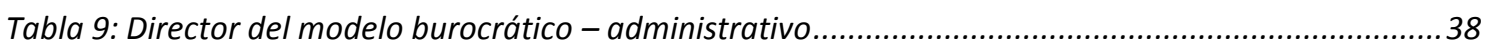

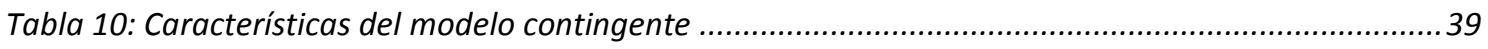

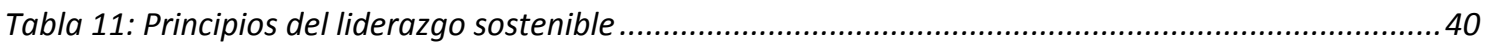

Tabla 12: Liderazgo transaccional versus liderazgo transformacional.................................................42

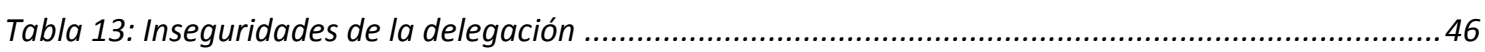

Tabla 14: Estrategias para potenciar la participación del alumnado......................................................53

Tabla 15: Puntos claves de la colaboración interinstitucional.........................................................55

Tabla 16: Evolución de los requisitos de acceso al cargo en España ..................................................66

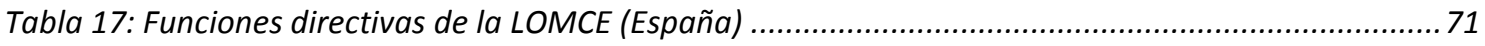

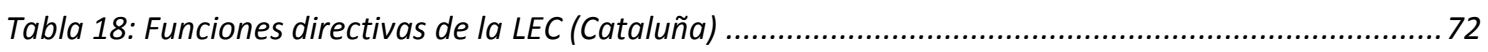

Tabla 19: Funciones directivas LEC centros concertados-privados................................................... 73

Tabla 20: Clasificación de las funciones directivas ......................................................................... 74

Tabla 21: Evolución de la formación directiva en España ..............................................................77

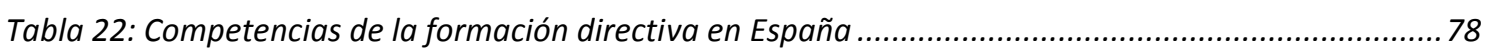

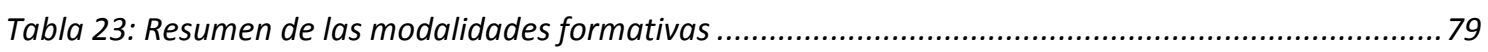

Tabla 24: Modalidades evaluativas de la formación .........................................................................79

Tabla 25: Módulos del curso de formación inicial en Catalunya .........................................................81

Tabla 26: Competencias directivas según Poblete \& García Olalla (2003) ............................................90

Tabla 27: Competencias directivas según Villa \& García Olalla (2003) ..................................................91

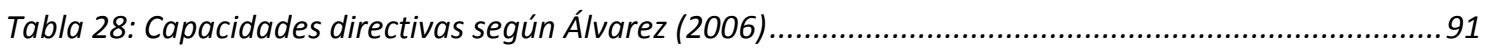

Tabla 29: Clasificación de competencias según Villa \& Poblete (2007)................................................92

Tabla 30: Clasificación de las competencias según Campo (2010) .................................................92

Tabla 31: Competencias de la dirección escolar según Teixidó ..............................................................93

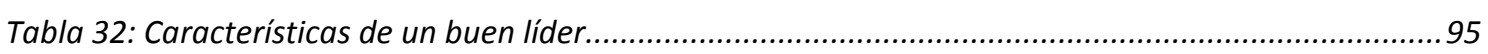

Tabla 33: Características, comportamientos, actitudes y habilidades de un líder efectivo......................95

Tabla 34: Problemas que enfrentan los directores ........................................................................ 103

Tabla 35: Motivos principales y problemas de los nuevos directores.................................................104

Tabla 36: Claves para convertir la experiencia en sabiduría ............................................................... 105 
Tabla 37: Rasgos característicos de la dirección femenina

Tabla 38: Percepción del liderazgo en función del género

Tabla 39: Insatisfacciones versus satisfacciones del cargo

Tabla 40: Razones por las que acceder o no acceder al cargo directivo.

Tabla 41: Clasificación de los motivos de acceso al cargo.

Tabla 42: Tabla comparativa de motivaciones iniciales

Tabla 43: Principales factores que provocan estrés a los directores

Tabla 44: Dimensiones del estrés del cargo directivo

Tabla 45: Valores del cargo directivo

Tabla 46: Rasgos de personalidad básicos

Tabla 47: Código deontológico aplicado a la dirección escolar.

Tabla 48: Prácticas de liderazgo.

Tabla 49: Prácticas de liderazgo de Leithwood \& Rielh.

Tabla 50: Prácticas de liderazgo para centros en contextos desafiantes ...........................................125

Tabla 51: Paradigmas de investigación educativa ........................................................................ 137

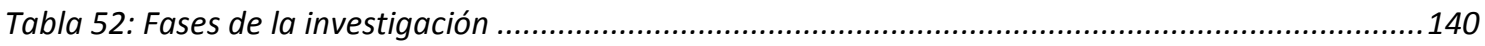

Tabla 53: Funciones de los servicios territoriales de educación ......................................................... 141

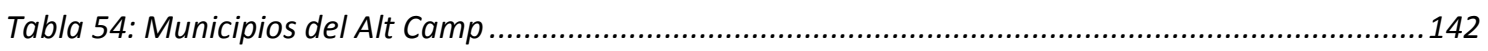

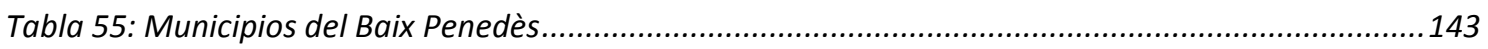

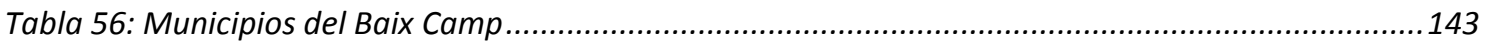

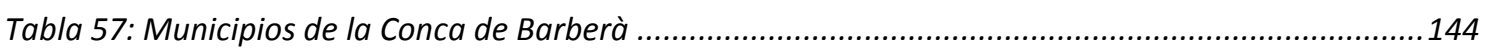

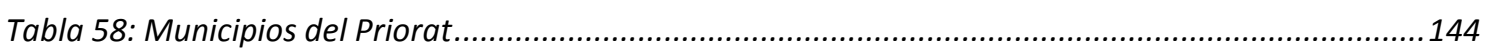

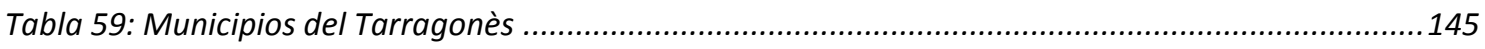

Tabla 60: Número de centros de Educación Primaria por Comarca ................................................... 146

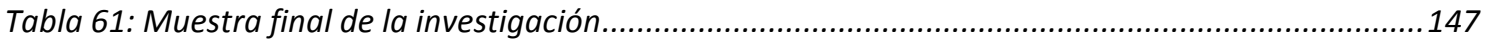

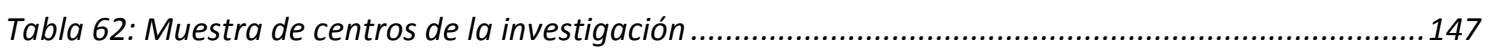

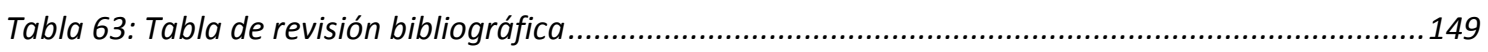

Tabla 64: Secuencia de pasos en una investigación mediante cuestionario .......................................153

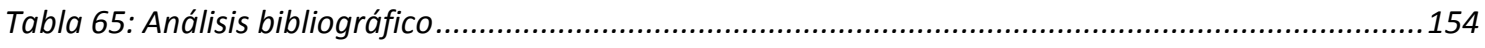

Tabla 66: Resumen de las palabras claves para la revisión documental............................................ 154

Tabla 67: Resumen del contenido y estructura del cuestionario .............................................................. 155

Tabla 68: Tipos de preguntas y objetivos del cuestionario ................................................................157

Tabla 69: Respuestas de la muestra según la tipología del centro.....................................................162

Tabla 70: Clasificación de coeficientes de alfa de Cronbach ...........................................................162

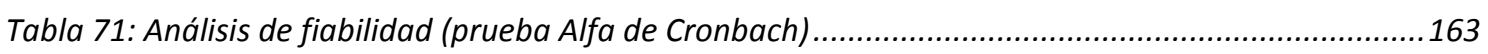

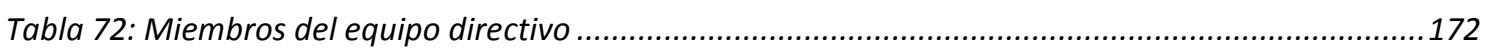

Tabla 73: Especificación de los "otros cargos" del equipo directivo ................................................... 172

Tabla 74: Otros motivos del nombramiento extraordinario según la tipología del centro ..................... 180 
Tabla 75: Razones iniciales para acceder al cargo de dirección

Tabla 76: Otras razones para acceder al cargo de dirección

Tabla 77: Valoración de la formación previa al cargo...

Tabla 78: Valoración de la formación durante el cargo

Tabla 79: Listado de capacidades directivas

Tabla 80: Otras capacidades directivas

Tabla 81: Componentes relevantes para el cargo de dirección 190

Tabla 82: Otros componentes relevantes para la dirección 190

Tabla 83: Valores del centro

Tabla 84: Valores del cargo directivo

Tabla 85: Valores personales del director

Tabla 86: Media del compromiso de la comunidad educativa

Tabla 87: Destinatarios de las acciones para mantener un compromiso alto.

Tabla 88: Media de la satisfacción

Tabla 89: Fuentes de la satisfacción del cargo directivo

Tabla 90: Fuentes de insatisfacción del cargo directivo

Tabla 91: Satisfacciones e insatisfacciones del cargo.

Tabla 92: Categorización del cambio de motivaciones.

Tabla 93: Factores que influyen en el rendimiento escolar

Tabla 94: Categorización de las necesidades formativas

Tabla 95: Categorización de las necesidades no formativas

Tabla 96: Categorización de los aspectos facilitadores de los Decretos.

Tabla 97: Categorización de los aspectos obstaculizadores de los Decretos 240

Tabla 98: Categorización expectativas del "decreto de plantillas"

Tabla 99: Categorización de las características personales

Tabla 100: Categorización del aprendizaje de las características personales

Tabla 101: Relación entre la auto percepción del compromiso y las acciones directivas.

Tabla 102: Relación entre la percepción del compromiso del profesorado y las acciones directivas .......247

Tabla 103: Relación de la percepción del compromiso de las familias y las acciones directivas

Tabla 104: Relación de la percepción del compromiso de los alumnos según las acciones directivas .....248

Tabla 105: Relaciones directas entre ítems de satisfacción

Tabla 106: Dobles relaciones entre ítems de satisfacción .

Tabla 107: Múltiples relaciones entre ítems de satisfacción:

Tabla 108: Relaciones directas entre ítems de situación actual.

Tabla 109: Múltiples relaciones entre ítems de situación actual

Tabla 110: Relaciones directas entre ítems de importancia.

Tabla 111: Múltiples relaciones entre ítems de importancia 252

Tabla 112: Relaciones directas entre situación actual y la satisfacción del cargo 
Tabla 113: Múltiple relación entre situación actual y satisfacción del cargo.

Tabla 114: Listado de acciones y actuaciones directivas ................................................................254

Tabla 115: Relaciones significativas entre acciones y actuaciones directivas .......................................255

Tabla 116: Relación múltiple de las actuaciones directivas..................................................................256

Tabla 117: Relación múltiple de las acciones directivas ...............................................................256

Tabla 118: Autopercepción del propio compromiso con factores influyentes en el éxito escolar ............260

Tabla 119: Compromiso del profesorado con factores influyentes en el éxito escolar............................261

Tabla 120: Compromiso de las familias con factores influyentes en el éxito escolar ................................262

Tabla 121: Compromiso del alumnado con factores influyentes en el éxito escolar ..............................263

Tabla 122: Conclusiones y objetivos de investigación ...............................................................266

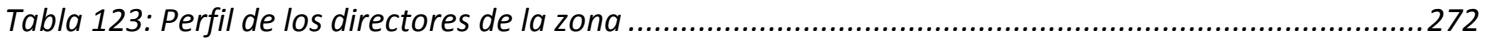

Tabla 124: Rasgos característicos de los estilos de dirección ..................................................................281

\section{ÍNDICE DE GRÁFICOS}

Gráfico 1: Número de años mínimo de experiencia docente para poder ser director. .............................65

Gráfico 2: Porcentaje de mujeres directoras y docentes según la Comunidad Autónoma ...................... 108

Gráfico 3: Centros participantes en relación al número de alumnos.................................................170

Gráfico 4: Centros participantes en relación al número de docentes en plantilla ..................................170

Gráfico 5: Alumnos que "promociona y supera adecuadamente" por ciclos en los centros ....................173

Gráfico 6: Directores participantes en función del género ............................................................174

Gráfico 7: Relación de la titularidad de los centros y el género del director ......................................175

Gráfico 8: Relación de la edad y el género de los directores participantes ............................................175

Gráfico 9: Relación del género del director y la experiencia directiva .......................................................176

Gráfico 10: Relación de la titularidad de los centros educativos y la experiencia directiva .....................176

Gráfico 11: Relación de la auto percepción del estilo directivo y el género de los directores ..................177

Gráfico 12: Relación de la auto percepción del estilo directivo y la titularidad del centro......................177

Gráfico 13: Relación de la edad del director y la auto percepción del estilo directivo ..............................178

Gráfico 14: Acceso al cargo en función de la titularidad del centro ......................................................179

Gráfico 15: Acceso al cargo según el número de miembros del equipo directivo ..................................179

Gráfico 16: Acceso al cargo según la experiencia directiva ........................................................... 180

Gráfico 17: Tiempo que dedica el director a docencia según la titularidad del centro .......................... 181

Gráfico 18: Tiempo que dedica el director a docencia según el género del director ...............................181

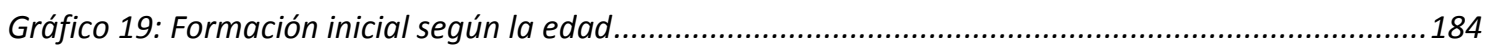

Gráfico 20: Formación inicial según la experiencia directiva........................................................184

Gráfico 21: Comparación de formaciones (inicial y continua) ......................................................... 186 
Gráfico 22: Formación permanente según la autopercepción del modelo directivo

Gráfico 23: Situación actual del centro versus importancia concedida por los directores .......................195

Gráfico 24: Porcentaje de la realización de las actuaciones del cargo directivo ....................................200

Gráfico 25: Valoración de las funciones de la dirección y su dificultad .................................................204

Gráfico 26: Porcentaje de directores que realizan las actuaciones ......................................................207

\section{ÍNDICE DE FIGURAS}

Figura 1: Las doce revoluciones del sistema educativo .................................................................

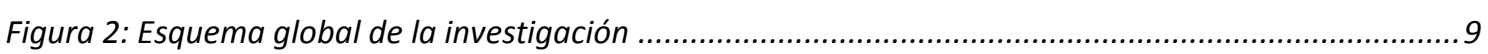

Figura 3: Panorámica de los tipos de liderazgo en organizaciones educativas ......................................41

Figura 4: Resumen de las leyes educativas españolas...............................................................62

Figura 5: Etapas de la dirección según Parkay \& Hall (1992) .......................................................... 101

Figura 6: Etapas de la dirección según Day \& Bakioglu (1996) ............................................................. 102

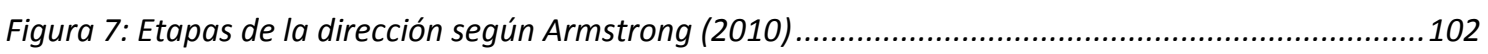

Figura 8: Valores personales del director escolar ................................................................ 121

Figura 9: Resumen de las investigaciones internacionales sobre el impacto del liderazgo .....................126

Figura 10: Elementos comunes de las prácticas de liderazgo ........................................................ 128

Figura 11: Características de la investigación educativa según el tipo de investigación ..........................138

Figura 12: Organigrama de los SSTT de Educación de Tarragona ........................................................142

Figura 13: Ventajas e inconvenientes de los cuestionarios online .................................................... 161

Figura 14: Clasificación de los centros educativos participantes en relación a la titularidad ..................169

Figura 15: Resumen de las acciones destinadas al profesorado .......................................................216

Figura 16: Resumen de las acciones destinadas al alumnado..........................................................216

Figura 17: Resumen de las acciones destinadas a las familias .....................................................217

Figura 18: Resumen de las acciones destinadas a la comunidad educativa .....................................218

Figura 19: Relación de la satisfacción del cargo directivo y la titularidad del centro..............................221

Figura 20: Resumen del cambio de las motivaciones directivas..........................................................229

Figura 21: Necesidades formativas de gestión de centros .................................................................234

Figura 22: Necesidades formativas en legislación educativa ......................................................234

Figura 23: Necesidades formativas en gestión del personal ........................................................235

Figura 24: Necesidades no formativas para la gestión del cargo ......................................................237

Figura 25: Resumen de las necesidades no formativas en recursos ........................................................238

Figura 26: Acciones directivas según la auto percepción del modelo directivo....................................257 


\section{ÍNDICE DE ILUSTRACIONES}

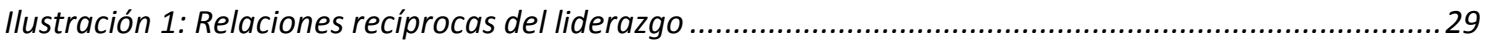

Ilustración 2: Modalidades de selección de los directores.....................................................................69

Ilustración 3: Experiencia profesional y formación para la dirección escolar en Europa............................. 76

Ilustración 4: Formación directiva durante el cargo............................................................................ 83

Ilustración 5: Relación entre diferentes tipos de necesidades ................................................................86

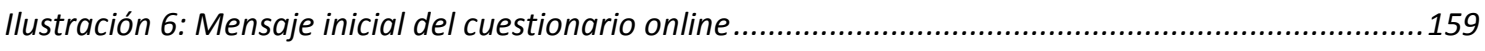

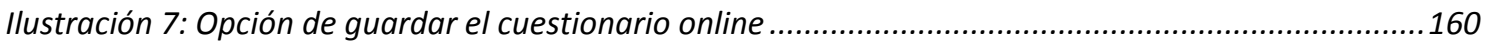

Ilustración 8: Plantilla del email recordatorio de participación ...............................................................161 


\section{GLOSARIO}

AMPAs: Asociación de Madres y Padres de Alumnos

AXIA: Asociación de Directivos de la Educación Pública de Cataluña

CAEP: Centros de atención educativa preferente

CINIIE: Centro Nacional de Innovación e Investigación Educativa

EAPC: Escuela de Administración Pública de Cataluña

ECTS: Sistema Europeo de Transferencia de Créditos

ID: Identificación

LEC: Ley de Educación en Cataluña

LGE: Ley General de Educación

LOCE: Ley Orgánica de Calidad en la Educación

LODE: Ley Orgánica del Derecho a la Educación

LOECE: Ley Orgánica del Estatuto de Centros Escolares

LOE: Ley Orgánica de Educación

LOGSE: Ley Orgánica de Ordenación General del Sistema Educativo

LOPEGC: Ley Orgánica de la Participación, la Evaluación y el Gobierno de los Centros.

LOMCE: Ley Orgánica para la Mejora de la Calidad Educativa

MECD: Ministerio de Educación Cultura y Deporte

NOFC: Normas de organización y funcionamiento del centro

OCDE: Organización para la Cooperación y el Desarrollo Económicos

ONGs: Organización no gubernamental

PAC: Plan anual de centro

PEC: Proyecto educativo de centro

RAE: Real academia española

SSTT: Servicios Territoriales

TIC: Tecnologías de la información y la comunicación

URV: Universitat Rovira i Virgili

ZER: Zona Escolar Rural 
DIRECCIÓN ESCOLAR Y LIDERAZGO

\section{PRIMARIA DE TARRAGONA}

ANÁLISIS DEL DESEMPEÑO DE LA FIGURA DIRECTIVA EN CENTROS DE EDUCACIÓN Marta Camarero Figuerola 


\section{RESUMEN}

La dirección escolar está considerada por la literatura científica el segundo factor más influyente en los resultados escolares, después de la acción del profesorado.

Nuestro estudio analiza las tendencias generales del ejercicio de la dirección escolar en referencia al perfil competencial y profesional de los directores en ejercicio; a las tareas y funciones que realmente desarrollan; a la satisfacción en relación a su cargo y sus necesidades para un óptimo liderazgo. También pretende contrastar estas tendencias con la normativa vigente y con las recomendaciones teóricas internacionales sobre liderazgo educativo, con la finalidad de identificar los modelos de mejora escolar que los equipos directivos desarrollan en los centros en las condiciones actuales.

Para ello se cuenta con una muestra representativa de 129 escuelas de educación primaria (públicas, concertadas y privadas) de los SSTT de Educación de Tarragona.

Se ha utilizado un cuestionario online destinado a los directores que recoge su opinión sobre el desarrollo de la función, así como sobre las condiciones que determinan su modelo de dirección. La pluralidad y representatividad de la muestra permite realizar un análisis diferencial de la dirección escolar en las diferentes tipologías de escuelas (rurales, urbanas, concertadas-privadas, de alta complejidad) y obtener información relativa a los modelos de dirección desarrollados.

Los resultados evidencian una mayor presencia de modelos directivos basados fundamentalmente en la gestión en contraste con los que se basan en el liderazgo pedagógico, así como el evitar actuaciones referidas a la coordinación y participación de la comunidad educativa en el gobierno de los centros. Los avances legales impulsan una progresiva profesionalización de los directores. Aparecen, además, relaciones entre el liderazgo, el género y la experiencia en el cargo.

Palabras clave: dirección escolar, educación primaria, liderazgo, modelos de dirección escolar, legislación y políticas educativas 


\section{RESUM}

La direcció escolar està considerada per la literatura científica el segon factor més influent en els resultats escolars, després de l'acció del professorat.

El nostre estudi analitza les tendències generals del exercici de la direcció escolar en referencia al perfil competencial y professional dels directors en exercici; a les tasques $\mathrm{i}$ funcions que realment desenvolupen; a la satisfacció en relació al seu càrrec i les seves necessitats per un òptim lideratge. També pretén contrastar aquestes tendències amb la normativa vigent $\mathrm{i}$ amb les recomanacions teòrica internacionals sobre el lideratge educatiu, amb la finalitat d'identificar els models de la millora escolar que els equips directius desenvolupen en els centres en les condicions actuals.

Per fer-ho possible es compta amb una mostra representativa de 129 escoles d'educació primària (públiques, concertades i privades) dels SSTT d'Educació de Tarragona.

S'ha utilitzat un qüestionari online destinat als directors que recull la seva opinió sobre el desenvolupament de la funció, així com sobre les condicions que determinen el seu model de direcció. La pluralitat i representativitat de la mostra permet realitzar un anàlisis diferencial de la direcció escolar en diferents tipologies de escola (rurals, urbanes, concertades-privades, d'alta complexitat) i obtenir informació relativa als models de direcció desenvolupats.

Els resultats evidencien una major presencia dels models directius basats fonamentalment en la gestió en contrast amb els que es basen en el lideratge pedagògic, així com evitar actuacions referides a la coordinació i participació de la comunitat educativa en el govern dels centres. Els avançaments legals impulsen una progressiva professionalització dels directors. Apareixen, a més, relacions entre el lideratge, el gènere i l'experiència en el càrrec.

Paraules Claus: direcció escolar, educació primària, lideratge, models de direcció escolar, legislació i polítiques educatives 


\section{ABSTRACT}

Scientific literature considers school management as the second more influential factor in schooling outcomes; the first one is the teacher staff action.

Our study analyzes the general trends of the exercise of school leadership regarding the professional competence profile of the directors in the exercise; the tasks and functions that really developed; the satisfaction in relation to their position and their needs for optimal leadership. It also aims to compare these trends with current legislation and international recommendations on educational leadership theory, in order to identify patterns of school improvement that teams develop in schools under current conditions.

To do that, we use a representative sample of 129 elementary schools (public schools, state-subsidised schools and private schools) in the Department of Education of Tarragona.

It has been used a questionnaire intended to the principals that picks up their opinions on the development of its function, as well as the conditions that determine their principalship model. The diversity and the representation of the sample, allows to carry out a distinguishing analysis of the school management within the different schools typology (rural, urban, state-subsided, private and with a high complexity) and to obtain information related to the management models developed.

The results show a greater presence of management based mainly on management in contrast to models that are based on the pedagogical leadership, as well as the avoidance of actions relating to the coordination and participation of the educational community in the governance of schools. The legal advances encourage a progressive professionalization of the principals. Also appear relationships between leadership, gender and experience in the job.

Keywords: School Leadership, Elementary Education, Leadership, Models of school leadership, Legislation and educational polices 
DIRECCIÓN ESCOLAR Y LIDERAZGO

\section{PRIMARIA DE TARRAGONA}

ANÁLISIS DEL DESEMPEÑO DE LA FIGURA DIRECTIVA EN CENTROS DE EDUCACIÓN Marta Camarero Figuerola 


\section{PUBLICACIONES DERIVADAS DE LA TESIS}

Barrios, Ch.; Camarero, M.; Tierno, J. M. \& Iranzo, P. (2015). Modelos y funciones de dirección escolar en España: el caso de Tarragona. Revista Iberoamericana de Educación, 67, 89-106. Consulta online en: http://www.rieoei.org/rie67a05.pdf

Camarero, M. (2015). La dirección escolar en educación primaria: liderazgo y éxito educativo. IV Congreso Internacional Multidisciplinar de Investigación Educativa, CIMIE. Valencia. (Pendiente de publicación en el libro de actas del congreso)

Iranzo, P.; Barrios, Ch.; Tierno, J.M. \& Camarero, M. (2014). Liderar o gestionar: desempeño de la dirección escolar en Tarragona. XIII Congreso Internacional de Formación del Professorado, AUFOP. Santander. Actas del congreso: http://www.congresoaufop2014.unican.es/wp-content/uploads/2013/12/ACTASAUFOP-2014.pdf

Iranzo, P.; Tierno, J.M,; Barrios, Ch. \& Camarero, M. (2015). How Does School Management Get The Commitment of The Educational Community. Education and transition Contributions from Educational Research (ECER). Budapest. Actas del congreso: http://www.eera-ecer.de/ecer-programmes/conference/20/contribution/34463/

Iranzo, P.; Barrios, Ch.; Tierno, J.M. \& Camarero, M. (2015). Perception Analysis Of the School Management Performance in the Tarragona Province (Spain). International Successful School Principalship Conference (ISSPP). Sevilla. 
Camarero, M. Recensión: Antúnez,S. (2012). Una brújula para la dirección escolar. Orientaciones para la mejora. México: Somos Maestros-Innovación y Asesoría Educativa. Serie Gestión Educativa.111 pp. UT. Revista de Ciències de l'Educació. Consulta online: http://revistes.publicacionsurv.cat/index.php/ute/article/view/447/430

Camarero, M. Recensión: Bazarra, L. \& Casanova, O. (2013). Directivos de Escuelas Inteligentes. ¿Qué perfil y habilidades exige el futuro? Madrid: Ediciones SM. 245 pp. Revista Educación XX1. Aceptada pendiente de publicación.

Camarero, M. Recensión: Santos Guerra, M.A. (2015). Las feromonas de la manzana. El valor educativo de la dirección escolar. Barcelona: Editorial Graó. 136 pp. Revista Bordón. Aceptada pendiente de publicación.

Camarero, M. Recensión: Blase, J. y Kirby, P.C. (2013). Estrategias para una dirección escolar eficaz: Cómo motivar, inspirar y liderar. Madrid: Narcea. 159 pp. Revista de currículum y formación del profesorado. Aceptada pendiente de publicación. 
n este capítulo se presenta el por qué y para qué de este trabajo. Empezaremos, pues, por exponer la (re)evolución de la escuela y los cambios de la figura directiva en los últimos años hasta la actualidad.

Para dar consistencia a nuestra elección del tema se expone la influencia de la dirección escolar y el liderazgo educativo en el éxito escolar de los centros educativos. Se presenta el propósito final, los objetivos y los supuestos básicos de los cuales parte este estudio. Se muestra los rasgos característicos y la estructura de este trabajo. Por último, se presenta los antecedentes sobre la temática en los últimos años. 


\section{Problema de investigación: justificación y propósito general}

Con el paso de los años, la escuela ha ido evolucionando y adaptándose a las necesidades del momento. El exclusivo cuaderno escolar ha sido substituido por los recursos tecnológicos y una gran diversidad de materiales didácticos.

Los valores que promueven la escuela hoy en día son: la participación, la tolerancia, la igualdad y la aceptación de la diversidad. Con la obligatoriedad de la escuela (hasta los 16 años) se ha garantizado la educación para todos.

Desde hace años la escuela es consciente de la necesidad de generar nuevas ideas, de crear y compartir conocimientos para resolver los problemas educativos en una sociedad que se transforma a gran velocidad y debe afrontar grandes cambios. Torres (2010) en su obra analiza la transformación del sistema educativo de las últimas décadas y cómo debe aprender un alumno en un mundo cada vez más dinámico.

Las transformaciones las denomina "las doce revelaciones":

Figura 1: Las doce revoluciones del sistema educativo

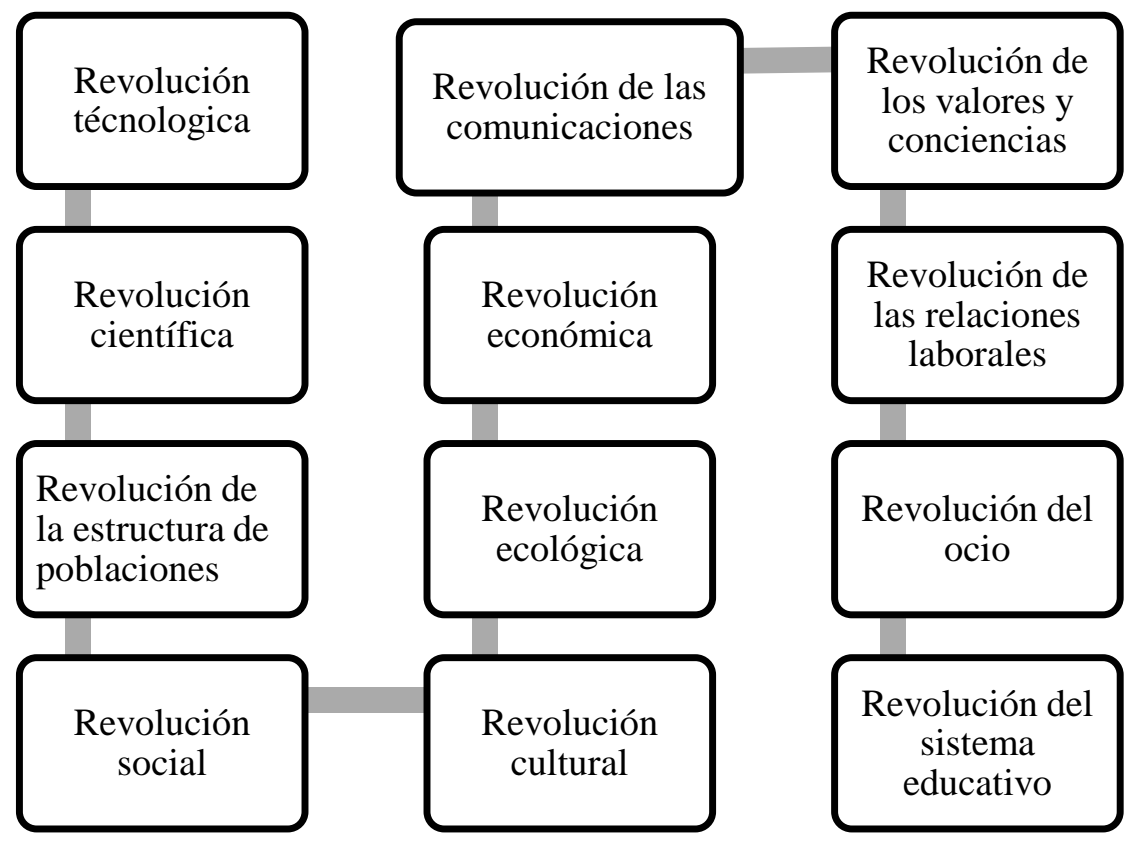

Fuente: Elaboración propia a partir de Torres (2010)

En toda esa transformación el papel del director ha tenido un papel crucial que también ha tenido que ir evolucionando. 
Al director de hace unos años se le exigía una buena administración de los recursos, del orden y del funcionamiento del centro. Además contaba con el respeto de los profesores y de la sociedad por su puesto como autoridad institucional (Álvarez, 2010a).

Actualmente el rol del director es multifacético (por la diversidad de funciones) y ambiguo (por las responsabilidades y retos que están en constante evolución) (GarcíaCarreño \& Olmo, 2013). Debe responder a los desafíos del contexto escolar y del momento histórico y social. Uno de los retos en la dirección es pasar de un enfoque directivo unipersonal a un planteamiento basado en el liderazgo compartido.

En nuestro contexto y hasta los años ochenta, el concepto de líder educativo provocaba cierto recelo por su asociación con el mundo empresarial y ajeno al mundo educativo. Se asociaba al liderazgo una visión individualista basada en el ejercicio de poder y caracterizada por una pérdida de tradiciones participativas y valores ya que su función era la de medir y supervisar (Gros et al., 2013).

La importancia de la dirección escolar y el liderazgo como elementos básicos para el éxito educativo, es avalada por amplio número de autores (Coronel, 1998; Santos, 2000; Fullan, 2002; Murillo, 2006; Cantón \& Arias, 2008; Montero, 2008; Teixidó, 2011; Gómez-Hurtado, 2011; Antúnez 2012; Rodríguez-Sabiote et al., 2013; Cantón, 2013; Barrios, Iranzo \& Tierno, 2013).

El perfil del director del centro, sus competencias y habilidades con las que desarrolla el cargo y el modelo de dirección tiene una influencia, directa e indirecta, en la mejora y funcionamiento del centro. En los últimos años el liderazgo tiene más protagonismo en las agendas educativas internacionales y han aumentado el número de estudios internacionales que enfatizan y apuestan por un perfil de directivo con características y habilidades de un líder con la finalidad de conseguir una mejora en los resultados académicos. La tendencia es convertir a los "directores gestores" en "líderes escolares" que promuevan un liderazgo compartido.

A pesar de que el éxito escolar está relacionado con la calidad de los sistemas educativos, desconocemos con precisión cuáles son los modelos y perfiles directivos en nuestro territorio ya que en el contexto español, existen pocos estudios que analicen en profundidad la dirección escolar de una zona o Comunidades Autónomas. La mayoría son estudios de casos (López \& Lavié, 2010; Martínez, Badia, \& Jolonch, 2013 
González, 2015) o investigaciones centradas en diferentes Comunidades Autónomas, entre otras, las referidas a la Comunidad del País Vasco (Pascual, Villa, \& Auzmend, 1993; Aramendi, Teixidó, \& Bernal, 2009), la Comunidad de Asturias (Álvarez \& Pérez, 2011), la Comunidad de Andalucía (Padilla, 2008a), la Comunidad de Canarias (Rodríguez et al., 2013), la Comunidad de Castilla y León (Cantón \& Arias, 2008), la ciudad autónoma de Ceuta (Cuevas, Díaz, \& Hidalgo, 2008) y la Comunidad de Madrid (Tejero \& Fernández, 2010).

Tomando como punto de partida esta falta de corpus teórico proveniente de investigaciones que presenten una visión global de los estilos de liderazgo y de los perfiles del ejercicio de dirección, esta investigación tiene el propósito general de conocer el perfil directivo, las tendencias generales del ejercicio de la dirección escolar y liderazgo de los centros educativos de primaria de los SSTT (servicios territoriales) de Educación de Tarragona (Cataluña-España).

Se pretende profundizar en el análisis de los diferentes tipos de dirección escolar y en el liderazgo de los directores para contribuir a la construcción de una visión más extensa de las tendencias directivas de la zona. Además, se pretende ofrecer una visión general de la dirección escolar de la zona y plantear mejoras sobre los diferentes tipos de dirección, teniendo en cuenta la tipología de los centros, los diferentes contextos educativos y las necesidades manifestadas de cada director. No nos centramos en la evaluación de los diferentes tipos de direcciones de los centros, sino en comprender y conocer el liderazgo y cuáles son las realidades y necesidades directivas de la zona.

En la exploración sobre el estado del arte hemos profundizado en bloques de contenido importantes como la normativa directiva de acceso y funciones, la profesionalización del cargo directivo, las características del desempeño del cargo directivo, los modelos de dirección, la satisfacción del cargo, las competencias directivas, el concepto de liderazgo educativo, los tipos y características del liderazgo, la relación del líder con la comunidad educativa y la relación entre liderazgo y el éxito educativo. Todo ello sin olvidar una visión internacional de los diferentes bloques temáticos.

Esta investigación, parte de los siguientes supuestos básicos: 


\section{1) CENTROS EDUCATIVOS: NUEVOS RETOS}

Los centros educativos, junto a otras instituciones sociales, son las instituciones que más rápido deberían evolucionar y transformarse. Afrontan nuevos retos constantemente y son los responsables de dar respuesta a las necesidades de la sociedad actual. Deben ser instituciones flexibles a los cambios. Además, los centros educativos son instituciones abiertas y conectadas al entorno, al alumnado, a las familias del alumnado y a otras instituciones o asociaciones. Consideramos que las colaboraciones de la comunidad educativa y las redes de escuelas contribuyen a la mejora del centro y al éxito escolar. Porque ¿De que serviría una escuela aislada del entorno y de su población?

Del mismo modo que la escuela evoluciona, las funciones y responsabilidades de la figura directiva se transforman (y amplían). Pensar que toda la responsabilidad y exigencia de los centros recae sobre la figura directiva, es creer en superhéroes. La realidad es que no existen superhéroes y que, en nuestro contexto, los directores proceden del cuerpo de docentes (y no tienen poderes, de hecho en ocasiones incluso padecen una falta de formación directiva). Entonces, ¿Cómo debe dirigir un director un centro educativo? La respuesta es: liderando.

\section{2) DIRECCIÓN ESCOLAR: UN MODELO BASADO EN EL LIDERAZGO}

La complejidad de los centros, su realidad multicultural, las exigencias cada vez más elevadas sobre los resultados académicos y calidad de la educación, hacen necesario que el director se convierta en el líder del centro. El liderazgo compartido es la manera más realista y eficaz de hacer frente a los retos de la actualidad y resolver las necesidades educativas y sociales del entorno del centro. Estamos ante un nuevo modelo de escuela que entiende los centros como una realidad dinámica y transformadora.

Todos los miembros de la comunidad educativa comparten los mismos objetivos (el gran objetivo será el éxito educativo del alumnado).

Los centros educativos necesitan una figura directiva que influya sobre los demás, sea buen comunicador, cercano y motive. El carisma, la personalidad, la comunicación y el 
compromiso, además de los conocimientos técnicos, son algunas de las características que otorgarán a la figura directiva el rol del líder de los líderes (el liderazgo del director debe potenciar el liderazgo de los profesores).

En este trabajo se considera el liderazgo educativo como un complemento imprescindible en el ejercicio directivo y se defiende la necesidad de promover un liderazgo para dar respuesta a los diferentes problemas, retos y desafíos de la actualidad cambiante.

\section{Los rasgos característicos de esta investigación:}

- Amplitud de la muestra: abandonando los estudios de caso para fijar el análisis en un conjunto más amplio como es la zona de los SSTT de Educación de Tarragona. Nos permitirá conocer las realidades directivas de la zona y dar voz al colectivo de los directores.

- Representatividad: participación de directores de centros de educación primaria públicos, concertados y privados de los SSTT de Educación de Tarragona.

- Carácter positivo de la redacción de la investigación: las necesidades directivas son tratadas como oportunidades para el cambio y convertidas en retos positivos.

- Propuestas de mejoras: establecer modelos de dirección a partir del contraste de informaciones, valoraciones y opiniones de los propios directores y ofrecer pautas para una dirección de éxito basada en el liderazgo.

Nuestro último y gran objetivo es compartir los resultados y propuestas de mejora con los directores de la zona. En la transferencia de los resultados tiene un papel importante los SSTT de Educación de Tarragona que han apoyado la investigación desde el inicio. 


\section{Estructura de la investigación}

Para mejor comprensión, esta investigación se organiza en siete capítulos que describen los aspectos teóricos, los aspectos metodológicos, el análisis de resultados, las conclusiones finales, consideraciones y limitaciones. Además de las referencias bibliográficas y los anexos.

El primer bloque del estudio es el marco conceptual, que agrupa la teoría referente a la temática del estudio. El Capítulo I: Dirección escolar y liderazgo, presenta la fundamentación teórica. Se aborda el concepto de "liderazgo" y "dirección escolar", se explican las diferencias entre líder y director, entre poder y autoridad. Se trata el debate de profesionalización del cargo directivo. Finalmente, se analizan las conductas de impacto y el tipo de influencia que ejerce el liderazgo en el éxito escolar de los centros.

En el Capítulo II: Modelos de liderazgo y dirección escolar, se analiza la evolución de la función directiva y los modelos de dirección escolar y liderazgo. Se enfatizan las diferencias entre el liderazgo transaccional y en el liderazgo transformacional. Se profundiza en los modelos de liderazgo transformacional, destacando la importancia de la Comunidad Educativa y su compromiso.

A continuación, en el Capítulo III: Dirección escolar: de los modelos a la práctica, se contextualiza la dirección escolar en su evolución legislativa, en los tipos de formación directiva y las necesidades formativas. Se profundiza en el desempeño del cargo. Se finaliza con una visión sobre prácticas de liderazgo eficaces.

El marco metodológico de la investigación agrupa la teoría sobre la justificación metodológica. En el Capítulo IV: Diseño y objetivos de la investigación, se describe el origen de la investigación educativa y las diferentes técnicas de recogida de información. Se expone el desarrollo metodológico del estudio empírico: preguntas de investigación, objetivos propuestos, el contexto del estudio, la población y muestra. Se define la elaboración y validación del principal instrumento de investigación del trabajo: el cuestionario.

En el Capítulo V: Análisis de resultados, se realiza la caracterización de la muestra diferenciando dos variables independientes: variable centro y variable director. Se elabora un doble análisis de los datos: por un lado, un análisis descriptivo organizado 
en los bloques del cuestionario; por otro, un análisis de variables cruzadas entre diferentes bloques. Los resultados obtenidos de los dos análisis, a partir del tratamiento estadístico, se presentan acompañados de tablas y gráficos.

La investigación se completa con la elaboración de las conclusiones finales, las limitaciones y las posibles líneas de mejora de proceso en el Capítulo VI: Conclusiones. Finalmente, los dos últimos capítulos, presentan la bibliografía citada y los anexos.

A continuación, se muestra el esquema de la investigación: 


\section{OBJETIVOS}

\section{Conocer la figura directiva y los estilos de liderazgo de los centros} educativos de primaria de la demarcación de Tarragona

Para:

Cómo:

\begin{tabular}{|c|}
\hline Describir el perfil \\
profesional de los \\
directores \\
escolares de los \\
SSTT \\
\end{tabular}
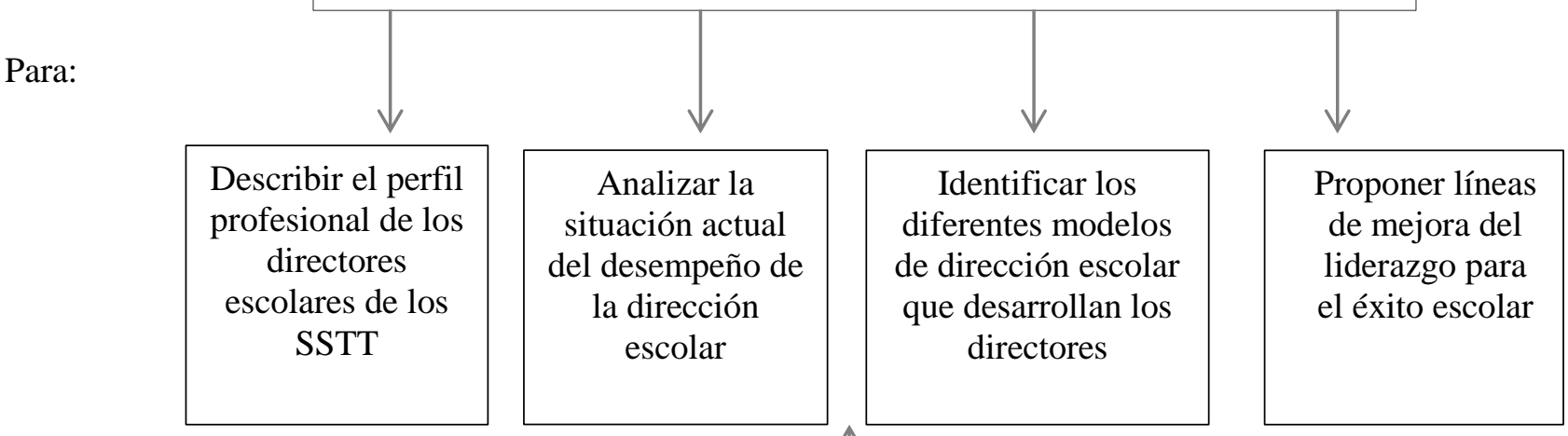

Proponer líneas de mejora del liderazgo para el éxito escolar

\section{Cón:}

Foco de atención:

La encuesta de percepción de los directores sobre su modelo de Dirección Escolar y Liderazgo, durante el curso 2013- 2014

Fundamentado en:

Analizar:

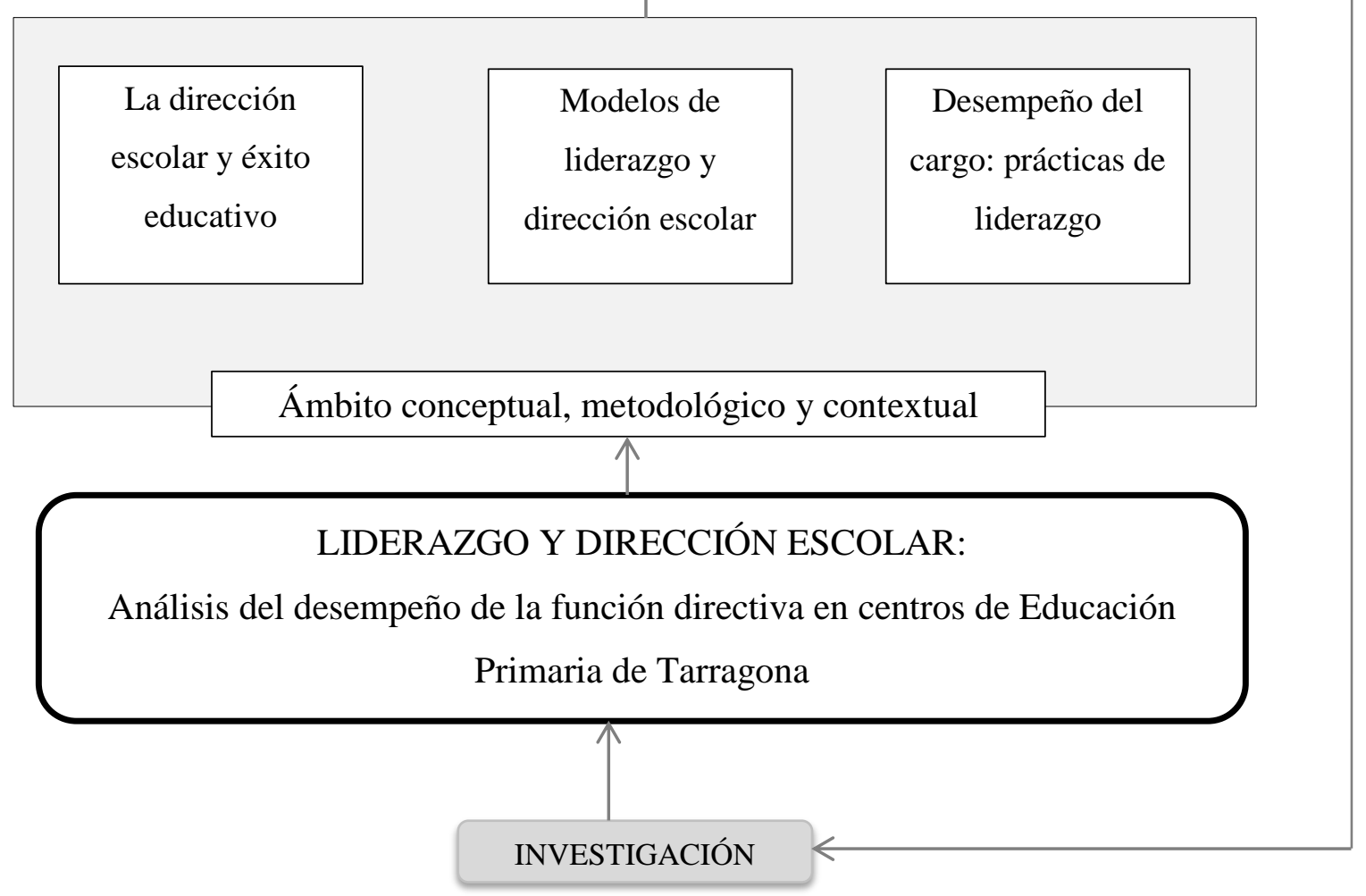




\section{Antecedentes de la investigación}

Cuando se buscan trabajos sobre esta temática, se observa un aumento considerable en los últimos años. Sin duda, el tema de estudio de esta tesis cada vez tiene más protagonismo en la actualidad nacional e internacional.

El siguiente cuadro ha sido realizado mediante la consulta en la base de datos TESEO y TDX, utilizando como principales criterios de búsqueda las expresiones:

- Dirección escolar

- Liderazgo educativo

- Educación primaria

- Modelos de dirección

Para completar la búsqueda, se han utilizado los descriptores universales establecidos por UNESCO:

Tabla 1: Descriptores código UNESCO

\begin{tabular}{|l|l|}
\hline CÓDIGO & \multicolumn{1}{c|}{ DESCRIPTOR } \\
\hline 580000 & PEDAGOGÍA \\
\hline 580202 & Organización y dirección de las instituciones \\
\hline 580204 & Educación básica \\
\hline 611412 & Liderazgo \\
\hline 580301 & Profesión y situación del profesorado \\
\hline
\end{tabular}

De los resultados de las búsquedas realizadas utilizando estos descriptores, se han seleccionado las siguientes tesis doctorales:

Tabla 2: Recopilatorio de tesis doctorales

\begin{tabular}{|c|l|l|l|}
\hline AÑO & AUTOR & TíTULO & UNIVERSIDAD \\
\hline 1992 & $\begin{array}{l}\text { CORONEL } \\
\text { LLAMAS, } \\
\text { MANUEL }\end{array}$ & $\begin{array}{l}\text { La facilitación del cambio en los centros } \\
\text { escolares: un estudio de caso sobre el papel del } \\
\text { director en los procesos de gestión y mejora } \\
\text { escolar. }\end{array}$ & SEVILLA \\
\hline 1993 & $\begin{array}{l}\text { ÁLVAREZ } \\
\text { FERNÁNDEZ, } \\
\text { MANUEL }\end{array}$ & $\begin{array}{l}\text { El perfil del director en el sistema educativo } \\
\text { español: influencia del modo de acceso y } \\
\text { modelo organizativo en el estilo de dirección. }\end{array}$ & UNED \\
\hline 1995 & $\begin{array}{l}\text { TEIXIDÓ } \\
\text { SABALLS, } \\
\text { JOAN }\end{array}$ & $\begin{array}{l}\text { Percepciones y expectativas en torno a los } \\
\text { directores de centros escolares. }\end{array}$ & $\begin{array}{l}\text { AUTÓNOMA } \\
\text { DE } \\
\text { BARCELONA }\end{array}$ \\
\hline 1996 & $\begin{array}{l}\text { GORROCHATE } \\
\text { GUI MARTELL, } \\
\text { ALFREDO }\end{array}$ & El liderazgo en los centros educativos. & NAVARRA \\
\hline
\end{tabular}




\begin{tabular}{|c|c|c|c|}
\hline 1997 & $\begin{array}{l}\text { BERNAL } \\
\text { AGUDO, } \\
\text { JOSE LUÍS }\end{array}$ & $\begin{array}{l}\text { El equipo directivo en los centros públicos de } \\
\text { primaria. Análisis de su actuación. }\end{array}$ & ZARAGOZA \\
\hline 1997 & $\begin{array}{l}\text { DEBÓN } \\
\text { LAMARQUE, } \\
\text { SANTIAGO }\end{array}$ & $\begin{array}{l}\text { La dirección escolar en España. Una función } \\
\text { en decadencia. Teorías y procesos de deterioro. }\end{array}$ & GRANADA \\
\hline 1998 & $\begin{array}{l}\text { GARCÍA } \\
\text { OLALLA, } \\
\text { ANA }\end{array}$ & $\begin{array}{l}\text { Análisis del funcionamiento de los equipos } \\
\text { directivos de centros educativos en el contexto } \\
\text { del Estado Español. }\end{array}$ & DEUSTO \\
\hline 2001 & $\begin{array}{l}\text { FERNANDEZ } \\
\text { SERRAT, } \mathrm{M}^{\mathrm{a}} \\
\text { LUISA }\end{array}$ & $\begin{array}{l}\text { Las relaciones de la dirección escolar con el } \\
\text { entorno desde una perspectiva micropolítica. }\end{array}$ & HUELVA \\
\hline 2002 & $\begin{array}{l}\text { VÁZQUEZ } \\
\text { RECIO, ROSA }\end{array}$ & $\begin{array}{l}\text { La dirección escolar y sus metáforas: símbolo, } \\
\text { acción y ética. }\end{array}$ & CÁDIZ \\
\hline 2005 & $\begin{array}{l}\text { CRUZ } \\
\text { HERNÁNDEZ, } \\
\text { ESTHER }\end{array}$ & $\begin{array}{l}\text { Los mecanismos de acceso a la dirección } \\
\text { escolar y el liderazgo educativo para las } \\
\text { escuelas efectivas de educación primaria en } \\
\text { México. }\end{array}$ & GRANADA \\
\hline 2006 & $\begin{array}{l}\text { TEJERO } \\
\text { GONZÁLEZ, } \\
\text { CARLOS M. }\end{array}$ & $\begin{array}{l}\text { Burnout y dirección escolar: análisis de la } \\
\text { influencia que sobre el síndrome ejercen las } \\
\text { variables perfil-demográfico profesional, } \\
\text { estrés, satisfacción e indefensión. }\end{array}$ & $\begin{array}{l}\text { COMPLUTENSE } \\
\text { DE MADRID }\end{array}$ \\
\hline 2006 & $\begin{array}{l}\text { ESCAMILLA } \\
\text { TISTIAN; } \\
\text { SERGIO A. }\end{array}$ & $\begin{array}{l}\text { El director escolar. Necesidades de formación } \\
\text { para un desempeño profesional. }\end{array}$ & $\begin{array}{l}\text { AUTÓNOMA } \\
\text { DE } \\
\text { BARCELONA }\end{array}$ \\
\hline 2008 & $\begin{array}{l}\text { DÍEZ ARCOS, } \\
\text { M }^{\mathrm{a}} \text { PERLA }\end{array}$ & $\begin{array}{l}\text { Profesoras y dirección escolar: análisis de las } \\
\text { causas de su baja representación en la } \\
\text { dirección de los centros públicos de la } \\
\text { comunidad de Madrid. }\end{array}$ & UNED \\
\hline 2010 & $\begin{array}{l}\text { GOMEZ } \\
\text { DELGADO, } \\
\text { ANA MARIA }\end{array}$ & $\begin{array}{l}\text { Formación inicial para la dirección escolar } \\
\text { como impulso para conseguir una dirección } \\
\text { competente en Andalucía. }\end{array}$ & HUELVA \\
\hline 2010 & $\begin{array}{l}\text { GARDA } \\
\text { MONTENEGRO, } \\
\text { VITALIA }\end{array}$ & $\begin{array}{l}\text { El liderazgo y supervisión del director en el } \\
\text { trabajo docente y su influencia en el clima } \\
\text { organizacional en una gestión escolar de } \\
\text { calidad. }\end{array}$ & GRANADA \\
\hline 2011 & $\begin{array}{l}\text { GOMEZ } \\
\text { HURTADO, } \\
\text { INMACULADA }\end{array}$ & $\begin{array}{l}\text { Dirección escolar y atención a la diversidad: } \\
\text { rutas para el desarrollo de una escuela para } \\
\text { todos. }\end{array}$ & HUELVA \\
\hline 2011 & $\begin{array}{l}\text { MENDES } \\
\text { ALVES, } \\
\text { ANACLETO }\end{array}$ & $\begin{array}{l}\text { El papel del líder en el logro de los centros } \\
\text { públicos de la enseñanza básica y secundaria } \\
\text { de Madeira. }\end{array}$ & CÁDIZ \\
\hline 2011 & $\begin{array}{l}\text { AGUILERA } \\
\text { VÁSQUEZ, } \\
\text { VICTOR F. }\end{array}$ & $\begin{array}{l}\text { Liderazgo y clima de trabajo en las } \\
\text { instituciones educativas de la fundación } \\
\text { "creando futuro". }\end{array}$ & ALCALÁ \\
\hline 2013 & $\begin{array}{l}\text { PEREZ } \\
\text { LOZANO, } \\
\text { JESUS }\end{array}$ & $\begin{array}{l}\text { Liderazgo escolar en la sociedad del } \\
\text { conocimiento. }\end{array}$ & $\begin{array}{l}\text { COMPLUTENSE } \\
\text { DE MADRID }\end{array}$ \\
\hline 2013 & $\begin{array}{l}\text { HORN KÜPFER, } \\
\text { ANDREA } \\
\text { ELIANA }\end{array}$ & $\begin{array}{l}\text { Liderazgo escolar en Chile y su influencia en } \\
\text { los resultados de aprendizaje. }\end{array}$ & $\begin{array}{l}\text { AUTÓNOMA } \\
\text { DE MADRID }\end{array}$ \\
\hline 2014 & $\begin{array}{l}\text { MEZA } \\
\text { CASCANTE, } \\
\text { DEYANIRA }\end{array}$ & $\begin{array}{l}\text { Liderazgo educativo: factores que determinan } \\
\text { el estilo de liderazgo en directores de escuela o } \\
\text { departamentos académicos en universidades }\end{array}$ & VALENCIA \\
\hline
\end{tabular}




\begin{tabular}{|l|l|l|l|}
\hline 2015 & $\begin{array}{l}\text { EVANS RISCO, } \\
\text { ELISABETH }\end{array}$ & $\begin{array}{l}\text { lnterracción entre inteligencia emocional y } \\
\text { estilos de liderazgo en directivos de } \\
\text { instituciones educativas. }\end{array}$ & VALENCIA \\
\hline 2015 & $\begin{array}{l}\text { GONZÁLEZ } \\
\text { BUSTAMANTE, } \\
\text { ANITA } \\
\text { MAGALY }\end{array}$ & Dirección escolar exitosa. Un estudio de casos. & $\begin{array}{l}\text { AUTÓNOMA } \\
\text { DE MADRID }\end{array}$ \\
\hline
\end{tabular}

A parte de las tesis doctorales, en los últimos años también han crecido el número de investigadores focalizados en la dirección escolar y el liderazgo. Un ejemplo es la creación de la Red de Investigación sobre Liderazgo y Mejora Educativa (RILME) con el objetivo de concertar el conocimiento, recursos y trayectoria de varios grupos de investigación de universidades españolas sobre la misma temática. Se trata de una red conformada hasta el momento por los siguientes grupos de investigación:

- Cambio Educativo para la Justicia Social (GICE) - Universidad Autónoma de Madrid

- Formación centrada en la Escuela (FORCE) - Universidad de Granada

- Grupo de Investigación Educativa (DOCE)- Universidad de Huelva

- Innovación, Desarrollo, Evolución y Asesoramiento en Educación (IDEA!) Universidad de Sevilla

Algunos de los proyectos de la red RILME son:

- Distribución del liderazgo en los centros escolares. Alcance y modalidades. Proyecto financiado por el Ministerio de Ciencia e Innovación dentro del Plan Nacional de I+D+i. Referencia: EDU2011-26436.

Investigador principal: Julián López Yáñez

- Liderazgo educativo para la Justicia Social

Proyecto financiado por el Ministerio de Ciencia e Innovación dentro del Plan Nacional de I+D+i. Referencia: EDU2010-18224.

Investigador principal: Javier Murillo Torrecilla

- Liderazgo centrado en el aprendizaje y su impacto en la mejora: Prácticas y resultados en Secundaria.

Proyecto financiado por el Ministerio de Ciencia e Innovación dentro del Plan Nacional de I+D+i. Referencia EDU2010-16131.

Investigador principal: Antonio Bolívar Botía. 
En la siguiente tabla aparecen distintas investigaciones, realizadas o en curso, sobre la temática a nivel nacional:

Tabla 3: Recopilación de investigaciones sobre la temática

\begin{tabular}{|c|c|c|}
\hline Investigador principal & Año & Título investigación \\
\hline Murillo Torrecilla, Javier & 1999 & La dirección escolar: Análisis e investigación. \\
\hline Teixidó Saballs, Joan & 2000 & $\begin{array}{l}\text { El acceso a la dirección de un centro educativo público. } \\
\text { Estudio de los factores mentales de los candidatos a la } \\
\text { dirección de centros educativos públicos, de nivel } \\
\text { primario y secundario, en los procesos de toma de } \\
\text { decisión en torno a la presentación de candidatura, } \\
\text { elaboración del proyecto de dirección e intervención en } \\
\text { el proceso electoral. }\end{array}$ \\
\hline Sánchez Moreno, Marita & 2002 & $\begin{array}{l}\text { La mujer en la dirección y gestión de las } \\
\text { organizaciones universitarias: problemática, estilos de } \\
\text { liderazgo y contribución al desarrollo institucional. }\end{array}$ \\
\hline López Yáñez, Julián & 2005 & $\begin{array}{l}\text { Liderazgo y desarrollo } \\
\text { organizaciones educativas. }\end{array}$ \\
\hline Iranzo García, Pilar & 2007 & $\begin{array}{l}\text { La mejoras de la función directiva en centros con un } \\
\text { alto grado de diversidad y en contextos de dificultad: } \\
\text { trabajo en red para conformar una zona educativa de } \\
\text { calidad. }\end{array}$ \\
\hline Murillo Torrecilla, Javier & 2010 & Liderazgo educativo para la justicia social. \\
\hline López Yáñez, Julián & 2011 & $\begin{array}{l}\text { Distribución del liderazgo en los centros escolares: } \\
\text { alcances y modalidades. }\end{array}$ \\
\hline Bolívar Botia, Antonio & 2013 & $\begin{array}{l}\text { Liderazgo pedagógico y desarrollo del centro como } \\
\text { comunidad profesional: prácticas de éxito en educación } \\
\text { obligatoria. }\end{array}$ \\
\hline Barrios Arós, Charo & 2013 & $\begin{array}{l}\text { La dirección y organización de centros educativos } \\
\text { como competencias del Practicum y TFG en alumnos } \\
\text { de grados de educación. }\end{array}$ \\
\hline Iranzo García, Pilar & 2014 & $\begin{array}{l}\text { Las nuevas exigencias para la dirección escolar en la } \\
\text { educación primaria: análisis y propuestas. }\end{array}$ \\
\hline
\end{tabular}

A nivel internacional, destacamos la International Successful School Principalship Project (ISSPP), fundada y coordinada por Christopher Day (Universidad de Nottingham). Se trata de una red centrada en el estudio del liderazgo y prácticas escolares de éxito. La red se inició en 2001 con representantes de ocho países (Australia, Canadá, China, Dinamarca, Inglaterra, Noruega, Suecia y Estados Unidos). En la actualidad la red está formada por 14 países (España está representada por el grupo RILME). 
DIRECCIÓN ESCOLAR Y LIDERAZGO

\section{PRIMARIA DE TARRAGONA}

ANÁLISIS DEL DESEMPEÑO DE LA FIGURA DIRECTIVA EN CENTROS DE EDUCACIÓN Marta Camarero Figuerola 
DIRECCIÓN ESCOLAR Y LIDERAZGO: ANÁLISIS DEL DESEMPEÑO DE LA FIGURA DIRECTIVA EN CENTROS DE EDUCACIÓN PRIMARIA DE TARRAGONA

Marta Camarero Figuerola

\section{A. MARCO CONCEPTUAL}


DIRECCIÓN ESCOLAR Y LIDERAZGO

\section{PRIMARIA DE TARRAGONA}

ANÁLISIS DEL DESEMPEÑO DE LA FIGURA DIRECTIVA EN CENTROS DE EDUCACIÓN Marta Camarero Figuerola 


\section{CAPÍTULO I: DIRECCIÓN ESCOLAR Y LIDERAZGO}

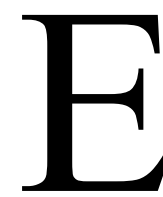

n este capítulo, se aborda el concepto de liderazgo y de dirección escolar conjuntamente ya que al realizar la revisión bibliográfica, se observa que la dirección escolar y el liderazgo son términos estrechamente relacionados.

De esta forma, es necesario en nuestro estudio conocer la tensión entre la dirección escolar y el liderazgo educativo; esa tensión tiene una evolución histórica recogida en los grandes modelos transaccional y transformacional.

Se mencionan las diferencias entre líder y director y entre poder y autoridad pero se enfatiza la complementación de la dirección escolar y liderazgo. Se plantea el debate de la profesionalización del cargo directivo. Se define qué es el éxito educativo y el impacto del liderazgo en él, concretando el tipo de influencia que ejerce el líder, así como el tipo de impacto del liderazgo en el centro. 


\subsection{Definición dirección escolar y liderazgo}

En relación al concepto de la dirección escolar, Argos \& Esquerra la definen como "un medio para mejorar la calidad de los centros educativos" (2014: 221). Y el liderazgo como "el punto de partida de cualquier mejora. Por tanto, recomienda fortalecer y apoyar a la dirección escolar (...)” (idem). Entendemos que es una función educativa vinculada a la organización, gestión y liderazgo de los centros y que se encarna en la figura del director escolar.

Respecto el concepto de liderazgo, existen numerosas definiciones, tantas como autores e investigaciones sobre la temática (Kaufmann, 1997). El aspecto en común en las diferentes definiciones es la definición del liderazgo como un proceso de influencia entre líder y los seguidores (comunidad escolar) con la finalidad de lograr las metas establecidas y los objetivos en común.

Destacamos algunas definiciones del concepto de liderazgo:

"El proceso de llevar a un grupo (o grupos) de personas en una determinada dirección, por (en la mayoría de los casos) medios no coercitivos (...) un "buen" liderazgo conduce a la gente en una dirección que es la que realmente conviene a largo plazo" (Kotter, 1990: 17-18).

"El liderazgo es el proceso de influir en las actividades de un individuo o un grupo en los esfuerzos que se realicen encaminados a logro de metas en una situación dada" (Hersey \& Blanchard, 1993: 2).

"Se puede definir el liderazgo como una cierta capacidad de transformar una visión en realidad” (Bennis, 1994).

"El liderazgo consiste en crear, alimentar y desarrollar la capacidad de los docentes y estudiantes para que se involucren en un buen aprendizaje” (Elmore, 2010).

"Definimos el liderazgo como el proceso de influir en otras personas de tal forma que se las anima a contribuir voluntariamente a la consecución de los objetivos grupales" (Haslam, Reicher, \& Platow, 2011: 79). 
"El liderazgo se percibe como el promotor del cambio organizativo e institucional. El líder, por tanto, tiene como misión promover y gestionar el cambio de la organización” (Villa, Escotet, \& Goñi, 2007: 53)

Como se observa, se enfatiza el liderazgo como un proceso de influencia (individual o de grupo) con la finalidad de lograr metas conjuntas. Es considerado la fuerza impulsora de la organización, con una función creadora, con proyección de futuro, de carácter participativo y persuasivo.

Según la Real Academia Española (RAE) un líder es:

Tabla 4: Definición de líder

\section{Líder.}

(Del ingl. leader, guía).

1. com. Persona a la que un grupo sigue, reconociéndola como jefe u orientadora.

2. com. Persona o equipo que va a la cabeza de una competición deportiva.

3. com. Construido en aposición, indica que lo designado va en cabeza entre los de su clase.

Es un líder quien dirige a un grupo de una manera carismática y motivadora. Por tanto, un líder necesita tener una capacidad innovadora, un toque "mágico" que motive. Además deber ver más allá y antes que los demás (Molinar \& Velázquez, 2005). El nombramiento de líder no lo asigna la organización, sino que lo otorga la comunidad educativa (Bazarra \& Casanova, 2013).

Existen algunos mitos sobre el concepto del liderazgo que Molinar \& Velázquez (2005) los desmienten argumentándolos de la siguiente manera:

1. "Hay muy pocos líderes": se está desperdiciando potencial de liderazgo de muchos profesionales en el mundo de la educación. Cada profesor puede ser líder.

2. “Los líderes están en puestos superiores": el liderazgo está en todos los puestos.

3. "El liderazgo es innato": el liderazgo, por el contrario, se puede aprender. Con motivación y entusiasmo se pueden desarrollar habilidades y actitudes propias del liderazgo, aunque en opinión de Bolívar (2011a: 257) "sea difícil llegar a ser líderes" si no se posen ciertas características innatas.

En cualquier caso apostamos por la capacitación de los directores a través de una acción formativa para ejercer un buen liderazgo educativo. 


\subsection{Perfil de manager versus Perfil de líder}

Los conceptos de director, jefe, líder, administrador, etc., suelen utilizarse de manera sinónima pero sus significados son diferentes y tienen características específicas.

Destacamos las diferencias entre los conceptos de: administrar y liderar. Mientras que "administrar" es cumplir con las responsabilidades del cargo directivo, "liderar" es orientar, influir en la acción u opinión (Meza, 2014) y qué, sí incluyen el liderazgo pedagógico y distribuido.

Bennis \& Nanus (2001) afirman que el director actúa utilizando los instrumentos y técnicas concretas de los recursos físicos de la organización. En cambio, el líder actúa utilizando los valores, los compromisos y las aspiraciones, es decir, actúa en los recursos emocionales. De ahí que Fullan (2002) afirme que los líderes deben actuar con seguridad en circunstancias complejas e inciertas.

Se entiende la dirección como un cargo, un puesto de trabajo, una función, que otorga un poder legítimo al manager (directivo). En cambio, el liderazgo le otorga autoridad ante un grupo basada en la influencia, en el carisma del líder. Por tanto el liderazgo no tiene por qué darse exclusivamente en el cargo directivo.

Álvarez (2010b) establece un cuadro con las diferencias entre acciones directivas y acciones de liderazgo:

Tabla 5: Diferencias entre manager y líder

\begin{tabular}{|c|c|}
\hline & $\begin{array}{l}\text { La planificación: conoce todos los procesos que tienen lugar en la escuela. Es } \\
\text { un buen gestor del tiempo y de las acciones que conducen a la consecución de } \\
\text { los objetivos. } \\
\text { - La gestión financiera: elabora y gestiona los presupuestos. }\end{array}$ \\
$\begin{array}{c}\text { El } \\
\text { manager } \\
\text { realiza: }\end{array}$ & $\begin{array}{l}\text { La organización del trabajo: crea estructuras formales en la organización, las } \\
\text { dota personal cualificado, define los perfiles y facilita los recursos. }\end{array}$ \\
& $\begin{array}{l}\text { Seguimiento y control de los procesos: conoce técnicas de seguimiento y } \\
\text { supervisión de los planes previamente establecidos y las estrategias para } \\
\text { reconducir acciones. }\end{array}$ \\
\end{tabular}




\begin{tabular}{|l|l|}
\hline & - Visión de futuro: tiene en cuenta los intereses de las personas que trabajan en el \\
& centro y las expectativas del alumnado. \\
& - Intuición: conoce o intuye que puede atribuir éxito al centro y las estrategias \\
El líder & para conseguirlo. \\
realiza: & - Crea equipo: implica a los colaboradores en los procesos clave y comparte su \\
& liderazgo. \\
& - Motiva: tiene la capacidad para animar a sus colaboradores e implicarlos en \\
& nuevos proyectos. \\
- Reconvierte los conflictos: tiene la habilidad de reconvertir un conflicto a través \\
de la mediación y controlar los aspectos "tóxicos".
\end{tabular}

Fuente: Elaboración propia a partir de Álvarez, 2010b: 24

Palomo (2008) realiza una recopilación de la diferenciación entre el perfil de manager y el perfil de líder de varios autores:

Tabla 6: Dirigir vs liderar

\begin{tabular}{|c|c|c|}
\hline Autor/es & Manager (dirigir) & Liderar \\
\hline Lowy \& Hood (2004) & Resuelve problemas & Gestiona dilemas \\
\hline $\begin{array}{l}\text { Nicolaou- Smokoviti } \\
\text { (2004) }\end{array}$ & $\begin{array}{l}\text { Legitimado por la organización y } \\
\text { sus estructuras }\end{array}$ & $\begin{array}{l}\text { Legitimado por la existencia de } \\
\text { seguidores voluntarios }\end{array}$ \\
\hline Spigener (2004) & $\begin{array}{l}\text { Rol funcional } \\
\text { Enfocado en las tareas } \\
\text { Dirige } \\
\text { Regula las actividades de los } \\
\text { demás }\end{array}$ & $\begin{array}{l}\text { Rol cultural } \\
\text { Enfocado a las prácticas y los } \\
\text { objetivos } \\
\text { Coach } \\
\text { Guía actividades para sí mismo, } \\
\text { en grupo e individualmente }\end{array}$ \\
\hline Zalenick (2004) & $\begin{array}{l}\text { Énfasis en lo racional y el control } \\
\text { Resuelve problemas } \\
\text { Se caracteriza por su inteligencia, } \\
\text { habilidades analíticas, } \\
\text { persistencia, tolerancia y por su } \\
\text { buena voluntad } \\
\text { Los objetivos dan respuesta a las } \\
\text { necesidades } \\
\text { Da respuesta a las ideas } \\
\text { Prefiere trabajar con personas } \\
\text { Sigue el curso de la vida }\end{array}$ & $\begin{array}{l}\text { Énfasis en la inspiración y en la } \\
\text { asunción de riesgos } \\
\text { Desarrolla nuevas ideas } \\
\text { Se caracteriza por su tolerancia } \\
\text { en situaciones de caos, pasión, } \\
\text { intensidad y por su empatía } \\
\text { Los objetivos se derivan de la } \\
\text { visión } \\
\text { Da forma a las ideas } \\
\text { A menudo le gusta estar solo } \\
\text { Considera que hay muchas vidas }\end{array}$ \\
\hline Ackoff (2003) & $\begin{array}{l}\text { Autoridad } \\
\text { Tiene subordinados } \\
\text { Objetivos: mantener y explotar las } \\
\text { ventajas del negocio }\end{array}$ & $\begin{array}{l}\text { Carisma } \\
\text { Tiene seguidores } \\
\text { Objetivo: llevar a cabo con éxito } \\
\text { las transformaciones } \\
\text { organizacionales }\end{array}$ \\
\hline $\begin{array}{c}\text { Alvesson \& } \\
\text { Sveningsoon }(2003)\end{array}$ & $\begin{array}{l}\text { Crea estabilidad } \\
\text { Es racional }\end{array}$ & $\begin{array}{l}\text { Genera cambios } \\
\text { Visionario }\end{array}$ \\
\hline
\end{tabular}




\begin{tabular}{|c|c|c|}
\hline Bennis (2003) & $\begin{array}{l}\text { Administra } \\
\text { Es una copia } \\
\text { Mantiene el centro } \\
\text { Confían en los controles } \\
\text { Visión a corto plazo } \\
\text { Pregunta cómo y cuándo } \\
\text { Le interesan los resultados } \\
\text { Aceptan el statu quo } \\
\text { Hacen las cosas correctamente }\end{array}$ & $\begin{array}{l}\text { Innova } \\
\text { Es original } \\
\text { Desarrolla en el centro } \\
\text { Inspiran confianza } \\
\text { Perspectiva a largo plazo } \\
\text { Pregunta qué y por qué } \\
\text { Vista puesta en el horizonte } \\
\text { Desafían su status quo } \\
\text { Hacen las cosas que se deben } \\
\text { hacer }\end{array}$ \\
\hline Caldwell (2003) & $\begin{array}{l}\text { Facilitador } \\
\text { Planifica, organiza, dirige, } \\
\text { controla, recompensa y castiga } \\
\text { Se centra en detalles pequeños }\end{array}$ & $\begin{array}{l}\text { Innovador } \\
\text { Tiene visión, explora } \\
\text { oportunidades, desencadena } \\
\text { cambios estratégicos, motiva } \\
\text { Crea grandes cambios }\end{array}$ \\
\hline Zimmermann (2001) & $\begin{array}{l}\text { Enfocado en las cuestiones micro } \\
\text { Capitán } \\
\text { Analista } \\
\text { Conductor } \\
\text { Controlador }\end{array}$ & $\begin{array}{l}\text { Enfocado en las cuestiones } \\
\text { macro } \\
\text { Visionario } \\
\text { Colaborador } \\
\text { Vendedor } \\
\text { Negociador }\end{array}$ \\
\hline Kotter (2001) & $\begin{array}{l}\text { Hace frente a la complejidad } \\
\text { Controla y resuelve problemas } \\
\text { Organiza y dota de personal } \\
\text { Planifica y presupuesta }\end{array}$ & $\begin{array}{l}\text { Hace frente a los cambios } \\
\text { Motiva e inspira a los demás } \\
\text { Aliena a las personas } \\
\text { Establece una dirección clara }\end{array}$ \\
\hline Kotter (1990) & $\begin{array}{l}\text { Los resultados de una gestión } \\
\text { eficaz se basan en la predicción, } \\
\text { el orden y consecución de } \\
\text { resultados para los Stakeholders }\end{array}$ & $\begin{array}{l}\text { Los resultados de un liderazgo } \\
\text { eficaz se basan en cambios } \\
\text { dramáticos y de éxito (nuevos } \\
\text { productos, nuevos procesos, } \\
\text { nuevos enfoques), resultando un } \\
\text { incremento notable en la } \\
\text { competitividad }\end{array}$ \\
\hline Rost (1998) & $\begin{array}{l}\text { Autoridad } \\
\text { Tiene subordinados } \\
\text { Orientado a producir y a vender } \\
\text { productos/servicios } \\
\text { Los productos y servicios resultan } \\
\text { de la coordinación de las } \\
\text { actividades de los directores y los } \\
\text { subordinados }\end{array}$ & $\begin{array}{l}\text { Influencia } \\
\text { Tiene colaboradores } \\
\text { Orientado a intentar cambios } \\
\text { reales } \\
\text { Los cambios se reflejan en los } \\
\text { objetivos de los líderes y de sus } \\
\text { colaboradores (seguidores) }\end{array}$ \\
\hline $\begin{array}{c}\text { Droullard \& Kleiner } \\
\text { (1996) }\end{array}$ & Evita y manipula & Confronta y crece \\
\hline
\end{tabular}

Fuente: Palomo (2008: 18-19)

Como podemos observar, el perfil de manager es un perfil más basado en estructuras y procesos técnicos mientras que el perfil de líder es más moral, espiritual y basado en el magnetismo más centrado en las personas y los procesos relacionales. 
Santos (2015) considera que el director puede ser un líder si ejerce una influencia carismática; un técnico si domina las estrategias profesionales y recursos del centro; un jefe si tiene capacidad de control y de sanción; un asesor si acompaña a otros miembros y comparte saberes especializados; un coordinador si sabe promover la colaboración entre todos los miembros y un animador si tiene habilidades comunicativas y empáticas.

A pesar de las diferencias de los diferentes perfiles, en la revisión de la literatura e investigaciones de la temática, se muestra que no existe ningún tipo de oposición entre el perfil de manager y el perfil de líder. Son perfiles complementarios ya que normalmente los buenos directores son buenos líderes y, generalmente, los buenos líderes son buenos directores (Kotter, 2000; Palomo, 2008).

Según Gómez-Hurtado (2012) es fácil caer en la trampa de percibir el liderazgo con una visión positiva y la dirección con una visión negativa (control). Es decir, definir el liderazgo como algo agradable y necesario y la dirección como algo que controla y es impersonal.

Para Ainscow et al., "el liderazgo y dirección permanecen inextricablemente ligados, pero se necesitan estrategias positivas para desarrollar el liderazgo en las escuelas y para reflejarlo en las estructuras de dirección" (2001: 108). Con la experiencia de estos autores, definen el liderazgo como un factor que influye decisivamente en su capacidad de enfrentarse a los cambios y realizar mejoras en los centros educativos.

Consideramos beneficioso unir y trabajar conjuntamente los dos conceptos y considerar la dirección y liderazgo como complementarios. A pesar de que a nivel teórico se puedan diferenciar los dos conceptos: la dirección (posición formal) que garantiza el funcionamiento en una realidad dada; y liderazgo (función) que contribuye a crear nuevas realidades (Bolívar, 2000), creemos que es una diferenciación forzada entre conceptos y realmente se deben conceptualizar como unidos, más cuando actualmente la dirección escolar se define como liderazgo pedagógico y distribuido.

Nuestro trabajo lo enfocamos en esa dirección: entender el liderazgo como un componente necesario para el ejercicio de la dirección escolar. 


\subsection{Poder versus autoridad}

"Un error que no debemos cometer cuando asumimos una nueva responsabilidad es confundir poder con autoridad. Ya en la antigua Roma esta distinción entre "potestas", y “autoritas" era meridianamente clara” (Bazarra, 2012:18).

Se suelen confundir los términos autoridad y poder. Se piensa que quien tiene la autoridad, de forma inmediata también tiene el poder (Gámez, Soria, \& López-Portillo, 2006). Consideramos importante establecer la diferenciación entre estos dos conceptos. La RAE define el término de autoridad y término poder como:

Tabla 7: Definición autoridad y poder

\section{Autoridad.}

(Del lat. auctorĭtas, -ātis)

1. f. Poder del que gobierna o ejerce el mando, de hecho o de derecho.

2. f. Potestad, facultad, legitimidad.

3. f. Prestigio y crédito que se reconoce a una persona o institución por su legitimidad o por su calidad y competencia en alguna materia.

4. f. Persona que ejerce o posee cualquier clase de autoridad.

5. f. Solemnidad, aparato.

6. f. Texto, expresión o conjunto de expresiones de un libro o escrito, que se citan o alegan en apoyo de lo que se dice.

\section{Poder.}

(Del lat. *potēre, formado según potes, etc.).

1. m. Dominio, imperio, facultad y jurisdicción que alguien tiene para mandar o ejecutar algo.

2. m. Gobierno de un país.

3. m. Acto o instrumento en que consta la facultad que alguien da a otra persona para que en lugar suyo y representándole pueda ejecutar algo. U. m. en pl.

4. m. Posesión actual o tenencia de algo. Los autos están en poder del relator.

5. m. Fuerza, vigor, capacidad, posibilidad, poderío.

6. m. Suprema potestad rectora y coactiva del Estado.

Fuente: RAE

"El poder es un acto; algo que se utiliza o se ejerce con el fin de sustentar el poder, la gente ejerce poder con conciencia de la identidad propia, para indicar a otro su conciencia de las obligaciones de su papel” (Robbins, 1996: 490). 
El poder es un concepto debatible acerca de su significado, sus usos adecuados y de los sujetos que lo ejercen. El poder se aplica mediante reglas y procedimientos que involucran jerarquía (Gámez et al., 2006).

Weber (1947) distingue así poder y autoridad: el poder involucra la fuerza o la coerción $\mathrm{y}$ es un factor importante como proceso interno en las organizaciones. En cambio, autoridad es una forma de poder que no implica poder. Su complimiento es voluntario.

La autoridad es aquel tipo de poder que los individuos conferimos a los directores. Weber (1970) establece diferentes tipos de autoridad:

- Autoridad legal: son la mayoría de relaciones de poder en las organizaciones actuales. Se basa en la creencia del derecho de aquellas personas que están en una jerarquía superior y tienen poder sobre los subordinados.

- Autoridad carismática: es la que proviene de la lealtad hacia el cargo directivo. Se basa en las características personales del directivo. Un directivo de autoridad carismática extiende más poder sobre sus subordinados que los que le otorgó la organización.

- Autoridad tradicional: se basa en la creencia del orden tradicional establecido (a través de una jerarquía).

Los autores Blase \& Kirby (2013) alegan que el reparto del poder no es símbolo de debilidad del director sino todo lo contrario: la autoridad de los directores se amplía cuando se comparte. Manifiestan que los directores eficaces sugieren, no imponen. Es decir, respetan las decisiones del profesorado para que éstos no perciban su ayuda como órdenes. Para conseguirlo, las intervenciones deben ser apropiadas y acompañadas de material y oportunidades para la actualización profesional.

En conclusión, el poder es la toma de decisiones que afecta a otros individuos, es imponer a otra persona la propia voluntad a partir de una posición jerárquica. En cambio, la autoridad es la capacidad de conseguir que los individuos hagan lo que uno quiere debido a su influencia personal (carisma). 


\title{
1.4 Éxito educativo y liderazgo
}

\begin{abstract}
A nivel internacional la dirección escolar está considerada un factor determinante en la mejora de los centros educativos en general y de manera específica en la mejora de los resultados escolares del alumnado. Los estudios internacionales sobre la eficacia escolar manifiestan que el liderazgo del director es una de las variables que más influye en el éxito escolar.
\end{abstract}

La dirección escolar y el liderazgo están considerados por la literatura científica el segundo factor más influyente en los resultados escolares, después de la acción del profesorado (Waite \& Nelson, 2005; Mulford, 2006; Leithwood, Harris, \& Hopkins, 2008; OCDE, 2008; Bolívar, 2010).

La comunidad científica internacional asume, también, la necesidad de una capacitación específica y profesional para el desarrollo de la función del liderazgo orientado hacia el éxito escolar.

En ese sentido, la OCDE (2009) ya identificaba cuatro líneas de actuaciones prioritarias: redefinir las responsabilidades y funciones del liderazgo para mejorar los resultados escolares, distribuir el liderazgo escolar, desarrollar habilidades para un liderazgo eficaz y aumentar el atractivo del liderazgo escolar como profesión.

A esas líneas prioritarias para todos los contextos escolares, en general, se sumaría la necesidad de un mejor estudio de la vinculación entre el liderazgo y el éxito escolar en contextos marcados por dificultades socioeconómicas y culturales (Dyson, 2008).

El liderazgo escolar es, por tanto, necesario para articular favorablemente las condiciones de la escuela y disponer de medios para mejorar la coordinación, la supervisión y la colaboración con los recursos del entorno.

Se entiende por "éxito en el liderazgo" la capacidad de conseguir resultados sostenibles a lo largo del tiempo. La sostenibilidad se asegura logrando retener a los talentos mediante la creación de un clima de trabajo que genere e inspire confianza, creatividad y favorezca los compromisos (Goleman, Boyatzis, \& McKee, 2010).

Por "éxito educativo" se entiende la capacidad de conseguir mejorar los resultados académicos de los alumnados. Para ello se hace necesario fomentar una formación más profesional a toda la comunidad educativa y trabajar conjuntamente para favorecer la 
calidad de la enseñanza. En ese sentido Bolívar \& Bolívar (2013) apuntan que el éxito educativo de un centro está influenciada por cinco componentes claves:

- Liderazgo de la dirección, liderazgo distribuido, que impulse todo el proceso de mejora.

- Conocimientos, competencias y disposiciones de los miembros individuales.

- Una comunidad profesional de aprendizaje donde los docentes trabajan colaborativamente para conseguir metas en el aprendizaje de los alumnos.

- Coherencia del programa: contenidos coherentes y coordinados, focalizados en unas metas claras.

- Recursos técnicos, alta calidad del currículum, libros y otros materiales de enseñanza, instrumentos de evaluación, equipos, etc.

En las escuelas eficaces el liderazgo está centrado principalmente en la gestión de los aprendizajes y en la mejora de las prácticas docentes y, en un segundo plano, en los aspectos más administrativos (Rodríguez, 2011).

Southword (2004) menciona las características de un liderazgo con impacto en los resultados:

- Los directivos líderes marcan diferencias. Promueven la innovación y crean espacios de intercambio profesional para el profesorado.

- Los factores externos y personales condicionan el estilo de liderazgo.

- Los líderes, con impacto, son personas positivas. Tienen altas expectativas sobre los miembros de la comunidad.

- Se basan en las personas. Cuidan la comunicación y se relacionan positivamente.

- Los objetivos, misión, visión y propósitos los tienen bien definidos y saben transmitirlo a los otros miembros de la comunidad.

- Sus acciones están orientadas a la mejora de resultados.

- El liderazgo no es un rol. Es un servicio que promueve los buenos resultados y que el profesorado se desarrolle profesionalmente.

Según Day et al. (2009), establecer una dirección (visión, expectativas, meta de grupo), desarrollar al personal, rediseñar la organización y gestionar los programas de enseñanza y aprendizaje, son prácticas de liderazgo que tienen un impacto en el aprendizaje del alumno. 
A nivel internacional, en los últimos años han aumentado, sobre todo en el ámbito anglosajón, las investigaciones que evidencian el carácter estratégico del liderazgo escolar en los procesos de mejora (Hallinger \& Heck, 2011; Leithwood, Patten \& Jantzi, 2010).

Gran parte de las evidencias se extraen a partir de estudios transversales y estudios de casos, pero hay pocos estudios longitudinales que proporcionen una visión más completa de los efectos del liderazgo en la mejora educativa (Thoonen et al., 2011) y en la inclusión social en los contextos desfavorecidos (Iranzo, Tierno \& Barrios, 2014; Sun \& Leithwood, 2012).

A la complejidad de la evaluación del aprendizaje de los alumnos (Ferreres \& González Soto, 2006) se suma la complejidad de los procesos de investigación que vinculan dirección e impacto en el aprendizaje de los alumnos.

Algunas investigaciones exhiben las funciones y responsabilidades que conducen a mejorar el aprendizaje del alumnado (Waters, Marzano, \& McNulty, 2003) y destacan la relevancia del papel y las tareas directivas en los centros educativos.

Respecto el impacto del liderazgo en el éxito educativo, el liderazgo del director influye en el ambiente escolar, en el profesorado, en las actitudes del personal del centro, en el aprendizaje del centro y en el rendimiento académico (Shatzer et al., 2014; Ten Bruggente et al., 2012) que están mediados por las condiciones que fomentan la capacidad de la escuela para el cambio (Leithwood et al., 2010).

Los efectos del liderazgo en el éxito educativo del centro pueden ser indirectos o directos.

Respecto a los indirectos se reflejan a través del trabajo del profesorado en sus aulas y en la modificación de sus prácticas. La evidencia empírica no es concluyente pero apunta a la influencia indirecta del liderazgo en el éxito educativo (Hallinger \& Heck, 2011):

- Crea ambientes de aprendizaje positivos para los estudiantes y el profesorado.

- Aumenta las expectativas académicas del currículum y el apoyo académico que los estudiantes reciben.

- Emplea estrategias de mejora coherentes con el estado cambiante de la escuela. 
- Apoya el aprendizaje profesional continuo del personal del centro, que a su vez facilita los esfuerzos de implementar y sostener el cambio educativo.

El director debe convertirse en el líder de los líderes y con su liderazgo promover el liderazgo docente. ¿Cómo? A partir de los efectos directos: facilitando al profesorado condiciones para el desarrollo de competencias en una cultura de colaboración y creando espacios de trabajo con el objetivo de mejorar entre todos la calidad escolar (Bolívar, López \& Murillo, 2013).

Heck \& Hallinger (2010) establecen una serie de relaciones recíprocas entre las diferentes variables que influyen en la mejora escolar:

Ilustración 1: Relaciones recíprocas del liderazgo

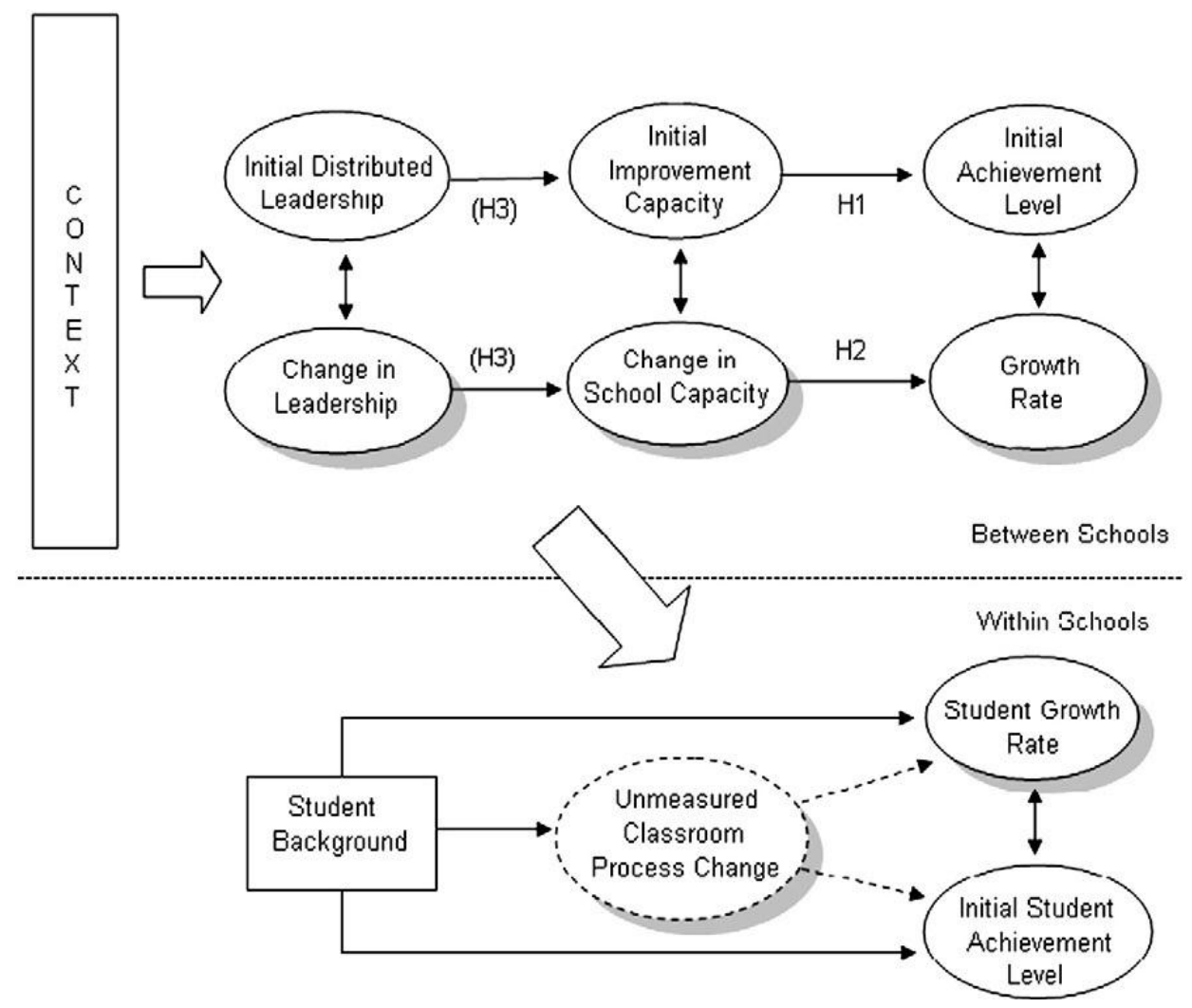

Fuente: Heck \& Hallinger (2010: 870)

Como observamos en la imagen, el contexto es una variable común que influye en las distintas variables, mientras que el liderazgo es una variable dinámica que puede tener mayor impacto en el cambio (Shatzer et al., 2014). 
Las flechas con dos puntas indican una relación de reciprocidad entre dos variables como: liderazgo inicial-cambio liderazgo, capacidad inicial-cambio en la capacidad de la escuela y éxito inicial- crecimiento de la escuela.

Heck \& Hallinger (2010) afirman que la vía para impulsar el desarrollo de la mejora de la escuela es el liderazgo distribuido ya que implica el desarrollo de una visión para el cambio, motiva y capacita a los miembros del centro educativo para lograr una visión conjunta.

Además, el liderazgo distribuido no se limita exclusivamente a los puestos formales y crea condiciones que apoyan y fomentan el aprendizaje profesional del profesorado para incrementar la capacidad de la escuela para conseguir un aumento de rendimiento de los estudiantes (Heck \& Hallinger, 2010; Leithwood et al., 2010).

A pesar de la influencia del contexto en las prácticas de liderazgo para conseguir una mejora en los resultados, otros autores como Sun \& Leithwood (2012) detectan que numerosas prácticas no tienen en cuenta el contexto del centro.

En las políticas supranacionales (OCDE y UNESCO) aparecen tres factores (humano, gestión y profesional) que convierten a un director en un líder educativo de calidad (Valle \& Martínez, 2010). Según la OCDE (Pont, Nusche, \& Moorman, 2009):

- El factor humano es la influencia que tiene el director con los diferentes miembros de la comunidad. Profesorado: debe motivar al profesorado, apoyarlos y orientarlos en su práctica profesional. Alumnado: es el responsable del nivel del aprendizaje y es el representante del centro.

- El factor de gestión en tanto el director es el responsable de autoadministrar y autogestionar el centro. Debe tener conocimientos sobre funciones administrativas y económicas.

- El factor profesional requiere una formación basada en habilidades, estrategias y competencias que capaciten al director más allá de las competencias estrictamente pedagógicas. 


\subsection{Profesionalización del cargo directivo}

La dirección requiere un conjunto de conocimientos, capacidades y competencias muy específicas y complejas que no se adquieren sólo con la acumulación de experiencia"

(Silva, 2012:4)

La profesionalización de los directores escolares y su formación ocupan las agendas internacionales porque influyen críticamente en el éxito educativo, desde el liderazgo pedagógico y distribuido.

En la actualidad, hay un debate sobre la profesionalización del cargo directivo. ¿Por qué profesionalización o no profesionalización de los directores? ¿Qué se entiende por profesionalización del cargo?

Según Tejada et al. (2009: 13) en cualquier profesión se precisa de una profesionalización que implica una identidad profesional, requisitos de acceso, formación, competencias profesionales, desarrollo profesional y procesos de evaluación del desempeño.

El concepto de profesionalización remite a la capacitación y dotación de condiciones profesionales para el desempeño de una función (Barrios, Iranzo y Tierno, 2013) y, como tal, implica etapas de desarrollo profesional.

Según Cantón (2013) la profesionalización es un proceso de formación (inicial y continuada de tipo especializado en dirección y liderazgo administrativo y pedagógico) para adquirir una categoría profesional o acreditación (sin separarse por completo de la docencia) de tipo permanente, que habilite para desarrollar y desempeñar la función de dirección y gestión de los centros educativos, a la vez que su desarrollo profesional, atendiendo a las demandas de la sociedad, y a las directrices y principios de la política educativa democrática. De esta manera, se conseguiría profesionalizar la dirección otorgando una cierta autonomía a los directores en la gestión y recursos sin dejar de rendir cuentas a la Administración.

Profesionalización sería considerar el cargo directivo como una profesión con las competencias específicas, estatus social, colegialidad, denominación y código ético, abandonando la visión del cargo directivo como un cargo temporal (Teixidó, 2007b). 
La certificación que actualmente se pide ha sido un pequeño paso hacia la profesionalización (Cantón, 2013).

Teixidó (2007b) señala dos modelos de profesionalización directiva: la profesionalización absoluta y la profesionalización según un modelo sociopolítico.

- La profesionalización absoluta: los directivos tienen voz propia, estatus profesional, defensa de intereses corporativos, sindicato de directores, representación del colectivo en organismos y el proceso de selección se basa en criterios de la formación, experiencia previa y las competencias profesionales. Implica un distanciamiento del director con la docencia.

- La profesionalización de un modelo sociopolítico: los directivos compaginan la dirección y la docencia. Es un cargo temporal y tienen una mayor proximidad con el colectivo docente del cual procede. Es un perfil orientado a buscar el consenso entre profesorado, familias y comunidad escolar, basándose en la negociación y el compromiso en torno a un proyecto educativo. El proceso de selección se basa en la elección/designación a cargo de la Comunidad Educativa.

Aunque ambos autores son del entorno español, los distintos países y contextos internacionales optan por uno u otro modelo. De hecho, internacionalmente, el requisito más común para acceder al puesto de director entre los diferentes países es un mínimo de cinco años de experiencia docente. Aunque en países como Bélgica, Letonia, Países Bajos, Suecia y Noruega la experiencia docente no es ningún requisito para el acceso a la dirección escolar (Europea/EACEA/Eurydice, 2013).

En España, según Barrios, Iranzo y Tierno (2013) se habría dado una resistencia al primer modelo debido a la búsqueda de direcciones más asamblearias tras años de dictadura política, lo cual habría llevado a procesos de desprofesionalización de la dirección escolar más prolongados y, a la luz de las posiciones expuestas, no del todo superados. Asimismo, se habría pasado por los mismos retos que la mayoría de los países para encontrar a candidatos apropiados para el cargo.

En países como Francia, Italia y Inglaterra la figura directiva ya está profesionalizada (Rodríguez-Sabiote et al., 2013). Consideramos que, en España, la importancia de la formación directiva ha aumentado pero aún estamos lejos de la profesionalización del cargo directivo. 
En las diferentes Comunidades Autónomas del estado español aparecen diferencias. Cataluña es una Comunidad Autónoma que apuesta por la profesionalización del cargo directivo con la creación de la figura del directivo profesional docente en el Decreto 155/2010 (Generalitat de Catalunya, 2010a) y con el punto n6 del Plan para la Mejora del Éxito Educativo (Generalitat de Catalunya, 2012): "Profesionalización de la dirección: fortalecimiento del liderazgo de los directores y de los equipos directivos".

La profesionalización de los directores escolares está en la agenda internacional y las universidades están implicadas, además de en su formación, en la investigación del mismo proceso de profesionalización (Iranzo, Barrios, Tierno \& Camarero, 2014).

La naturaleza de la dirección escolar - ya sea una ocupación o una profesión-, según Viñao (2004) depende de:

- La formación, cualificación o requisitos exigidos según normativa

- El modo y criterios de selección

- Las funciones o tareas que asignan según normativa

En España existe un debate sobre la profesionalización del cargo directivo. Los que están a favor argumentan que, con el aumento de tareas y funciones que asume actualmente la dirección, es necesaria una profesionalización para poder desempeñar el cargo correctamente y asumir todas las responsabilidades de la dirección.

Declaran que es necesaria la profesionalización del cargo ya que con la formación del docente no es suficiente para poder ejercer el cargo con eficacia. Además, defienden la conveniencia de una dirección fuerte, capaz de tomar decisiones con criterio propio, con independencia del estamento docente y para ello consideran indispensable su consolidación laboral (Teixidó, 2010).

En cambio, los que están en contra manifiestan que una formación dirigida exclusivamente a aquéllos que dirigen provoca un distanciamiento entre la dirección y la comunidad educativa que condiciona las relaciones que se establecen en la estructura organizativa (Vázquez Recio, 2002).

La profesionalización de la dirección escolar, si se convierte en un cuerpo de profesionales para toda la vida, puede provocar que se convierta en una zona privada y jerarquizada, además de perder la visión del aula si no se ejerce como docente (Santos, 
2015). Santos también se opone a crear un cuerpo diferenciado como si unos hubieran nacido para coordinar y otros para que les coordinen o unos para mandar y otros para que los manden.

Teixidó (2010) manifiesta que la formación debe ser para todos los miembros del centro educativo y no exclusiva para los cargos directivos ya que esto puede provocar un sentimiento excluyente y marcar una jerarquía entre aquellos miembros que reciben formación y los que no

¿Pero qué piensan los directores españoles, los protagonistas de esta profesionalización? Valle Aparicio (2013) en su investigación pregunta a los directores qué sistema de dirección educativa prefieren: una dirección por un docente (actual) o una dirección profesional. Los resultados manifiestan que el $63 \%$ prefiere una dirección por un docente frente al $36 \%$ que apuesta por una dirección profesional. Los directores que prefieren una dirección no profesionalizada destacan que es importante que éstos no pierdan el contacto con las aulas.

Una postura conciliadora seria profesionalizar la dirección pero manteniendo un tiempo de docencia.

En conclusión, la profesionalización de la figura directiva se encuentra presente en el debate de la mejora de la calidad educativa. En España se han impulsado leyes y políticas dirigidas a tal propósito aunque con despliegues lentos y desiguales entre las comunidades (Iranzo, Tierno \& Barrios, 2014). 


\section{CAPÍTULO II: \\ MODELOS DE LIDERAZGO Y DIRECCIÓN ESCOLAR}

n este bloque se analiza la evolución de la función directiva en la escuela y de los modelos de dirección escolar y liderazgo más actuales. Se destaca el carácter social del liderazgo y se define como un fenómeno social.

La literatura científica destaca el liderazgo transaccional y en el liderazgo transformacional como los dos grandes modelos de liderazgo escolar. Se enfatiza las diferencias entre estos dos modelos. Además se profundiza en los diferentes estilos de dirección del liderazgo transformacional así como la importancia de la Comunidad Educativa y su compromiso. 


\subsection{Evolución de los modelos sobre la función directiva}

Tradicionalmente, la visión de liderazgo era exclusivamente individual y atribuida al cargo del director escolar (Bolívar, López \& Murillo, 2013; Maureira, Moforte \& Gonzálvez, 2014). Hoy en día esta visión ha evolucionado hacia una perspectiva colectiva que integra las atribuciones y acciones de diferentes personas en un único esfuerzo, coordinado y dirigido, con el fin de mejorar los elementos que influyen en el aprendizaje (Anderson, 2010).

El dinamismo y la complejidad del día a día en los centros exige un liderazgo a todos los niveles y no exclusivamente de los cargos que ocupan una posición formal (Bolívar, 2011a). A partir de las exigencias de cada contexto, problema o incertidumbre surge de dentro del grupo el líder adecuado y no siempre es el mismo ya que la situación "hace" al líder (Lorenzo, 2012).

En los primeros estudios se analizaba el liderazgo como una variable independiente en relación a la escuela o la mejora educativa. Sin embargo, en la actualidad se ha observado que el liderazgo está influenciado por las características del entorno de las escuelas (Hallinger \& Heck, 2011; Mulford \& Silins, 2009) y que el aprendizaje implica la existencia de vínculos causales entre las intenciones y acciones de los líderes y los resultados del aprendizaje escolar (Hallinger \& Heck, 2011). Lorenzo (2012) destaca cuatro componentes que interaccionan para definir el liderazgo:

Tabla 8: Componentes del liderazgo

\begin{tabular}{|c|c|}
\hline LÍDER & \multicolumn{2}{c|}{ SEGUIDORES Y SISTEMA DE RELACIONES } \\
\hline PROYECTO COMPARTIDO & LIDERAZGO \\
\hline
\end{tabular}

Fuente: Elaboración propia a partir de Lorenzo (2012)

Podemos afirmar que el liderazgo es un fenómeno social (Sánchez-Moreno \& Hernández, 2014) que se define a partir de las relaciones entre el líder y sus seguidores, las características del proyecto escolar y del contexto educativo y social de cada escuela.

Por ese motivo, en la actualidad hay una diversidad de modelos y estilos directivos. Cada modelo de dirección tiene sus peculiaridades que le otorgan fortalezas, al tiempo que ofrecen puntos débiles en cuanto a la potencialidad (Valle Aparicio, 2013). 
Entendemos por modelo directivo un esquema teórico de un sistema o de una realidad compleja que se elabora para facilitar su comprensión y el estudio de su conducta (RAE). En cambio, entendemos por estilo directivo los diferentes estilos de conducta, el carácter propio, la manera de actuar y la forma de comportamiento. Los estilos de dirección son medios diferentes para alcanzar un mismo fin: el mantenimiento de la estabilidad de un centro (Díez, 2004). Por tanto, hay tantos estilos de dirección, como directores existen.

Existen algunos aspectos que determinan y configuran los diferentes estilos directivos (Álvarez, 2010a; Antúnez, 2000a) éstos son: la historia y normativa del sistema educativo, la historia y cultura institucional o el contexto del centro, las características personales y profesionales de cada director y las características personales y profesionales de la comunidad educativa.

A pesar de la variedad de estilos, hay unos rasgos característicos de cada dirección que permiten clasificar los estilos. Por ejemplo, Viñao (2000) clasifica los estilos de dirección en los siguientes modelos:

1. Modelo tradicional: la dirección se basa en realizar las funciones establecidas en las normativas y su formación depende de la exigencia legislativa.

2. Modelo no profesional: accede al cargo con los mínimos requisitos, su formación se desarrolla a través del ejercicio directivo. Su dirección es participativa y colegiada.

3. Modelo del liderazgo pedagógico: el director gestiona, dinamiza y motiva para lograr unos objetivos educativos.

4. Modelo neoliberal: organización y actuación en la escuela como una empresa.

Otra clasificación de estilos directivos es la de Álvarez (2010b): modelo burocrático y administrativo y el modelo contingente.

El Modelo burocrático y administrativo: son los primeros modelos que aparecieron con la finalidad de organizar el trabajo de los centros educativos. En este modelo cada trabajador tiene una función en concreto (especialidad). La jerarquía está definida a partir de los reglamentos internos. Los procesos de enseñanza-aprendizaje se basan en la definición del currículum o programas de estudio desde la Administración. La selección y promoción del personal están basadas en unos requisitos. 
Los comportamientos del director del modelo burocrático-administrativo son:

Tabla 9: Director del modelo burocrático - administrativo

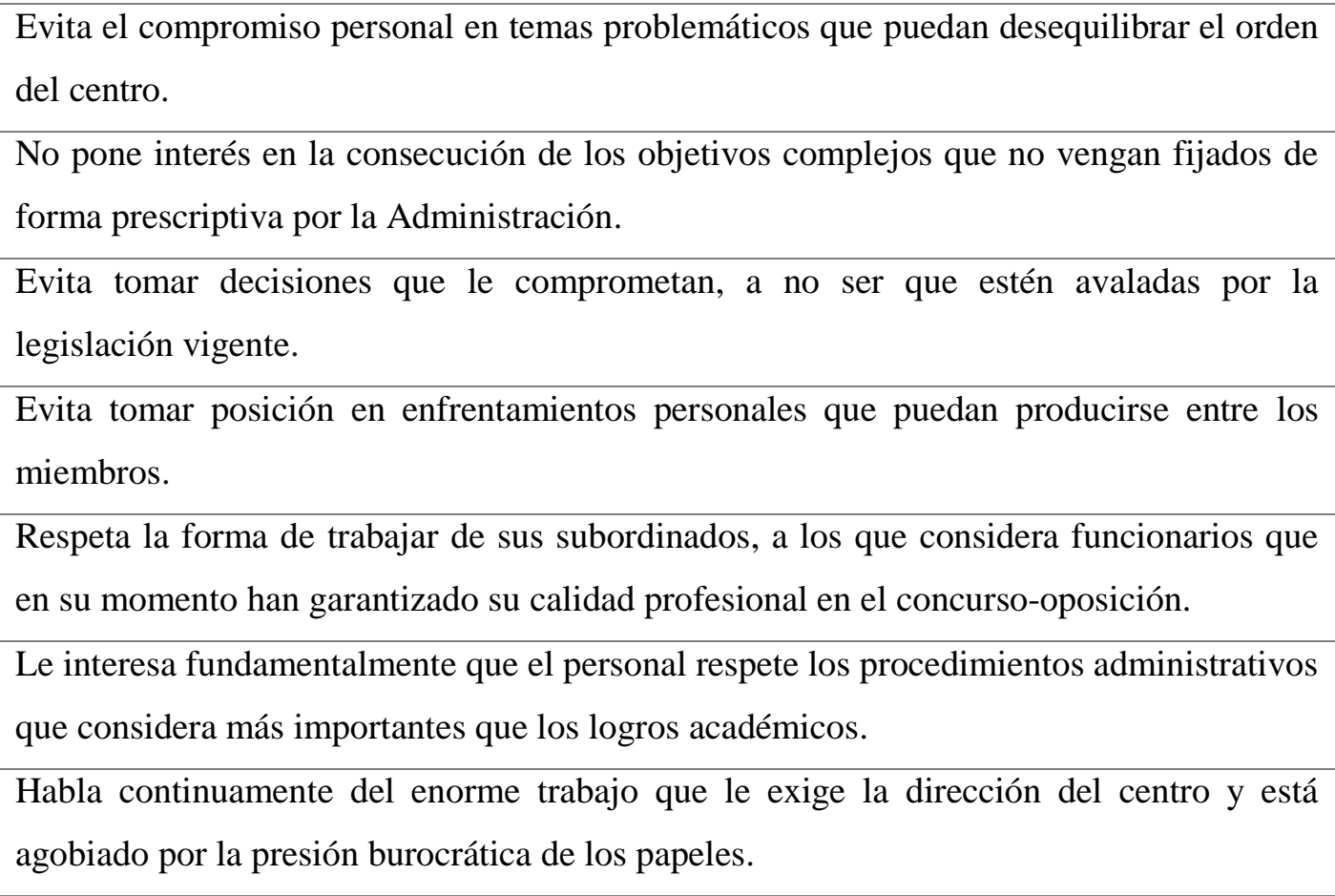

Fuente: Álvarez (2010b: 41)

El segundo modelo es el modelo contingente. Este modelo se define a partir de la "situación" en concreto de cada centro. La dirección se basa en el clima organizacional y las relaciones del centro. Los incentivos estimulan al grupo a superar las dificultades y afrontar cambios, se valora la antigüedad en el centro y existen diferentes ritmos de trabajo en función de la política de implicación.

Los autores Blanchard y Hersey (citados por Álvarez, 2010b) establecen diferentes estilos directivos a partir de la combinación entre el "saber" y el "querer" de los directores.

En la siguiente tabla se observan las distintas combinaciones de estilos directivos: 
Tabla 10: Características del modelo contingente

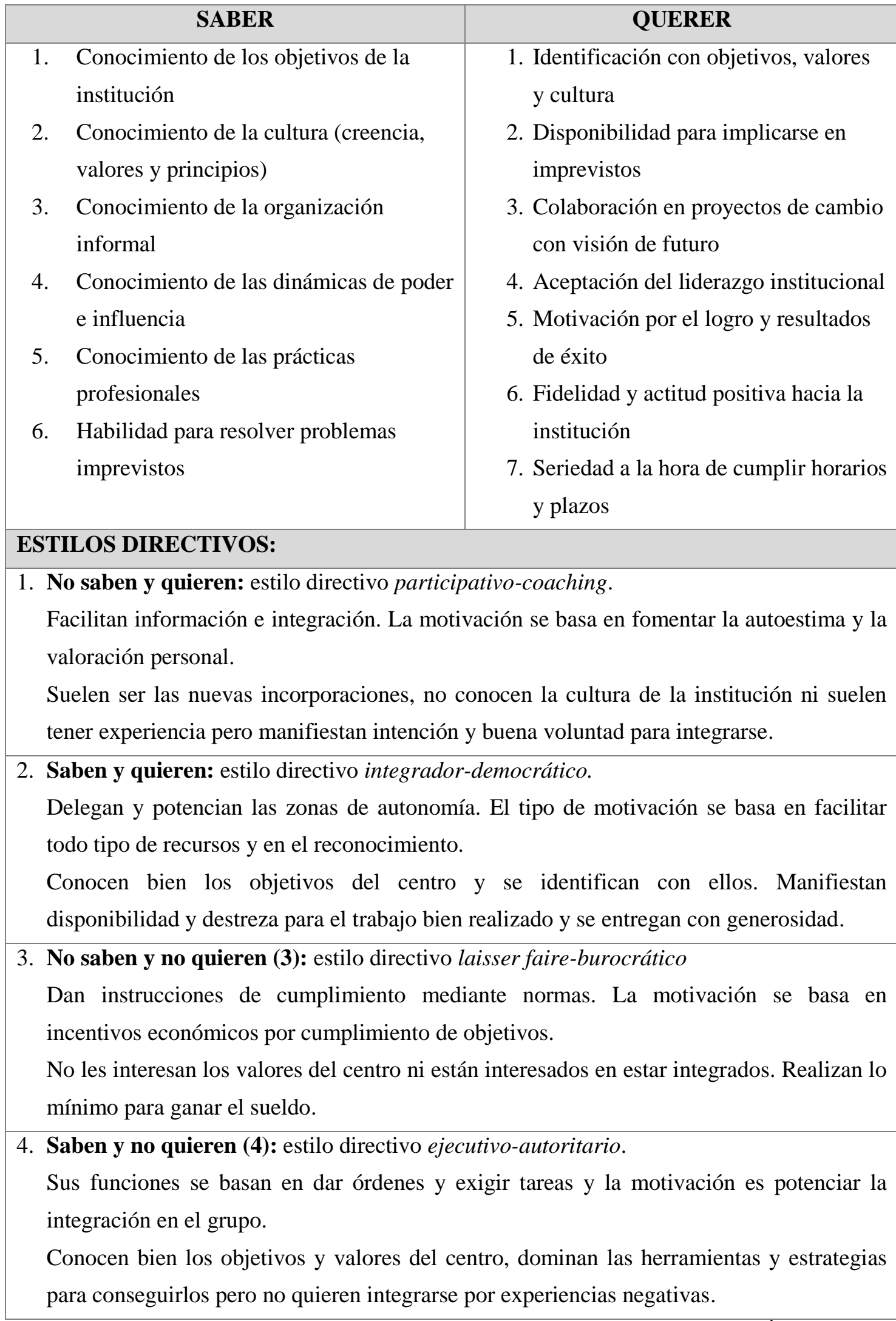

Fuente: Elaboración propia a partir de Álvarez (2010b) 
Independientemente del estilo de dirección, todos los directores deben responder a las exigencias y funciones determinadas de su cargo establecidas por las leyes educativas de cada país o región. A pesar de que la funciones de los directores están reguladas por legislación, las leyes no establecen tanto un modelo de dirección concreto, sino las medidas legales en las que éste debe desarrollarse (Barrios, Camarero, Iranzo \& Tierno, 2015).

\subsection{Modelos de liderazgo escolar}

A finales de los 80, esos mismos autores, Blanchard y Hersey, manifiestan que el liderazgo es situacional. Un liderazgo será distinto en función de la situación, contexto, relaciones con los colaboradores y la forma de dirigir el centro. El carácter social del liderazgo dificulta la posibilidad de señalar un único modelo eficaz, ya que un líder puede ser bueno en su contexto educativo y social pero no en otro diferente (Escudero, 2009; Ten Bruggente et al., 2012).

Independientemente del tipo de liderazgo, debe ser sostenible. La sostenibilidad se refiere a la conservación y desarrollo de lo esencial. Para Hargreaves \& Fink (2008) el liderazgo sostenible se basa en siete principios:

Tabla 11: Principios del liderazgo sostenible

\section{Principio 1:}

El liderazgo sostenible es importante. Preserva, protege y fomenta el aprendizaje profundo y amplio para todos, en unas relaciones de atención a los demás.

\section{Principio 2:}

El liderazgo sostenible perdura. Conserva y mejora los aspectos más valiosos del aprendizaje y la vida a lo largo del tiempo, año tras año, de un líder al siguiente.

\section{Principio 3:}

El liderazgo sostenible se extiende. Sostiene el liderazgo de los demás, a la vez que depende de él.

\section{Principio 4:}

El liderazgo sostenible no perjudica su entorno sino que lo mejora activamente, y para ello busca formas de compartir los conocimientos y los recursos con los centros educativos vecinos y la comunidad social. 


\section{Principio 5:}

El liderazgo sostenible fomenta la diversidad e impide la estandarización alineada de la política, el currículo, la evaluación y el desarrollo y la formación del profesorado en la enseñanza y el aprendizaje. Estimula la diversidad, aprende de ella y crea la cohesión y la interconexión entre sus componentes, ricos por su propia variedad.

\section{Principio 6:}

El liderazgo sostenible desarrolla los recursos humanos y materiales, no los reduce. Renueva la energía de las personas. El liderazgo sostenible es un liderazgo prudente y con iniciativa que no desperdicia ni el dinero ni las personas.

\section{Principio 7:}

El liderazgo sostenible, en su propósito de construir un futuro mejor, respeta el pasado y sobre él construye el presente.

Fuente: Elaboración propia a partir de Hargreaves \& Fink (2008)

Diferentes autores establecen diferentes clasificaciones de estilos de liderazgo en las organizaciones educativas. Conde \& García-Carmona (2013) ofrecen una panorámica de ellas:

Figura 3: Panorámica de los tipos de liderazgo en organizaciones educativas

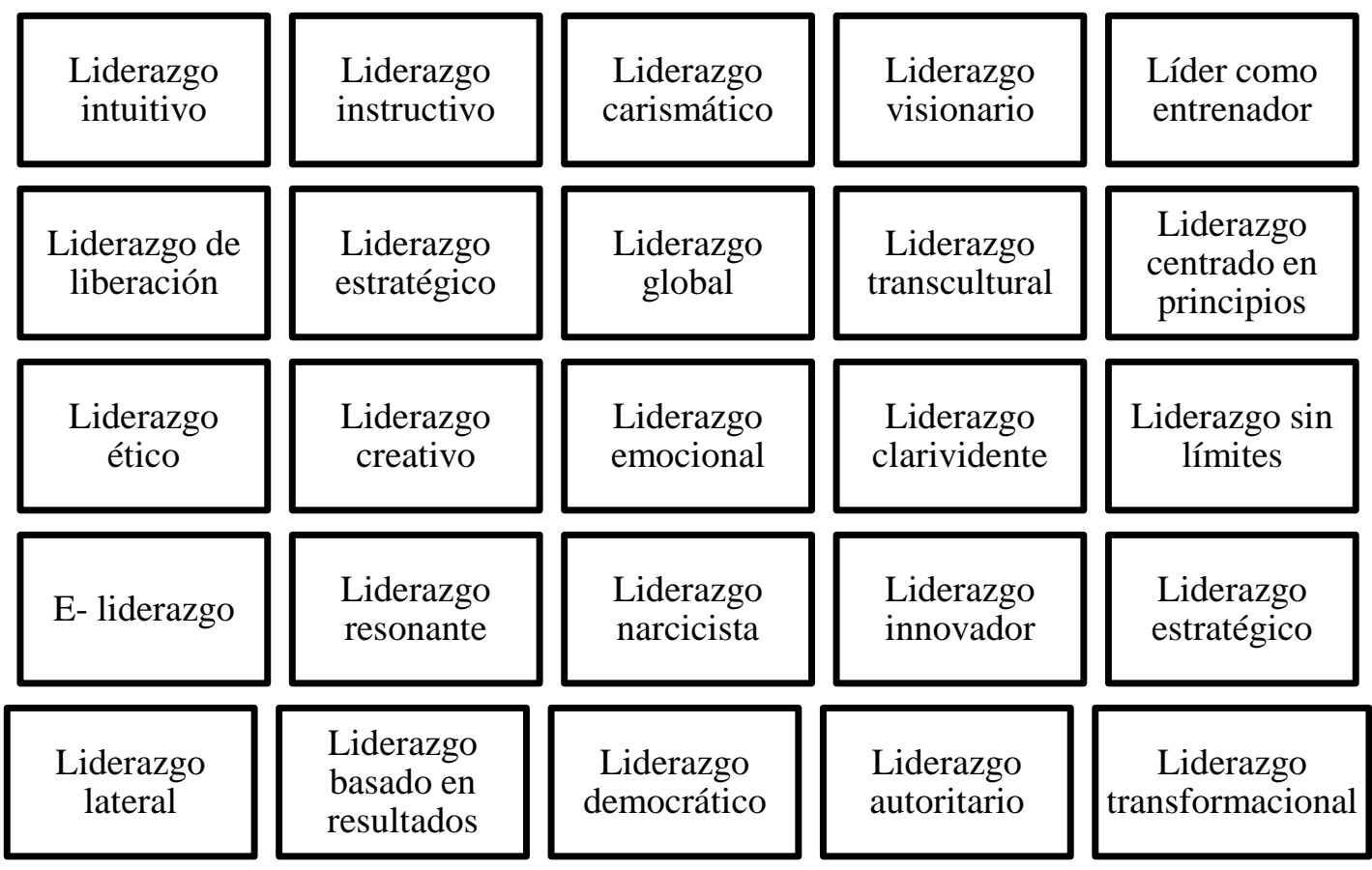

Fuente: Elaboración propia a partir de Conde \& García-Carmona(2013) y García-Carmona \& Conde (2013) 
En cualquier caso, la literatura científica destaca el liderazgo transaccional y el

liderazgo transformacional como los dos grandes modelos de liderazgo escolar que en la actualidad se ubican los diferentes estilos directivos. A continuación observamos las principales diferencias del liderazgo transaccional y del liderazgo transformacional, que según Álvarez (1998) son:

Tabla 12: Liderazgo transaccional versus liderazgo transformacional

\begin{tabular}{|c|c|}
\hline LIDERAZGO TRANSACCIONAL & LIDERAZGO TRANSFORMACIONAL \\
\hline Líder burocrático & Líder transformacional \\
\hline Le preocupan los papeles & Le preocupan las personas \\
\hline Dirige desde el pasado de la Ley & Dirige hacia el futuro. Es visionario \\
\hline Calidad es procedimiento & Calidad es satisfacción del cliente \\
\hline $\begin{array}{l}\text { Influye en sus subordinados por el prestigio } \\
\text { del conocimiento de la normativa }\end{array}$ & $\begin{array}{l}\text { Influye en sus colaboradores porque es capaz } \\
\text { de ilusionarlos con su visión }\end{array}$ \\
\hline Las relaciones son verticales, descendentes & Las relaciones son horizontales, ascendentes \\
\hline Los docentes son funcionarios & Los docentes son profesionales \\
\hline Ejerce una gestión administrativa burocrática & Ejerce una gestión de cultura de participación \\
\hline Crea cultura de la norma & Crea cultura de la creatividad \\
\hline Trabaja por departamentos & Trabaja en equipo \\
\hline Representa a la Administración & Representa a la comunidad educativa \\
\hline Se centra en el desarrollo de estructuras & Se centra en el crecimiento del personal \\
\hline No selecciona al personal, sólo lo encuentra & $\begin{array}{l}\text { Selecciona al personal con criterios } \\
\text { profesionales desde la visión }\end{array}$ \\
\hline
\end{tabular}

Atendiendo a estas características se observa que, globalmente, el liderazgo transaccional corresponde más a lo que hemos definido como director-manager; mientras que el liderazgo transformacional tiende más al tipo de liderazgo por el que venimos apostando. 


\subsubsection{Liderazgo transaccional}

El liderazgo transaccional es un intercambio coste-beneficio o de recompensas entre líder y el personal subordinado (Ramos, 2005). Es decir, un liderazgo basado en la recompensa-castigo, un intercambio de incentivos.

Bass, citado por Pascual \& et al., (1993), define el liderazgo transaccional como la tarea directiva de clarificar los requisitos del trabajo y premiar por cumplirlos. Identifica dos factores en el liderazgo transaccional:

- Recompensa contingente: se trata de la recompensa que ofrece el líder para reforzar la conducta apropiada de los subordinados. El líder ofrece y promete recompensas a las acciones que el menciona que deben realizarse y castiga las acciones no deseadas.

- Dirección por excepción: el líder solo interviene cuando existen problemas o errores que dificultan la consecución de los objetivos.

Según Gimeno (1995) este tipo de liderazgo se centra en las tareas, garantiza las condiciones de trabajo para el profesorado con la finalidad de que el profesorado oriente sus actividades hacia el logro de metas (marcadas por el director).

Se trata de un liderazgo efectivo en aquellas escuelas que tienen un propósito claro y estático (Horn, 2013).

En definitiva, los líderes transaccionales son líderes burocráticos, que enfatizan los aspectos impersonales del desempeño del cargo directivo como la planificación, el presupuesto, los horarios, etc. No consultan ya que ellos tienen el poder (del cargo). Sus actuaciones se basan en responder a las normas y a los valores organizacionales, es un simple gestor. Su perfil está más relacionado con una autoridad burocrática sobre el profesorado. En general, estos modelos han sido substituidos por una perspectiva más colaborativa y distribuida (Bolívar, 2010). 


\subsubsection{Liderazgo transformacional}

Mientras que el liderazgo transaccional se centra en el cumplimiento de los objetivos establecidos, el liderazgo transformacional se centra, además, en el crecimiento y desarrollo de la comunidad educativa.

El liderazgo transformacional es el encargado de motivar a los miembros del centro para alcanzar nuevos retos, desarrollarse profesionalmente y potenciar su autoestima. Tiene un efecto en el clima escolar.

Para ser un buen líder transformacional, Bass (2000) establece cuatro tipos de conductas relacionadas con el carisma, la inspiración, la estimulación intelectual y la consideración individualizada.

Según Molero (2011: 134) las estrategias de los líderes transformacionales para motivar son:

- Aumentar el nivel de comprensión de los seguidores acerca del trabajo a realizar.

- Hacer que los seguidores transciendan su propio interés en beneficio del interés del grupo.

- Cambiar la importancia de la jerarquía de necesidades de los seguidores de forma que las necesidades más elevadas, como la autorrealización, adquieran más importancia que las necesidades más básicas, como los beneficios materiales.

\section{En líder transformacional se caracteriza por convertir al profesorado en líder de su actividad educativa.}

Los directores deben desarrollar un liderazgo transformacional que recoja las siguientes dimensiones: ser promotor de estilo participativo y expresar un carisma personalizador (Evans, 2015).

Potenciar el liderazgo docente a partir del propio (del líder) y las tareas principales que realiza hacia el profesorado son: motivarlos ofreciéndoles recursos y remarcando la importancia que tiene su trabajo en el aprendizaje y éxito académico de los alumnos ya que considera al profesorado el instrumento clave para la calidad del centro. Manifiesta la confianza que tiene en los profesores y a la vez potencia su autoestima. Trabaja para armonizar los intereses profesionales del profesorado con la satisfacción del alumnado. 
En relación con los alumnos, establece una relación personal con ellos, es visible y es una figura cercana y amable. Interviene en las situaciones de conflicto en una posición neutral para así ganar respeto y autoridad. Valora la colaboración de los alumnos en actividades y proyectos del centro.

Las bases sobre las que se construye este modelo de liderazgo (Álvarez, 2010a) son:

1. Carisma: permite entusiasmar y transmitir confianza.

2. Consideración individual: proporciona tiempo y atención a las necesidades individuales.

3. Estimulación intelectual: estimula todas las potencialidades para la creatividad, la innovación y el cambio para una enseñanza de calidad.

4. Liderazgo compartido/cultura de la participación: crea condiciones para colaborar conjuntamente. Delega entre el profesorado para que desarrollen su propio liderazgo con sus alumnos.

5. Trabajo en equipo: crea la sinergia necesaria para conseguir mejores resultados.

6. Formación continua: es el medio fundamental para el crecimiento personal y forma de implicarse en la aplicación de nuevas tecnologías.

7. Representante institucional: representa un rol simbólico de autoridad y da ejemplo de trabajo duro, disponibilidad y honestidad en sus acciones.

8. Inspiración: estimula la capacidad de innovación y creatividad.

9. Tolerancia psicológica: posee y manifiesta dosis de sentido de humor para las situaciones más tensas.

En definitiva, el liderazgo transformacional "reconoce y potencia a las personas, gestiona las estructuras y contribuye a cambiar la cultura de la organización teniendo en cuenta la ética y los valores” (Medina, 2011: 13).

El liderazgo transformacional se concreta actualmente en tres modelos interdependientes (Mulford, 2006; Murillo, 2006; Hopkins \& Highman, 2007; Ainscow \& West, 2008; Cantón \& Arias, 2008; Bolívar, 2010; Iranzo, Tierno \& Barrios, 2014):

- Liderazgo Pedagógico, Instructivo o Liderazgo para el aprendizaje

- Liderazgo distribuido, participativo o colegiado

- Liderazgo contextualizado o social 
Independientemente del tipo de liderazgo, hay que asumir la necesidad de una delegación de tareas directivas entendidas como un acto de gestión. Es confiar a otra persona un conjunto de actividades y conlleva un margen de autonomía y confianza. Woycikowska et al., (2008) se plantean la cuestión de ¿Por qué se debe delegar? Sus respuestas son los siguientes motivos: permite liberarse de cargas, motivar a sus colaboradores y aumentar la eficacia.

En general, la liberación de cargas permite a los directores centrarse en las tareas esenciales de su función (proyecto educativo, elaboración del presupuesto, etc.). La delegación motiva ya que significa que concede confianza. También aumenta la eficacia ya que la delegación de responsabilidades hace que a quien se delega sea el experto y el responsable de tomar la decisión porque conoce el terreno de actuación.

Cuando se delega o se es delegado, pueden aparecen miedos e inseguridades que pueden frenar la delegación. Algunas de las incertidumbres que hay que superar:

Tabla 13: Inseguridades de la delegación

\begin{tabular}{|c|c|}
\hline Por parte del delegante & $\begin{array}{l}\text { - Puede provocar un sentimiento de inseguridad personal al temer } \\
\text { no dominar todos los datos } \\
\text { - Experimentar dificultades para clarificar los objetivos, definir las } \\
\text { obligaciones, etc. } \\
\text { - Deseo de conservar el poder }\end{array}$ \\
\hline Por parte del delegado & $\begin{array}{l}\text { - El miedo a no ser comprendido (no ser reconocido) } \\
\text { - El miedo a la crítica } \\
\text { - La falta de confianza en uno mismo } \\
\text { - El miedo al trabajo adicional } \\
\text { - La tendencia a la dependencia }\end{array}$ \\
\hline
\end{tabular}

Fuente: Elaboración propia a partir de Woycikowska et al., (2008:51-53)

A continuación, vamos a desarrollar cada uno de los modelos:

\section{- Liderazgo Pedagógico, Instructivo o Liderazgo para el aprendizaje}

Se define como la dirección activa que orienta la visión, metas y expectativas de la escuela hacia los aprendizajes de los alumnos y la mejora de las condiciones para ello. Se trata de un liderazgo entendido como supervisión pedagógica (Iranzo, Tierno \& Barrios, 2014). 
Es aquella persona que tiene capacidad de convencimiento para conseguir que los profesores se entusiasmen y motiven con su trabajo (Greenfield citado en Álvarez, $2010 \mathrm{~b}$ ) por lo que dedica la mayor parte del tiempo a crear un buen ambiente de trabajo. Tiene un efecto en el desempeño escolar. Analiza las prácticas que impactan en el profesorado y en la organización con la finalidad de mejorar las experiencias de aprendizaje (Hopkins \& Highman, 2007; Ainscow \& West, 2008; Sammons \& Bakkum, 2011).

Respecto el funcionamiento y organización del centro se basa en un liderazgo compartido con su equipo que facilita la implicación del personal en el proyecto del centro. Cuando aparece un conflicto interviene ejerciendo la autoridad de su cargo aunque conoce los puntos fuertes y débiles de todas las áreas, utiliza criterios de carácter didáctico, controla el absentismo y la puntualidad de alumnos y profesores. Impulsa una gestión de sugerencias y quejas que facilita la participación de todos los que estén interesados.

Conoce las dinámicas de enseñanza-aprendizaje del profesorado. Crea y facilita espacios de intercambio profesional entre los docentes para crear una cultura de trabajo en equipo. Mantiene una comunicación activa y proporciona un feedback sobre la actuación educativa y docente. Se implica personalmente en los conflictos del centro y apoya al profesorado en el aula. Gestiona personalmente la acogida de los nuevos profesores o sustitutos.

Posee una información actualizada sobre los resultados y evaluaciones de los alumnos. Conocen los conflictos del centro y quien los provoca. Además, tiene información fiable sobre las condiciones de trabajo del alumnado en casa y del apoyo familiar que reciben.

Con las familias mantiene buenas relaciones, promueve su implicación en los procesos educativos mediante un plan de acción del centro. Además destina recursos económicos y de tiempo para potenciar la relación con las familias.

A modo general, Álvarez (2010b: 53) define 5 dimensiones de este tipo de liderazgo:

1. Dimensión del proyecto de dirección: define y comunica la visión de la enseñanza orientada hacia el aprendizaje. Exige tener ideas, planteamientos y es capaz de imaginar un tipo de centro comprometido con los valores educativos. 
2. Dimensión de la instrucción: comprende el tiempo que se debe dedicar a la coordinación, articulación del currículo como elemento esencial de su trabajo como directivo.

3. Dimensión de la formación para asesorar, orientar y apoyar al profesorado: desarrolla los programas educativos (curriculares o de orientación) y las actividades complementarias vinculadas al aprendizaje.

4. Dimensión de la interacción y las relaciones humanas: promueve un clima positivo de aprendizaje. Exige ejercer con valentía y sin pudor la autoridad instruccional.

5. Dimensión de la evaluación: crea espacio para el seguimiento y la supervisión de todos los procesos educativos del centro facilitando al profesorado un feedback enriquecedor mediante la observación clínica de su actividad educativa.

Villa, Villardón y Villar citados en Meza (2014: 69) realizan una síntesis de las acciones que desarrollan los directores que ejercen un liderazgo pedagógico:

- Dan prioridad al currículum y a los temas de enseñanza, se dedican a las metas del centro educativo.

- Gestionan y movilizan recursos para el cumplimiento de las metas.

- Generan altas expectativas, con base en el respeto por los profesores, alumnos y toda la comunidad.

- Plantean la política instruccional por medio de la comunicación con los profesores; apoyo y participación en actividades de desarrollo del profesorado; y divulgan el conocimiento de materiales curriculares.

- Ofrecen ayuda a los estudiantes y profesores para su mejoramiento; la evaluación docente se caracteriza por visitas frecuentes al aula, criterios de evaluación claros y la retroalimentación positiva y constructiva.

- Demuestran compromiso con las metas académicas, habilidad para desarrollar y articular una visión clara y un fuerte rendimiento de los objetivos coherentes con las metas establecidas.

- Consultan con el profesorado y otros grupos para implicarlos en la toma de decisiones. Estimulan a los profesores para intercambiar ideas, las comisiones de apoyo son eficaces y se enfatiza la indagación y el cambio. 
- Reconocen el tiempo como un recurso escaso e imponen orden y disciplina para disminuir los factores que distraigan el desarrollo del proceso de aprendizaje.

El autoanálisis y la evaluación en este liderazgo son considerados elementos generadores de calidad educativa y fundamentos de la función dirección directiva para la mejora de los centros y el desarrollo profesional del profesorado (Day \& Al., 2009).

En definitiva, el liderazgo pedagógico está centrado en la mejora de los procesos de enseñanza y aprendizaje y, por tanto, en el éxito educativo (Iranzo, Tierno \& Barrios, 2014: 374).

\section{- Liderazgo distribuido, participativo o colegiado}

El modelo de liderazgo enfatiza las culturas colaborativas y se redefine como práctica democrática de la dirección "dispersada" y entretejida por relaciones horizontales (García Olalla, Poblete, \& Vila, 2006; Murillo, 2006; Bolívar, 2011a; Iranzo, Tierno \& Barrios, 2014).

Este liderazgo aparece a partir de un liderazgo emergente, de la toma de decisiones participativa y del empoderamiento de los profesionales del centro y de los equipos gestionados (Turnbull, Mann, \& Creasy, 2007).

Está orientado a capacitar profesionalmente al profesorado y configurar el centro como una comunidad profesional de aprendizaje (Gros et al., 2013).

Reconoce múltiples personas, y no sólo las que ocupan cargos oficiales, como fuentes de influencia en diferentes ocasiones y con efectos positivos en los resultados académicos. Quien tiende a ejercer un liderazgo distribuido, tiende a ser un líder de los líderes (Bolívar, 2011a).

Según el mismo autor, el profesorado ha de convertirse en un líder (teachers as leaders) y marcar la diferencia en sus aulas. El liderazgo distribuido consiste en unos procesos determinados de planificar la organización, se trata de una capacidad colectiva de liderazgo (Bolívar, 2011b; Bolívar \& Bolívar, 2013). El profesorado, familias y alumnado deben ejercer, a su modo y en su contexto, el liderazgo de modo distribuido (Gros et al., 2013). 
Destacan, pues, 5 dimensiones que definen el liderazgo distribuido: contexto, cultura, cambio, relaciones y actividad (Leithwood, 2009; Spillane, 2012).

Para Krichesky \& Murillo (2011) el liderazgo docente constituye la base que sostiene y promueve la mejora del centro. Los miembros de la comunidad educativa se sienten comprometidos y empoderados con los objetivos del centro. En definitiva, se trata de entender la escuela como "comunidad" y dentro de la "comunidad" (Murillo, 2006; Cantón \& Arias, 2008).

Para Iranzo, Tierno \& Barrios (2014) este liderazgo rediseña la organización y supera el liderazgo transaccional porque no se limita a condiciones existentes y metas dadas, sino que transforma alternando las condiciones del centro y del aula para mejorar el centro educativo. En conclusión, este liderazgo enfatiza las culturas colaborativas y de compromiso con la comunidad educativa, incluyendo la colaboración interinstitucional en las zonas educativas. Está demostrado, a través de análisis de diferentes investigaciones, que el liderazgo tiene más influencia cuando está distribuido (Day et al., 2010).

Los autores Apple \& Beane (1997) contribuyeron a asociar la participación democrática de la comunidad educativa con el éxito escolar. Esta influencia es notablemente más visible en los contextos más vulnerables.

En el ámbito escolar, Santos (2015) menciona cuatro triángulos para la mejora de la dirección escolar: el de las condiciones de la mejora (querer, saber y poder), el del contenido de la mejora (discurso, actitudes y prácticas), el de las estrategias de la mejora (investigación, perfeccionamiento e innovación) y por último el que se refiere a los ámbitos de la mejora: escuela, familia y sociedad. Este último es el que explica mejor el tipo de liderazgo distribuido.

Se parte de la premisa de que la escuela no tiene posibilidad de mejorar sin contar con el apoyo de todos los miembros de la comunidad educativa. Por ese motivo se debe cuidar el aprendizaje del alumnado pero también facilitar el desarrollo profesional de los docentes y procurar asesorar pedagógicamente a las familias del centro. La sociedad no puede estar al margen de lo que sucede en los centros educativos.

Si se aumenta la motivación, la participación y el compromiso de los diferentes miembros de la comunidad, se aumenta la calidad del centro y el éxito educativo 
(Gairín, 2011). El mismo autor define la participación como "un continuo que refleja diferentes grados de acceso a la toma de decisiones (dar y recibir información, aceptar y dar opiniones, consultar y hacer propuestas, delegar atribuciones, co-decidir, cogestionar, autogestionar)” (ibídem: 133)

A continuación, analizamos su implicación en diferentes colectivos que conforman la escuela:

A) El bienestar de los docentes y el rendimiento de los alumnos en el aula están estrechamente relacionados. Por ese motivo, y entre otros aspectos, es importante cuidar el bienestar de los docentes ya que la acción de los docentes es el factor más influyente en el éxito escolar del alumnado (Waite \& Nelson, 2005; Mulford, 2006; Bonals, 2007; Leithwood et al., 2008; OCDE, 2008; Bolívar, 2010).

Tejada (2013) afirma que con el cambio de cultura docente, el profesorado requiere mejorar su práctica, reflexionar sobre su práctica, la metodología de trabajo y los procesos de planificación y evaluación del aprendizaje del alumno.

El profesorado tiene la misión de transmitir nuevos conocimientos a los alumnos con el fin de darles nueva vida y no sean únicamente reproductores y repetidores de los mismos. Según Jiménez-González, González-Soto \& Fandos (1997, es necesario que los profesores sean originales (alejarse de lo tradicional) y creativos (realizar invenciones y teorías no conocidas hasta el momento).

González-Soto en Jiménez-González, González-Soto \& Fandos (1997:313) manifiesta que el profesor no es "el eje central del proceso en el sentido de que realmente se convertía en centro y vértice global de dicho proceso". Actualmente el profesor es planificador, el motivador y el facilitador de la participación de los alumnos en su aprendizaje.

Sartre (1963) establece los siguientes tipos de relaciones entre docentes:

- Reciprocidad positiva: se caracteriza por la estima entre los diferentes miembros de la institución basada en relaciones de confianza. Las relaciones se favorecen mutuamente ya que cada individuo aporta algo a los otros. 
- Reciprocidad negativa: se caracteriza por la sensación de amenaza que se siente frente a otros miembros. Las relaciones pueden frenar, dificultar o paralizar los proyectos.

Entre los docentes existen, o pueden existir, relaciones interpersonales con cierta tensión. Los motivos de las tensiones pueden ser diversos, pero generalmente las tensiones nacen a partir del enfrentamiento entre diferentes opiniones, maneras de trabajar, actitudes poco tolerantes, diferentes valores personales o por un error en la comunicación.

Cierto es que la existencia de docentes con roles negativos (conocidos como docentes tóxicos) puede generar un clima de trabajo poco agradable y realizar interferencias entre el profesorado, en la realización de tareas e incluso en el funcionamiento de la escuela.

La mayoría de los estudios sobre la dirección escolar se basan de forma genérica en las estrategias y comportamientos utilizados por los directores, y no se centran tanto en la influencia de sus diferentes actuaciones sobre el profesorado.

Por ese motivo, los autores Blase \& Kirby (2013) inician una investigación desde la perspectiva del profesorado. Profundizan en las estrategias que utilizan los directores para mejorar la motivación, implicación e innovación del profesorado, con el objetivo de conocer qué tipo de interacciones producen más beneficios y son más eficaces según los docentes.

Después de analizar las 1.323 respuestas que obtuvieron de 836 profesores, las estrategias para una dirección escolar eficaz las clasifican en:

1. Valorar y reconocer los logros de cada docente.

2. Tener buenas expectativas y saber transmitirlas.

3. Fomentar la participación de todos los docentes.

4. Garantizar la autonomía profesional del docente.

5. Realizar un liderazgo que apoye el trabajo de los profesores.

6. Sugerir versus imponer.

7. Emplear de manera positiva la autoridad formal.

8. Ser reflejo de lo posible. Liderazgo y personalidad. 
B) En relación al alumnado, en tanto se trata de uno de los participantes más importantes "debe estar" implicado y comprometido con el centro pero, sobre todo, con su propio aprendizaje. Antúnez \& Gairín (2006) proponen un listado de estrategias para potenciar la participación de los estudiantes:

Tabla 14: Estrategias para potenciar la participación del alumnado
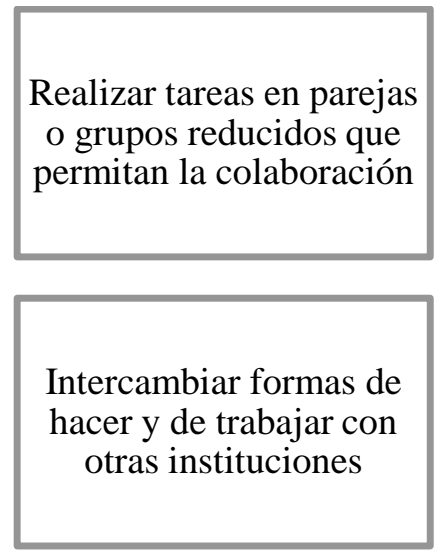

Fortalecer el sentimiento de pertenencia al grupo y de corresponsabilidad del lugar que ocupa en el grupo

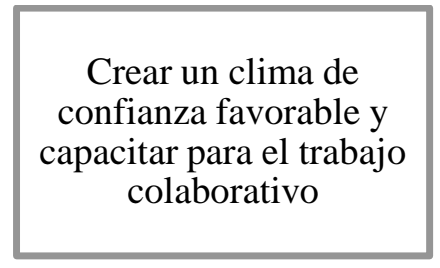

Desarrollar planes de acogida y apoyo a los estudiantes nuevos en el centro educativo

Diseñar y desarollar tareas individuales y corporativas atractivas y estimulantes
Potenciar la convicción de que todos tienen la misma importancia y todos pueden aportar por igual

Ofrecer la posibilidad de trabajar objetivos y tareas relevantes, creativas y no rutinarias

Velar para que exista una congruencia entre las acciones y los principios y valores con el centro

Fuente: elaboración propia a partir de Antúnez \& Gairín (2006)

El papel del director es motivar al profesorado para que ejerza su liderazgo con los alumnos.

Las asambleas son un instrumento para comprender, cuestionar, valorar, interesarse por el alumnado además de facilitar y mejorar las relaciones interpersonales (Puig et al., 2000). Los mismos autores manifiestan que las asambleas son unas prácticas educativas esenciales en los centros educativos. Definen la asamblea como un momento escolar organizado para que los alumnos y docentes puedan hablar de temas del trabajo escolar, de organización de actividades, de temas de convivencia o de aspectos informativos, con la finalidad de optimizar la convivencia y el rendimiento escolar. 
En definitiva, las funciones de las asambleas son: informar, analizar, tomar decisiones u organizar actividades. Siempre basado en el diálogo, teniendo en cuenta la distribución del turno de palabra basándose en el respeto de la diversidad de opiniones.

C) En relación a las familias, en la actualidad los padres y madres del alumnado están representados por los AMPAS (Asociaciones de madres y padres). La Constitución y las diversas normativas, otorgan a las familias el derecho y la obligación a participar en las comisiones y consejos escolares.

Aun así, si se analiza la participación familiar real familiar sería escasa. Gairín (2011) enumera algunas de las posibles barreras que frena la participación de este colectivo:

- Los objetivos educativos no están consensuados con las familias.

- Las familias en las reuniones sólo plantean problemas de bajo rendimiento.

- La mayoría de las familias no conocen internamente el centro, ni a los profesores (exceptuando el tutor de sus hijos).

- El profesorado desconoce las preocupaciones, expectativas y prácticas educativas de las familias.

- El tutor carece de una visión global de sus alumnos y desconoce el desarrollo de los alumnos en otras asignaturas.

- Los encuentros profesorado-familias no abordan los aspectos positivos del alumnado.

- Los profesores convocan escasamente a las familias de alumnado no problemático.

- Las familias participan si obtienen algún beneficio para sus hijos y no por el bien general.

Esa serie de dificultades conlleva diferentes niveles de participación de las familias.

Santos (2015: 70) establece diferentes tipos de participación:

- Participación regalada: cuando se considera que la participación de las familias es un regalo y no un derecho y un deber que ellas tienen.

- Participación recortada: cuando se les limitan algunas actividades.

- Participación condicionada: cuando se acepta esa participación pero con restricciones impuestas desde el centro. 
- Participación trucada: cuando pueden participar con tal de no llevar la contraria a la dirección.

- Participación formalizada: cuando se tienen en cuenta solamente los aspectos burocráticos y formales, pero no los esenciales.

- Participación feminizada: cuando solamente las madres asisten a las actividades propuestas por la escuela.

En cualquier caso, la participación de la familia y la sociedad no puede estar al margen de la función educativa. Pero esta participación debe ser real, permanente y en todos los aspectos.

D) En cuanto al entorno "la práctica de la colaboración entre los centros educativos y de éstos con otras instituciones es creciente aunque escasa, en términos generales, pudiendo afirmar la inexistencia de una cultura real de la colaboración" (Gairín, 2011: 106)

Todas las escuelas están, o deberían estar, vinculadas a los contextos. Es fundamental que se conozca el contexto y el entorno socio-económico, cultural y lingüístico (Palomares, 2011) para poder ofrecer una educación basada en las necesidades individuales, las desigualdades y la diversidad del alumnado, a partir de proyectos educativos.

Las experiencias de colaboración interinstitucional se centran, muchas de ellas, en temas informativos o de gestión, en lugar de hacerlo en torno a unos objetivos compartidos o un proyecto.

Varios son los aspectos que se deben considerar al iniciar la colaboración:

Tabla 15: Puntos claves de la colaboración interinstitucional

No existen fórmulas con validez mundial Importancia del contexto
A pesar de las diferencias entre centros, hay elementos en común con los que trabajar
La coordinación entre centros respeta la autonomía de decisión de los mismos 
Dificultades de la coordinación: estabilidad del profesorado y cultura organizativa

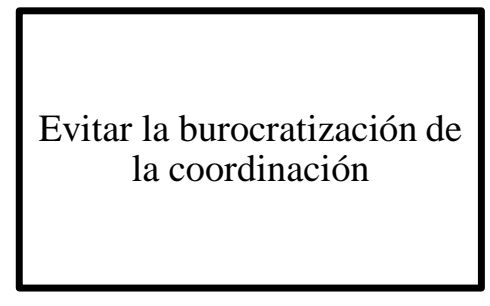

La coordinación en la tutorizacion se basa en buscar herramientas para el alumnado
La coordinación en la gestión debe mejorar la comunicación entre los centros y la tramitación de documentos
La coordinación entre centros debe centrarse en los trabajos por areas o por competencias básicas
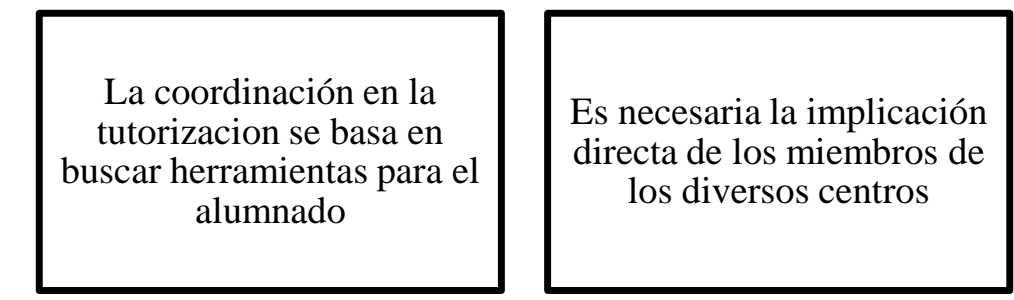

Fuente: Elaboración propia a partir de Darder (2001)

Respecto a la relación de los centros con las instituciones y asociaciones, Palomares (2011:178-180) señala las siguientes vinculaciones de las Administraciones, municipios y ayuntamientos y otro tipos de asociaciones:

- Administraciones: estimulan la relación de los centros con su entorno partiendo de los factores básicos que configuran el entorno.

- Municipios: colaboran e intervienen en actividades educativas para estimular, apoyar y asesorar a los centros. Cada vez más, los centros educativos participan con actividades culturales locales.

- Ayuntamientos: aportan las ayudas económicas para la conservación y mantenimiento de los centros e incluso para ampliar las instalaciones o para ofertar actividades de formación permanente. Las instalaciones educativas pueden ser utilizadas por los Ayuntamientos para actividades no lucrativas.

- Otro tipo de asociaciones: ONGs, grupos religiosos, asociaciones de vecinos, etc., pueden colaborar con las instituciones educativas.

De manera general, este autor apunta los siguientes principios para fomentar la interrelación Escuela-Sociedad:

1. Fomentar la participación y el asociacionismo en la comunidad educativa.

2. Elaborar proyectos educativos globales de ámbito territorial.

3. Diseñar proyectos conjuntos con los diversos sectores de la comunidad.

4. Introducir la cultura del trabajo en la escuela.

5. Propiciar la autonomía del centro. 
6. Potenciar el interculturalismo de la Escuela y su entorno.

7. Considerar los sistemas de comunicación como creadores de opciones y valores.

Para mantener el compromiso de la Comunidad Educativa, Bazarra (2012) propone las siguientes claves:

- Fomentar y cuidar la relación bidireccional entre la organización y el profesional: el compromiso no se genera sin esfuerzo consciente y planificado por parte del centro.

- Gestión del compromiso: a través de palancas activables que el centro debe saber cómo y cuándo activar.

- Conocer los factores que favorecen el compromiso: para cada centro son distintos los factores que benefician el compromiso.

Según el mismo autor, una persona comprometida lo está intelectualmente, emocionalmente y físicamente. El compromiso intelectual se basa en su capacidad, formación y energía intelectual con la que colabora en el centro. El compromiso emocional se basa en la actitud positiva y entusiasta que muestra hacia el centro, se siente parte y comparte los valores que identifican al centro o al proyecto y por último, el compromiso físico, se basa en realizar las actividades y funciones, demuestra una capacidad de resistencia y perseverancia ante las dificultades.

En definitiva, la participación de la comunidad educativa debería ser transversal (vincularse tanto con la educación formal, no formal e informal), contextualizada y comprometida con el fin de convertir el centro en una auténtica comunidad escolar de aprendizaje para todos (Gairín, 2011).

\section{- Liderazgo contextualizado}

"Es un liderazgo que reconoce los contextos en los que actúan las escuelas, tanto en el plano social y económico, que envuelve a sus alumnos, como en el de la política y la práctica, relevante para superar la desventaja” (Ainscow \& West, 2008: 173).

El liderazgo contextualizado y social se basa en los contextos sociales, económicos y políticos en los que actúan las escuelas (Mulford, 2006; Hopkins \& Highman, 2007). 
Este liderazgo amplia las responsabilidades de los líderes escolares a una estrategia social en la que la institución es sólo un agente entre otros muchos (Iranzo, Tierno \& Barrios, 2014).

Se destaca la importancia de la visión social y constructivista. Se centra en la participación de alumnos, docentes y comunidad educativa enfatizando en la importancia de los valores y los proyectos compartidos.

Según Ainscow \& West (2008: 173) algunas de las características prácticas de éste liderazgo son:

- El reconocimiento del papel importante pero limitado que desempeña la escolarización en la superación de la desventaja.

- La disposición a participar en las estrategias y los trabajos locales junto con otros especialistas en educación y expertos no educativos dentro de una red de atención.

- La disposición a pensar más allá de los objetivos, los rendimientos medidos y los beneficios institucionales.

- La comprensión de los contextos sociales y económicos de los niños, las familias y las comunidades y del papel de otros organismos en esos contextos.

- La capacidad de dirigir la escuela, no sólo para elevar el rendimiento, sino para establecer conexiones con las culturas y expectativas de los niños y las familias. 


\section{CAPÍTULO III: DIRECCIÓN ESCOLAR: DE LOS MODELOS A LA PRÁCTICA}

$7 \mathrm{n}$ este capítulo se repasa la evolución general de las diversas leyes educativas desde la perspectiva de la dirección escolar y la enseñanza primaria especificando en el acceso y funciones del cargo directivo.

Se especifica la formación que reciben los directores para y durante el desempeño del cargo. Se describen las competencias y características de los directores, el desarrollo profesional, la influencia del género en el desempeño del cargo directivo, las motivaciones y satisfacciones del cargo y se destaca la importancia de la ética. Se finaliza con una visión sobre prácticas de liderazgo eficaces. 


\subsection{Evolución legislativa Española}

En este apartado, en primer lugar, repasaremos la evolución de las diversas leyes educativas desde la perspectiva de la dirección escolar y la enseñanza primaria apoyándonos en estudios de diversos autores: Egido, 1995; Villa \& García Olalla, 2003; MECD, 2004; Batanaz, 2005; Álvarez, 2006b; Teixidó et al., 2006; Teixidó, 2007b; de Puelles, 2008; Padilla, 2008a; Montero, 2008, 2010; Sarramona, 2010; Valle \& Martínez, 2010; Rodríguez Pulido et al., 2013; Barrios, Iranzo \& Tierno, 2013.

Por otra parte analizaremos aspectos concretos referidos al acceso y funciones de la dirección.

\subsubsection{Leyes españolas: De la L.G.E (1970) a la L.O.M.C.E (2013)}

Destacamos el Decreto 985/1967 (MEC, 1967) cuyo Reglamento del Cuerpo de Directores Escolares convierte al director en un cuerpo independiente al cuerpo docente. Hacia al final del período dictatorial, en 1970, se creó la Ley General de Educación (LGE). Se trata de una ley con planteamientos inscritos en una tradición educativa liberal y un intento de modernizar la estructura del sistema educativo. Debía dar respuesta al rápido cambio social y económico de aquellos tiempos y superar las contradicciones internas en las que había caído el sistema por sucesivas reformas sectoriales (MECD, 2004).

Diseña un sistema unitario, flexible y se estructura el sistema en cuatro niveles: preescolar, educación general básica, Enseñanzas Medias y Enseñanza Universitaria. Se establece una educación básica común desde los seis hasta los catorce años de edad. Produce un acercamiento de la figura directiva con el cuerpo de docentes ya que el director tenia docencia (mínima) y se reformularon sus funciones (dirigir, orientar y ordenar todas las actividades del centro).

Tras la muerte del dictador Francisco Franco se genera un nuevo marco político democrático que se recoge en la Constitución de 1978. Su capítulo 27 se centra en la legislación educativa. Posteriormente aparece la Ley Orgánica de Estatutos de Centros Escolares (LOECE) en 1980.

En 1985 se crea la Ley Orgánica del Derecho de Educación (LODE). Vigente en la actualidad es considerada como un pilar firme del sistema educativo español 
(Torreblanca, 2010). En el artículo primero establece el derecho a una educación, obligatoria y gratuita, para todos los españoles y extranjeros residentes en España con la finalidad de desarrollar la propia personalidad y la realización de una actividad útil a la sociedad. Se crea el consejo escolar que tiene la función, además de otras competencias fundamentales, de elegir entre los postulados al equipo directivo.

Este modelo organizativo ubica en un papel exclusivamente representativo la figura del director: la dirección apenas tiene diez funciones frente las catorce del consejo escolar (Álvarez, 2013). La dirección deja de ser un asunto que sólo corresponde al director para ser pensada como un trabajo en grupo: el equipo directivo. Esta ley establece las bases del actual modelo de dirección.

\section{La Ley Orgánica de Ordenación General del Sistema Educativo (LOGSE) en 1990,} es una ley más orientada a la reforma del currículum. No aporta novedades significativas a la ley anterior en lo que respecta a las funciones y modo de elección de la dirección. La LOGSE extiende la escolaridad obligatoria y gratuita hasta los 16 años y refuerza la diversidad e identidad cultural, linguiística y educativa de cada Comunidad Autónoma, reconociendo el bilingüismo y la inclusión de materias propias de cada cultura de cada territorio.

\section{La Ley Orgánica de la Participación, la Evaluación y el Gobierno de los Centros} Docentes (LOPEGCD) en 1995, adecua la realidad aprobada en la LOGSE y la LODE. Define la función directiva de los centros públicos (procedimiento de elección, nombramiento, acreditación). Propone una serie de medidas (con énfasis en la evaluación) para lograr una educación de calidad para todos. Se observa un avance hacia la profesionalización directiva.

La Ley Orgánica de Calidad de la Educación (LOCE) de 2002, obviaba la elaboración del proyecto de dirección, y reforzaba la figura del director asignándole funciones que antes dependían del consejo escolar. Sitúa al director como un elemento básico para la calidad del sistema educativo (Valle \& Martínez, 2010) y la dirección de centros adquiere un papel relevante, especialmente en los procesos de evaluación y rendición de cuentas ante la Administración (Barrios, Iranzo \& Tierno, 2013).

En 2006, la Ley Orgánica de Educación (LOE), supone otro avance en la definición de un modelo de dirección más profesional. Mejora la categoría del director mediante 
reconocimientos e incentivos. Persigue una estabilidad del sistema educativo para alcanzar la máxima calidad de la educación con la mayor equidad social posible (de Puelles, 2008).

Hasta el momento la última ley educativa es la Ley Orgánica para la Mejora de la Calidad Educativa (LOMCE) de 2013. Supone la sexta ley educativa desde el fin de la dictadura. La novedad que introduce es el procedimiento de selección del director y, en la práctica, esta ley puede significar retornar a un director como representante ejecutivo de la administración. Destaca la incoherencia de querer dar autonomía a los centros pero a la vez pretender centralizar el sistema educativo. La ley fue recibida con duras críticas (Bolívar \& San Fabián, 2013; Cantón, 2013; Escudero, 2013; Vilalta, 2013). Por ejemplo, Escudero define la LOMCE como "el emisario de la crisis en educación y manifiesta la insensibilidad y la dureza de las nuevas condiciones sociales y educativas "'(2013:19).

En España la educación ha sido uno de los principales frentes de luchas ideológicas y políticas. La educación está politizada y no existe una reforma educativa apolítica (Estruch, 2002b). Autores como Álvarez (2006b) y Cantón (2013) afirman que ninguna de las anteriores reformas educativas han valorado la dirección como un elemento clave para el éxito educativo. En todas ellas la dirección ha oscilado entre el perfil político de carácter social-representativo o el perfil administrativo-burocrático.

Para concluir este apartado, se hace referencia a una reflexión de Cantón: «Ninguna de estas leyes ha considerado a la dirección como aliada para conseguir que sus reformas lleguen a desarrollarse con éxito en el seno de los centros educativos; más bien se la ha considerado un Caballo de Troya con el que introducirse en ellos» (2013:165)

Figura 4: Resumen de las leyes educativas españolas

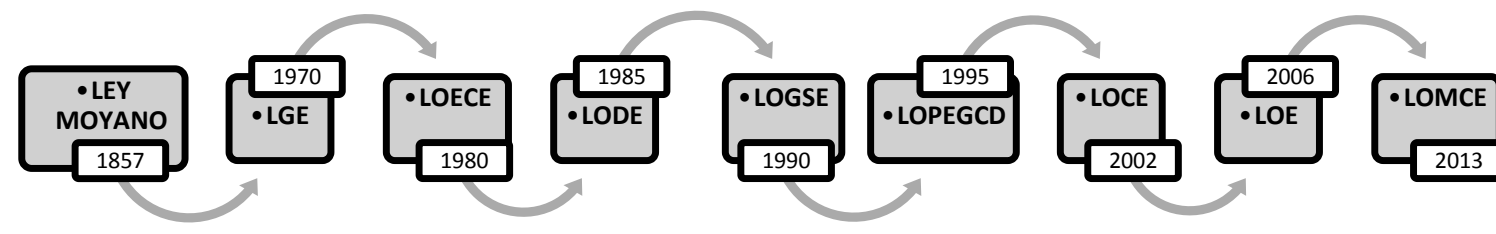

Fuente: Elaboración propia 


\subsubsection{Leyes Catalanas: de la L.E.C (2009) a la actualidad}

El modelo de organización del sistema educativo español, a partir de la Constitución Española de 1978, paulatinamente ha transferido funciones, servicios y recursos a las diferentes Comunidades Autónomas. Cataluña fue de las primeras Comunidades Autónomas, juntamente con el País Vasco, en recibir los primeros recursos para ejercer sus competencias en educación. Actualmente todas las comunidades han asumido funciones, servicios y recursos en materia de educación.

El modelo descentralizado de la administración del sistema educativo distribuye las competencias entre el Estado, las Comunidades Autónomas, las Administraciones Locales y los centros educativos. La Administración Educativa Central otorga poder y capacidad ejecutiva a las Administraciones Educativas de cada Comunidad Autónoma para llevar a cabo las competencias educativas. Por ese motivo, cada Comunidad Autónoma tiene su propio modelo de Administración (en algunos casos se organizan en Consejerías de Educación y en otros como Departamento de educación).

Por lo que respecta a la Comunidad Autónoma de Cataluña, en 2009 por primera vez se aprueba una Ley Educativa de Catalunya (LEC). Para Sarramona (2010) esta ley es un complemento necesario para el Estatuto de Autonomía de Cataluña aprobado en 2006 y una forma de manifestar la voluntad de autogobierno.

La LEC, en el artículo 142.3, hace referencia a la dirección escolar, orientada a la mejora de resultados académicos. Se vincula la autonomía de centros a la complejidad del desarrollo de la función directiva (artículo 116) y se apuesta por una profesionalización de la dirección escolar a partir de tres decretos que enfatizan un liderazgo pedagógico en la gestión y dirección escolares de los centros:

- El decreto de Autonomía de los Centros Educativos (Generalitat de Catalunya, 2010a), conocido como "decreto de autonomía". Supone poder intervenir activamente en el currículum y organizaciones escolares para garantizar el éxito escolar. El ejercicio de autonomía de los centros educativos y la toma de decisiones queda delimitado. Propone un liderazgo fuerte y distribuido con una autonomía supeditada a la evaluación de resultados y procesos. 


\section{- El decreto de la dirección de los centros educativos públicos y del personal} directivo profesional docente (Generalitat de Catalunya, 2010b), conocido como “decreto de dirección". En este decreto, el ejercicio del liderazgo en los centros educativos se orienta a estimular la participación de la comunidad escolar, especialmente en el consejo escolar y en el claustro, de acuerdo con lo que establecen las leyes y se distinguen dos figuras de dirección: personal directivo profesional docente atendiendo al grado de complejidad del centro y personal directivo docente que lo hará en el resto (Generalitat de Catalunya, 2010b).

Recientemente, el Decreto 29/2015 de modificación del Decreto 155/2010 de la dirección de los centros educativos públicos y del personal directivo profesional docente (Generalitat de Catalunya, 2015) realiza cambios en: el proceso de selección (se introduce como requisito tener la certificación acreditativa de la formación directiva y se suprime el requisito de estar prestando servicio en un centro público). Modifica la proporción de las comisiones de selección (aumentando a un 50\% los representantes de las escuelas) y la selección de méritos académicos y profesionales acreditados para los aspirantes (se valora de manera especial la experiencia previa en un equipo directivo y se suprime la preferencia de las candidaturas de profesores del centro).

\section{- El decreto por el cual se regulan los procedimientos para definir el perfil y la} provisión de los puestos de trabajo docentes (Generalitat de Catalunya, 2014a), conocido como el "decreto de plantillas". Otorga a los directores capacidades como en la gestión del personal con el fin de contar con el profesorado más adecuado para el proyecto educativo que define al centro. Este decreto favorece la gestión de las direcciones, tanto para dotar de continuidad los equipos docentes de los centros educativos como para intervenir en la selección de personal docente.

Después de esta visión general de las leyes educativas de los últimos años, nos centraremos en aspectos normativos más concretos como: el acceso al cargo y las funciones directivas. 


\subsubsection{Acceso al cargo directivo}

Generalmente, el requisito básico para acceder al puesto de director es la experiencia docente. Hay pocos países europeos en los que la experiencia docente no es hasta ahora un requisito. Esos países son: Bélgica (Comunidad flamenca y Comunidad germanófona), Suecia, Letonia, Países Bajos y Noruega, ya que con el título de docente sirve para acceder al cargo. La realidad es que a pesar de que no sea un requisito, los directores que acceden al cargo tienen experiencia (Comisión Europea/EACEA/Eurydice., 2013).

En los países europeos que exigen experiencia docente, el número de años de experiencia varía desde los 3 años (Francia, Lituania Estonia y Bulgaria) hasta los 16 años (Chipre). En países como Dinamarca, Alemania, Austria, Finlandia, Islandia y Reino Unido exigen experiencia pero no determinan el número de años.

"En general, se exige un mínimo de cinco años de experiencia docente para acceder al puesto de director de centro" (Comisión Europea/EACEA/Eurydice., 2013: 119)

En la siguiente gráfica, podemos ver los diferentes países y el número de años de experiencia para acceder al cargo:

Gráfico 1: Número de años mínimo de experiencia docente para poder ser director.

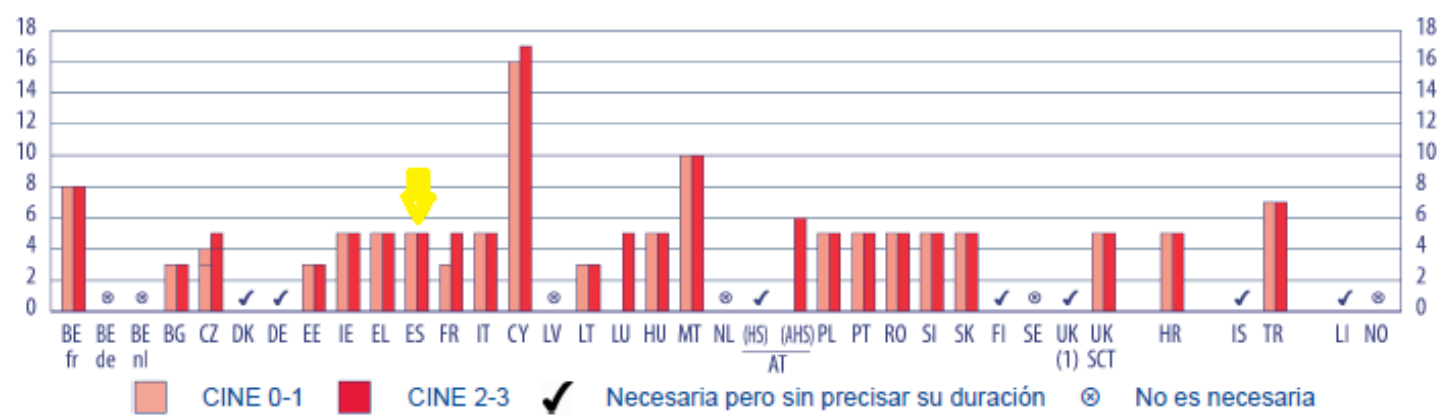

Fuente: Comisión Europea/EACEA/Eurydice (2013: 120)

Además de los requisitos básicos, la mayoría de los países europeos aplican condiciones adicionales como: experiencia administrativa (Grecia, Chipre, Lituania, el Reino Unido y Turquía) o tener formación en competencias para el liderazgo (Malta, Rumanía, Reino Unido (Inglaterra y Gales) y Lituania). 
En España, las Administraciones Educativas de cada Comunidad Autónoma pueden añadir otros requisitos como, por ejemplo, el certificado de la lengua cooficial en Comunidades Autónomas bilingües (Comisión Europea/EACEA/Eurydice., 2013).

Según Valle \& Martínez, (2010) España es el único país del contexto europeo que solicita explícitamente, como requisito para acceder al cargo, la elaboración del Proyecto de Dirección donde se incluyan los objetivos, líneas de actuación y evaluación del mismo.

En la siguiente tabla se resume la evolución de los requisitos de acceso al cargo (en centros públicos) de dirección en función de las leyes educativas en España:

Tabla 16: Evolución de los requisitos de acceso al cargo en España

\begin{tabular}{|c|c|}
\hline LODE (1985) & $\begin{array}{l}\text { - Ser profesor del centro (mínimo un año de experiencia). } \\
\text { - Tres años de experiencia docente. }\end{array}$ \\
\hline LOGSE (1990) & $\begin{array}{l}\text { - } \quad \text { Ser profesor del centro (mínimo un año de experiencia). } \\
\text { - } \quad \text { Tres años de experiencia docente. } \\
\text { - } \quad \text { Funcionario de carrera. } \\
\text { - } \quad \text { Tener un destino definitivo. }\end{array}$ \\
\hline LOPEGCD (1995) & $\begin{array}{l}\text { - } \quad \text { Ser profesor del centro (mínimo un año de experiencia). } \\
\text { - } \quad \text { Funcionario de carrera (mínimo cinco años). } \\
\text { - } \quad \text { Cinco años de experiencia docente directa. } \\
\text { - } \quad \text { Tener un destino definitivo. } \\
\text { - } \quad \text { Acreditarse por las Administraciones educativas para la función directiva. } \\
\text { - } \quad \text { Elaboración del proyecto de dirección. }\end{array}$ \\
\hline LOCE (2002) & $\begin{array}{l}\text { - } \quad \text { Funcionario de carrera (mínimo cinco años). } \\
\text { - } \quad \text { Cinco años de experiencia docente directa. } \\
\text { - } \quad \text { Prestar servicio en algún centro educativo. } \\
\text { - } \quad \text { Acreditar méritos académicos. }\end{array}$ \\
\hline LOE (2006) & $\begin{array}{l}\text { - } \text { Funcionario de carrera (mínimo cinco años). } \\
\text { - } \quad \text { Cinco años de experiencia docente directa. } \\
\text { - } \quad \text { Prestar servicio en algún centro educativo. } \\
\text { - } \text { Presentar un proyecto de dirección. } \\
\text { - } \quad \text { Acreditar méritos académicos. } \\
\text { - } \quad \text { Se priorizan los candidatos procedentes el propio centro. }\end{array}$ \\
\hline LOMCE (2013) & $\begin{array}{l}\text { - } \text { Funcionario de carrera (mínimo cinco años). } \\
\text { - } \quad \text { Cinco años de experiencia docente. } \\
\text { - } \quad \text { Estar en posesión de la certificación acreditativa de un curso de formación } \\
\text { sobre el desarrollo de la función directiva. } \\
\text { - } \quad \text { Presentar un proyecto de dirección. } \\
\text { - } \quad \text { Acreditar méritos académicos. }\end{array}$ \\
\hline
\end{tabular}

Fuente: Elaboración propia 
Se observa, con el paso del tiempo y el cambio de las leyes educativas, una consolidación de los requisitos de acceso relativo a los años de experiencia docente, la justificación a través de un proyecto educativo de centro, los méritos profesionales de cada candidato, la experiencia previa en cargos de dirección, gestión y/o trabajo en equipo, además de una formación específica previa.

La acreditación para el acceso se obtiene mediante la experiencia y valoración positiva del trabajo previo desarrollado en los cargos correspondientes, en tareas de coordinación pedagógica, organización, gestión y participación en órganos de gobierno como en el ejercicio de la función docente (Rodríguez Sabiote et al., 2013). También, desde la LOPEGCD con una formación que acredite para la dirección.

Respecto el modo de acceso al cargo de dirección es variable dependiendo de la ley, contexto educativo y titularidad de centro. En cualquier caso, según Aramendi et al., (2008) el proceso y el procedimiento a través del cual los directores acceden al cargo tienen incidencia directa en el clima de trabajo, en el sistema de relaciones y, en general, en la calidad de la acción educativa que se desarrolla en el centro.

Esta evolución del acceso al cargo refleja la intención de formalizar y profesionalizar cada vez más el ejercicio del cargo directivo. Según Álvarez, (2010b) el modo de acceso que fijan las leyes y el tipo de organización condicionan poderosamente el perfil y estilo de dirección.

Teixidó define el acceso al cargo como: "la punta del iceberg de una realidad compleja y controvertida; es la parte visible, en la cultura escolar imperante” (2007b: 41).

En Europa existen tantos modos de acceso como sistemas educativos existentes. Según el informe Key Data on Teachers and School Leaders in Europe (Comisión Europea/EACEA/Eurydice., 2013) la selección abierta es el método más utilizado para acceder al cargo. Dos tercios de los países europeos seleccionan a los directores mediante esta selección.

La difusión de las plazas vacantes y la selección de los candidatos corresponden a los propios centros. La regularidad de este acceso varía dependiendo del país y de la normativa. Algunos ejemplos serían: 
En Irlanda las vacantes se anuncian en el centro y en una web nacional y es la autoridad local la encargada de seleccionar y nombrar al director.

En el Reino Unido los centros administrados por las autoridades locales deben informar de la vacante al menos a toda Inglaterra y Gales, nombrar comité de selección, entrevistar a los aspirantes, recomendar y aprobar el nombramiento de uno de los candidatos entrevistados.

La selección mediante concurso-oposición consiste en un concurso público organizado de manera centralizada. Actualmente once países seleccionan a partir de este modelo.

En Lituania se divide la selección en dos fases: primero la autoridad (independiente) evalúa las competencias de los candidatos y, si se supera esta evaluación, se puede participar en el concurso organizado por el propietario del centro (Administración o municipio).

El concurso-oposición en España tiene las siguientes etapas: en un primer lugar, la Administración publica anualmente la convocatoria de selección "basada en méritos" abierta a los funcionarios docentes de carrera. Posteriormente, los candidatos presentan su candidatura al centro. A continuación, una "comisión de selección” evalúa las solicitudes, los méritos académicos y profesionales y el proyecto de dirección. Finalmente, una vez superadas todas las etapas anteriores, el candidato es nombrado por la administración educativa por un periodo renovable de cuatro años.

Alemania, Grecia, Chipre y Luxemburgo son los únicos países que se basan en un método de selección de lista de candidatos. Grecia cada 4 años elabora unas tablas de evaluación para la selección y nombramiento de los directores en función de la cantidad de puntos que hayan obtenido los candidatos durante su carrera (cuentan las publicaciones, la formación continua, los años de experiencia). A los candidatos con más puntos se les realiza una entrevista para determinar quién accede al puesto de director. 


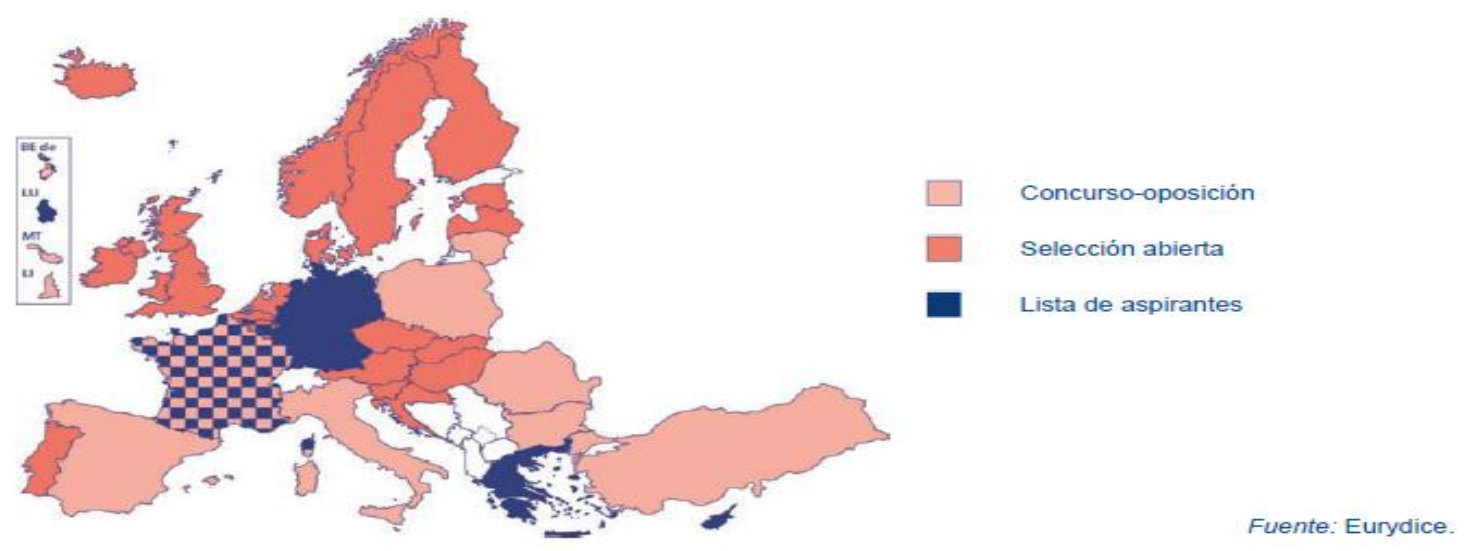

Fuente: Comisión Europea/EACEA/Eurydice (2013:123)

En España (y en otros países que han sufrido sistemas dictatoriales) se han dado sistemas de acceso llamados participativos (Álvarez, 2006b). El modo de acceso ha evolucionado de un modelo participativo basado en la elección democrática de la comunidad educativa (representada por el consejo escolar) a un procedimiento de selección basado en los méritos de los candidatos (LOMCE).

En lo que respecta al modo de acceso en los centros de carácter privado o concertado, normalmente depende de la elección del titular del centro. En las leyes educativas españolas se observa la siguiente evolución:

En la LODE se específica un proceso distinto para acceder a la dirección de los centros: "El director de los centros concertados será designado, previo acuerdo entre el titular y el consejo escolar, de entre profesores del centro: con un año de permanencia en el mismo o tres de docencia en otro centro docente de la misma entidad titular. El acuerdo del consejo escolar del centro será adoptado por mayoría absoluta de sus miembros. (MEC, 1985: 21021)

En la LOPEGCD se establece una disposición adicional, la séptima, sobre el apoyo a la función directiva de los centros concertados: "Las Administraciones educativas posibilitarán, para el ejercicio de la función directiva en los centros concertados, unas compensaciones económicas y profesionales, análogas a las previstas para los cargos directivos de los centros públicos[...] Dichas compensaciones deberán ser, en todo caso, acordes con la responsabilidad y la dedicación exigidas” (MEC, 1995: 33661) 
En referencia a la designación del director en los centros privados-concertados en la LOCE, el papel determinante lo tiene la titularidad del centro, es decir, la persona o entidad responsable del mismo. En la LOE, al igual que en la LOPEGCD, las Administraciones educativas posibilitarán unas compensaciones económicas para el ejercicio de la función directiva en los centros privados concertados. En la LOMCE, se mantiene que el director del centro es nombrado por el titular previo un informe aceptado por la mayoría de los miembros del Consejo Escolar (MECD, 2013: 97919).

En Cataluña, la LEC dedica un capítulo, el II, a los centros concertados y el capítulo III, a los centros privados no-concertados. El número de funciones de director es menor en comparación con las funciones de los directores de centros públicos, por lo que la ley les otorga más libertad de actuación.

A pesar de ello Antúnez (2011) afirma que "aún hoy, la normativa regula con detalle los requisitos y formas de acceso a la dirección de los centros públicos, no reglamenta cómo proceder en los privados concertados dejando en manos de la titularidad una decisión que pocas veces se somete a la consulta y debido control social de los Consejos Escolares" (ibídem: 1).

\subsubsection{Funciones y tareas de la dirección}

Las funciones directivas, al igual que las leyes educativas, han ido evolucionando y adaptándose a las necesidades del momento. Después de analizar las funciones directivas desde la LODE hasta la actualidad, se observa que muchas de las funciones directivas son similares en la mayoría de las leyes (con breves modificaciones en el redactado). En la LOMCE se recogen las anteriores y aumenta el número de funciones (pasan de 12 a 17).

A continuación, en la siguiente tabla se pueden observar las funciones directivas establecidas por normativa en la ley actualmente vigente: 
Tabla 17: Funciones directivas de la LOMCE (España)

\section{FUNCIONES DIRECTIVAS LOMCE (2013)}

1) Ostentar la representación del centro y representar a la Administración educativa en el mismo y hacerle llegar a ésta los planteamientos, aspiraciones y necesidades de la comunidad educativa.

2) Dirigir y coordinar todas las actividades del centro, sin perjuicio de las competencias atribuidas al Claustro de profesores y al Consejo Escolar.

3) Ejercer al dirección pedagógica, promover la innovación educativa e impulsar planes para la consecución de los objetivos del proyecto educativo.

4) Garantizar el cumplimiento de las leyes y demás disposiciones vigentes.

5) Ejercer la jefatura de todo el personal adscrito al centro.

6) Favorecer la convivencia en el centro, garantizar la mediación en la resolución de los conflictos e imponer medidas disciplinarias que correspondan a los alumnos, en cumplimiento de la normativa vigente sin perjuicio de las competencias atribuidas al Consejo Escolar. Se promoverá la agilización de los procedimientos para la resolución de los conflictos en los centros.

7) Impulsar la colaboración con las familias, con instituciones y con organismos que faciliten la relación del centro con el entorno, y fomentar un clima escolar que favorezca el estudio y el desarrollo de cuantas actuaciones propicien una formación integral en conocimientos y valores de los alumnos.

8) Impulsar las evaluaciones internas del centro y colaborar en las evaluaciones externas y en la evaluación del profesorado.

9) Convocar y presidir los actos académicos y las sesiones del Consejo Escolar y del Claustro y ejecutar los acuerdos adoptados en el ámbito de sus competencias.

10) Realizar contrataciones de obras, servicios y suministros, así como autorizar gastos de acuerdo con el presupuesto del centro, ordenar pagos y visar las certificaciones y documentos oficiales del centro.

11) Proponer a la Administración educativa el nombramiento y cese de los miembros del equipo directivo, previa información al Claustro de profesores y al Consejo Escolar.

12) Aprobar los proyectos y normas a los que refiere el capítulo II del Título V de la presente ley.

13) Aprobar la programación general anual, sin perjuicio de las competencias del Claustro del profesorado, en relación con la planificación y organización docente.

14) Decidir sobre la admisión de alumnos y alumnas, con sujeción a lo establecido en la Ley Orgánica y disposiciones que la desarrollen.

15) Aprobar la obtención de recursos complementarios de acuerdo con lo establecido en el artículo 122.3.

16) Fijar las directrices para la colaboración, con fines educativos y culturales, con las Administraciones locales, con otros centros, entidades y organismos.

17) Cualesquiera otras que le sean encomendadas por la Administración educativa. 
En Cataluña, la LEC establece las funciones directivas acompañada de las actuaciones directivas correspondientes.

Tabla 18: Funciones directivas de la LEC (Cataluña)

\section{FUNCIÓN DE REPRESENTACIÓN}

1) Representar al centro.

2) Ejercer la representación de la Administración Educativa en el centro.

3) Presidir el Consejo Escolar, el Claustro de profesores y los actos académicos del centro.

4) Trasladar las aspiraciones y las necesidades del centro a la Administración Educativa y vincular al centro los objetivos y las prioridades de la Administración.

\section{FUNCIÓN DE DIRECCIÓN Y LIDERAZGO PEDAGÓGICO}

1) Formular la propuesta inicial del proyecto educativo y las modificaciones y adaptaciones correspondientes.

2) Velar para que se aprueben un despliegue y una concreción del currículum coherentes con el proyecto educativo y garantizar el cumplimiento.

3) Asegurar la aplicación de la carta de compromiso educativo, del proyecto lingüístico y de los planteados tutoriales, coeducativos y de inclusión, y también de entre todos los otros planteamientos educativos del proyecto educativo recogidos en el proyecto de dirección.

4) Garantizar que el catalán sea la lengua vehicular de la educación, administrativa y de comunicación en las actividades del centro, de acuerdo con el título II y el proyecto lingüístico.

5) Establecer los elementos organizativos del centro determinados por el proyecto educativo.

6) Proponer, de acuerdo con el proyecto educativo y las asignaciones presupuestarias, la relación de puestos de trabajo del centro y las modificaciones sucesivas.

7) Instar que se convoque el procedimiento de provisión de puestos a los que se hace referencia en el artículo 124.1 i presentar las propuestas las cuales hacen referencia al artículo 115.

8) Orientar, dirigir y supervisar las actividades del centro y dirigir la aplicación de la programación general anual.

9) Impulsar, de acuerdo con los indicadores de progreso, la evaluación del proyecto educativo y, eventualmente, de los acuerdos de corresponsabilidad.

10) Participar en la evaluación del ejercicio de las funciones del personal docente y de otro personal destinado al centro, con la observación, si se estima, de la práctica docente al aula.

\section{FUNCIÓN EN RELACIÓN CON LA COMUNIDAD ESCOLAR}

1) Velar para la formulación y el cumplimiento de la carta de compromiso educativo del centro.

2) Garantizar el cumplimiento de las normas de convivencia i adoptar las mesuras disciplinarias correspondientes.

3) Asegurar la participación del Consejo Escolar.

4) Establecer canales de relación con las asociaciones de madres y padres de los alumnos, y si se estima, con las asociaciones de alumnos. 


\section{FUNCIONES RELATIVAS A LA ORGANIZACIÓN Y FUNCIONAMIENTO DEL CENTRO}

1) Impulsar la elaboración y la aprobación de las normas de organización y funcionamiento del centro y dirigir la aplicación.

2) Nombrar a los responsables de los órganos de gestión y coordinación establecidos en el proyecto educativo.

3) Emitir la documentación oficial de carácter académico establecida por la normativa vigente.

4) Visar las certificaciones.

5) Asegurar la custodia de la documentación académica y administrativa para el secretario/a.

6) Autorizar los gastos y ordenar los pagos de acuerdo con el presupuesto acordado.

7) Contratar bienes y servicios dentro de los límites establecidos por la Administración Educativa y actuar como órgano de contratación.

8) Dirigir y gestionar el personal del centro para garantizar que cumplen sus funciones, la cual cosa conlleva, si se estima, a la observación de la práctica docente en el aula.

9) El director tiene cualquiera otra función que le asignen las ordenanzas y todas las relativas al gobierno del centro no asignadas a ningún otro órgano.

Fuente: Elaboración propia a partir de la LEC (2009)

La LEC establece unas funciones comunes para todos los centros educativos concertados y privados y unas específicas para los concertados:

Tabla 19: Funciones directivas LEC centros concertados-privados

\begin{tabular}{|c|c|}
\hline \multirow[t]{2}{*}{ En común: } & $\begin{array}{l}\text { 1. Dirigir y coordinar todas las actividades educativas del centro de acuerdo con el } \\
\text { proyecto educativo }\end{array}$ \\
\hline & 2. Presidir los actos académicos y las reuniones de los órganos colegiados \\
\hline \multirow{4}{*}{$\begin{array}{l}\text { Privados y } \\
\text { Concertados }\end{array}$} & 3. Dirigir la actividad docentes del centro y de su personal \\
\hline & 4. Emitir certificaciones y documentos académicos \\
\hline & $\begin{array}{l}\text { 5. Adoptar las medidas disciplinarias pertinentes respecto los alumnos delante de } \\
\text { problemas graves o de convivencia en el centro }\end{array}$ \\
\hline & $\begin{array}{l}\text { 6. Impulsar la aplicación del proyecto educativo y, eventualmente, de los acuerdos } \\
\text { de la corresponsabilidad y mantener a disposición de la Administración } \\
\text { educativa la información sobre estos procesos. }\end{array}$ \\
\hline \multirow{2}{*}{$\begin{array}{l}\text { Sólo centros } \\
\text { concertados }\end{array}$} & 7. Ejercer de órgano competente para la defensa del interés superior del alumnado \\
\hline & $\begin{array}{l}\text { 8. Las que atribuyan las normas de organización y funcionamiento del centro en el } \\
\text { ámbito educativo. }\end{array}$ \\
\hline
\end{tabular}

Fuente: Elaboración propia a partir de la LEC (2009) 
Autores como Santos (2015), analizan las funciones haciendo la siguiente distinción:

- Funciones pedagógicamente pobres: aquéllas que su ejercicio no tiene una relación directa con el proceso educativo, mejora de relaciones o éxito escolar.

- Funciones pedagógicamente ricas: tienen un efecto directo en la mejora del centro, en el buen clima del centro y también en el desarrollo profesional del directivo.

Tabla 20: Clasificación de las funciones directivas

\begin{tabular}{|c|l|}
\hline $\begin{array}{c}\text { Funciones } \\
\text { pedagógicamente } \\
\text { pobres }\end{array}$ & - Las burocráticas y de tramitación de documentos \\
& - Las relativas al bricolaje \\
& - Las de control y disciplina \\
\hline \multirow{2}{*}{ Funciones } & - Las de sustitución de profesores \\
\hline pedagógicamente ricas & - La animación de un proyecto educativo \\
& - La investigación educativa \\
& - La coordinación pedagógica \\
& - La estimulación de iniciativas didácticas \\
& - La evolución interna del proceso \\
& - El perfeccionamiento del profesorado \\
\hline
\end{tabular}

Fuente: Elaboración propia a partir de Santos (2015: 30)

Esta perspectiva será utilizada para analizar los resultados de nuestro estudio.

\subsection{Formación para la dirección}

"La formación de los directores y directoras de los centros educativos constituye un requisito para la mejora de la educación escolar” (Antúnez, 2011:1).

Iniciamos este apartado de formación convencidas de que con una buena formación para el cargo se consigue una mejora del desempeño. La formación influye en el perfil del director que queremos fomentar: si se pretende potenciar un modelo de dirección basado en el liderazgo distribuido pedagógico y distribuido, la formación deberá basarse en cuestiones relacionadas con estrategias de participación, comunicación, innovación, etc. En cambio, si se pretende potenciar un modelo de dirección basado en la burocracia, la formación se basará en mecanismos de gestión y administración del centro. 
Además si se tiene en cuenta que las tareas directivas en un centro las realizan el director, el jefe de estudios y el secretario, la formación debería ser para todo el equipo directivo (Antúnez, 2000a) ya que el liderazgo debe de ser distribuido.

Respecto a los tipos de formación, existen diferentes clasificaciones de la formación directiva que responden, sobre todo, al momento en que se recibe. En estudios realizados a nivel internacional Pont (2008) habla de formación preparatoria para ocupar el cargo, formación para nuevos directores y formación permanente para antiguos directores y la OCDE (2009) las clasifica en acciones de formación inicial, programas de inducción y formación profesional continua. Vázquez Toledo \& Bernal (2008) clasifican la formación en: formación básica, formación previa al acceso al cargo, formación inicial, formación de noveles y formación permanente. A continuación explicamos cada tipo de formación:

La formación básica sería la destinada a todos los miembros de la organización; la formación previa a aquellos docentes interesados en desempeñar cargos directivos; la formación inicial a los directores que hayan superado el proceso de selección; la formación de noveles es la destinada a directores con menos de dos años de experiencia y la formación permanente es la destinada a los más experimentados.

Antúnez (2000) distingue entre la formación para y en la función directiva. La función "para" sería la correspondiente a la formación previa al acceso a la función directiva y la formación "en" sería la formación permanente, continua o recurrente durante el desarrollo del cargo.

En esta investigación entendemos como formación previa la formación inicial para la función directiva y formación continua para denominar la formación en la función directiva, basada en la clasificación anterior de Antúnez (2000).

En Inglaterra, Finlandia, Irlanda del Norte e Israel cuentan con todos los tipos de formación. Mientras que Chile, Irlanda, Países Bajos y Noruega no tienen programas de iniciación a la dirección sino que los tienen para los directivos en activo. El resto de países analizados por Pont, Nusche, \& Moorman (2009) cuenta con una formación previa o introducción 


\subsubsection{Formación previa al cargo}

La formación inicial es la formación para la función directiva. Este tipo de formación la realizan candidatos preseleccionados o futuros candidatos al cargo.

En general, según el informe Eurydice (Comisión Europea/EACEA/Eurydice., 2013: 120) "la mayoría de los países ofrecen programas especificos de formación para la dirección, pero varían su duración y contenido, así como los tipos de centros que los imparten" incluso en aquéllos países en los que dicha formación no es requisito para acceder al puesto:

Ilustración 3: Experiencia profesional y formación para la dirección escolar en Europa

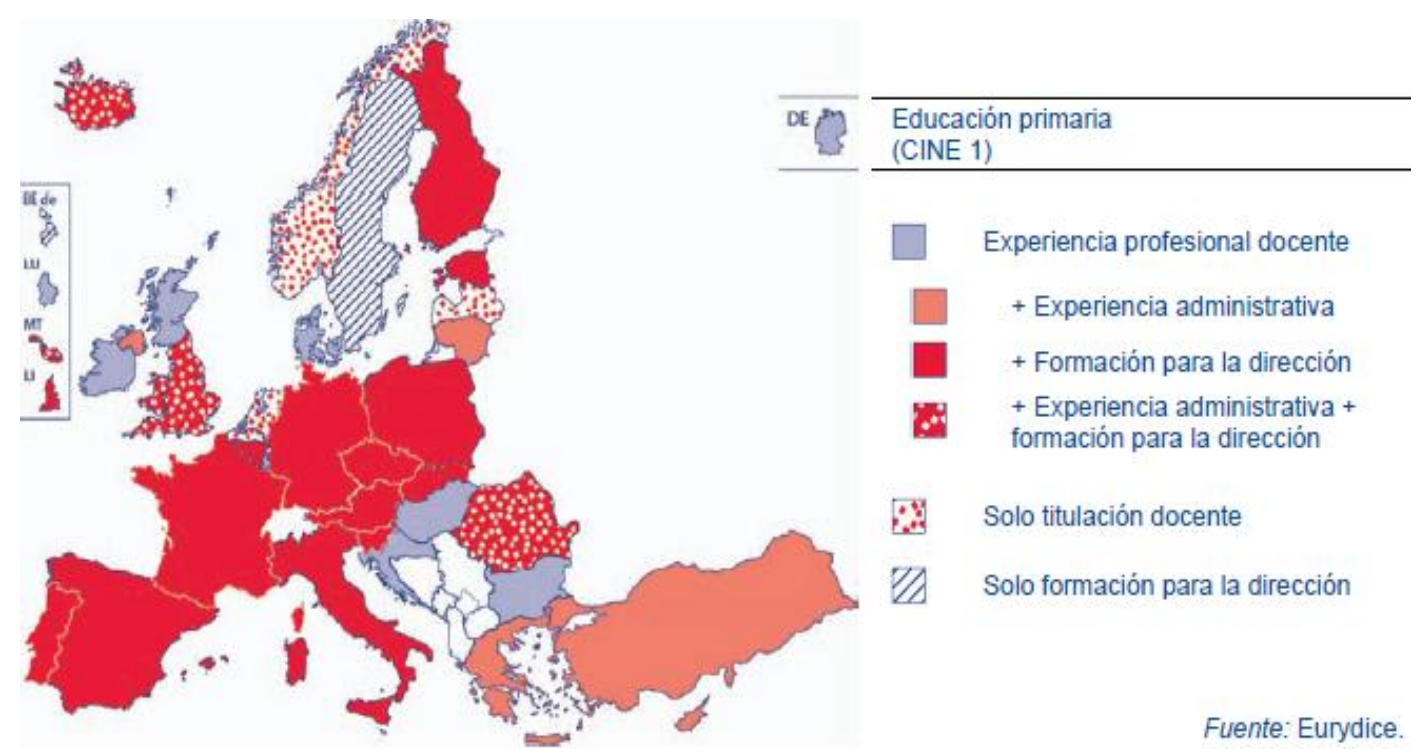

Fuente: Comisión Europea/EACEA/Eurydice (2013: 118)

En la mayoría de los países europeos la formación directiva se adquiere antes del nombramiento oficial del cargo. Pero en países como la República Checa, Francia, Austria, Eslovaquia y Suecia, los nuevos directores pueden adquirir el titulo formativo en un período de tiempo después de su nombramiento.

La duración de la formación inicial oscila ente una semana (Rumania) a realizar un Máster de 60 ECTS (Malta).

El contenido formativo común en las formaciones directivas son: formación en gestión, trabajo en equipo, competencias en comunicación y liderazgo, desarrollo del centro educativo, normativa y organización escolar. 
En algunos países el contenido es totalmente práctico, pero en otros combinan la teoría con la práctica. La superación de la formación acredita para ejercer el cargo de director.

Los autores García-Garduño, Slater, \& López-Gorosave (2011), muestran una visión de la formación más allá de la Unión Europea:

- En Estados Unidos los programas de formación se basan en un programa de maestría en administración educativa centrados en el liderazgo y la dirección escolar.

- En Corea existe un sistema muy competitivo para el ingreso a la dirección escolar basado en la acreditación de un programa de formación y una selección a partir de los méritos.

- En el continente Africano los expertos manifiestan una falta de programas de formación para impulsar la profesionalización de los puestos de dirección.

- En México no existen programas para formar a los profesores que aspiran a la dirección de escuelas de educación básica.

En España, los primeros antecedentes de la formación directiva se encuentran en el 1932 con las Escuelas Superiores de Magisterio y en las secciones de pedagogía en asignaturas relacionadas con la formación de directores. Con el paso del tiempo la formación exigida ha ido cambiando. En la siguiente tabla se observa la evolución:

Tabla 21: Evolución de la formación directiva en España

\begin{tabular}{|c|l|}
\hline LGE (1970) & $\begin{array}{l}\text { Se ofrecen cursos para directores impartidos en algunas universidades } \\
\text { por los Institutos de Ciencias de la Educación (ICEs, creados en 1969). }\end{array}$ \\
\hline LODE (1985) & No se demanda ninguna formación específica para acceder al cargo. \\
\hline LOPEGCD (1995) & $\begin{array}{l}\text { Se constituye como requisito una formación inicial específica y se } \\
\text { establecen programas de formación continua. }\end{array}$ \\
\hline LOGSE (1990) & $\begin{array}{l}\text { No aportan grandes cambios en la materia de formación para la } \\
\text { dirección escolar. }\end{array}$ \\
\hline LOCE (2002) & $\begin{array}{l}\text { Se exige la superación de un curso de formación sobre el desarrollo } \\
\text { de la función directiva. Curso impartido por la Escuela de la } \\
\text { Administración Pública o por instituciones en que delegan, } \\
\text { generalmente Universidades. }\end{array}$ \\
\hline LEC (2009)
\end{tabular}


En el Real Decreto 894/2014 (MECD, 2014) se especifican los módulos de contenido y las competencias genéricas y específicas de los cursos:

Tabla 22: Competencias de la formación directiva en España

\begin{tabular}{|l|l|}
\hline \multicolumn{1}{|c|}{ COMPETENCIAS GENÉRICAS } & \multicolumn{1}{|c|}{$\begin{array}{c}\text { MÓDULOS DE } \\
\text { CONTENIDO }\end{array}$} \\
\hline $\begin{array}{l}\text { 1. Liderazgo y fomento del trabajo en equipo } \\
\text { 2. Motivación }\end{array}$ & $\begin{array}{l}\text { Módulo I: Marco normativo } \\
\text { aplicable a los centros } \\
\text { 3. Gestión de la información y la toma de decisiones } \\
\text { 4. Comunicación }\end{array}$ \\
$\begin{array}{l}\text { 5. Gestión de conflictos y la convivencia } \\
\text { 6. Organización, gestión y coordinación de un centro docente }\end{array}$ & $\begin{array}{l}\text { Módulo II: Organización y } \\
\text { gestión de centros docentes }\end{array}$ \\
$\begin{array}{l}\text { 7. Control y supervisión } \\
\text { 8. Gestión del cambio y la innovación }\end{array}$ & Módulo III: Gestión de los \\
\hline \multicolumn{1}{|c|}{ COMPETENCIAS ESPECÍFICAS } & recursos del centro docente \\
\hline $\begin{array}{l}\text { 1. El marco normativo aplicable a los centros docentes } \\
\text { 2. El uso de las TIC }\end{array}$ & $\begin{array}{l}\text { Módulo IV: Factores clave } \\
\text { 3. La gestión administrativa y económica }\end{array}$ \\
$\begin{array}{l}\text { 4. La dirección de documentos institucionales } \\
\text { 5. La organización de tiempos y espacios } \\
\text { 6. La participación de la comunidad educativa y la promoción de } \\
\text { la imagen externa }\end{array}$ & $\begin{array}{l}\text { Módulo V: Rendición de } \\
\text { cuentas y calidad educativa }\end{array}$ \\
7. La gestión institucional & Módulo VI: Proyecto de \\
8. La evolución, los planes de mejora y el fomento de la calidad & dirección \\
\hline
\end{tabular}

Fuente: Elaboración propia a partir del Real Decreto 894/2014

Las características comunes en todos los cursos es una duración mínima de 120 horas y la obtención de un certificado válido para todo el territorio nacional durante 8 años.

Entre las Comunidades Autónomas no existe uniformidad en el modelo y contenido de la formación según Gómez Delgado (2011) y Montero (2013) ya que la formación puede desarrollarse según distintas modalidades. Los cursos son una estrategia rápida de transmitir conocimiento a partir de la asistencia o seguimiento de las sesiones formativas. Estos pueden complementarse con otras actividades como casos prácticos, trabajos en grupo, trabajos individuales, etc. y pueden ser intensivos, extensivos, a distancia o mixtos.

A continuación se observan las diferentes modalidades formativas y evaluativas de la formación directiva en función de la Comunidad Autónoma: 
Tabla 23: Resumen de las modalidades formativas

\begin{tabular}{|c|l|}
\hline Ponencias & $\begin{array}{l}\text { Andalucía, Aragón, Asturias, Baleares, Cantabria. Castilla la } \\
\text { Mancha, Castilla León, Cataluña, Extremadura, Galicia, La } \\
\text { Rioja, Madrid, Navarra, País Vasco y Comunidad Valenciana. }\end{array}$ \\
\hline $\begin{array}{c}\text { Formación online } \\
\text { Casos prácticos }\end{array}$ & $\begin{array}{l}\text { Andalucía, Baleares, Canarias, Castilla León y Murcia. } \\
\text { Cataluña, Galicia y Navarra. }\end{array}$ \\
\hline Tutela & $\begin{array}{l}\text { Andalucía, Aragón, Canarias, Cantabria, Castilla la Mancha, } \\
\text { Castilla León, Extremadura y Murcia. }\end{array}$ \\
\hline $\begin{array}{c}\text { Grupos de trabajo } \\
\text { Trabajo colaborativo } \\
\text { Se exige elaboración de una } \\
\text { memoria final }\end{array}$ & Andalucía y Castilla León. \\
\hline $\begin{array}{c}\text { Se exige la reelaboración del } \\
\text { proyecto de Dirección }\end{array}$ & Cataluña, Castilla León y Extremadura. \\
\hline \multicolumn{2}{|c|}{ Fuente: Elaboración propia a partir de Gómez Delgado (2011: 207-208) } \\
\hline
\end{tabular}

Tabla 24: Modalidades evaluativas de la formación

\begin{tabular}{|c|l|}
\hline $\begin{array}{c}\text { Seguimiento de sesiones } \\
\text { formativas }\end{array}$ & $\begin{array}{l}\text { Aragón, Cantabria, Baleares, Canarias, Cataluña, Murcia y } \\
\text { País Vasco. }\end{array}$ \\
\hline Trabajos & $\begin{array}{l}\text { Aragón, Cantabria, Baleares, Canarias, Castilla León, } \\
\text { Cataluña, Comunidad de Madrid y Murcia. }\end{array}$ \\
\hline Memoria de dirección & $\begin{array}{l}\text { Andalucía, Aragón, Canarias, Cantabria, Galicia, Murcia y } \\
\text { Comunidad Valenciana }\end{array}$ \\
\hline $\begin{array}{c}\text { Informes de evaluación de } \\
\text { ponentes, inspección- tutores }\end{array}$ & Andalucía, Aragón, Canarias, Cantabria y Murcia \\
\hline Cuestionarios de evaluación & Castilla León \\
\hline Prueba escrita-Autoevaluación & Comunidad de Madrid \\
\hline
\end{tabular}

Fuente: Elaboración propia a partir de Gómez Delgado (2011: 209)

Este tipo de formación simboliza el anticipar, preparar para resolver conflictos y situaciones que sucederán en el desempeño del cargo. Formar significa proveer a los individuos de una armadura que los proteja y unas herramientas con las que pueda intervenir en el contexto en el que desarrollará su labor, para mejorarlo (Fernández, 2006). 
Sin embargo Cantón \& Arias (2008) realizaron un análisis de los cursos formativos, a partir del cual definían a los directores como: "representantes de la Administración, en suma, son docentes con experiencia y gestores acreditados, personas orientadas a las tareas" (2008: 244).

Más adelante Cantón (2013) critica el tipo de formación de directores afirmando que los cursos de formación directiva estan basados en la normativa: "se señala que se forman en organización escolar, pero realmente la formación es en Legislación Educativa y en el BOE” (2013:168).

La formación no debe basarse exclusivamente en aspectos legislativos, administrativos y formales, sino basarse en liderazgo y afrontamiento al cambio (Bernal, 2006). Contenidos deben estar conectados a la realidad social y educativa de los centros y con coherencia entre el modelo de dirección del centro y el modelo de formación.

Por lo que respecta a la formación inicial en Cataluña, se parte de la base del Real Decreto 894/2014 y se realiza en la Escuela de Administración Pública de Catalunya (EAPC) (Generalitat de Catalunya, 2013) o en los centros en los que delegan y reconocen como las Universidades públicas y privadas.

Los objetivos de la formación EAPC en materia de formación de directores son:

- Capacitar la dirección profesional de los centros para un liderazgo pedagógico y organizativo que posibilite la gestión autónoma de los centros.

- Desarrollar el conjunto de estrategias, técnicas y habilidades profesionales que permitan elaborar el proyecto de dirección orientado a la mejora de resultados académicos.

Los cursos, de manera general, superan ampliamente el mínimo establecido por la normativa de la Administración Central: tienen una duración de 155 horas de las cuales 127 son presenciales y 28 no presenciales.

Los contenidos de los cursos son divididos en 10 módulos de contenido, más un módulo en el que se realiza el proyecto de dirección. A continuación se observa el contenido formativo de cada módulo: 
Tabla 25: Módulos del curso de formación inicial en Catalunya

\section{Módulo 1: Marco normativo}

Conceptos básicos para la acción directiva de los centros educativos

\section{Módulo 2: Liderazgo transformacional}

Promoción del cambio directivo de los centros educativos

Módulo 3: Gestión pedagógica

La implementación del proyecto educativo del centro en el aula

Módulo 4: Gestión organizativa

El centro al servicio del aprendizaje

\section{Módulo 5: Gestión de personal}

La definición de los recursos humanos para el desarrollo del proyecto educativo del centro

Módulo 6: Gestión del contexto

Redes colaboradoras internas y externas

Módulo 7: Gestión de recursos económicos y materiales

Optimización eficiente del servicio público

Módulo 8: Estrategia

Planificación de procesos

\section{Módulo 9: Sistema global de indicadores}

Evaluación del centro para la mejora

\section{Módulo 10: Identidad directiva}

Deontología y psicología directiva

\section{Módulo del proyecto de dirección}

Diseño del proyecto de gestión integral para la mejora del servicio educativo

Fuente: Elaboración propia a partir de la Generalitat de Catalunya (2013)

\subsubsection{Formación durante el cargo}

La formación continua o permanente seria la formación realizada en la función directiva. A diferencia de la formación previa, la formación permanente no es un requisito normativo para la carrera directiva aunque sí se destaca su necesidad para el cargo directivo, teniendo en cuenta que las personas que ejercen el cargo directivo han sido formadas para el desempeño de tareas docentes.

El aumento de la complejidad en las demandas sociales que exigen habilidades específicas y tomar decisiones directivas, requiere una capacitación actualizada. Entendemos la formación permanente como una fuente de seguridad en el desempeño de las acciones y funciones directivas. A la vez que adquiere mayor seguridad en el 
cargo, adquirirá mayor motivación y compromiso que podrá contagiar al resto de la comunidad educativa.

Para Antúnez (2011) los inspectores son el colectivo idóneo para realizar las formaciones y el apoyo a los directores escolares ya que los inspectores acompañan y asesoran de manera directa a los directores y a sus equipos directivos. Los lugares donde pueden producir una incidencia de la mejora de la formación son: en los gabinetes de planificación y evaluación de planes/programas y en las zonas escolares a través de seminarios, grupos de trabajo y reuniones.

En Europa, según el informe Eurydice (Comisión Europea/EACEA/Eurydice., 2013) la formación durante el cargo, o formación permanente, se considera en la mayoría de los países, concretamente en 23, una obligación profesional para los directores de los centros Mientras, en 14 países la formación permanente es opcional para los directores aunque se fomenta y anima a participar.

Existen diferentes organizaciones e instituciones que realizan la formación (Comisión Europea/EACEA/Eurydice., 2013). Por ejemplo:

- La Academia Holandesa de Dirección (órgano independiente no gubernamental) en Holanda. Tiene como objetivo facilitar a los directores de centros de educación primaria el acceso a actividades de formación permanente opcionales.

- La Academia de la Dirección en Austria, donde se ofrece formación en innovación para el cambio del sistema educativo a través de la formación permanente.

- El Centro Nacional para la Dirección en Educación en Eslovenia donde se ofrece formación a los directores y aspirantes a directores.

- El Instituto Nacional de cualificación y Educación del Ministerio de Educación en Bulgaria forma a los directores en diferentes cursos de capacitación desarrollados a lo largo del año.

- El Instituto de Dirección Educativa. y la Calificación Profesional Nacional para la Dirección en Reino Unido se dirige a profesores que aspiran a ser directores. En el Reino Unido el Colegio Nacional de Dirección de Centros ofrece una amplia gama de oportunidades de formación permanente. Destacar el Head Start, un programa de formación durante los primeros años como directores de centro para quienes acaban de obtener la cualificación profesional. 
Ilustración 4: Formación directiva durante el cargo

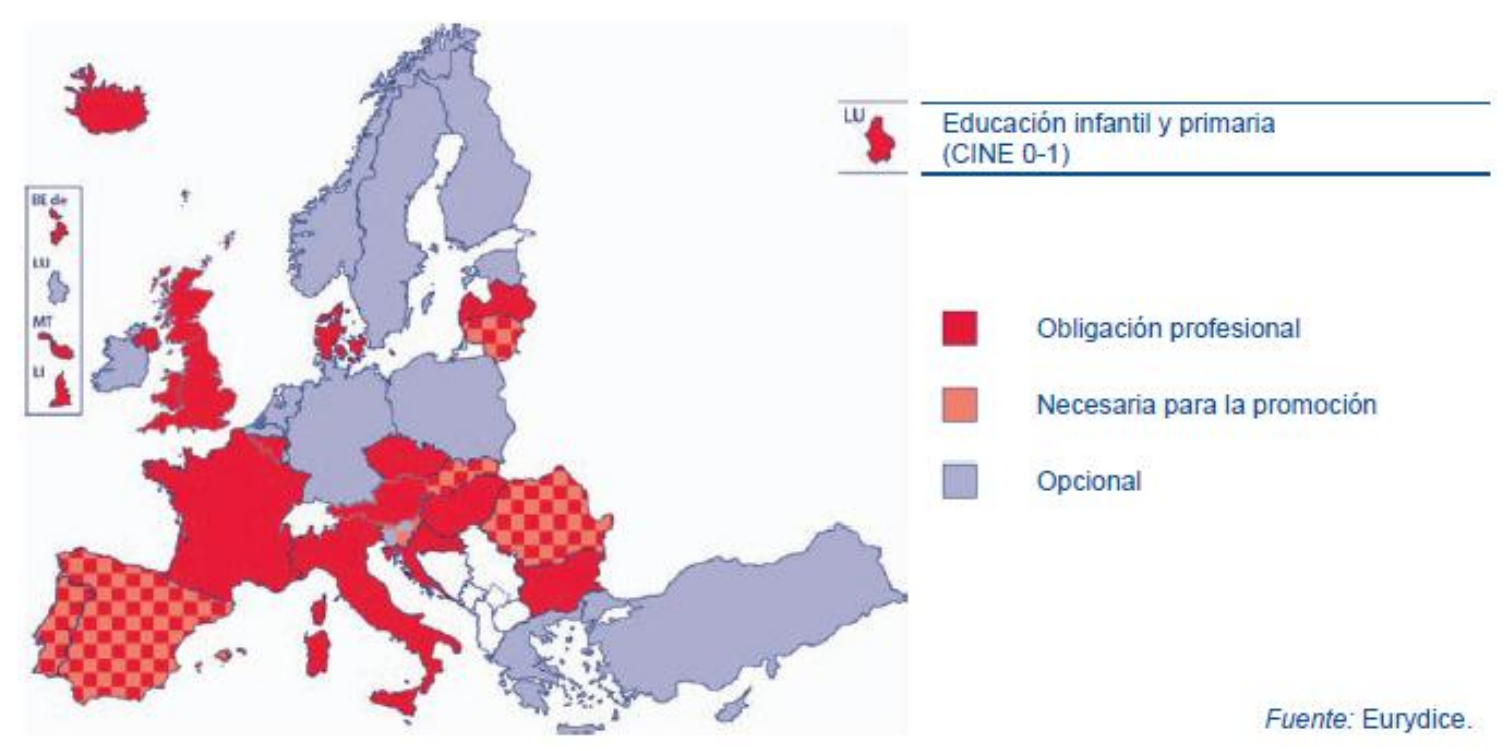

Fuente: Comisión Europea/EACEA/Eurydice. (2013: 136)

En el estudio TIMSS 2011(International Association for the Evaluation of Educational Achievement, 2011) se preguntó a los directores por el tiempo destinado a las actividades de formación permanente. La escala de puntuación era: ningún/poco, algo o mucho. Del total de directores, un 58\% respondió dedicar "algún tiempo" a la formación.

El 70\% de los directores de Rumanía, Eslovenia y Croacia manifiestan dedicar "mucho tiempo" a la formación ya que es un deber profesional o se necesita para la promoción profesional. En conclusión: "En la mayoría de países los directores de centro dedican al menos algún tiempo a actividades de formación permanente" (Comisión Europea/EACEA/Eurydice., 2013: 125) a pesar que el mismo informe expone que un $10 \%$ de los directores de Alemania, España, Suecia y Noruega manifiestan "no dedicar ningún tiempo" a actividades de formación durante el mandato.

En España, Escamilla (2006) afirma que la mayoría de los directores ha adquirido su formación mediante su propia experiencia (experiencia docente y en el día a día en el cargo directivo). Deben potenciarse acciones formativas centradas en considerar y priorizar las características del desempeño de la función directiva para lograr mejoras educativas en los centros. 
Más recientemente Chavarria (2013) continua afirmando que "la formación permanente, continua y recurrente está, por ahora, muy desatendida y debería formalizarse a partir de una oferta amplia, modular y muy específica”(2013:28).

En Cataluña existe una Asociación de directivos de educación pública, al margen de la EAPC, que ofrece una formación directiva orientada a conseguir una nueva dirección comprometida con el aprendizaje del alumnado y con la mejora del rendimiento académico y a preparar a los directivos para un liderazgo fuerte y distribuido con una visión transformadora (AXIA, 2015).

Los cursos de AXIA ofrecen una formación modular de 16 horas (12h presenciales y $4 \mathrm{~h}$ de trabajo individual). Los cursos cuentan con el reconocimiento del Departamento de Educación de la Generalitat.

Algunos ejemplos de cursos que ofrece AXIA son:

- Herramientas para la gestión personal

- Liderazgo pedagógico para el aprendizaje

- Planificación de procesos

- Organización eficiente para el aprendizaje

- Gestión de la información y la comunicación

- Autoevaluación de la función directiva

- Identidad directiva

AXIA organiza jornadas que constituyen: un espacio de formación que, durante varios días, proporciona nuevos elementos formativos para mejorar las competencias genéricas y específicas, actividades directivas que tengan utilidad en sus entornos educativos y especialmente en el liderazgo creativo de la gestión del conocimiento del equipo docente. Se realizan conferencias de expertos de la temática y realización de talleres como técnicas de entrevista, habilidades comunicativas personales o técnicas de observación directa. 


\subsubsection{Necesidades formativas}

"Los tiempos de formación son tiempos de energía, de ilusión" (Bazarra \& Casanova, 2013:108)

El director es considerado un "primus inter pares" (Cantón \& Arias, 2008; García Olalla et al., 2006; Teixidó, 2010) más cercano a la figura docente (al finalizar el mandato vuelve a la función docente) que a un líder.

La formación universitaria que reciben es común a la del cuerpo de profesorado, a pesar de que los directores son los encargados de realizar tareas diferentes al resto de los docentes y asuman competencias y responsabilidades singulares.

Puede parecer lógico que dentro de la formación inicial (universitaria) de los maestros se abordara este tipo de preparación pero no es así de forma generalizada. Son pocas las universidades que hacen referencia a la función directiva y las que lo hacen suelen convertirla en una asignatura optativa (Fernández, 2006; Rodríguez Pulido et al., 2013).

La formación de profesores y la mejora profesional de los directivos deben ir acompañados por un diagnóstico previo de necesidades (Beltrán de Tena et al., 2004). La clasificación de necesidades formativas más conocida es la del autor Bradshaw (1972) que distingue entre: necesidades normativas, necesidades expresadas, necesidades percibidas y necesidades comparativas.

Gairín \& et al., (1995) las definen en su estudio sobre las necesidades de formación de los equipos directivos de los centros educativos:

- Necesidades normativas: basadas en el establecimiento, por parte de un experto o un grupo de expertos, de unos niveles teóricamente deseables de satisfacción de cada necesidad. Se identifican con las necesidades del sistema, o con las exigencias normativas.

- Necesidades expresadas: o coincidentes con lo manifestado. Se identifican en gran parte con las demandas.

- Necesidades percibidas o experimentadas. Son las basadas en la percepción de cada persona o grupo de personas sobre determinada carencia. Resultan, por tanto, una apreciación subjetiva, condicionada por factores psicológicos y psicosociológicos particulares. 
- $\quad$ Necesidades comparativas: resultado de la comparación entre diferentes situaciones o grupos.

Estos mismos autores consideran que los referentes de estas necesidades pueden ser personales o sociales. Con los referentes personales estarían relacionadas las necesidades expresadas y las necesidades formativas. En cambio con los referentes sociales las necesidades comparativas y las necesidades percibidas. Consideran que la clasificación es diferenciadora pero no excluyente. Es decir, desde una perspectiva dinámica integraría los diferentes tipos y podrían cambiar o desparecer con el tiempo.

A continuación, en la ilustración podemos observar las relaciones entre las distintas necesidades asociadas a los referentes:

Ilustración 5: Relación entre diferentes tipos de necesidades

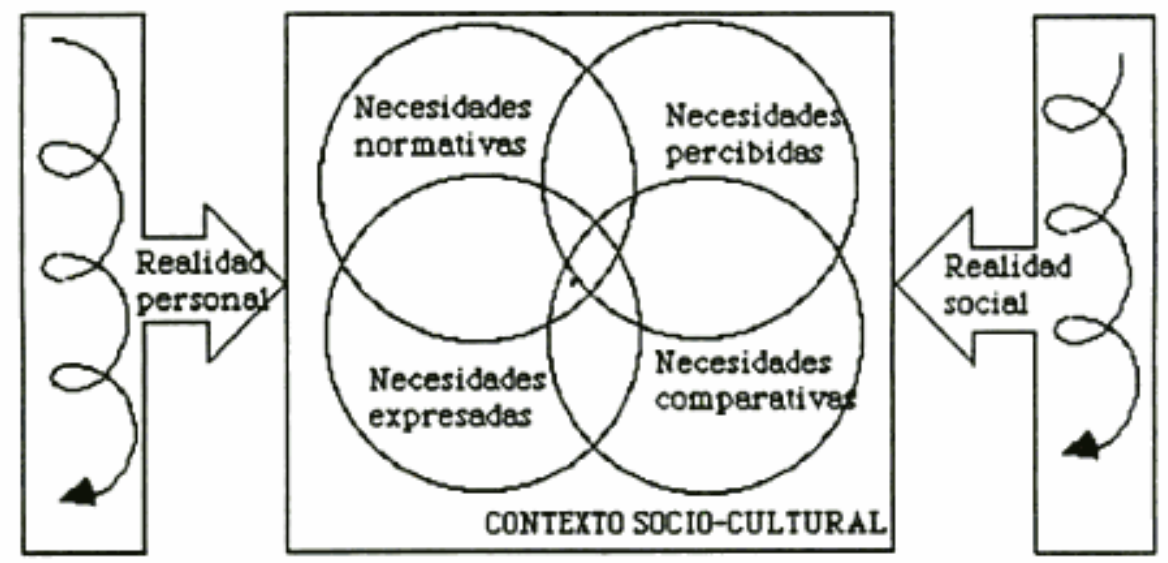

Fuente: Gairín et al. (1995: 90)

Para mejorar los programas de formación, estos se deben diseñar escuchando y valorando las voces de sus destinatarios. Es decir, es necesario revisar y actualizar, de manera constante, los contenidos de la formación y articular las formaciones a través de itinerarios. Uno de los déficits de los programas de formación son su falta de continuidad (Silva, 2012).

Cano \& Gradaïlla (2012) realizaron un grupo de discusión de directores con diferentes grados de experiencia (del novel al más experimentado) de centros de educación primaria y educación secundaria para conocer las necesidades de la formación inicial y formación continua a partir de la propia experiencia y formación. En los resultados hubo unanimidad respecto a la necesidad de una formación básica previa para todos y 
una formación permanente más diversificada, en función del tipo de centro y de la necesidad de una formación continua individualizada en función del contexto, del tipo de centro, del acceso al cargo y de la personalidad del director, es decir, una formación continua personalizada que responda a necesidades concretas.

Varios autores, investigan para conocer las diferentes necesidades formativas de los directores escolares. Por ejemplo, Vázquez Recio (2002) manifiesta que la excesiva normatividad administrativa ha creado la necesidad de formar en materia administrativa, encaminada más a la interpretación, análisis y comprensión del sentido de las normas, a la adquisición y desarrollo de habilidades para aplicar la norma; Padilla (2008) afirma que las necesidades que tienen los directores se basan en el desempeño de la dirección y destacan la falta de apoyo de la Administración y la insuficiente preparación profesional; Álvarez, (2010a) señala la desproporción de funciones de los ámbitos ejecutivos, administrativos e institucional, en comparación con los ámbitos de innovación e integración propios del liderazgo directivo y Gómez Delgado (2012) señala la distancia entre las necesidades de los directores escolares y la formación que reciben para el cargo.

Por último, Caballero (2003) concluye que los ámbitos en los que los directores consideran estar peor preparados son:

- Organización de servicios escolares (comedor, transporte)

- Evaluación de centros

- Modelos, estrategias y técnicas relativas a la formación del profesorado en ejercicio

- Evaluación de programas

- Psicología aplicada y orientación escolar

- Didáctica general: modelos didácticos, metodologías innovadoras, sociología de la educación, etc.

- Técnicas de gestión

- Dinámicas de grupo 
En cambio, los ámbitos en los que se consideran estar mejor preparados son:

- Relaciones con los padres

- Cumplimentar documentos oficiales

- Relaciones interpersonales

- Organización general del centro

- Infraestructura material y de espacios

- Organización de actividades complementarias

- Planificación (PEC, PAC, memoria, etc.)

- Legislación escolar en aspectos generales y específicos.

Caballero (2003) detecta que este último grupo de funciones, necesita una menor formación teórica y una mayor práctica para aprender a desarrollar los contenidos.

Para finalizar, una de las quejas más generalizadas entre los directores es el descontento con los horarios en los que se realiza la formación (Gómez Delgado, 2012).

\subsection{Desempeño del cargo directivo}

En su último libro, Santos (2015) hace una metáfora de la dirección escolar asemejándola con las feromonas de la manzana. Explicación de la metáfora: las manzanas desprenden unas feromonas de manera natural por lo que, si las metes en una bolsa, las maduras harán madurar a las verdes. En ese sentido, el autor manifiesta que la dirección escolar ha de ser una influencia silenciosa, persistente y beneficiosa que haga crecer a quienes están al lado.

Ese tipo de desempeño viene condicionado por algunos rasgos asociados a las competencias, al género, a los estadios profesionales, a la ética profesional y a la (in)satisfacción del cargo a partir de los cuales hemos estructurado este epígrafe.

\subsubsection{Competencias y características directivas}

"Un enfoque competencial supone un cambio de perspectiva: en lugar de centrarse en las tareas o funciones, lo hace en competencias que deben tener los que ocupan funciones directivas" (Bolívar, 2011a: 256). 
Se entiende por competencia la capacidad de movilizar varios recursos (conocimientos, habilidades y/o actitudes) para hacer frente al cargo directivo.

En el proyecto "Definición y Selección de Competencias" (DeSeCo) de la OCDE (2005) define una competencia como "más que conocimientos y destrezas. Involucra la habilidad de enfrentar demandas complejas, apoyándose en y movilizando recursos psicosociales (incluyendo destrezas y actitudes) en un contexto particular" (2005:3).

Tejada (2009) clasifica las competencias en: competencias teóricas o conceptuales (analizar, comprender, interpretar, conocimientos del contexto general, estrategias cognitivas), competencias psicopedagógicas y metodológicas (saber aplicar el conocimiento, procedimientos, destrezas, habilidades) y competencias sociales (saber relacionarse y colaborar con otras personas de forma comunicativa y constructiva, actitudes, valores y normas, feedback, trabajo en equipo, negociación, relación interpersonal, liderazgo, etc.)

Álvarez (2010b) diferencia entre: funciones, tareas y competencias. Las funciones son obligaciones del cargo determinadas por la normativa vigente. Las tareas son las actividades que deben realizarse para cumplir la función. Por último, las competencias son el conjunto de conocimientos y habilidades que tiene el directivo para desempeñar con éxito las funciones y realizar las tareas.

Teixidó (2007a: 10) menciona las siguientes características de las competencias:

- Las competencias se adquieren. Son el resultado de un proceso de superación tendente a la obtención y la integración de recursos personales para adecuarlos a las posibilidades y las demandes del entorno profesional y/o personal.

- Las competencias son útiles en la medida que permiten que la persona se plantee retos de superación adecuados a sus posibilidades y contribuyen a un mejor desempeño de las tareas inherentes al puesto de trabajo.

- Las competencias son objetivas, dado que se manifiestan en comportamientos observables, pero también son subjetivas en tanto que dependen de la percepción humana. Aquí entran en juego las diversas perspectivas preceptuales: autopercepción, metapercepción. 
- Las competencias no son directamente observables. Se trata de un concepto abstracto, una inferencia, a la que se llega tras la observación del comportamiento en situaciones relevantes.

El saber (conocimiento), el saber hacer (habilidad), el saber estar (actitud), el querer hacer (motivación) y el poder hacer (recursos) determinan el desarrollo de las competencias directivas (Pereda, Berrocal, \& López, 2002).

Una actuación competente se caracteriza por la utilización e identificación de los recursos de que dispone y tiene a su alcance. Por lo tanto, las competencias son factores importantes para el desempeño y mejora del cargo directivo.

Pero según Bolívar, (2011a) las competencias profesionales no se aprenden con tan sólo asistir a formaciones sino con el ejercicio de buenas prácticas (práctica y experiencia).

Es importante identificar las competencias claves para un liderazgo directivo efectivo (Donoso et al., 2012) ya que un liderazgo efectivo requiere de una serie de competencias.

Existen múltiples clasificaciones de las competencias. Unos autores hablan de competencias directivas, otros de competencias para el liderazgo y otros de habilidades. Desde la perspectiva de nuestro trabajo destacamos algunas que inciden en una dirección basada en el liderazgo, independientemente de cómo las denominan los diferentes autores. Poblete \& García Olalla (2003) enumeran las siguientes competencias directivas:

Tabla 26: Competencias directivas según Poblete \& García Olalla (2003)

\begin{tabular}{|l|l|}
\hline Planificación & Negociación \\
\hline Toma de decisiones & Coaching \\
\hline Relaciones interpersonales & Orientación al logro \\
\hline Pensamiento analítico sistémico & Espíritu emprendedor \\
\hline Comunicación & Innovación \\
\hline Resistencia al estrés & Orientación al aprendizaje \\
\hline Liderazgo & Comportamiento ético \\
\hline
\end{tabular}

Fuente: Elaboración propia 
Villa \& García Olalla (2003) clasifican las competencias en tres categorías:

Tabla 27: Competencias directivas según Villa \& García Olalla (2003)

\begin{tabular}{|l|}
\hline Competencias personales \\
\hline -Relaciones personales \\
- Habilidades \\
comunicativas \\
-Disponibilidad \\
-Honestidad
\end{tabular}

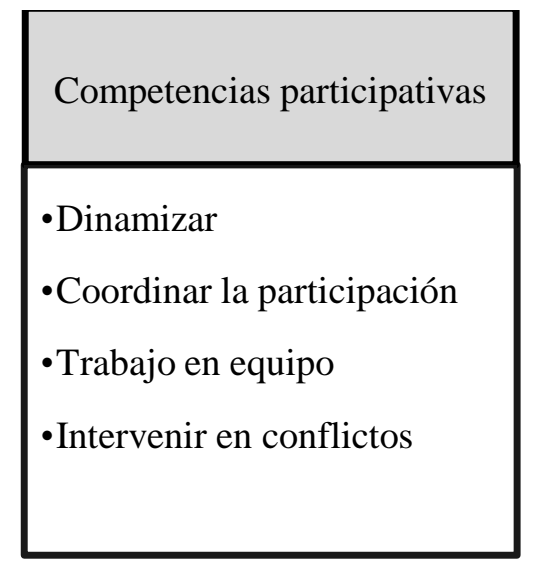

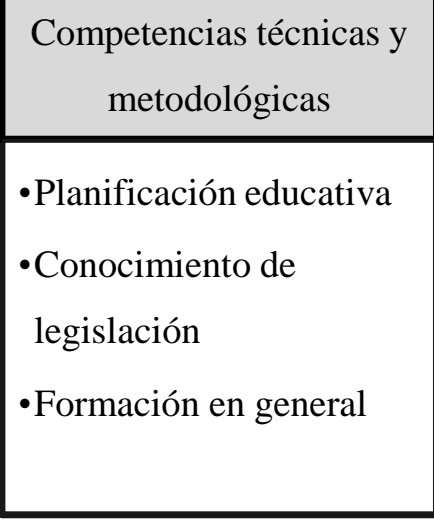

Fuente: Elaboración propia

Según estos autores, los directores dicen priorizar las competencias personales $\mathbf{y}$ participativas frente a las competencias técnicas y metodológicas.

Álvarez (2006a) habla de capacidades directivas en lugar de competencias y establece las siguientes:

Tabla 28: Capacidades directivas según Álvarez (2006a)

\begin{tabular}{|ll|}
\hline 1. & Organizar el trabajo propio y de sus colaboradores \\
\hline 2. & Tomar decisiones personalmente y en equipo \\
\hline 3. & Controlar y supervisar los procesos y las personas \\
\hline 4. & Planificar y crear estructuras operativas \\
\hline 5. & Ajustar la actividad a procedimientos normativos previos \\
\hline 6. & Elaborar proyectos de innovación \\
\hline 7. & Estudiar e investigar nuevas estrategias de aprendizaje \\
\hline 8. & Motivar e incentivar al personal \\
\hline 9. & Relacionarse e interaccionar \\
\hline 10. & Implicar a la gente alrededor de un proyecto que ilusione \\
\hline
\end{tabular}

Fuente: Elaboración propia 
Villa \& Poblete (2007) distribuyen las competencias en categorías y subcategorías:

Tabla 29: Clasificación de competencias según Villa \& Poblete (2007)

\begin{tabular}{|c|c|c|}
\hline Categoría & Subcategoría & Competencias directivas \\
\hline \multirow{4}{*}{ Instrumentales } & Cognitivas & $\begin{array}{l}\text { Pensamiento reflexivo, lógico, sistémico, práctico y } \\
\text { creativo. }\end{array}$ \\
\hline & Metodológicas & $\begin{array}{l}\text { Gestión del tiempo, resolución de conflictos, toma de } \\
\text { decisiones, planificación y estrategias de aprendizaje. }\end{array}$ \\
\hline & Tecnológicas & Conocimientos informáticos y de bases de datos. \\
\hline & Lingüísticas & Comunicación verbal y escrita. \\
\hline \multirow[b]{2}{*}{ Interpersonales } & Individuales & $\begin{array}{l}\text { Automotivación, adaptación al cambio y al entorno. } \\
\text { Valores y ética. }\end{array}$ \\
\hline & Sociales & $\begin{array}{l}\text { Diversidad, comunicación interpersonal, trabajo en } \\
\text { equipo, mediación de conflictos y negociación. }\end{array}$ \\
\hline \multirow{4}{*}{ Sistémicas } & $\begin{array}{l}\text { De capacidad } \\
\text { emprendedora }\end{array}$ & Creatividad y capacidad innovadora. \\
\hline & $\begin{array}{c}\text { De } \\
\text { organización }\end{array}$ & Gestión por objetivos y gestión de proyectos. \\
\hline & De liderazgo & Influencia, estimulación intelectual y delegación. \\
\hline & De logro & Orientación a la mejora de resultados. \\
\hline
\end{tabular}

Fuente: Elaboración propia

Por último, Campo (2010) agrupa en 4 categorías las diferentes competencias directivas:

Tabla 30: Clasificación de las competencias según Campo (2010)

\begin{tabular}{|c|c|c|c|}
\hline $\begin{array}{l}\text { Cualidades } \\
\text { personales }\end{array}$ & $\begin{array}{c}\text { Destrezas } \\
\text { interpersonales }\end{array}$ & $\begin{array}{l}\text { Capacidad de } \\
\text { dirección y } \\
\text { liderazgo }\end{array}$ & $\begin{array}{l}\text { Destrezas } \\
\text { técnicas de } \\
\text { gestión }\end{array}$ \\
\hline $\begin{array}{l}\text {-Flexibilidad } \\
\text { - Constancia } \\
\text { - Autonomía } \\
\text { - Fiabilidad } \\
\text {-Equilibrio }\end{array}$ & $\begin{array}{l}\text {-Empatía } \\
\text { - Asertividad } \\
\text {-Escucha activa } \\
\text { - Claridad en la } \\
\text { exposición } \\
\text { - Trabajo en equipo }\end{array}$ & $\begin{array}{l}\text { - Delegación } \\
\text { - Motivación } \\
\text { - Desarrollo } \\
\text { personal } \\
\text { - Apertura al } \\
\text { exterior } \\
\text { - Liderazgo }\end{array}$ & $\begin{array}{l}\text { - Planificación de } \\
\text { proyectos } \\
\text { - Comprensión del } \\
\text { contexto } \\
\text { - Negociación } \\
\text { - Distribución de } \\
\text { recursos }\end{array}$ \\
\hline
\end{tabular}

Fuente: Elaboración propia 
En el cuestionario utilizado en nuestra investigación se utiliza la enumeración de las diecisiete competencias directivas que establece Teixidó (2007a). En el anexo 1 se pueden consultar las definiciones que establecen para cada una de las competencias del siguiente listado:

Tabla 31: Competencias de la dirección escolar según Teixidó

\begin{tabular}{l} 
1. Adaptación al cambio \\
2. Autogestión \\
3. Autonomía \\
4. Comunicación \\
5. Compromiso \\
6. Participación \\
7. Orientación al aprendizaje de los alumnos \\
8. Organización \\
9. Liderazgo \\
10. Fortaleza interior \\
11. Control emocional \\
12. Desarrollo personal \\
13. Resolución de problemas \\
14. Relaciones interpersonales \\
15. Energía \\
16. Trabajo en equipo \\
17. Desarrollo profesionales de colaboraciones \\
\hline Fuente: Elaboración propia a partir de Teixidó (2007b: 24-26)
\end{tabular}

Para analizar los resultados del cuestionario nos centraremos en la clasificación de las competencias directivas de Campo (2010).

Además de todas las competencias mencionadas, se espera que el director sepa y tome decisiones, que se ocupe de los conflictos, que asuma la responsabilidad y esté a disposición de los demás, que tenga sentido común, que mantenga el autocontrol y ofrezca una imagen de serenidad y sea empático y accesible (Woycikowska et al., 2008).

Molinar \& Velázquez (2005) manifiesta que todo líder debe tener las siguientes competencias:

- Ser proactivo: tomar la iniciativa y hacerse responsable. Hacer que las cosas sucedan. 
- Crear el futuro: estimular a las personas para que piensen y miren más allá del presente y se centren en el futuro. Estimulan la inspiración.

- Motivar a los demás: mover las voluntades de las personas y persuadirlas.

- Desarrollar relaciones humanas: transmitir sus pensamientos, sus metas, sus conocimientos y su experiencia.

Álvarez (2010b), por su parte establece los siguientes bloques de competencias que considera esenciales para el liderazgo:

1. Competencias del pensamiento estratégico: promover y gestionar procesos de cambio. Implicar a diferentes miembros de la comunidad en esta visión compartida.

2. Competencias de gestión del aprendizaje: liderar los procesos de enseñanza, supervisar a los docentes y promover el desarrollo profesional.

3. Competencias de relación con las personas: desarrollar redes de comunicación e influencia en otras personas.

4. Competencias para la creación y animación de estructuras organizativas: crear un ambiente de trabajo compartido, con estructuras que faciliten la coordinación.

Robinson (2010) menciona tres conjuntos de competencias básicas con interdependencia entre ellas para el desarrollo de un liderazgo eficaz:

1. Desarrollar conocimiento pedagógico sobre el proceso de enseñanzaaprendizaje: vincular el conocimiento curricular y pedagógico con las dimensiones de gestión.

2. Saber resolver los conflictos del centro: resolver los conflictos mediante su función de su liderazgo y conocimiento pedagógico.

3. Fomentar la confianza relacional con toda la comunidad educativa: destacar que el liderazgo es un proceso social basado en la confianza.

En relación a las características, según Fullan (2002) un líder eficaz debe tener un fin ético, entender el cambio, construir relaciones, crear y compartir conocimiento además de otorgar coherencia.

Blanchard \& Miller citado en Woycikowska et al., (2008) proponen un listado de características que debe tener un buen líder: 
Tabla 32: Características de un buen líder

\begin{tabular}{|l|l|}
\hline \multirow{2}{*}{$\begin{array}{l}\text { Un } \\
\text { líder... }\end{array}$} & $\begin{array}{l}\text { Aprecia la diferencia entre liderazgo y nivel jerárquico. Desciende de su pedestal, se } \\
\text { pone en contacto con el terreno, escucha a sus colaboradores, arrima el hombro } \\
\text { (después del café matinal, no olvida lavar él mismo su taza) }\end{array}$ \\
\cline { 2 - 2 } & $\begin{array}{l}\text { Está allí para servir (a los demás), no para servirse de ellos (en su carrera) } \\
\text { Es capaz de crear una visión de futuro para sus equipos y darles valores para la } \\
\text { acción }\end{array}$ \\
\hline Hace crecer a sus colaboradores. Hace más uso de su inteligencia que de sus brazos \\
\hline Aprende constantemente y reinventa sin cesar \\
\hline Reconoce los logros de sus colaboradores y los valora \\
\hline Posee valores y se gana la confianza de sus colaboradores \\
\hline
\end{tabular}

Álvarez (2010b) menciona las siguientes características, habilidades, actitudes y comportamientos de un líder:

Tabla 33: Características, comportamientos, actitudes y habilidades de un líder efectivo

1. Tiene una visión clara del futuro del centro y valores personales que todos conocen

2. Comparte con el profesorado un proyecto de trabajo

3. Potencia las relaciones humanas entre todos los miembros de la comunidad escolar

4. Hace seguimiento de las decisiones tomadas y evalúa la actividad del profesorado

5. Posee altas expectativas de la gente que colabora en un proyecto de gestión

6. Crea un clima de trabajo ordenado que proporciona seguridad a la gente

7. Se preocupa de los resultados académicos de los alumnos y de sus colaboradores

1. Sabe trabajar en equipo respetando las diferencias como un valor que enriquece al grupo

2. Sabe tomar decisiones personales y en equipo y asumir el compromiso que implica

3. Es capaz de implicar a los demás en un trabajo colectivo

4. Tiene habilidad para armonizar los intereses de los miembros con los objetivos del centro y las expectativas de los clientes

5. Se comunica convincentemente con argumentos consistentes y respetuosos con las opiniones diferentes

6. Proporciona instrucciones claras para que se trabaje con eficacia

Tiene habilidad para hacer valoraciones, diagnosticar situaciones nuevas y problemas que afecten al trabajo de la escuela 


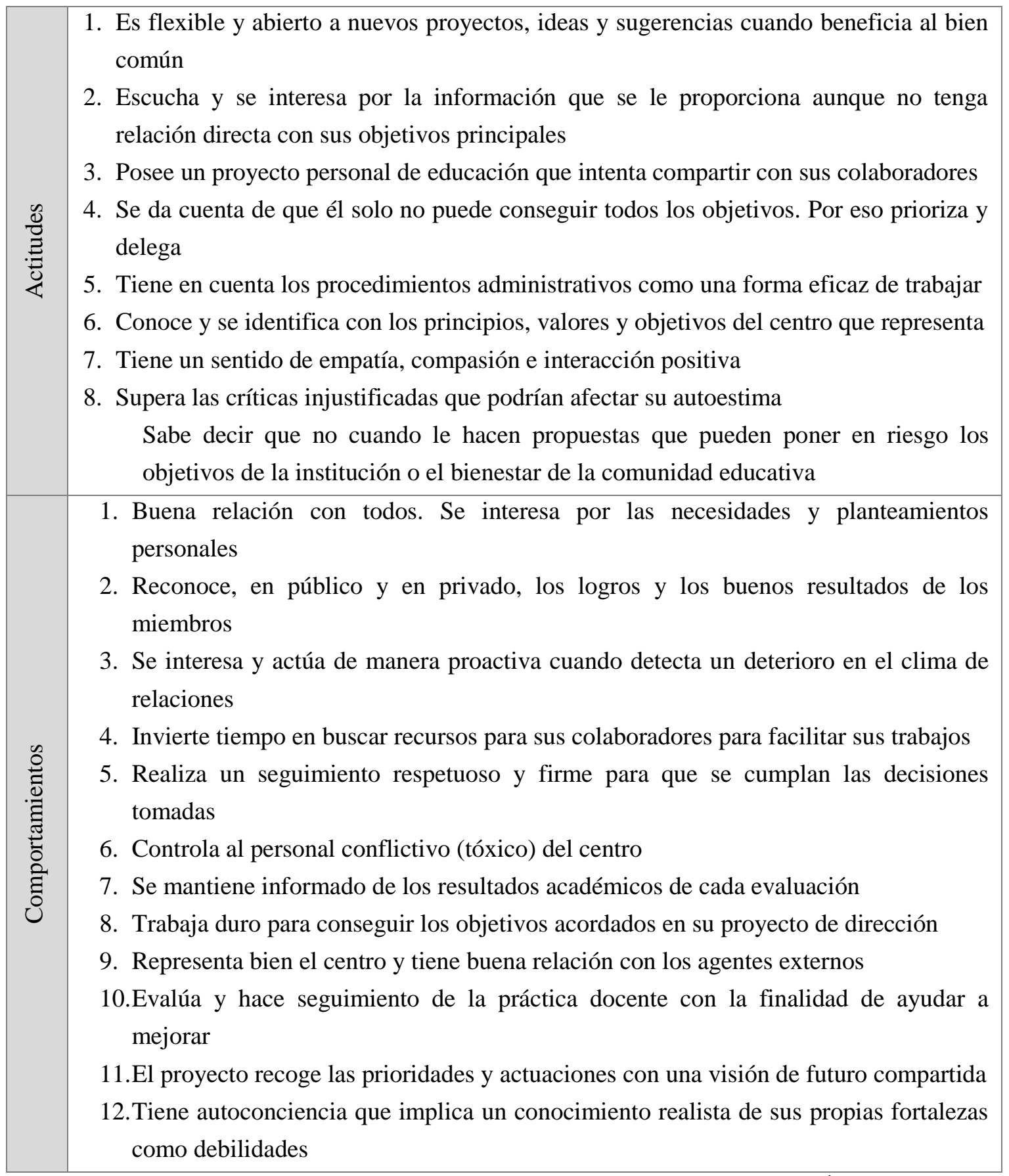

Fuente: Elaboración propia a partir de Álvarez (2010b)

Bazarra \& Casanova (2013) mencionan unas habilidades técnicas para liderar con éxito y que nos parece interesante analizar:

\section{- Uso inteligente del tiempo}

En el día a día, los directores deben de actuar de "apagafuegos" y el tiempo corre en su contra. El tiempo es un recurso limitado, irreversible, no se puede alargar, ni comprar, ni ahorrar ni almacenar. Por esos motivos es importante organizar, gestionar y optimizar el tiempo que se dispone. 


\section{- Motivación}

La motivación se da internamente, el director tan sólo puede dar razones para esa automotivación a los demás miembros de la comunidad educativa a través de gestos, valoraciones positivas, haciendo que se sientan satisfechos y orgullosos de pertenecer al centro.

Las personas desmotivadas tienden a buscar una zona de comodidad y realizar siempre las mismas acciones. Para motivar a los que no lo están se deben proponer retos activos, dar responsabilidades y potenciar el sentimiento de pertinencia.

\section{- Delegación de funciones}

"La dirección de la escuela no está bien concebida cuando se la compara con una locomotora que arrastra a los vagones, como una fuerza que tira de todos. Ha de ser, más bien, un factor que aglutine todas las fuerzas en el sentido deseado" (Santos, 2000:64).

En la actualidad ya nadie concibe el liderazgo únicamente a la figura directiva sino que se extiende a todo el equipo directivo y a todos los niveles de la comunidad escolar. La cultura del centro ha evolucionado del individualismo a la participación y colectivismo. Los líderes, deben conseguir unir la fuerza y el compromiso de todos los miembros de la comunidad educativa.

¿Por qué delegar? Porque una dirección centralizadora y autoritaria aplasta la creatividad e iniciativas del resto de comunidad y acaba provocando una desprofesionalización para los docentes ya que no les permite pensar ni actuar.

Delegar es confiar. El líder deber marcar unos objetivos a cumplir con autonomía y libertad en su consecución. Destacar que en el liderazgo distribuido no se plantea la distribución de responsabilidades como delegación.

\section{- Reuniones eficaces}

Para que las reuniones sean eficaces es necesario tener clara la finalidad de cada encuentro. No debe abusarse del exceso de convocatorias y las que se realicen deben caracterizarse por una planificación de calidad. 
Los directores deben evitar las reuniones previsibles y aburridas que normalmente se hacen por rutina. Las reuniones deben estar preparadas a conciencia y tener unos objetivos marcados. Se debe informar, antes de la reunión, qué temas se tratarán. Informar, formar, analizar y debatir, investigar e innovar, acordar y tomar decisiones o crear un buen clima son algunas de las clases de reuniones según el objetivo de la misma.

Las reuniones son un instrumento útil y valioso y, a la vez, el más peligroso ya que pueden aparecer situaciones problemáticas como: tensiones entre los participantes, desviarse del tema, silencio prolongados cuando se requiere participación, observar cierto desánimo y desorientación o interrupciones.

\section{- Resolución de conflictos}

El conflicto se origina cuando dos o más personas tienen finalidades diferentes e intereses opuestos o desiguales. El director debe tener la capacidad de analizar, mediar y resolver los problemas que pueden aparecer en el día a día entre los diferentes miembros de la comunidad.

Se distinguen dos tipos de conflictos: los funcionales y los disfuncionales. Mientras los primeros son los que el enfrentamiento provoca y estimulan una mejora en el funcionamiento del centro, los segundos provocan guerras internas no resueltas y dañan la consecución de las metas del centro.

El gran objetivo es transformar los conflictos en oportunidades para la institución.

\section{- Toma de decisiones}

Decidir es actuar y actuar implica una responsabilidad. Las decisiones nos describen ya que definen la personalidad, los intereses y el modo en el que nos relacionamos. Para tomar una decisión es necesaria una reflexión ya que las decisiones son oportunidades para mejorar y toda decisión tiene unos efectos.

Las buenas decisiones, según Bazarra \& Casanova (2013), se basan en un $90 \%$ de información y un 10\% de inspiración. Al delegar las decisiones se reparten y comparten. Cada líder consulta antes de tomar una decisión. La consulta no se basa en conocer la opinión sino también hacer partícipes a los docentes del centro. 


\section{- Trabajo en equipo}

Trabajar en equipo significa que se comparten los objetivos y la finalidad. Primero de todo, se debe diferenciar entre:

- Trabajo en equipo: la responsabilidad es colectiva. Supone multiplicar capacidades.

- Trabajo en grupo: la responsabilidad es individual. Supone sumar trabajos.

Según Rajadell (2002) el equipo es indispensable para el cambio y una mejora. Se entiende como un colectivo de profesionales que trabajan de manera articulada y cohesionada. La diversidad de conocimientos, experiencias y punto de vista, permite enriquecer al equipo.

En el equipo se asumen unos roles para garantizar el buen funcionamiento y lograr los objetivos. Las debilidades, las carencias técnicas (falta de seguimiento, poca comunicación, etc.) y las carencias emocionales (posponer los conflictos, individualismo, no escuchar, falta de empatía, etc.) son los factores que dificultan el desarrollo del trabajo en equipo.

Para trabajare en equipo se deben tener claras tres características básica: los objetivos como equipo, la responsabilidad de cada miembros en el equipo y la igualdad de oportunidades para lograr la consecución del éxito (Rajadell, 2002).

\section{- Acompañamiento y desarrollo de la carrera profesional}

Acompañar es crear unas relaciones entre el director y cada uno de los miembros del centro, en especial con el profesorado. Se trata de intercambiar y contrastar visiones, ideas y experiencias, de escuchar, de reflexionar conjuntamente y lo más importante, de establecer compromisos y acciones para la mejora conjunta.

Para el acompañamiento es básico generar espacios de reflexión y progreso. Lo ideal es que los directores puedan actuar como mentores con su profesorado. Los directores deben dar ejemplo con sus actitudes, compromiso y acciones para animar al resto de la comunidad.

\section{- Gestión del talento}

Sin sonar a tópico, las escuelas están llenas de talento que necesitan ser descubiertos. Talento de los profesores, del alumnado y de las familias. 
El aprendizaje no es sólo cosa de niños; si queremos que los niños aprendan es necesario actualizar toda la capacidad de enseñanza de los docentes del centro.

El verbo aprender debe ser conjugado por alumnos, profesores, padres y por el equipo directivo. El mayor error es dejar de aprender y de formarse.

\section{- Comunicación}

"La comunicación forma parte hoy en día de las funciones esenciales de un centro. Es una función de palabra, de representación, un estado de espíritu, un deber, una necesidad en la que el director es primordial" (Woycikowska et al., 2008:141).

Según Gan (2007) frecuentemente, los llamados planes de información (o comunicación) incluyen sólo información. La diferencia principal entre información y comunicación es:

"Informar es poner en relación a las personas con los acontecimientos. Comunicar es poner en relación a las personas entre sí, en un proceso que conlleve influencia mutia entre quienes participan” (ibídem, 144)

El diálogo permite acercarse a todos los miembros de la comunidad para comunicar las intenciones y objetivos. La comunicación es esencial para lograr que todos se sientan el proyecto educativo propio y estén comprometidos y con el éxito de cualquier proceso. La comunicación tiene una tiple faceta: informativa, persuasiva y emotiva (Rajadell, 2001).

La comunicación es una de las herramientas más eficaces. Una buena comunicación implica: escuchar, transmitir, empatizar y preguntar. Todo esto acompañado del feedback (Bazarra, 2012). Es necesario que tengamos claro qué queremos decir y que el receptor tenga claro lo que está escuchando.

\section{- Habilidades emocionales para dirigir}

"Todo lo relacionado con la dirección de personas necesita dos manuales: uno técnico y otro emocional, ya que exige conocimientos y habilidades técnicas así como emocionales y sociales" (Bazarra \& Casanova, 2013: 223).

La inteligencia emocional es la capacidad de comprender y gestionar de manera correcta las emociones de quien nos rodea y la del propio director. 
Concluimos este apartado constatando que existe una gran coincidencia entre las habilidades, actitudes y conocimientos que necesitan los directores y los líderes. Los directores deben estar preparados para superar dificultades y liderar cuando sea necesario y los líderes deben saber y estar capacitados para dirigir un centro escolar (Gómez-Hurtado, 2012).

\subsubsection{Desarrollo profesional de los directores}

En la literatura hay diferentes clasificaciones de las fases por las que pasan los directores a lo largo de su carrera directiva (Parkay \& Hall, 1992; Day \& Bakioglu, 1996; Weindling, 1999; Armstrong, 2010). Todas las clasificaciones comparten la idea de una evolución en la experiencia directiva: la primera fase se caracteriza por un periodo lleno de incertidumbres y miedos. Esta fase puede marcar el desarrollo de las siguientes ya que puede ser estresante y hasta traumática.

Es a partir de los 2-3 años que el director se adapta y se ajusta al cargo, gracias a la experiencia, y empieza a desarrollarse como profesional. Finalmente, aparecen las etapas de estabilidad y en las últimas etapas puede darse una autorealización o, en el caso contrario, un desencanto (García-Garduño, Slater, \& López-Gorosave, 2011).

Una de las primeras clasificaciones en el ámbito educativo la realizan Parkay \& Hall en 1992. Los autores clasifican las etapas de desarrollo profesional del director escolar en:

Figura 5: Etapas de la dirección según Parkay \& Hall (1992)

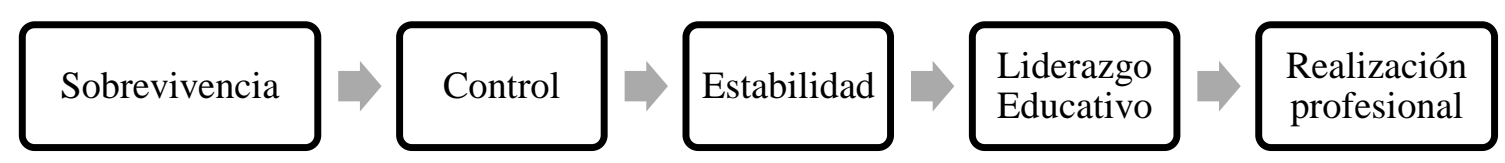

Fuente: Elaboración propia

A partir del estudio realizado por Day \& Bakioglu en 1996 con directores de Inglaterra en el que se identifican unas etapas de socialización del cargo directivo. GarcíaGarduño, Slater, \& López-Gorosave (2010) realizan un resumen de cada fase: 
Figura 6: Etapas de la dirección según Day \& Bakioglu (1996)
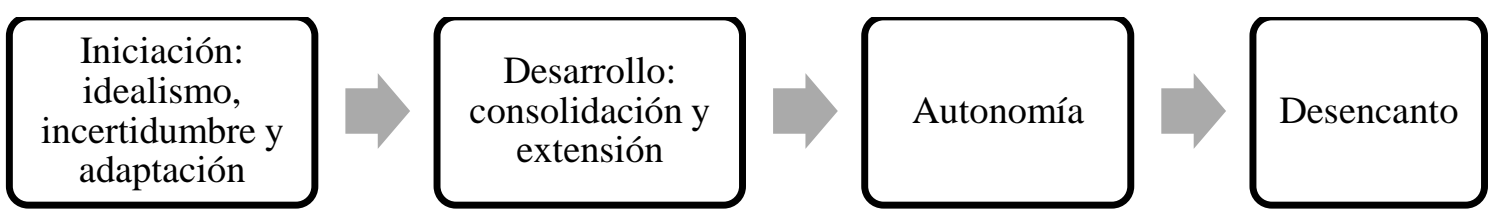

Fuente: Elaboración propia

- La fase de iniciación puede alargarse hasta los 3 años de experiencia. Es el primer contacto del director con el centro y puede ser fácil o difícil, dependiendo de la popularidad con la que el director se enfrenta a su mandato.

- La fase de desarrollo, aparece entre el cuarto y el octavo año en el cargo. En función de la autoestima del director, el entusiasmo inicial varía. Es la etapa más estimulante y satisfactoria de la carrera directiva.

- En la fase de autonomía el director ya está establecido en el cargo. Las experiencias le otorgan una confianza y un mejor manejo en situaciones complicadas.

- Por último, la fase de desencanto destaca por la pérdida del entusiasmo, confianza y aumento de estrés del cargo.

La siguiente clasificación de etapas, la realizada por Weindling (1999), es más extensa y distingue las diferentes fases directivas:

- Fase de iniciación y encuentro en el cargo: los dos primeros meses.

- Fase de hacerse cargo: a partir de los 3 meses hasta el primer año.

- Fase de reacomodo: se da a partir del segundo año.

- Fase de refinamiento: entre el cuarto y quinto año.

- Fase de consolidación: Entre el quinto y el séptimo año.

- Fase de la cima: a partir del octavo año.

Una última clasificación que recogemos es la realizada por Armstrong (2010). El periodo comprendido entre los dos y tres años en el cargo representa la etapa más difícil; es un periodo que produce incertidumbre, inseguridad y aprehensión.

Figura 7: Etapas de la dirección según Armstrong (2010)
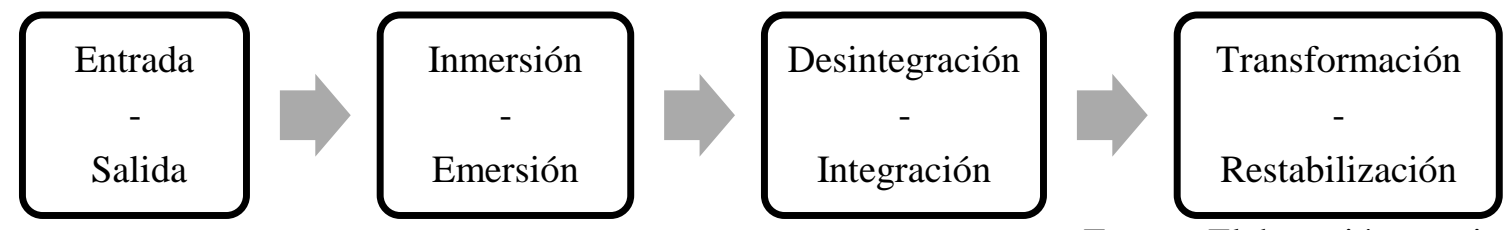

Fuente: Elaboración propia 
A nivel internacional, existen diferentes asociaciones académicas que investigan la situación de los directores noveles en diferentes países del mundo como: The international Begging Principal Study (IBPS) - Universidad de Washington o Internacional Study Principal Preparation (ISPP) - Universidad de Edimburg \& Universidad de Calgary.

En la investigación de García-Garduño, Slater, \& López-Gorosave (2010) realizada en México, se analiza a directores noveles de educación primaria, de ambos géneros para establecer cuáles son los principales problemas que manifiestan los directores noveles:

Tabla 34: Problemas que enfrentan los directores

\begin{tabular}{|c|l|l|}
\hline \multicolumn{2}{|l|}{ Problemas basados en: } \\
\hline Administración & - Exceso de burocracia \\
& - Tiempo insuficiente para llenar y entregar documentos \\
& - Carga administrativa del PEC \\
\hline Docentes & - - & Plantilla incompleta \\
& - & Falta de compromiso y participación en el trabajo \\
& - & Llegadas tarde y salir temprano \\
& - & La influencia del estilo de dirección del anterior director \\
& - & Reconocimiento de la autoridad del director \\
& - & Conflictos interpersonales entre los docentes \\
& - & Entender y aceptar la dinámica de los docentes \\
\hline Alumnos & - & Desempeño académico y disciplina \\
& - & Seguridad y bienestar \\
\hline Familia y & - & Insatisfacción de los padres con el desempeño de los maestros \\
comunidad & - & Relación tensa con los padres \\
\hline Festivales y & - Tiempo para organizar festivales y eventos \\
eventos & - Participación y compromiso de los docentes \\
\hline
\end{tabular}

Fuente: Elaboración propia a partir de García-Garduño, Slater, \& López-Gorosave (2010: 106)

Más tarde, realizan un estudio comparativo sobre los problemas más comunes y los motivos iniciales de los directores noveles en diferentes países del mundo (GarcíaGarduño, Slater, \& López-Gorosave, 2011). 
Tabla 35: Motivos principales y problemas de los nuevos directores

\begin{tabular}{|c|c|c|}
\hline & MOTIVOS INICIALES & PROBLEMAS QUE ENFRENTAN \\
\hline CHINA & - Poder y prestigio & $\begin{array}{l}\text { - Reformas curriculares } \\
\text { - La moral de los docentes } \\
\text { - Falta de fondos para mejorar las } \\
\text { instalaciones } \\
\text { - Desarrollo profesional de los docentes }\end{array}$ \\
\hline COREA & $\begin{array}{ll}\text { - } & \text { Fama } \\
\text { - } & \text { Llevar a cabo sus proyectos }\end{array}$ & $\begin{array}{l}\text { - Resolución de conflictos entre } \\
\text { docentes, estudiantes y autoridades } \\
\text { - Falta de fondos para la mejorar las } \\
\text { instalaciones } \\
\text { - Relación con el sindicato de profesores }\end{array}$ \\
\hline TAILANDIA & & $\begin{array}{l}\text { - } \text { Relación con el Consejo Escolar } \\
\text { - } \text { Crear una mejor imagen de la escuela. } \\
\text { - } \text { Enfrentar al mismo tiempo actividades } \\
\text { diversas }\end{array}$ \\
\hline TURQUÍA & $\begin{array}{ll}\text { - } & \text { Prestigio social } \\
\text { - } & \text { Responsabilidad social } \\
\text { - } & \text { Mejorar la vida de los } \\
\text { estudiantes }\end{array}$ & 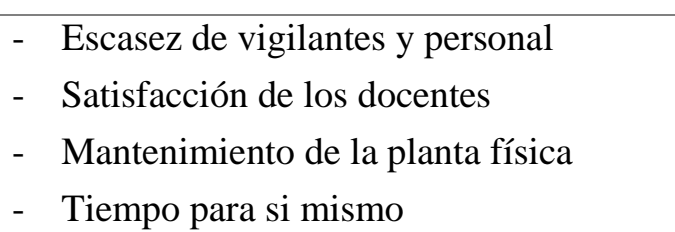 \\
\hline ESPAÑNA & $\begin{array}{ll}\text { - } & \text { Oportunidad de mejorar la } \\
& \text { realidad educativa } \\
\text { - } & \text { Liberación de docencia } \\
\text { - } & \text { Mayor remuneración } \\
\text { - } & \text { Ejercicio de poder } \\
\text { - } & \text { Prestigio }\end{array}$ & $\begin{array}{l}\text { - Encontrar un equipo directivo de } \\
\text { confianza } \\
\text { - Falta de apoyo del antecesor, docentes } \\
\text { y padres }\end{array}$ \\
\hline $\begin{array}{c}\text { ÁFRICA } \\
\text { (Varios } \\
\text { países) }\end{array}$ & & $\begin{array}{l}\text { - Estudiantes que no pueden pagar las } \\
\text { cuotas y comprar los libros de texto. } \\
\text { - } \text { Escasez de equipo } \\
\text { - } \text { Planta física limitada (Kenia) }\end{array}$ \\
\hline
\end{tabular}

Fuente: Elaboración propia a partir de García-Garduño, Slater \& López-Gorosave (2011: 36)

"La antigüedad por sí sola no constituye una garantía de desarrollo profesional de los directivos ni de desarrollo organizativo de los centros" (Villa \& García Olalla, 2003:13)

Los años de experiencia no se transforman automáticamente en sabiduría. Para que la experiencia sea una base de mejora educativa, hacen falta algunas condiciones: 
Tabla 36: Claves para convertir la experiencia en sabiduría

\begin{tabular}{|c|c|}
\hline Querer aprender & - $\quad$ Poner en cuestión \\
\hline Reconocer los errores & - $\quad$ Saber reflexionar \\
\hline Saber escuchar & - Hacer autocrítica \\
\hline Saber observar & - Abrirse a las criticas \\
\hline Conocer el contexto & - Implicarse afectivamente \\
\hline Comprender la cultura de la escuela & - Reflexionar por escrito \\
\hline Hacer preguntas & - Compartir la experiencia \\
\hline
\end{tabular}

Fuente: Santos (2015:24)

Generalmente, en las últimas fases de la dirección se observa el desgaste de la motivación que las caracteriza. En un inicio los directores acceden al cargo con una ilusión e idealismo que acaba desapareciendo en la última etapa por desgaste del cargo. Pero ¿cuándo se debe realizar el cambio de director?

En los últimos años, la dirección escolar refleja una tendencia constante a favorecer la continuidad de los directores en el cargo. Aunque todavía contemple la no profesionalización y la vuelta a la docencia al finalizar el mandato, Teixidó \& Bofill (2007) establecen unas fases por las que todo director debe plantearse y reflexionar antes de acceder o cesar el cargo:

1. Consumir preferentemente antes de...: se basa en plantearse cuántos años les gustaría estar en el cargo. No fijarse un límite temporal improrrogable pero si reflexionar sobre la dirección.

2. Ciclos de vida de los directivos: alternar los períodos de dedicación al ejercicio con otros períodos de dedicación a cuestiones didácticas. El cambio es visto como un estímulo, como una oportunidad para adaptarse a nuevas realidades y afrontar nuevos retos de superación personal y no como un fracaso.

3. Planifica tu cambio: planificación para el favorecer el cambio. Una vez tomada la decisión debe hacerlo público con la intención de facilitar la sensibilización y provocar un debate interno que favorezca la aparición de candidaturas.

4. Forma a tu sucesor: actuar de mentor. Con la aparición de candidatos de manera natural en el centro se van asumiendo de manera progresiva mayores cuotas de responsabilidad (liderazgo compartido). 
5. Atención a los primeros síntomas: hacer caso a los primeros indicadores (desgana, irritabilidad, desmotivación) de que es el momento de relevar el cargo.

6. Elige el momento: finalizar la dirección cuando el centro se encuentre en un momento de bonanza institucional para poder tener la sensación de "haber cumplido".

7. Ante la crisis ;dimisión!: tiene lugar cuando la situación desborda al director y éste plantea el cese repentino aduciendo causas de fuerza mayor. La dimisión no es la solución más oportuna ante una situación de crisis.

8. Sensaciones finales "del fracaso a la oportunidad": dejar el cargo puede convertirse en un proceso traumático. No debe interpretarse como un fracaso sino un acceso a nuevas oportunidades (profesionalmente y personalmente) en las que vas a poder aplicar todo el aprendizaje adquirido en la dirección.

9. La subida al cielo y la vuelta a los infiernos: la subida al cielo con el acceso al cargo y el descenso al infierno con el abandono puede evitarse si se tiene siempre en mente que la función básica es la docencia y que volverá a dedicarse a ella.

10. Prepárate para superar el "mono": superar la desaparición de algunos de los "privilegios" como el el acceso privilegiado a toda la información, reducción de horas lectivas, acudir a inauguraciones y actos protocolarios.

\subsubsection{Género y dirección escolar}

Tradicionalmente, y aún en la actualidad, la mayoría de los puestos de responsabilidad en cualquier ámbito están ocupados por hombres. El porcentaje de mujeres que se dedican a la enseñanza es superior al de los hombres pero aun así el porcentaje de mujeres en cargos directivos es inferior al de los hombres (Vázquez Recio, 2002). En España el 93\% de los rectores de las universidades públicas y el $86 \%$ de los catedráticos son hombres (Cuadrado, 2011)

Este apartado se centra en la situación de la mujer en el cargo directivo en centros de educación primaria, analiza los motivos de la escasa representación femenina y los estilos de dirección según el género.

Hace unos años se creía que la mujer tenía unos rasgos adversos al ejercicio directivo de un centro escolar. Según Helgesen (citado en Díez, 2004) los motivos que excluían a las mujeres del cargo eran: 
- Demasiado centradas en dar importancia a los vínculos afectivos.

- Dificultad para considerar la dirección como un "gran juego".

- Escasa capacidad para captar lo esencial del trabajo en equipo dado su poca afición a los deportes competitivos como el fútbol.

- Necesidad de desarrollar un mayor respeto hacia las estructuras jerárquicas y disminuir las dudas sobre su efectividad.

Parece mentira que esos motivos, en algún momento de la historia, desvaloraran a las mujeres. Hoy en día ya nadie piensa (o son minoría) que la poca representación de la mujer en cargos directivos sea por falta de competencias o habilidades sino que son debidas a otras causas que analizamos más adelante.

A nivel internacional, las mujeres en los cargos directivos están sobrerrepresentadas en los centros de educación primaria. Alrededor del 75\% de los directores en Bulgaria, Austria, Polonia, Eslovaquia, Reino Unido e Islandia son mujeres (Comisión Europea/EACEA/Eurydice., 2013).

En España, el Centro Nacional de Innovación e Investigación Educativa (CINIIE), juntamente con el Instituto de la mujer, ha realizado varios estudios con la finalidad de recabar, analizar y difundir la situación de las mujeres (y hombres) en el sistema educativo. En cuestión de género y dirección escolar se destacan tres grandes ejes temáticos:

1. Estudios sobre la presencia de las mujeres en los cargos directivos

2. Análisis de los motivos de la escasa representación femenina en dichos cargos

3. Estudios sobre la existencia de varios estilos de dirección en función del género

Respecto el primer eje temático, en el último estudio (CINIIE. \& Instituto de la Mujer., 2012) han constatado un leve incremento de la presencia de las mujeres en los cargos de representación en el sistema educativo en comparación con los estudios del año 2001. La incorporación de las mujeres en cargos de dirección es tímida pero progresiva.

Según ese estudio, $79,60 \%$ es el porcentaje de mujeres docentes frente al $54,20 \%$ de mujeres directoras. A pesar del incremento de la presencia de las mujeres y de que el número de mujeres docentes es mayor que el de hombres, especialmente en educación primaria, la dirección escolar está capitaneada mayoritariamente por hombres. 
Al fragmentar los datos de directoras en función de las comunidades autónomas se obtienen los siguientes resultados:

Gráfico 2: Porcentaje de mujeres directoras y docentes según la Comunidad Autónoma

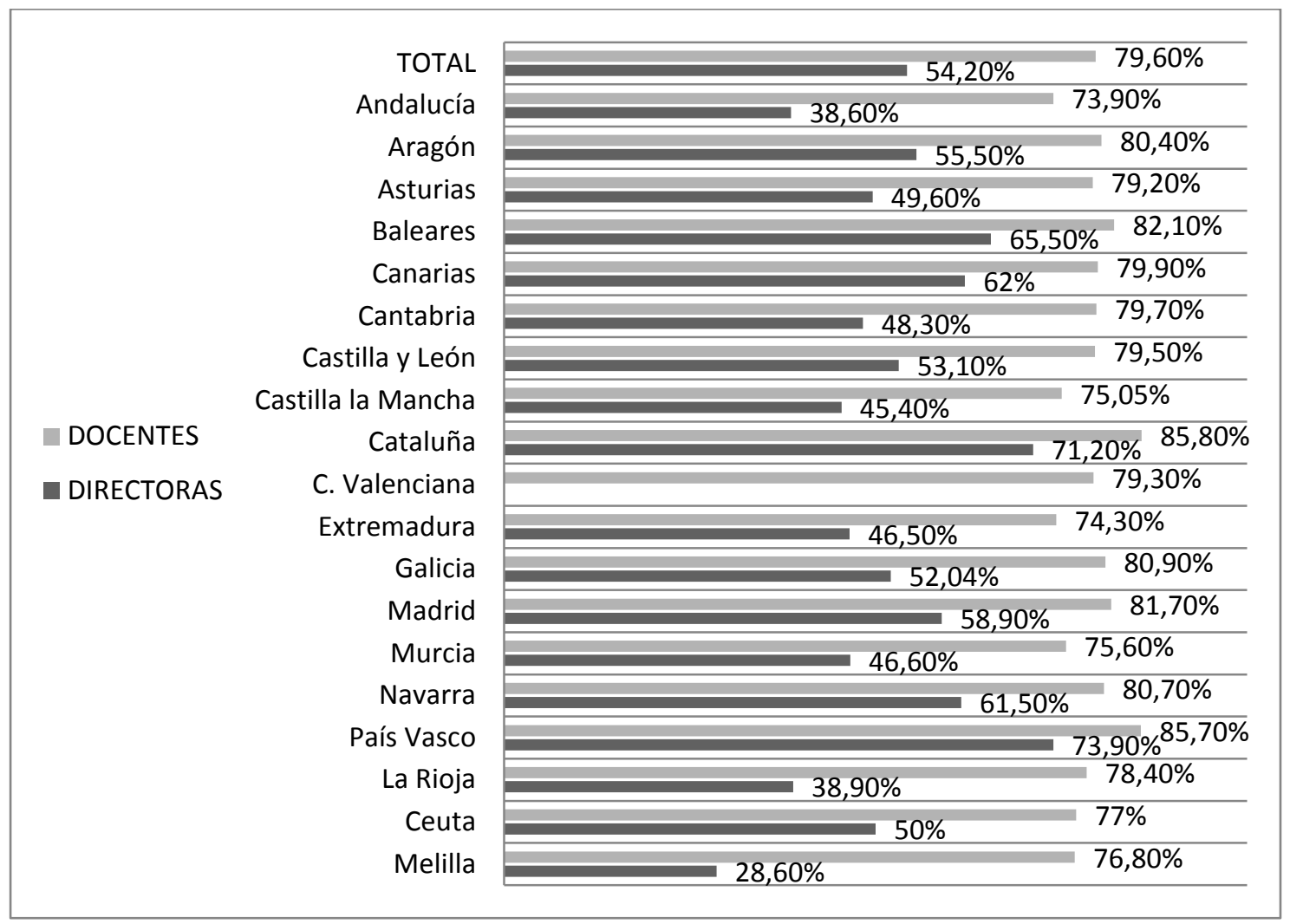

Fuente: Elaboración propia a partir de CINIIE \& Instituto de la Mujer (2012: 18)

Se observa que:

- Cataluña es la región con más mujeres docentes (85,80\%). En segunda posición aparece el País Vasco $(85,70)$ y en tercera posición las Baleares $(82,10 \%)$.

- Andalucía es la región con menos mujeres docentes (73,90\%), seguido de Extremadura $(74,30 \%)$ y de Castilla la Mancha $(75,05 \%)$.

- País Vasco es la región con más mujeres en el cargo directivo (73,9\%). En segundo lugar aparece Catalunya $(71,20 \%)$ y en tercer lugar las Baleares $(65.5 \%)$.

- Melilla es la región con menos mujeres en el cargo directivo $(28,6 \%)$, seguida de Andalucía con $(38,60 \%)$ y la Rioja $(38,90 \%)$.

Esta dificultad de acceso a los cargos directivos de las mujeres se la conoce como el "techo de cristal" (Glass ceiling) y hace referencia a una barrera "invisible". 
Respecto el segundo eje temático, la escasa representación femenina, Santos (2015) afirma que el sexismo impregna todos los ámbitos de la sociedad, de la familia y de la escuela. Las mujeres, a pesar de demostrar un mayor rendimiento que los hombres, hay un momento que desaparecen. Este fenómeno lo bautiza como "la falla del género". Menciona el siguiente listado de las causas de la (auto) exclusión de las mujeres en el cargo:

- La necesidad de atender la casa

- La obligación de cuidar a los niños

- La posibilidad de quedar embarazada

- La falta de confianza en sí misma

- La historia condicionada

- La atribución causal errónea

- Estereotipos femeninos

- La falacia de la excepción

- La mala experiencia

Padilla (2008b) en una investigación en Andalucía, analiza los motivos y barreras que limitan el acceso de las mujeres a la dirección escolar en educación infantil y primaria. Los resultados destacan que el $76 \%$ de las profesoras piensan que no hay ninguna discriminación en el acceso al cargo directivo. Reconocen que las responsabilidades familiares o el tener otras responsabilidades son las razones por las que no acceden al puesto. Cuando se les pregunta si les gustaría o aceptarían ser directoras el 58\% responde "no, en ningún caso", el 28\% "no en mi centro, sí en otros”, el 12\% "sí, en cualquier caso y un $2 \%$ "sí en mi centro, no en otros". En conclusión, el $86 \%$ de las profesoras de este estudio contestan negativamente al deseo o aceptación de ser directoras, al menos en su centro.

El nivel educativo de los centros (Díez, 2004; Kaparou \& Bush, 2007; CINIIE \& Instituto de la Mujer, 2012) influye en la variable género puesto que se observa que la proporción de directoras desciende a medida que aumenta el nivel educativo. En los centros de mayor tamaño es habitual encontrar a hombres, pero no tan sólo en la dirección de centros educativos, sino también en los puestos ejecutivos de la Administración Educativa o de la Inspección. También la titularidad del centro es una 
variable a considerar puesto que en los centros de carácter privado la participación femenina es ligeramente superior (CINIIE \& Instituto de la Mujer, 2012).

En el estudio realizado en la comunidad de Madrid por Tejero \& Fernández (2007) vinculan el estado civil con el acceso al cargo directivo. Los resultados (con diferencias estadísticas significativas) evidencian que hay más mujeres directoras solteras, separadas, divorciadas o de órdenes religiosas que mujeres casadas. Además, las mujeres directoras tienen menos hijos que los hombres directores y los tienen con una edad más avanzada (Padilla, 2008b; Tejero \& Fernández, 2007).

En la literatura se utiliza el concepto de barreras profesionales para referirse a las condiciones, internas o externas, que dificultan el progreso profesional. Las barreras externas son aquéllas que marcan el entorno y ambiente laboral, incluyen la discriminación en los procesos de selección de personal, en la promoción, en la exclusión de la mujer en ciertos puestos, diferencias salariales, falta de políticas adecuadas para atender la maternidad e incluso el acoso laboral. En cambio, se entiende por barreras internas los conflictos internos y presiones psicológicas que provocan una autoexclusión de determinados puestos a causa de una baja autoestima, falta de expectativas o conflicto con el rol familiar versus el rol de trabajadora.

Varias investigaciones nos muestran que ante la pregunta: ¿Por qué hay tan pocas mujeres acceden al cargo directivo? las razones que aducen los directores (indiferentemente del género) confirman una tradición patriarcal que impide tomar conciencia sobre estas discriminaciones culturales (Lorente, 2012).

En cada cultura y país existen representaciones implícitas sobre el rol del hombre y de las mujeres que se asumen de forma inconsciente y se traducen en creencias sobre las características propias y deseables de cada género y se van reproduciendo en la sociedad actual (CINIIE. \& Instituto de la Mujer., 2012).

Respecto el tercer y último eje temático basado en los estilos de dirección en función el género, desde la perspectiva de dirección escolar, se define la dirección "femenina" como un estilo de dirección que concede más importancia a la colaboración y a la pedagogía y se orienta más hacia las personas. En cambio, la dirección "masculina" se define como un estilo más orientado a los resultados y más autoritario. (CINIIE. \& Instituto de la Mujer., 2012). 
Según Díez (2004: 201) los rasgos más destacados del estilo femenino son:

Tabla 37: Rasgos característicos de la dirección femenina

1. Estilo más democrático, dialogante, pedagógico, consensuado y mediador. Una actitud más receptiva y participativa.

2. Un liderazgo más multidireccional y multidimensional, favoreciendo el desarrollo de valores y acciones colectivas.

3. Un ejercicio del liderazgo más firme y constante.

4. Más creativas en las propuestas para ejercer la dirección.

5. Más comunicativas y abiertas a las relaciones personales, a las propuestas de sus compañeros y a escuchar sin enjuiciar.

6. Desarrollan políticas de cooperación y participación.

7. Potencian relaciones interpersonales.

8. Disponibilidad para el cambio.

9. Crean un clima de colegialidad y gestión colaborativa con el profesorado.

10. Construyen redes informales, propiciando cohesión y vínculos entre los componentes.

11. Les preocupa el abuso de poder y utilizan la coacción como último recurso.

12. Potencian el "aprender con y los demás".

13. Clara preferencia por enfoques consultivos y cooperativos.

14. Habilidad para combinar y reconciliar expectativas y experiencia promoviendo el compromiso colectivo de los componentes de la organización.

15. Desarrollo de políticas de cuidado y apoyo mutuo.

16. Mayor atención a los sentimientos y al uso de la inteligencia emocional.

Fuente: Elaboración propia a partir de Díez (2004)

Según Coronel, Carrasco, \& Moreno (2012) las directoras crean un ambiente de cuidado y atención a las relaciones. Se preocupan por facilitar un clima propicio para el trabajo en coordinación y equipo. Fomentan las actividades extraescolares y cuidan la representación, contacto y colaboración ante las instancias externas. Suelen tener una relación cercana con los alumnos del centro. Los rasgos distintivos de su estilo de liderazgo es el democrático, su estilo es cercano, próximo, directo y sensible con las personas.

Respecto al estilo de liderazgo, Díez (2004) menciona las siguientes diferencias: 
Tabla 38: Percepción del liderazgo en función del género

\begin{tabular}{|l|l|}
\hline \multicolumn{1}{|c|}{ MASCULINO } & \multicolumn{1}{c|}{ FEMENINO } \\
\hline Liderazgo más marcado y unipersonal & Liderazgo más difuminado y compartido \\
\hline No permiten demasiado diálogo & Mayor capacidad de negociar, ceder \\
\hline Disponibilidad de tiempo & $\begin{array}{l}\text { Dedicación compartida con aspectos } \\
\text { familiares }\end{array}$ \\
\hline Autoritario & $\begin{array}{l}\text { Delegación de funciones; se comparten } \\
\text { responsabilidades }\end{array}$ \\
\hline Vía de prestigio y reconocimiento social & Vía de servicio a la comunidad \\
\hline Trabajo individual & Capacidad de trabajo en equipo \\
\hline Baja sensibilidad al contexto & Elevada sensibilidad al contexto \\
\hline $\begin{array}{l}\text { Gestión del tiempo: prisas por presión a favor } \\
\text { de la rendición de cuentas }\end{array}$ & $\begin{array}{l}\text { Gestión del tiempo: generosas con el tiempo } \\
\text { dedicado a los demás }\end{array}$ \\
\hline Carácter cerrado de las tareas & Carácter abierto e interminable de la tarea \\
\hline Priorización de la imagen del "bien hecho" & Idealización del perfeccionismo en lo "hecho" \\
\hline $\begin{array}{l}\text { Liderazgo autocrático-directivo: orientación a a } \\
\text { la gestión, toma de decisiones unipersonal }\end{array}$ & $\begin{array}{l}\text { Liderazgo } \\
\text { orientado a las relaciones, toma de decisiones } \\
\text { conjunta }\end{array}$ \\
\hline Control de la información & Compartir información \\
\hline Cultura balcanizada & Cultura cooperativa \\
\hline Liderazgo transaccional & Liderazgo transformacional \\
\hline
\end{tabular}

Fuente: Díez (2004)

Para avanzar es necesario romper con los estereotipos que rodean al género femenino y al género masculino y potenciar una dirección eficaz basada en la compaginación de los aspectos positivos de cada género (CINIIE. \& Instituto de la Mujer., 2012).

Algunos autores consideran más interesante analizar cómo las normas de género regulan el comportamiento organizativo más que remarcar las diferencias directivas en función del género (Sánchez-Moreno, 2009) y afirman que no es riguroso identificar el estilo de dirección sólo teniendo en cuenta la variable género ya que existen otras dimensiones como las contextuales o las estructurales que influyen en la forma de ejercer la dirección (Santos, 2015).

Para finalizar queremos destacar la afirmación de Gros et al.: "No existe acuerdo en relación con la existencia de modelos femeninos y masculinos; por ello, debemos tener en cuenta factores como la propia identidad, el rol desempeñado o la organización donde se ejerce, que pueden mediatizar que se desarrollen unas competencias u otras, 
independientemente de la variable género. (...) Tanto hombres como mujeres, ejercen un liderazgo contextualizado, en el que pueden encontrarse rasgos del modelo femenino y del masculino" (2013: 14).

\subsubsection{Motivación y satisfacción del cargo}

A nivel internacional, existen dificultades para atraer candidatos al puesto de directivo escolar ya que en la balanza pesan más las desventajas que las ventajas (Howley, Adrianaivo, \& Perry, 2005). A nivel nacional, habría una tendencia a una baja disponibilidad para ocupar cargos de dirección (Antúnez, 2000b; Estruch, 2002a, 2002b; Batanaz, 2005; García Olalla, Poblete y Vila, 2006; Aramendi, Teixidó, \& Bernal, 2009) a pesar de que en los últimos años habría aumentado, levemente, la predisposición para ocuparlos (Iranzo, Tierno, \& Barrios, 2014).

En la investigación realizada por Álvarez (2013) se muestra que el 40-45\% de las candidaturas quedan desiertas y la Administración es la encargada de nombrar a un director provisional por un año a causa de la ausencia de candidatos. Es decir, tan sólo un 50-55\% de los directores se presentan voluntariamente como candidatos al cargo.

Valle Aparicio, (2013) en su investigación con una muestra de 234 directores de centros de educación infantil y primaria de Valencia, destaca que el 52\% de los directores accedieron al cargo presentando una candidatura frente al $29 \%$ que accedió al cargo por un impulso de la Inspección o de la Administración, un 14,5\% que accedió a partir de un nombramiento obligatorio y un $5 \%$ por otras vías. Es decir, el $48 \%$ de los directores de la investigación, accedieron al cargo de manera "provocada" y no por elección propia.

Teixidó (2000) analiza los motivos de ausencia de los candidatos y afirma que en el aparente desinterés por acceder a la dirección se ocultan diversas situaciones como: confrontaciones, estrategias de continuidad, evitar la evaluación del consejo escolar o voluntarios ocultos.

El gran interrogante en la actualidad es: ¿Por qué hay una ausencia de candidatos al cargo? El exceso de trabajo, el tener que tomar posición en los conflictos, estrés al cargo y no ser reconocidos socialmente son las razones que más se mencionan. 
En la actualidad el reto está en qué hacer para que los directores quieran serlo (Royo (2012) y estén motivados en su mandato.

Respecto a los motivos de los directores para acceder al cargo, Villa \& García Olalla (2003) los dividen en: motivos intrínsecos y motivos extrínsecos. La mayoría de los motivos son intrínsecos.

- Motivos intrínsecos son: mejorar el funcionamiento del centro, prestar un servicio a la comunidad, etc.

- Motivos extrínsecos son: el deseo de promoción y conseguir méritos profesionales.

Vázquez Recio (2002), recoge algunos de los motivos que más manifiestan los docentes por los que sí que accederían al cargo (satisfacción) pero también recoge los motivos para no optar al cargo directivo (insatisfacción).

Tabla 39: Insatisfacciones versus satisfacciones del cargo

\section{SATISFACCIONES}

- El deseo de mejora del centro

- El deseo de ejercer el cargo

- Insatisfacciones ante el trabajo realizado por el equipo directivo anterior

- Ser un reto personal

- Ser un reto profesional

\section{INSATISFACCIONES}

- La insatisfacción del trabajo de dirección

- La falta de incentivos económicos

- Las insuficientes compensaciones

- El estrés que ocasiona la función directiva

- El excesivo trabajo

- La falta de tiempo

- La doble función de ser representante de la administración educativa y del centro

- La conflictividad inherente al desempeño del cargo

- La inestabilidad del cargo al no ser permanente

- La falta de apoyo por parte de la administración

- La falta de poder real en los centros

- La ambigüedad que rodea al mandato de los nuevos directores

- El reconocimiento social y profesional mínimo

- La incomprensión del papel del director por los compañeros del centro

- Ser una figura de autoridad que supervisa, controla e incluso sanciona a compañeros

- Volver a formar parte del equipo docente tras finalizar la candidatura

Fuente: Elaboración propia a partir de Vázquez Recio (2002:86-87) 
Además, existen unas razones concretas por las que querer y no querer ser director escolar:

Tabla 40: Razones por las que acceder o no acceder al cargo directivo

\begin{tabular}{|l|ll|}
\hline & - & Porque me apetece coordinar a un grupo con un proyecto en común que nos \\
& unifique, respetando y valorando las diferencias \\
& - & Porque soy de los que más quiero acceder al cargo de los que no quieren y alguien \\
& tiene que serlo...
\end{tabular}

Según Santos (2015), la dirección tiene los siguientes peligros:

1) Profesionalismo (en contra de la conversión de la dirección en un cuerpo de profesionales que la ejercen durante toda la vida)

2) Gerencialismo (la conversión del director en un gestor)

3) Personalismo (el carácter unipersonal de la dirección)

4) Sexismo (el sexismo que impregna toda la sociedad)

5) Perennialismo (los directores de toda la vida)

6) Autoritarismo (sin autonomía por la Administración) 
Silva (2012) afirma que la fidelización con el cargo a través de un estímulo de una formación atractiva (articulada, pertinente, útil y motivadora para el desarrollo personal) puede conseguir directores más comprometidos, satisfechos y eficientes.

También en la normativa se regula la aplicación de incentivos en los cargos directivos (méritos profesionales, incentivos económicos o liberación de horas lectivas).

El ser meros burócratas, la excesiva responsabilidad, la carga de trabajo, la inseguridad por falta de especificación/formación, la fuerte implicación y las escasas compensaciones (Valle Aparicio, 2013) harían de la dirección un cargo poco atractivo.

Por otra parte, destacar que la disponibilidad para repetir candidatura (asumir otro mandato) es mayor que la motivación inicial para el acceso (Villa \& García Olalla, 2003). Este dato nos muestra que a pesar del aumento de responsabilidades, existen gratificaciones a lo largo del mandato que compensan algún que otro "mal trago".

El acceso al cargo tiene como base unas expectativas personales como: "La satisfacción de una legítima ambición, la esperanza de una promoción profesional a través de unas responsabilidades nuevas, la posibilidad de realizarse llevando a cabo sus propias elecciones (Woycikowska et al., 2008: 19).

Santos (2015) defiende que conocer los motivos por los que acceden los directores al cargo nos puede ayudar a conocer el grado de compromiso y la calidad de las decisiones. Clasifica de motivos iniciales en: Motivos ricos (inspirados en el deseo y la voluntad), motivos pobres (no tienen vinculación directa con dimensiones educativas) y motivos espurios (los menos confesables y sin ninguna relación con la educación).

Algunos ejemplos de los diferentes motivos:

Tabla 41: Clasificación de los motivos de acceso al cargo

\begin{tabular}{|c|l|}
\hline & - Hacer un proyecto de escuela nuevo o mejorar el que ya está \\
& - Impulsar una experiencia de innovación de la institución \\
- Coordinar un grupo de profesionales sirviendo de ejemplo y guía \\
Motivos \\
$\begin{array}{c}\text { pedagógicamente } \\
\text { ricos }\end{array}$ & $\begin{array}{l}\text { - Pyudar a la comunidad a superar los conflictos que han surgido en la } \\
\text { - Proponer y organizar experiencias de formación }\end{array}$ \\
& $\begin{array}{l}\text { - Guiar y animar a los profesores jóvenes que se incorporen al centro } \\
\text { - Escuchar a todos quienes quieran proponer iniciativas de mejora } \\
\text { - Reflexionar sobre el desarrollo del proyecto educativo }\end{array}$ \\
\hline
\end{tabular}




\begin{tabular}{|c|c|}
\hline $\begin{array}{c}\text { Motivos } \\
\text { pedagógicamente } \\
\text { pobres }\end{array}$ & $\begin{array}{l}\text { - Cambiar de dedicación porque ya son muchos años de docente y } \\
\text { desea vivir más experiencias } \\
\text { - Ganar una cantidad de dinero que haga frente a las necesidades } \\
\text { familiares o satisfacción de intereses personales } \\
\text { - Tener una parcela de poder e influencia que potencie la autoestima } \\
\text { - Experimentar, asumir retos, explorar una realidad desconocida } \\
\text { - Demostrarse a sí mismo que es capaz de hacerlo } \\
\text { - Disfrutar del pequeño o gran prestigio que supone ser elegido }\end{array}$ \\
\hline Motivos espurios & $\begin{array}{l}\text { - Vengarse de algún compañero que previamente ha ejercido la } \\
\text { dirección } \\
\text { - Ejercer un poder sobre los demás. Un poder algo sádico basado en } \\
\text { hacer sufrir a los demás } \\
\text { - Ceder a las presiones de colegas con el fin de que no acceda a la } \\
\text { dirección }\end{array}$ \\
\hline
\end{tabular}

Fuente: Elaboración propia a partir de Santos (2015: 34-35)

En las investigaciones de Valle Aparicio (2013) y Rodríguez Pulido et al., (2013) se observan los motivos iniciales para el acceso del cargo directivo:

Tabla 42: Tabla comparativa de motivaciones iniciales

\begin{tabular}{|c|c|}
\hline Rodríguez Pulido et al., (2013) & Valle Aparicio (2013) \\
\hline 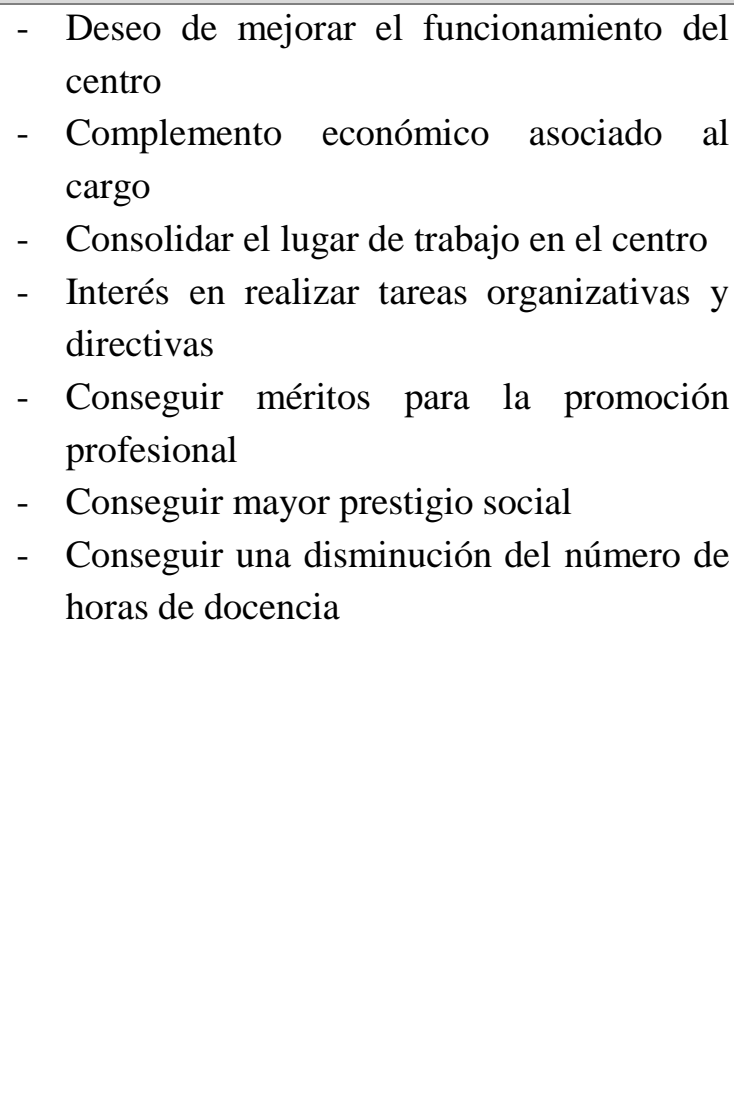 & $\begin{array}{l}\text { - Voluntad de mejorar el centro } \\
\text { - Reto y compromiso profesional } \\
\text { - Como experiencia profesional diversa, } \\
\text { dentro de la carrera docente } \\
\text { - Mantener la línea de trabajo del centro y } \\
\text { consolidación del nivel conseguido } \\
\text { - Disposición de autonomía y capacidad de } \\
\text { decisión } \\
\text { - Promoción profesional } \\
\text { - Interés por la dirección y organización } \\
\text { escolar } \\
\text { - A solicitud de algunos compañeros/as } \\
\text { - Por petición expresa de la Inspección u otro } \\
\text { órganos educativos } \\
\text { - Por el complemento económico } \\
\text { - Evitar a otro candidato del mismo centro o } \\
\text { de otro } \\
\text { - Consolidar la posición y prestigio en el } \\
\text { centro } \\
\text { - Reducción de carga docente } \\
\text { - Prestigio social }\end{array}$ \\
\hline
\end{tabular}

Fuente: Elaboración propia a partir de Valle Aparicio (2013: 5) y Rodríguez Pulido et al., (2013) 
Como se observa, ambos autores coinciden con el motivo de acceder al cargo, en primer lugar, por conseguir una mejora en el centro pero también se observan algunos motivos pedagógicamente pobres según definiría Santos.

El estrés laboral, en este caso estrés directivo, es la situación de presión y tensión que se origina en la vida profesional. Las causas del estrés pueden ser muy variadas: aumento de responsabilidades, no saber gestionar el tiempo, relaciones complicadas con los compañeros, falta de autoestima, sentimiento de soledad, etc.

Algunas investigaciones analizan los principales factores que provocan estrés a los directores. Villa \& Gairín, en 1996, destacan que los principales problemas percibidos por los directores de centros públicos y concertados son:

Tabla 43: Principales factores que provocan estrés a los directores

\begin{tabular}{|l|}
\hline Falta de tiempo \\
\hline Alta exigencia por parte de la Administración \\
\hline Falta de apoyo de la Administración \\
\hline Carencia de autonomía \\
\hline Excesiva burocracia \\
\hline Escasa clarificación de funciones \\
\hline Necesidad de mayor formación \\
\hline $\begin{array}{l}\text { Inestabilidad de las plantillas docentes ( y directivas) } \\
* \text { Solo en los centros públicos }\end{array}$ \\
\hline
\end{tabular}

Fuente: Elaboración propia a partir de Villa \& Gairín (1996)

En la investigación realizada por Tejero, Fernández \& Carballo (2010) se concluye que los directores presentaban un bajo nivel de estrés (2,55 sobre 5). Tan sólo un $21 \%$ de los directores de la muestra del estudio declaraba un nivel de estrés alto.

En la variable género aparece una diferencia estadística significativa: las mujeres padecen un estrés ligeramente superior al de los hombres (2,63 versus 2,50). No aparece ninguna diferencia significativa en relación a la titularidad del centro (públicos versus concertados-privados).

Los autores agrupan el estrés en las siguientes dimensiones: 
Tabla 44: Dimensiones del estrés del cargo directivo

\begin{tabular}{|rl|c|}
\hline \multicolumn{1}{|c|}{ Estresores relacionados con: } & Valor \\
\hline 1. & La sobrecarga de tareas & $2,87 / 5$ \\
\hline 2. & Administración educativa y la ambigüedad del rol & $2,72 / 5$ \\
\hline 3. & El profesorado y el conflicto del rol & $2,65 / 5$ \\
\hline 4. & El alumnado, las quejas y la dirección de reuniones & $2,58 / 5$ \\
\hline 5. & Origen de las familias & $2,22 / 5$ \\
\hline 6. & La propia dinámica del equipo directivo & $2.20 / 5$ \\
\hline 7. & Gestión del personal no docente & $1,88 / 5$ \\
\hline
\end{tabular}

Fuente: Elaboración propia a partir de Tejero \& Fernández (2010:133)

\subsection{7 Ética y dirección}

"Afirmar valores (sobre todo en momentos de crisis o simplemente de duda) permite encontrar una identidad. Es una fuente de identificación (y de remotivación) para cada individuo" (Woycikowska et al., 2008: 211).

Las actuaciones y decisiones de los directores en el día a día requieren de juicios morales. Son decisiones valorativas que implican un compromiso ético (Vázquez Recio, 2002).

A partir de los valores se crean unas referencias que marcan las reglas y los estilos de funcionamiento en un centro educativo. Los valores dan personalidad al centro y es importante que se conozcan y reconozcan como propios por parte de toda la comunidad educativa ya que estos refuerzan el compromiso e implicación.

Los autores Sammons \& Bakkum (2011), destacan la necesidad de que la dirección escolar sea ejercida desde unos propósitos morales y en todos los niveles del centro (dentro y fuera del aula).

Todas las instituciones educativas tienen unos valores del centro y una misión educativa. En la mayoría de los casos esos valores y misiones son difundidos y explicados en la página web del centro o en las sesiones de puertas abiertas y pueden incidir en la decisión de las familias en matricular a sus hijos en un centro u otro. 
Los valores del centro marcan las líneas de actuación, son un elemento clave y les diferencian del resto de centro, orientado la actuación y la filosofía de trabajo y los fundamentos del proyecto educativo. Éstos deben ser recordados en las conversaciones, decisiones y elecciones (Woycikowska et al., 2008) para lograr una coherencia.

En relación con los valores del cargo directivo, serían los valores que determinan el desempeño del cargo directivo en el centro. Se diferencia entre: 1) valores del día a día, 2) valores de las relaciones y 3) valores del liderazgo del cargo.

Tabla 45: Valores del cargo directivo

\begin{tabular}{|c|c|}
\hline $\begin{array}{c}\text { Valores del } \\
\text { día a día }\end{array}$ & $\begin{array}{l}\text { - Claridad: Objetivos claros. Consiste en actos de comunicación transparente. } \\
\text { - Coherencia: Los actos deben ser coherentes. La coherencia favorece la } \\
\text { motivación. } \\
\text { - Coraje: básico para una actitud del éxito. Requiere energía. } \\
\text { - Competencia: no se imponen los derechos enciclopédicos sino la habilidad, } \\
\text { juicio, ingenio en sus funciones. } \\
\text { - Consideración por cada persona, da valor a cada acto con independencia de } \\
\text { su puesto en el centro. }\end{array}$ \\
\hline $\begin{array}{l}\text { Valores de } \\
\text { las } \\
\text { relaciones }\end{array}$ & $\begin{array}{l}\text { - Lealtad: con todos los miembros de la comunidad educativa. } \\
\text { - Transparencia: las actitudes y decisiones deben ser argumentadas, respetando } \\
\text { los principios y valores del centro. } \\
\text { - Diálogo: acepta las confrontaciones e intercambios de opiniones siempre } \\
\text { basándose en el respeto. }\end{array}$ \\
\hline $\begin{array}{l}\text { Valores del } \\
\text { liderazgo } \\
\text { del cargo }\end{array}$ & $\begin{array}{l}\text { - Valor humano positivo: se debe creer en el hombre. Para ello se deben poseer } \\
\text { ciertas convicciones para movilizarlos en torno a un proyecto. } \\
\text { - Creer en el progreso: estar convencido de que aún quedan cosas por } \\
\text { descubrir. } \\
\text { - Convencido de la posibilidad de educar a los jóvenes: confiar en el potenciar } \\
\text { de educación. El éxito no depende sólo de los materiales sino de la } \\
\text { innovación, la motivación y el compromiso de los implicados. }\end{array}$ \\
\hline
\end{tabular}

Fuente: Elaboración propia a partir de Woycikowska et al. (2008: 213-215)

En cuanto a los valores personales de los directores son inseparables los valores personales de los valores del cargo directivo. Al igual que no existen dos centros iguales tampoco existen direcciones escolares ni directores iguales. La personalidad, carácter y sobre todo los valores, hacen a cada director único. 
Los valores personales que los directores deben mostrar, según Palomero (2013), son:

- Sentido común: actuar con coherencia, responsabilidad y sensatez.

- Gran confianza en uno mismo: saber manejar la adversidad.

- Escucha interior: escuchar la voz interior y la conciencia sin autoengaño.

- Un equipaje de afectividad: ser capaces de expresar afecto, agradecimiento y valoración. Ser receptivos.

- Una reserva de emociones: poder enfrentarse a dificultades y superarlas.

Según Bazarra \& Casanova (2013) los rasgos básicos para dirigir centros son:

Tabla 46: Rasgos de personalidad básicos

\begin{tabular}{|c|c|c|c|c|c|}
\hline $\begin{array}{c}\text { Actitud de } \\
\text { servicio }\end{array}$ & Respeto & $\begin{array}{c}\text { Sentido del } \\
\text { humor }\end{array}$ & Paciencia & Generosidad & Flexibilidad \\
\hline Afabilidad & $\begin{array}{c}\text { Honradez, } \\
\text { sinceridad }\end{array}$ & $\begin{array}{c}\text { Visión } \\
\text { abierta }\end{array}$ & $\begin{array}{c}\text { Humildad, } \\
\text { Naturalidad }\end{array}$ & Compromiso & Coherencia \\
\hline
\end{tabular}

Fuente: Bazarra \& Casanova (2013: 94)

Para estas autoras, también hay rasgos de personalidad que dificultan la dirección. Ejemplos de estos rasgos son: no respetar la diversidad, tener miedo al cambio y a innovar, tender a lo complicado, buscar las normas como base de las relaciones, la hiperactividad (falta de paciencia), escasa autonomía, tener miedo a arriesgarse o tener una actitud negativa (pensar que todo lo malo les sucede a ellos).

En definitiva, después de analizar las diferentes clasificaciones consideramos que los valores personales esenciales para el cargo directivo son:

Figura 8: Valores personales del director escolar

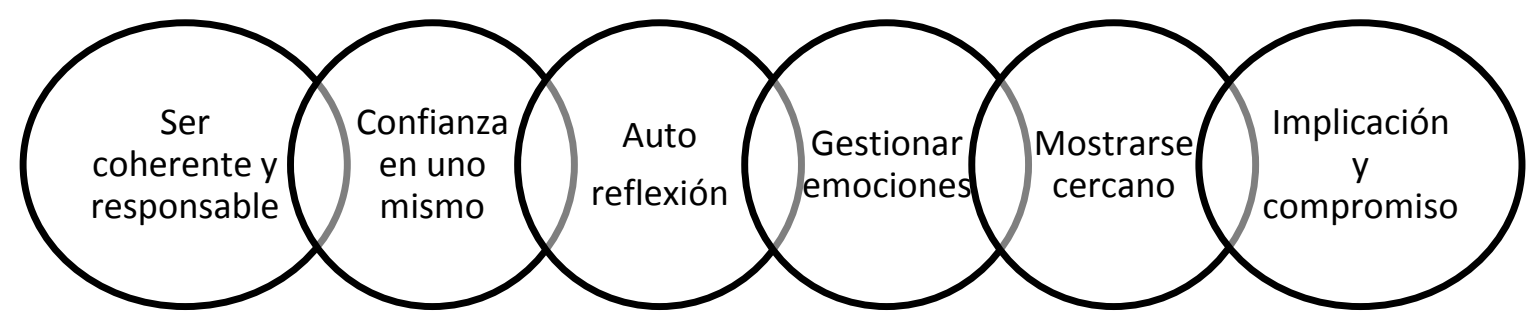

Fuente: Elaboración propia 
Para finalizar este apartado, mencionar el decálogo deontológico que se debería aplicar a la dirección escolar redactado por Álvarez (2010b):

Tabla 47: Código deontológico aplicado a la dirección escolar

1. Tomar decisiones teniendo siempre presente el bien común

Se concreta en la armonización de los intereses de los profesores, los objetivos de la institución y las expectativas de los clientes.

2. Asumir el compromiso moral

Implica defender siempre a las personas más débiles frente a aquellos que abusan de su poder.

3. Posicionarse de forma justificada ante lo correcto frente a posturas incorrectas

Plantearse de forma clara y pública el principio de lo correcto frente a lo incorrecto en la gestión, tanto de los asuntos públicos como privados.

4. Gestionar la misión de la organización combinando el sentido ético con el sentido de la eficacia

Como consecuencia, implicar a sus colaboradores en la definición de la dimisión y en el tipo de alumno que se quiere educar.

5. Asumir la responsabilidad de crear un clima de trabajo ordenado y grato

Implica controlar y vigilar a aquellas personas tóxicas que dificultan o impiden el trabajo bien hecho de los demás.

6. Manifestar siempre una actitud honesta

Supone ser coherente entre lo que se piensa y lo que se hace, entre los valores, principios y convicciones y los actos que definen su comportamiento como líder.

7. Propiciar un clima de relaciones humanas positivo y respetuoso con todas las personas

Asumir el rol de mediador en los conflictos personales con el principio gano-ganas.

8. Relacionarse desde lo positivo de cada persona que conforma el equipo de colaboradores

Con el fin de implicar a todos en un proyecto institucional que respete y armonice la diversidad.

9. Ante la ambigüiedad y la incertidumbre entre los intereses del profesorado y del alumnado

Definirse por el respeto a la conciencia profesional de los miembros teniendo siempre presentes los derechos del alumnado.

10. En las situaciones de violencia, defender siempre las posiciones del más débil por diferencias de género, de procedencia o de poder

Esto implica arriesgar parcelas de poder y pérdida de vínculos y fidelidades.

Fuente: Elaboración propia a partir de Álvarez (2010b: 99-100) 
Existe un liderazgo centrado en las emociones y valores del líder, conocido como liderazgo emocional (Goleman et al., 2010; Goleman, 2012). Los valores necesarios para ser un líder emocional, según Goleman (2012), son:

- La autoconciencia: implica comprender en profundidad las emociones, los puntos fuertes, las debilidades, las necesidades y los impulsos. Es la concepción que tiene una persona sobre sus valores y sus objetivos.

- La autogestión: se trata de una conversación interior continuada que nos libera de la presión en la que pueden encerrarnos nuestros propios sentimientos. Deben controlar los sentimientos e impulsos y mantener la calma en momentos tensos.

- La empatía: no equivale a la sensiblería, ni a adoptar las emociones de los demás como propias, ni tampoco tratar de complacer a todo el mundo.

- La capacidad social: no se trata de una cuestión simple de simpatía, sino de una simpatía con un objetivo determinado (hacer avanzar). La motivación, la actitud positiva y la popularidad favorecen la capacidad social.

\subsection{Prácticas de liderazgo eficaces para la mejora escolar}

En relación a las prácticas de liderazgo eficaces, Sun \& Leithwood (2012) afirman que: tener o crear estructuras colaborativas y ofrecer una asistencia individualizada, son las prácticas con más impacto en la mejora. En la realización de las prácticas influye el nivel de madurez y el estadio de desarrollo del director (Horn, 2013).

Shatzer, Caldarella, Hallam \& Brown (2014) asocian las siguientes prácticas de liderazgo al éxito educativo:

- Reunirse con el profesorado para hablar sobre las necesidades de los estudiantes

- Analizar el rendimiento de los resultados con el profesorado y el alumnado

- Controlar las posibles interrupciones en el aula

- Animar a los profesores a utilizar el tiempo de clase de manera efectiva

- Reconocer a los estudiantes que demuestren una mejora académica

- Proporcionar expectativas y recompensas apropiadas para el profesorado

- Fomentar el reconocimiento en las asambleas y en las reuniones con los padres. 
En la siguiente tabla aparecen distintas prácticas de liderazgo de diferentes autores:

Tabla 48: Prácticas de liderazgo

\begin{tabular}{|c|c|}
\hline Robinson & $\begin{array}{l}\text { - } \\
\text { - } \text { Obtablecer de metas y expectativas conjuntas } \\
\text { - } \\
\text { - Planificar, coordinar y evaluar el aprendizaje y currículum } \\
\text { - } \\
\text { Promoción y participación en el aprendizaje y desarrollo profesional de un entorno ordenado y de apoyo }\end{array}$ \\
\hline Louis et al & $\begin{array}{ll} & \text { Compartir el liderazgo con los profesores } \\
\text { - } & \text { Desarrollar relaciones de confianza entre profesores } \\
\text { - Provisionar medios para la mejora de la enseñanza }\end{array}$ \\
\hline Day et al. & $\begin{array}{ll}\text { - } & \text { Definir la visión, valores y dirección, construyendo confianza } \\
\text { - } & \text { Mejorar las condiciones para la enseñanza y el aprendizaje } \\
\text { - } & \text { Reestructurar la organización: rediseñar roles y responsabilidades } \\
\text { - } & \text { Mejorar la enseñanza y el aprendizaje } \\
\text { - } & \text { Rediseñar y enriquecer el currículum. } \\
\text { - } & \text { Mejorar la calidad del profesorado } \\
\text { - } & \text { Construir relaciones dentro de la comunidad escolar } \\
\text { - } & \text { Construir relaciones fuera de la comunidad }\end{array}$ \\
\hline
\end{tabular}

Fuente: Elaboración propia a partir de Bolívar (2013)

Se observa que la mayoría de prácticas de liderazgo están enfocadas a la relación entre líder y sus seguidores, la importancia de tener objetivos compartidos y definidos para así enfocar todas las actuaciones a mejorar las condiciones de la escuela. Leithwood \& Rielh proponen las siguientes prácticas de liderazgo:

Tabla 49: Prácticas de liderazgo de Leithwood \& Rielh

\begin{tabular}{|l|}
\hline Establecer direcciones de futuro: \\
Desarrollar un compromiso compartido de todo el personal sobre la organización, sus \\
actividades y metas \\
\hline - Construir de una visión compartida \\
- Fomentar la aceptación de objetivos grupales \\
- Crear altas expectativas \\
\hline Desarrollar al personal: \\
Potenciar las capacidades y habilidades del personal para la realización de metas comunes. \\
\hline - Prestar atención personalizada a los docentes \\
- Estimular intelectualmente al personal \\
- Provisión de modelos de actitud y comportamiento con la realización de las metas \\
\hline
\end{tabular}




\section{Rediseñar la organización:}

Nuevas condiciones de trabajo que permita al personal del centro un mayor desarrollo de sus motivaciones y capacidades.

- Construir una cultura colaborativa

- Estructurar la organización para que facilite el trabajo

- Crear relaciones productivas con la familia y comunidad

- Conectar la escuela con su entorno

\section{Gestionar:}

Los programas de enseñanza y aprendizaje. supervisar la escuela (recursos materiales y humanos).

- Dotar de personal y de recursos materiales

- Facilitar apoyo técnico a los docentes (supervisión, evaluación, coordinación)

- Monitorizar las prácticas de los docentes

- Evitar distracciones del personal de lo que no es su trabajo

Fuente: elaboración propia a partir de Anderson $(2010,39)$

En todos los modelos directivos, el liderazgo tiene un impacto positivo pero en las escuelas en contextos vulnerables los efectos son más visibles (Anderson, 2010).

En los contextos desfavorecidos las prácticas suelen estar centradas en el clima de trabajo. Day (2014) establece las siguientes prácticas de liderazgo para zonas de alta marginación y delincuencia donde los desafíos son persistentes:

Tabla 50: Prácticas de liderazgo para centros en contextos desafiantes

\begin{tabular}{|l|l|}
\hline $\begin{array}{l}\text { Crear ambientes de } \\
\text { estudio agradables para } \\
\text { que los estudiantes } \\
\text { eleven sus expectativas } \\
\text { de logro. }\end{array}$ & $\begin{array}{l}\text { Crear oportunidades } \\
\text { para que los } \\
\text { estudiantes tengan una } \\
\text { visión más optimista } \\
\text { de sus perspectivas de } \\
\text { vida y laborales. }\end{array}$ \\
\hline
\end{tabular}

Fuente: Elaboración propia a partir de Day (2014)

Bolívar et al., (2013) proponen las siguientes prácticas del Liderazgo para la justicia Social:

- Identificar y articular una visión de la escuela centrada en la justicia social

- Potenciar una cultura escolar en y para la justicia social

- Los miembros de la comunidad escolar y su desarrollo personal, social y profesional son la máxima prioridad.

- Centrarse en la mejora de los procesos de enseñanza y aprendizaje 
- Potenciar la creación de comunidades profesionales de aprendizaje

- Promover la colaboración entre la escuela y la familia, potenciando el desarrollo de culturas educativas en las familias

- Expandir el capital social de los estudiantes valorizado por las escuelas

Existen algunas posturas críticas en relación a las prácticas del liderazgo. Por ejemplo, Lumby (2013) afirma que el liderazgo distribuido se ha convertido en una teoría con prácticas prescritas en las cuales supuestamente el profesorado está acreditado y en realidad es un fenómeno profundamente político repleto de usos y abusos de poder.

Realizada una revisión de la literatura internacional (centrada en las publicaciones sobre la influencia del liderazgo en la mejora escolar más recientes 2009-2015, en la educación primaria y contextos desfavorecidos, destacamos los siguientes trabajos:

Figura 9: Resumen de las investigaciones internacionales sobre el impacto del liderazgo

Heck \& Hallinger (2010)

Robinson (2011)

Bruggente Lyuten, Scheerens \&

Sleegers (2012)
- Lugar: Estados Unidos

-Participantes: 197 directores de escuelas de educación primaria

- Resultados: Los resultados apuntan a que el liderazgo escolar y

la capacidad de la organización contribuyen de manera significativa al aumento del aprendizaje de los estudiantes en lectura y matemáticas.

-Lugar: Inglaterra

- Participantes: 21 directores de escuela primaria en Inglaterra

- Resultados: Durante 4 años analizan las percepciones de los directores respecto a los cambios del sistema. Los resultados indican que los directivos aceptan el cambio y los nuevos roles y utilizan las reformas para fomentar la capacidad de liderazgo en su equipo.

- Lugar: Países Bajos.

-Participantes: 97 directores de escuelas de educación secundaria:

- Resultados: Observan una relación significativa y positiva entre el comportamiento del líder y la orientación hacia los resultados y el desarrollo 
May, Huff, \& Goldring (2012)

Naicker \& Mestry (2013)

Shatzer, Caldarella Hallam, \& Brown

(2014)
-Lugar: Sureste de Estados Unidos

-Participantes: 37 escuelas de educación primaria y secundaria

- Resultados: El estudio longitudinal de 3 años muestra la gran influencia de los factores contextuales en el logro de los estudiantes y en las acciones que los directores deben realizar para mejorar el éxito en la enseñanza

-Lugar: África del Sur

-Participantes: 15 profesores de las escuelas públicas de primaria

- Resultados: Revelan que la mayoría de las prácticas están arraigadas en el liderazgo clásico y las prácticas de liderazgo distributivo se ven obstaculizadas por las estructuras jerárquicas y la toma de decisiones no participativa

-Lugar: Oeste Estados Unidos

-Participantes: 590 maestros de 37 escuelas de educación primaria

- Resultados: Muestran que el liderazgo de instrucción tiene más efectos en el rendimiento que el liderazgo transformacional

-Lugar: Islandia

-Participantes: 10 directores

Helga (2014)
- Resultados: Durante 10 años analizan las decisiones de los directores que favorecen cambios significativos y de impacto. Las prácticas son más eficaces cuando todas las actividades se basan en conseguir los objetivos comunes y compartidos

Fuente: Elaboración propia

Se observa que es complejo conocer el impacto real del liderazgo en los resultados escolares (Ruiz, 2013) ya que las prácticas están influenciadas por el contexto y sus efectos se manifiestan a medio plazo (3-5años).

A pesar de la variedad de prácticas analizadas podemos agruparlas en los siguientes bloques: 
Figura 10: Elementos comunes de las prácticas de liderazgo

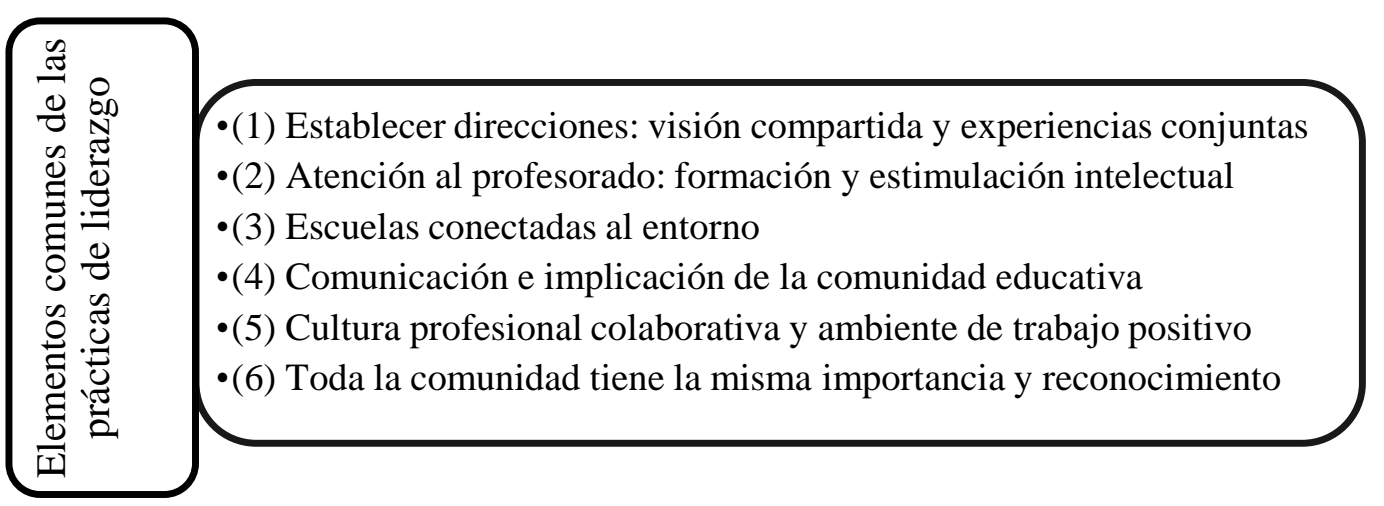

Fuente: Elaboración propia

Para desarrollar las prácticas eficaces es necesario establecer direcciones (1) desarrollando el compromiso y una visión compartida con objetivos grupales y pactados entre los miembros.

El profesorado es un elemento clave en el desarrollo y éxito de las prácticas educativas. El líder debe potenciar sus habilidades y capacidades (2), prestar apoyo individual, estimular intelectualmente y ser un modelo ejemplar de comportamiento. Las escuelas son instituciones conectadas al entorno social y cultural (3). Las prácticas deben fortalecer la cultura profesional, potenciar las relaciones con la comunidad y establecer contacto con instituciones externas. Para conseguirlo es fundamental ser una escuela cercana y tener comunicación (4) con la comunidad para obtener su implicación y respaldo en los diferentes proyectos. La creación de estructuras que faciliten el trabajo colaborativo con un ambiente de trabajo positivo (5) y una cultura de confianza con relaciones basadas en el respeto y el sentimiento de pertenecer al grupo y donde todos tienen la misma importancia y reconocimiento (6) en la toma de decisiones.

En las prácticas se observa una influencia recíproca entre líderes y seguidores. El líder debe resolver inquietudes y apoyar al profesorado en todo el proceso para que el cambio sea un éxito (Anderson, 2010; Hall, 2013) ya que durante la aplicación de las prácticas puede haber resistencia por parte de algún miembro. 
DIRECCIÓN ESCOLAR Y LIDERAZGO: ANÁLISIS DEL DESEMPEÑO DE LA FIGURA DIRECTIVA EN CENTROS DE EDUCACIÓN PRIMARIA DE TARRAGONA

Marta Camarero Figuerola 
DIRECCIÓN ESCOLAR Y LIDERAZGO

\section{PRIMARIA DE TARRAGONA}

ANÁLISIS DEL DESEMPEÑO DE LA FIGURA DIRECTIVA EN CENTROS DE EDUCACIÓN Marta Camarero Figuerola 


\section{CAPÍTULO IV: DISEÑO Y OBJETIVOS DE LA INVESTIGACIÓN}

ras la realización de la fundamentación teórica de nuestro tema de investigación, incluida la visión internacional, y partiendo de la base que nos aportan, describiremos en este capítulo las bases metodológicas de la investigación que han servido de guía a lo largo de todo el proceso. Justificaremos la selección de los aspectos que intervienen en el proceso de investigación como los paradigmas educativos, los métodos y las técnicas de investigación y concluiremos con las razones que nos han promovido a optar por un enfoque descriptivo en el estudio.

Presentaremos los objetivos de nuestro estudio junto a las preguntas de investigaciones. Se presenta el contexto donde se desarrolla el estudio, se describe la población del estudio y se profundiza en los criterios para la selección de la muestra. Se detalla el proceso de elaboración y validación del principal instrumento del estudio: el cuestionario. Se presenta el tratamiento y codificación de los datos obtenidos así como el análisis de los mismos. 


\subsection{Enfoques teóricos de la investigación educativa}

Creemos conveniente, antes de empezar la descripción del proceso, definir el concepto de investigación educativa. La etimología del término investigación proviene del latín investigare (investigar) e investigio (investigación) que significa indagar, inquirir, hallar.

Autores clásicos en la temática de la investigación educativa, como Best, definen la investigación como "el proceso más formal, sistemático e intensivo de llevar a la práctica el método científico de análisis de la realidad social y educativa” (1982: 7). Para Kerlinger: "la investigación científica debe ser sistemática, controlada, empírica y crítica al abordar las proposiciones hipotéticas sobre supuestas relaciones existentes entre los fenómenos naturales"(1975: 11).

Jiménez \& Tejada (1997) definen la investigación educativa como un proceso destinado a elaborar un corpus de conocimientos centrado en el mundo educativo.

A través de la investigación pretendemos llegar a descubrir la verdad y que ésta nos permita explicar de forma coherente unos determinados fenómenos (García-Llamas, González-Galán \& Ballesteros, 2001: 77). Los objetivos de la investigación educativa deben ser, según estos autores:

- Favorecer el crecimiento sobre el campo educativo.

- Ayudar e influir en la toma de decisiones sobre las relaciones de la educación.

- Generar formas, procedimientos e instrumentos de actuación práctica en el proceso educativo.

- Contribuir al desarrollo y la difusión de los conocimientos de base empírica.

- Formar investigadores que puedan afrontar nuevos retos de la educación.

La investigación educativa está dirigida a la búsqueda sistemática de nuevos conocimientos, con el fin de que éstos sirvan de base para la comprensión de los procesos de enseñanza y aprendizaje (Ballester, Nadal \& Amer, 2014).

Definimos la investigación educativa como un proceso sistemático de recogida y de análisis lógico de información (datos) con un fin concreto. Sin duda la investigación educativa se ha convertido en una fuente valiosa ya que proporciona información válida 
y conocimientos precisos sobre la educación con el propósito de tomar decisiones informadas (McMillan \& Schumacher, 2007).

En cualquier caso hay que ser consciente que, inevitablemente, las investigaciones se desempeñan desde unos planteamientos ideológicos que mediatizan la manera de entender y abordar el objeto de estudio, dando lugar a diferentes paradigmas de investigación. En la investigación educativa intervienen diferentes perspectivas, metodologías y concepciones paradigmáticas (Jiménez \& Tejada, 1997).

El tema debate de los paradigmas se basaba en el tipo de metodología: la cuantitativa frente a la cualitativa; explicar frente a comprender; investigación positivista frente a investigación humanista (Latorre, del Rincón \& Arnal, 2003).

A esta dicotomización tradicional se añade una perspectiva crítica que en la actualidad tiene cada vez más protagonismo en el desarrollo de la investigación educativa.

El término paradigma procede del griego "paradeigma”. Autores clásicos como Kuhn y Lakatos, citados por García-Llamas, González-Galán \& Ballesteros (2001: 83) definen el término paradigma. Kuhn identifica el paradigma con las relaciones científicas que durante un tiempo proporcionan modelos de problemas y soluciones a una comunidad científica, pero cuando la comunidad se replantea el paradigma, entra en crisis y surge un cambio de paradigma. En cambio Lakatos opina que los diferentes paradigmas no compiten entre sí, sino que se complementan y tienden a coexistir.

Procederemos a presentar los tres grandes paradigmas de referencia en la investigación educativa:

\section{1) El paradigma positivista:}

Es el paradigma imperante de la Pedagogía de comienzos del siglo XX que actualmente se mantiene pero, según Ballester, Nadal \& Amer (2014), con cambios producidos por las aportaciones de Popper, Kuhn, Lakatos, Feyerabend, etc. Su aspiración es descubrir las leyes por las que se rigen los fenómenos educativos y elaborar teorías científicas que guíen la acción educativa.

Colás \& Buendía, (1998) convienen en que la aplicación de este paradigma implica los siguientes supuestos: 
- Los objetos, los conceptos y los métodos de las ciencias naturales son aplicables a las indagaciones científico-sociales.

- Las normas lógicas que guían el modelo de explicación en las ciencias naturales pueden utilizarse en las ciencias sociales.

- Las leyes científicas son universales y persisten fuera del espacio y del tiempo.

- Los datos aportados por el método científico son objetivos ya que la investigación es neutra y aséptica.

- Toda ciencia se plantea los mismos tipos de objetivos: la explicación, la predicción y el control.

Según Popkewitz citado en García-Llamas, González-Galán \& Ballesteros (2001: 85), éstas son las características del paradigma positivista:

- La existencia de teorías universales, no sujetas a contextos de actuación concretos.

- Independencia de los enunciados científicos de los fines y valores de los sujetos.

- La visión cambiante del mundo social en sus variables más representativas.

- Es preciso definir operativamente estas variables y alcanzar medidas fiables de las mismas.

- La importancia de la Estadística como ciencia instrumental de análisis e interpretación de datos.

Observamos que para los positivistas la realidad es fragmentable y puede ser observada y controlada para explicar la realidad y generar conocimiento a través de un procedimiento hipotético-deductivo. Las teorías de este paradigma tienen una base normativa que permiten establecer generalizaciones en cualquier contexto.

Consideramos que optar por este enfoque en nuestro estudio supondría prestar atención a los aspectos más superficiales y visibles, descuidando factores fundamentales para nosotros como el entorno, los valores, la experiencia, etc. $y$, especialmente, la percepción de los propios sujetos sobre esos aspectos.

\section{2) El paradigma interpretativo:}

El paradigma interpretativo persigue describir de forma detallada y objetiva las conductas naturales. La finalidad es comprender los fenómenos educativos, a través de percepciones e interpretaciones de los sujetos que intervienen en la acción educativa. "No se busca la generalización sino el desarrollo de conocimientos concretos sobre 
comunidades también concretas" (Ballester, Nadal \& Amer, 2014: 48). "Pretende sustituir las nociones científicas de explicación, predicción y control del paradigma positivista por las nociones de comprensión, significación y acción (Latorre et al., 2003: 42). Enfatiza la comprensión e interpretación de la realidad educativa, aceptando que la realidad es dinámica, múltiple y holística.

La investigación descriptiva pone el énfasis en "las condiciones o conexiones existentes; prácticas que prevalecen; opiniones, puntos de vista o actitudes que se mantienen; procesos en marcha; efectos que se sienten o tendencias que se desarrollan” (Best, 1982: 91).

Según Hernández (1995) los rasgos más representativos de este paradigma son:

- La vida social se genera y mantiene gracias a las interacciones entre los sujetos como por sus comportamientos en comunidad (formas de vida influenciadas por el contexto social)

- La conducta social no se puede explicar sin tener en cuenta las interpretaciones particulares de los sujetos (ya que es más compleja y diferenciada que otros seres vivos)

- El conocimiento pedagógico no es universal y no sirve para espacios y contextos indeterminados y esto implica que las teorías son relativas puesto que cada comunidad actúa con criterios propios que pueden evolucionar en el transcurso del tiempo.

Este paradigma no pretende una generalización del conocimiento. La finalidad de la investigación será comprender los fenómenos educativos a través del análisis de las percepciones e interpretaciones de sujetos que participan en las investigaciones.

Nuestro estudio tiene como finalidad conocer y comprender la realidad de la dirección escolar y liderazgo de los directores, Considerando la importancia de la visión de los participantes y la importancia del contexto. Por lo tanto el enfoque interpretativo será el enfoque de nuestra investigación. 


\section{3) El paradigma crítico:}

Este enfoque aparece con la intención de ser una alternativa a los anteriores paradigmas y "trata de superar tanto el reduccionismo de la primera como el conservadurismo de la segunda” García-Llamas, González-Galán \& Ballesteros (2001: 88)

Desde esta visión se concibe la realidad como dinámica y evolutiva. La finalidad del paradigma no es tan sólo explicar y comprender la realidad, sino contribuir a la mejora de la misma con una transformación. La "teoría" es inseparable de la "práctica". Introduce la ideología de forma explícita y la autorreflexión crítica en los procesos del conocimiento.

Según Colás y Buendía (1998: 51) las características identificativas de este paradigma son:

- El conocimiento se construye siempre por intereses que parten de las necesidades naturales y adquieren su forma por las condiciones históricas y sociales.

- La explicación de la realidad no es objetiva ni neutral, ya que responde a un determinado interés humano, al que presta su servicio. El interés emancipador, uno de los intereses que guían la actividad humana, pretende la autonomía racional liberadora del hombre. En el conocimiento emancipador adquieren gran importancia la relación entre hechos, valores y múltiples formas del contexto histórico social.

- La misión es sacar a la luz las causas subyacentes a las limitaciones sociales con objeto de superar los problemas sociales.

- La metodología es la crítica ideológica y también se incorporan procedimientos de psicoanálisis.

La reflexión es imprescindible en este enfoque. Se defiende una postura dialéctica en lo referente a la naturaleza del conocimiento (importancia de la ideología). El conocimiento está orientado a la mejora del ser humano en su contexto social (visión democrática del conocimiento). Los sujetos son elementos activos en la construcción de la realidad y son los protagonistas y co-partícipes de la propia investigación. 
Enfoque orientado hacia la praxis, con la finalidad de comprender la realidad para mejorarla o cambiarla. El plan de actuación abierto y flexible en su desarrollo secuencial.

Para finalizar, como hemos podido observar, los intereses, la ontología y el propósito de cada paradigma son diferentes. A continuación, a modo de resumen, se observa la tabla comparativa de los tres grandes paradigmas de la investigación educativa que acabamos de presentar:

Tabla 51: Paradigmas de investigación educativa

\begin{tabular}{|c|c|c|c|}
\hline Dimensión & Positivista & Interpretativo & Crítico \\
\hline Intereses & $\begin{array}{c}\text { Explicar, controlar, } \\
\text { predecir }\end{array}$ & $\begin{array}{l}\text { Comprender, interpretar } \\
\text { (comprensión mutua } \\
\text { compartida) }\end{array}$ & $\begin{array}{l}\text { Emancipar, criticar e } \\
\text { identificar el potencial } \\
\text { para el cambio }\end{array}$ \\
\hline $\begin{array}{c}\text { Ontología } \\
\text { (naturaleza } \\
\text { de la } \\
\text { realidad) }\end{array}$ & $\begin{array}{l}\text { Dada, singular, tangible, } \\
\text { fragmentable, } \\
\text { convergente }\end{array}$ & $\begin{array}{l}\text { Construida, holística, } \\
\text { divergente, múltiple }\end{array}$ & Construida, holística \\
\hline $\begin{array}{c}\text { Relación } \\
\text { sujeto/objeto }\end{array}$ & $\begin{array}{l}\text { Independiente, neutral, } \\
\text { libre de valores }\end{array}$ & $\begin{array}{l}\text { Interrelación, relación } \\
\text { influida por factores } \\
\text { subjetivos }\end{array}$ & $\begin{array}{l}\text { Interrelacionados. } \\
\text { Relación incluida por el } \\
\text { fuerte compromiso para } \\
\text { el cambio }\end{array}$ \\
\hline $\begin{array}{c}\text { Propósito } \\
\text { (generalización) }\end{array}$ & $\begin{array}{l}\text { Generalizaciones libres } \\
\text { de contexto y tiempo, } \\
\text { leyes, explicaciones: } \\
\text { deductivas, } \\
\text { cuantitativas, centradas } \\
\text { en semejanzas }\end{array}$ & \multicolumn{2}{|c|}{$\begin{array}{l}\text { Hipótesis de trabajo en contexto y tiempo dado, } \\
\text { explicaciones idiográficas, inductivas, cualitativas, } \\
\text { centradas en diferencias }\end{array}$} \\
\hline $\begin{array}{l}\text { Explicación } \\
\text { (causalidad) }\end{array}$ & $\begin{array}{c}\text { Causas reales, } \\
\text { temporalmente } \\
\text { precedentes o } \\
\text { simultáneas }\end{array}$ & \multicolumn{2}{|c|}{ Interacción de factores } \\
\hline $\begin{array}{l}\text { Axiología } \\
\text { (papel de los } \\
\text { valores) }\end{array}$ & Libre de valores & $\begin{array}{l}\text { Valores dados. Influyen } \\
\text { en la selección del } \\
\text { problema, teoría, método } \\
\text { y análisis }\end{array}$ & $\begin{array}{c}\text { Valores dados. Crítica } \\
\text { de ideología }\end{array}$ \\
\hline
\end{tabular}

Fuente: Elaboración propia a partir de Koetting (1984:296)

Tradicionalmente se ha diferenciado entre los enfoques cualitativos y cuantitativos. En la siguiente tabla comparativa podemos observar la naturaleza de la investigación con metodología cuantitativa y con metodología cualitativa a partir de las características de todas las investigaciones: 
Figura 11: Características de la investigación educativa según el tipo de investigación

\begin{tabular}{|c|c|c|}
\hline CARACTERÍSTICAS & $\begin{array}{l}\text { INVESTIGACIÓN } \\
\text { CUANTITATIVA }\end{array}$ & $\begin{array}{c}\text { INVESTIGACIÓN } \\
\text { CUALITATIVA }\end{array}$ \\
\hline $\begin{array}{c}\text { OBJETIVIDAD y/o } \\
\text { CONFIRMABILIDAD: } \\
\text { Calidad en los procedimientos de análisis } \\
\text { y control de sesgos y subjetividad. }\end{array}$ & \multicolumn{2}{|c|}{$\begin{array}{c}\text { Descripción explícita de la recogida de datos y } \\
\text { de los procedimientos de análisis }\end{array}$} \\
\hline $\begin{array}{l}\text { PRECISIÓN: } \\
\text { Utilización de un lenguaje técnico que no } \\
\text { genere dudas (unívoco). }\end{array}$ & $\begin{array}{l}\text { Media y porcentajes } \\
\text { estadísticos }\end{array}$ & $\begin{array}{c}\text { Descripción } \\
\text { detallada }\end{array}$ \\
\hline $\begin{array}{c}\text { VERIFICACIÓN: } \\
\text { Revisión y discusión del diseño y } \\
\text { resultados. Desarrollo del corpus de } \\
\text { conocimiento e identificación de nuevas } \\
\text { preguntas de investigación. }\end{array}$ & $\begin{array}{l}\text { Resultados } \\
\text { replicados }\end{array}$ & $\begin{array}{l}\text { Extensión del } \\
\text { entendimiento }\end{array}$ \\
\hline $\begin{array}{l}\text { EXPLICACIÓN DETALLADA: } \\
\text { Reducción de las realidades complejas a } \\
\text { explicaciones sencillas. }\end{array}$ & $\begin{array}{l}\text { Preferencia por las } \\
\quad \text { explicaciones } \\
\text { menos complicadas }\end{array}$ & $\begin{array}{c}\text { Resumen de } \\
\text { generalizaciones }\end{array}$ \\
\hline $\begin{array}{c}\text { EMPIRISIMO: } \\
\text { Perspectiva pragmática. Suspensión } \\
\text { temporal de la experiencia personal y de } \\
\text { las opiniones. }\end{array}$ & Datos numéricos & Fuentes, evidencias \\
\hline $\begin{array}{c}\text { RAZONAMIENTO LÓGICO: } \\
\text { Empleo de reglas lógicas establecidas } \\
\text { (razonamiento deductivo, razonamiento } \\
\text { inductivo). }\end{array}$ & $\begin{array}{l}\text { Fundamentalmente } \\
\text { deductiva }\end{array}$ & $\begin{array}{l}\text { Fundamentalmente } \\
\text { inductiva }\end{array}$ \\
\hline $\begin{array}{c}\text { CONCLUSIONES } \\
\text { PROVISIONALES: } \\
\text { Todas las disciplinas científicas contienen } \\
\text { interpretaciones restringidas. }\end{array}$ & $\begin{array}{l}\text { Enunciados de } \\
\text { probabilidad } \\
\text { estadística }\end{array}$ & $\begin{array}{l}\text { Resumen } \\
\text { provisional de } \\
\text { interpretaciones }\end{array}$ \\
\hline
\end{tabular}

Fuente: Elaboración propia a partir de McMillan \& Schumacher (2007:14)

En nuestro caso en la investigación se ha utilizado una metodología cuantitativa pero desde planteamientos interpretativos, ya que la mirada no está puesta en la generalización de datos sino en la comprensión de la realidad que viven los directores escolares en nuestro contexto. 


\subsection{Objetivos de la investigación}

Todo proceso de investigación surge de la necesidad de resolver un interrogante o incrementar o profundizar en el conocimiento de un fenómeno educativo (Ballester, Nadal \& Amer, 2014). Para realizar una investigación viable, se ha de realizar una reducción de tema amplio a un problema particular, ya que si los problemas son demasiado generales, los resultados son difíciles de interpretar (McMillan \& Schumacher, 2007).

Las preguntas que nos planteamos al iniciar este estudio son:

- ¿Cuáles son las características más comunes en el perfil de los directores?

- ¿Cuáles son las funciones y tareas más realizadas por los directores? ¿cuáles son las más difíciles?

- ¿Qué modelo de dirección es el más común en los centros de educación primaria?

- ¿Influyen las características del centro en el perfil del director?

- ¿Qué necesidades formativas y no formativas tienen los directores?

- ¿Qué aporta más satisfacción e insatisfacción en el cargo directivo?

- ¿Cuáles son las motivaciones principales para acceder al cargo?

- ¿Existe relación entre el estilo de dirección y la mejora del centro?

El propósito general de nuestra investigación es conocer la figura directiva y los estilos de dirección y liderazgo de los centros educativos de primaria de los servicios territoriales de Educación de Tarragona.

Para el logro del propósito general pretendemos alcanzar los siguientes objetivos:

1. Describir el perfil profesional de los directores de las escuelas de los SSTT de Educación de Tarragona.

2. Analizar la situación actual del desempeño de la dirección escolar.

3. Identificar los diferentes modelos de dirección escolar y liderazgo que desarrollan los directores de la zona.

4. Proponer líneas de mejora del liderazgo para el éxito escolar. 


\subsection{Fases del trabajo de investigación}

Una vez planteada la metodología, se presentan de manera esquemática las fases que hemos seguido en el desarrollo de la investigación. En la siguiente tabla aparece el detalle de cada una de las fases:

Tabla 52: Fases de la investigación

\begin{tabular}{|c|c|c|}
\hline FASE & INSTRUMENTOS & PERÍODO \\
\hline \multicolumn{3}{|l|}{ 1. PREINVESTIGACIÓN } \\
\hline $\begin{array}{l}\text { - } \begin{array}{l}\text { Sensibilización y necesidad } \\
\text { de la investigación }\end{array} \\
\text { - } \quad \text { Revisión documental }\end{array}$ & $\begin{array}{l}\text { Revisión documental } \\
\text { bibliográfica }\end{array}$ & $\begin{array}{c}\text { Diciembre } 2013 \\
\text { - } \\
\text { Enero } 2014 \\
\begin{array}{c}\text { Durante toda la } \\
\text { investigación }\end{array}\end{array}$ \\
\hline \multicolumn{3}{|l|}{ 2. DEFINICIÓN } \\
\hline $\begin{array}{ll}\text { - } & \text { Formulación del problema de } \\
\text { investigación } \\
\text { - } & \text { Selección de la muestra } \\
\text { - } & \text { Elaboración de instrumentos } \\
\text { - } & \text { Validación del cuestionario }\end{array}$ & $\begin{array}{l}\text { Cuestionario directores } \\
\text { Validación expertos } \\
\text { Prueba Piloto }\end{array}$ & $\begin{array}{c}\text { Enero } 2014 \\
\quad- \\
\text { Febrero } 2014\end{array}$ \\
\hline \multicolumn{3}{|l|}{ 3. APLICACIÓN } \\
\hline $\begin{array}{ll}\text { - } & \text { Contacto con los centros } \\
\text { - } & \text { Activación del cuestionario } \\
\text { - } & \text { Desactivación del } \\
& \text { cuestionario }\end{array}$ & $\begin{array}{l}\text { Plataforma online } \\
\text { Lime Survey }\end{array}$ & $\begin{array}{c}\text { Marzo } 2014 \\
- \\
\text { Julio } 2014\end{array}$ \\
\hline \multicolumn{3}{|l|}{ 4. ANÁLISIS } \\
\hline $\begin{array}{ll}\text { - } & \text { Vaciado de los cuestionario } \\
\text { - } & \text { Tratamiento y categorización } \\
\text { de las respuestas } \\
\text { - } & \text { Análisis de los resultados }\end{array}$ & $\begin{array}{c}\text { Programa estadístico } \\
\text { SPSS }\end{array}$ & $\begin{array}{l}\text { Agosto } 2014 \\
\quad- \\
\text { Abril } 2015\end{array}$ \\
\hline \multicolumn{3}{|l|}{ 5. RESULTADOS } \\
\hline $\begin{array}{ll}- & \text { Conclusiones } \\
\text { - } & \text { Nuevas perspectivas }\end{array}$ & $\begin{array}{l}\text { Revisión documental } \\
\text { Revisión resultados }\end{array}$ & $\begin{array}{c}\text { Mayo } 2015 \\
- \\
\text { Octubre } 2015\end{array}$ \\
\hline
\end{tabular}

Fuente: Elaboración propia 


\subsection{Contextualización de la investigación}

La organización política de España permite que las comunidades autónomas tengan competencias en legislación educativa. No obstante, hay una ley educativa marco para toda España. La Administración educativa en Cataluña, a su vez, se estructura en zonas educativas que delimitan territorios con cierta autonomía de gestión.

En la provincia de Tarragona existen dos demarcaciones en materia educativa: la zona sur que es gestionada por los SSTT de Terres de l'Ebre y la zona norte gestionada por los SSTT de Tarragona. En esta zona es donde se ubica nuestra investigación.

\section{Servicios Territoriales de Educación de Tarragona}

Los STTT de Educación de Tarragona son los encargados de administrar las directrices del Departamento de Educación en centros de titularidad pública y también los centros concertados-privados del territorio.

Las funciones de los SSTT de educación (Generalitat de Catalunya, 2015) son las siguientes:

Tabla 53: Funciones de los servicios territoriales de educación

Ejecutar las directrices del Departamento, tanto por lo que se refiere a la educación en centros docentes de titularidad pública como en centros docentes privados.

Ejecutar las funciones de inspección educativa, a través de la Inspección de Educación Territorial.

Ejecutar las directrices del Departamento en materia de servicios educativos y formación permanente.

Ejecutar las directrices del Departamento en materia de prevención de riesgos laborales.

Ejecutar las directrices del Departamento relativas a los programas específicos de formación profesional.

Supervisar las obras de construcción y de mejora y remodelación en centros docentes de titularidad del departamento.

Gestionar el personal docente y de administración y servicios adscritos a puestos de trabajos en el ámbito territorial.

Ejecutar y supervisar las tareas de administración general.

Cualquier otra que le sea encomendada por el consejero, la Secretaria General, la Secretaria de Políticas Educativas o las direcciones generales.

Fuente: Elaboración propia a partir de Generalitat de Cataluña, 2015 
A continuación se observa el organigrama del cual dependen los SSTT:

Figura 12: Organigrama de los SSTT de Educación de Tarragona

\section{GENERALITAT DE CATALUÑA}

President de la Generalitat

Consejo Ejecutivo o Govierno

Departamento de Educación

Secretaría General de Educación

\section{Servicios Territoriales (SSTT) de Educación de Tarragona}

Fuente: Elaboración propia

El ámbito territorial que abarca los SSTT de Educación a Tarragona es el correspondiente a las comarcas de: Alt Camp, Baix Camp, Baix Penedès, Conca de Barberà, Priorat y Tarragonès con un total de 217 centros educativos distribuidos de la siguiente manera:

- Alt Camp: tiene una superficie de $538 \mathrm{~km}^{2}$ con una población de 44.578 habitantes. Valls es la capital de la comarca. Los centros de educación primaria se agrupan en: 14 públicos, 3 concertados y 3 zonas rurales ( 9 centros rurales).

Tabla 54: Municipios del Alt Camp

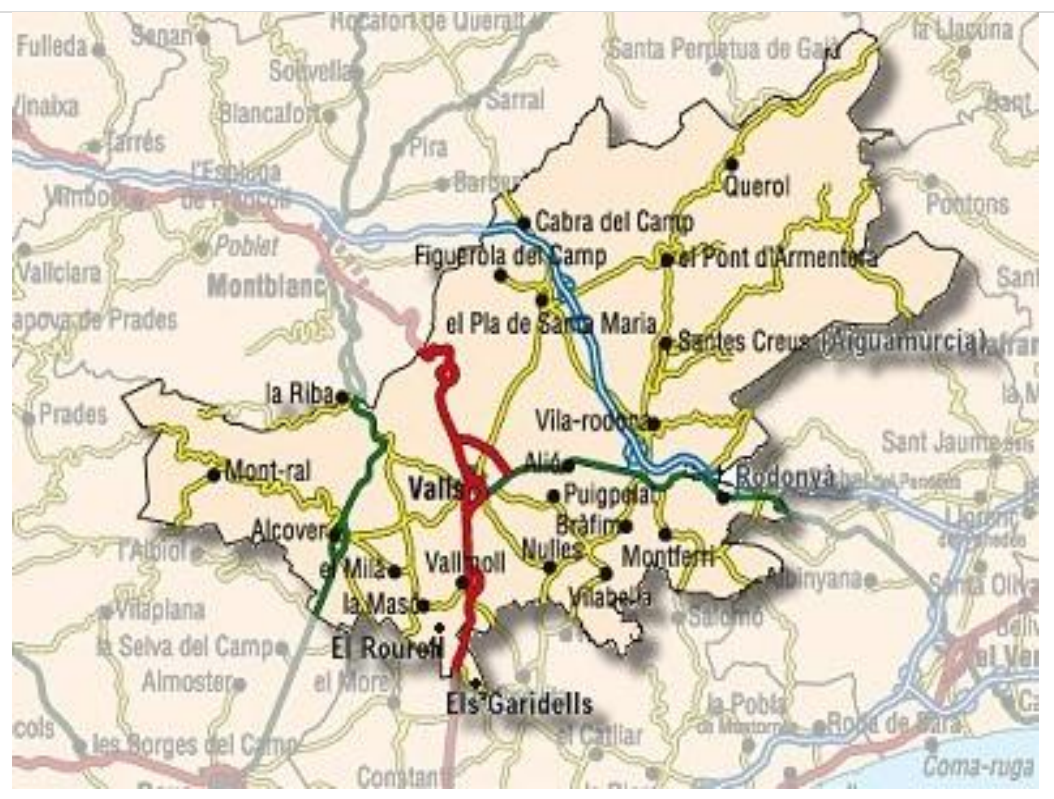

Aiguamúrcia

Alcover

Alió

Bràfim

Cabra del Camp

El Milà

El Pla de Santa Maria

El Pont d'Armentera

Figuerola del Camp

La Masó

La Riba

Nulles

Puigpelat

Rodonyà

Vallmoll

Valls

Vilabella

Vila-rodona

Fuente: imagen extraída de la web gencat.cat 
- Baix Penedès: tiene una superficie de $338 \mathrm{~km}^{2}$ con una población de 100.262 habitantes .Vendrell es la capital de la comarca. Los centros de educación primaria se agrupan en: 24 públicos, 3 concertados y 1 zona rural $(2$ centros rurales).

Tabla 55: Municipios del Baix Penedès

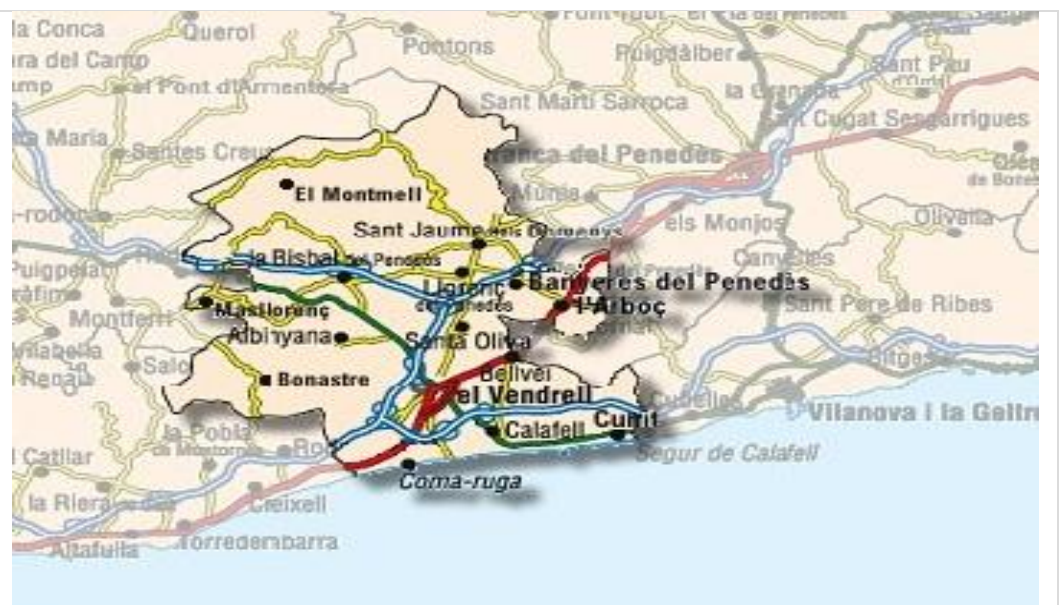

Albinyana
Banyeres del Penedès
Bellvei
Bonastre
Calafell
Cunit
El Montmell
El Vendrell
La Bisbal del Penedès
L'Arboç
Llorenç del Penedès
Masllorenç
Sant Jaume dels
Domenys
Santa Oliva

Fuente: imagen extraída de la web gencat.cat

- Baix Camp: tiene una superficie de $273 \mathrm{~km}^{2}$ con una población de 190.249 habitantes. Reus es la capital de la comarca. Los centros de educación primaria se agrupan en: 47 públicos, 12 concertados y 2 zonas rurales (4 centros rurales).

Tabla 56: Municipios del Baix Camp

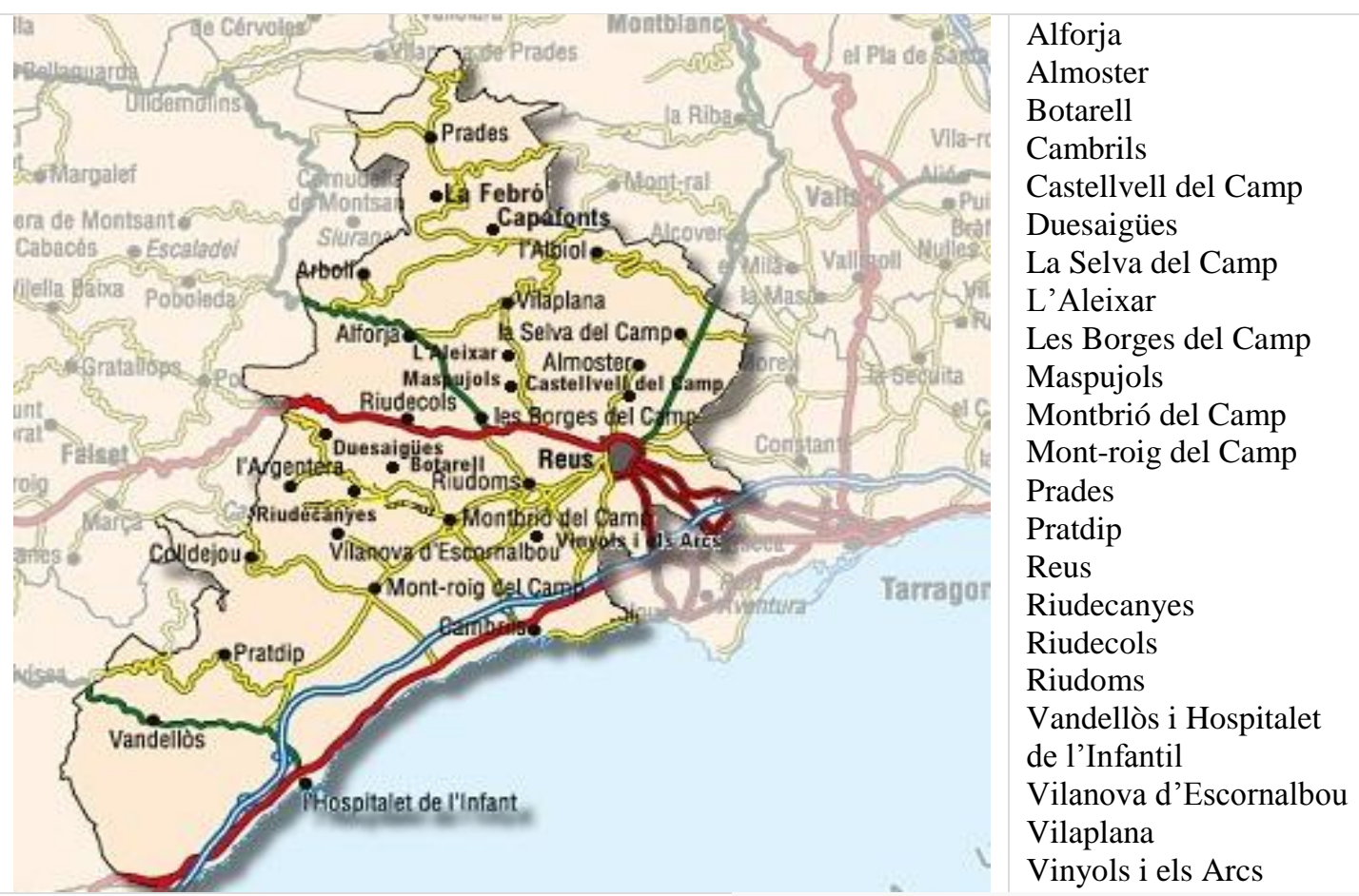

Fuente: imagen extraída de la web gencat.cat 
- Conca de Barberà: tiene una superficie de $650 \mathrm{~km}^{2}$ con una población de 20.723 habitantes. Montblanc es la capital. Los centros de educación primaria se agrupan en: 4 públicos, 3 concertados y 2 zonas rurales ( 7 centros rurales).

Tabla 57: Municipios de la Conca de Barberà

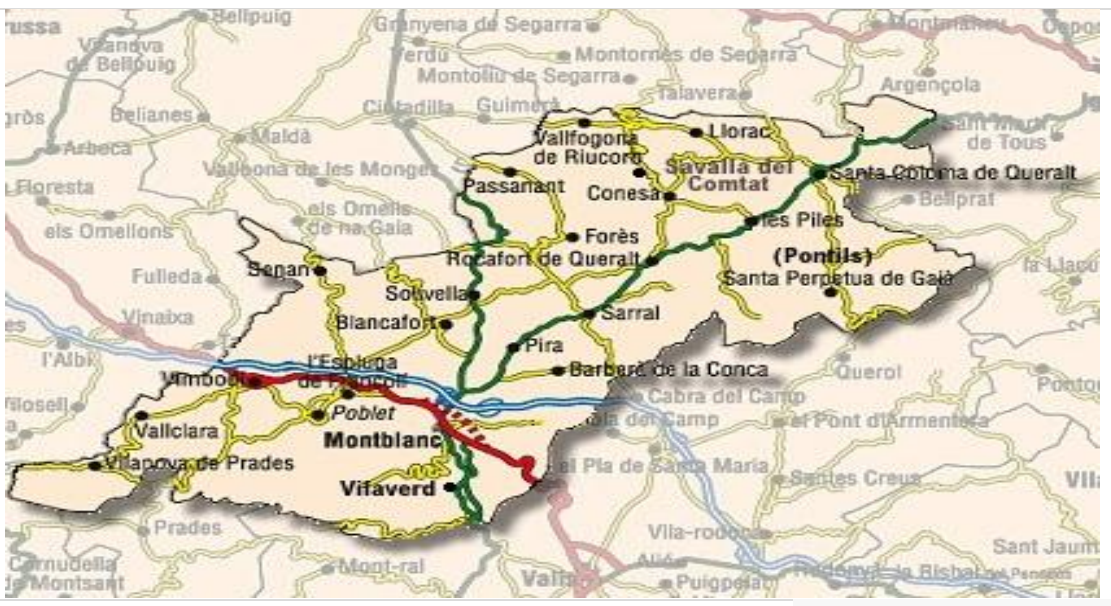

Barberà de la Conca

Blancafort

L'Espluga de Francolí

Montblanc

Pira

Rocafort de Queralt

Santa Coloma de

Queralt

Sarral

Solivella

Vilaverd

Vimbodí i Poblet

Fuente: imagen extraída de la web gencat.cat

- Priorat: tiene una superficie de 499 km² con una población de 9.550 habitantes.

Falset es la capital de la comarca. Los centros de educación primaria se agrupan en: 3 públicos, ningún concertado y 5 zonas rurales (12 centros rurales).

Tabla 58: Municipios del Priorat

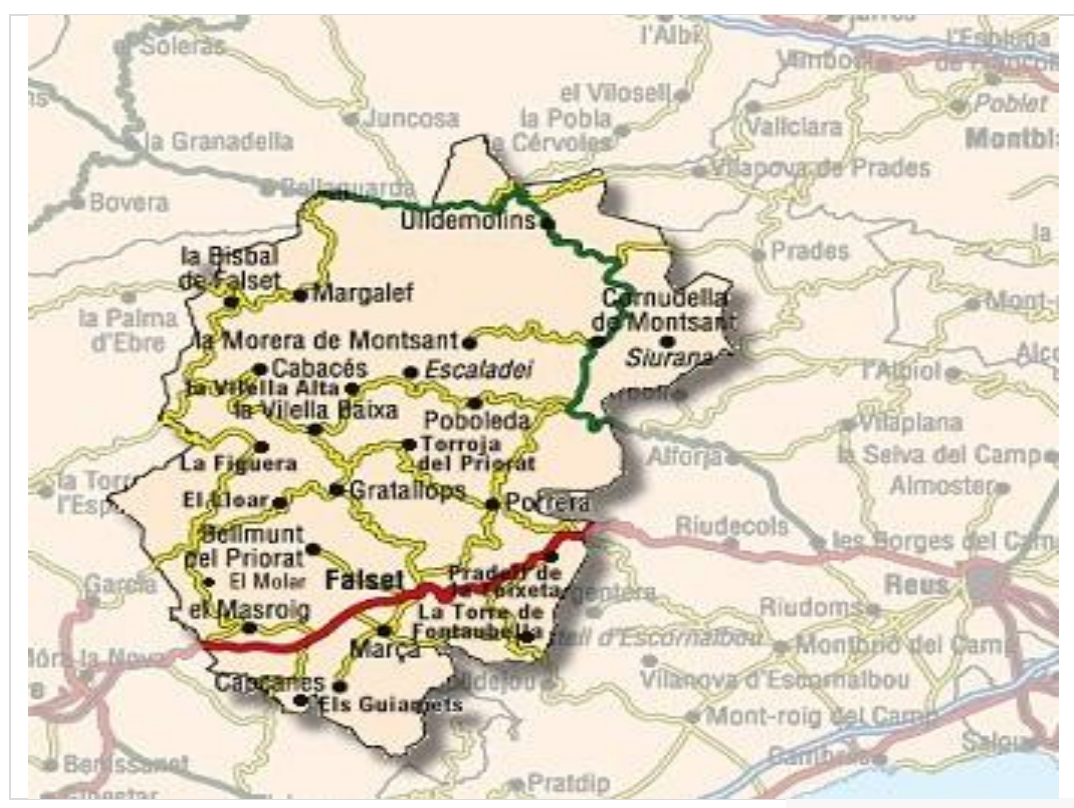

Bellmunt del Priorat

Cabaçés

Capçanes

Cornudella de

Montsant

El Masroig

El Molar

Els Guiamets

Falset

Gratallops

La Bisbal de Falset

La Vilella Baixa

Marçà

Poboleda

Porrera

Ulldemolins

Fuente: imagen extraída de la web gencat.cat 
- Tarragonès tiene una superficie de $319 \mathrm{~km}^{2}$ con una población de 250.306 habitantes. Tarragona es la capital de la comarca. Los centros de educación primaria se agrupan en: 55 públicos, 14 concertados y el único centro privado.

Tabla 59: Municipios del Tarragonès

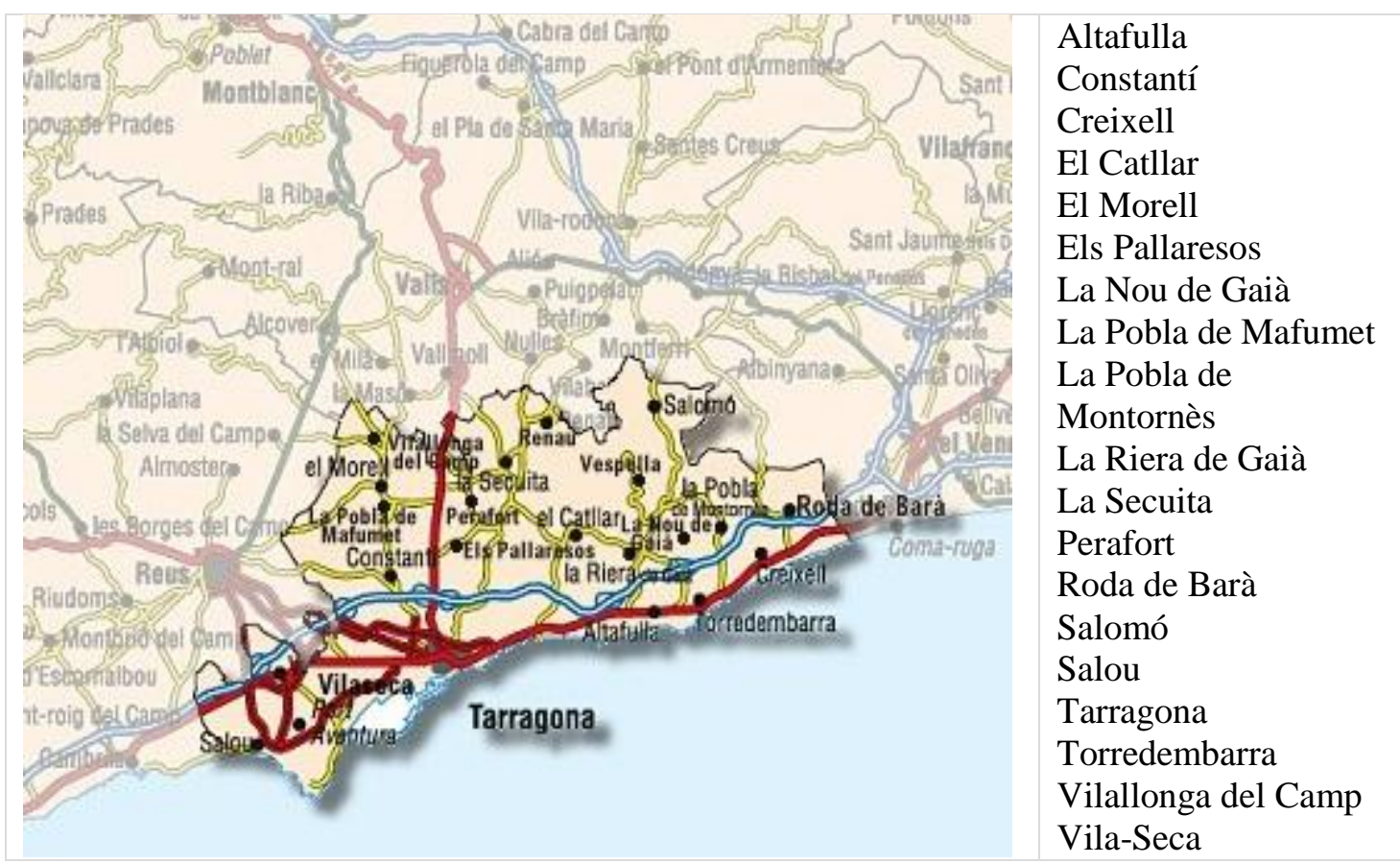

Fuente: imagen extraída de la web gencat.cat

Los centros escolares, según su titularidad, se clasifican en:

- Centros públicos: la titularidad de estos centros corresponde a la administración pública (Departamento de Educación).

- Centros concertados: la titularidad corresponde a una persona física o a una persona jurídica de carácter privado pero el centro tiene una financiación de fondos públicos.

- Centros privados: la titularidad corresponde a una persona física o a una persona jurídica de carácter privado. No recibe ningún fondo público.

Según la ubicación del centro los clasificamos en:

- Centros rurales: se encuentran en poblaciones de pocos habitantes, por lo que se trata de centros educativos pequeños. Una de las características más representativas de los centros rurales es su estructura de grupo multigrado (aulas con alumnado de diferentes cursos y etapas educativas). El Decreto 195/1988 (Generalitat de Catalunya, 1988) regular las zonas rurales con la finalidad de compartir recursos 
(humanos y materiales), preparar y realizar actividades conjuntas que fomenten la socialización del alumnado. Los centros se agrupan con otros centros de las poblaciones cercanas y constituyen una ZER (Zona Escolar Rural). Las ZERs suelen estar formadas por dos o más escuelas rurales con un proyecto educativo común.

- Centros urbanos: se encuentran en las áreas urbanas o en el extrarradio. Los centros urbanos son más grandes en comparación con los centros rurales. Los alumnados son agrupados por cursos y etapas educativas. Cada centro tiene un proyecto educativo, una normativa, una visión y misión propia.

\subsection{Población y muestra de la investigación}

La población de la que parte la investigación está compuesta por los 217 colegios de la demarcación de los SSTT de Tarragona de Educación Primaria.

De éstos 181 son centros públicos, 35 centros concertados y un único centro es privado. A través de la web de la Generalitat de Cataluña, accedimos al listado de centros de Educación Primaria de cada comarca:

Tabla 60: Número de centros de Educación Primaria por Comarca

\begin{tabular}{|l|c|c|c|c|c|c|c|}
\hline $\begin{array}{c}\text { EDUCACIÓN } \\
\text { PRIMARIA }\end{array}$ & Tarragonès & $\begin{array}{c}\text { Conca de } \\
\text { Barberà }\end{array}$ & Priorat & $\begin{array}{c}\text { Alt } \\
\text { Camp }\end{array}$ & $\begin{array}{c}\text { Baix } \\
\text { Penedès }\end{array}$ & $\begin{array}{c}\text { Baix } \\
\text { Camp }\end{array}$ & TOTAL \\
\hline Centros públicos & 55 & 11 & 15 & 24 & 26 & 50 & $\mathbf{1 8 1}$ \\
\hline Centros concertados & 14 & 3 & - & 3 & 3 & 12 & $\mathbf{3 5}$ \\
\hline Centros privados & 1 & - & - & - & - & - & $\mathbf{1}$ \\
\hline TOTAL & $\mathbf{7 0}$ & $\mathbf{1 4}$ & $\mathbf{1 5}$ & $\mathbf{2 7}$ & $\mathbf{2 9}$ & $\mathbf{6 2}$ & $\mathbf{2 1 7}$ \\
\hline
\end{tabular}

Fuente: Elaboración propia

Para calcular el tamaño de la muestra, se parte de la fórmula estadística para población finita con margen de error del $\mathbf{0 . 0 5} \%$. Obteniendo una muestra de 139 centros.

Para determinar la composición de la muestra se ha utilizado un criterio probabilístico (muestreo aleatorio) y un muestreo estratificado que comprende la división de la población en grupos con el fin de obtener una muestra representativa de toda la población (Cohen \& Manion, 2002). 
Se ha mantenido el criterio de muestreo por cuotas para obtener representación de los diferentes tipos de centro (público, concertado y privado) y de las diferentes comarcas (para garantizar la representatividad geográfica). En el caso de las ZER (Zona Escolar Rural), además de mantener el criterio aleatorio de su elección, se ha incluido el conjunto de escuelas de cada zona escolar rural para analizarlas como contextos singulares.

En la siguiente tabla se resume la composición general de la muestra según la tipología del centro:

Tabla 61: Muestra final de la investigación

\begin{tabular}{|l|c|c|}
\hline $\begin{array}{c}\text { EDUCACIÓN } \\
\text { PRIMARIA }\end{array}$ & $\begin{array}{c}\text { Población total } \\
\text { (STT- TGN) }\end{array}$ & Muestra \\
\hline Centros públicos $^{*}$ & 181 & 116 \\
\hline Centros concertados & 35 & 22 \\
\hline Centros privados & 1 & 1 \\
\hline TOTAL & $\mathbf{2 1 7}$ & $\mathbf{1 3 9}$ \\
\hline \multicolumn{2}{|c|}{ Fuente: Elaboración propia } \\
\hline
\end{tabular}

*Los centros públicos (181) se dividen en 144 centros urbanos y 37 centros rurales.

De los 116 de la muestra, 99 son centros urbanos y 17 son centros rurales (5 zonas rurales).

Ampliamos información de la muestra, representando los centros según tipología y comarca:

Tabla 62: Muestra de centros de la investigación

\begin{tabular}{|c|c|c|c|c|c|}
\hline \multirow{8}{*}{ 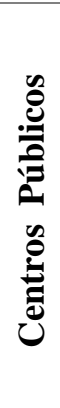 } & COMARCA & POBLACIÓN & $\begin{array}{l}\% \text { POBLACIÓN } \\
\text { TOTAL }\end{array}$ & $\begin{array}{l}\text { CÁLCULO \% } \\
\text { MUESTRA }\end{array}$ & $\begin{array}{l}\text { REDONDEO } \\
\text { MUESTRA }\end{array}$ \\
\hline & Conca de Barberà & 11 & $6,08 \%$ & $7,05 \%$ & 7 \\
\hline & Priorat & 15 & $8,29 \%$ & $9,61 \%$ & 10 \\
\hline & Tarragonès & 55 & $30,39 \%$ & $35,25 \%$ & 35 \\
\hline & Alt Camp & 24 & $13,26 \%$ & $15,38 \%$ & 15 \\
\hline & Baix Penedès & 26 & $14,36 \%$ & $16,66 \%$ & 17 \\
\hline & Baix Camp & 50 & $27,62 \%$ & $32,04 \%$ & 32 \\
\hline & TOTAL & 181 & $100 \%$ & - & 116 \\
\hline \multirow{8}{*}{ 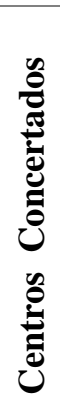 } & COMARCA & POBLACIÓN & $\begin{array}{l}\% \text { POBLACIÓN } \\
\text { TOTAL }\end{array}$ & $\begin{array}{c}\text { CÁLCULO \% } \\
\text { MUESTRA }\end{array}$ & $\begin{array}{c}\text { REDONDEO } \\
\text { MUESTRA }\end{array}$ \\
\hline & Conca de Barberà & 3 & 8,57 & 1,89 & 2 \\
\hline & Priorat & 0 & 0,00 & 0,00 & 0 \\
\hline & Tarragonès & 14 & 40,00 & 8,80 & 9 \\
\hline & Alt Camp & 3 & 8,57 & 1,89 & 2 \\
\hline & Baix Penedès & 3 & 8,57 & 1,89 & 2 \\
\hline & Baix Camp & 12 & 34,29 & 7,54 & 7 \\
\hline & TOTAL & 35 & $100 \%$ & - & 22 \\
\hline
\end{tabular}




\begin{tabular}{|c|c|c|c|c|c|}
\hline \multirow{8}{*}{ 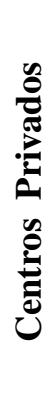 } & COMARCA & POBLACIÓN & $\begin{array}{c}\text { \% POBLACIÓN } \\
\text { TOTAL }\end{array}$ & $\begin{array}{c}\text { CÁLCULO \% } \\
\text { MUESTRA }\end{array}$ & $\begin{array}{c}\text { REDONDEO } \\
\text { MUESTRA }\end{array}$ \\
\hline & Conca de Barberà & 0 & 0,00 & - & 0 \\
\hline & Priorat & 0 & 0,00 & - & 0 \\
\hline & Tarragonès & 1 & 100,00 & 1 & 1 \\
\hline & Alt Camp & 0 & 0,00 & - & 0 \\
\hline & Baix Penedès & 0 & 0,00 & - & 0 \\
\hline & Baix Camp & 0 & 0,00 & - & 0 \\
\hline & TOTAL & 1 & $100 \%$ & - & 1 \\
\hline
\end{tabular}

Fuente: Elaboración propia

\subsection{Métodos y técnicas de recogida de información}

Entendemos por métodos "la gama de aproximaciones empleadas en la investigación educativa para reunir los datos que van a emplearse como base para la inferencia y la interpretación, para la explicación y la predicción” (Cohen \& Manion, 2002: 71).

Las técnicas están estrechamente ligadas al método. Según Colás \& Buendía (1998: 62) entienden por técnicas las formas y modalidades en las que se pueden concretar cada una de las etapas u operaciones de cualquiera de los métodos de investigación.

Las principales técnicas, según Fernández (2005) son: los documentos, las entrevistas, la observación y los cuestionarios.

En nuestro caso el análisis de documentos oficiales y revisión documental junto al cuestionario, principal instrumento de recogida de datos, permitirán describir la realidad de la dirección escolar y liderazgo en la zona de Tarragona (Cataluña-España).

A continuación, detallaremos las técnicas utilizadas en nuestro estudio.

\section{Revisión documental}

Documentarse y revisar la información referente al problema de estudio es una fase importante e imprescindible de cualquier investigación. La revisión documental permite a los investigadores interpretar con mayor fundamento el significado de los resultados al tiempo que conoce estudios que ya se han realizado. 
Según Latorre, del Rincón \& Arnal, (2003: 60) la revisión documental ayuda al investigador a:

1) Definir y delimitar el problema

2) Situar al estudio en una perspectiva histórica y contextual

3) Evitar replicaciones innecesarias

4) Seleccionar métodos y técnicas

5) Relacionar los hallazgos de conocimientos previos y sugerir otras investigaciones.

Se considera una fuente documental cualquier entidad que proporcione información y conocimiento útil para la elaboración de la ciencia (Latorre, del Rincón \& Arnal, 2003).

Diferentes ejemplos de fuentes son: archivos, bases de datos, referencias bibliográficas, revistas, informes, actas, conferencias, películas, experiencias, etc. En la actualidad, las bases de datos electrónicas son el recurso más ágil y rápido para la revisión documental.

En la investigación, la revisión documental ha sido un proceso intensivo durante los primeros meses y extenso durante toda la investigación. A continuación, mostramos la tabla de análisis que nos ha facilitado la estructura de la revisión bibliográfica:

Tabla 63: Tabla de revisión bibliográfica

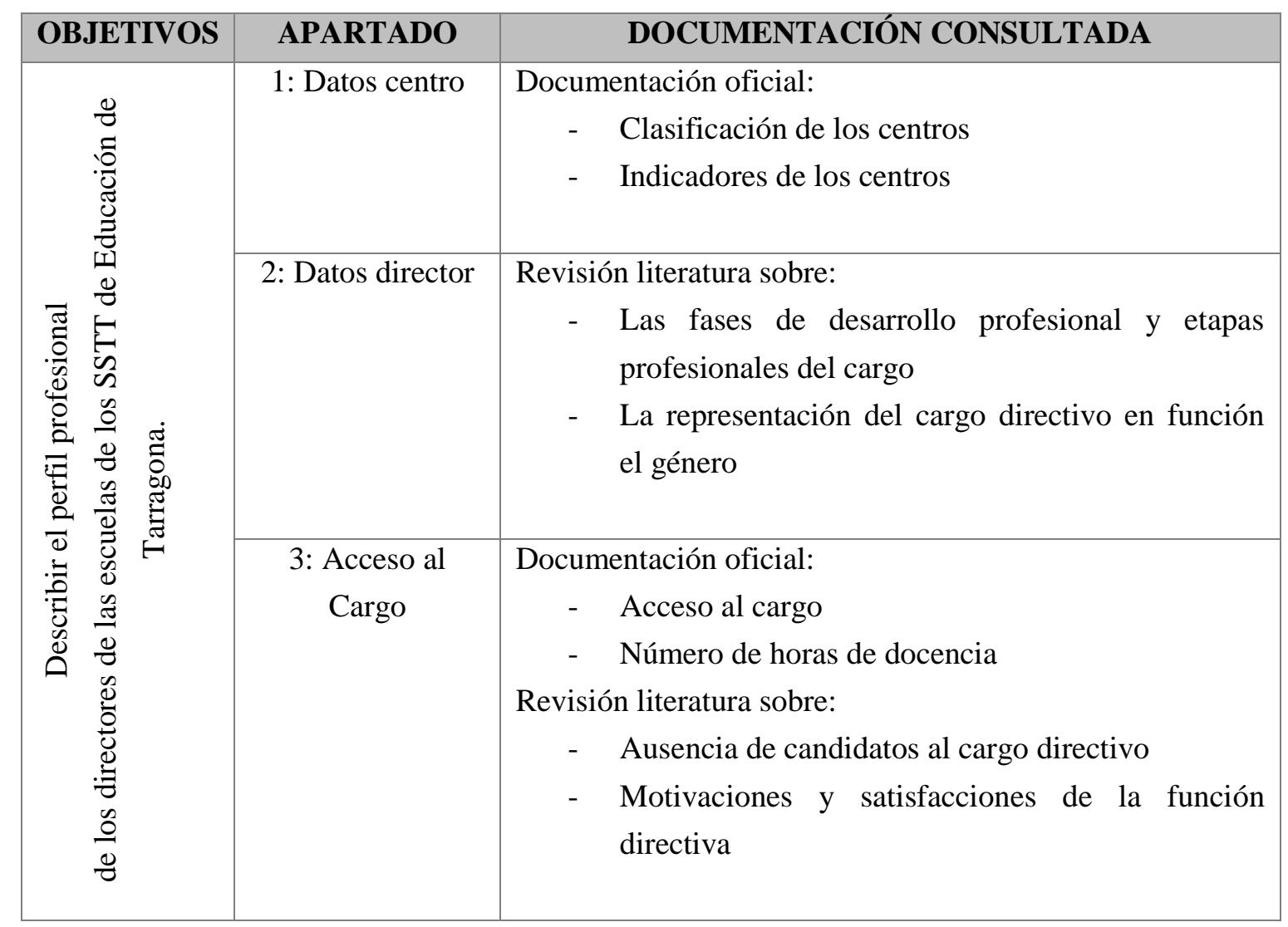




\begin{tabular}{|c|c|c|}
\hline \multirow{5}{*}{ 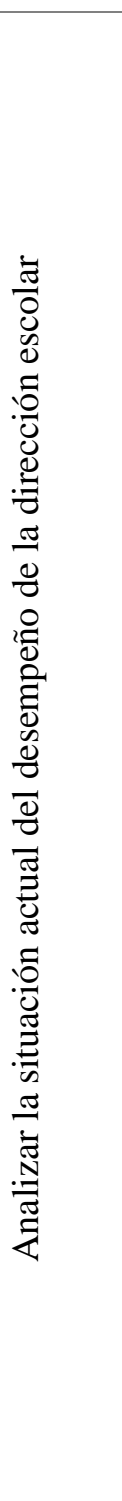 } & 4: Formación & $\begin{array}{l}\text { Documentación oficial: } \\
\text { - } \quad \text { Formación (requisito normativo de acceso) } \\
\text { Revisión literatura sobre: } \\
\text { - } \quad \text { Tipos de formación directiva } \\
\text { - } \quad \text { Competencias del cargo directivo }\end{array}$ \\
\hline & 5: Ejercicio Cargo & $\begin{array}{l}\text { Documentación oficial: } \\
\text { - } \quad \text { Leyes educativas } \\
\text { - } \quad \text { Decretos dirección } \\
\text { Revisión literatura sobre: } \\
\text { - } \quad \text { Actuaciones del cargo directivo } \\
\text { - } \quad \text { Funciones más desarrolladas por los directores }\end{array}$ \\
\hline & 6: Compromiso & $\begin{array}{l}\text { Revisión literatura sobre: } \\
\text { - Participación de la comunidad educativa en los } \\
\text { centros. } \\
\text { - Implicación de los directores } \\
\text { - Acciones para fomentar el compromiso de la } \\
\text { comunidad educativa }\end{array}$ \\
\hline & 7: Satisfacción & $\begin{array}{l}\text { Revisión literatura sobre: } \\
\text { - } \quad \text { Que es el liderazgo } \\
\text { - } \quad \text { Prácticas de liderazgo eficaz } \\
\text { - } \quad \text { Que produce más satisfacción a los directores }\end{array}$ \\
\hline & General & $\begin{array}{l}\text { Revisión literatura sobre: } \\
\text { - } \quad \text { Estrés del cargo } \\
\text { - } \quad \text { Dificultades del cargo directivo } \\
\text { - } \quad \text { Cambio cultural en la escuela } \\
\text { - } \\
\text { Influencia del entorno }\end{array}$ \\
\hline 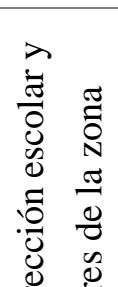 & 5: Valores & $\begin{array}{l}\text { Revisión literatura sobre: } \\
\text { - } \quad \text { Valores del cargo directivo } \\
\text { - } \quad \text { Valores para una cultura del cambio } \\
\text { - } \quad \text { Ética del cargo directivo } \\
\text { - }\end{array}$ \\
\hline $\begin{array}{ll}\exists & 0 \\
0 & 0 \\
0 & 0 \\
0 & 0 \\
0 & 0 \\
0 & 0 \\
0 & 0 \\
0 & \Xi \\
\Xi & 0\end{array}$ & $\begin{array}{l}\text { 5: Ejercicio del } \\
\quad \text { cargo }\end{array}$ & $\begin{array}{l}\text { Revisión literatura sobre: } \\
\begin{aligned} \text { - } & \text { Principales actuaciones del cargo directivo } \\
\text { - } & \text { Diferencias entre líderes y gestores }\end{aligned}\end{array}$ \\
\hline 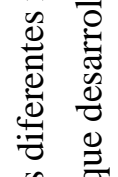 & $\begin{array}{l}\text { 6: Modelo } \\
\text { dirección }\end{array}$ & $\begin{array}{l}\text { Documentos oficiales: } \\
-\quad \text { Funciones y tareas establecidas por la normativa }\end{array}$ \\
\hline 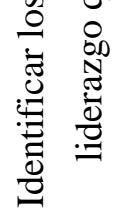 & $\begin{array}{c}\text { 9: } \\
\text { Autopercepción }\end{array}$ & $\begin{array}{l}\text { Revisión literatura sobre: } \\
-\quad \text { Roles directivos escolares } \\
\text { - } \quad \text { Estilos de liderazgo escolar }\end{array}$ \\
\hline
\end{tabular}




\begin{tabular}{|c|c|c|}
\hline \multirow{2}{*}{ 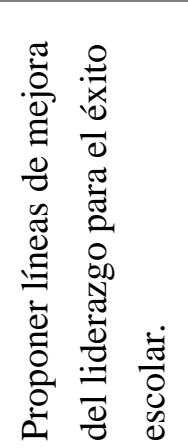 } & 9: Reflexión & $\begin{array}{l}\text { Revisión literatura sobre: } \\
\text { - Necesidades formativas y no formativas de los } \\
\text { directores } \\
\text { - } \text { Dificultades del cargo }\end{array}$ \\
\hline & $\begin{array}{l}\text { Análisis } \\
\text { resultados }\end{array}$ & $\begin{array}{l}\text { A partir del análisis de todos los apartados, observar } \\
\text { debilidades o dificultades para proponer líneas de mejora } \\
\text { de liderazgo para aumentar o potenciar el éxito educativo } \\
\text { en los centros }\end{array}$ \\
\hline
\end{tabular}

Fuente: Elaboración propia

\section{Cuestionario}

El cuestionario es un instrumento de investigación basado en una serie de preguntas realizadas con el fin de describir y/o relacionar las características de un fenómeno para responder al problema de la investigación (Latorre, del Rincón \& Arnal, 2003). Se consideran una fuente de información exploratoria o previa para identificar problemas, clarificar conceptos (Jiménez \& Tejada, 1997) y puede ser definido como un conjunto de preguntas o ítems acerca de un problema determinado, que constituye el objeto de la investigación, y cuyas respuestas han de estar contestadas por escrito (Tejada, 2007: 102).

Según Cohen \& Manion (2002: 131): “La encuesta reúne los datos en un momento particular con la intención de: a) describir la naturaleza de las condiciones existentes, o b) identificar normas o patrones contra los que se puedan comparar las condiciones existentes, o c) determinar las relaciones que existen entre acontecimientos específicos"

El cuestionario realizado se estructura en preguntas abiertas que dan la palabra a los directores y preguntas cerradas donde los directores expresan su percepción sobre aspectos concretos.

El cuestionario es el método descriptivo empleado más comúnmente en investigación educativa. La finalidad del método es conocer las actitudes, creencias, opiniones, hábitos, deseos, necesidades, etc. Los cuestionarios sirven para describir y explicar, además de obtener estimaciones generales que permiten establecer comparaciones entre subgrupos y buscar relaciones entre las variables (Latorre, del Rincón \& Arnal, 2003).

Según Schutt citado por McMillan \& Schumacher (2007), la popularidad del cuestionario se debe a su: versatilidad, eficiencia y posibilidad de generalización. Los 
cuestionarios se consideran versátiles y eficaces ya que son adaptables y pueden aplicarse a cualquier temática, además de recoger información creíble sobre muchas variables. Son el único medio para poder conseguir una descripción representativa (desde el punto de vista estadístico) de las opiniones, actitudes y otras características de la población.

Los tipos de cuestionarios se diferencian en: encuesta descriptiva y encuesta analítica. La anterior distinción raramente se da en la investigación educativa ya que la mayor parte de las encuestas sirven para ambos propósitos (Ballester, Nadal \& Amer, 2014). En función de la dimensión temporal, un cuestionario puede ser: transversal o longitudinal. La encuesta transversal se realiza una única vez y durante un período de corta duración para conocer la situación en el momento de la realización o en el pasado más reciente. En cambio, las encuestas longitudinales se realizan dos o más veces en un periodo de larga duración.

El instrumento principal de nuestra investigación es un cuestionario mixto (descriptivo y analítico) y transversal, que tiene como finalidad describir, establecer comparaciones entre subgrupos y buscar relaciones entre las variables. Se trata de un cuestionario elaborado ad hoc, fundamentado en un análisis bibliográfico y en los resultados de investigaciones precedentes.

La elaboración de cuestionarios implica un cuidadoso desarrollo de las preguntas, de los procedimientos de muestreo y del diseño global de los cuestionarios para asegurar la fiabilidad y la validez del instrumento.

Respecto las fases en la elaboración del cuestionario según el autor Martínez (2002) son:

1. Describir la información que se necesita

2. Redactar las preguntan y escoger el tipo de preguntas

3. Redactar un texto introductorio y las instrucciones

4. Diseñar el aspecto formal del cuestionario

Según Tejada (2007) el proceso de construcción de un cuestionario sigue las siguientes fases:

1. Construcción

2. Ensayo piloto

3. Distribución 
Los autores McMillan \& Schumacher (2007) ofrecen una visión más detallada de los pasos del proceso de realización del cuestionario:

Tabla 64: Secuencia de pasos en una investigación mediante cuestionario

\section{DEFINIR LA FINALIDAD Y LOS OBJETIVOS \\ Definir los objetivos del cuestionario y como serán utilizados los resultados \\ 2. SELECCIONAR LOS RECURSOS Y LA POBLACIÓN \\ Delimitar la población del estudio en función de los objetivos \\ 3. ELEGIR Y DESARROLLAR TÉCNICAS PARA LA RECOGIDA DE DATOS}

Elegir las técnicas estandarizadas para la recogida de datos

\section{INSTRUCCIONES}

Especificar las instrucciones de la realización para evitar la ambigüedad

5. MUESTREO

Seleccionar a los participantes que asegura la representación de la población

6. CARTA DE DIFUSIÓN

Informar al entrevistado sobre la investigación a partir de una carta (si es posible, cartas personalizadas)

7. ENSAYO Y APLICACIÓN

Mejorar la claridad y el formato. Conocer el tiempo de realización y observar un patrón de probables respuestas

\section{SEGUIMIENTO}

Realizar un seguimiento normalmente aumenta un 10-20\% las respuestas

\section{NO CONTESTADAS}

La baja participación puede alterar los resultados (sobre todo si no se consigue un mínimo del $70 \%$ de respuesta)

Fuente: Elaboración propia a partir de McMillan \& Schumacher (2007)

Las fases anteriores han sido consideradas durante el diseño, validación y aplicación de nuestro instrumento cuyo proceso analizaremos más adelante.

\subsection{Elaboración y validación del cuestionario}

El cuestionario está concebido para conocer el tipo de dirección escolar, las percepciones y las satisfacciones/insatisfacciones de los directores de la zona con su cargo.

El proceso de elaboración del cuestionario ha sido un proceso largo y complejo. No está basado en ningún otro cuestionario. El cuestionario ha sido elaborado a partir de la 
revisión bibliográfica para recabar información exhaustiva sobre el tema de estudio a la vez que abarcable para su análisis así como para obtener el acuerdo de la Administración Educativa.

Se ha realizado un análisis de las fuentes bibliográficas más relevantes a nivel nacional e internacional sobre la dirección escolar y el liderazgo. Para el análisis bibliográfico se han revisado las siguientes fuentes de información:

Tabla 65: Análisis bibliográfico

\begin{tabular}{|c|l|}
\hline $\begin{array}{c}\text { Literatura } \\
\text { científica en bases } \\
\text { de datos }\end{array}$ & ERIC, ISI Web of Knowledge, Redalyc, Scopus \\
\hline $\begin{array}{c}\text { Libros y capítulos } \\
\text { de libros }\end{array}$ & $\begin{array}{l}\text { Autores más relevantes de la comunidad científica nacional e } \\
\text { internacional }\end{array}$ \\
\hline $\begin{array}{c}\text { Revistas científicas } \\
\text { Devistas científicas (prioritariamente revistas clasificadas en el } \\
\text { Ranking JCR) } \\
\text { oficiales }\end{array}$ & $\begin{array}{l}\text { Legislación española } \\
\text { Legislación y decretos catalanes } \\
\text { Documentación del Departamento de Educación de la Generalitat de } \\
\text { Catalunya }\end{array}$ \\
\hline
\end{tabular}

Fuente: Elaboración propia

Para realizar la búsqueda se han utilizado las siguientes palabras claves de base:

Tabla 66: Resumen de las palabras claves para la revisión documental

\begin{tabular}{|l|l|}
\hline BLOQUES: & \multicolumn{1}{|c|}{ Palabras claves } \\
\hline Datos del Centro & $\begin{array}{l}\text { \#TipologíaCentro; \#TamañoCentro; \#EtapasEducativas; } \\
\text { \#EquipoDirectivo; \#PromociónCentro }\end{array}$ \\
\hline Datos del Director & \#PerfilProfesional; \#AñosExperiencia \\
\hline Acceso al Cargo & \#AccesoCargo; \#MotivacionesDeAcceso; \#HorasDocencia \\
\hline Formación Específica & \#Formación; \#Competencias; \#Profesionalización \\
\hline Ejercicio del Cargo & $\begin{array}{l}\text { \#Componentes; \#Valores; \#SituaciónDelCentro } \\
\text { \#AccionesDirectivas; \#Ética }\end{array}$ \\
\hline Modelo de Dirección & $\begin{array}{l}\text { \#FuncionesNormativa; \#DificultadFunciones; } \\
\text { \#ActuacionesDirectivas; \#CompromisoComunidad; } \\
\text { \#RelaciónComunidad; \#AccionesParaFomentarCompromiso }\end{array}$ \\
\hline Satisfacción & \#SatisfacciónCargo; \#InsatisfacciónCargo; \#CambioSatisfacciones \\
\hline Resultados & $\begin{array}{l}\text { \#FactoresPositivo; \#RendimientoEscolar; \#ÉxitoEscolar } \\
\text { \#DecretosDirección }\end{array}$ \\
\hline Reflexiones & \multicolumn{2}{|l}{ \#- \#NecesidadesNOFormativas; } \\
\hline
\end{tabular}

Fuente: Elaboración propia 
Respecto a la estructura del cuestionario, se dividió en nueve bloques temáticos debido a la amplitud de preguntas (34 preguntas). A continuación explicamos, brevemente, cada bloque del cuestionario junto sus indicadores:

Tabla 67: Resumen del contenido y estructura del cuestionario

\begin{tabular}{|c|c|}
\hline \multirow[t]{2}{*}{$\begin{array}{l}\text { Datos del } \\
\text { centro }\end{array}$} & $\begin{array}{l}\text { Recoge información sobre la tipología del centro, las etapas educativas, el } \\
\text { número de profesorado y alumnado, los cargos que componen el equipo } \\
\text { directivo y los resultados globales del curso anterior. }\end{array}$ \\
\hline & $\begin{array}{l}\text { Indicadores: } \\
\begin{aligned} \text { - } & \text { Tipología de centros de la zona } \\
\text { - } & \text { Características de los centros educativos } \\
\text { - } & \text { Organización de los equipos directivos }\end{aligned}\end{array}$ \\
\hline \multirow[t]{2}{*}{$\begin{array}{l}\text { Datos del } \\
\text { director }\end{array}$} & $\begin{array}{l}\text { Hace referencia a las características personales y profesionales de los directores: } \\
\text { edad, género, experiencia directiva, experiencia en otros cargos directivos y } \\
\text { experiencia docente. }\end{array}$ \\
\hline & $\begin{array}{l}\text { Indicadores: } \\
\begin{array}{l}\text { - } \\
\text { - }\end{array} \text { Exfil de los directores escolares } \\
\text { Expencia profesional de los directores }\end{array}$ \\
\hline \multirow[t]{2}{*}{$\begin{array}{l}\text { Acceso al } \\
\text { cargo }\end{array}$} & $\begin{array}{l}\text { Hace referencia al acceso al cargo directivo, las motivaciones iniciales para } \\
\text { acceder al cargo y al número de horas de docencia directa que realizan }\end{array}$ \\
\hline & $\begin{array}{l}\text { Indicadores: } \\
\begin{aligned} \text { - } & \text { Diferentes procesos de acceso al cargo directivo } \\
\text { - } & \text { Principales motivos de acceso al cargo } \\
\text { - } & \text { Número de horas de docencia directa de los directores }\end{aligned}\end{array}$ \\
\hline \multirow[t]{2}{*}{$\begin{array}{l}\text { Formación } \\
\text { función } \\
\text { directiva }\end{array}$} & $\begin{array}{l}\text { Se basa en la formación específica recibida antes de acceder al cargo y durante } \\
\text { su ejercicio. También recoge la valoración de la formación recibida y de sus } \\
\text { capacidades directivas. }\end{array}$ \\
\hline & $\begin{array}{l}\text { Indicadores: } \\
\begin{array}{ll}\text { - } & \text { Tipo de formación recibida por los directores } \\
\text { - } & \text { Valoración de los directores sobre la formación directiva } \\
\text { - } & \text { Necesidades, formativas y no formativas de los directores }\end{array}\end{array}$ \\
\hline \multirow[t]{2}{*}{$\begin{array}{l}\text { Ejercicio } \\
\text { del cargo }\end{array}$} & $\begin{array}{l}\text { Se basa en los componentes y valores considerados importantes para el } \\
\text { desarrollo del cargo directivo. En la reflexión sobre la situación actual - } \\
\text { importancia que le conceden a diferentes aspectos del centro y con qué } \\
\text { frecuencia realizan diferentes acciones directivas. }\end{array}$ \\
\hline & $\begin{array}{l}\text { Indicadores: } \\
\begin{aligned} \text { - } & \text { Valores del cargo y personales más relevantes del cargo } \\
\text { - } & \text { Competencias más relevantes para el desempeño del cargo } \\
\text { - } & \text { Tareas y funciones más desarrolladas por los directores } \\
\text { - } & \text { Características de liderazgo en los modelos de dirección a partir de las } \\
& \text { actuaciones desarrolladas por los directores }\end{aligned}\end{array}$ \\
\hline
\end{tabular}




\begin{tabular}{|c|c|}
\hline \multirow[t]{2}{*}{$\begin{array}{l}\text { Modelo de } \\
\text { dirección }\end{array}$} & $\begin{array}{l}\text { Hace referencia a qué funciones realizan más los directores y el grado de } \\
\text { dificultad de cada función; a la frecuencia con la que realizan las diferentes } \\
\text { actuaciones; la percepción del grado de compromiso de la comunidad educativa } \\
\text { y las acciones que potenciaría o desarrolla para conseguirlo. }\end{array}$ \\
\hline & 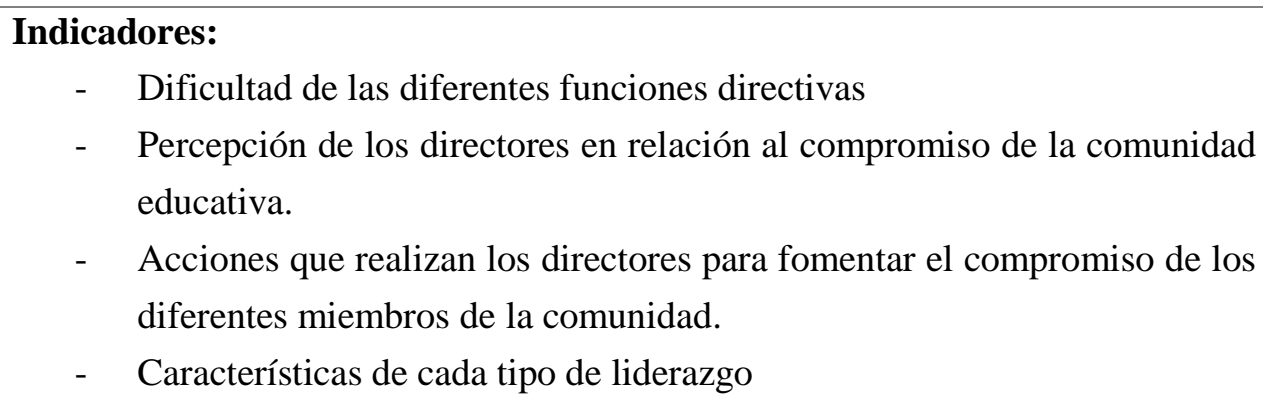 \\
\hline \multirow[t]{2}{*}{ Satisfacción } & $\begin{array}{l}\text { Recoge información sobre la satisfacción de diferentes aspectos; los aspectos } \\
\text { más satisfactorios y más insatisfactorios del cargo; y si las motivaciones iniciales } \\
\text { de acceso al cargo han cambiado. }\end{array}$ \\
\hline & $\begin{array}{l}\text { Indicadores: } \\
\text { - } \quad \text { Funciones y actuaciones producen más satisfacción o insatisfacción a los } \\
\text { directores. } \\
\text { - } \quad \text { Aspectos influyen en el cambio de satisfacciones }\end{array}$ \\
\hline \multirow[t]{2}{*}{ Resultados } & $\begin{array}{l}\text { Se basa en conocer qué aspectos se asocian con una influencia más positiva en el } \\
\text { éxito escolar del centro. }\end{array}$ \\
\hline & $\begin{array}{l}\text { Indicadores: } \\
\text { - } \quad \text { Aspectos consideran los directores que influyen en los resultados } \\
\text { académicos }\end{array}$ \\
\hline \multirow[t]{2}{*}{$\begin{array}{c}\text { Para } \\
\text { finalizar... }\end{array}$} & $\begin{array}{l}\text { Recoge información sobre las necesidades formativas y no formativas; la opinión } \\
\text { de los diferentes decretos vigentes de dirección; y una reflexión final sobre qué } \\
\text { modelo de dirección consideran que ejercen. }\end{array}$ \\
\hline & $\begin{array}{l}\text { Indicadores: } \\
\begin{aligned} \text { - } & \text { Diferentes decretos directivos y normativa educativa vigente } \\
\text { - } & \text { Necesidades formativas y no formativas de los directores } \\
\text { - } & \text { Modelo directivo se sienten más identificados los directores }\end{aligned}\end{array}$ \\
\hline
\end{tabular}

Fuente: Elaboración propia

El cuestionario está compuesto por diferentes tipos de preguntas: preguntas cerradas de selección múltiple, cerradas de selección de respuesta única, preguntas de escala (tipo Likert con escala del 1 al 5) y también de preguntas abiertas para conocer las opiniones o percepciones más introspectivas y vivenciales de los encuestados.

Según Ballester, Nadal \& Amer (2014), las preguntas abiertas permiten descubrir nuevas respuestas y opiniones que no se habían previsto, además de evitar que las respuestas estén sesgadas por los investigadores, ya que el entrevistado tiene mayor 
libertad en sus respuestas. Es necesario añadir preguntas abiertas en razón de la información buscada (Bécue, Lebart \& Rajadell, 1992)

La decisión de combinar diferentes tipos de preguntas se debe a que los cuestionarios con preguntas totalmente cerradas eliminan, en cierta medida, la implicación personal del encuestado y reduce el nivel de reflexión en la respuesta. Aunque en las preguntas abiertas se realice un tratamiento estadístico, a partir de un proceso de categorización, aportan una visión más personal del encuestado. En la siguiente tabla se muestra el número y el tipo de preguntas utilizadas:

Tabla 68: Tipos de preguntas y objetivos del cuestionario

\begin{tabular}{|c|c|c|}
\hline $\begin{array}{c}\text { BLOQUES } \\
\text { TEMÀTICOS }\end{array}$ & $\begin{array}{c}\text { PREGUNTAS } \\
\text { CUESTIONARIO }\end{array}$ & TIPOS DE PREGUNTA \\
\hline $\begin{array}{l}\text { 1. DATOS DEL } \\
\text { CENTRO }\end{array}$ & $\begin{array}{l}1.1 ; 1.2 ; 1.3 ; 1.4 ; \\
1.5 ; 1.6 \text { y } 1.7\end{array}$ & $\begin{array}{l}\text { - Preguntas cerradas excluyentes } \\
\text { - Preguntas cerradas NO excluyentes }\end{array}$ \\
\hline $\begin{array}{l}\text { 2. DATOS DEL } \\
\text { DIRECTOR }\end{array}$ & $2.1 ; 2.2$ y 2.3 & $\begin{array}{l}\text { - Preguntas dicotómicas } \\
\text { - Preguntas numéricas }\end{array}$ \\
\hline $\begin{array}{l}\text { 3. ACCESO AL } \\
\text { CARGO }\end{array}$ & $3.1 ; 3.2$ y 3.3 & $\begin{array}{l}\text { - Preguntas cerradas excluyentes } \\
\text { - Preguntas numéricas } \\
\text { - Preguntas cerradas ordinales } \\
\text { (excluyentes y ordenadas por intensidad) }\end{array}$ \\
\hline $\begin{array}{l}\text { 4.FORMACIÓN } \\
\text { ESPECÍFICA }\end{array}$ & $4.1 ; 4.2$ y 4.3 & $\begin{array}{l}\text {-Preguntas cerradas excluyentes } \\
\text { - Preguntas de escala }\end{array}$ \\
\hline $\begin{array}{l}\text { 5.EJERCICIO DEL } \\
\text { CARGO }\end{array}$ & $5.1 ; 5.2 ; 5.3$ у 5.4 & $\begin{array}{l}\text {-Preguntas cerradas ordinales } \\
\text { (excluyentes y ordenadas por intensidad) } \\
\text {-Preguntas abiertas } \\
\text {-Preguntas de escala }\end{array}$ \\
\hline $\begin{array}{l}\text { 6.MODELO DE } \\
\text { DIRECCIÓN }\end{array}$ & $\begin{array}{l}6.1 ; 6.2 ; 6.3 ; 6.4 \mathrm{y} \\
6.5\end{array}$ & $\begin{array}{l}\text {-Preguntas cerradas ordinales } \\
\text { (excluyentes y ordenadas por intensidad) } \\
\text { - Preguntas abiertas }\end{array}$ \\
\hline 7.SATISFACCIÓN & $7.1 ; 7.2$ y 7.3 & $\begin{array}{l}\text {-Preguntas cerradas ordinales } \\
\text { (excluyentes y ordenadas por intensidad) } \\
\text { - Preguntas abiertas }\end{array}$ \\
\hline 8. RESULTADOS & 8.1 & $\begin{array}{l}\text { - Preguntas cerradas (excluyentes, } \\
\text { ordenadas por intensidad) }\end{array}$ \\
\hline $\begin{array}{l}\text { 9. REFLEXIONES } \\
\text { FINALES }\end{array}$ & $\begin{array}{l}9.1 ; 9.2 ; 9.3 ; 9.4 \mathrm{y} \\
9.5 .\end{array}$ & $\begin{array}{l}\text { - Preguntas abiertas } \\
\text { - Preguntas cerradas excluyentes }\end{array}$ \\
\hline
\end{tabular}

Fuente: Elaboración propia 
En relación a la validación del cuestionario, el primer borrador fue revisado por las directoras de la tesis. Sus sugerencias se dirigieron tanto a aspectos de formales como de contenido.

El segundo borrador se envió para su revisión a dos profesores de otras universidades y a la dirección de los Servicios Territoriales de Educación de Tarragona.

Validador Externo 1: Catedrático de Didáctica y Organización Educativa. Especialista en dirección y gestión de centros. Autor de diferentes libros y artículos sobre dirección escolar y formación de directivos, gestión escolar, etc.

Validador Externo 2: Catedrático de Didáctica y Organización Educativa. Especialista en evaluación, innovación y formación de formadores. Autor de diferentes libros y artículos sobre procesos de investigación científica.

Validador Externo 3: Directora de los Servicios Territoriales de educación de Tarragona en el año 2014.

Incorporando las nuevas sugerencias, se elabora un tercer borrador que se utiliza como pre-test aplicado a dos directores que no formaban parte de la muestra. Sus propuestas de mejora se han basado en la comprensión de los ítems, el tiempo de realización, el funcionamiento de la plataforma online, etc.

Validador Pre-Test 1: Ex director de un centro de educación primaria durante 18 años.

Validador Pre-Test 2: Directora de un centro de educación primaria desde hace 11 años.

A partir de sus consideraciones se elabora el instrumento definitivo que se presenta en el anexo 2.

\subsection{Aplicación del cuestionario}

Como hemos dicho al inicio del trabajo, esta investigación cuenta con la aprobación y el apoyo del Departamento de Educación de Tarragona. Por ese motivo, desde la dirección del Departamento se envió un correo electrónico a los directores de la muestra informándoles y animándoles a participar en la investigación. 
Acto seguido, desde la plataforma online Lime Survey, se envió un correo electrónico a los directores con el acceso al cuestionario. La plataforma identificaba cada director con una ID y automáticamente generaba un link único de acceso.

La realización del cuestionario no ha sido anónima, ya que se basaba en unos criterios de selección de muestra concretos, pero sí que se aseguró a los directores un tratamiento de datos absolutamente confidencial y así se les hizo saber.

Se decidió realizar el cuestionario online para poder conseguir una rápida distribución a toda la muestra sin limitaciones ni desplazamientos territoriales. Otras ventajas son la facilidad en el registro de las respuestas y la generación automática de una base de datos en la plataforma, hecho que simplifica el proceso de registro y exportación de los datos, además de facilitar el control de participación de la muestra y una cumplimentación mucho más rápida (Ballester, Nadal \& Amer, 2014).

La plataforma LimeSurvey permitió personalizar completamente el diseño del cuestionario. La opción de "visualización" permitía observar el diseño final y la estructura de las preguntas que verían los directores de la muestra.

A continuación, se observa las principales características del cuestionario online:

Ilustración 6: Mensaje inicial del cuestionario online

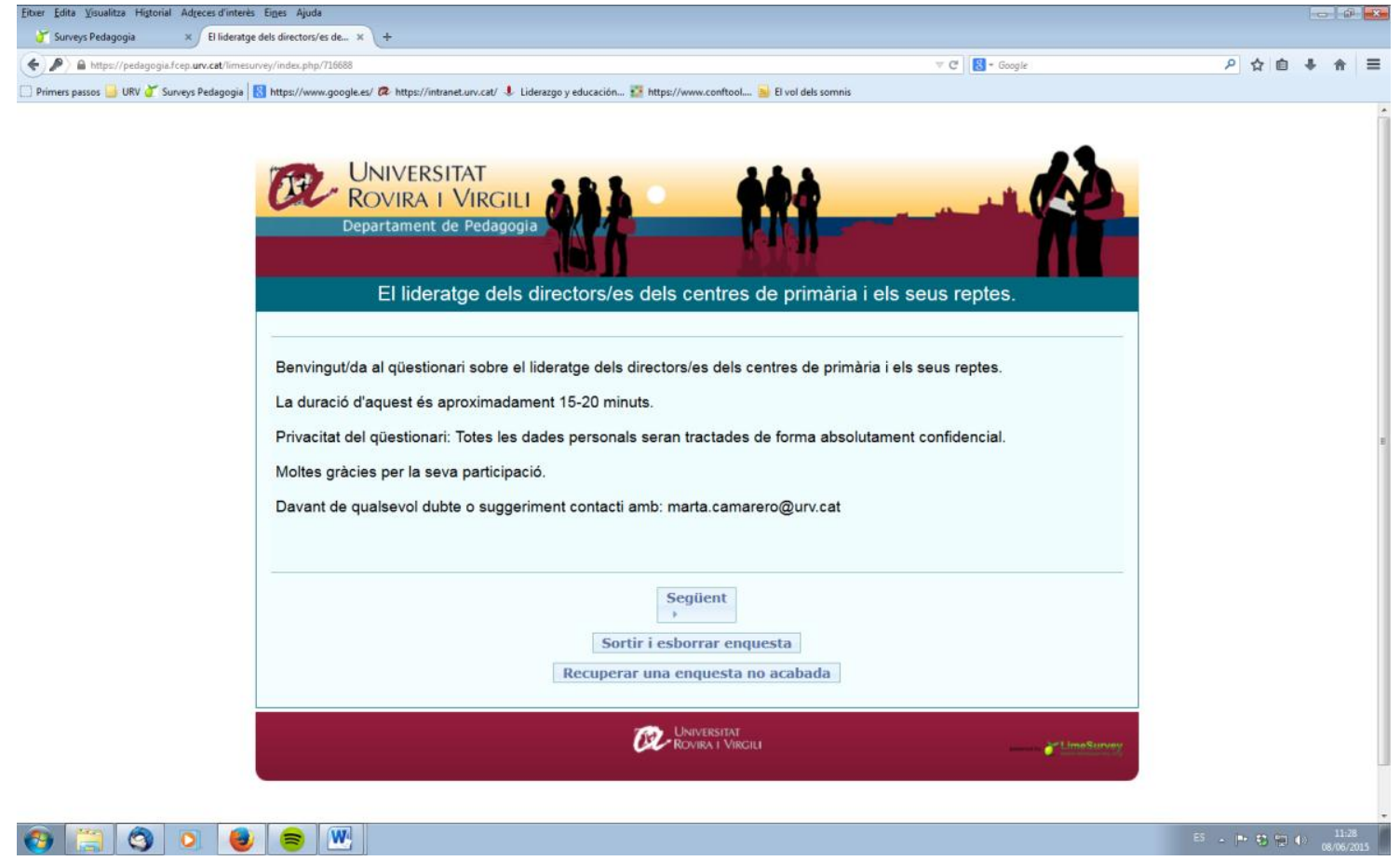

Fuente: Captura de la plataforma Lime Survey 
Al tratarse de un cuestionario extenso se activó la opción de "guardar y continuar más tarde” permitiendo así gestionar la realización del cuestionario en función del tiempo disponible.

Ilustración 7: Opción de guardar el cuestionario online

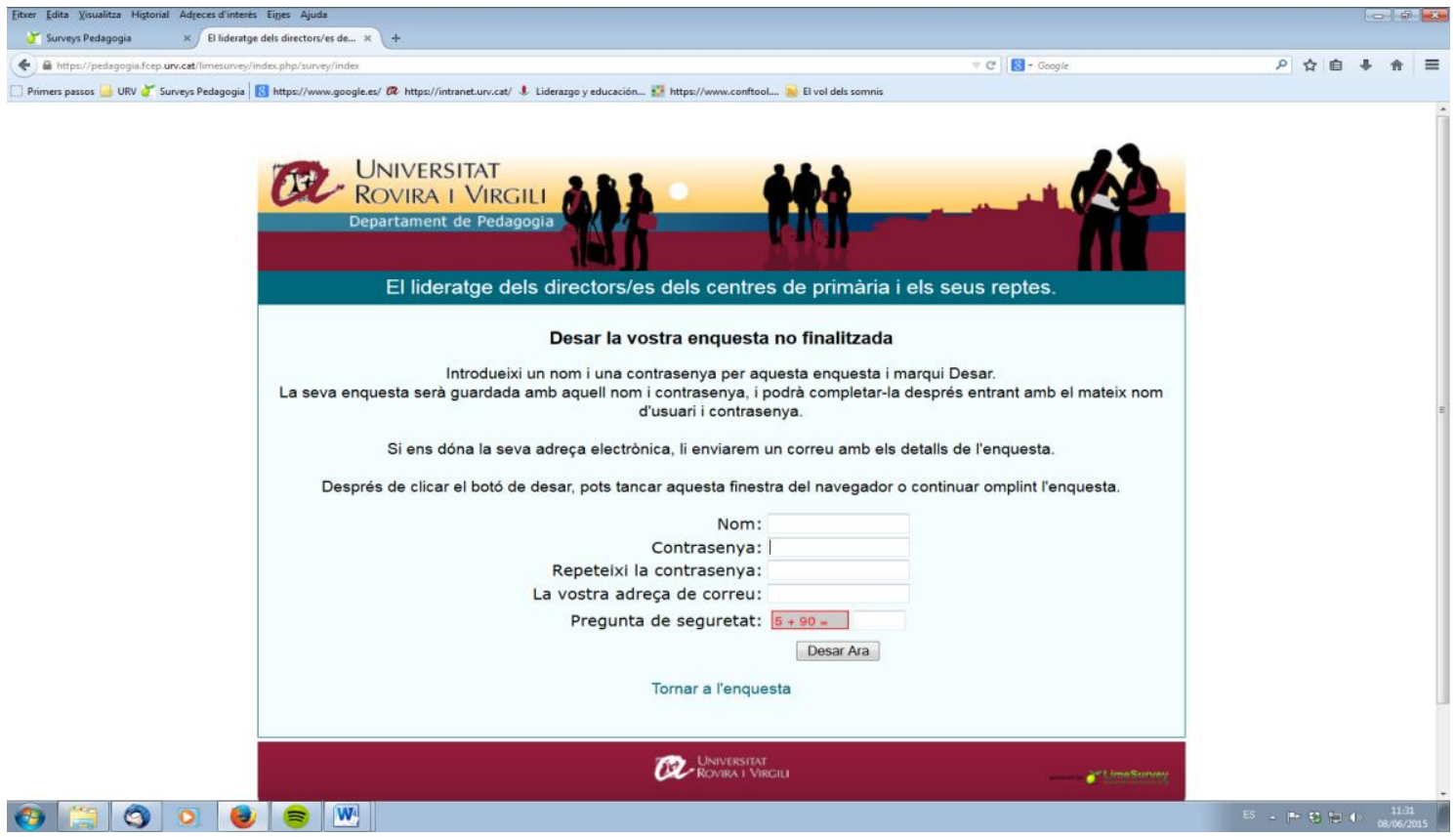

Fuente: Captura de la plataforma Lime Survey

Si algún director prefería contestar el cuestionario en papel y lápiz, la plataforma ofrecía la "versión imprimible del cuestionario". A pesar de disponer de esta opción nadie la utilizó.

Gracias al seguimiento detallado de la plataforma conocíamos los últimos accesos de los directores y podíamos ver hasta qué bloque habían contestado. De esta manera si observábamos que un director hacía días que no accedía a la plataforma le enviábamos un correo recordatorio o contactábamos telefónicamente para ofrecerle la opción de terminar la encuesta vía telefónica o en formato papel (enviándole un documento Word con los bloques que le faltaban contestar). 
Ilustración 8: Plantilla del email recordatorio de participación

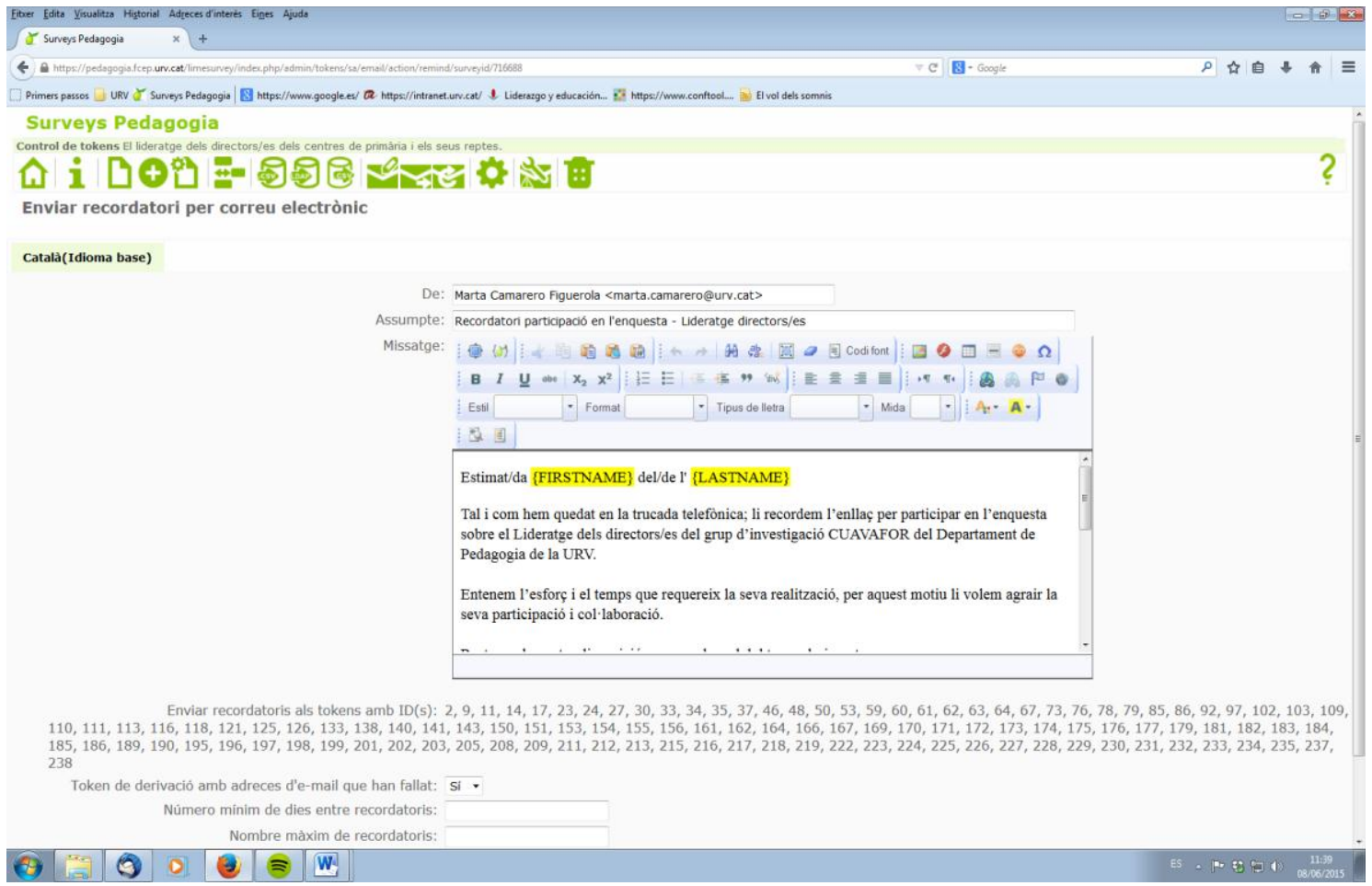

Fuente: Captura de la plataforma Lime Survey

Como se sabe, la aplicación de los cuestionarios online, en general, presentan las siguientes ventajas e inconvenientes:

Figura 13: Ventajas e inconvenientes de los cuestionarios online

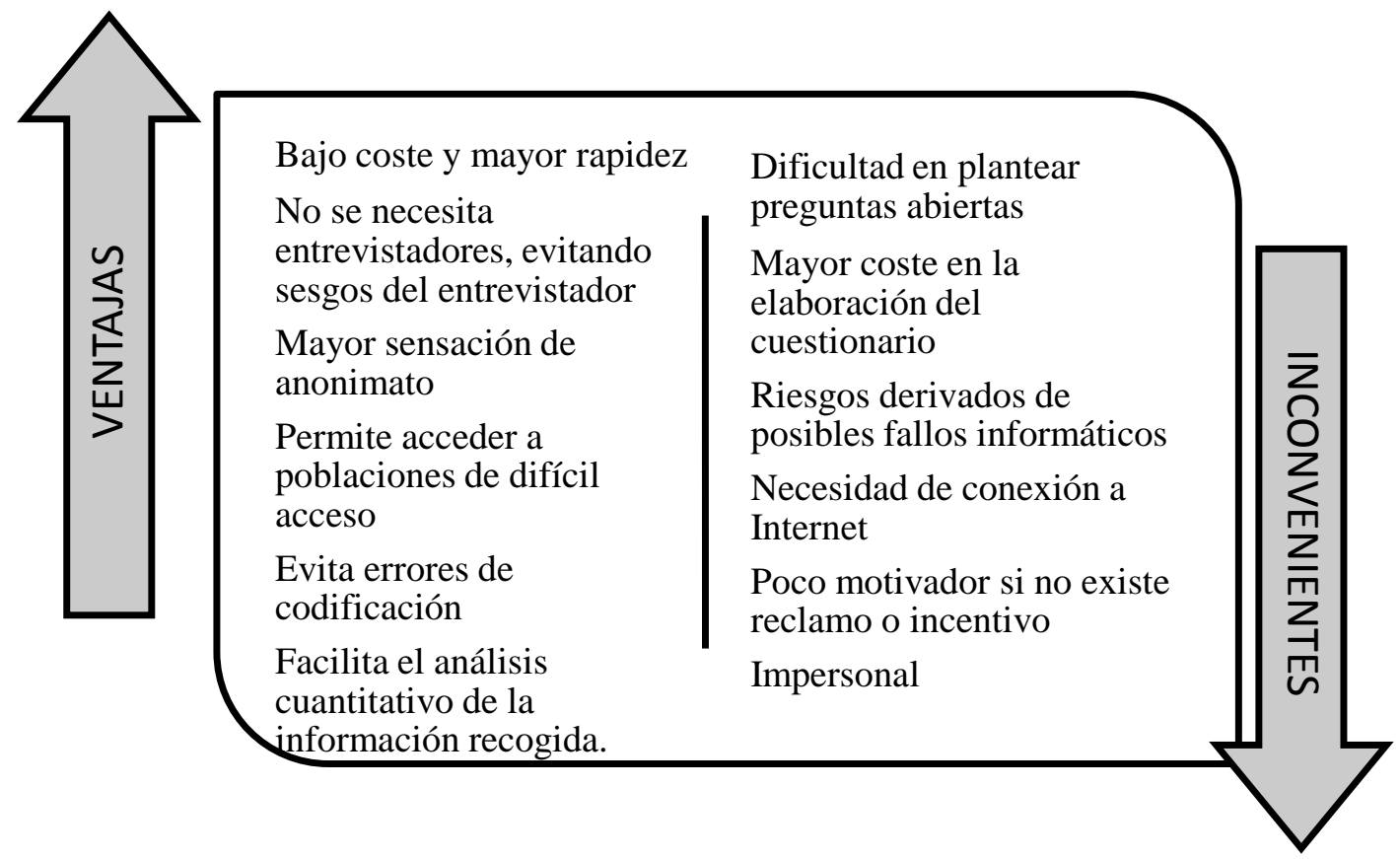

Fuente: Elaboración propia a partir de Bisquerra (2004) 
El cuestionario estuvo activo durante un mes y medio. Obtuvimos un total de 128 respuestas que representan un $\mathbf{9 2 , 0 9 \%}$ de participación.

En la siguiente tabla podemos observar el número de cuestionarios completados según la tipología del centro.

Tabla 69: Respuestas de la muestra según la tipología del centro

\begin{tabular}{|l|c|c|c|c|}
\hline $\begin{array}{c}\text { EDUCACIÓN } \\
\text { PRIMARIA }\end{array}$ & $\begin{array}{c}\text { Población total } \\
\text { (STT- TGN) }\end{array}$ & Muestra & $\begin{array}{c}\text { Cuestionarios } \\
\text { Válidos }\end{array}$ & $\begin{array}{c}\text { \% de } \\
\text { participación }\end{array}$ \\
\hline Centros públicos & 181 & 116 & 112 & $96,55 \%$ \\
\hline Centros concertados & 35 & 22 & 15 & $68,18 \%$ \\
\hline Centros privados & 1 & 1 & 1 & $100 \%$ \\
\hline TOTAL & $\mathbf{2 1 7}$ & $\mathbf{1 3 9}$ & $\mathbf{1 2 8}$ & $\mathbf{9 2 , 0 9 \%}$ \\
\hline
\end{tabular}

Fuente: Elaboración propia

\subsection{Fiabilidad del cuestionario}

Para comprobar la fiabilidad del cuestionario y la consistencia interna se ha realizado la prueba de Alfa de Cronbach. Se trata de un método de consistencia interna que permite estimar la fiabilidad de un instrumento a través de un conjunto de ítems (con escala tipo Likert) que miden una misma dimensión teórica y que están altamente correlacionados (Frías Navarro, 2014)

Cuanto más se acerque el resultado de la prueba a 1, mayor es la fiabilidad de los ítems analizados. George \& Mallerty (2003: 231) establecen los siguientes criterios generales para clasificar los coeficientes de la prueba de Alfa de Cronbach.

Tabla 70: Clasificación de coeficientes de alfa de Cronbach

\begin{tabular}{|l|}
\hline Coeficiente alfa $>0,9$ es excelente \\
\hline Coeficiente alfa $>0,8$ es bueno \\
\hline Coeficiente alfa $>0,7$ es aceptable \\
\hline Coeficiente alfa $>0,6$ es cuestionable \\
\hline Coeficiente alfa $>0,5$ es pobre \\
\hline Coeficiente alfa $<0,5$ es inaceptable \\
\hline
\end{tabular}

Fuente: Elaboración propia a partir de George y Mallery (2003)

Observamos que estadísticamente un buen resultado sería a partir del $\mathbf{0 , 8}$. 
Seleccionamos las preguntas realizadas con escala de Likert de nuestro cuestionario y le aplicamos la prueba. Realizamos las diferentes pruebas y comprobamos que, de manera general, la fiabilidad de nuestros ítems es buena (superior a 0,8). En algunas preguntas la fiabilidad es excelente $(0,9)$ o aceptable $(0,7)$ pero en otras preguntas, con ítems generales y no tan concretos, el coeficiente es cuestionable $(0,6)$ o pobre $(0,5)$. En ningún caso hay ningún coeficiente inaceptable $(<0,5)$

Tabla 71: Análisis de fiabilidad (prueba Alfa de Cronbach)

\section{Pregunta cuestionario}

Coeficiente obtenido

Pregunta 3.3: Razones para acceder al cargo de dirección 0,665

Pregunta 4.3: Autovaloración de sus capacidades 0.925

Pregunta 5.3a: Situación actual del ejercicio de dirección en el centro 0,821

Pregunta 5.3b: Importancia que le concedes a la dirección en el centro 0,857

Pregunta 5.4: Frecuencia de la realización de actuaciones (generales) 0,575

Pregunta 6.1a: Realización de las funciones directivas 0,771

Pregunta 6.1b: Dificultad en la realización de las funciones directivas 0,938

Pregunta 6.2: Frecuencia de realización de las actuaciones directivas (normativa) 0,720

Pregunta 6.3: Percepción del grado de compromiso Pregunta 7.1: Satisfacción del cargo directivo
0,848

0,852

Fuente: Elaboración propia

\subsection{Tratamiento y codificación de los datos}

El programa elegido para el tratamiento y análisis de datos ha sido el SPSS, para Windows versión 22, que es uno de los paquetes estadísticos más utilizados en las investigaciones educativas.

La descripción de los datos del cuestionario se ha llevado a cabo por bloques temáticos, presentando en un primer lugar la caracterización de la muestra de directores (variable director) y la tipología de centros (variable centro), seguido del análisis descriptivo por bloques. En los bloques temáticos, se llevó a cabo la descripción de los datos cruzada con las variables (variable director y variable centro) con la finalidad de obtener un análisis descriptivo más detallado y significativo. 
Para este primer análisis se utilizó la estadística descriptiva bivariada a partir de correlaciones (en los datos cuantitativos) y las tablas de contingencia (en los datos cualitativos). Se aplicó la prueba Chi Cuadrado de Pearson para conocer si entre las variables implicadas existe una relación significativa (estadísticamente significativa a un nivel de 0,05 de significación).

En el segundo análisis, independientemente del bloque del cuestionario, se cruzan diferentes variables para observar las correlaciones entre las distintas preguntas y bloques del cuestionario. Se emplea el estadístico de Spearman para las tablas de contingencia y el análisis ANOVA y las pruebas de Chi Cuadrado en las variables ordinales. Nos centramos exclusivamente en correlaciones entre 0,4 a 0,7 (correlación moderada) y entre 0,7 a 1 (correlación alta) con un nivel de significancia $(0,01)$.

Utilizando los procedimientos explicados anteriormente se obtiene la lectura directa y cruzada de los datos del cuestionario para responder a los objetivos de nuestra investigación. En ambos análisis se resaltan las diferencias estadísticamente significativas de los resultados.

El proceso de la codificación se generó en un primer momento automáticamente a partir del programa estadístico SPSS. En la matriz de datos figuran todos los sujetos que han formado parte de la investigación (primera columna de la tabla). Las siguientes columnas corresponden cada una de ellas a una variable del cuestionario. Para identificar las variables de manera rápida y sencilla se etiquetó cada variable con una abreviatura.

A la hora de codificar las variables se atendió a la siguiente tipología (Bisquerra, 2004; García-Llamas, González-Galán \& Ballesteros, 2001; Latorre, del Rincón \& Arnal, 2003; McMillan \& Schumacher, 2007)

- Variables nominales: los valores hacen referencia a características que no se pueden cuantificar. Pueden ser dicotómicas (dos categorías) o politómicas (más de dos categorías). La escala de medida es la nominal.

- Variables ordinales: los valores establecen un orden sin que exista una distancia exacta entre ellos. Permiten clasificar a los encuestados según el orden que ocupan. La escala de medida es la ordinal. 
- Variables de intervalo: los valores hacen referencia a intervalos que van de un valor mínimo a un valor máximo. Como las anteriores también establecen orden pero se conoce la distancia exacta entre un intervalo y otro. La escala de medida es la escala.

Para la codificación de las variables nominales y ordinales, se asignó a cada variable de las categorías un valor (numérico).

En cambio, en las preguntas abiertas, previamente se analizó el contenido de cada una de las respuestas obtenidas, agrupando las respuestas en categorías temáticas que dieron lugar a una serie de variables que permitieron la codificación de las respuestas.

Con la codificación se pudieron tratar estas preguntas abiertas como una variable nominal politómica. 
DIRECCIÓN ESCOLAR Y LIDERAZGO

\section{PRIMARIA DE TARRAGONA}

ANÁLISIS DEL DESEMPEÑO DE LA FIGURA DIRECTIVA EN CENTROS DE EDUCACIÓN Marta Camarero Figuerola 


\section{CAPÍTULO V: ANÁLISIS RESULTADOS}

n el siguiente capítulo se presenta el análisis de los datos derivados del
cuestionario online realizado en el marco de nuestra investigación y
respondido por los directores de centros de primaria de la zona. Se presenta la caracterización de la muestra participantes en función de la variable de centro y de la variable de director.

Se obtienen los resultados a partir de dos análisis de datos. El primer análisis se realiza una lectura descriptiva de cada bloque del cuestionario y en el segundo se realiza un análisis de las variables cruzadas entre los diferentes bloques. En ambos análisis se inciden en las diferencias estadísticamente significativas. 
Antes de empezar con el tratamiento de los datos, se realiza la comprobación de los cuestionarios, en adelante denominada corrección del cuestionario. La corrección se basa en identificar y eliminar los errores cometidos por los participantes sobre todo de formato en las respuestas. A continuación de la corrección se realiza una codificación de las encuestas, asignando un número de código a cada respuesta (Cohen \& Manion, 2002).

La estructura de este capítulo tiene dos partes. En el primer análisis, se realiza una lectura descriptiva de los datos obtenidos en cada bloque del cuestionario y se resaltan las diferencias estadísticamente significativas halladas en cada pregunta a partir del análisis ANOVA de un factor y la prueba de Chi Cuadrado, de la variable centro (titularidad del centro, tipología de escuela, número de alumnos y docentes, centros de máxima complejidad y miembros del equipo directivo) y la variable perfil (género, edad, horas de docencia directa, experiencia directiva, experiencia en otro cargo del equipo directivo, experiencia como coordinador y autopercepción del modelo de dirección).En el caso del análisis de las preguntas abiertas, categorizamos las respuestas y referenciamos algunas citas textuales de los directores. Las citas se muestran de manera anónima y utilizando una identificación (ID) más el número del caso indicado en el aplicativo informático. En el comentario de las preguntas abiertas, se sintetizan y se explican las diferentes opiniones, ilustrándose con las citas textuales "más contundentes".

En un segundo análisis se "cruzan" diferentes preguntas, independientemente del bloque del cuestionario al que correspondan. Con este análisis se observan las correlaciones entre las distintas preguntas del cuestionario y se destacan los datos estadísticamente significativos a partir de aplicar Spearman, ANOVA y Chi Cuadrado.

\subsection{Caracterización de la muestra}

En este apartado presentamos los datos de caracterización de la muestra participante en la investigación (amplían la información que ya mencionábamos en el capítulo anterior sobre el tamaño y la composición de la muestra participante). El conjunto de estos ítems conforman la variable centro y la variable director que servirán de variables principales para el primer análisis. 


\subsubsection{Variable centro}

El primer bloque del cuestionario se compone de una serie de preguntas orientadas a describir los diferentes centros educativos participantes en el estudio.

\section{- Titularidad del centro}

La muestra abarca centros de primaria públicos, concertados y privados. Los directores de centros públicos se clasifican en: directores de escuelas urbanas, directores de escuela rural y directores de zonas rurales. Los directores de centros concertados se analizan de manera conjunta con el único director de centro privado de la zona, lo que garantiza, además, el anonimato de este director en el análisis de las preguntas.

En la siguiente figura observamos el número de directores de cada tipo y el porcentaje que representan del total de directores participantes.

Figura 14: Clasificación de los centros educativos participantes en relación a la titularidad

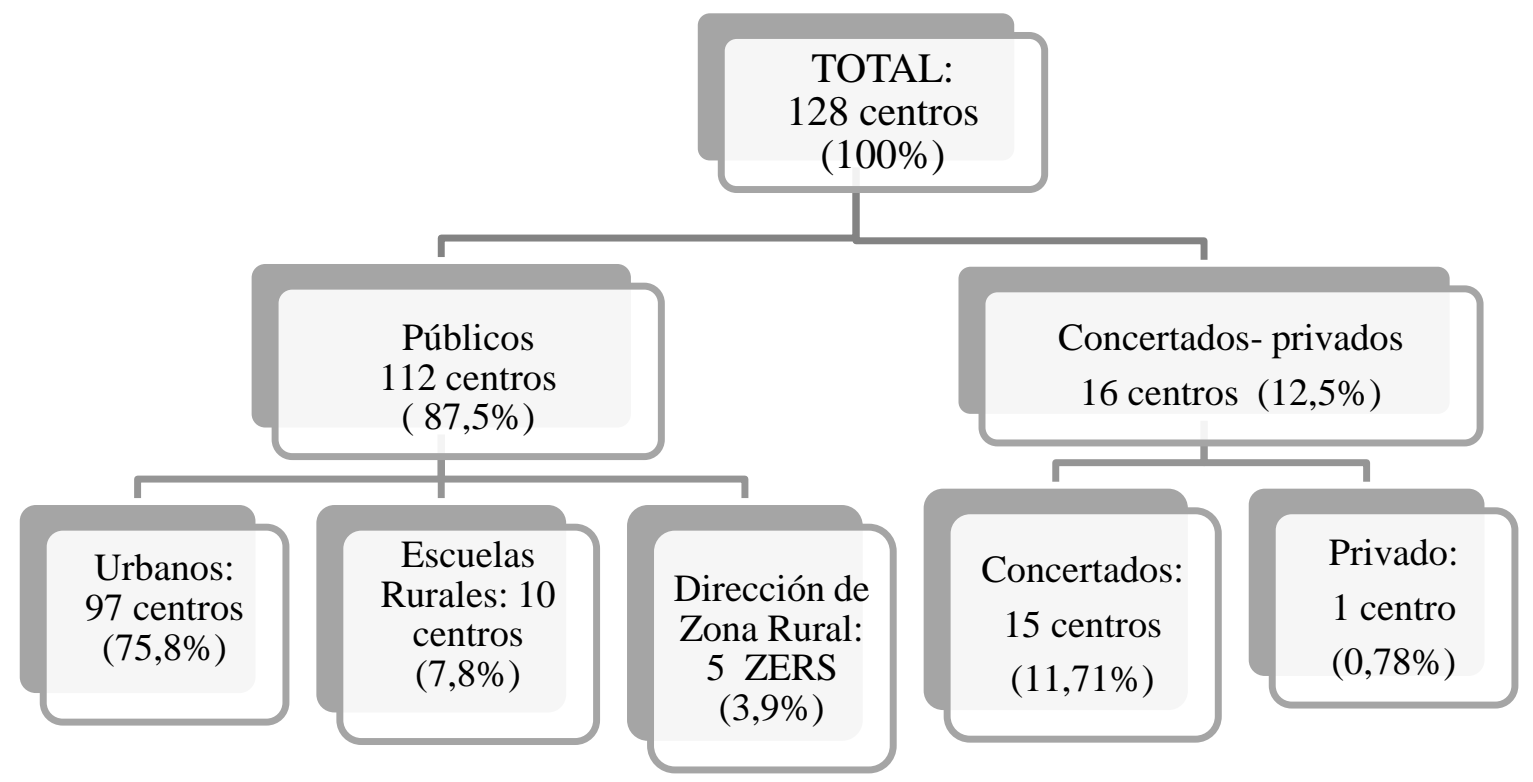

- Etapas educativas del centro

Todos los centros analizados cuentan con las etapas de educación infantil y de educación primaria. En cambio, sólo un $11,7 \%$ de la muestra (15 centros), cuentan también con la etapa de educación secundaria, de los cuales sólo uno es de carácter público. 
- Número total de alumnos en el centro

De los centros educativos participantes, hay un centro con 11 alumnos (valor mínimo) en contraposición a un centro con 1.400 alumnos (valor máximo). La media aritmética es de 347,71 alumnos (desviación típica de 254,29), dato que su gran dispersión solo nos indica la gran variedad de centros existentes, por lo que los agrupamos en bloques.

En el siguiente gráfico observamos los porcentajes de cada agrupación. Las agrupaciones se establecen a partir del criterio de: centro grande (un mínimo de 451 alumnos), centro mediano (entre 276 a 450 alumnos), centro pequeño (entre 101 a 275 alumnos) y centro de zona rural (máximo de 100).

Gráfico 3: Centros participantes en relación al número de alumnos

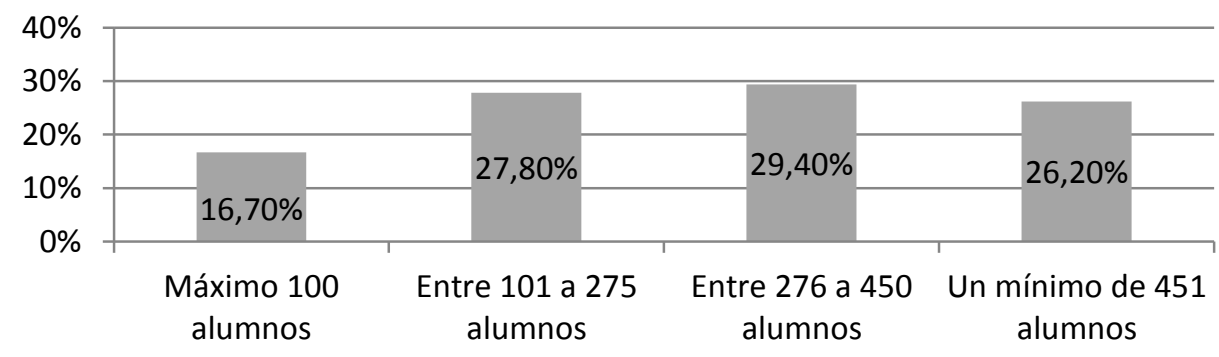

- Número total de docentes en el centro

En cuanto al número de docentes, hay un centro con un único profesor (valor mínimo) y un centro con 102 profesores (valor máximo). La media en los centros de la muestra es de 25,79 docentes (desviación típica de 17,02).

Las agrupaciones tienen similitud con la escala de la anterior pregunta: centro grande (más de 30 docentes), centro mediano (entre 20 y 29 docentes), centro pequeño (entre 10 y 19 docentes) y centro de zona rural (9 docentes o menos).

Gráfico 4: Centros participantes en relación al número de docentes en plantilla

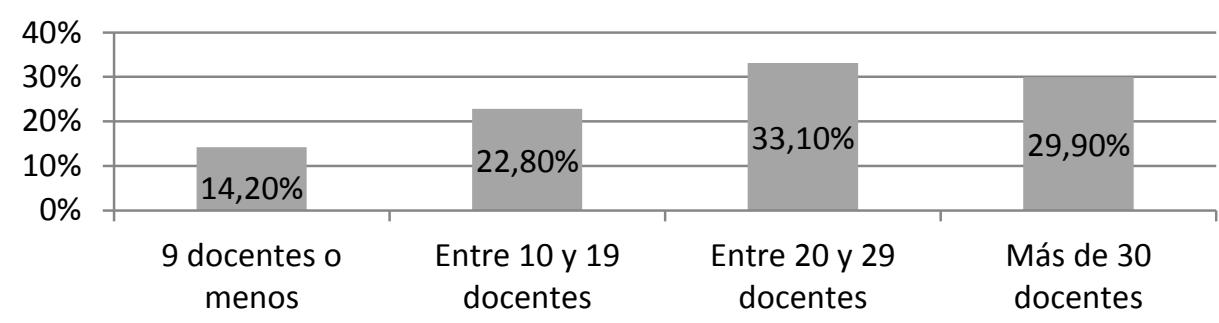


- Necesidades Educativas Especiales del alumnado

La pregunta inicial sobre el porcentaje de alumnado de los centros que tienen necesidades educativas especiales (con dictamen), recién llegados, situaciones socioeconómicas desfavorecidas o dificultades de aprendizaje, ha sido eliminada del análisis debido a que no era confiable (puntuaciones entre $0 \%$ y más de 100\%). Esto puede ser debido, por ejemplo, a posibles errores de interpretación de la pregunta como indicar el valor absoluto y no el porcentaje.

Al no disponer de esa información optamos por centrarnos en los datos que aparecen en la Resolución ENS/906/2014 (Generalitat de Catalunya, 2014b) que basándose en indicadores como el: bajo nivel de instrucción de los padres, la baja cualificación profesional de los padres, padres en el paro, porcentaje de alumnos con necesidades específicas diagnosticadas y porcentaje de alumnado inmigrante, dictamina qué centros son reconocidos como "Centros de Atención Educativa Preferente" (CAEP).

A los centros con esta consideración, la Administración educativa ofrece unos recursos específicos para poder llevar a cabo propuestas educativas que mejoren su situación. Estos centros normalmente se encuentran en el extrarradio de las áreas urbanas o en entornos sociales y económicos desfavorecidos.

A partir de la Resolución ENS/906/2014, del curso 2013/2014., creamos en el SPSS una nueva variable dicotómica (sí/no) llamada "Centros de máxima complejidad”.

Del total de la muestra, (19 centros, aproximadamente un 15\%) son reconocidos por la Generalitat como centros de alta complejidad. Observamos que todos ellos son de titularidad pública y están situados en zonas periféricas de las ciudades.

\section{- Componentes del equipo directivo}

En la pregunta sobre qué cargos forman el equipo directivo, los directores podían seleccionar entre los diferentes opciones: director, jefe de estudios y secretario. En el caso que fuera necesario podían marcar la opción "otros" y especificar el nombre del cargo. 
Aproximadamente un $70 \%$ de los directores seleccionan la estructura de: director + jefe de estudios + secretario. Es la estructura más común del equipo directivo, aunque en la siguiente tabla podemos observar otras combinaciones de equipos directivos. Por ejemplo, hay equipos formados exclusivamente por una persona (director) o dos personas (director-secretario, director-jefe de estudios o director-otros).

Estas estructuras directivas corresponden a centros pequeños o escuelas rurales. Los equipos directivos más numerosos (4 miembros) corresponden a centros concertadosprivados.

Tabla 72: Miembros del equipo directivo

\begin{tabular}{|l|c|c|}
\hline \multicolumn{1}{|c|}{ Componentes del equipo directivo } & Frecuencia & Porcentaje \\
\hline Director & 11 & $8,6 \%$ \\
\hline Director y otros & 2 & $1,6 \%$ \\
\hline Director y secretario & 9 & $7 \%$ \\
\hline Director, secretario y otros & 1 & $0,8 \%$ \\
\hline Director y jefe de estudios & 3 & $2,3 \%$ \\
\hline Director, jefe de estudios y otros & 7 & $5,5 \%$ \\
\hline Director, jefe de estudios y secretario & 90 & $70,3 \%$ \\
\hline Director, jefe de estudios, secretario y otros & 5 & $3,9 \%$ \\
\hline TOTAL & $\mathbf{1 2 8}$ & $\mathbf{1 0 0 \%}$ \\
\hline
\end{tabular}

La opción "otros" es marcada por 15 centros, de los cuales 12 son centros concertadosprivados. En la tabla siguiente especificamos la opción de "otros" cargos directivos:

Tabla 73: Especificación de los "otros cargos" del equipo directivo

\begin{tabular}{|c|l|}
\hline Frecuencia & \multicolumn{1}{|c|}{ Otros componentes del equipo directivo } \\
\hline 3 & Subdirector \\
\hline 2 & Coordinadores de ciclo \\
\hline 1 & Coordinadora pedagógica + Jefa estudios adjunta \\
\hline 1 & Titular + Jefe de administración \\
\hline 1 & Coordinador de calidad \\
\hline 1 & Jefe de estudios de primaria \\
\hline 1 & Titular + coordinador pedagógico + coordinador pastoral \\
\hline 1 & Titular + Subdirectora \\
\hline 1 & Titular + coordinador de calidad + coordinador pastoral \\
\hline
\end{tabular}


Podemos observar que la composición de los equipos directivos va desde 1 miembro (escuela rural) hasta un máximo de 6 miembros (escuelas concertadas).

A partir de ahora, se entiende como "equipo directivo pequeño" los formados por un máximo de 2 miembros y "equipo directivo grande” los formados por un mínimo de 3 miembros.

\section{- Resultados académicos del curso 2012/2013}

Esta última pregunta hace referencia a los resultados globales de educación primaria de los centros respecto el curso anterior (2012-2013) por ciclos (inicial, medio y superior), diferenciando el porcentaje de alumnos que "promociona y supera adecuadamente", "no promociona" o "promociona aunque no supera adecuadamente".

Decidimos centrarnos en el apartado de "promociona y supera adecuadamente" para conocer el porcentaje de alumnado que supera con éxito académico los diferentes ciclos.

Se observa que los porcentajes de alumnos que promocionan y superan adecuadamente son elevados en todos los ciclos de educación primaria. Pero se identifica un ligero declive en el porcentaje de alumnos que promocionan a medida que ascienden desde el ciclo inicial al ciclo superior.

Gráfico 5: Alumnos que "promociona y supera adecuadamente" por ciclos en los centros

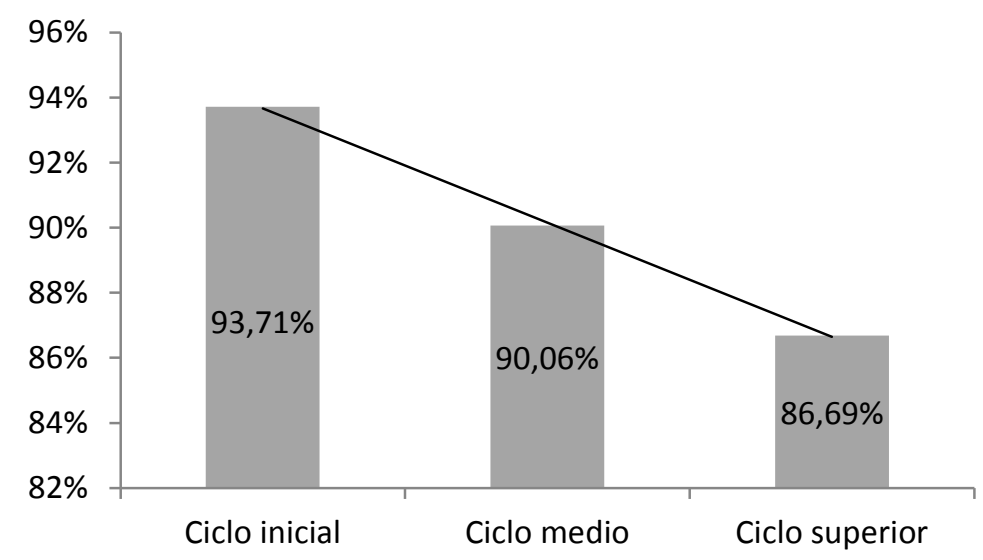




\subsubsection{Variable director}

El segundo bloque del cuestionario, se centra en los datos personales y profesionales de los directores participantes con el objetivo de conocer los perfiles directivos de la zona. Los siguientes ítems conforman la variable perfil que más adelante relacionaremos con otros ítems.

- Género

En el estudio han participado un 69,5\% de mujeres (89 directoras) y 30,5\% de hombres (39 directores).

Gráfico 6: Directores participantes en función del género

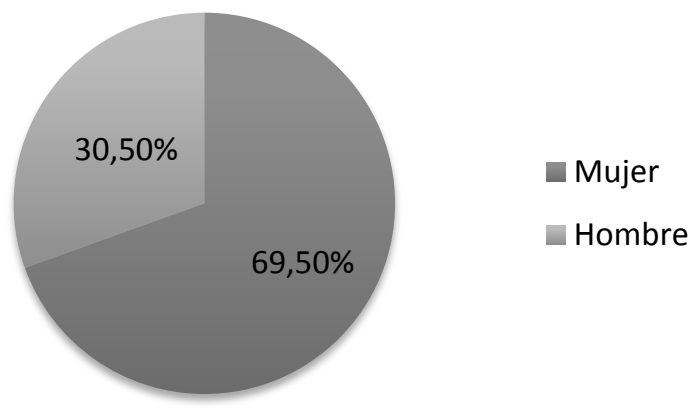

Aunque en un primer momento puede parecer que la muestra está feminizada, cabe señalar que en el conjunto de docentes del conjunto de comarcas que conforman la Delegación Educativa de Tarragona el de 83,76\% son mujeres y un 16,24\% hombres (Institut de estadística de Catalunya, 2015). Por lo que se observa una ligera "masculinización" de la dirección en la zona (si se tiene en cuenta la distribución de la población).

Cabe destacar la menor participación de las mujeres en la dirección en los centros de titularidad concertada-privada (tan sólo 6 mujeres de las 89 dirigen un centro concertado). En el siguiente gráfico podemos observar la distribución del género en relación la titularidad de los centros. 
Gráfico 7: Relación de la titularidad de los centros y el género del director

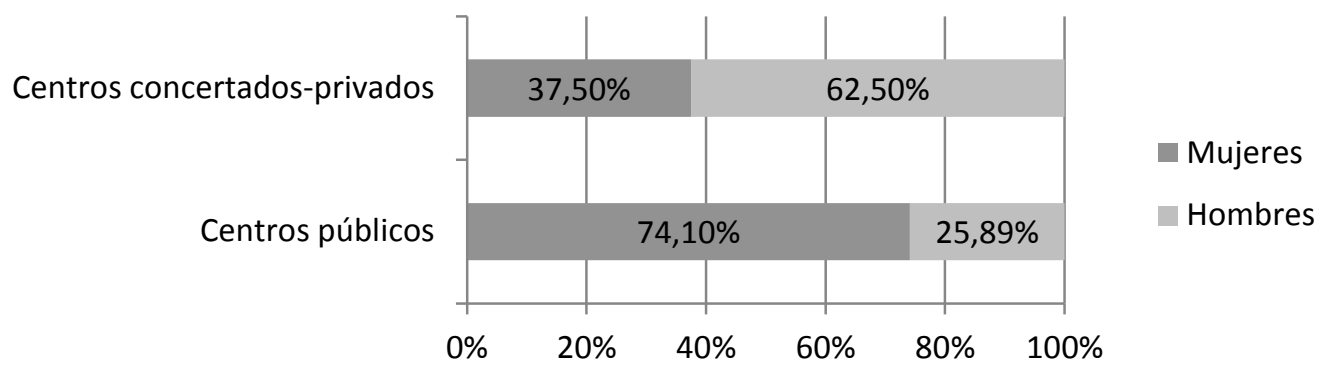

Dada la importancia que se concede al género en cuando al desarrollo de funciones directivas y de liderazgo, en las siguientes características también mostraremos cómo se distribuyen los datos en función del género.

\section{- Edad}

La edad de los directores va desde los 31 hasta los 65 años. La edad media es de 50,49 años (desviación típica de 7,40). Un 22,7\% de los directores tienen un máximo de 45 años, un $43 \%$ tienen entre 46 y 54 años y el 34,4\% restante tiene 55 años o más.

Gráfico 8: Relación de la edad y el género de los directores participantes

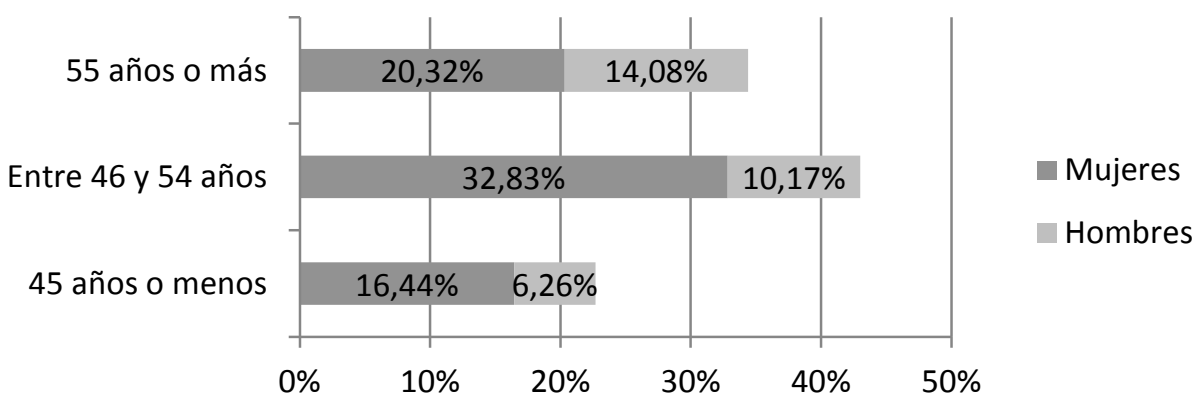

- Experiencia profesional

La experiencia profesional de los directores en el cargo directivo va desde los 2 meses hasta los 30 años de experiencia. La media de la experiencia como director es de 9,68 años (desviación típica de 6,812).

Un 47,6\% (59 directores) tienen un mínimo de 9 años de experiencia en dirigir un centro escolar, un 31,5\% (39 directores) declaran tener entre 5 y 8 años de experiencia. Los directores entre 2 y 4 años de experiencia representan un 13,7\% de la muestra (17 directores) y un 7,3\% (9 directores) llevan, como mucho, un año en el cargo. 
Gráfico 9: Relación del género del director y la experiencia directiva

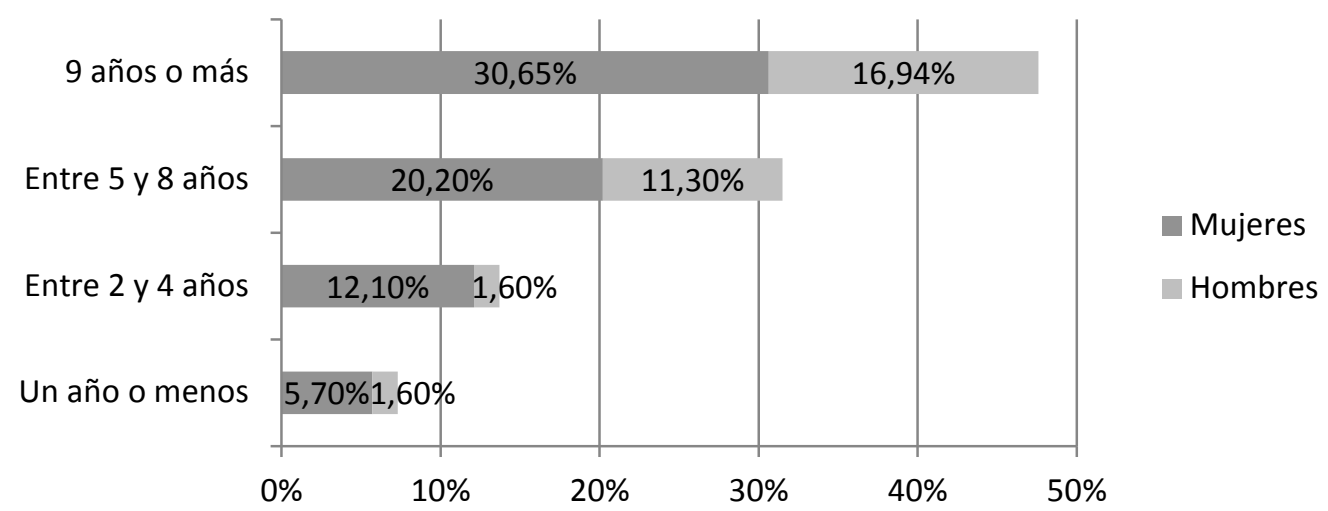

En los centros públicos el $44 \%$ de directores (55 directores) tiene 9 años o más de experiencia en dirección. Un 25\% (31 directores) tiene entre 5 y 8 años de experiencia, un $13 \%$ (16 directores) tiene entre 2 y 4 años y sólo el 6,5\% de los directores (8 directores) son noveles.

Gráfico 10: Relación de la titularidad de los centros educativos y la experiencia directiva

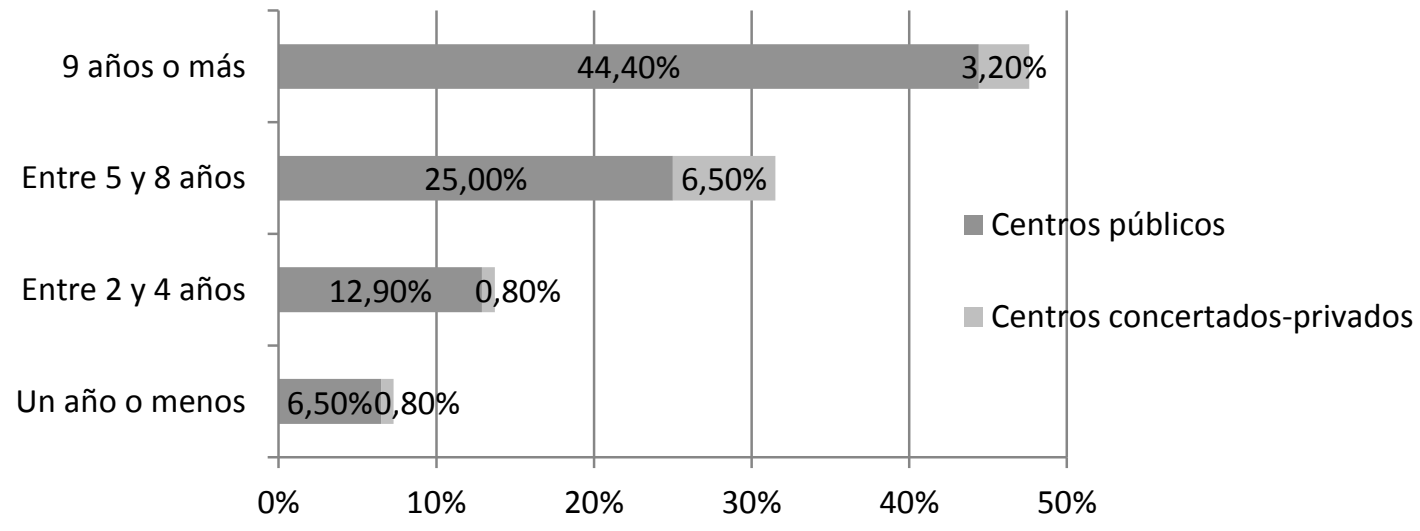

En relación a la experiencia docente, los directores tienen una experiencia que va desde un mínimo de 7 años hasta un máximo de 39 años de experiencia. La media de la experiencia docente es de 25,97 años (desviación típica de 8,17).

Aproximadamente el $47 \%$ de los directores de la muestra (60 personas) tiene experiencia, en el mismo centro, de jefe de estudios o secretario. Un $40 \%$ de los directores (51 en total) tiene experiencia en el centro como coordinador de ciclo u otros cargos de coordinación. 


\section{- Modelo de dirección}

Para definir el perfil directivo, consideramos relevante comentar la última pregunta del cuestionario sobre cómo definen su propio ejercicio de dirección. Los estilos directivos que se proponían en el cuestionario eran: coordinar, mandar, liderar, gestionar y opción "otros" (especificando).

Los modelos de dirección con los que autodefinen su ejercicio se basan en: la gestión (46\%), el liderazgo (30\%), la coordinación (17\%) y ningún director selecciona la opción de "mando".

Un 7\% de los directores señala la opción "otros", especificando las siguientes respuestas: "Sirvo a la comunidad educativa" (ID 157), "Lidero y gestiono con coordinación" (ID 149), "Soy una afortunada" (ID 137), "Soy mediadora” (ID 88), “Tomo las decisiones más comprometidas" (ID 103).

Gráfico 11: Relación de la auto percepción del estilo directivo y el género de los directores

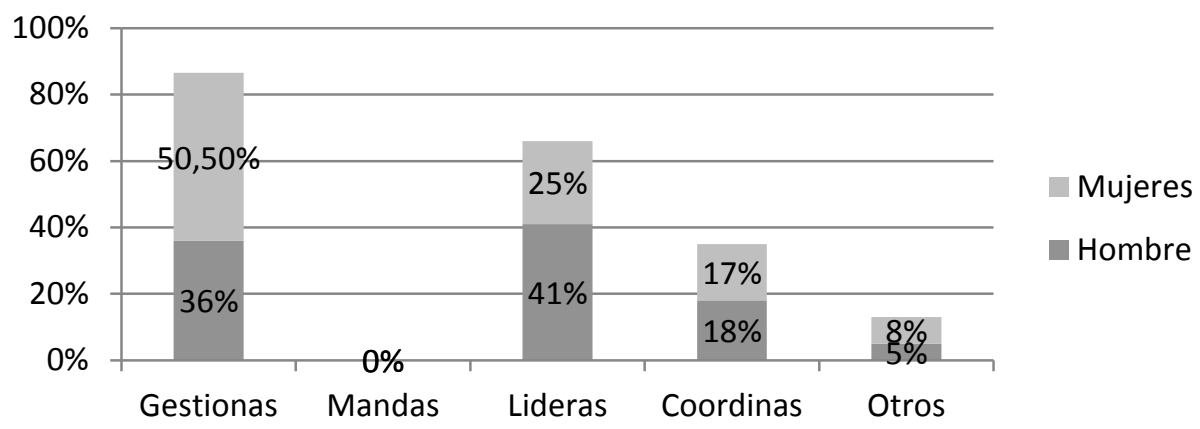

Se observa que el mayor porcentaje de hombres, un $41 \%$ dice liderar en su día a día, versus un $25 \%$ de las mujeres de la muestra. En cambio, el mayor porcentaje de mujeres $(50,50 \%)$ dice gestionar en su día a día versus un $36 \%$ de los hombres.

Gráfico 12: Relación de la auto percepción del estilo directivo y la titularidad del centro

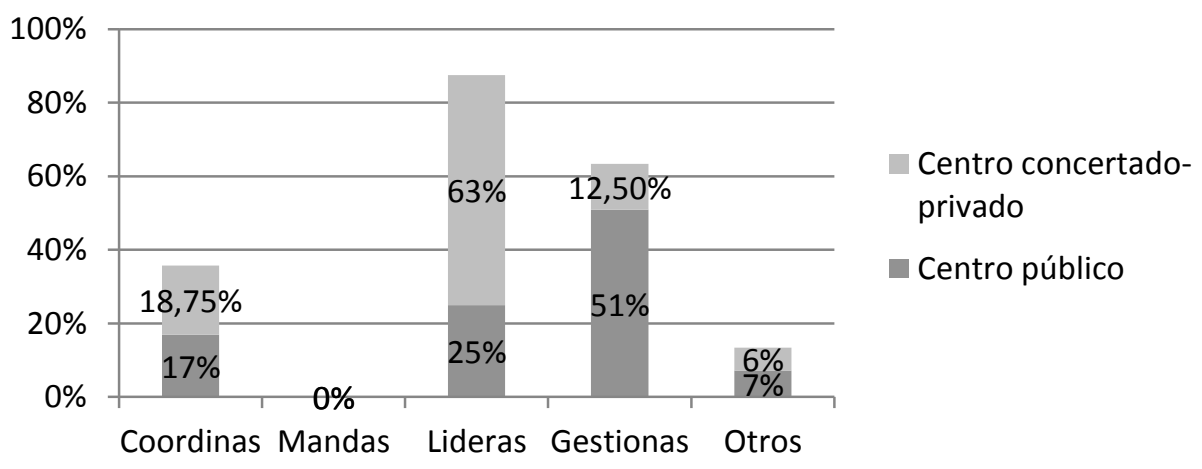


El 63\% de los directores de los centros concertados-privados de la muestra consideran que en su día a día lideran. En cambio, el 51\% de los directores de los centros públicos consideran que gestionan.

Por último, en relación la edad de los directores con su auto percepción, se obtienen los siguientes resultados:

Gráfico 13: Relación de la edad del director y la auto percepción del estilo directivo

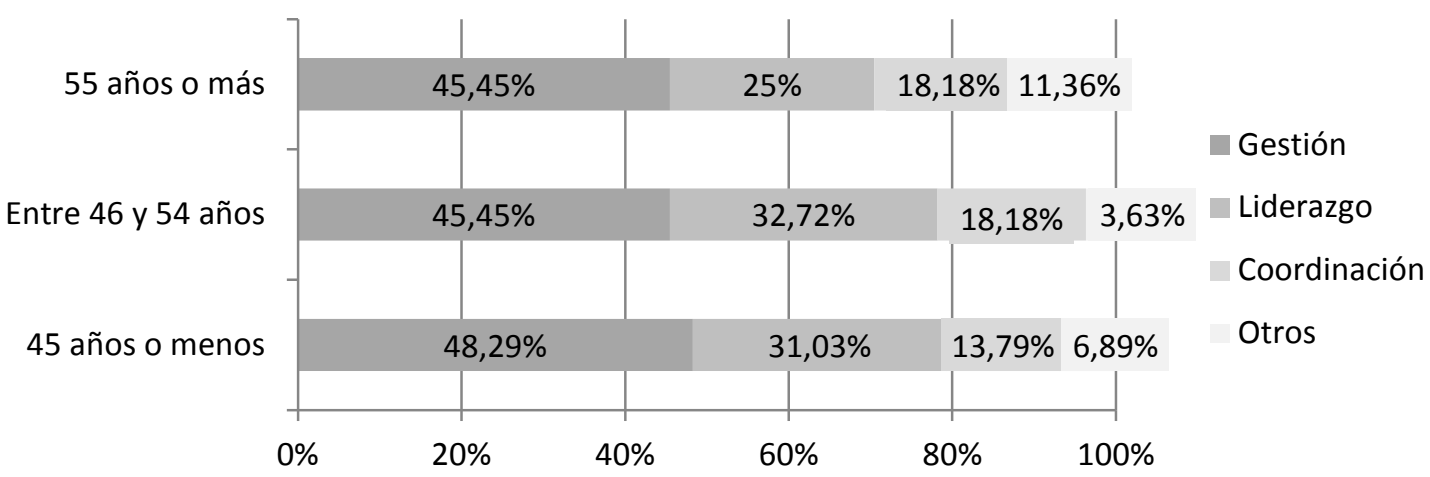

Observamos que independientemente de la franja de edad, la mitad de los directores considera que gestionan habitualmente. Por lo tanto, la edad no tiene una relación directa con los modelos de gestión de los directores.

A continuación presentamos los datos obtenidos en los bloques del cuestionario sobre: el acceso al cargo, la formación directiva, el ejercicio del cargo, el modelo directivo, la satisfacción y los resultados.

\subsection{Análisis descriptivo por bloques del cuestionario}

Realizamos una lectura directa de los datos en la que se presentan frecuencias, porcentajes y medias para cada una de las variables.

\subsubsection{Acceso al cargo}

Se incluyen ítems que nos aportan información para tener una visión más amplia en lo que respecta el acceso al cargo y sobre las motivaciones iniciales de los directores para acceder al mismo. 
- Modo de acceso al cargo directivo

Alrededor del $72 \%$ de los directores accedieron al cargo de dirección a partir de un concurso de méritos siendo la única candidatura, versus un 5,5\% que accedieron al cargo a partir de un concurso de méritos entre varias candidaturas. Alrededor de un 23\% de los directores fueron nombrados extraordinariamente por la Administración (en centros públicos) o por el titular (en centros concertados-privados).

Estadísticamente aparecen diferencias significativas en función de la titularidad del centro, del número de miembros de los equipos directivos y de la experiencia como director.

Gráfico 14: Acceso al cargo en función de la titularidad del centro

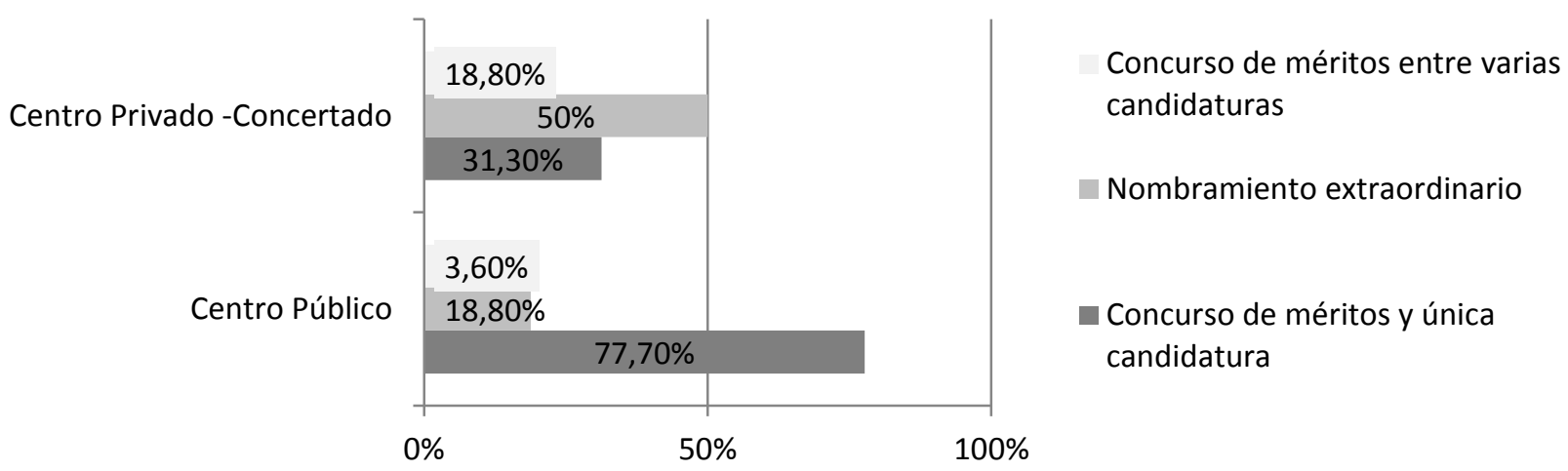

A partir de los resultados anteriores, se infiere que los directores de centros públicos acceden al cargo mayoritariamente a través de un concurso de méritos y única candidatura en contraposición a los directores de centros concertados-privados que mayoritariamente acceden al cargo a partir del nombramiento extraordinario por parte del titular del centro.

Gráfico 15: Acceso al cargo según el número de miembros del equipo directivo

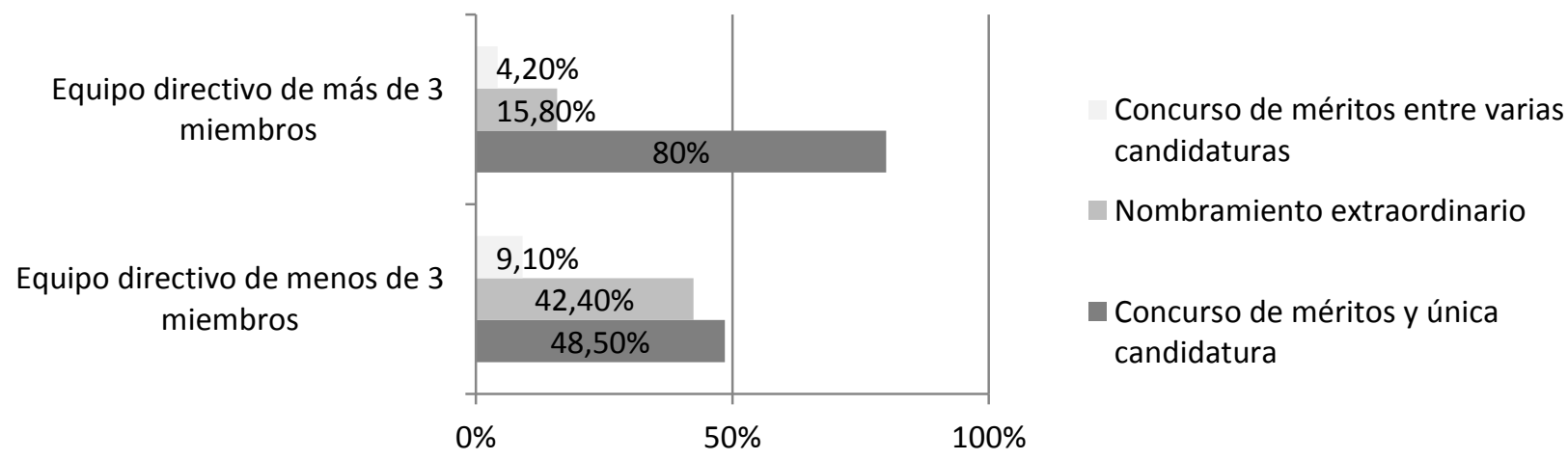


En los equipos directivos pequeños observamos que los directores acceden al cargo en su gran mayoría a partir de un nombramiento extraordinario por parte de la Administración. En cambio, en los equipos directivos grandes el director el índice de acceso por esta vía es mucho menor, reduciéndose a un $42 \%$ y por lo tanto aumentando los directores que acceden por propia voluntad en concurso de méritos.

Gráfico 16: Acceso al cargo según la experiencia directiva

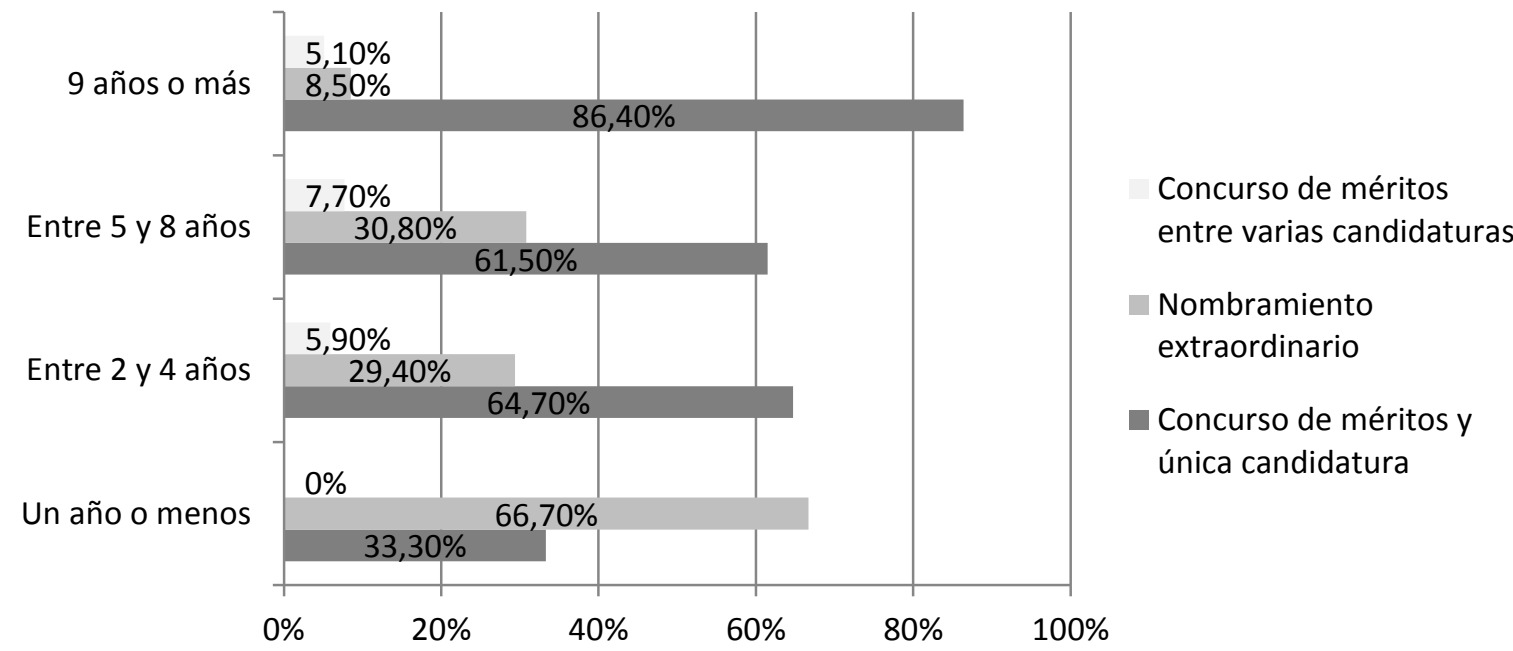

Según los años de experiencia, la manera de acceder al cargo también varía. Aunque hay pocos casos de directores con un año o menos de experiencia, se observa que la mayoría de ellos han accedido a través de un nombramiento extraordinario en contraposición a los directores con 9 o más años de experiencia, que accedieron a través de un concurso de méritos y única candidatura.

Los motivos por los que se llevaron a cabo los 29 nombramientos extraordinario, que suponen el 23\% de la muestra, fueron: centro de nueva creación ( 8 directores), ausencia de candidatos (5 directores), ausencia de candidatos con requisitos (3 directores) y la opción "otros" (13 directores). Los 13 directores que marcaron la opción "otros" especificaron los siguientes motivos:

Tabla 74: Otros motivos del nombramiento extraordinario según la tipología del centro

\begin{tabular}{|c|l|}
\hline $\begin{array}{c}\text { Centro privado- } \\
\text { concertado } \\
\text { (por el titular) }\end{array}$ & Propuesto por la titularidad (6 directores) \\
\cline { 2 - 2 } & Sustitución directora anterior (1 director) \\
\hline
\end{tabular}




\begin{tabular}{|c|l|}
\hline \multirow{3}{*}{ Centro público } & Jubilación anterior director (3 directores) \\
(por la Administración) & Cese director anterior (1 director) \\
\cline { 2 - 2 } & $\begin{array}{l}\text { Dimisión del director anterior (1 director) } \\
\text { Contribuir a aumentar la competencia académica y } \\
\text { personal de los alumnos (1 director) }\end{array}$ \\
\hline
\end{tabular}

- Docencia directa

Sólo un director no realiza ninguna hora de docencia directa con el alumnado en contraste con un director que realiza 27 horas de docencia semanalmente. El promedio de tiempo de docencia que realizan los directores a la semana es de 10,81 horas (desviación típica de 5,56)

Aproximadamente un $44 \%$ de los directores realiza entre 9 y 16 horas de docencia a la semana, seguido de un $42 \%$ de los directores que tienen 8 horas o menos. Solamente un $14 \%$ los directores tienen 17 horas o más de docencia directa.

En el siguiente gráfico podemos observar el tiempo que dedican a docencia los directores según la titularidad del centro y el género.

Gráfico 17: Tiempo que dedica el director a docencia según la titularidad del centro

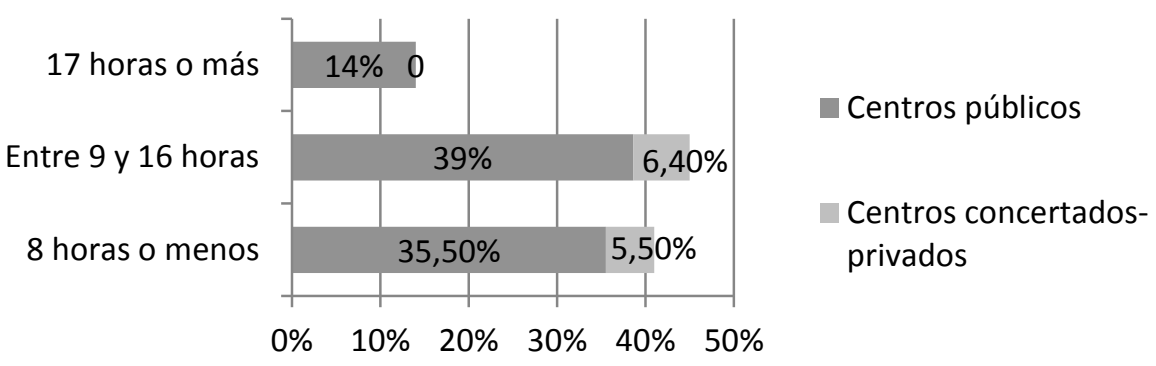

Gráfico 18: Tiempo que dedica el director a docencia según el género del director

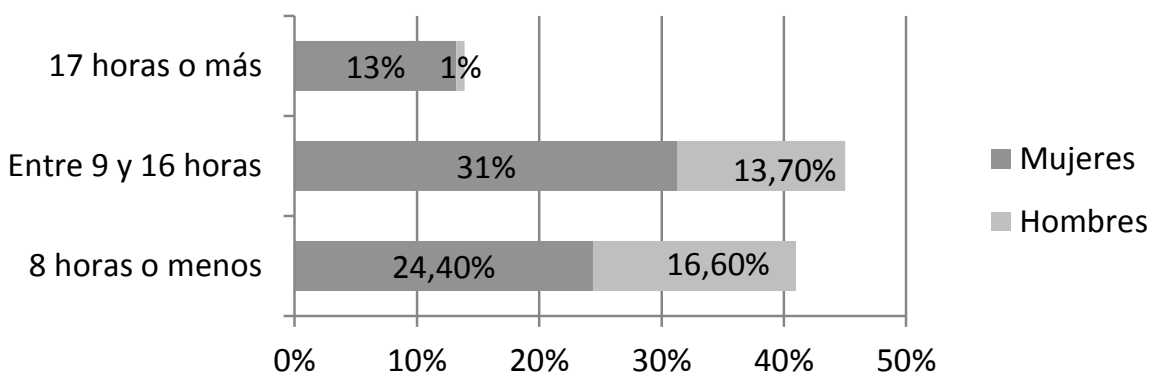


Observamos que son directoras que dirigen centros públicos las que realizan más horas de docencia directa con los alumnos.

- Motivación inicial para acceder al cargo

Cuando les pedimos a los directores que valoren del 1 al 5 las razones iniciales por las que accedieron al cargo, las más valoradas son mejorar el funcionamiento del centro, seguida de promover proyectos de innovación. En cambio, las menos valoradas son: tener un complemento económico y tener un prestigio social.

Tabla 75: Razones iniciales para acceder al cargo de dirección

\begin{tabular}{|l|c|c|c|c|c|}
\hline & $\mathrm{N}$ & Mín. & Máx. & Media & Desv. típ. \\
\hline Mejorar el funcionamiento del centro & 118 & 1 & 5 & 4,53 & 0,93 \\
\hline $\begin{array}{l}\text { Conseguir méritos para la promoción } \\
\text { profesional }\end{array}$ & 109 & 1 & 5 & 2,07 & 1,23 \\
\hline Aceptar el encargo de los compañeros & 115 & 1 & 5 & 3,30 & 1,48 \\
\hline Obtener más prestigio social & 108 & 1 & 5 & 1,54 & 0,90 \\
\hline Obtener un complemento económico & 110 & 1 & 5 & 1,97 & 1,10 \\
\hline Tener más autonomía & 109 & 1 & 5 & 2,75 & 1,33 \\
\hline Tener poder de decisión & 114 & 1 & 5 & 2,89 & 1,27 \\
\hline Promover proyectos de innovación & 121 & 1 & 5 & 4,48 & 0,85 \\
\hline Tener contacto con la comunidad educativa & 117 & 1 & 5 & 4,19 & 1,06 \\
\hline Otros motivos & 22 & 1 & 5 & 4,41 & 1,22 \\
\hline
\end{tabular}

A continuación, identificaremos las diferencias estadísticamente significativas:.

En función de la tipología del centro, obtenemos los siguientes resultados: los directores de centros concertados-privados valoran más alto $(4,93)$ la motivación inicial de promover proyectos de innovación que los directores de centros públicos $(4,42)$. Este ítem es significativamente valorado a la baja por los directores de centros en contextos de alta complejidad $(4,05)$ en comparación con centros que no lo son $(4,56)$.

Los directores de zonas rurales $(2,92)$ y los más jóvenes $(2,76)$ valoran más alto la motivación inicial de conseguir méritos para la promoción profesional en contraposición con los directores de escuelas urbanas $(1,97)$ y los directores de entre 46 y 54 años $(1,96)$ y los directores de 55 años o más $(1,74)$. 
Los directores de género masculino en comparación al género femenino puntúan de manera más elevada el acceso al cargo para conseguir prestigio social, (1,80 versus $1,41)$.

Para los directores de centros medianos el tener más poder de decisión es una de las motivaciones iniciales de acceso al cargo $(3,30)$ frente a los directores de centros rurales (3), de centros pequeños $(2,37)$ o de centros grandes $(2,75)$.

Profundizando en el apartado de "otros motivos" para acceder al cargo, se obtienen las siguientes respuestas:

Tabla 76: Otras razones para acceder al cargo de dirección

\begin{tabular}{|l|c|}
\cline { 2 - 2 } \multicolumn{1}{l|}{} & $\begin{array}{c}\text { Frecuencia } \\
\text { (directores) }\end{array}$ \\
\hline Dar continuidad a proyectos del centro & 6 \\
\hline Estar implicada en la mejora de la escuela y de la sociedad & 6 \\
\hline Liderar un cambio en la escuela & 5 \\
\hline Ilusión por iniciar un proyecto en un centro de nueva creación & 5 \\
\hline Reto personal & 5 \\
\hline Dar respuesta al servicio que propone la Institución Titular & 3 \\
\hline Habilidad para trabajar con equipos humanos & 2 \\
\hline Ayudar a hacer un buen equipo directivo, con ideas y trabajo en equipo & 2 \\
\hline Era la única con requisitos para acceder al cargo & 2 \\
\hline Experiencia profesional en cargos directivos & 2 \\
\hline Decisión de la Administración al pertenecer a la misma ZER & 1 \\
\hline Impedir que alguien externo al centro se encargue de la dirección & 1 \\
\hline Tener el apoyo de mis compañeros & 1 \\
\hline Desde que empecé hasta ahora las motivaciones son diferentes & 1 \\
\hline
\end{tabular}

Las razones tienen una relación directa con la posibilidad de dar continuidad a los proyectos educativos, la implicación personal del director con su mejora de la escuela y de la sociedad.

En los centros de nueva creación, la principal motivación de los directores es iniciar un proyecto innovador. 


\subsubsection{Formación directiva}

Se analiza la formación inicial en el ámbito de la dirección (previa al cargo) y la formación permanente (durante el cargo) que reciben los directores.

- Formación previa al cargo

Un 69\% (88 directores) afirma haber recibido formación inicial, frente a un 31\% (40 directores) que no la ha recibido.

Existen diferencias significativas en relación a la edad de los directores, a la experiencia como director y a la experiencia como coordinador en el centro.

Gráfico 19: Formación inicial según la edad

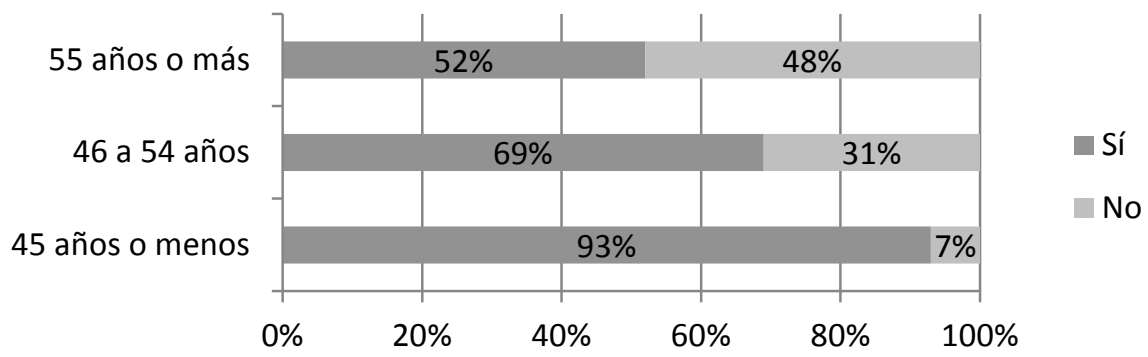

La formación inicial está más presente en el grupo de directores más jóvenes. Del grupo de directores con más edad, tan sólo el 52\% ha recibido formación previa.

Gráfico 20: Formación inicial según la experiencia directiva

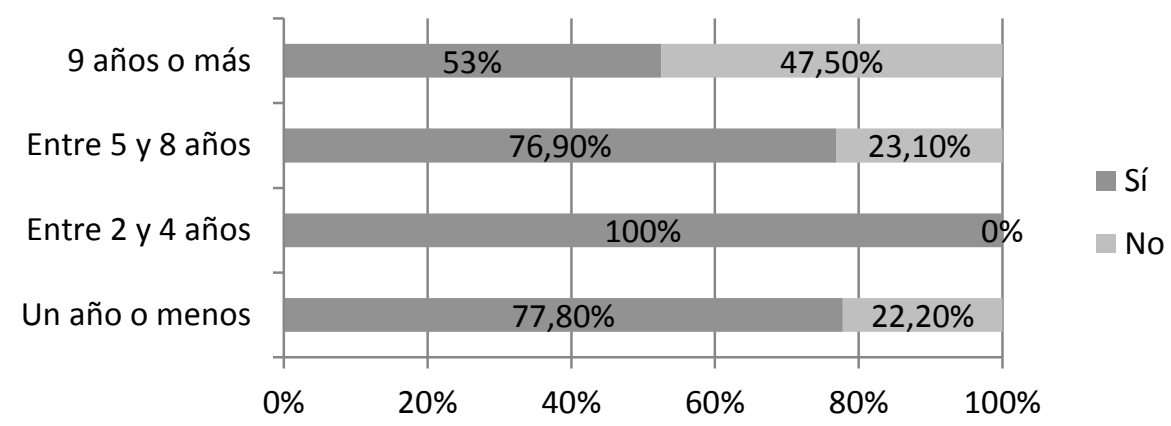

Los directores más experimentados son los que recibieron menos formación inicial. En la actualidad, la formación previa es uno de los requisitos para poder acceder al cargo directivo. Por ese motivo, los profesores con menos experiencia directiva son los que más formación inicial han recibido. 
En relación a la experiencia como coordinador, el $80 \%$ de los directores con experiencia en coordinaciones ha recibido formación frente a un $61 \%$ que no la ha recibido.

No se observa ninguna diferencia significativa entre la formación inicial y la variable centro (titularidad, tipología, $\mathrm{n}^{\circ}$ de alumnos o $\mathrm{n}^{\mathrm{o}}$ de profesores).

- Valoración de la formación previa al cargo

Para conocer la valoración de los directores de la formación inicial recibida nos basamos en la escala de valores de Kirkpatrick \& Kirkpatrick (2007): la satisfacción, el aprendizaje, la aplicación y el impacto de la formación recibida.

Les pedimos a los directores que valoren del 1 al 5 la formación inicial recibida. En el análisis de los resultados observamos que la satisfacción de la formación recibida es el aspecto más valorado. En cambio, el impacto de la formación recibida es el aspecto con menor valoración.

Tabla 77: Valoración de la formación previa al cargo

\begin{tabular}{|l|r|r|r|r|r|} 
& N & Mín. & Máx. & Media & $\begin{array}{c}\text { Desv. } \\
\text { Típ. }\end{array}$ \\
\hline Satisfacción de la formación inicial recibida & 88 & 1 & 5 & 4,05 & 0,84 \\
\hline $\begin{array}{l}\text { Aprendizaje de la formación inicial recibida } \\
\text { Aplicación en el centro de la formación inicial } \\
\text { recibida }\end{array}$ & 88 & 1 & 5 & 3,89 & 0,88 \\
\hline Impacto de la formación recibida & 88 & 1 & 5 & 3,88 & 0,88 \\
\hline
\end{tabular}

- Formación durante el cargo

Aproximadamente un 83\% (106 directores) responden que están recibiendo formación durante su mandato. Tan sólo hay un 17\% (22 directores) que manifiesta no estar recibiendo formación durante el ejercicio del cargo. 
Gráfico 21: Comparación de formaciones (inicial y continua)

Formación previa al cargo

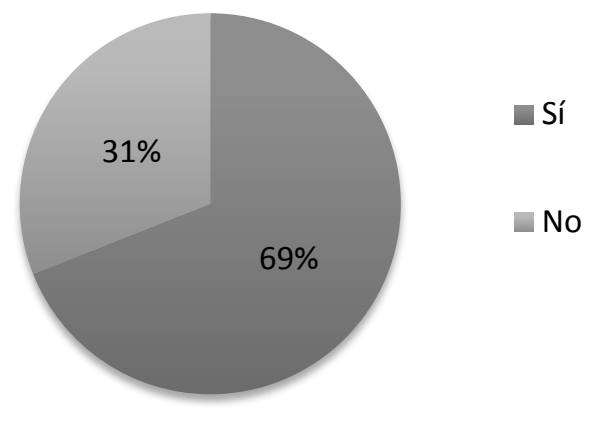

Formación durante el cargo

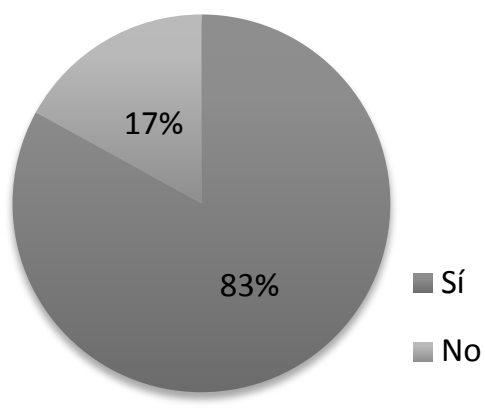

El porcentaje de directores que reciben formación continua es más elevado que el de los que han recibido formación inicial.

Existe una diferencia significativa en relación a la autopercepción del estilo de liderazgo que realizan en su día a día los directores del centro.

Gráfico 22: Formación permanente según la autopercepción del modelo directivo

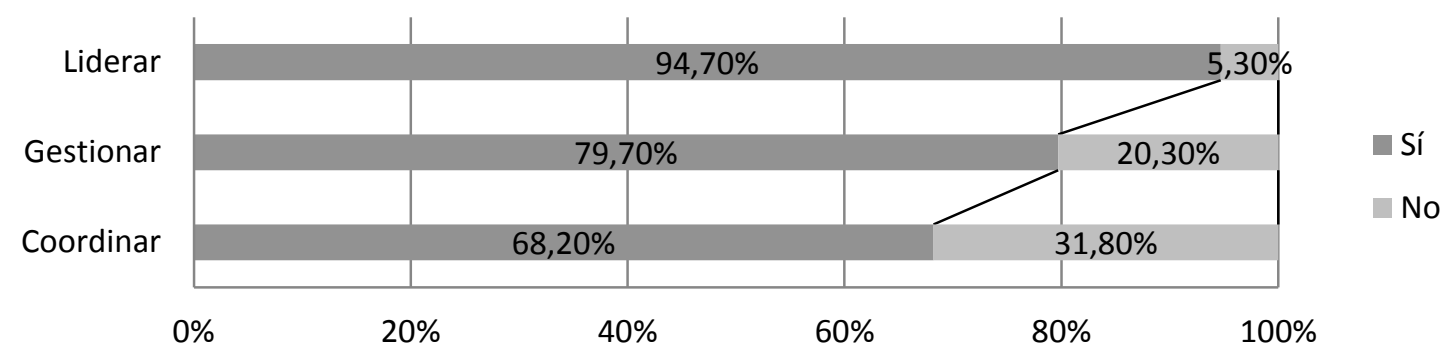

Como podemos observar, los directores que se autodefinen con un modelo de liderazgo son los que más se forman en comparación con los directores que se incluyen en un modelo de gestión o de coordinación.

Al igual que en la formación inicial, no se observa ninguna diferencia significativa en relación a las variables de centro.

- Valoración de la formación durante el cargo

El mejor aspecto valorado de la formación continua por los directores es la aplicación en el centro de la formación recibida. El aspecto menos valorado sigue siendo el impacto en el rendimiento de los alumnos. 
Tabla 78: Valoración de la formación durante el cargo

\begin{tabular}{|c|c|c|c|c|c|}
\hline & $\mathrm{N}$ & Mín. & Máx. & Media & $\begin{array}{l}\text { Desv. } \\
\text { típ. }\end{array}$ \\
\hline Satisfacción de la formación continua recibida & 105 & 2 & 5 & 3,90 & 0,88 \\
\hline Aprendizaje de la formación continua recibida & 105 & 1 & 5 & 3,84 & 0,92 \\
\hline $\begin{array}{l}\text { Aplicación en el centro de la formación continua } \\
\text { recibida }\end{array}$ & 106 & 2 & 5 & 3,97 & 0,82 \\
\hline $\begin{array}{l}\text { Impacto (mejora en el rendimiento de los } \\
\text { alumnos) }\end{array}$ & 100 & 1 & 5 & 3,56 & 1,02 \\
\hline
\end{tabular}

- Valoración de las capacidades

Para centramos en la valoración de sus propias capacidades como director, les pedimos que valoren del 1 (mínimo) al 5 (máximo) una serie de competencias. En general, todas son elevadas aunque el compromiso ético es la que consideran tener más desarrollada, seguida de la participación y del trabajo en equipo. Las capacidades que se auto perciben como menos desarrolladas son el liderazgo, la autonomía y la autogestión.

Tabla 79: Listado de capacidades directivas

\begin{tabular}{|l|r|r|r|r|r|}
\hline & N & Mín. & Máx. & Media & Desv. típ. \\
\hline Adaptación al cambio & 128 & 0 & 5 & 4,16 & 0,85 \\
\hline Comunicación & 128 & 0 & 5 & 4,18 & 0,74 \\
\hline Control emocional & 128 & 0 & 5 & 3,99 & 1,01 \\
\hline Autonomía & 128 & 0 & 5 & 3,93 & 1,00 \\
\hline Trabajo en equipo & 128 & 0 & 5 & 4,38 & 0,76 \\
\hline Liderazgo & 128 & 0 & 5 & 3,92 & 0,96 \\
\hline Organización & 128 & 0 & 5 & 4,17 & 0,81 \\
\hline Resolución de problemas & 128 & 0 & 5 & 4,23 & 0,70 \\
\hline Relaciones interpersonales & 128 & 0 & 5 & 4,21 & 0,82 \\
\hline Autogestión & 128 & 0 & 5 & 3,98 & 0,91 \\
\hline Compromiso ético & 128 & 0 & 5 & 4,61 & 0,91 \\
\hline Fortaleza interior & 128 & 0 & 5 & 4,13 & 0,97 \\
\hline Orientación al aprendizaje & 128 & 0 & 5 & 4,02 & 0,92 \\
\hline Participación & 128 & 0 & 5 & 4,44 & 0,84 \\
\hline Energía & 128 & 0 & 5 & 4,27 & 1,02 \\
\hline Desarrollo profesional & 128 & 0 & 5 & 4,12 & 0,91 \\
\hline Desarrollo personal & 128 & 0 & 5 & 4,17 & 0,94 \\
\hline Otras capacidades & 128 & 0 & 5 &, 40 & 1,32 \\
\hline
\end{tabular}


Las respuestas obtenidas de la opción "otras capacidades" ( necesarias para el desarrollo del cargo directivo) son:

Tabla 80: Otras capacidades directivas

\begin{tabular}{|l|c|c|c|c|l|c|}
\hline Motivación & Formación & Liderar * & Vocación & Experiencia & Mediación & Empatía \\
\hline Implicación & Tolerancia & $\begin{array}{c}\text { Visión } \\
\text { estratégica }\end{array}$ & $\begin{array}{c}\text { Relación } \\
\text { Comunidad }\end{array}$ & $\begin{array}{c}\text { Selección } \\
\text { profesionales }\end{array}$ & Discreción & Orientación \\
\hline
\end{tabular}

*Liderar: Aparece en "otras capacidades" a pesar de estar en el listado de capacidades.

Con la comparación de medias a partir del análisis ANOVA de un factor, destacan las siguientes diferencias significativas:

\section{- Según la tipología}

Los directores de centros rurales valoran significativamente a la baja las siguientes competencias en comparación con los directores de centros urbanos:

- Autonomía (3,40 versus 4)

- Liderazgo (3,47 versus 3,98)

- Resolución de problemas (3,87 versus 4,27)

- Autogestión (3,33 versus 4,06)

- Compromiso ético (4,07 versus 4,68)

- Fortaleza interior (3,33 versus 4,24)

- Desarrollo profesional (3,67 versus 4,18)

- Desarrollo personal (3,47 versus 4,27)

- $\quad$ Según el número de docentes del centro

Los directores de centros rurales valoran más bajo las siguientes capacidades en comparación con los directores de centros medianos:

- $\quad$ Control emocional (3,33 versus 4,14)

- Fortaleza interior(3,56 versus 4,33 
- Según la complejidad del centro escolar

Los directores de centros de alta complejidad valoran más alta su capacidad de autogestión $(4,42)$, en comparación con los directores de centros que no son de alta complejidad $(3,90)$.

\section{- Según las horas de docencia a la semana}

Los directores que realizan un máximo de 8 horas de docencia a la semana valoran más su capacidad en autonomía $(4,19)$ y autogestión $(4,21)$ en comparación los directores que realizan entre 9 y 16 horas de docencia $(3,71$ y 3,9) y los directores que realizan más de 17 horas $(3,83$ y 3,56).

- $\quad$ Según la experiencia como coordinador de ciclo u otras coordinaciones

Los directores sin experiencia en coordinaciones consideran que tienen más desarrollada la capacidad de adaptación al cambio $(4,26)$, en comparación con los directores con experiencia en coordinación $(4,02)$.

\subsubsection{Ejercicio del cargo}

Nos centramos en el desarrollo del ejercicio del cargo, los valores que identifican a los centros, el cargo y la personalidad de los directivos y la situación actual de la dirección en los centros educativos.

- Componentes más relevantes para el cargo directivo

Los directores habían de seleccionar un máximo de tres valores de un listado. El mayor porcentaje de directores selecciona el componente de gestión como el más importante para el desarrollo del cargo directico. La dinamización es el segundo componente, seguido de la colaboración. El componente menos relevante es el de autonomía.

En la siguiente tabla aparecen, ordenados de mayor a menor importancia, los componentes más relevantes para el cargo según la opinión de los directores: 
Tabla 81: Componentes relevantes para el cargo de dirección

\begin{tabular}{|l|c|c|}
\cline { 2 - 3 } \multicolumn{1}{l|}{} & N & Porcentaje \\
\hline Gestión & 83 & $64,8 \%$ \\
\hline Dinamización & 69 & $53,9 \%$ \\
\hline Colaboración & 52 & $40,6 \%$ \\
\hline Ética & 43 & $33,6 \%$ \\
\hline Carisma & 39 & $30,5 \%$ \\
\hline Reflexión & 39 & $30,5 \%$ \\
\hline Innovación & 35 & $27,3 \%$ \\
\hline Creatividad & 15 & $11,7 \%$ \\
\hline Autonomía & 6 & $4,7 \%$ \\
\hline
\end{tabular}

Sólo tres directores marcaron la opción "otros componentes" que añadieron los siguientes componentes como relevantes:

Tabla 82: Otros componentes relevantes para la dirección

\begin{tabular}{|c|}
\hline Gestión de las relaciones humanas \\
\hline Liderazgo \\
\hline Empatía \\
\hline
\end{tabular}

A continuación, analizamos las diferencias significativas:

\section{- Según la titularidad del centro}

Los directores de centros concertados-privados valoran los siguientes componentes como más relevantes para el cargo directivo en comparación con los directores de centros públicos: Carisma (56\% versus 17\%) e Innovación (50\% versus $24 \%$ ).

En cambio, la dinamización es un componente más relevante para los directores de centros públicos (59\%) que para los directores de centros concertados-privados (19\%).

\section{- $\quad$ Según el número de alumnos del centro}

Para los directores de escuelas rurales (38\%) o de escuelas grandes (39\%) es relevante la innovación como un componente de la función directiva. En cambio, para los directores de escuelas pequeñas $(22 \%)$ o de escuelas medianas $(13,5 \%)$ no es tan relevante. 
- $\quad$ Según el equipo directivo

Para aquellos directores que tienen un equipo directivo grande es más relevante el componente de dinamización (60\%) que para aquellos directores que tienen un equipo directivo pequeño $(36 \%)$.

\section{- $\quad$ Según las horas de docencia directa}

Los directores que realizan 17 horas o más de docencia a la semana consideran relevante la autonomía para el cargo (17\%) en comparación a los directores que realizan menos horas de docencia (5\%).

\section{- $\quad$ Según la experiencia como director}

Los directores más noveles (un año o menos de experiencia) consideran más relevante el componente de la colaboración (78\%) en comparación con los directores más veteranos (9 años o más de experiencia) (27\%).

\section{- Según la autopercepción del modelo de dirección}

Para los directores que dicen liderar, el carisma es un componente relevante (47\%) en comparación con los directores que dicen coordinar (27\%) o los directores que dicen gestionar $(22 \%)$.

- Valores más importantes del centro educativo, del cargo y de la persona

Basándonos en la clasificación de Woycikowska et al., (2008) nos interesó conocer, en un primer lugar, los valores con los que los directores definen su centro, su cargo directivo y, por último, qué valores les definen como personas. Se trata de una pregunta abierta, en la que los directores debían escribir un máximo de tres valores en las diferentes categorías (centro, cargo y persona).

Se obtienen un total de 321 de valores de centro que categorizamos de la siguiente manera: 
Tabla 83: Valores del centro

\begin{tabular}{|c|c|c|c|}
\hline $\mathbf{N}$ & \multicolumn{2}{|c|}{ Categorías } & Explicación de la categorías \\
\hline 42 & Colaboración & \multirow{11}{*}{ 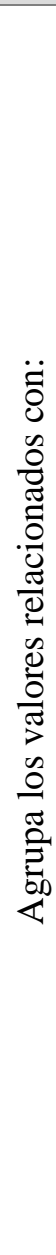 } & La cooperación, la participación y el trabajo en equipo. \\
\hline 39 & Innovación & & La creatividad y la constante actualización del centro. \\
\hline 39 & Superación & & $\begin{array}{l}\text { El esfuerzo, la búsqueda de excelencia, la calidad, la formación y la } \\
\text { motivación. }\end{array}$ \\
\hline 36 & Implicación & & El compromiso, la responsabilidad y el trabajo. \\
\hline 31 & $\begin{array}{l}\text { Principios de } \\
\text { identidad }\end{array}$ & & $\begin{array}{l}\text { La identidad del centro por tradición escolar, prestigio y valores } \\
\text { éticos de los centros. }\end{array}$ \\
\hline 30 & $\begin{array}{l}\text { Organización } \\
\text { y gestión }\end{array}$ & & $\begin{array}{l}\text { El orden, la autonomía, la planificación, la coherencia y la } \\
\text { planificación del centro. }\end{array}$ \\
\hline 26 & Dinamización & & $\begin{array}{l}\text { La actividad constante en el centro, el dinamismo y la dinámica de } \\
\text { trabajo. }\end{array}$ \\
\hline 24 & Buen clima & & $\begin{array}{l}\text { El compañerismo, la convivencia, el carisma y el acogimiento a los } \\
\text { miembros. }\end{array}$ \\
\hline 23 & Inclusión & & La atención a la diversidad, la igualdad y la integración. \\
\hline 19 & $\begin{array}{c}\text { Atención } \\
\text { personalizada }\end{array}$ & & $\begin{array}{l}\text { La cercanía, la comunicación, contacto con las familias y alumnos, } \\
\text { atención personalizada, la flexibilidad horaria y la complicidad. }\end{array}$ \\
\hline 11 & $\begin{array}{l}\text { Abierto al } \\
\text { entorno }\end{array}$ & & La vinculación del centro con el entorno. \\
\hline
\end{tabular}

La colaboración es el valor más destacado por los directores para su centro, seguido de la innovación y la superación. La implicación también es un valor altamente reconocido por los directores que engloba conceptos como la responsabilidad, el trabajo y el compromiso.

También aparecen otros valores como los principios de identidad, el valor organizativo y de gestión del centro, la dinamización del centro y de las actividades programadas. Se alude a la necesidad de tener un buen clima con todos los miembros de la comunidad, de velar por la integración y la atención a la diversidad. La atención personalizada y el ser un centro abierto al entorno, son los valores mencionados en menor grado por los directores. 
En los valores del cargo directivo se obtienen un total de 312 respuestas que también fueron categorizadas en:

Tabla 84: Valores del cargo directivo

\begin{tabular}{|c|c|c|c|}
\hline $\mathbf{N}$ & \multicolumn{2}{|l|}{ Categorías } & Explicación de la categorías \\
\hline 73 & Implicación & \multirow{10}{*}{ 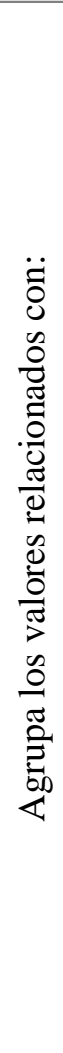 } & $\begin{array}{l}\text { La dedicación, la constancia, el compromiso, la responsabilidad, } \\
\text { el trabajo, la exigencia y el esfuerzo }\end{array}$ \\
\hline 57 & $\begin{array}{l}\text { Organización y } \\
\text { gestión }\end{array}$ & & $\begin{array}{l}\text { La coherencia, la coordinación, la visión estratégica, la } \\
\text { negociación, las decisiones y la planificación. }\end{array}$ \\
\hline 39 & Ética & & $\begin{array}{l}\text { La tolerancia, la empatía, la asertividad, el equilibrio, la equidad, } \\
\text { la honestidad y la integración. }\end{array}$ \\
\hline 33 & Profesionalidad & & $\begin{array}{l}\text { La reflexión, el control emocional, la paciencia, la motivación, la } \\
\text { experiencia y la formación. }\end{array}$ \\
\hline 32 & Colaboración & & $\begin{array}{l}\text { La cooperación, el compartir, la participación y el trabajo en } \\
\text { equipo. }\end{array}$ \\
\hline 27 & Comunicación & & $\begin{array}{l}\text { El contacto, la flexibilidad, el saber escuchar, el dialogo, la } \\
\text { transparencia y la divulgación. }\end{array}$ \\
\hline 20 & Innovación & & La creatividad. \\
\hline 19 & Dinamización & & Las actividades del centro, el dinamismo y la dinámica de trabajo. \\
\hline 11 & Liderazgo & & El liderazgo compartido \\
\hline 1 & Valor negativo & & Aparece un único valor negativo (absorbente). \\
\hline
\end{tabular}

Los valores más destacados por los directores en relación al cargo directivo son la implicación y la organización y gestión. La ética en el cargo es considerada un factor importante, al igual que la profesionalidad y la colaboración.

No podemos olvidar la importancia de la comunicación en el desarrollo del cargo directivo y la capacidad de innovación y dinamización de las actividades y proyectos que tienen lugar en el centro. Para todo ello es necesaria la capacidad de liderazgo, basada en la distribución de tareas y responsabilidades para obtener así un mayor éxito educativo y aumentar el compromiso de la comunidad educativa.

Se detecta un valor negativo en relación a la falta de tiempo disponible para atender todas las responsabilidades que implica el cargo. 
En relación a los valores personales, obtenemos un total de 314 respuestas que fueron categorizadas de la siguiente manera:

Tabla 85: Valores personales del director

\begin{tabular}{|c|c|c|c|}
\hline $\mathbf{N}$ & \multicolumn{2}{|c|}{ Categorías } & Explicación de la categorías \\
\hline 72 & Compromiso & & $\begin{array}{l}\text { La dedicación, la implicación, el trabajo, la responsabilidad, la } \\
\text { reflexión y la estima al centro. }\end{array}$ \\
\hline 57 & Ética & & $\begin{array}{l}\text { La empatía, la mediación, la atención, el respeto, la integración, la } \\
\text { honestidad y la amabilidad. }\end{array}$ \\
\hline 38 & Comunicación & & $\begin{array}{l}\text { El contacto, la flexibilidad, el saber escuchar, las buenas relaciones, } \\
\text { el carisma y la confianza. }\end{array}$ \\
\hline 38 & Motivación & 3 & $\begin{array}{l}\text { El entusiasmo, la ilusión, la dinamización, la práctica, el buen } \\
\text { humor y la positividad. }\end{array}$ \\
\hline 33 & Superación & & $\begin{array}{l}\text { El esfuerzo, la resiliencia, el sacrificio, la constancia, la iniciativa, } \\
\text { la exigencia y la autocrítica. }\end{array}$ \\
\hline 28 & $\begin{array}{l}\text { Organización } \\
\text { y gestión }\end{array}$ & $\Xi$ & $\begin{array}{l}\text { La coherencia, el liderazgo, la visión global del centro y la } \\
\text { organización. }\end{array}$ \\
\hline 21 & Colaboración & & El trabajo en equipo, la participación y el compartir. \\
\hline 15 & Innovación & & La creatividad \\
\hline 1 & Valor negativo & & Aparece un único valor negativo (insatisfacción) \\
\hline
\end{tabular}

El compromiso, tiene una relación directa con el valor que más destaca como inherente al cargo directivo: la implicación. La ética también tiene un papel importante en los valores personales de los directores.

Se otorga importancia a la comunicación y al cuidado de las relaciones con la comunidad educativa. También, se destaca la importancia de estar motivados, tener un carácter positivo y luchador para hacer frente a los retos constantes del cargo y así conseguir las metas.

La organización y gestión se valoran en el sentido de tener una visión global del centro, coherencia en las decisiones y actuaciones y basarse en un liderazgo distribuido. A nivel personal también valoran la colaboración, el trabajo en equipo y la innovación. Se detecta un valor negativo relacionado con el exceso de exigencia de uno mismo, que provoca insatisfacción. 
- Situación actual del ejercicio de la dirección e importancia que le conceden

Los directores puntúan un listado de ítems del 1 (grado mínimo) al 5 (grado máximo) sobre cómo creen que está su centro en la actualidad y la importancia que le conceda a estos mismos ítems.

Gráfico 23: Situación actual del centro versus importancia concedida por los directores

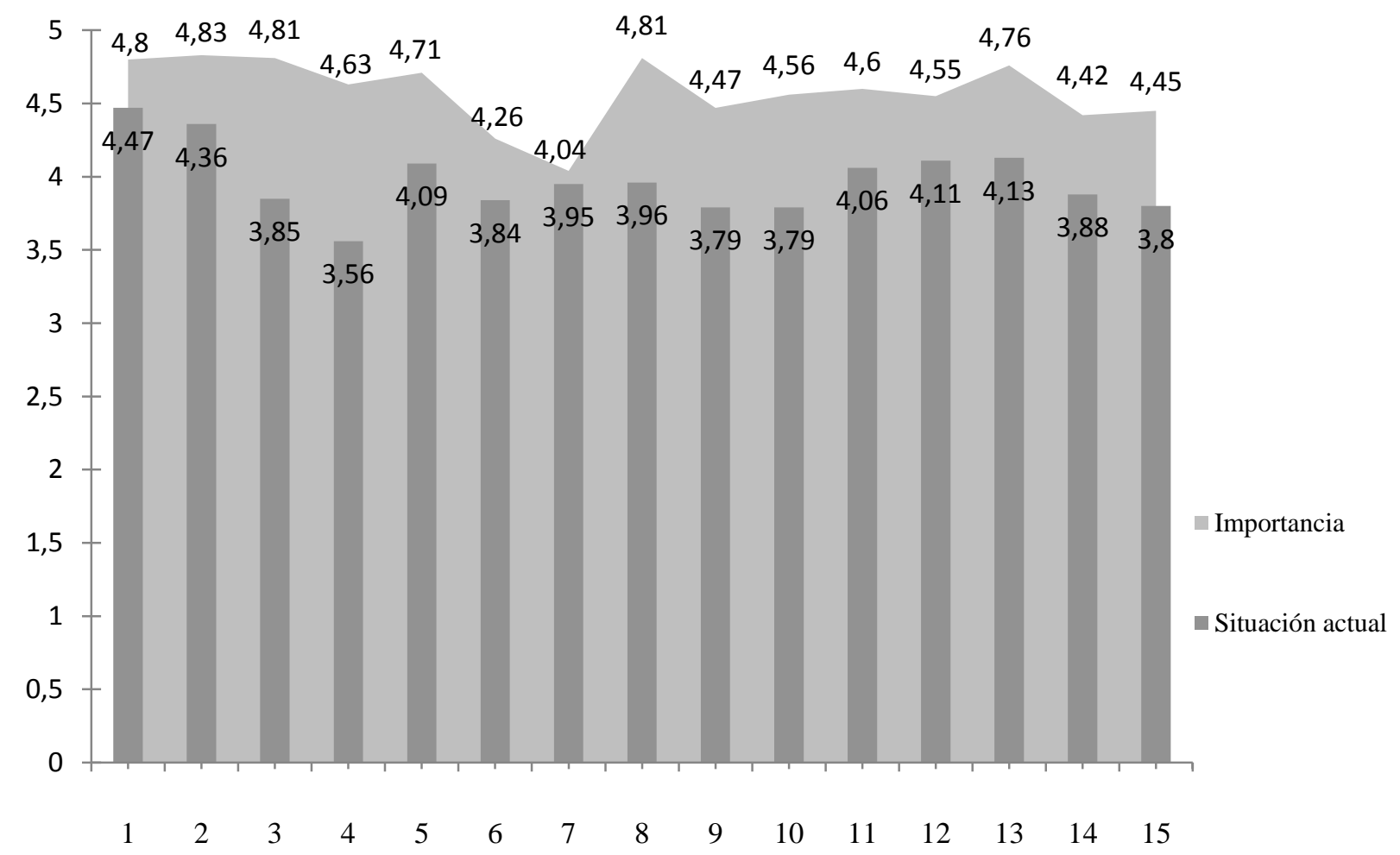

ITEMS:

1. Liderazgo compartido entre el equipo directivo

2. Seguimiento de los acuerdos

3. Entusiasmo del profesorado

4. Colaboración de las familias en los procesos educativos

5. Convivencia en la comunidad educativa

6. Vinculación del centro con su entorno social a partir de proyectos

7. Representación institucional

8. Éxito escolar del centro

9. Creación y aplicación de proyectos innovadores

10. Planteamiento del trabajo escolar como actividad colectiva

11. Mediación de conflictos

12. Gestión de recursos del centro

13. Relación de las familias con el centro

14. Delegación de responsabilidades y tareas hacia el profesorado

15. Control del estrés que conlleva el cargo 
Los resultados de esta valoración nos ayudarán a conocer la percepción sobre las situaciones de cada centro, sobre las actuaciones que más realizan los directores y la importancia concedida a cada una de ellas.

Respecto a la situación actual, todas las valoraciones alcanzan puntuaciones elevadas (se encuentran entre el 3,5 y el 4,5 sobre 5). El liderazgo compartido entre el equipo directivo es el aspecto que los directores consideran que tienen mejor resuelto. En cambio, los directores consideran que el ítem que peor tienen es la colaboración de las familias en los procesos educativos del centro.

En cuanto a la importancia, todos los ítems están entre el 4 y el 5 (sobre 5). $\mathrm{El}$ seguimiento de los acuerdos es el aspecto al que mayor importancia conceden los directores. En cambio, el ítem al que otorgan una menor importancia (a pesar de que todas las valoraciones son elevadas) es a la representación institucional.

Todas las situaciones actuales del ejercicio de la dirección están por debajo de la importancia que le conceden a ese mismo aspecto lo que indica que son elementos que, a juicio de los directores, podrían mejorar.

En el gráfico 23, se observa que en los ítems de representación institucional, liderazgo compartido entre el equipo docente y seguimiento de los acuerdos, la distancia entre la situación actual y la importancia es menor, lo que denota que la percepción de la situación actual de estos aspectos no difieren esencialmente del ideal.

En cambio, los ítems de colaboración de las familias en los procesos educativos, entusiasmo del profesorado y éxito escolar del centro tienen una distancia mayor entre la percepción sobre la situación actual y la importancia, por lo que son puntos clave de mejora.

\section{a. Diferencias significativas de la situación actual de cada ítem}

Las diferencias significativas obtenidas en el apartado de situación actual, se han agrupado en los diferentes bloques: 


\section{- $\quad$ Según la titularidad del centro}

Los directores de los centros públicos valoran más positivamente, en comparación con los directores de centros concertados y privados, su situación actual en relación a la vinculación del centro con su entorno social a partir de proyectos $(3,89$ versus 3,53$)$, la gestión de los recursos del centro $(4,20$ versus 3,47$)$ y el control del estrés que conlleva el cargo $(3,86$ versus 3,40$)$.

\section{- $\quad$ Según el número de docentes del centro}

Los directores de centros rurales valoran más positivamente, en comparación con los directores de centros pequeños, la situación del éxito escolar (4,33 versus 3,72). En cambio, los directores de centros pequeños valoran más positivamente, en comparación con los directores de centros grandes, su situación actual en relación al planteamiento de trabajo escolar como una actividad colectiva $(4,79$ versus 4,29$)$.

\section{- $\quad$ Según el equipo directivo}

Los directivos que forman parte de equipos pequeños valoran más alto, en comparación con los directores con un equipo directivo grande, la situación actual del entusiasmo del profesorado del centro (4,14 versus 3,76), el éxito escolar del centro (4,33 versus 3,85), la creación y aplicación de proyectos innovadores $(4,07$ versus 3,71$)$ y el planteamiento de trabajo escolar como una actividad colectiva $(4,15$ versus 3,69). En cambio, los directivos con equipos más grandes consideran que la situación actual gestión de recursos del centro es mejor (4,18 versus 3,86$)$.

\section{- Según las horas de docencia directa a la semana}

Los directores que realizan a partir de 9 horas de docencia a la semana en comparación con los directores que realizan 8 horas o menos de docencia, valoran más alto la situación del seguimiento de los acuerdos $(4,47$ versus 4,19).

\section{- $\quad$ Según la experiencia directiva}

Según la experiencia directiva, los directores con un año o menos en comparación con los directores con una experiencia entre 2 y 4 años, valoran más bajo la situación actual del éxito escolar del centro (3 versus 4,06). 
- Según la complejidad del centro escolar

Los directores de centros de alta complejidad, en comparación con los directores en contextos no tan desafiantes, valoran más alto la mediación de conflictos $(4,47$ versus 3,99). En cambio, puntúan más bajo la colaboración de las familias en los procesos educativos $(3,06$ versus 3,64$)$ y el éxito escolar del centro $(3,53$ versus 4,03$)$.

\section{- $\quad$ Según el género del director}

Las mujeres, en comparación con los hombres, puntúan más alto la situación actual de la mediación de conflictos $(4,19$ versus 3,79$)$ y el estrés que conlleva el cargo directivo $(3,90$ versus 3,58$)$

\section{- Según la autopercepción del modelo directivo}

Los directores que dicen liderar, en comparación con los que dicen coordinar, puntúan más alto la situación actual de la representación institucional (4,29 versus 3,71) y la gestión de recursos del centro $(4,21$ versus 3,67$)$. En cambio, los directores que dicen gestionar, en comparación con los que dicen coordinar, puntúan más elevado el estado actual del estrés que conlleva el cargo $(3,91$ versus 3,43$)$.

\section{b. Diferencias significativas de la importancia que le conceden a cada ítem}

Las diferencias significativas obtenidas en el apartado de importancia, se han agrupado en los diferentes bloques:

\section{- Según la titularidad del centro}

Los directores de los centros públicos puntúan significativamente más alto la importancia que le conceden a los siguientes ítems: Planteamiento de trabajo escolar como una actividad colectiva (4,63 versus 4,13), mediación de conflictos $(4,67$ versus $4,13)$, gestión de los recursos del centro $(4,66$ versus 3,80) y la relación de las familias con el centro $(4,81$ versus 4,40$)$.

Teniendo en cuenta la tipología del centro, existe una diferencia significativa: los directores de los centros urbanos en comparación con los directores de escuelas rurales dan más importancia a el seguimiento de los acuerdos $(4,85$ versus 4,62). 
- $\quad$ Según el número de docentes del centro

Los directores de centros pequeños otorgan más importancia a diferentes ítems, en comparación con los directores de centros rurales que otorgan menos importancia al seguimiento de los acuerdos (5 versus 4,71), al entusiasmo del profesorado del centro (5 versus 4,63) y al control del estrés que conlleva el cargo $(4,72$ versus 4,12$)$.

Los directores de centros grandes, en comparación con los directores de centros pequeños, dan menor importancia al planteamiento de trabajo escolar como una actividad colectiva $(4,71$ vs 4,29) y a la relación de las familias con el centro (4,97 vs 4,63).

\section{- Según el equipo directivo}

Los directores de equipos grandes, en comparación con los equipos directivos pequeños, dan más importancia al liderazgo compartido (4,86 versus 4,60), la gestión de los recursos del centro $(4,68$ versus 4,17$)$ y la relación de las familias con el centro $(4,82$ versus 4,57).

\section{- Según la experiencia como coordinador de ciclo u otras coordinaciones}

Los directores con experiencia en coordinación, en comparación con los directores sin experiencia, dan más importancia al liderazgo compartido entre el equipo directivo (4,92 versus 4,72$)$.

En cambio, los directores sin experiencia, en comparación con los directores con experiencia en la coordinación, le otorgan mayor importancia a la vinculación del centro con su entorno social a partir de proyectos $(4,38$ versus 4,08$)$.

\section{- Según la edad del director}

Los directores más jóvenes (45 años o menos), en comparación con los directores más mayores, le conceden mayor importancia al entusiasmo del profesorado del centro (4,96 versus 4,70). Los directores de entre 46 y 54 años, en comparación con los directores de más edad, le dan mayor importancia al éxito escolar del centro (4,92 versus 4,70). 


\section{- $\quad$ Según el género}

Las mujeres, en comparación con los hombres, le dan más importancia a la mediación de conflictos (4,73 versus 4, 33), a las relaciones de las familias con el centro $(4,83$ versus 4,62) y al control de estrés que conlleva el cargo $(4,54$ versus 4,26).

- Frecuencia con las que realizan las siguientes acciones

Los directores han valorado con qué frecuencia (del nunca al siempre) realizan una serie de acciones que conlleva el ejercicio del cargo.

Gráfico 24: Porcentaje de la realización de las actuaciones del cargo directivo

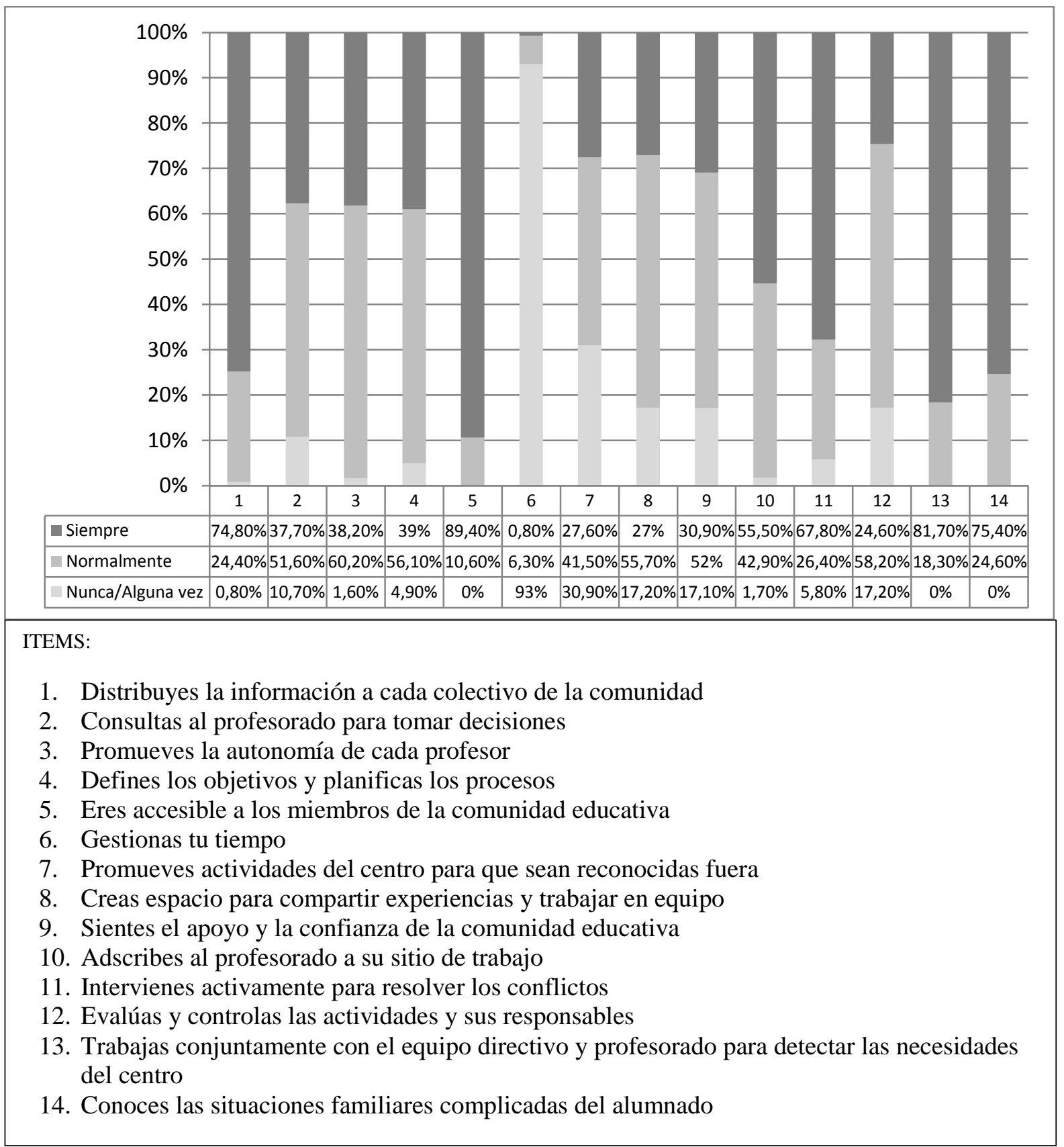


Las acciones que siempre realizan los directores son: un 89,5\% de directores manifiestan ser accesibles a todos los miembros de la comunidad educativa. Un $82 \%$ dicen trabajar conjuntamente con el equipo directivo y el profesorado para detectar las necesidades del centro y un $75 \%$ dicen conocer las situaciones familiares complicadas del alumnado y distribuir la información a cada colectivo.

En general, según los directores, todas las acciones se realizan normalmente. A parte, destacamos la gestión del tiempo, ya que un $93 \%$ de los directores no la realiza o rara vez lo hace. Este dato nos evidencia la dificultad que perciben los directores de la muestra para planificar el tiempo de manera adecuada y ajustada.

A continuación se comentan las diferencias significativas halladas:

\section{- $\quad$ Según la titularidad del centro}

Un $40 \%$ de los directores de los centros públicos siempre consulta al profesorado para tomar decisiones, frente a un $20 \%$ de los directores de centros concertados. En cambio, el $40 \%$ de los directores de centros concertados- privados dicen no consultar (o rara vez), versus un $6,5 \%$ de los directores de centros públicos.

Un $61,5 \%$ de los directores de centros públicos dicen adscribir siempre al profesorado a su puesto de trabajo versus un $13.3 \%$ de los directores de centros concertadosprivados. Si bien es cierto que alrededor del $87 \%$ de estos directores dicen realizarlo normalmente.

En relación a la intervención activa en la resolución de conflictos, aproximadamente un $72 \%$ de los directores de centros públicos dicen intervenir siempre, versus un $40 \%$ de los directores de centros concertados-privados que dicen realizarlo siempre y otro $40 \%$ que dicen realizarlo normalmente.

La evaluación y control de las actividades y sus responsables es el único ítem que los directores de centros concertados-privados dicen realizar siempre (un 33\%), versus un $23 \%$ de los directores de los centros públicos. Alrededor del 19\% de los directores de centros públicos dicen no realizar nunca o rara vez esta actuación y tan solo un 7\% de los directores de centros concertados-privados dicen no hacerlo. 
- Según la tipología del centro

Aproximadamente un $92 \%$ directores de centros urbanos dicen estar siempre accesibles a los miembros de la comunidad educativa, versus el $71 \%$ de los directores de centros rurales. El resto de los directores de centros rurales (un 29\%) dicen estar normalmente accesibles.

En cambio, consultar al profesorado para tomar decisiones, los directores de centros rurales (un 71\%) dicen hacerlo siempre, versus el 33\% de los directores de centros urbanos. En estos centros, el 56\% de los directores normalmente consulta al profesorado en temas decisivos.

\section{- Según el número de alumnos en los centros}

En los centros rurales, el $75 \%$ de los directores consulta siempre al profesorado en la toma de decisiones, frente al 35,5\% de los centros grandes. Conforme el número de alumnos va creciendo, el porcentaje va disminuyendo.

En relación a la creación de espacios para compartir experiencias y para trabajar en equipo vuelven a ser los centros rurales, los que siempre realizan la acción (58\% de los directores). En los centros con más alumnos entre el 58 y el $65 \%$ de los directores realiza la acción normalmente.

Los directores que siempre sienten el apoyo y la confianza de la comunidad educativa son el 55\% de los centros rurales. De los directores de centros grandes, tan sólo un 16\% dicen sentir siempre el apoyo de la comunidad. El porcentaje de directores que menos sienten el apoyo de la comunidad corresponde al $21 \%$ de los directores de centros pequeños.

\section{- Según el número de docentes en los centros}

El 78\% de los directores de centros rurales, siempre consultan al profesorado para la toma de decisiones. Cuanto más elevado es el número de docentes menor es el porcentaje. Entre el 52 y $62 \%$ de los directores consulta normalmente. El 14\% de los directores que no consultan o rara vez consultan son directores de centros grandes. 
En cambio, el mayor porcentaje (44\%) de directores que promueven siempre las actividades del centro para que sean reconocidas fuera son los directores de centros grandes. En contraposición, un 39\% de los directores de centros rurales que dicen no promover o sólo de manera esporádica actividades con proyección exterior.

- $\quad$ Según la complejidad del centro escolar

El mayor porcentaje de los directores de centros no complejos (58\%) dicen siempre adscribir al profesorado versus un $41 \%$ de los directores de centros de alta complejidad. Además, un $12 \%$ de los directores de centros más complejos dicen adscribir nunca o rara vez al profesorado a su puesto de trabajo.

\section{- Según el género del director}

El 62,5\% de las mujeres adscriben siempre al profesorado a su puesto de trabajo. En cambio, el 59\% de los hombres normalmente adscriben al profesorado.

\section{- Según las horas de docencia a la semana}

Un $71 \%$ de los directores que realizan 17 horas o más de docencia siempre consultan al profesorado para tomar las decisiones, frente al $25 \%$ de los directores que realizan 8 horas o menos. El 15\% de directores con menos horas de docencia reconoce no consultar (o casi nunca) al profesorado.

Por otro lado, el 94\% de los directores con 8 horas o menos de docencia está siempre accesible a los miembros de la comunidad educativa, frente al $71 \%$ de los directores con más de 17 horas de docencia a la semana.

\section{- $\quad$ Según la autopercepción del modelo directivo}

Los directores que consultan siempre al profesorado en la toma de decisiones son los que dicen coordinar $(54,5 \%)$, frente a los que dicen gestionar $(35,2 \%)$ y liderar $(34,2 \%)$. Los directores que dicen no consultar (o casi nunca) al profesorado son un $21 \%$ de los que dicen liderar y un $7 \%$ de los que dicen gestionar.

Los que dicen liderar son los que siempre promueven las actividades del centro en el exterior (42\%), frente al $20 \%$ de los que dicen gestionar o el $18 \%$ de los que dicen coordinar. Un $42 \%$ de los directores que dicen gestionar, nunca o rara vez promueven actividades fuera del centro. 
Los directores que siempre sienten el apoyo y confianza de la comunidad educativa son los que dicen liderar (53\%), frente el $27 \%$ de los que dicen coordinar y el $16 \%$ de los que dicen gestionar.

Por último, los directores que siempre evalúan y controlan las actividades y sus responsables son un $42 \%$ de los que dicen liderar, frente al $17 \%$ de los que dicen gestionar y el 14\% de los que dicen coordinar.

\subsubsection{Modelo de dirección}

Para recoger información destinada a conocer el modelo de dirección de los directores de la muestra, se han realizado preguntas sobre las funciones y actuaciones extraídas de la normativa vigente sobre en qué medida realizan dichas funciones y el nivel de dificultad de las mismas.

También se valora el compromiso que perciben los directores en los diferentes miembros de la comunidad educativa y las acciones realizan para potenciar y/o conseguir este compromiso.

- En qué grado realizas las funciones y cuál es el nivel de dificultad

Las funciones directivas son extraídas de la actual ley educativa de Cataluña, LEC (2009). Los directores valoran (del 1 al 5) el grado de realización de las funciones y el grado de dificultad de cada una de ellas.

Gráfico 25: Valoración de las funciones de la dirección y su dificultad

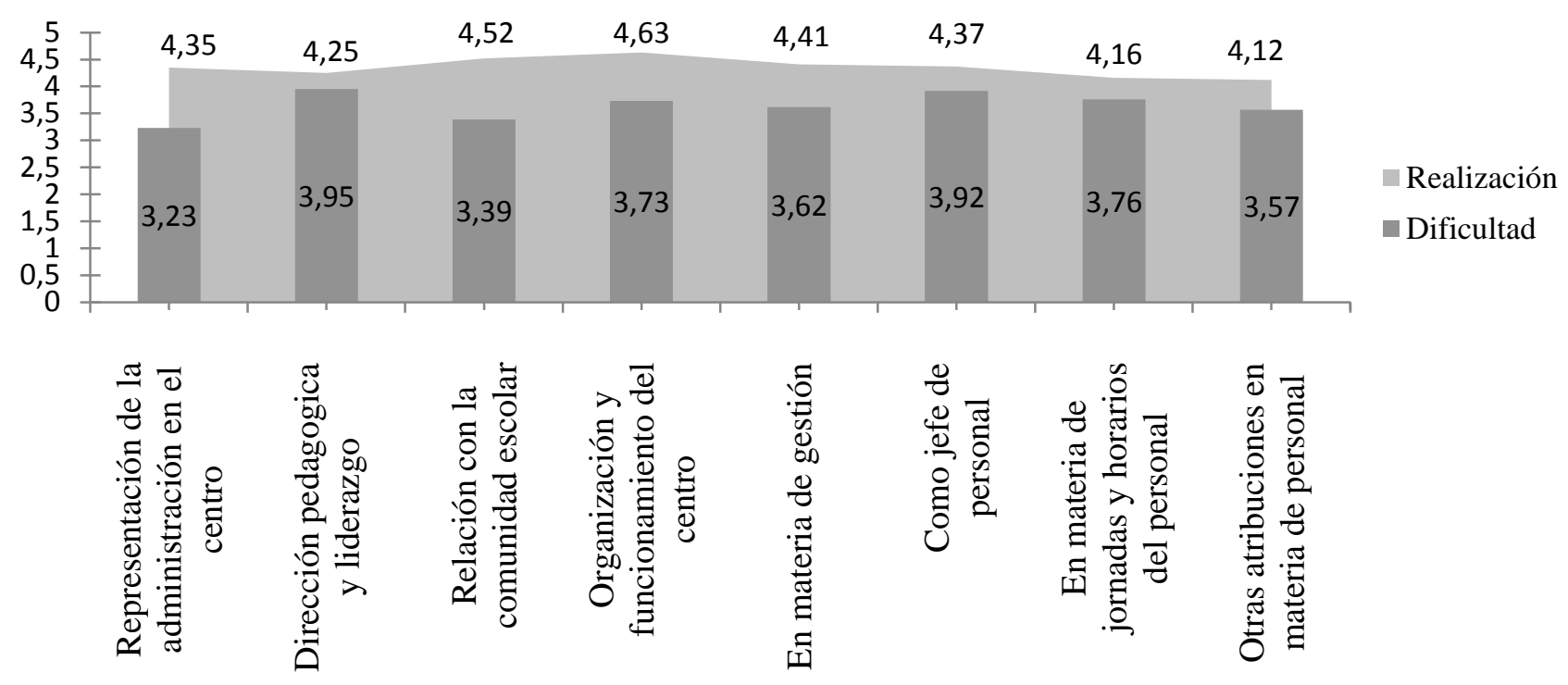


En general, todas las funciones son llevadas a cabo de manera elevada (ninguna es valorada con menos de 4 puntos sobre 5).

Entendemos que la alta valoración de las funciones realizadas se debe a que forman parte de la normativa que los directores deben cumplir. Los directores manifiestan realizar más la función genérica de organización y funcionamiento del centro y la función menos realizada es la de otras atribuciones en materia de personal.

En el gráfico también se representa el grado de dificultad de cada una de las anteriores funciones. La mayor dificultad está relacionada con la dirección pedagógica y liderazgo $y$ la correspondiente a jefe de personal.

\section{ANÁLISIS DE LA REALIZACIÓN DE LAS FUNCIONES}

A continuación, se analizan las diferencias estadísticamente significativas del apartado de realización de las funciones:

\section{- $\quad$ Según la titularidad}

Los directores de centros públicos, en comparación con los directores de centros concertados-privados, dicen realizan más las siguientes funciones:

- Representación de la Administración en el centro (4,41 versus 3,94)

- Organización y funcionamiento del centro (4,67 versus 4,38)

- En materia de gestión $(4,48$ versus 3,94$)$

- En materia de jornadas y horarios del personal (4,26 versus 3,50)

- Otras atribuciones en materia de personal $(4,29$ versus 3,08)

En cambio, los directores de centros concertados-privados, en comparación con los centros públicos, dicen realizar más la función de dirección pedagógica y liderazgo $(4,63$ versus 4,19$)$.

\section{- $\quad$ Según el número de alumnos en el centro}

Los directores de centros pequeños son los que más dicen realizan la función de otras atribuciones en materia de personal. En cambio, los que menos realizan esta función son los directores de los centros más grandes. 
- Según la tipología del centro

Los directores de centros urbanos, en comparación con los directores de centros rurales, realizan más la función de jefe de personal (4,41 versus 4).

- $\quad$ Según el equipo directivo

Los directores con equipos directivos grandes, en comparación con los directores con equipos pequeños, realizan más las siguientes funciones:

- Materia en gestión $(4,48$ versus 4,20$)$

- Otras atribuciones en materia de personal $(4,26$ versus 3,65$)$

- $\quad$ Según la experiencia directiva

Los directores con más experiencia directiva, en comparación con los directores que tienen entre 2 y 4 años, son los que realizarían más la función de representación de la Administración en el centro (4,48 versus 3,81$)$.

- $\quad \underline{\text { Según la autopercepción del modelo directivo }}$

Los directores que dicen liderar realizan más la función de dirección pedagógica y liderazgo $(4,43)$, seguidos de los que dicen gestionar $(4,20)$ y de los que dicen coordinar (4).

\section{ANÁLISIS DE LA DIFICULTAD DE LAS FUNCIONES}

A continuación, se destacan las diferencias estadísticamente significativas del apartado de dificultad de las funciones:

\section{- Según el equipo directivo}

Los directores con equipos directivos grandes, en comparación con los que tienen un equipo pequeño, manifiestan más dificultad en las siguientes funciones:

- Dirección pedagógica y liderazgo $(4,10$ versus 3,52$)$

- Relación con la Comunidad Escolar (3,54 versus 2,97)

- Organización y funcionamiento del centro $(3,88$ versus 3,28$)$ 
- Según las horas de docencia a la semana

Los directores con más docencia a la semana, en comparación con los directores que realizan entre 9 y 16 horas, son los que perciben menos dificultad en la función de la relación con la comunidad escolar (2,88 versus 3,73$)$ seguidos de los directores que realizan 8 horas o menos de docencia $(3,21)$.

- Con qué frecuencia realizan las actuaciones

En relación con las funciones anteriores, se pregunta a los directores con qué frecuencia (escala de nunca a siempre) realizan un listado de actuaciones extraídas de la normativa.

Gráfico 26: Porcentaje de directores que realizan las actuaciones

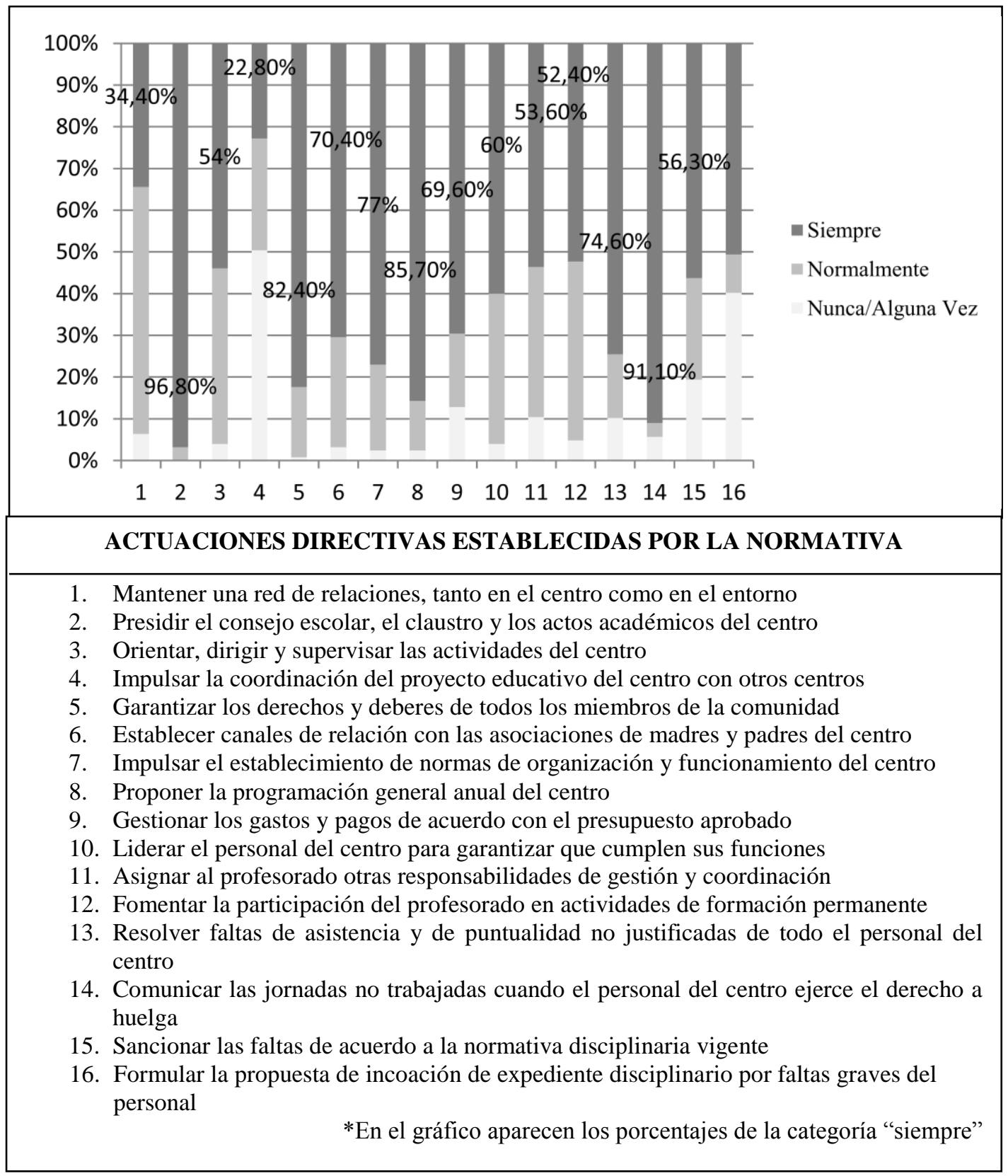


Alrededor de un $97 \%$ de los directores dicen siempre presidir el consejo escolar, el claustro y los actos académicos del centro. Seguido de un $91 \%$ de directores que comunican siempre las jornadas no trabajadas cuando el personal del centro ejerce su derecho a huelga.

Por el contrario, la acción que dicen realizar con menos frecuencia es impulsar la coordinación del proyecto educativo del centro con otros centros, ya tan sólo el $23 \%$ de los directores dicen realizarla siempre, y mantener siempre una red de relaciones con el centro y con el entorno, tan solo realizada por un $34 \%$ de los directores.

Las diferencias significativas halladas son:

\section{- $\quad$ Según la titularidad del centro}

Los directores de los centros públicos, en comparación con los directores de centros concertados-privados, realizan siempre las siguientes funciones:

- Presiden el consejo escolar, el claustro del profesorado y los actos académicos del centro (99\% versus $81 \%$ )

- Establecen canales de relación con las Asociaciones de Madres y Padres de los alumnos (74\% versus $44 \%)$

- Gestionan los gastos y los pagos de acuerdo con el presupuesto aprobado (76\% versus $25 \%)$

- Resuelven las faltas de asistencia y de puntualidad no justificadas de todo el personal del centro ( $83 \%$ versus $14 \%)$

- Comunican las jornadas no trabajadas cuando el personal del centro ejerce el derecho a huelga (96\% versus $53 \%)$

\section{- Según la tipología del centro}

El $42 \%$ de los directores de centros rurales impulsan siempre una coordinación del proyecto educativo del centro con otros centros. El 54\% de los directores de centros urbanos manifiestan que nunca o rara vez impulsan el proyecto educativo con otros centros.

En cambio, en la asignación al profesorado del centro otras responsabilidades de gestión y de coordinación docente, el $31 \%$ de los directores de centros rurales dicen 
asignar responsabilidades nunca o rara vez (en contraposición con el $8 \%$ de los centros urbanos).

\section{- $\quad$ Según el número de alumnos del centro}

El 95\% de los directores de centros rurales gestionan siempre los gastos y los pagos de acuerdo con el presupuesto aprobado; en cambio tan sólo un $67 \%$ de los directores de centros grandes lo realizan siempre, ya que el $21 \%$ de estos directores afirma que nunca o rara vez gestiona los pagos.

\section{- $\quad$ Según el equipo directivo}

Los directores con equipos directivos grandes, en comparación con los directores con equipo directivos pequeños, realizan siempre en un porcentaje más elevado las siguientes actuaciones:

- Presiden el consejo escolar, el claustro del profesorado y los actos académicos del centro (99\% versus $91 \%)$

- Impulsan el establecimiento de normas de organización y funcionamiento del centro $(79 \%$ versus $72 \%)$

- Resuelven faltas de asistencia y de puntualidad no justificadas de todo el personal del centro ( $81 \%$ versus $55 \%)$

El 26\% de los directores con equipos directivos pequeños dicen no gestionar los gastos y los pagos de acuerdo con el presupuesto aprobado (tan sólo el 8,5\% de los directores con equipos directivos grandes dicen no hacerlo).

En cambio, el $58 \%$ de los directores con equipos directivos grandes nunca o rara vez impulsan la coordinación del proyecto educativo del centro con otros centros, frente al $29 \%$ de los directores con equipos pequeños que dicen no hacerlo.

\section{- $\quad$ Según la edad del director}

El $71 \%$ de los directores con 45 años o menos asignan siempre al profesorado del centro otras responsabilidades de la gestión y coordinación docente, frente al 41,5\% del grupo de directores entre 46 y 54 años.

El 82\% de los directores más jóvenes siempre formulan la propuesta de incoación de expediente disciplinario por faltas graves del personal. En cambio el $50 \%$ de los 
docentes con más edad y el $47 \%$ de los directores entre 46 y 54 años dicen no hacerlo nunca o muy pocas veces.

- $\quad$ Según las horas de docencia a la semana

El 98\% de los directores con entre 9 y 16 horas de docencia a la semana comunican siempre las jornadas no trabajadas cuando el personal del centro ejerce el derecho a huelga, frente al $84 \%$ de los directores que realizan 8 horas o menos de docencia.

- $\quad$ Según la autopercepción del modelo directivo

El porcentaje más alto de los directores que siempre orientan, dirigen y supervisan las actividades del centro son los directores que dicen liderar (68\%). En contraposición, el porcentaje más alto de los que dicen no orientar, dirigir y supervisar las actividades del centro corresponde a directores que dicen coordinar (14\%).

Por otro lado, los directores que siempre comunican las jornadas no trabajadas cuando el personal del centro ejerce el derecho a huelga son los que dicen gestionar con un $98 \%$, seguido del $91 \%$ de los que dicen coordinar y el $81 \%$ de los que dicen liderar.

- $\quad$ Según la experiencia como coordinador de ciclo u otras coordinaciones

El porcentaje de los directores que tienen experiencia en coordinación es más elevado, en comparación con los directores que no tienen experiencia en las siguientes actuaciones:

- Proponen siempre la programación general anual del centro (96\% versus $79 \%$ )

- Sancionan las faltas de acuerdo con la normativa disciplinaria vigente (72\% versus $44 \%$ )

- Percepción del compromiso de la comunidad educativa

Los directores valoran del 1 al 5 el grado de compromiso que consideran que tienen los diferentes colectivos de la comunidad en relación a diferentes aspectos. 
Tabla 86: Media del compromiso de la comunidad educativa

\begin{tabular}{|l|r|r|r|r|r|}
\hline & N & Mín. Máx. Media & Desv. típ. \\
\hline Del cargo directivo con el funcionamiento del centro & 128 & 1 & 5 & 4,84 & 0,51 \\
\hline Del cargo directivo con la comunidad educativa & 128 & 2 & 5 & 4,74 & 0,53 \\
\hline Del profesorado con el éxito escolar & 128 & 1 & 5 & 4,50 & 0,67 \\
\hline Del profesorado con proyectos del centro y comunidad & 128 & 3 & 5 & 4,37 & 0,64 \\
\hline Del profesorado con la familia & 128 & 1 & 5 & 4,34 & 0,67 \\
\hline De las familias con proyectos del centro y comunidad & 128 & 1 & 5 & 3,83 & 0,88 \\
\hline De las familias con los resultados de sus hijos/as & 128 & 1 & 5 & 3,84 & 0,88 \\
\hline Del alumnado con sus resultados & 128 & 1 & 5 & 3,96 & 0,80 \\
\hline Del alumnado con proyectos del centro y comunidad & 128 & 1 & 5 & 4,04 & 0,82 \\
\hline
\end{tabular}

Los directores opinan que su propio compromiso con el funcionamiento del centro y con la comunidad educativa es muy positivo (son las dos puntuaciones más elevadas y cercanas al 5 grado máximo de valoración). En cambio, observamos una leve disminución en la percepción que tienen los directivos respecto al compromiso del profesorado, del alumnado y de las familias.

A continuación, se detallan diferencias significativas:

\section{- Según la tipología del centro}

Los directores de centros urbanos, en comparación con los directores de centros rurales, perciben más alto su propio compromiso con el funcionamiento del centro (4,88 versus $4,46)$.

\section{- $\quad$ Según el número de alumnos del centro}

Los directores que perciben más alto el compromiso del profesorado con los proyectos del centro y comunidad son los directores de centros rurales $(4,72)$. En cambio, los que menos perciben el compromiso del profesorado en proyectos son los directores de centros medianos $(4,22)$. 
- $\quad$ Según el número de docentes del centro

Los directores de centros rurales, en comparación con los directores de centros grandes, perciben más alto el compromiso del profesorado con los proyectos del centro y la comunidad $(4,73$ vs 4,21$)$.

\section{- $\quad$ Según el equipo directivo}

Los directores con equipos directivos pequeños, en comparación con los directores que tienen un equipo grande, perciben más alto el compromiso del profesorado con los proyectos del centro y la comunidad (4,57 versus 4,30).

\section{- Según la complejidad del centro escolar}

Los directores de centros de alta complejidad, en comparación con los centros que no lo son, perciben significativamente más bajo el compromiso de las familias con los proyectos del centro y la comunidad (3,12 versus 3,94), el compromiso de las familias con los resultados de sus hijos $(3$ versus 3,97$)$ y el compromiso del alumnado con sus resultados $(3,47$ versus 4,04$)$.

- $\quad$ Según el número de horas de docencia a la semana

Los directores que más alto perciben el compromiso del profesorado con los proyecto del centro y la comunidad son los directores que realizan 17 horas o más $(4,60)$. Los directores que realizan menos horas de docencia son los que perciben más bajo el compromiso del profesorado $(4,20)$.

\section{- $\quad$ Según la experiencia como jefe de estudios o secretario}

Los directores que previamente no han ejercido como jefe de estudios o secretario, en comparación con los que tienen experiencia, perciben más alto el propio compromiso con la comunidad educativa $(4,85$ versus 4,60$)$ y el compromiso del alumnado con los proyectos del centro y la comunidad $(4,18$ versus 3,88$)$.

A continuación, las preguntas abiertas nos permitirán conocer las diferentes acciones que realizan para mantener o mejorar el nivel de compromiso de los diferentes miembros de la comunidad educativa. 
- Acciones para conseguir potenciar el compromiso de la comunidad educativa

Esta pregunta deben contestar sólo los directores que perciben bajo (1-2 sobre 5) el compromiso de los diferentes miembros de la comunidad.

Se obtienen un total de 20 referencias de 13 directores diferentes, que se han clasificado a partir de los destinatarios y de si se trata de acciones para potenciar la comunicación o acciones para potenciar la relación con el entorno.

Las acciones que los directores consideran relevantes para mejorar el compromiso del alumnado son: "implicación del alumnado con los proyectos del centro y sus resultados académicos" (ID 9) y “trabajar más la atención a los alumnos [...]” (ID 49).

En el mayor número de referencias, los destinatarios son las familias. Las acciones que potenciarían los directores para mejorar el compromiso de los familiares se dirigen a "buscar canales de relación entre la familia y la escuela" (ID 10), ofrecer "más charlas destinadas a los padres y madres para ofrecerles herramientas para ayudar a sus hijos [...] Actividades en el aula para implicar a los padres en el día a día del proceso educativo de sus hijos y el trabajo con la escuela [...]” (ID 49). Abrir la escuela a la comunidad y al entorno "[...] Para encontrar vínculos de unión que ayuden a un cambio de actitud de las familias" (ID 50).

Además, se detectan una serie de respuestas que no son acciones sino explicaciones de la realidad del contexto del centro "en ciertos entornos cuesta la participación de las familias" (ID 39); “Participación de las familias muy puntual ya que las familias de origen distinto a los nuestros les cuesta mucho implicarse en el aprendizaje de sus hijos porque no entienden nuestro idioma” (ID 58).

- Acciones que desarrollan para conseguir el compromiso de la comunidad

Esta pregunta se dirige a los directores que consideran alto el compromiso (3-5 sobre 5) de los diferentes miembros de la comunidad.

Se obtienen un total de 214 referencias de 73 directores, que se han clasificado en función de los destinatarios de las acciones. 
Tabla 87: Destinatarios de las acciones para mantener un compromiso alto

\begin{tabular}{|c|l|}
\hline $\mathbf{N}^{\mathbf{0}}$ acciones & \multicolumn{1}{|c|}{ Destinatarios } \\
\hline 57 & Profesorado \\
\hline 54 & Modelo de dirección \\
\hline 40 & Familias \\
\hline 37 & Comunidad Educativa \\
\hline 13 & Alumnado \\
\hline 13 & Entorno \\
\hline
\end{tabular}

Algunas acciones están relacionadas con su modelo de dirección. Los directores que consideran que en su día a día gestionan realizan acciones en relación a la comunicación como "dar las máximas facilidades de comunicación y feedback" (ID 17) y "dedicar un buen porcentaje del tiempo de dirección a la atención personalizada y/o grupal" (ID 105). También realizan acciones sobre su propio compromiso: "trabajo con ilusión y con muchas ganas y sé que eso se "traspasa" y sirve de ejemplo de funcionamiento" (ID 12); además de autoevaluarse, formarse y tener iniciativa personal. Las acciones basadas en el control y coordinación del centro se centran en examinar todos los temas que afectan a la escuela como la "elaboración de criterios metodológicos para establecer una línea de escuela” (ID 119).

Los directores que asumen un modelo de coordinación "[...] conocen las familias, conocen a los alumnos, forman parte de las diferentes comisiones de evaluación” (ID 35). En relación al control y coordinación del centro, "presiden y dinamizan los órganos de gobierno, participación y gestión del centro: equipo directivo, claustro de maestros, consejo escolar [...] formar parte de los órganos de seguimiento académico del alumnado" (ID 104).

En cuanto a los directores que se encuadran en el modelo de liderazgo, centran su acción en mantener buenas redes y estrategias de comunicación e información, además de "valorar todas las iniciativas" (ID 1). Las acciones centradas en su propio compromiso son: dedicar y "proponer actividades para la mejora constante" (ID 15) y de "reflexión, trabajo, liderazgo, respeto, dialogo constructivo, humildad, formación, innovación y coordinación. En todo momento busco la profesionalidad” (ID 46). 
En referencia a las acciones de control y coordinación del centro se concretan en "valoraciones y evaluaciones internas al inicio y al final del curso" (ID 15) y trabajar en equipo.

Las acciones destinadas al profesorado (basadas en el propio compromiso del director con el profesorado) son: asesorar, escuchar, motivar y apoyar al profesorado; "Hablar y escuchar a los compañeros e intentar motivarlos para conseguir una implicación mayor a nivel personal y profesional” (ID 62).

Las acciones para mantener y fomentar la comunicación son esenciales para cuidar las relaciones entre equipo directivo y docentes. La asistencia y la participación en las reuniones periódicas del centro o entrevistas individuales son los medios que los directores tienen para mantener una relación cercana y poder ejercer su influencia positiva en el profesorado.

Los directores intentan mantener la plantilla de docentes estable, profesional y motivada con el proyecto del centro. Si se trata de un centro con cambios constantes en las plantillas es complicado mantener el compromiso de los docentes ya que muchos están temporalmente (“de paso") y no se implican lo suficiente en el centro.

Las acciones de trabajo conjunto con el profesorado son reflexionar sobre las prácticas educativas, programar y consensuar juntos, elaborar conjuntamente criterios de evaluación por áreas y niveles además de diseñar y desarrollar conjuntamente buenas prácticas y materiales curriculares. "Impulso del trabajo colectivo del profesorado entre las diferentes etapas para favorecer la coherencia en el proceso educativo" (ID 119).

También se destaca la delegación de tareas y la dinamización del claustro de profesores. "Dar más responsabilidades a todo el claustro para equiparar el grado de exigencia entre ellos" (ID 29). "Incluir todo el profesorado según sus capacidades y actitudes en los proyectos" (ID 49). Otras acciones demuestran un interés por mantener actualizada la formación del profesorado del centro, a través de la oferta y recomendación de diferentes acciones formativas. También se considera importante impulsar proyectos innovadores e interdisciplinarios que motiven al profesorado: "Desde la dirección se apoyan los proyectos del centro y se impulsa la participación en proyectos de innovación educativa” (ID 63). 
Figura 15: Resumen de las acciones destinadas al profesorado

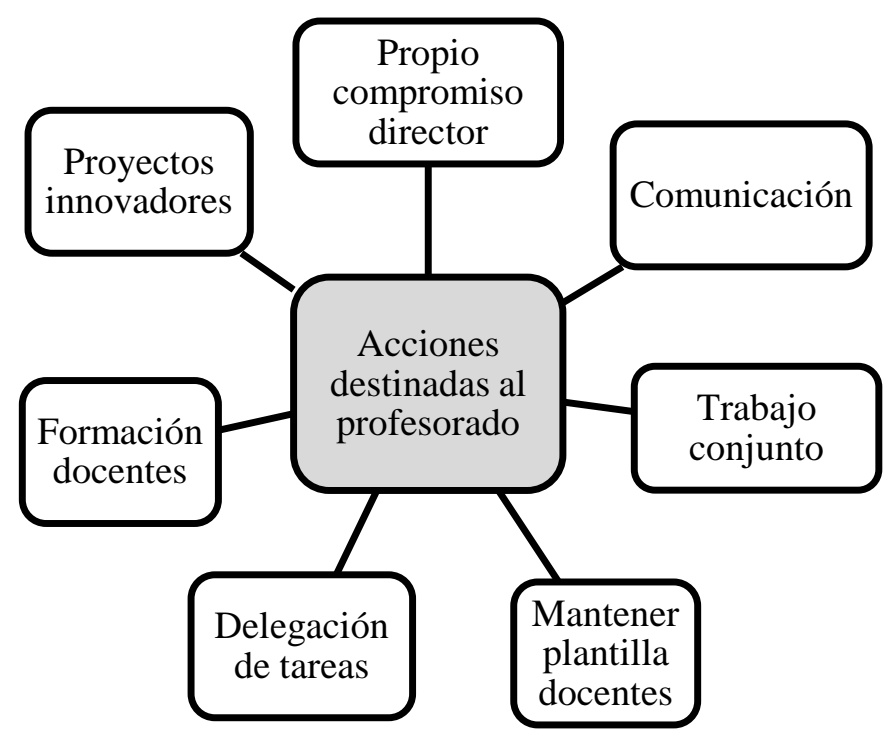

Para mantener alto el compromiso del alumnado, los directores realizan dos tipos de acciones: las directas y las indirectas. El primer grupo son acciones en las cuales el director tiene un contacto directo con el alumnado como "ejercer la docencia a todos los grupos-clase de primaria con un mínimo de una sesión semanal por grupo" (ID 104), “realizar asambleas y tutorías individualizadas" (ID 99).

El segundo grupo, corresponde a las acciones indirectas que realiza el director pero que influyen en el alumnado. Algunas de estas acciones son facilitar recursos y técnicas de estudio para mejorar los aprendizajes y asistir a las sesiones de evaluación de todos los cursos para el conocimiento del seguimiento individual de cada alumno. "Seguir los procesos de aprendizaje de los alumnos en cuanto a las programaciones del aula, los resultados de evaluación y la realización de deberes" (ID 55).

Figura 16: Resumen de las acciones destinadas al alumnado

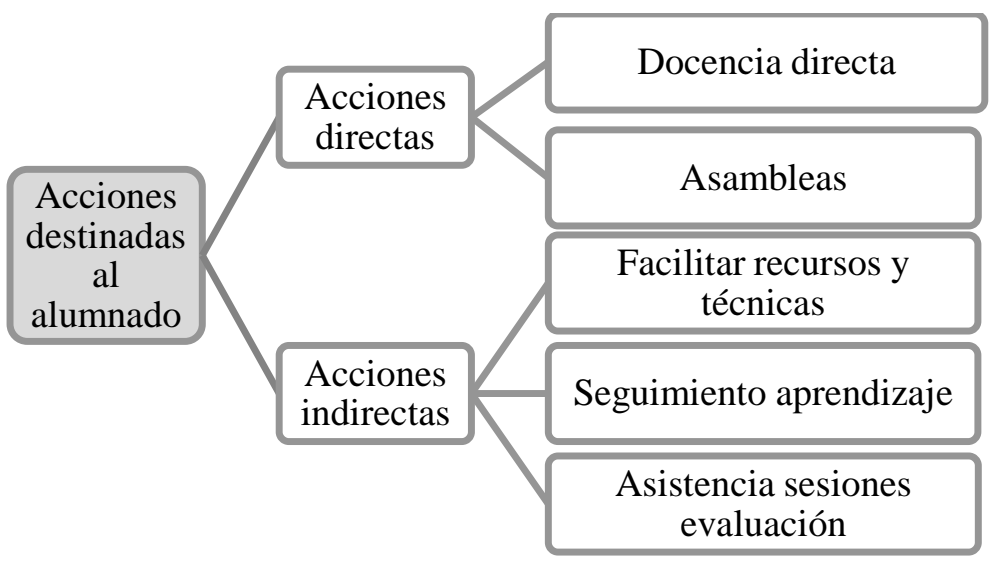


Respecto las acciones que los directores realizan para conseguir el compromiso de las familias, se basan en facilitar la comunicación ofreciendo un horario flexible para atender a las familias de un modo más cercano y realizar el número de reuniones que sean necesarias, siempre con un "trato personalizado a las familias” (ID 27). Además de mantener un contacto permanente con la utilización de las nuevas tecnologías "Gestionar dinámica de blogs, webs, la revista trimestral, el Twitter, entrevistas con las familias, encuentros formales e informales con las familias y sus representantes" (ID 70).

Los directores mantienen contacto regular con las Asociaciones de Madres y Padres de los Alumnos (AMPA) y coordinan varias actividades de manera conjunta "relacionarse con las familias a través de trabajos con la junta del AMPA”(ID 55).

Las acciones que realizan para implicar a las familias en las actividades en el centro se focalizan en valorar el trabajo de los padres, crear un consejo de participación de familias, abrir las actividades a su participación de las familias y programar clases en las que la familia se tenga que implicar. "[...] estamos mejorando su participación en el centro, colaborando en la dinámica del centro, en las tareas educativas que complementen con su experiencia, como por ejemplo: charlas de expertos en un aspecto curricular, taller de manualidades, etc." (ID 107).

Figura 17: Resumen de las acciones destinadas a las familias

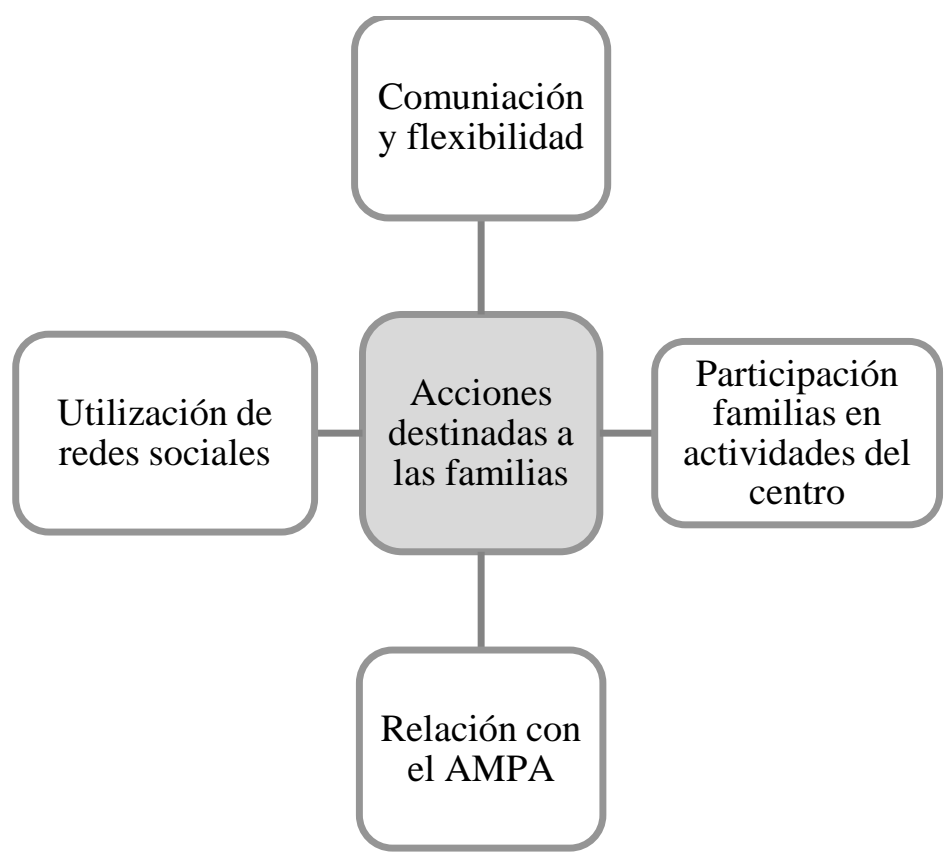


Las acciones generales destinadas a potenciar un compromiso de toda la comunidad educativa son: promover encuentros para "valorar las aportaciones personales de los diferentes miembros de la comunidad educativa" (ID 15), dedicar las horas necesarias a atender a toda la comunidad educativa, trabajar en equipo y de manera coordinada, "resolución de conflictos de manera dialogada con los diferentes miembros de la comunidad educativa” (ID 70) y proponer proyectos innovadores “ [...] que puedan animar al personal de la comunidad educativa. Por ejemplo, escuelas verdes, impulso lectura, etc. "(ID 43).

Los directores manifiestan que todas estas acciones están especificadas en la programación anual y en su proyecto educativo de centro "a través de determinadas acciones y sus indicadores previstos en el proyecto de dirección como [...] tengo más de 45 indicadores en mi proyecto” (ID 23), “[...] en el proyecto de dirección está muy bien definido el plan de actuación [...]" (ID 63).

Figura 18: Resumen de las acciones destinadas a la comunidad educativa

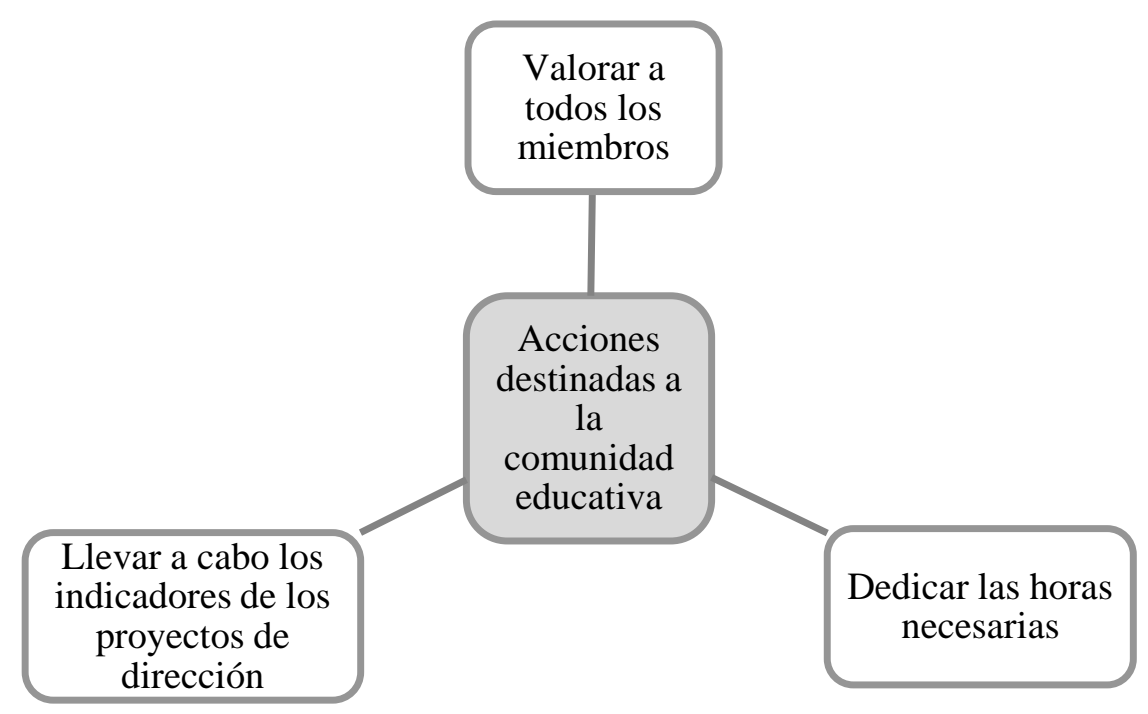

Para finalizar, las acciones destinadas al entorno pretenden potenciar la comunicación y coordinación con ayuntamientos y servicios sociales de la zona para "desarrollar actividades y proyectos en relación con el entorno social y con sus entidades" (ID 38) y tener "buenas relaciones con las administraciones y entidades del barrio, etc." (ID 88). 
En definitiva, para lograr una mejora escolar es necesario conseguir el compromiso de todos los miembros de la comunidad escolar. Sobre todo aquellos miembros que tradicionalmente han tenido un papel secundario en la escuela (familias y entorno). También detectamos que aún sigue siendo una asignatura pendiente la relación y trabajo en red entre los centros educativos.

\subsubsection{Satisfacción}

Para profundizar en la satisfacción del cargo directivo, se pide a los directores que valoren los ítems que les aporten más satisfacción. Se destacan los aspectos que han aportado más satisfacción y también insatisfacción a los directores y si las motivaciones de acceso al cargo se han visto modificadas con la experiencia directiva.

- Valorar el grado de satisfacción

Los directores valoran del 1 (mínimo) al 5 (máximo) el grado de satisfacción que le proporcionan diferentes ítems.

Tabla 88: Media de la satisfacción

\begin{tabular}{|c|c|c|c|c|c|}
\hline & $\mathrm{N}$ & Mín. & Máx. & Media & $\begin{array}{l}\text { Desv. } \\
\text { típ. }\end{array}$ \\
\hline La implicación del equipo docente en el funcionamiento del centro & 124 & 2 & 5 & 4,48 & 0,66 \\
\hline Las tareas realizadas por el equipo directivo & 124 & 3 & 5 & 4,61 & 0,52 \\
\hline $\begin{array}{l}\text { La utilidad del proyecto educativo para definir los valores del } \\
\text { centro }\end{array}$ & 122 & 2 & 5 & 4,23 & 0,75 \\
\hline $\begin{array}{l}\text { La participación y colaboración de los alumnos en los proyectos } \\
\text { del centro }\end{array}$ & 123 & 1 & 5 & 4,27 & 0,82 \\
\hline Las oportunidades para crear proyectos innovadores y creativos & 123 & 2 & 5 & 4,27 & 0,75 \\
\hline El reconocimiento social que recibes como director & 121 & 1 & 5 & 3,43 & 1,04 \\
\hline $\begin{array}{l}\text { Las relaciones de los miembros del centro con los padres de los } \\
\text { alumnos }\end{array}$ & 124 & 2 & 5 & 4,15 & 0,73 \\
\hline Los procedimientos para gestionar los recursos & 123 & 1 & 5 & 3,95 & 0,81 \\
\hline $\begin{array}{l}\text { La disposición de los docentes para encontrar espacios de trabajo } \\
\text { conjuntos }\end{array}$ & 121 & 2 & 5 & 4,12 & 0,77 \\
\hline El apoyo de la Administración en tu tarea de director & 120 & 1 & 5 & 3,67 & 0,97 \\
\hline
\end{tabular}




\begin{tabular}{|c|c|c|c|c|c|}
\hline $\begin{array}{l}\text { La coordinación y cooperación con el entorno social del centro } \\
\text { (asociaciones, escuelas ...) }\end{array}$ & 122 & 1 & 5 & 3,98 & 0,86 \\
\hline La relación de los docentes con el equipo directivo & 124 & 3 & 5 & 4,52 & 0,55 \\
\hline El grado de cumplimiento de los acuerdos & 124 & 2 & 5 & 4,35 & 0,64 \\
\hline La competencia docente del profesorado & 123 & 2 & 5 & 4,31 & 0,63 \\
\hline La libertad y autonomía para tomar decisiones & 122 & 2 & 5 & 4,19 & 0,74 \\
\hline
\end{tabular}

Los ítems más valorados, y por lo tanto, que producen más satisfacción a los directores, son los relacionados con el equipo directivo o docente como: las tareas realizadas por el equipo directivo, la relación de los docentes con el equipo directivo y la implicación del equipo docente en el funcionamiento del centro.

Los aspectos menos valorados por los directores son el reconocimiento social que reciben al ser director/a y el apoyo de la Administración con su tarea directiva.

Se detallan, a continuación las diferencias significativas:

- Según la titularidad del centro

A los directores de centros concertados-privados, en comparación con los directores de centros públicos, les producen más satisfacción:

- La utilidad del proyecto educativo para definir los valores del centro (4,75 versus 4.15)

- $\quad$ El grado de cumplimiento de los acuerdos $(4,81$ versus 4,29$)$

- La libertad y autonomía para tomar decisiones (4,56 versus 4,13)

En cambio, a los directores de centros públicos, en comparación con los directores de centros concertados-privados, les producen más satisfacción:

- Los procedimientos para gestionar los recursos $(4,03$ versus 3,44)

- El apoyo de la administración en la tarea directiva (3,77 versus 3,06)

- La coordinación y cooperación con el entorno social del centro (4,07 versus $3,44)$ 
Las siguientes figuras resumen los anteriores aspectos:

Figura 19: Relación de la satisfacción del cargo directivo y la titularidad del centro
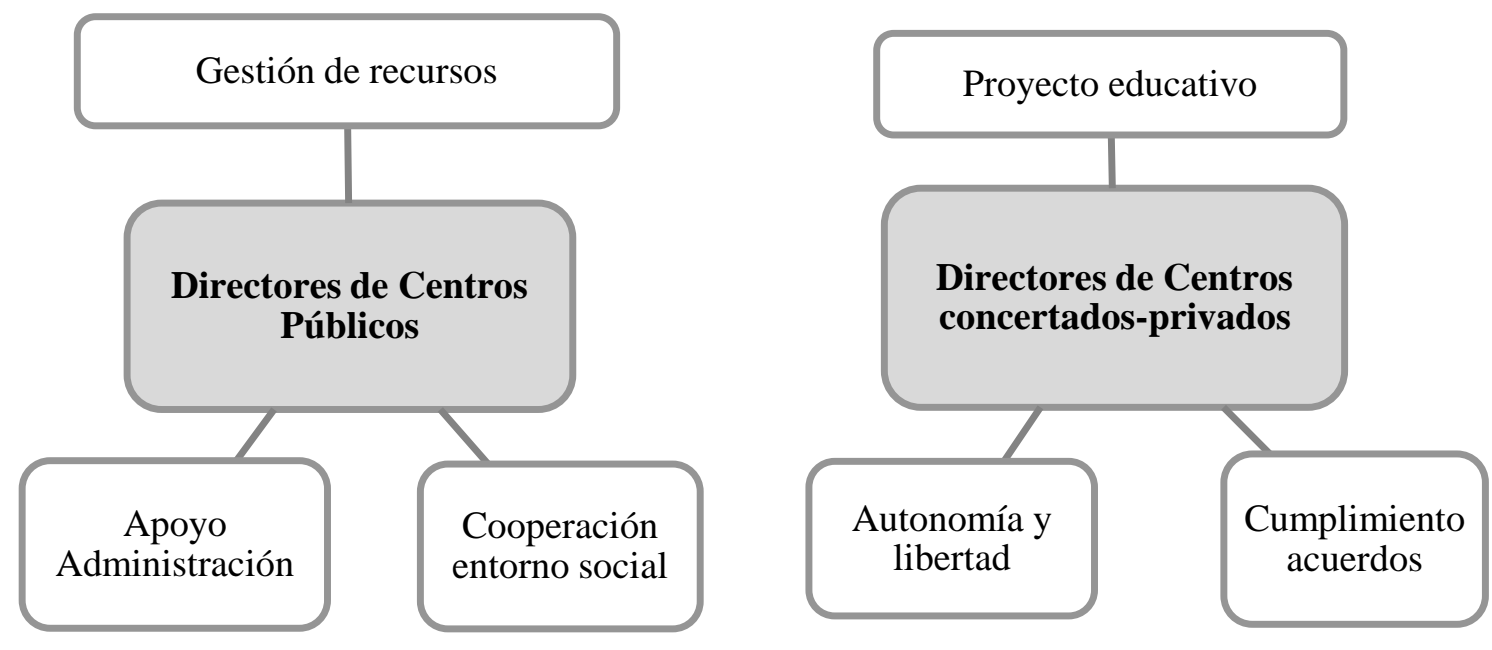

- Según la tipología del centro

A los directores de centros rurales, en comparación con los directores de centros urbanos, les proporciona más satisfacción la coordinación y la cooperación con el entorno social del centro (asociaciones, escuelas, etc.) (4,54 versus 3,92).

\section{- Según el número de docentes del centro}

A los directores de centros rurales, les produce más satisfacción $(4,60)$ la competencia docente del profesorado. En cambio, a los directores de centros grandes les produce más satisfacción $(4,66)$ el grado de cumplimiento de los acuerdos que a los directores de escuelas medianas $(4,14)$.

\section{- Según la complejidad del centro escolar}

Los directores de centros de alta complejidad, en comparación con los directores de centros que no lo son, valoran más bajo la satisfacción de los siguientes aspectos:

- El reconocimiento social que reciben como director (2,84 versus 3,54)

- Los procedimientos para gestionar los recursos ( 3.50 versus 4,03) 
- $\quad$ Según el equipo directivo

A los directores con equipos directivos pequeños, en comparación con los directores con equipos grandes, les producen más satisfacción los siguientes aspectos:

- La utilidad del proyecto educativo para definir los valores del centro (4,50 versus 4,13)

- $\quad$ El grado de cumplimiento de los acuerdos (4,63 versus 4,26)

- La competencia docente del profesorado (4,59 versus 4,21)

- La libertad y autonomía para tomar decisiones $(4,47$ versus 4,09$)$

- $\quad$ Según el género

A las mujeres, en comparación con los hombres, les produce más satisfacción la participación y colaboración de los alumnos en los proyectos del centro (4,38 versus $4,03)$.

- Según las horas de docencia a la semana

Los directores con más horas de docencia (17 horas o más), en comparación con los directores con menos horas, les produce más satisfacción la competencia docente del profesorado $(4,59$ versus 4,14$)$.

\section{- Según la autopercepción del modelo directivo}

A los directores que dicen liderar, en comparación con los directores que dicen gestionar, les produce más satisfacción la libertad y autonomía para tomar decisiones $(4,41$ versus 4,02$)$.

\section{- $\quad$ Según la experiencia como jefe de estudios o secretario}

Los directores que no han tenido experiencia anterior como jefe de estudios o secretario, en comparación con los directores que tiene experiencia, valoran más alto la satisfacción de las oportunidades para crear proyectos innovadores y creativos (4,40 versus 4,12 ). 
- Fuentes de satisfacción del cargo directivo

En cuanto a los aspectos más gratificantes durante el tiempo que llevan en el cargo, se obtienen un total de 299 referencias de 111 directores, categorizada en:

Tabla 89: Fuentes de la satisfacción del cargo directivo

\begin{tabular}{|c|l|}
\hline $\mathbf{N}^{\mathbf{0}}$ referencias & \multicolumn{1}{|c|}{ Categorías } \\
\hline 96 & Mejoras realizadas \\
\hline 62 & Buena comunicación y relaciones \\
\hline 28 & Aplicación de proyectos \\
\hline 27 & Apoyo del claustro \\
\hline 20 & Experiencia adquirida \\
\hline 20 & Participación familias y comunidad \\
\hline 20 & Satisfacción del alumnado \\
\hline 19 & Reconocimiento externo \\
\hline
\end{tabular}

El gran volumen de satisfacciones hace referencia a las mejoras realizadas con éxito en el centro. La mayor satisfacción para los directores es ver cómo los objetivos se logran y "avanzar como escuela" (ID 114), mantener una "dinámica de mejora continua" (ID 192). Sobre todo les satisface "la mejora de los resultados académicos y la cohesión social” (ID 105) además de mantener el buen nivel escolar y el prestigio de la escuela.

Las relaciones personales y profesionales con los docentes, familias y alumnado son también fuentes de satisfacción para la dirección: "el buen ambiente entre los miembros de la comunidad educativa" (ID 153), "la cohesión del grupo de maestros, padres y alumnos" (ID 147).

Además, del buen clima laboral, la cooperación y trabajo en equipo entre los diferentes miembros de la comunidad educativa, la consolidación y el sentimiento de pertenecer a la escuela.

En lo que respecta a los proyectos del centro, "potenciar proyectos de innovación" (ID 43) y "llevar a cabo un proyecto innovador y de calidad" ((ID 243) provocan satisfacción en los directivos. Sobre todo "conseguir proyectos de innovación” (ID 239) y "ver cómo se hace realidad el proyecto" (ID 76). 
Respecto a los docentes, a los directores les produce satisfacción "tener un buen equipo docente con ganas de cambio” (ID 157), además de que estén implicados y comprometidos con la escuela. Obtener "respuesta positiva del claustro ante todas las propuestas efectuadas" (ID 75) y sobre todo "mantener el apoyo del claustro durante tanto tiempo" (ID 88).

A partir de la experiencia adquirida, los directores también mencionan una serie de satisfacciones relacionadas con el tener una visión y conocimiento global del centro, la adquisición de nuevos conocimientos, el "aumento de la seguridad en las tareas" (ID 58), superar obstáculos y el “crecer personalmente y profesionalmente” (ID 204).

Aunque no todos los directores tienen el mismo número de horas de docencia directa con el alumnado, el vínculo entre alumnado y director provoca satisfacciones: el agradecimiento de los alumnos, "el cariño de los alumnos” (ID 120), la evolución y “progreso del alumnado” (ID 183) y "ver que los alumnos tienen éxito cuando van al instituto" (ID 274).

En los centros que cuentan con la participación e implicación de las familias y la comunidad educativa, se generan dinámicas satisfactorias para los directivos: "ver que la comunidad responde positivamente" (ID 233), "llegar a acuerdos con toda la comunidad educativa" (ID 229) o "la implicación de toda la comunidad educativa en el seguimiento de los proyectos de la escuela” (ID 280).

Además, las muestras de apoyo, la proximidad de las familias y observar la satisfacción de los padres provoca satisfacción (reconocimiento): "la valoración de la escuela en el entorno" (ID 77), "la buena valoración que hacen las instituciones de nuestro centro" (ID 274) o "el reconocimiento institucional de la función de la escuela" (ID 197).

Cabe destacar una respuesta en la que se manifiesta no tener satisfacciones "como director": "al ser una escuela pequeña, el cargo de director no me ha aportado ninguna satisfacción como director. Sí como profesor." (ID 253) 
- Fuentes de insatisfacción del cargo directivo

En cuanto a los aspectos menos gratificantes, se han obtenido un total de 250 referencias de 109 directores, que categorizamos en:

Tabla 90: Fuentes de insatisfacción del cargo directivo

\begin{tabular}{|c|l|}
\hline $\mathbf{N}^{\mathbf{0}}$ referencias & \multicolumn{1}{|c|}{ Categorías } \\
\hline 50 & Falta de recursos \\
\hline 49 & Conflictos \\
\hline 43 & Exceso de trabajo \\
\hline 29 & Poca implicación en general \\
\hline 24 & Falta de actitud profesional \\
\hline 23 & Poca implicación de la Administración \\
\hline 21 & Resultados insatisfactorios \\
\hline 11 & Cambios de políticas educativas \\
\hline
\end{tabular}

La falta de recursos es la mayor insatisfacción por parte de los directores. Se alude a falta de recursos humanos: "las dificultades que conlleva gestionar con recursos humanos limitados" (ID 37) y la precariedad económica de los centros provocada por los recortes: "falta de presupuesto para tirar adelante algunos proyectos" (ID 75); "la disminución de la inversión económica en los últimos cursos” (ID 173). Además de la dependencia de la Administración para la gestión de personal del centro, los problemas estructurales "la relación con el ayuntamiento en relación al mantenimiento del edificio" (ID 111) y la inestabilidad de las plantillas de docentes.

Los conflictos con las familias, profesionales o sociales son otra fuente de insatisfacción para los directores encuestados.

Concretamente con las familias, lo que les produce más insatisfacción son: "algunas reacciones desproporcionadas de algunas familias" (ID 51), "la intolerancia de algunos padres" (ID 114) o "la dificultad para conectar con determinados sectores de familias" (ID 178).

Las insatisfacciones provocadas por conflictos profesionales son: los "conflictos interpersonales con los docentes" (ID 36) y los “conflictos con el equipo” (ID 298). 
Los conflictos sociales engloban las problemáticas sociales, la dificultad de resolver problemas sociales, los conflictos causados por la falta de respeto o el no querer dialogar y la incomprensión: "comprobar que las personas olvidan dos conceptos muy básicos: la buena voluntad y el sentido común” (ID 76).

Una de las causas de insatisfacción más generalizada para los directores es el exceso de trabajo del cargo. Sus quejas se centran en el exceso de burocracia que implica la dirección del centro: "exceso de funciones administrativas (aplicativos informáticos ...)" (ID 115), "la gestión administrativa (documentos, certificados...) (ID 135). En el caso de la dirección de una escuela rural " [...] cada escuela ha de llenar los papeles, documentos y aplicaciones. Por lo tanto, hacemos la faena cuatro veces (tres por escuela más una de ZER) cuando se puede hacer solamente una vez" (ID 253). Además de la burocracia, otro de los motivos de insatisfacción es el exceso de responsabilidades: "asumir responsabilidades de hechos que a veces no dependen de ti" (ID 147) y "la dificultas para resolver problemas socioeconómicos de las familias” (ID 126).

En cuanto a la implicación, se diferencia entre la poca implicación de manera global, la poca implicación o falta de actitud profesional y la poca implicación de la Administración. De manera general, es fuente de insatisfacción: "la falta de implicación de algún sector" (ID 298), "la falta de cumplir los acuerdos" (ID 85) o "la falta de apoyo en según qué momentos” (ID 287). En relación a la falta de actitud profesional de los docentes, los causantes de la insatisfacción son "el poco compañerismo" (ID 186), la poca implicación de algunos profesionales, "el poco entusiasmo de algún profesor" (ID 137) y "la incompetencia de algunos profesores que pasan por el centro" (ID 51).

La poca implicación de la Administración se relaciona con "el poco reconocimiento de las funciones directivas por parte de la Administración” (ID 57), “el ser "un número" y no poder aportar opinión en decisiones en el proceso educativo" (ID 88) o la "falta de coherencia en algunas acciones por parte de la Administración” (ID 60). En referencia a los centros concertados encontramos una queja respecto a "la discriminación, a veces, por parte de la Administración y compañeros por ser una escuela concertada” (ID 120). 
Los resultados insatisfactorios que provocan sentimientos de fracaso escolar son: "objetivos incompletos" (ID 62), el poco reconocimiento y "el avance insuficiente en las prácticas docentes y en los resultados educativos" (ID 204).

Por último, los cambios en las políticas educativas y como consecuencia "la inestabilidad del sistema educativo" (ID 63) por "la falta de rigor y consenso en los cambios del sistema educativo" (ID 116), provocan también insatisfacción en los directores.

La siguiente tabla es una síntesis de los aspectos que producen más satisfacciones e insatisfacciones a los directivos:

Tabla 91: Satisfacciones e insatisfacciones del cargo

\begin{tabular}{|c|c|c|c|}
\hline Satisfacciones & \multicolumn{2}{|c|}{ Referencias } & Insatisfacciones \\
\hline Mejoras realizadas & 96 & & \\
\hline Buena comunicación y relaciones & 62 & & \\
\hline & & 50 & Falta de recursos \\
\hline & & 49 & Conflictos \\
\hline & & 43 & Exceso de trabajo \\
\hline & & 29 & Poca implicación general \\
\hline Aplicación de proyectos & 28 & & \\
\hline Apoyo del claustro & 27 & & \\
\hline & & 24 & Falta de actitud profesional \\
\hline & & 23 & Poca implicación de la Administración \\
\hline & & 21 & Resultados insatisfactorios \\
\hline Experiencia adquirida & 20 & & \\
\hline Participación de las familias y comunidad & 20 & & \\
\hline Satisfacción del alumnado & 20 & & \\
\hline Reconocimiento externo & 19 & & \\
\hline & & 11 & Cambios de políticas educativas \\
\hline
\end{tabular}

- Cambio de las motivaciones

Los directores explican, de manera abierta, el motivo por el que sus motivaciones han cambiado o se mantienen desde el acceso al cargo hasta la actualidad. Se obtienen un total de 96 referencias de 90 directores, categorizadas en: 
Tabla 92: Categorización del cambio de motivaciones

\begin{tabular}{|c|l|}
\hline $\mathbf{N}^{0}$ referencias & \multicolumn{1}{|c|}{ Categorías } \\
\hline 57 & Se mantienen \\
\hline 19 & Aumentan \\
\hline 10 & Disminuyen \\
\hline 10 & Cambian \\
\hline
\end{tabular}

La mitad de los directores considera que sus motivaciones iniciales se mantienen, es decir, que no ha habido ningún cambio en las motivaciones: "sigo con mis convicciones, valores y continúo siendo perseverante y constante para lograr los objetivos que me propongo" (ID 57), “creo que no han cambiado sino que se han consolidado" (ID 130).

La experiencia adquirida ayuda a mantener dicha motivación "la motivación no ha cambiado, pero la experiencia te hace ser más realista” (ID 143), "con el tiempo aprendes a gestionar tus emociones y según qué cosas ya no te afectan como antes. Aprendes a relativizar los hechos" (ID 147).

El conseguir mejoras es otro de los motivos por los que se mantiene la motivación con el paso de los años en el cargo de dirección: “mantengo las mismas motivaciones que en el momento de presentar candidatura o de acceder al cargo. He ido reformulando algunos objetivos en función del grado de realización y de las circunstancias del contexto (ID 89), “comencé muy motivada y continuo así. Para mi, cada curso escolar es un nuevo reto que lo encaro con ilusión y entusiasmo" (ID 149).

Lógicamente, en el caso de los directores noveles "hace muy poco tiempo y son las mismas" (ID 233) o "hace muy poco tiempo para poder valorarlo, es el primer año" (ID 246).

En segundo lugar, el $20 \%$ de las respuestas hacen referencia a que las motivaciones aumentan. El aumento se debe principalmente a su experiencia directiva: "mucha más motivación debido a la experiencia" (ID 186), "se han ampliado y asegurado con la experiencia" (ID 58), "al principio, estaba ansiosa para conseguir cambios y resultados inmediatos. Con el tiempo, he aprendido a ser paciente y estratégica [...]" (ID 204). 
También se debe a las mejoras logradas y a la motivación por seguir trabajando para lograrlas: "las motivaciones que me impulsan a seguir son básicamente las referidas a dar continuidad al proyecto inicial y a la mejora de los resultados educativos de los alumnos [...]" (ID 182), “me mueve la motivación de mejorar diariamente [...]” (ID 232).

En tercer lugar, el $10 \%$ de respuestas restantes hacen referencia a que las motivaciones disminuyen. La disminución se debe a las dificultades sociales: "la realidad social ha cambiado mucho y ahora es mucho más difícil gestionar todo el entorno y proponer nuevos objetivos [...]”" (ID 123). También se debe al aumento de tareas relacionadas con el cargo: "[...] ahora se necesita más tiempo para hacer las tareas que corresponderían a otros perfiles profesionales como servicios sociales, psicóloga, maestro, policía, etc. El tiempo que dedicas a estas tareas (para las cuales no estamos preparados) lo sacas de poder liderar mejor el centro en todos su ámbitos" (ID 88).

Por último, el $10 \%$ de las respuestas hacen referencia a los directores cuyas motivaciones cambian a nivel cualitativo (sin especificar si aumentan o disminuyen) a lo largo de sus mandatos por las modificaciones producidas en la dirección: "la dirección es ahora más cualificada y más técnica. Hay una motivación explícita por conseguir buenos resultados de los alumnos [...]" (ID 205) y por los cambios sociales actuales: "en cada momento las circunstancias han sido diferentes" (ID 37).

Además con la experiencia del cargo la visión cambia y las motivaciones se vuelven ajustadas a la realidad. También cambia la visión del cargo directivo: "al principio era poner orden y diseñar la escuela que queríamos. Ahora me motiva el conseguir sacar el máximo de cada alumnos y hacerlos competentes y sobre todo felices [...]” (ID 211).

Figura 20: Resumen del cambio de las motivaciones directivas

\begin{tabular}{|l|}
\hline \multicolumn{1}{|c|}{$\begin{array}{c}\text { Se mantienen } \\
(60 \%)\end{array}$} \\
\hline -Para los \\
directores \\
noveles \\
-Por la asimilación \\
de la experiencia \\
directiva \\
-Para conseguir \\
mejoras \\
\hline
\end{tabular}
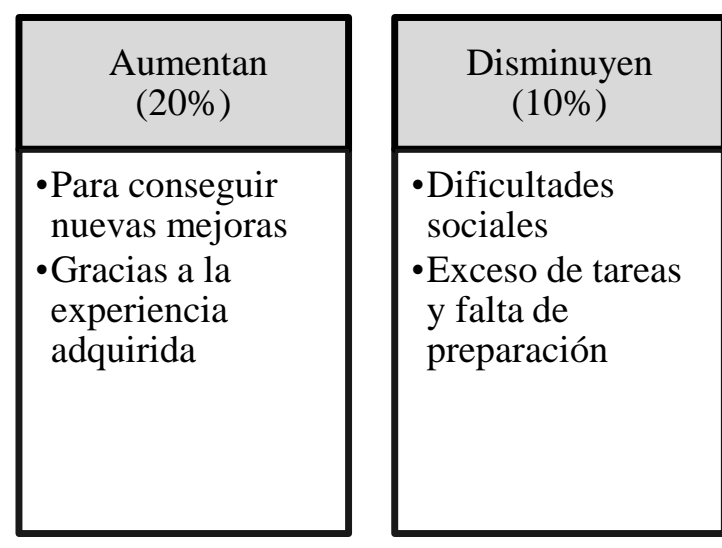

Cambian $(10 \%)$

- Por el cambio

social y

normativo

-Por la asimilación

de la experiencia

directiva 


\subsubsection{Resultados escolares}

Se pide a los directores que seleccionen un máximo de tres factores de un listado que consideren que actualmente están influenciando positivamente en el rendimiento escolar de su centro.

Tabla 93: Factores que influyen en el rendimiento escolar

\begin{tabular}{|l|c|c|}
\hline \multicolumn{1}{l|}{} & Frecuencia & Porcentaje \\
\hline Estabilidad de los equipos docentes & 65 & $50,8 \%$ \\
\hline $\begin{array}{l}\text { Autonomía organizativa: planificación del currículum en función de las } \\
\text { necesidades del contexto }\end{array}$ & 47 & $36,7 \%$ \\
\hline Procesos de enseñanza-aprendizaje & 42 & $32,8 \%$ \\
\hline $\begin{array}{l}\text { Apoyo y cooperación de las familias y el profesorado para conseguir } \\
\text { mejoras }\end{array}$ & 41 & $32 \%$ \\
\hline Motivación y apoyo de todos los miembros del centro & 39 & $30,5 \%$ \\
\hline Control del profeso del alumnado & 34 & $26,6 \%$ \\
\hline Organización y articulación curricular en relación a los procesos & 18 & $14,1 \%$ \\
\hline $\begin{array}{l}\text { Desarrollo de un sentimiento de pertenecer al centro entre los diferentes } \\
\text { miembros }\end{array}$ & 22 & $12,2 \%$ \\
\hline $\begin{array}{l}\text { Altas expectativas de la comunidad educativa sobre el rendimiento del } \\
\text { alumnado }\end{array}$ & 9 & $7 \%$ \\
\hline Trabajo colaborativo con otros centros de la zona & 7 & $5.5 \%$ \\
\hline Contexto del centro & 6 & $4,7 \%$ \\
\hline Interacción con el entorno institucional & 2 & $1,6 \%$ \\
\hline Promoción de un intercambio profesional entre el profesorado & 1 & $0,8 \%$ \\
\hline
\end{tabular}

La mitad de los directores (aproximadamente un 51\%) considera que el factor más relacionado con una mejora en el rendimiento escolar es la estabilidad de los equipos docentes. Como se ha mencionado anteriormente, la inestabilidad de las plantillas es un tema que preocupa a los directores. La autonomía organizativa es, para casi un $37 \%$ de los directores, el segundo factor que más promueve el éxito del centro.

Los factores menos seleccionados por los directores tienen relación con el trabajo en red y la colaboración con otros profesionales (promoción de un intercambio profesional entre el profesorado), con otros centros educativos (interacción con el entorno institucional) y con el contexto del centro.

La selección de los factores seleccionados puede variar en función de las características de las variables de centro o director. Las diferencias significativas halladas son: 
- $\quad$ Según la tipología del centro

El $43 \%$ de los directores de centros rurales considera que el trabajo colaborativo con otros centros de la zona influye positivamente en los resultados del centro. Tan sólo un $1 \%$ de los directores de centros urbanos selecciona este ítem.

\section{- $\quad$ Según el número de alumnos y docentes en el centro}

Entre el $30 \%$ y el $35 \%$ de los directores de escuelas rurales considera relevante el trabajo colaborativo con otros centros de la zona. En cambio, los directores de centros grandes no consideran que este aspecto tenga influencia positiva en su éxito educativo.

Por otra parte, el $29 \%$ de los directores de centros grandes consideran que la organización y articulación curricular en relación a los procesos les influye positivamente. También seleccionan este ítem un 14\% de los directores de centros pequeños.

\section{- $\quad$ Según la complejidad del centro escolar}

El 37\% de los directores de centros que no son de alta complejidad seleccionan el ítem de apoyo y cooperación de las familias y del profesorado para conseguir mejoras como influencia positiva en el rendimiento escolar de su centro, frente a un $5 \%$ de los directores de centros de alta complejidad.

\section{- $\quad$ Según el equipo directivo}

El 19\% de los directores con equipos directivos pequeños consideran que el trabajo colaborativo con otros centros de la zona influye positivamente en los resultados del centro. Tan sólo un $1 \%$ de los directores con un equipos directivos grandes seleccionan este ítem.

\section{- $\quad$ Según el género}

El $46 \%$ de los hombres, frente el $27 \%$ de las mujeres, considera que los procesos de enseñanza-aprendizaje influyen positivamente en el rendimiento escolar.

\section{- $\quad$ Según la edad del director}

El 50\% de los directores con más edad (a partir de 55 años) considera que el clima constructivo entre los miembros de la comunidad es un aspecto que influye 
positivamente en su rendimiento escolar, frente al 25,5\% de los directores entre 46 y 54 años y el 28\% de los directores más jóvenes (45 años o menos).

Por otra parte, los directores más jóvenes consideran el contexto del centro un factor positivo para el rendimiento (14\%). Tan sólo el 4,5\% de los directores con más edad seleccionan este ítem y ningún director entre 46 y 54 años lo selecciona.

\section{- $\quad$ Según las horas de docencia}

Los directores con más horas de docencia (17 horas o más), en comparación con los que realizan un máximo de 8 horas, consideran influyentes los siguientes aspectos:

- Trabajo colaborativo con otros centros de la zona (33\% versus 1,9\%)

- Motivación y apoyo a todos los miembros del centro (44\% versus 17\%)

La organización y articulación curricular en relación a los procesos es valorada por un $21 \%$ de los directores con menos docencia. En cambio, ningún director que realiza 17 horas de docencia a la semana la señala como factor influyente en el rendimiento escolar.

\section{- Según la experiencia directiva}

Los directores más noveles (56\%) y los que tienen entre 2 y 4 años de experiencia (59\%) seleccionan la motivación y apoyo a todos los miembros del centro como factor influyente en el rendimiento, en contraste con un $19 \%$ de los directores más experimentados ( 9 años o más).

Las altas expectativas de la comunidad educativa sobre el rendimiento de los alumnos son valoradas como un factor influyente por el $12 \%$ de los directores con 2 y 4 años de experiencia y para los directores con un mínimo de 9 años de experiencia. Los directores con entre 5 y 8 años de experiencia y los noveles ( 1 años o menos) no seleccionan este ítem.

\section{- Según la experiencia como coordinador de ciclo u otras coordinaciones}

El 27,5\% de los directores con experiencia en la coordinación consideran que está influyendo positivamente en sus resultados el desarrollo de un sentimiento de pertenecer al centro entre los diferentes miembros, en comparación con el 10\% de los directores que no tienen experiencia en la coordinación. 


\subsubsection{Para finalizar}

Se analizan un conjunto de preguntas abiertas sobre las necesidades de los directores (formativas y no formativas), el análisis de los decretos que regulan la función directiva y, por último, una valoración de las características personales que consideran de ayuda para el desarrollo del ejercicio de dirección. Este bloque se caracteriza por una baja participación en comparación con los otros bloques, no obstante, se han identificado algunas tendencias.

\section{- Necesidades directivas}

En lo que respecta a las necesidades (formativas y no formativas), los directores podían indicar un máximo de 3 aspectos en cada apartado.

En cuanto a las necesidades formativas, se obtienen un total de 247 referencias de 95 directores, categorizadas en:

Tabla 94: Categorización de las necesidades formativas

\begin{tabular}{|c|l|}
\hline $\mathbf{N}^{\mathbf{0}}$ referencias & \multicolumn{1}{|c|}{ Categorías } \\
\hline 62 & Formación para la gestión del centro \\
\hline 46 & Formación en legislación \\
\hline 42 & Formación para la gestión del personal \\
\hline 24 & Formación en liderazgo \\
\hline 19 & Formación continua \\
\hline 17 & Formación en metodologías y estrategias \\
\hline 14 & Formación para el cargo (general) \\
\hline 13 & Formación en tecnología \\
\hline 8 & Conocer experiencias directivas \\
\hline 1 & Ninguna necesidad formativa \\
\hline
\end{tabular}

La necesidad formativa que más reconocen y reclaman tiene relación con la gestión del centro: formación en temas de administración, de gestión económica y académica.

También necesitan formación sobre las últimas actualizaciones e innovaciones en materia de gestión educativa para realizar la burocracia de una manera eficaz y conocer "modelos de gestión ágiles y efectivos" (ID 149) y una formación centrada en la evaluación del centro y de competencias “cultura evaluativa” (ID 296). 
Figura 21: Necesidades formativas de gestión de centros

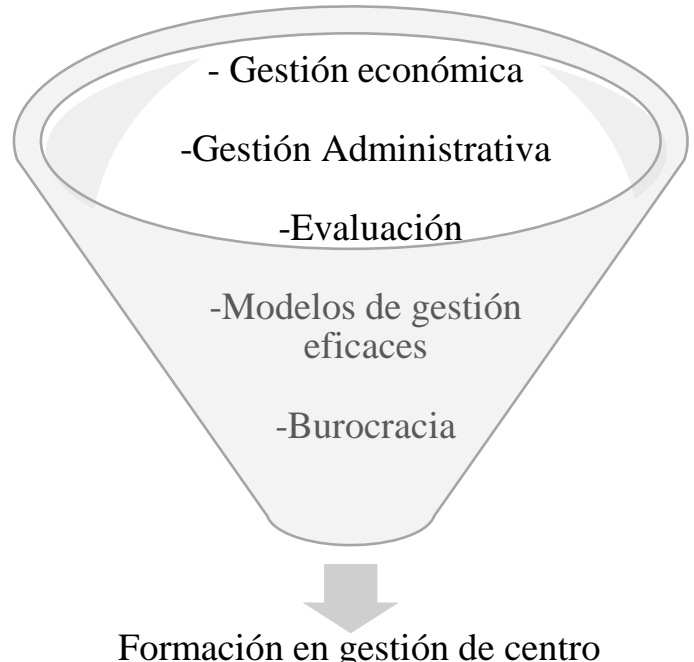

En cuanto a la legislación educativa, mencionan una necesidad de formación en leyes, en normas jurídicas, sobre el reglamento y un asesoramiento legal sobre aspectos judiciales. Además los directores manifiestan la necesidad de una "comprensión en los cambios de normativa constantes" (ID144) y de "información rápida y clara de las novedades (decretos, normativas...)" (ID225).

Figura 22: Necesidades formativas en legislación educativa

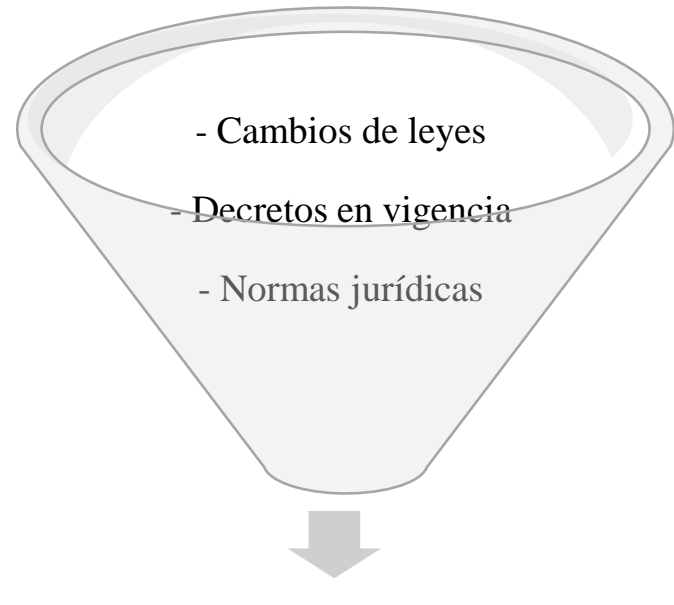

Formación en legislación educativa

Respecto a la formación para la gestión del personal, manifiestan necesidades de formación para gestionar grupos de personas y equipos, gestión docente y desarrollo de las habilidades sociales e interpersonales. 
Además querrían conocer dinámicas de grupo para mejorar las relaciones humanas y la comunicación con, y entre, la comunidad educativa. También demandan formación sobre mediación y conocer "estrategias de resolución de conflictos" (ID 151).

Figura 23: Necesidades formativas en gestión del personal

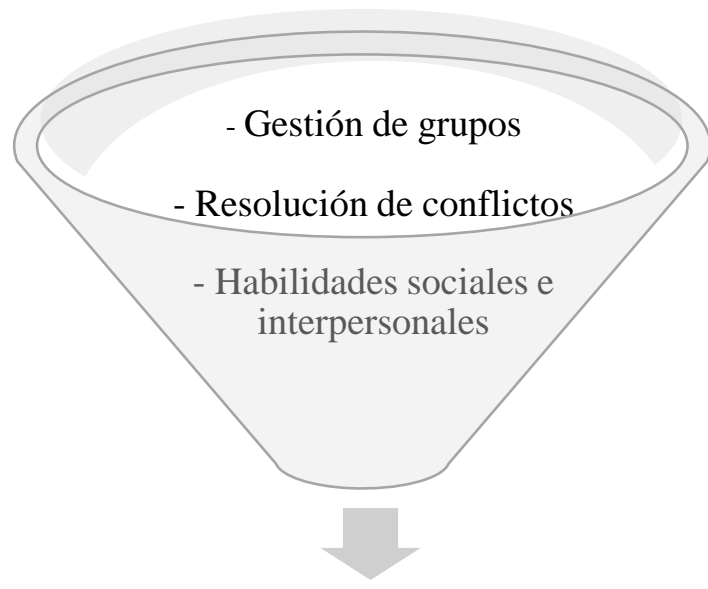

Formación en gestión del personal

Algunos de los directores reclaman "formación en liderazgo" (ID 180). Ya sea "liderazgo de equipos de trabajo” (ID 101), “liderazgo pedagógico” (ID 58) o “liderazgo transformacional” (ID 296).

En el apartado de formación continua se agrupan todas las respuestas de carácter genérico en relación a: "formación constante" (ID 275), "seminarios" (ID 152), “conferencias de temas monográficos" (ID 280) y a la actualización de la formación de manera permanente: "aspectos curriculares nuevos que van surgiendo" (ID 43), “actualización pedagógica” (ID 284).

En relación a las metodologías y estrategias, necesitan formación en innovación para tener "conocimientos de las diversas metodologías" (ID 246). Además de formación sobre inteligencia emocional o trabajo por competencias.

Asimismo los directores manifiestan necesitar formación tecnológica sobre el uso de los aplicativos informáticos de la Administración que deben utilizar para tareas administrativas: "aplicación de las nuevas herramientas informáticas” (ID 191). 
En el apartado de formación para el cargo se recogen otras necesidades formativas que los directores consideran importantes. Se trata de formaciones en diferentes ámbitos como: en psicología, gestión del estrés, gestión de emociones, idiomas (concretamente, la lengua inglesa), cursos de coaching y necesidades educativas especiales.

Algunos directores aluden a la necesidad de realizar "jornadas de trabajo de directores" (ID 158), “intercambios de experiencias" (ID 109), “conocer in situ otros sistemas educativos” (ID 101). Además de compartir experiencia están interesados en “conocer las prácticas de gestión de centros educativos con mucho éxito escolar a nivel internacional" (ID 130).

En cuanto a las necesidades no formativas, se obtiene un total de 199 referencias de 81 directores que categorizadas en:

Tabla 95: Categorización de las necesidades no formativas

\begin{tabular}{|c|l|}
\hline $\mathbf{N}^{\mathbf{0}}$ referencias & \multicolumn{1}{|c|}{ Categorías } \\
\hline 56 & Gestión del cargo \\
\hline 54 & Recursos \\
\hline 28 & Habilidades sociales \\
\hline 22 & Equipo \\
\hline 20 & Relación con agentes externos \\
\hline 11 & Relación con otros directores \\
\hline 7 & Legislación \\
\hline 1 & Ninguna necesidad no formativa \\
\hline
\end{tabular}

La principal necesidad que manifiestan los directores hace referencia a la gestión del cargo: “disponer más tiempo para la coordinación” (ID 135) y la gestión, gestionar y organizar correctamente el tiempo del trabajo.

También manifiestan la necesidad de tener "más autonomía curricular" (ID 72) y la capacidad de "resolver adecuadamente los conflictos" (ID 225), la necesidad de delegar tareas y responsabilidades, de tener más autocontrol y control del estrés y ganar seguridad en el cargo para tomar decisiones. 
Figura 24: Necesidades no formativas para la gestión del cargo

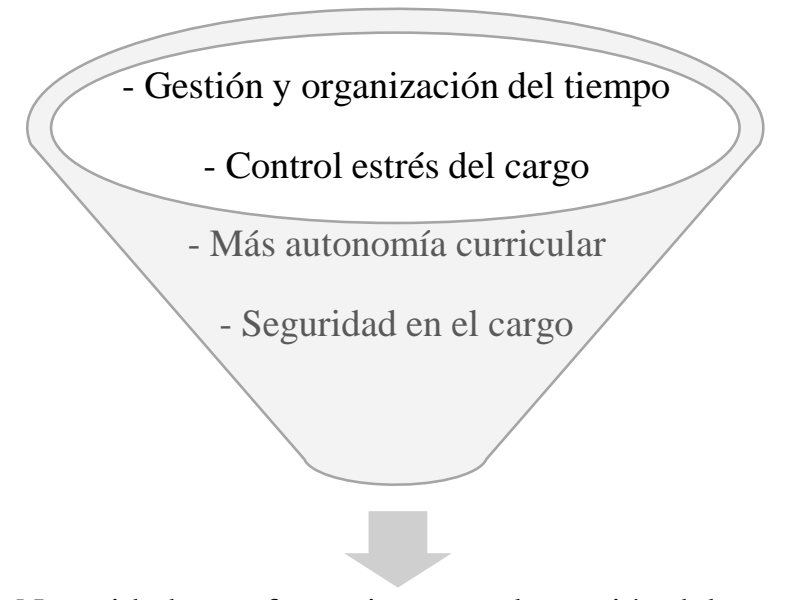

Necesidades no formativas para la gestión del cargo

El momento actual que vive la sociedad marca la segunda gran necesidad que manifiestan los directores respecto a los recursos: "menos recortes" (ID 45), ya sean entre recursos económicos, recursos humanos o recursos materiales.

En relación a los recursos económicos manifiestan la necesidad de un "incremento de recursos y ayudas para actividades fuera del centro" (ID 233), además de "una mejora en la remuneración de la función directiva" (ID 114) y una "mejora retributiva” (ID $62)$.

Respecto a los recursos humanos, los directores dicen necesitar "más recursos humanos” (ID 242), además de “incrementar la plantilla docente” (ID 277) y poder tener una "estabilidad en la plantilla" (ID 147). También reclaman contar con "apoyo administrativo" (ID 42).

Por último, en relación a los recursos materiales aparecen necesidades relacionadas con las obras y el "mantenimiento del edificio" (ID 77). Además de obtener "recursos materiales suficientes para poder atender las necesidades de mejora del centro, sobretodo en el campo tecnológico, laboratorios, idiomas, biblioteca [...]” (ID 130). 
Figura 25: Resumen de las necesidades no formativas en recursos
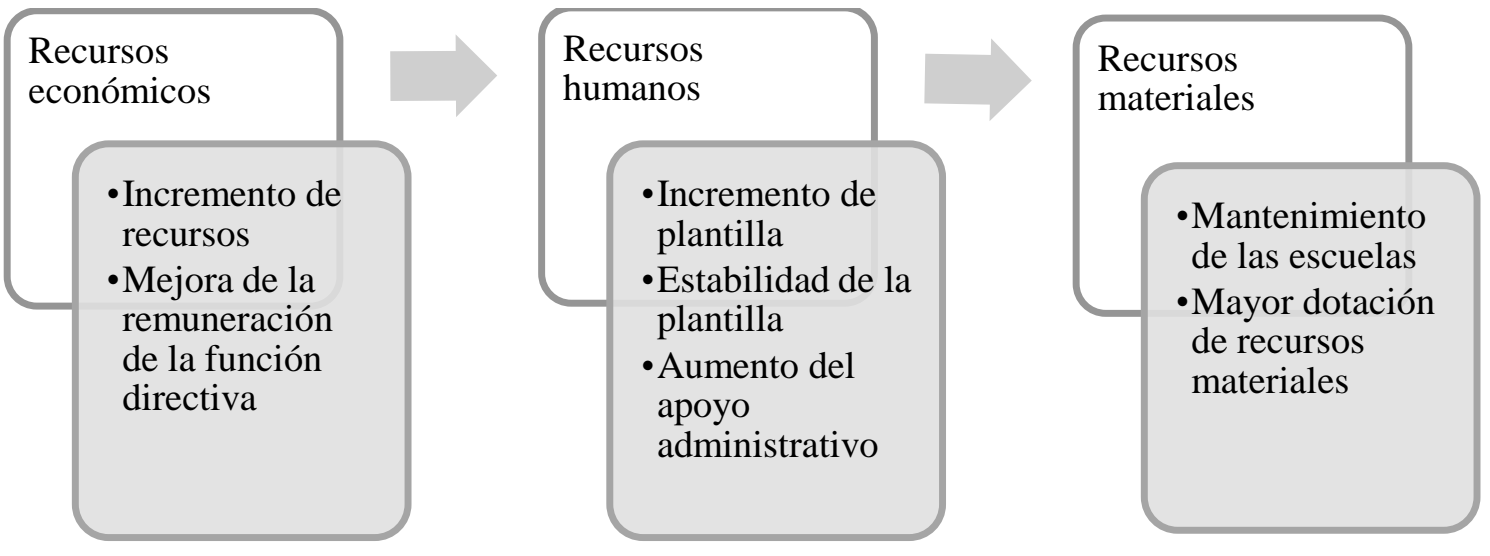

Las necesidades sobre habilidades sociales hacen referencia a "saber detectar quien tiene ideas para tirar hacia delante proyectos" (ID 105), tener "sentido común y buena voluntad" (ID 227) y ser positivo y empático, además de tener buenas "habilidades comunicativas" (ID 284).

Respecto al equipo de profesionales, las necesidades están basadas en el deseo de tener "un buen clima de convivencia" (ID 289), un equipo directivo cohesionado y fuerte, de "disponer de un equipo docente competente profesionalmente y personal PAS cualificado" (ID 130). Todo ello para conseguir una implicación de toda la comunidad educativa y una "implicación de las familias y el cumplir los acuerdos" (ID 29).

En cuanto a las relaciones de agentes externos, los directores reclaman más apoyo y "más confianza administrativa" (ID 280), un "mayor apoyo de la inspección" (ID 29) y sobretodo "más reconocimiento de la tarea directiva" (ID 276).

La necesidad de contactar con otros directores vuelve a aparecer en las necesidades no formativas. Los directores consideran importante el compartir espacios de experiencias, tener "tiempo para conocer realidades de otras escuelas" (ID 269), y crear una "red de consulta y compartir dudas y experiencias" (ID 137).

Respecto la normativa y la legislación, necesitan "mejorar los derechos laborales" (ID 280) y piden una "estabilidad legislativa. Un acuerdo social para no cambiar tan a menudo la normativa" (ID 151). 
- Decretos reguladores de la función directiva

Se pide a los directores 3 aspectos facilitadores y 3 obstaculizadores en su ejercicio derivados de los decretos de "Autonomía” y "Dirección” en su ejercicio directivo.

Respecto a los aspectos facilitadores de los decretos vigentes sobre dirección escolar, se obtienen un total de 171 referencias de 73 directores categorizadas en:

Tabla 96: Categorización de los aspectos facilitadores de los Decretos

\begin{tabular}{|c|l|}
\hline $\mathbf{N}^{\mathbf{0}}$ referencias & \multicolumn{1}{|c|}{ Categorías } \\
\hline 60 & Autonomía \\
\hline 41 & Mejora de gestión y organización \\
\hline 19 & Estabilidad de la plantilla \\
\hline 16 & Normativa \\
\hline 14 & Profesionalización \\
\hline 9 & Liderazgo \\
\hline 12 & Ningún aspecto \\
\hline
\end{tabular}

El principal aspecto facilitador es la "mejora de la autonomía del centro" (ID 62), ya que existe "la posibilidad de una gestión más autónoma de las direcciones de acuerdo con las características del centro" (ID 197). Con dicha autonomía pueden "adecuar la acción educativa para mejorar los resultados" (ID 86) y "poner en práctica lo que crees que será un éxito” (ID 193). Más facilidad para “llevar a cabo proyectos educativos propios" (ID 32) y "adecuar el proyecto educativo al contexto social y cultural donde está ubicado" (ID 167).

El segundo aspecto que destacan es la mejora en la gestión y organización de los centros: "la modernización de la gestión” (ID 151), la "mejor adaptación a la realidad del centro" (ID 269), el “agilizar los procesos" (ID 298) y el tener "más flexibilidad en la organización" (ID 182) son algunos de los aspectos que remarcan como facilitadores como consecuencia de la aplicación de los decretos.

La estabilidad de la plantilla, es el tercer aspecto que mencionan como facilitador ya que, con los decretos, los directores pueden "escoger al profesorado" (ID 48), “consolidar o mantener los docentes en el centro” (ID 249), “mejorar la gestión de las plantillas" (ID 191) y “definir las atribuciones de los cargos” (ID 233). 
La normativa aparece como un aspecto facilitador ya que "aclara las funciones" (ID 124) y "clarifica las competencias" (ID 58). Los directores tienen "un mayor reconocimiento legal" (ID 30), "protección legal” (ID 285) y ayuda a elaborar las normas de organización y funcionamiento del centro

En relación con la normativa, la profesionalización del cargo directivo aparece como un aspecto facilitador. Gracias al "refuerzo del papel de la dirección" (ID 289), "la mejora de la imagen de la gestión directiva" (ID 151) o "el reconocimiento social del cargo" (ID 284).

Algunos directores mencionan "la capacidad de liderazgo" (ID 154) o "la distribución en función de las necesidades" como aspectos que facilitan los decretos.

Respecto a los aspectos obstaculizadores de los decretos vigentes sobre dirección escolar, se obtienen un total de 124 referencias de 61 directores categorizadas en:

Tabla 97: Categorización de los aspectos obstaculizadores de los Decretos

\begin{tabular}{|c|l|}
\hline $\mathbf{N}^{\mathbf{0}}$ referencias & \multicolumn{1}{|c|}{ Categorías } \\
\hline 34 & Dificultades de aplicación \\
\hline 28 & Aumento de responsabilidades \\
\hline 15 & No tener apoyo de profesionales \\
\hline 13 & No preparación \\
\hline 10 & Pseudoautonomía \\
\hline 16 & Ningún aspecto \\
\hline
\end{tabular}

El principal aspecto obstaculizador es la dificultad de aplicación de los decretos en los centros por "falta de recursos humanos y económicos" (ID 197), "aplicativos informáticos que no funcionan" (ID 163) o debido a la"complejidad de la normativa" (ID 285) y "la falta de una cultura de evaluación" (ID 111) y que exigen "una nueva adaptación” (ID 182). Los directores consideran que los decretos se centran en "conceptos muy generales y a veces poco concretos" (ID 242) y que existen “discrepancias entre las posibilidades teóricas y la gestión real” (ID 284).

Los directores señalan que los decretos implican "más responsabilidades con las mismas horas y retribución” (ID 115) y “[...] asumir decisiones que hasta ahora realizaba la Administración" (ID 48). A esta abundancia de responsabilidades 
directivas se le suma una "excesiva burocracia" (ID 32) y una "gestión más compleja" (ID 285).

Los directores declaran una "falta de confianza en las direcciones" (ID 147) que provoca un "rechazo por parte del profesorado" (ID 227). Además "el poco compromiso de algunos sectores de docentes" (ID 151) y "la imagen del director como autoritario" (ID 289) provoca “reticencias por parte de algunos profesores" (ID 62). Una referencia insiste en la "falta apoyo de la Administración a las direcciones" (ID 276).

La pseudoautonomía es otro elemento obstaculizador, es decir, una "autonomía delimitada (en el fondo no es autonomía)” (ID 242) y "poca autonomía en temas importantes" (ID 137) como "no tener autonomía horaria” (ID 69) o "estar limitada por unos presupuestos" (ID 105).

La "poca formación” (ID 87) y la "poca información” (ID 124) para aplicar las novedades de los decretos son otras dificultades que manifiestan los directores ya que "[el decreto] otorga muchas responsabilidades con una formación escasa” (ID 105).

\section{- Nuevo "Decreto de Dirección"}

Se pregunta a los directores sobre sus expectativas sobre el nuevo Decreto de definición de perfil y provisión de puestos de trabajo docentes, conocido en la comunidad educativa como el "Decreto de plantillas". El decreto modifica el proceso de contratación de los docentes y otorga mayor capacidad de decisión a los directores de los centros educativos, que podrán elegir hasta un 50\% de la plantilla del profesorado de los centros. El decreto fue publicado en marzo del 2014 y será aplicado en el curso académico 2015/2016. Se obtienen un total de 118 referencias de 95 directores categorizadas en:

Tabla 98: Categorización expectativas del "decreto de plantillas"

\begin{tabular}{|c|l|}
\hline $\mathbf{N}^{\mathbf{0}}$ referencias & \multicolumn{1}{c|}{ Categorías } \\
\hline 62 & Tener autonomía para poder seleccionar la plantilla \\
\hline 18 & Responder a las diferentes necesidades \\
\hline 16 & Visión positiva del decreto \\
\hline 16 & Preocupación por un mal uso \\
\hline 4 & No afecta (centros concertados-privados) \\
\hline 2 & No leído \\
\hline
\end{tabular}


Más de la mitad de las referencias recogidas sobre las expectativas ante el nuevo decreto está relacionada con tener autonomía para la selección de profesionales en su plantilla y poder contar con profesionales motivados que tengan un perfil idóneo para desarrollar los proyectos educativos de los centros: "intervenir en la definición de la plantilla docente y en la asignación de perfiles singulares a determinados lugares de trabajo de acuerdo con el proyecto educativo" (ID 36). La estabilidad de las plantillas docentes es otro de los aspectos que esperan que el nuevo decreto consiga: "posibilidad de, poco a poco, hacer una plantilla estable e implicada en la mejora de la escuela en general" (ID 43).

También esperan disponer de autonomía para llevar a cabo nuevos proyectos atractivos e innovadores: "espero que sea la oportunidad para realizar un proyecto educativo fuerte y un centro atractivo al cual quieran venir a trabajar profesionales bien formados" (ID 58) y “[...] poder echar fuera a quien realmente no sirve” (ID126). Del mismo modo, esperan que sean los equipos directivos los que gestionen los recursos de los centros "que sea un instrumento para consolidar el protagonismo de los equipos directivos a la hora de gestionar los recursos humanos de un centro educativo" (ID 62).

De igual forma, esperan que el decreto responda a las necesidades de cada centro y sobre todo que "ayude a la mejora de los centros" (ID 173). Algunas mejoras serían “disminución de la ratio profesor-alumno” (ID 180), “cubrir las bajas desde el primer día [...]” (ID 253) y que “las ZERS tengan un tratamiento específico [...]” (ID 57).

Algunas respuestas, aunque positivas, sólo apuntan a posibles beneficios genéricos: "espero que realmente sea eficaz y busque la mejora en la calidad de la enseñanza" (ID 242) y "facilite la faena del equipo directivo y que la normativa sea simple y clara para poder aplicarla sin problemas" (ID 87). Algunos de los directores consideran que muchos de los puntos del decreto son susceptibles de diferentes interpretaciones y " [...] hace falta tiempo para poder valorar y entender los puntos. [...] y también hace falta que nos asesoren y nos acompañen en el despliegue del decreto [...]” (ID 114).

Este hecho genera incertidumbre de cómo se aplicará el decreto: "si sabemos hacer un buen uso será una buena herramienta" (ID 47), "hará falta evitar el mal uso y los favoritismos" (ID 29), “puede comportar peligros si no se reglamenta bien (amiguismos, arbitrariedad...)" (ID 30), “que todos lo apliquen con rigor y 
transparencia" (ID 214). Solamente un director se posiciona totalmente en contra del nuevo decreto.

Por último, un grupo de directores de centros concertados-privados considera que "no nos afecta" (ID 37), ya que "en nuestro centro es la titularidad quien se encarga de ese tema" (ID 93).

- Características personales importantes para el cargo y su aprendizaje

Se trata de identificar las características personales consideradas relevantes para el cargo de dirección. Se obtienen un total de 119 referencias de 98 directores categorizadas en:

Tabla 99: Categorización de las características personales

\begin{tabular}{|c|l|}
\hline $\mathbf{N}^{\mathbf{0}}$ referencias & \multicolumn{1}{|c|}{ Categorías } \\
\hline 26 & Habilidades comunicativas \\
\hline 25 & Liderazgo \\
\hline 18 & Valores personales \\
\hline 12 & Responsabilidad \\
\hline 11 & Habilidades sociales \\
\hline 11 & Organización \\
\hline 10 & Gestión emociones \\
\hline 6 & Capacidad innovadora \\
\hline
\end{tabular}

La principal característica para el cargo tiene relación con las habilidades comunicativas. Es necesario tener "empatía y capacidad de comunicación con todos los miembros de la comunidad educativa" (ID 32) además de "saber escuchar, compartir y razonar [...]” (ID 71). En definitiva, para el ejercicio directivo es imprescindible saber "comunicar, escuchar y no tener miedo a equivocarse" (ID 129) y cuidar "las relaciones humanas, la tolerancia y la empatía” (ID 242).

Las características relacionadas con el liderazgo son también fundamentales para el cargo: "ser lider, aunque tiene que ser un liderazgo compartido con el resto del equipo directivo" (ID 130). En cambio, hay otros directores que promueven "el liderazgo distribuido donde todos participen y se impliquen [...]” (ID 197). 
Todos entienden el liderazgo "[...] como algo positivo de cara a la gestión, coordinación y consecución de tareas diferentes" (ID 191). Para potenciar el liderazgo "hace falta confiar mucho en tus compañeros de equipo directivo, saber delegar y aplicar el liderazgo distribuido" (ID 214) y sobre todo tener "capacidad de decisión y de liderar" (ID 88).

Algunos de los valores personales son: la "asertividad, la capacidad de reflexión, el sentido común” (ID 37), “tener empatía con los alumnos, profesores y padres” (ID 93) y ser "humilde, tener sentido del humor, ser honesto y dominar las emociones" (ID 105). Se trata de "características más relacionadas con la propia personalidad que con la formación” (ID 89) de los directores.

La responsabilidad es básica para la dirección ya que "si no tienes responsabilidad ya no te planteas ejercer un cargo directivo" (ID 137). Además de "tener un compromiso con el centro y con la comunidad [...] (ID 138) e " [...] implicación en el funcionamiento del día a día” (ID 149). Es imprescindible "tener muchas ganas de trabajar y de animar a la gente de tu alrededor a tirar hacia delante la escuela" (ID 152).

Los directores han de desarrollar las habilidades sociales para "gestionar grupos" (ID 43), "trabajar en equipo y ser transparente [...]" (ID 180) y sobre todo "conocer bien a todo su profesorado" (ID 60). En definitiva, "el director ha de ser una persona dialogante y comprensiva, pero a la vez tiene que saber poner a todo el mundo en su sitio y hacer que todas las personas de la comunidad educativa cumplan con su deber" (ID 131). El ejercicio del cargo implica tener habilidades de organización: "capacidad de síntesis y simplificación” (ID 52) y “[...] buena gestión de recursos económicos” (ID 62) y de gestión.

La gestión de las emociones, "el equilibrio emocional [...]" (ID 116), es trascendental para el cargo. Es importante "ser resiliente y mentalmente fuerte ya que recibes muchos golpes y muy injustos y tienes que saber sobreponerte y tirar hacia delante” (ID 143); tener capacidad de control y "tratar los temas con tranquilidad y paciencia [...] (ID 195). 
Por último, una de las características más importantes del director es tener capacidad innovadora: "ser una persona dinámica, impulsora [...]" (ID 158) y "estar al día con todos los cambios que van surgiendo, tanto tecnológicos como pedagógicos” (ID 60).

En relación a cómo han adquirido las anteriores características personales, se obtienen un total de 94 referencias de 66 directores categorizadas en:

Tabla 100: Categorización del aprendizaje de las características personales

\begin{tabular}{|c|l|}
\hline $\mathbf{N}^{\mathbf{0}}$ referencias & \multicolumn{1}{|c|}{ Categorías } \\
\hline 56 & Experiencia (día a día) \\
\hline 25 & Formación (cursos) \\
\hline 12 & Innato (personalidad) \\
\hline 1 & Otras respuestas \\
\hline
\end{tabular}

No hay una manera única y exclusiva de aprender a ser director escolar. Por ejemplo, una misma persona menciona diferentes maneras de aprender y todas son compatibles entre ellas.

La manera más común en la que aprenden los directores es a través de la experiencia cotidiana en el centro. A partir de la experiencia pueden aprender "del día a día y la evolución como persona” (ID 42), "con la edad y maneras de hacer" (ID 47), "con el trabajo en equipo" (ID 138) y con "la experiencia docente y la educación personal” (ID 43). También aprenden "por ensayo-error" (ID 249).

También se alude a la formación más formal, a partir de los cursos: "las herramientas y estrategias que te ofrecen los cursos” (ID 253) y “cursos en los que he podido compartir con otros directores el funcionamiento de las escuelas” (ID 262).

El carácter del director y "la manera de hacer", propias de la personalidad del director, son habilidades innatas: "hay características que están más relacionadas con la propia personalidad que con la formación" (ID 89)

Por último, en otras maneras de aprender, destacamos un director que manifiesta que “nunca se aprende suficiente” (ID 201). 


\subsection{Análisis de variables cruzadas}

En este segundo análisis, cruzaremos preguntas de diferentes apartados para observar si existen correlaciones entre ellas. Para cruzar datos en los procesos de análisis consideraremos dos variables simultáneamente. Se calculan las correlaciones en el caso que los valores sean cuantitativos y se realizan las tablas de contingencia en el caso de que ambos valores sean cualitativos. En las tablas de contingencia se muestra el porcentaje de la distribución de cada uno de los ítems y se interpretan los casos más relevantes, empleando el estadístico de Spearman. En las variables ordinales se utiliza el análisis ANOVA y pruebas de chi-cuadrado.

En este análisis de lectura cruzada de datos, no se han presentado de una a una de manera exhaustiva todas las variables, sino sólo aquellas entre las que existe significación estadística. Nos centramos exclusivamente en correlaciones entre 0,4 a 0,7 (correlación moderada) y entre 0,7 a 1 (correlación alta) con un nivel de significancia $(0,01)$.

\subsubsection{Acciones directivas y autopercepción del compromiso}

Se pretende conocer si se producen asociaciones significativas entre la autopercepción del compromiso de la comunidad educativa y las acciones que realizan los directores. En primer lugar, los directores que perciben más alto su propio compromiso con:

\section{- La comunidad educativa}

Tabla 101: Relación entre la auto percepción del compromiso y las acciones directivas

\begin{tabular}{|c|c|c|c|}
\hline \multicolumn{4}{|c|}{ La comunidad educativa } \\
\hline Acciones directivas: & Nunca/rara vez & Normalmente & Siempre \\
\hline $\begin{array}{l}\text { Crear espacios para compartir experiencias y } \\
\text { para trabajar en equipo }\end{array}$ & 4,43 & 4,80 & 4,82 \\
\hline $\begin{array}{l}\text { Sentir el apoyo y la confianza de la comunidad } \\
\text { educativa }\end{array}$ & 4,53 & 4,70 & 4,92 \\
\hline $\begin{array}{l}\text { Trabajar conjuntamente con el equipo } \\
\text { directivo y los docentes para detectar las } \\
\text { necesidades educativas del centro }\end{array}$ & NP* & 4,48 & 4,79 \\
\hline $\begin{array}{l}\text { Conocer las situaciones familiares más } \\
\text { complicadas de los alumnos }\end{array}$ & NP* & 4,55 & 4,80 \\
\hline
\end{tabular}


En segundo lugar, los directores que perciben más alto el compromiso del profesorado con:

Tabla 102: Relación entre la percepción del compromiso del profesorado y las acciones directivas

\begin{tabular}{|c|c|c|c|}
\hline \multicolumn{4}{|c|}{ La familia } \\
\hline Acciones directivas: & Nunca/rara vez & Normalmente & Siempre \\
\hline Definir los objetivos y planificar los procesos & 4,50 & 4,18 & $\mathbf{4 , 5 1}$ \\
\hline $\begin{array}{l}\text { Conocer las situaciones familiares más } \\
\text { complicadas de los alumnos }\end{array}$ & $\mathrm{NP}^{*}$ & 3,96 & 4,44 \\
\hline \multicolumn{4}{|c|}{ El éxito escolar } \\
\hline Acciones directivas: & Nunca/rara vez & Normalmente & Siempre \\
\hline $\begin{array}{l}\text { Sentir el apoyo y la confianza de la comunidad } \\
\text { educativa }\end{array}$ & 4,21 & 4,45 & $\mathbf{4 , 7 8}$ \\
\hline $\begin{array}{l}\text { Conocer las situaciones familiares más } \\
\text { complicadas de los alumnos }\end{array}$ & NP* & 4,28 & 4,59 \\
\hline \multicolumn{4}{|c|}{ Los proyectos del centro y comunidad } \\
\hline Acciones directivas: & Nunca/rara vez & Normalmente & Siempre \\
\hline $\begin{array}{l}\text { Sentir el apoyo y la confianza de la comunidad } \\
\text { educativa }\end{array}$ & 4 & 4,26 & 4,73 \\
\hline $\begin{array}{l}\text { Conocer las situaciones familiares más } \\
\text { complicadas de los alumnos }\end{array}$ & NP* & 4,11 & 4,45 \\
\hline
\end{tabular}

Estas son las acciones que siempre realizan los directores que perciben el compromiso del profesorado. En relación la familia, se destaca la acción de definir los objetivos y planificar los procesos, ya que entre los directores que siempre y los que nunca o rara vez lo hacen, se percibe el compromiso del profesorado de manera casi idéntica.

En tercer lugar, los directores que perciben más alto el compromiso de las familias con:

Tabla 103: Relación de la percepción del compromiso de las familias y las acciones directivas

\section{Los proyectos del centro}

\begin{tabular}{|c|c|c|c|}
\hline Acciones directivas: & Nunca/rara vez & Normalmente & Siempre \\
\hline $\begin{array}{l}\text { Sentir el apoyo y la confianza de la comunidad } \\
\text { educativa }\end{array}$ & 3,42 & 3,68 & 4,22 \\
\hline $\begin{array}{l}\text { Conocer las situaciones familiares más } \\
\text { complicadas de los alumnos }\end{array}$ & NP* & 3,24 & 3,99 \\
\hline \multicolumn{4}{|c|}{ Los resultados de sus hijos } \\
\hline Acciones directivas: & Nunca/rara vez & Normalmente & Siempre \\
\hline Promueven la autonomía de los profesores & 2 & 3,75 & 3,98 \\
\hline Gestionar el tiempo & $\mathbf{3 , 8 9}$ & 3,25 & 2 \\
\hline
\end{tabular}




\begin{tabular}{|l|c|c|c|}
\hline $\begin{array}{l}\text { Promover actividades del centro para que } \\
\text { sean reconocidas fuera }\end{array}$ & 3,65 & 3,74 & $\mathbf{4 , 1 5}$ \\
\hline $\begin{array}{l}\text { Sentir el apoyo y la confianza de la comunidad } \\
\text { educativa }\end{array}$ & 3,56 & 3,71 & $\mathbf{4 , 1 7}$ \\
\hline $\begin{array}{l}\text { Conocer las situaciones familiares más } \\
\text { complicadas de los alumnos }\end{array}$ & NP* & 3,24 & $\mathbf{3 , 9 9}$ \\
\hline \begin{tabular}{l}
$\mathrm{NP} *$ Ninguna puntuación \\
\hline
\end{tabular}
\end{tabular}

Se observa que la mayoría de las acciones están relacionadas con el compromiso de las familias en referencian con los resultados de los hijos. Se destaca la acción de gestionar el tiempo, ya que los directores que nunca o rara vez gestionan su tiempo perciben más alto el compromiso de las familias en contraposición a los directores que siempre gestionan su tiempo.

Por último, los directores que perciben más alto el compromiso del alumnado con:

Tabla 104: Relación de la percepción del compromiso de los alumnos según las acciones directivas

\begin{tabular}{|c|c|c|c|}
\hline \multicolumn{4}{|c|}{ Los proyectos del centro y comunidad } \\
\hline Acciones directivas: & Nunca/rara vez & Normalmente & Siempre \\
\hline $\begin{array}{l}\text { Consultar al profesorado para tomar } \\
\text { decisiones }\end{array}$ & 3,83 & 3,90 & 4,28 \\
\hline Promover la autonomía de los profesores & 2,5 & 3,99 & 4,19 \\
\hline Gestionar tiempo & 4,08 & 3,75 & 2 \\
\hline $\begin{array}{l}\text { Sentir el apoyo y la confianza de la comunidad } \\
\text { educativa }\end{array}$ & 3,78 & 3,90 & 4,41 \\
\hline $\begin{array}{l}\text { Intervenir activamente para resolver los } \\
\text { conflictos }\end{array}$ & 3,14 & 4,08 & 4,13 \\
\hline $\begin{array}{l}\text { Conocer las situaciones familiares más } \\
\text { complicadas de los alumnos }\end{array}$ & NP* & 3,66 & 4,16 \\
\hline \multicolumn{4}{|c|}{ Sus resultados } \\
\hline Acciones directivas: & Nunca/rara vez & Normalmente & Siempre \\
\hline Gestionar tiempo & 4,01 & 3,38 & 3 \\
\hline $\begin{array}{l}\text { Sentir el apoyo y la confianza de la comunidad } \\
\text { educativa }\end{array}$ & 3,83 & 3,79 & 4,28 \\
\hline $\begin{array}{l}\text { Conocer las situaciones familiares más } \\
\text { complicadas de los alumnos }\end{array}$ & $\mathrm{NP}^{*}$ & 3,68 & 4,03 \\
\hline
\end{tabular}

Se observa que la mayoría de las acciones están relacionadas con el compromiso del alumnado en relación con los proyectos del centro y la comunidad. Se destaca, de nuevo, el ítem de gestionar el tiempo ya que los directores que nunca o rara vez lo hacen perciben más alto el compromiso del alumnado tanto con sus resultados como con los proyectos del centro y la comunidad. 
En conclusión, el conocer las situaciones familiares más complicadas de los alumnos y el sentir el apoyo y la confianza de la comunidad educativa son las acciones directivas más vinculadas con la alta percepción de los directores con los diferentes miembros de la comunidad.

\subsubsection{Satisfacción del cargo}

Se trata de conocer las correlaciones (significativas estadísticamente) entre los diferentes aspectos que producen satisfacción señalados por los directores.

Se observan las siguientes relaciones directas:

Tabla 105: Relaciones directas entre ítems de satisfacción

\begin{tabular}{|c|l|}
\hline $\begin{array}{r}\text { rS } \\
(\mathrm{p}<0,01)\end{array}$ & Satisfacción de: \\
\hline \multirow{3}{*}{0,41} & Las tareas realizadas por el equipo directivo \\
\hline \multirow{2}{*}{0,43} & La implicación del equipo docente en el funcionamiento del centro \\
\hline \multirow{2}{*}{0,44} & La libertad y autonomía para tomar decisiones \\
\hline & El grado del cumplimento de los acuerdos \\
\hline & Los procedimientos para gestionar los recursos \\
\hline
\end{tabular}

A continuación, las relaciones con dos ítems:

Tabla 106: Dobles relaciones entre ítems de satisfacción

\begin{tabular}{|c|l|}
\hline $\begin{array}{c}\mathbf{r S} \\
(\mathrm{p}<0,01)\end{array}$ & Satisfacción de los procedimientos para gestionar los recursos con: \\
\hline 0,42 & Las relaciones de los miembros del centro con los padres de los alumnos \\
\hline 0,44 & El reconocimiento social que recibe como director \\
\hline $\mathbf{r S}$ & \\
$(\mathrm{p}<0,01)$ & Satisfacción del cumplimiento de los acuerdos con: \\
\hline 0,42 & La relación de los docentes con el equipo directivo \\
\hline 0,43 & La implicación del equipo docente en el funcionamiento del centro \\
\hline
\end{tabular}


Por último, los ítems de satisfacción con múltiples relaciones:

Tabla 107: Múltiples relaciones entre ítems de satisfacción:

\begin{tabular}{|c|c|}
\hline $\begin{array}{c}\mathbf{r S} \\
(\mathrm{p}<0,01)\end{array}$ & $\begin{array}{l}\text { Satisfacción de las oportunidades para crear proyectos innovadores } \\
\text { y creativos con: }\end{array}$ \\
\hline 0,42 & La utilidad del proyecto educativo para definir los valores del centro \\
\hline 0,43 & Las tareas realizadas por el equipo directivo \\
\hline 0,43 & $\begin{array}{l}\text { La participación y colaboración de los alumnos en los proyectos del } \\
\text { centro }\end{array}$ \\
\hline 0,46 & La implicación del equipo docente en el funcionamiento del centro \\
\hline $\begin{array}{c}\mathbf{r S} \\
(\mathrm{p}<0,01)\end{array}$ & $\begin{array}{l}\text { Satisfacción de la disposición de los docentes para encontrar espacios } \\
\text { de trabajo conjuntos con: }\end{array}$ \\
\hline 0,43 & $\begin{array}{l}\text { La participación y colaboración de los alumnos en los proyectos del } \\
\text { centro }\end{array}$ \\
\hline 0,45 & Las relaciones de los miembros del centro con los padres de los alumnos \\
\hline 0,46 & $\begin{array}{l}\text { La satisfacción de las oportunidades para crear proyectos innovadores y } \\
\text { creativos }\end{array}$ \\
\hline $\begin{array}{c}\mathbf{r S} \\
(\mathrm{p}<0,01)\end{array}$ & $\begin{array}{l}\text { Satisfacción de la coordinación y cooperación con el entorno social } \\
\text { del centro (asociaciones, escuelas, etc.) con: }\end{array}$ \\
\hline 0,44 & Los procedimientos para gestionar los recursos \\
\hline 0,47 & $\begin{array}{l}\text { La disposición de los docentes para encontrar espacios de trabajos } \\
\text { conjuntos }\end{array}$ \\
\hline 0,53 & Las relaciones de los miembros del centro con los padres de los alumnos \\
\hline 0,54 & Del apoyo de la Administración en la tarea directiva \\
\hline $\begin{array}{c}\mathbf{r S} \\
(\mathrm{p}<0,01)\end{array}$ & Satisfacción de la competencia docente del profesorado: \\
\hline 0,42 & La utilidad del proyecto educativo para definir los valores del centro \\
\hline 0,42 & $\begin{array}{l}\text { La disposición de los docentes para encontrar espacios de trabajo } \\
\text { conjunto }\end{array}$ \\
\hline 0,43 & Las oportunidades para crear proyectos innovadores y creativos \\
\hline 0,45 & La relación de los docentes con el equipo directivo \\
\hline 0,49 & La implicación del equipo docente en el funcionamiento del centro \\
\hline 0,63 & La satisfacción del grado de cumplimiento de los acuerdos \\
\hline
\end{tabular}

\subsubsection{Situación actual e importancia del cargo directivo}

Se trata de conocer si existen relaciones estadísticamente significativas entre la situación actual del ejercicio del cargo y la importancia que se le otorga.

En cuanto a la situación actual se observan las siguientes relaciones directas: 
Tabla 108: Relaciones directas entre ítems de situación actual

\begin{tabular}{|c|l|}
\hline $\begin{array}{c}\text { rS } \\
(\mathrm{p}<0,01)\end{array}$ & Situación actual: \\
\hline 0,40 & $\begin{array}{l}\text { Del seguimiento del centro } \\
\text { Del liderazgo compartido entre el equipo directivo }\end{array}$ \\
\hline 0,40 & $\begin{array}{l}\text { El planteamiento del trabajo escolar como una actividad colectiva } \\
\text { El éxito escolar }\end{array}$ \\
\hline 0,44 & $\begin{array}{l}\text { La colaboración de las familias en los procesos educativos promovidos } \\
\text { por el centro }\end{array}$ \\
\hline 0,44 & $\begin{array}{l}\text { Del entusiasmo del profesorado del centro } \\
\text { La vinculación del centro con su entorno social a partir de proyectos }\end{array}$ \\
\hline 0,45 & \begin{tabular}{l} 
El entusiasmo del profesorado del centro \\
\hline \multirow{2}{*}{ El escolar }
\end{tabular} \\
\hline & $\begin{array}{l}\text { La colaboración de las familias en los procesos educativos promovidos } \\
\text { por el centro }\end{array}$ \\
\hline $\begin{array}{l}\text { La convivencia en la comunidad educativa } \\
\text { La colaboración de las familias en los procesos educativos promovidos } \\
\text { por el centro }\end{array}$ \\
\hline
\end{tabular}

En cuanto a las múltiples relaciones entre los ítems de la situación actual, se observan:

Tabla 109: Múltiples relaciones entre ítems de situación actual

\begin{tabular}{|c|l|}
\hline $\begin{array}{c}\mathbf{r S} \\
(\mathrm{p}<0,01)\end{array}$ & La situación actual de la relación de las familias con el centro con: \\
\hline 0,42 & El éxito escolar \\
\hline 0,42 & El planteamiento del trabajo escolar como una actividad colectiva \\
\hline 0,56 & La convivencia en la comunidad educativa \\
\hline $\begin{array}{c}\mathbf{r S} \\
(\mathrm{p}<0,01\end{array}$ & $\begin{array}{l}\text { La situación actual de la delegación de responsabilidades y tareas } \\
\text { hacia el profesorado con: }\end{array}$ \\
\hline 0,41 & El entusiasmo del profesorado del centro \\
\hline 0,50 & La vinculación del centro con su entorno social a partir de proyectos \\
\hline
\end{tabular}

En cuanto a la importancia, se observan las siguientes relaciones directas:

Tabla 110: Relaciones directas entre ítems de importancia

\begin{tabular}{|c|l|}
\hline $\begin{array}{c}\boldsymbol{r} \boldsymbol{S} \\
(p<0,01)\end{array}$ & Importancia: \\
\hline 0,40 & Al planteamiento del trabajo escolar como actividad colectiva \\
\hline \multirow{2}{*}{0,44} & A la vinculación del centro con su entorno social a partir de proyectos \\
\hline & A la representación institucional \\
\hline & A la vinculación del centro con su entorno social a partir de proyectos \\
\hline
\end{tabular}




\begin{tabular}{|c|c|}
\hline \multirow[t]{2}{*}{0,45} & Al entusiasmo del profesorado \\
\hline & Al seguimiento de los acuerdos \\
\hline \multirow[t]{2}{*}{0,45} & A la gestión de recursos del centro \\
\hline & A la mediación de conflictos \\
\hline \multirow[t]{2}{*}{0,45} & A la convivencia en la comunidad educativa \\
\hline & $\begin{array}{l}\text { A la colaboración de las familias en los procesos educativos promovidos } \\
\text { por el centro }\end{array}$ \\
\hline \multirow[t]{2}{*}{0,47} & Al seguimiento de los acuerdos \\
\hline & Al liderazgo compartido entre el equipo directivo \\
\hline \multirow[t]{2}{*}{0,50} & A la vinculación del centro con su entorno social a partir de proyectos \\
\hline & $\begin{array}{l}\text { A la colaboración de las familias en los procesos educativos promovidos } \\
\text { por el centro }\end{array}$ \\
\hline
\end{tabular}

En cuanto a las múltiples relaciones entre los ítems de la importancia, se observan:

Tabla 111: Múltiples relaciones entre ítems de importancia

\begin{tabular}{|c|c|}
\hline $\begin{array}{c}\mathbf{r S} \\
(p<0,01)\end{array}$ & $\begin{array}{l}\text { La importancia que le conceden a la mediación de conflictos } \\
\text { escolares con: }\end{array}$ \\
\hline 0,505 & $\begin{array}{l}\text { La colaboración de las familias en los procesos educativos promovidos } \\
\text { por el centro }\end{array}$ \\
\hline 0,505 & La vinculación del centro con su entorno social a partir de proyectos \\
\hline 0,505 & El planeamiento del trabajo escolar como una actividad colectiva \\
\hline $\begin{array}{c}\mathbf{r S} \\
(\mathrm{p}<0,01)\end{array}$ & $\begin{array}{l}\text { La importancia que le conceden a la relación de las familias con el } \\
\text { centro con: }\end{array}$ \\
\hline 0,49 & La mediación de conflictos \\
\hline 0,49 & La convivencia en la comunidad educativa \\
\hline 0,54 & La mediación de conflictos El entusiasmo del profesorado del centro \\
\hline $\begin{array}{c}\mathbf{r S} \\
(\mathbf{p}<\mathbf{0 , 0 1})\end{array}$ & $\begin{array}{l}\text { La importancia que le conceden a la delegación de responsabilidades } \\
\text { y tareas al profesorado con: }\end{array}$ \\
\hline 0,42 & $\begin{array}{l}\text { La colaboración de las familias en los procesos educativos promovidos } \\
\text { por el centro }\end{array}$ \\
\hline 0,48 & Al planteamiento del trabajo escolar como una actividad colectiva \\
\hline $\begin{array}{c}\mathbf{r S} \\
(\mathbf{p}<0,01)\end{array}$ & $\begin{array}{l}\text { La importancia que le conceden al control del estrés que conlleva el } \\
\text { cargo con: }\end{array}$ \\
\hline 0,47 & La gestión de recursos del centro \\
\hline 0,49 & La representación institucional \\
\hline
\end{tabular}




\subsubsection{Satisfacción del cargo y la situación actual del cargo directivo}

La satisfacción del cargo directivo está asociada con la valoración de los directores sobre la situación actual del ejercicio directivo. Existen diferentes relaciones significativas y directas entre la situación actual y la satisfacción del cargo, concretamente:

Tabla 112: Relaciones directas entre situación actual y la satisfacción del cargo

\begin{tabular}{|c|c|}
\hline $\begin{array}{c}r S \\
(p<0,01)\end{array}$ & Situación actual y satisfacción del cargo \\
\hline \multirow[t]{2}{*}{0,400} & $\begin{array}{l}\text { La situación actual de la colaboración de las familias en los procesos } \\
\text { educativos promovidos por el centro }\end{array}$ \\
\hline & La satisfacción de la competencia docente del profesorado \\
\hline \multirow[b]{2}{*}{0,409} & La situación actual de la representación institucional \\
\hline & $\begin{array}{l}\text { La satisfacción de la coordinación y cooperación con el entorno social } \\
\text { del centro (asociaciones, escuelas, etc.) }\end{array}$ \\
\hline \multirow[b]{2}{*}{0,439} & La situación actual de la creación y aplicación de proyectos innovadores \\
\hline & $\begin{array}{l}\text { La satisfacción de la utilidad del proyecto educativo para definir los } \\
\text { valores del centro }\end{array}$ \\
\hline \multirow[t]{2}{*}{0,491} & $\begin{array}{l}\text { La satisfacción de las relaciones de los miembros del centro con los } \\
\text { padres de los alumnos }\end{array}$ \\
\hline & La situación actual de la relación de las familias con el centro \\
\hline
\end{tabular}

Se observa un único ítem con una doble relación:

Tabla 113: Múltiple relación entre situación actual y satisfacción del cargo

\begin{tabular}{|c|l|}
\hline $\begin{array}{c}\mathbf{r S} \\
(\mathbf{p}<\mathbf{0 , 0 1})\end{array}$ & $\begin{array}{l}\text { La situación actual del entusiasmo del profesorado con la } \\
\text { satisfacción de: }\end{array}$ \\
\hline 0,425 & La implicación del equipo docente en el funcionamiento del centro \\
\hline 0,411 & La competencia docente del profesorado \\
\hline
\end{tabular}

\subsubsection{Satisfacción del cargo e importancia del cargo directivo}

Se detectan dos relaciones significativas de la satisfacción del cargo directivo con la importancia que le conceden. La primera es la satisfacción de la coordinación y cooperación con el entorno social del centro (asociaciones, escuelas) que se vincula a la importancia de la vinculación del centro con el entorno social ( $\mathrm{rS}=0,427, \mathrm{p}<0,01)$. 
La segunda relación es la satisfacción de los procedimientos para gestionar los recursos que se relaciona con la importancia de la representación institucional $(\mathrm{rS}=0,426, \mathrm{p}$ $<0,01)$.

\subsubsection{Acciones y actuaciones directivas}

Se trata de identificar las relaciones estadísticamente significativas entre las acciones directivas extraídas de la revisión teórica y las actuaciones directivas extraídas de la normativa vigente en Cataluña (LEC, 2009).

A continuación, se muestran las relaciones lineales estadísticamente significativas entre las acciones y actuaciones directivas:

Tabla 114: Listado de acciones y actuaciones directivas

\begin{tabular}{|c|c|}
\hline ACCIONES DIRECTIVAS & ACTUACIONES DIRECTIVAS \\
\hline $\begin{array}{l}\text { 1. Distribuyes la información a cada colectivo de la } \\
\text { comunidad } \\
\text { 2. Consultas al profesorado para tomar decisiones } \\
\text { 3. Promueves la autonomía de cada profesor } \\
\text { 4. Defines los objetivos y planificas los procesos } \\
\text { 5. Eres accesible a los miembros de la comunidad } \\
\text { educativa } \\
\text { 6. Gestionas tu tiempo } \\
\text { 7. Promueves actividades del centro para que sean } \\
\text { reconocidas fuera } \\
\text { 8. Creas espacio para compartir experiencias y } \\
\text { trabajar en equipo } \\
\text { 9. Sientes el apoyo y la confianza de la comunidad } \\
\text { educativa } \\
\text { 10. Adscribes al profesorado a su puesto de trabajo } \\
\text { 11. Intervienes activamente para resolver los } \\
\text { conflictos } \\
\text { 12. Evalúas y controlas las actividades y sus } \\
\text { responsables } \\
\text { 13. Trabajas conjuntamente con el equipo directivo } \\
\text { y profesorado para detectar las necesidades del } \\
\text { centro } \\
\text { 14. Conoces las situaciones familiares complicadas } \\
\text { del alumnado }\end{array}$ & $\begin{array}{l}\text { 1. Mantener una red de relaciones, tanto en el centro } \\
\text { como en el entorno } \\
\text { 2. Presidir el consejo escolar, el claustro y los actos } \\
\text { académicos del centro } \\
\text { 3. Orientar, dirigir y supervisar las actividades del } \\
\text { centro } \\
\text { 4. Impulsar la coordinación del proyecto educativo del } \\
\text { centro con otros centros } \\
\text { 5. Garantizar los derechos y deberes de todos los } \\
\text { miembros de la comunidad } \\
\text { 6. Establecer canales de relación con las asociaciones } \\
\text { de madres y padres del centro } \\
\text { 7. Impulsar el establecimiento de normas de } \\
\text { organización y funcionamiento del centro } \\
\text { 8. Proponer la programación general anual del centro } \\
\text { 9. Gestionar los gastos y pagos de acuerdo con el } \\
\text { presupuesto aprobado } \\
\text { 10. Liderar el personal del centro para garantizar que } \\
\text { cumplen sus funciones } \\
\text { 11. Asignar al profesorado otras responsabilidades de } \\
\text { gestión y coordinación } \\
\text { 12. Fomentar la participación del profesorado en } \\
\text { actividades de formación permanente } \\
\text { 13. Resolver faltas de asistencia y de puntualidad no } \\
\text { justificadas de todo el personal del centro } \\
\text { 14. Comunicar las jornadas no trabajadas cuando el } \\
\text { personal del centro ejerce el derecho a huelga } \\
\text { 15. Sancionar las faltas de acuerdo a la normativa } \\
\text { disciplinaria vigente } \\
\text { 16. Formular la propuesta de incoación de expediente } \\
\text { disciplinario por faltas graves del personal }\end{array}$ \\
\hline
\end{tabular}


Tabla 115: Relaciones significativas entre acciones y actuaciones directivas

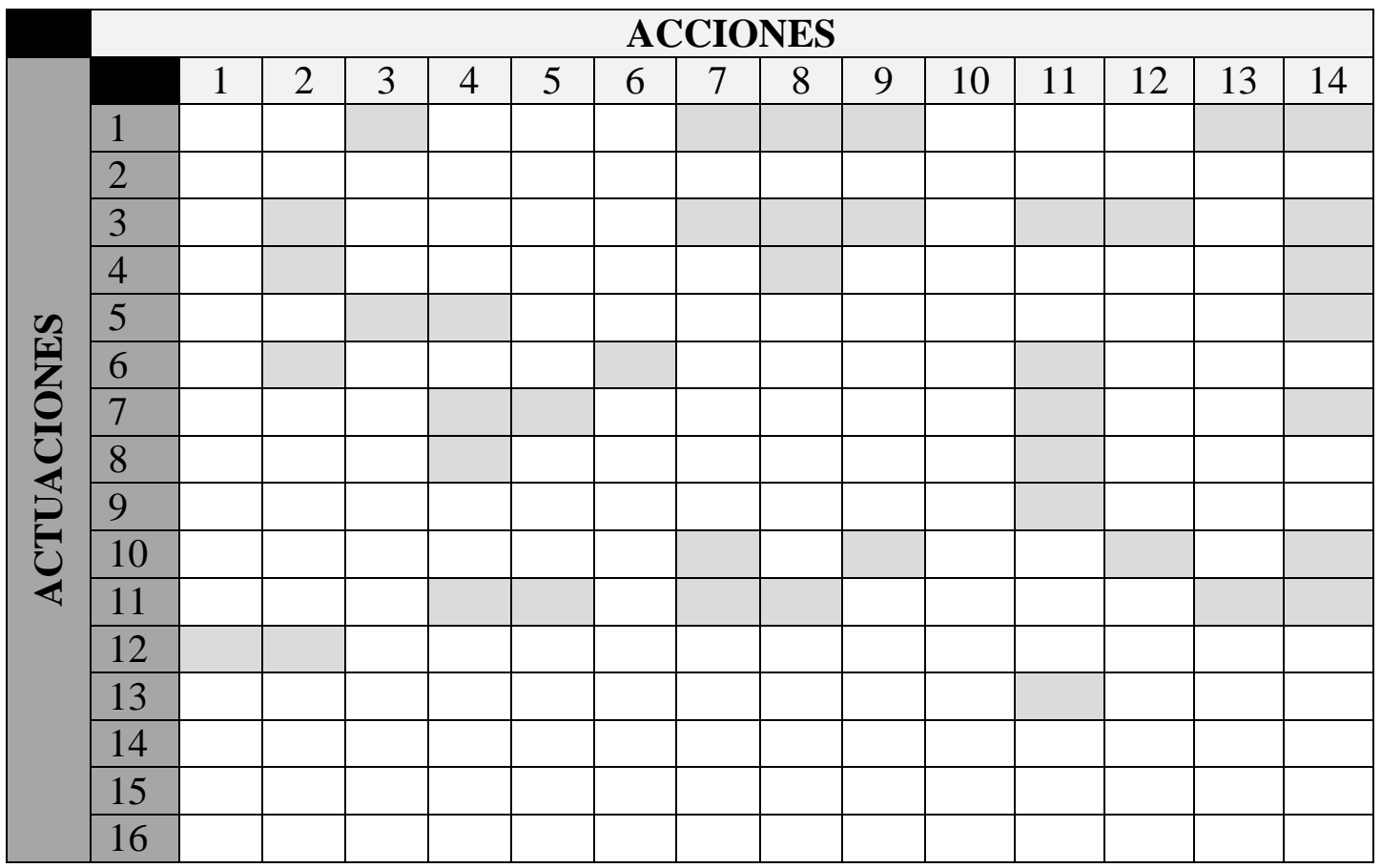

Aparecen un total de 42 relaciones significativas entre actuaciones y acciones directivas. Los ítems de adscribir al profesorado a su puesto de trabajo y presidir el consejo escolar, el claustro y los actos académicos no muestran ninguna relación significativa con ningún otro ítem. Comunicar las jornadas no trabajadas cuando el personal del centro ejerce el derecho a huelga, sancionar las faltas de acuerdo a la normativa disciplinaria vigente y formular la propuesta de incoación de expediente disciplinario por faltas graves del personal son actuaciones directivas que, aunque están presentes en la normativa directiva, tampoco tienen ninguna relación directa con ninguna actuación ni acción.

Las relaciones unívocas entre acciones y actuaciones directivas son:

- La acción de distribuir la información a cada colectivo de la comunidad con la actuación de fomentar la participación del profesorado en actividades en actividades de formación permanente.

- La acción de gestionar el tiempo con la actuación de establecer canales de relación con las asociaciones de madres y padres del centro.

- La actuación de gestionar los gastos y pagos de acuerdo con el presupuesto aprobado con la acción de la intervención activamente para resolver los conflictos. 
- La actuación de resolver faltas de asistencia y de puntualidad no justificadas de todo el personal del centro con la acción de intervenir activamente para resolver los conflictos.

Por último, los ítems con más relaciones directas estadísticamente significativas:

Tabla 116: Relación múltiple de las actuaciones directivas

\begin{tabular}{|c|ll|}
\hline & 1. & Consultar al profesorado para tomar decisiones \\
Orientar, dirigir & 2. & Promover actividades del centro para que sean reconocidas fuera \\
y supervisar las & 3. & Crear espacios para compartir experiencias y trabajar en equipo \\
actividades del & 4. & Sentir el apoyo y la confianza de la comunidad educativa \\
centro & 5. & Intervenir activamente para resolver los conflictos \\
& 6. & Evaluar y controlar las actividades y sus responsables \\
& 7. & Conocer las situaciones familiares complicadas del alumnado \\
\hline $\begin{array}{c}\text { Asignar al } \\
\text { profesorado otras }\end{array}$ & 1. & Definir los objetivos y planificas los procesos \\
responsabilidades & 3. & Ser accesible a los miembros de la comunidad educativa \\
de gestión y & 4. & Crear espacios para compartir experiencias y trabajar en equipo \\
coordinación & 5. & Trabajar conjuntamente con el equipo directivo y profesorado para \\
& 6etectar necesidades del centro \\
\hline
\end{tabular}

Tabla 117: Relación múltiple de las acciones directivas

Intervenir activamente para resolver los conflictos

Conocer las situaciones familiares complicadas del alumnado
1. Orientar, dirigir y supervisar las actividades del centro

2. Establecer canales de relación con las asociaciones de madres y padres del centro

3. Impulsar el establecimiento de normas de organización y funcionamiento del centro

4. Proponer la programación general anual del centro

5. Gestionar los gastos y pagos de acuerdo con el presupuesto aprobado

6. Resolver faltas de asistencia y de puntualidad no justificadas de todo el personal del centro

1. Mantener una red de relaciones, tanto en el centro como en el entorno

2. Orientar, dirigir y supervisar las actividades del centro

3. Impulsar la coordinación del proyecto educativo del centro con otros centros

4. Garantizar los derechos y deberes de todos los miembros de la comunidad

5. Impulsar el establecimiento de normas de organización y funcionamiento del centro

6. Liderar el personal del centro para garantizar que cumplen sus funciones

7. Asignar al profesorado otras responsabilidades de gestión y coordinación 
Para concluir, entendemos que los ítems que no tienen ninguna relación significativa se tratan de actuaciones o acciones que se realizan de manera puntual. En cambio, los ítems que tienen múltiples relaciones serían actuaciones y acciones que están más presentes en el día a día del centro y son más frecuentes y complejas.

\subsubsection{Acciones directivas y la autopercepción del modelo directivo}

Se trata de identificar relaciones significativas entre la autopercepción de los directores con su modelo directivo y las acciones directivas que realizan.

El análisis de la varianza (ANOVA) muestra las siguientes diferencias significativas:

Los directores que se auto definen en un modelo de liderazgo realizan más las acciones de promover actividades del centro para que sean reconocidas fuera $(4,26)$ en comparación con los directores que dicen coordinar $(3,86)$ o gestionar $(3,73)$. También sienten más el apoyo y la confianza de la comunidad educativa $(4,45)$. En cambio los que dicen coordinar $(4)$ o gestionar $(3,95)$ lo sienten menos. Por último, evalúan y controlan más las actividades y sus responsables $(4,32)$ en comparación a los directores que dicen coordinar (4) o gestionar $(3,91)$.

La última diferencia significativa en este apartado, tiene relación con los directores que dicen gestionar ya que son los que menos definen los objetivos y planifican los procesos $(4,20)$ en comparación con los que dicen liderar $(4,47)$ o coordinar $(4.45)$.

Figura 26: Acciones directivas según la auto percepción del modelo directivo

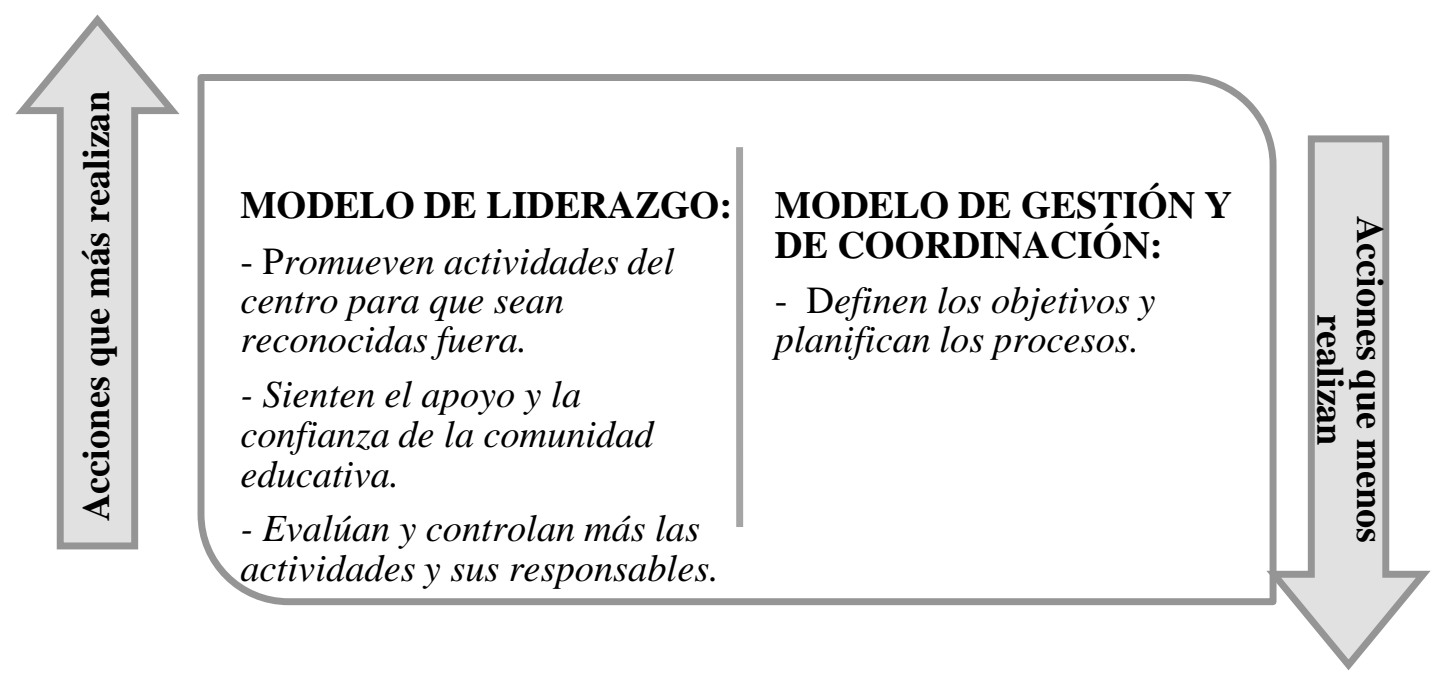




\subsubsection{Funciones directivas y las actuaciones directivas}

Las funciones directivas y las actuaciones han sido extraídas de la normativa vigente en Cataluña.

A pesar de que en la normativa las funciones y actuaciones están relacionadas, en las respuestas de los directores sólo aparece una relación estadísticamente significativa. Se trata de función de otras atribuciones en materia de personal con la actuación de resolver las faltas de asistencia y de puntualidad no justificadas de todo el personal del centro $(\mathrm{rS}=0,500, \mathrm{p}<0,01)$.

Profundizando en las funciones directivas, aparecen las siguientes relaciones entre ítems estadísticamente significantes:

- La función de organización y funcionamiento del centro con la función de la relación con la comunidad escolar $(\mathrm{rS}=0,470, \mathrm{p}<0,01)$.

- La función en materia de gestión con la realización de las funciones de organización y funcionamiento del centro $(\mathrm{rS}=0,516, \mathrm{p}<0,01)$.

- La función normativa que tiene más relaciones significativas es la de otras atribuciones en materia de personal con la función de relación con la comunidad escolar $(\mathrm{rS}=0,436$, $\mathrm{p}<0,01)$, con materia de gestión $(\mathrm{rS}=0,435, \mathrm{p}<0,01)$, con la función como jefe de personal $(\mathrm{rS}=0,580, \mathrm{p}<0,01)$ y con la función de materia de jornadas y horarios del personal $(\mathrm{rS}=0,512, \mathrm{p}<0,01)$.

Entre las actuaciones directivas, aparecen las siguientes relaciones significativas:

El impulsar el establecimiento de normas de organización y funcionamiento del centro con el establecer canales de relación con las asociaciones de padres y madres de los alumnos $(\mathrm{rS}=0,401, \mathrm{p}<0,01)$.

La actuación de asignar al profesorado del centro otras responsabilidades de gestión y coordinación docente con la actuación de liderar el personal del centro para garantizar que cumplen sus funciones ( $\mathrm{rS}=0,411, \mathrm{p}<0,01)$.

El sancionar las faltas de acuerdo con la normativa disciplinaria vigente con el resolver las faltas de asistencia y de puntualidad no justificadas de todo el personal del centro $(\mathrm{rS}=0,403, \mathrm{p}<0,01)$. 
Y por último, el formular la propuesta de incoación de expediente disciplinario por faltas graves de personal con el resolver las faltas de asistencia y de puntualidad no justificadas de todo el personal del centro $(\mathrm{rS}=0,415, \mathrm{p}<0,01)$ y con el sancionar las faltas de acuerdo con la normativa disciplinaria vigente $(\mathrm{rS}=0,761, \mathrm{p}<0,01)$.

\subsubsection{Compromiso de la comunidad y factores del éxito escolar}

Se comparan las medias obtenidas de la autopercepción del director sobre su propio compromiso y el de toda la comunidad con la puntuación otorgada a distintos factores que consideran influyentes para conseguir el éxito escolar en el centro.

Para comparar las medias lo hacemos a partir de un intervalo de confianza para la media al 95\%. Un intervalo de confianza es el rango de valores con una probabilidad determinada, en este caso de $95 \%$, en el cual conocemos el límite inferir y el límite superior de cada media. Al realizar el intervalo, se distinguen aquellos ítems que están por debajo del límite inferior y también los que están por encima del límite superior.

La influencia del trabajo colaborativo con otros centros de la zona $(4,7)$ en el éxito escolar está por debajo del límite inferior $(4,8)$.

En cambio, tener altas expectativas de la comunidad (5), la interacción con el entorno institucional (5) y la promoción de un intercambio entre docentes (5) son ítems que están por encima del valor superior $(4,9)$ para una influencia positiva en el éxito escolar.

Respecto la percepción del propio compromiso de los directores con la comunidad educativa, el clima constructivo entre los miembros de la comunidad $(4,6)$ es el ítem que está por debajo del límite inferior (4,7). Sin embargo la interacción con el entorno institucional (5) y la promoción de un intercambio entre docentes (5) vuelven a ser ítems que están por encima del valor positivo $(4,9)$. 
Tabla 118: Autopercepción del propio compromiso con factores influyentes en el éxito escolar

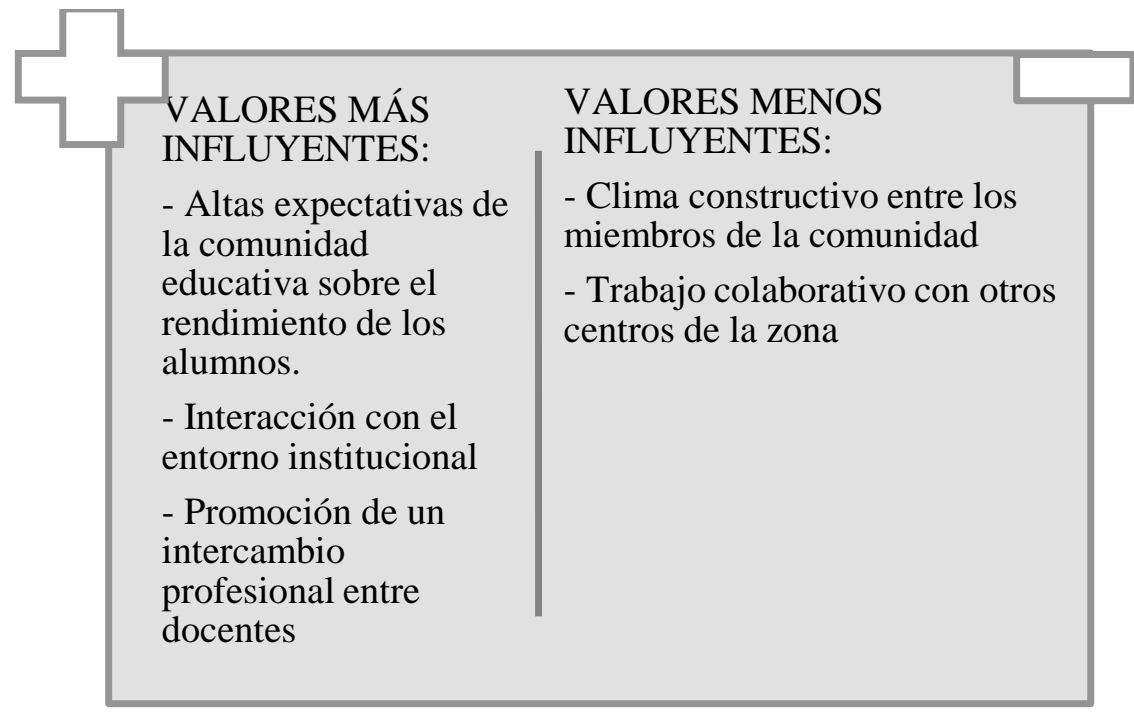

Respecto la percepción de los directores sobre el compromiso del profesorado:

\section{- Con el éxito escolar}

La autonomía organizativa: planificación del currículum en función de las necesidades del contexto $(4,3)$, el contexto del centro $(4,3)$ y la promoción de un intercambio entre docentes (4) son los ítems que están por debajo del valor inferior $(4,7)$ y no se observa ningún ítem por encima del valor superior $(4,9)$.

\section{- Con los proyectos del centro y comunidad}

Los procesos de enseñanza-aprendizaje (4,2), la organización y articulación curricular en relación a los procesos (4,2), el contexto del centro (4,2) y la promoción de un intercambio entre docentes (4) son ítems que están por debajo del valor inferior $(4,3)$. Tan sólo el trabajo colaborativo con otros centros de la zona $(4,7)$ está por encima del valor superior $(4,5)$.

\section{- Con la familia}

Los procesos de enseñanza-aprendizaje (4,2), las altas expectativas de la comunidad educativa sobre el rendimiento de los alumnos $(4,2)$ y la promoción de un intercambio entre docentes (3) son los ítems que están por debajo del valor inferior $(4,3)$. En cambio, el trabajo colaborativo con otros centros de la zona $(4,6)$ y la interacción con el entorno institucional (5) son ítems por encima del valor superior $(4,5)$. 
Tabla 119: Compromiso del profesorado con factores influyentes en el éxito escolar

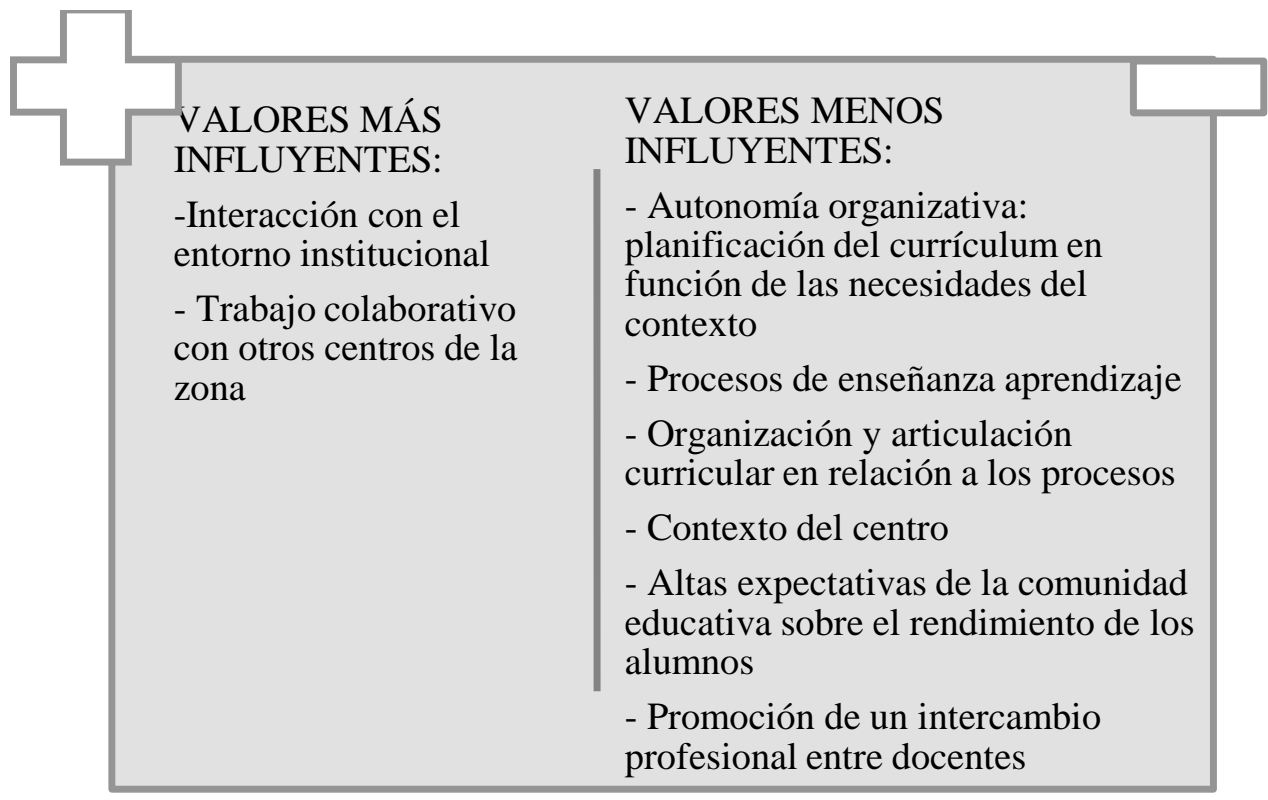

La percepción de los directores sobre el compromiso de las familias:

\section{- Con los proyectos del centro y comunidad}

El apoyo y cooperación de las familias y el profesorado para conseguir mejoras $(4,1)$, el trabajo colaborativo con otros centros de la zona $(4,3)$ y el contexto del centro $(4,2)$ son los ítems que están por encima del valor superior (4). En cambio, los procesos de enseñanza - aprendizaje $(3,6)$ y la promoción de un intercambio profesional entre docentes (2) están por debajo del valor inferior $(3,7)$.

\section{- Con los resultados de sus hijos/as}

La promoción de un intercambio profesional entre docentes (2) es el único valor que está por debajo del valor inferior (3,7). En cambio, el apoyo y cooperación de las familias y el profesorado para conseguir mejoras (4,1), el trabajo colaborativo con otros centros de la zona (4,3) y el contexto del centro (4,2) y la interacción con el entorno institucional $(4,5)$ son ítems que están por encima del valor superior (4). 
Tabla 120: Compromiso de las familias con factores influyentes en el éxito escolar

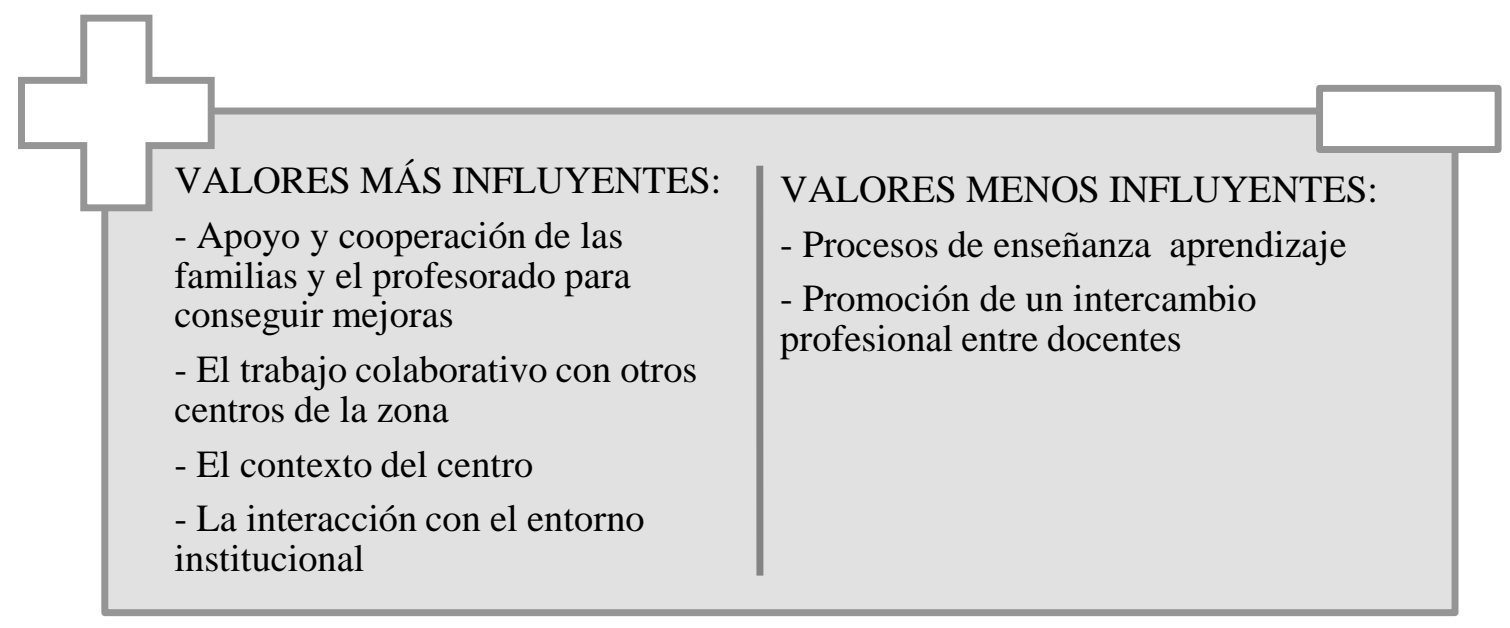

La percepción de los directores sobre el compromiso del alumnado:

\section{- $\quad$ Con sus resultados}

El apoyo y cooperación de les familias y el profesorado para conseguir mejoras (4,2), trabajo colaborativo con otros centros de la zona (4,4), contexto del centro $(4,3)$ y la interacción con el entorno institucional $(4,5)$ son ítems que se encuentran por encima del valor superior (4,1). Sin embargo, el clima constructivo entre los miembros de la comunidad (3,8), control del progres del alumnado $(3,8)$ y la promoción de un intercambio profesional entre docentes (3) estan por debajo del valor inferior $(3,9)$.

\section{- Con los proyectos del centro y comunidad}

El clima constructivo entre los miembros de la comunidad (3,8), motivación y apoyo a todos los miembros del centro $(3,9)$ y la promoción de un intercambio profesional entre docentes (3) son ítems que están por debajo del valor inferior (4). En cambio trabajo colaborativo con otros centros de la zona $(4,6)$ y el contexto del centro $(4,5)$ son ítems que se encuentran por encima del valor superior $(4,1)$. 
Tabla 121: Compromiso del alumnado con factores influyentes en el éxito escolar

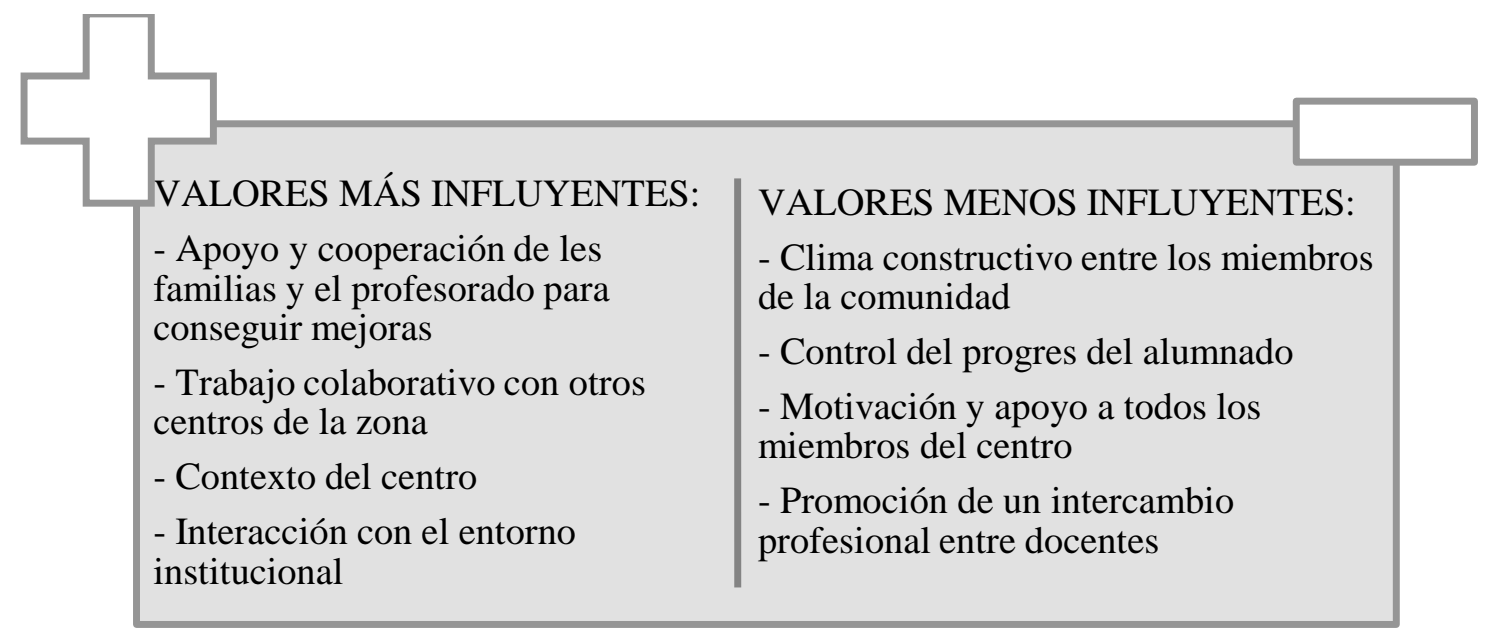

Para concluir este apartado, se destaca que la promoción de un intercambio profesional entre docentes la valora por encima del límite superior según la auto percepción del propio compromiso de los directores. Sin embargo, el mismo ítem es valorado por debajo del límite inferior para la percepción del compromiso del profesorado, de las familias y de los alumnos.

También se observa que el trabajo colaborativo con otros centros de la zona es valorado por encima del límite superior para la percepción del compromiso del profesorado, familias y alumnos. En cambio, el mismo ítem para la auto percepción del propio compromiso de los directores es valorado por debajo del límite inferior.

Por último, mientras que el contexto del centro está valorado por encima del límite superior según la percepción del compromiso de las familias y alumnado. Es valorado por debajo del límite inferior para la auto percepción del propio compromiso de los directores. 
DIRECCIÓN ESCOLAR Y LIDERAZGO

\section{PRIMARIA DE TARRAGONA}

ANÁLISIS DEL DESEMPEÑO DE LA FIGURA DIRECTIVA EN CENTROS DE EDUCACIÓN Marta Camarero Figuerola 


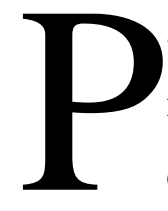

ara finalizar, en este apartado se presentan las conclusiones de nuestra investigación. La estructura del capítulo corresponde a los objetivos principales de este estudio. Inicialmente se muestra el perfil del director que hay actualmente en las escuelas de educación primaria de la zona. En segundo lugar se presenta la concepción de la dirección por los directores y la situación actual.

A continuación se describen las características de cada estilo de dirección y liderazgo escolar. Y por último, se proponen líneas de mejora del liderazgo para el éxito escolar a partir de consideraciones dirigidas a los diferentes agentes implicados en la dirección escolar en los centros de educación primaria.

Se finaliza con la mención de las limitaciones del estudio y futuras líneas de investigación. 


\subsection{Conclusiones}

En este capítulo, se aborda la complicada tarea de resumir en, relativamente, poco espacio todo aquello que nos ha aportado la investigación realizada.

En primer lugar se explicitan las principales conclusiones que se han ido elaborando a partir del propósito general y los objetivos definidos al inicio de la investigación.

En el cuadro siguiente detallamos las unidades de significación que hemos establecido, a la vez que las relacionamos con los propósitos que nos planteábamos al iniciar este estudio.

Tras dar respuesta a los objetivos de la investigación, se desprenden una serie de consideraciones. Consideraciones dirigidas a las distintas instancias que, de una u otra forma, intervienen y están implicadas en la dirección escolar.

Tabla 122: Conclusiones y objetivos de investigación

\section{UNIDADES DE SIGNIFICADO}

OBJETIVOS INVESTIGACIÓN

\section{A) CONCLUSIONES}

1- Perfil directivo 1

2- Concepción y situación de la dirección escolar 2

3- Estilos de dirección y liderazgo escolar $3 / 2 / 1$

4- Acciones para potenciar el liderazgo y el éxito escolar 5

B) CONSIDERACIONES

1- Administración Educativa

2- Universidad / Instituto Ciencias de la Educación (ICE) 5

3- Centros educativos

4- Equipos directivos

Finalmente se lleva a cabo una reflexión general sobre el proceso de la investigación en la cual se manifiestan los puntos fuertes o aportaciones y las debilidades o limitaciones. Se concluye con unas líneas de investigación futuras, que permitan profundizar y ampliar esta investigación. 


\subsubsection{Perfil directivo}

A partir del propósito general de esta investigación:

\section{"Conocer la figura directiva y los estilos de dirección y liderazgo de los centros educativos de primaria de los SSTT de Educación de Tarragona"}

Con el primer objetivo se intenta describir el perfil profesional de los directores de las escuelas ubicadas en el marco geográfico que dependen de los SSTT de Educación de Tarragona.

Las características personales que definen a los directores de los centros de primaria se resumiría en un retrato de: mujer de 50 años de edad, con 25 años de experiencia docente y con 9 años de experiencia directiva y una autopercepción de su modelo de dirección basado en la gestión de la escuela.

En cuanto al género nos encontramos que, del total de directores, un 69,5\% son mujeres y un $30,5 \%$ hombres. La figura docente en nuestro contexto está representada por un $84 \%$ de mujeres y un $16 \%$ de hombres. Estos datos nos evidencian la existencia de una masculinización y un cierto desequilibro al ocupar cargos directivos que aumenta notablemente en directores de más de 55 años. La dirección escolar en educación primaria está capitaneada mayoritariamente por hombres (CINIIE. \& Instituto de la Mujer., 2012). Esta "falla del género" puede deberse, entre otros aspectos, a la autoexclusión de las mujeres por el sexismo impregnado en los ámbitos de la sociedad, familia y escuela (Santos, 2015). Existe el reto de trabajar para romper los estereotipos que la sociedad asigna en función del género.

La edad del $43 \%$ de los directores oscila entre los 46 y 54 años y el $48 \%$ de los directores tienen una experiencia directiva de un mínimo 9 años de los cuales el $75 \%$ aproximadamente son mujeres. Este dato junto con el referido al género, nos hace plantear, como mínimo, tres puntos:

- Uno, es que los directores con más edad - y a la vez con más experiencia docenteson los que actualmente, en la mayoría de los centros, están al cargo de la dirección.

- Dos, los cargos de Dirección se mantienen durante largos periodos, ya que hay una "tradición" de la dirección escolar de repetir varias candidaturas. 
- Tres, que las mujeres, dejan de repetir candidatura a partir de los 55 años, donde el porcentaje baja al 59\% aproximadamente.

Perales (Fundació Jaume Bofill, 2015), manifiesta que en la actualidad hay una tendencia al alza en el hecho que las candidaturas directivas en los centros se tripliquen.

Este dato justifica porqué alrededor de la mitad de los directores de la muestra tienen un mínimo de 9 años de experiencia. Estos directores se encuentran profesionalmente en la fase de autonomía según Day \& Bakioglu (1996), están establecidos en el puesto y las experiencias directivas le otorgan seguridad y un mejor desempeño del cargo.

Consideramos importante reflexionar sobre el perennialismo del cargo directivo ya que este hecho puede provocar una limitación de acceso a nuevos profesionales formados recientemente en dirección. Recordemos que "la antigüedad por sí sola no constituye una garantía de desarrollo profesional de los directivos ni de desarrollo organizativo de los centros" (Villa \& García Olalla, 2003:13). Ni los años de experiencia se transforman automáticamente en sabiduría sin aprender a reconocer los errores cometidos, saber escuchar y observar, conocer el contexto, comprender la cultura de la escuela, hacerse preguntas, abrirse a las críticas, saber reflexionar, poner en cuestión y querer aprender (Santos, 2015). Por otra parte sería un componente que iría definiendo la profesionalización de la dirección si va acompañado de formación y rendición de cuentas.

En general, los directores tienen una experiencia docente de más de 25 años de los cuales la mayoría -o los últimos años- han sido en el centro que actualmente dirigen. Además de la experiencia docente antes de acceder al cargo directivo, el $47 \%$ de los directores tiene experiencia en otro cargo del equipo directivo (jefe de estudios o secretario). Estos datos nos evidencia el proceso gradual de acceso al cargo de la mitad de los directores: experiencia docente, experiencia en el equipo directivo o coordinador de ciclo y finalmente acceder al cargo directivo.

Chavarría (Fundació Jaume Bofill, 2015) manifiesta que en muchos casos el acceso al cargo directivo de la escuela pública funciona igual que el de la escuela concertadaprivada ya que el representante del titular propone un candidato, "el heredero" que acaba presentándose como candidato. Este "heredero" normalmente suele ser algún componente del anterior equipo directivo. 
El modo de acceso al cargo para un $72 \%$ de los directores es el concurso de méritos siendo la única candidatura presentada. Este dato demuestra un proceso gradual de acceso al cargo que elimina una competencia entre varios candidatos para acceder al cargo. Este proceso desdibuja la atracción real del cargo ya que no sabemos si realmente pocos maestros quieren ser directores o si se debe a la interiorización de la cultura escolar del acceso gradual. En el caso de los centros concertados-privados, la mitad de los directores han sido seleccionados por el titular del centro para ocupar el puesto directivo y se percibe cierta competencia entre diferentes candidatos para acceder al cargo.

Respecto a la afirmación “de no quieren ser directores” Barrios, Iranzo \& Tierno (2013) desmienten el mito de que nadie quiera ser director ya que en los últimos años el número de profesores que se han formado para ser directores ha aumentado.

Los procesos de selección y el proceso de renovación de los directores escolares deben considerarse como oportunidades para renovar los centros escolares. En la actualidad no se estaría aprovechando a los profesores formados y motivados para ejercer la función directiva (Fundació Jaume Bofill, 2015).

En cuanto al número de horas a la semana de docencia directa, un $44 \%$ de los directores realiza entre $9-16$ horas y un $42 \%$ realizan 8 horas o menos. En el caso de los directores de escuelas rurales, el número de horas de docencia que realiza es de 17 horas o más a la semana debido a las características propias del centro rural. Cuanto más grande es el centro más distancia existe entre la función docente y la función directiva ya que destina menos horas de docencia y más a la dirección escolar. Esto nos evidenciaría la relación directa de docencia directa con el tamaño de las escuelas.

El principal motivo de acceso al cargo es el deseo por mejorar el funcionamiento del centro. Resultado que coincide con otros estudios sobre este tema (Rodríguez Pulido et al., 2013; Valle Aparicio, 2013; Santos, 2015). Atendiendo a la clasificación que ofrece Santos (2015) sobre los motivos de acceso, la mayoría de directores manifiestan motivos pedagógicamente ricos como: mejorar el funcionamiento del centro y promover proyectos de innovación. Estos resultados nos evidenciarían que cuando un profesor toma la decisión de aceptar el cargo directivo, se trataría de una decisión meditada y basada en la estima del centro. Los directores, excepcionalmente, también destacaron 
algunos motivos pedagógicamente pobres como disfrutar del prestigio social que supone ser elegido, ganar un aumento de sueldo.

En lo que se refiere a la formación inicial, la totalidad de los directores noveles afirman haber recibido formación inicial. Este hecho es consecuencia directa de las normativas vigentes, que la establecen como requisito para acceder al cargo. Así se plantea en la estructuración de los cursos de formación inicial, que abogan por una cierta profesionalización de los directores, desde una visión de liderazgo pedagógico y organizativo.

La mayoría de directores con más experiencia en el cargo no recibieron formación inicial, aunque valoran positivamente la formación continua. En muchos de estos casos, los directores con mayor experiencia provienen de cargos previos como jefes de estudios o coordinadores de ciclo. La formación recibida a raíz de dichos cargos, así como la experiencia en los mismos, se identifica, por su parte, como la única formación inicial que han tenido para el cargo de dirección. Los directores que recibieron formación inicial la valoran satisfactoriamente aunque reconocen que el impacto de la formación recibida en la mejora en el rendimiento de los alumnos ha sido bajo.

En cuanto a la formación continua, la mayoría de los directores han recibido formación continua. Estadísticamente aparecen diferencias significativas en función del modelo de dirección en el que se auto definen. Siendo los directores que consideran que "lideran" los que más manifiestan haber recibido formación continua. Este hecho apunta a la idea de que aquellos directores que ven el liderazgo como una función básica de su cargo estarían más preocupados por recibir formación que les capacite para asumir dicho papel (en contraposición con los que dicen "coordinar" o "gestionar").

El aspecto más valorado de la formación continua es la aplicación en el centro de la formación recibida y el menos valorado es, de nuevo, el impacto en la mejora en el rendimiento de los alumnos. Constituye pues, un aspecto que se debería tener en cuenta en el diseño de la formación de directores.

Los directores perciben que las competencias que tienen mejor desarrolladas son: el compromiso ético, la participación y el trabajo en equipo. En cambio, las menos son: el liderazgo, la autonomía y la autogestión. Según la clasificación de Campo (2010) las destrezas interpersonales (empatía, asertividad, escucha activa, claridad en la 
exposición, trabajo en equipo) son las más desarrolladas en contraposición a la capacidad de dirección y liderazgo (delegar, motivar, desarrollo personal, apertura al exterior, liderazgo).

De manera general, perciben como fortaleza las competencias basadas en trabajos colaborativos y participativos en los centros. Como debilidad aparecerían las competencias más individuales que pueden asociarse con carencias personales de dotes de liderazgo o por las limitaciones del propio sistema educativo (en el caso de la autonomía y autogestión).

El principal componente para un buen desempeño del cargo y una buena dirección, según los directores, es la gestión. Esto nos evidencia la visión de la dirección escolar entendida como gestora del centro educativo (parte más administrativa y burocrática). De hecho, el modelo basado en la gestión es el que casi la mitad de los directores reconoce tener.

En relación con este resultado, la investigación de Murillo \& Hernández-Castilla (2015) sobre la distribución del tiempo de los directores en los centros de Educación Primaria, se afirma que los directores dedican un $46 \%$ de su tiempo y tareas administrativas, un $29 \%$ a tareas pedagógicas y un $22 \%$ en las reuniones. Se concluye que "si queremos buenos directores, necesitamos líderes pedagógicos, no gestores” (2015:17).

En cuanto a los valores con los que definen sus centros, se basan en la colaboración, la innovación y la superación. Destacan la visión del trabajo en equipo, el interés por una constante actualización e innovación y el esfuerzo por lograr mejoras en la educación y en la formación de toda la comunidad educativa. Los valores con los que definen su cargo son la implicación, la gestión y la ética. Remarcan la dedicación, compromiso, responsabilidad, exigencia y esfuerzo de su cargo además de la necesidad de planificar y tomar decisiones. Destacan la ética como fundamental para el ejercicio del cargo basado en la equidad, honestidad y la empatía. Por último, destacan valores personales como su compromiso, su ética y sus habilidades comunicativas.

En relación al aspecto que produce más satisfacción a los directores es la implicación del equipo docente en el funcionamiento del centro. Además de conseguir los objetivos marcados, tener buenas relaciones personales y profesionales con la comunidad educativa y poder llevar a cabo proyectos innovadores. Por lo tanto es coherente que los 
aspectos que generan más insatisfacción sean la falta de recursos, los conflictos entre diferentes miembros de la comunidad y el exceso de trabajo y responsabilidad del cargo.

Por último, hacemos mención a la autopercepción del modelo directivo en el que se definen los directores. Los datos denotan que casi la mitad de los directores se consideran gestores. El $46 \%$ de los directores se consideran gestores del centro aunque cabe señalar que el $30 \%$ de los directores se definen como líderes y un $17 \%$ se ven como coordinadores del centro. En lo que se refiere a la autopercepción de líder está asociada a los hombres (41\% del total de hombres) en cambio, la autopercepción de la coordinación está asociada a las mujeres (50,5\% del total de mujeres).

En resumen, el perfil actual de los directores de la zona se caracteriza de la siguiente manera:

Tabla 123: Perfil de los directores de la zona

\section{RESUMEN DEL PERFIL DIRECTIVO}

Género: Femenino

Años de experiencia directiva: 9 o más

Tipo de acceso:

Concurso de méritos y única candidatura

Horas de docencia directa:

En función del tamaño del centro. Más cuanto más pequeño es el centro.

\section{Competencias más desarrolladas:}

Compromiso ético, participación, trabajo en equipo
Edad: 46-54 años

Experiencia en otros cargos directivos: Sí

Motivos de acceso: 1) Mejorar el centro educativo, 2) Promover proyectos de innovación

\begin{tabular}{l|l} 
Formación Inicial: & Formación Continua: \\
Sí $(69 \%)-$ No $(31 \%)$ & Sí $(83 \%)-$ No $(17 \%)$
\end{tabular}

Componentes para una buena dirección: gestión, dinamización y colaboración

Valores del centro:

- Colaboración

- Innovación

- Superación
Competencias menos desarrolladas:

Liderazgo, autonomía y autogestión

\section{Satisfacción de los directores:}

- Mejoras realizadas.

- Buena comunicación y relaciones.

- Aplicación de los proyectos.

\section{Valores del cargo:}

- Implicación

- Organización/Gestión

- Ética
Valores personales:

- Compromiso

- Ética

- Comunicación

\section{Insatisfacciones de los directores:}

- Falta de recursos

- Conflictos

- Exceso de trabajo

Principal satisfacción: Implicación del equipo docente en el funcionamiento del centro

Modelo de dirección: Basado en la gestión 


\subsubsection{Concepción y situación de la dirección escolar}

Con el segundo objetivo de la investigación se pretende analizar la situación actual del desempeño de la dirección escolar.

El análisis de la situación actual de la dirección escolar se basa en qué aspectos consideran los directores que están mejor trabajados en sus centros. Destacan el liderazgo compartido entre el equipo directivo como el aspecto más desarrollado en la dirección del centro. En cambio, la colaboración y participación de las familias en los procesos educativos del centro es un aspecto que los directores consideran que deben trabajar y mejorar. Los directores de escuelas rurales destacan positivamente su situación respecto el éxito escolar del centro. Los directores de centros de alta complejidad valoran significativamente más alto la mediación de conflictos en cambio puntúan más bajo la colaboración y participación de las familias y el éxito escolar.

De estos datos se concluye que el liderazgo compartido al que se refieren los directores es tan sólo un liderazgo limitado al equipo directivo, de distribución de tareas por las responsabilidades de cargos (director, jefe de estudios, secretario) no se trata de un liderazgo distribuido y abierto a toda la comunidad educativa.

El seguimiento de los acuerdos es el aspecto al que más importancia otorgan los directores especialmente en los centros que hemos clasificado como urbanos, ya que en los rurales parece que esta función se desarrolla de manera suficiente. Sin embargo la representación institucional es el aspecto al que conceden menor importancia a pesar de que se trata de una función normativa (MECD, 2013) y por lo tanto supone una de las actuaciones que señalan realizar más.

Las acciones directivas (acciones extraídas de la revisión teórica) que más efectúan los directores son: estar siempre accesibles a todos los miembros de la comunidad educativa, trabajar en equipo junto el profesorado para detectar necesidades, conocer las situaciones familiares más complejas y distribuir información pertinente a cada colectivo de la comunidad educativa.

Las actuaciones anteriores se fundamentan principalmente en las habilidades sociales que permiten al director mostrarse cercano, conocer y escuchar las necesidades de los diferentes miembros de la comunidad y detectar necesidades y poderlas solventar. 
En el caso de los directores de escuelas rurales serían los de dicen ser menos accesibles a la comunidad educativa. Esta diferencia significativa la atribuiríamos a que son los directores que más horas de docencia realizan. En cambio son los que más consultan al profesorado en la toma de decisiones y crean espacios para compartir experiencias y trabajar en equipo. Además son los directores que más sienten el apoyo y la confianza de la comunidad educativa.

La actuación más ardua para los directores es la gestión del propio tiempo ya que un 93\% de los directores dice no logra gestionarlo, lo que evidencia la dificultad de planificar el tiempo de manera adecuada. La falta de tiempo es uno de los factores principales que produce estrés directivo (Villa \& Gairín, 1996; Vázquez Recio, 2002).

En lo que se refiere a las funciones normativas de la dirección escolar, establecidas por la ley de educación de Cataluña, LEC (2009), como era de esperar, todas dicen ser realizadas en grado alto por los directores. Se destaca la función de organización y funcionamiento del centro como la función que más realizan. Según el nivel de dificultad la función de dirección pedagógica y liderazgo y la de jefe de personal son las funciones que los directores perciben como más dificultosas. En este sentido, la percepción altamente difícil del liderazgo pedagógico es congruente con el rol todavía prevalente de "primus inter pares" (García Olalla, Poblete \& Vila, 2006; Cantón \& Arias, 2008) de los directores, más cercano a la docencia que al liderazgo y derivado de la no profesionalización de esta figura.

Las actuaciones normativas (extraídas de la normativa vigente en Cataluña (LEC, 2009) que más realizan los directores son la de representación del centro y el presidir el consejo escolar, claustro y los diferentes actos académicos que se celebren en el centro escolar. En contraposición, la que desarrollan en menor frecuencia es la de coordinación con otros centros y la de mantener una red de relaciones con el centro y con el entorno. Los directores de escuelas rurales son los que más realizarían esta coordinación, dada su tipología de escuela, con otros centros educativos.

En otras palabras, la dirección escolar está centrada fundamentalmente en el propio centro y no en la colaboración con otros centros escolares o instituciones de la zona, a pesar de ser señalado como uno de los aspectos más influyentes en el éxito escolar tanto por profesores, como familias y alumnos. 
Convertir las funciones normativas en actuaciones más específicas nos ha sido útil para identificar las actuaciones que los directores realizan y que, se asocian a un estilo de dirección concreto. Los directores que más orientan, dirigen y supervisan las actividades del centro son los directores que dicen liderar en contraposición a los que dicen coordinar. En cambio, los directores que más se ocupan de tareas ligadas con la función de jefe de personal como por ejemplo de comunicar las jornadas no trabajadas cuando el personal del centro ejerce su derecho a huelga son los directores que dicen gestionar en contraposición a los que dicen liderar. Cuando analicemos el siguiente objetivo especificaremos las diferencias de cada estilo directivo.

En lo que se refiere a la percepción de los directores sobre el propio compromiso es muy elevado en la línea que apunta Álvarez (2010b) cuando afirma que el compromiso del director es imprescindible en el ejercicio directivo y para promover un liderazgo ya que es un valor personal que destaca en una dirección escolar.

Cuando se trata del compromiso de los diferentes colectivos de la comunidad educativa se observa que los directores perciben un compromiso menor tanto en el profesorado como familias y alumnos.

A pesar de ello los directores reconocen como uno de los valores más influyentes en el éxito escolar el hecho de tener altas expectativas de la comunidad educativa sobre el rendimiento de los alumnos. Los directores de escuelas rurales, son los que más alto percibiría el compromiso del profesorado con los proyectos del centro y comunidad.

Respecto las familias, los directores de centros de alta complejidad son los que más bajo valoran el compromiso de las familias con los proyectos del centro y la comunidad, el compromiso de las familias con los resultados de sus hijos y el compromiso del alumnado con sus resultados.

El compromiso de los diferentes miembros de la comunidad educativa aumenta la calidad y el éxito educativo (Gairín, 2011). Por ese motivo, la baja percepción del compromiso de la comunidad educativa de los directores de nuestra muestra nos obliga a reflexionar acerca de si es posible liderar una escuela con una baja confianza en los miembros de la comunidad. Parece ontológicamente imposible y se apuntaría a una necesidad de regenerar la capacidad de los directores de dirigir los centros con visiones creativas, socializadoras y potenciadoras que aminoren las tendencias a la desconfianza 
y el cansancio que se observa en algunos grupos de directores con muchos años de experiencia.

En este punto hacemos mención a las acciones para promover el compromiso de la comunidad escolar que realizan los directores en los centros. El mayor número de actuaciones están destinadas al profesorado ya que son considerados los pilares fundamentales en el funcionamiento y éxito de los centros escolares. Las acciones se basan en mostrarse cercano, motivar, apoyar, asesorar, escuchar a los docentes.

Otro gran grupo de acciones están destinadas al propio director, es decir, son acciones que realizan para preservar su compromiso. Las acciones destinadas al alumnado se dividen en acciones directas e indirectas.

Las acciones directas son: realizar docencia directa y participar en las asambleas. En cambio, las acciones indirectas son: facilitar recursos y técnicas de estudio para mejorar su aprendizaje, seguimiento del aprendizaje y asistir a las reuniones de evaluación.

Las acciones destinadas a las familias se basan en una comunicación abierta y flexible a partir de la utilización de las redes sociales con la finalidad de mostrarse más cercano a las familias. El contacto regular con el AMPA y promover actividades conjuntas con la finalidad de conseguir que las familias, o el mayor número de familias, se involucren en el centro.

En general para fomentar y mantener el compromiso de la comunidad educativa es necesario fomentar y cuidar las relaciones bidireccionales (Bazarra, 2012). Conseguir la participación de los diferentes colectivos con la finalidad de transformar el centro en una auténtica comunidad escolar de aprendizaje para todos (Gairín, 2011).

El factor más influyente en los resultados del centro para el $51 \%$ de los directores de la muestra es la estabilidad de los equipos docentes. En cambio, los factores relacionados con el trabajo en red y en colaboración con otros profesionales o centros son los que los directores consideran que menos afectan al éxito del centro educativo. Esto nos evidencia, como mínimo, dos cuestiones:

- Una, la preocupación de los directores en mantener una plantilla de docentes estable. 
- Dos, los directores no ven necesaria la interacción con otros centros educativos ni con el entorno institucional ya que no consideran que esto mejore ni favorezca a los resultados académicos, a pesar que como ya hemos apuntado, los directores lo señalan como aspectos influyentes.

Los directores rurales son los que considerarían que el trabajo colaborativo con otros centros de la zona mejoran los resultados del centro.

Por lo que respecta a las necesidades formativas, no todos los directores tienen las mismas. Las necesidades varían en función de sus características personales, especialmente la edad y la experiencia en cargos de gestión y coordinación; y tienen una relación directa con las etapas de adaptación, estabilidad y autorrealización que todo director atraviesa, haciéndose más diversas y concretas, a medida que la experiencia en el cargo aumenta.

No obstante, tres temas principales son en los que los directores manifiestan más necesidades: gestión del centro, gestión de personal y legislación educativa. Estos datos coinciden con los resultados de las investigaciones de Vázquez Recio (2002) y Padilla (2008). Paradójicamente estos tópicos ya aparecen en los módulos de contenidos de la formación que se ofrece, por lo que deberíamos preguntarnos el CÓMO se están conceptualizando, diseñando, impartiendo y valorando esos cursos. Existe una distancia entre las necesidades formativas y la formación que reciben para el cargo (Gómez, 2012).

Por otra parte la mayoría de directores reconocen como una de las funciones más difíciles de desarrollar la dirección pedagógica y liderazgo, por lo que las acciones formativas deberían dotar a los directores de competencias de liderazgo pedagógico, coordinación interna y relaciones sinérgicas con la comunidad, así como de establecimiento de redes de colaboración entre directores que fortalezcan proyectos específicos de mejora escolar. Sin estos recursos, es muy fácil caer en modelos directivos que evitan el ejercicio de esas competencias y se instalan en inercias gerencialistas.

Respecto a las necesidades no formativas, los directores destacan la necesidad de una formación de gestión del cargo directivo que les ayude al que confiera control del estrés, más seguridad en el desempeño del cargo y que facilite estrategias para organizar y 
gestionar el tiempo. Además critican duramente los recortes sufridos en los centros escolares en los últimos años y destacan la necesidad de incrementar los recursos económicos (mejorar la remuneración de la función directiva), los recursos humanos (incrementar la plantilla, aumento del apoyo administrativo) y recursos materiales (mantenimiento de las escuelas, mayor dotación de materiales).

En cuanto al ámbito legislativo, los directores valoran que los decretos que regulan la dirección facilitan la autonomía de los centros, mejoran la gestión y organización de éstos y proporciona cierta estabilidad a la plantilla docente. La parte negativa es la complejidad de aplicarlos, el aumento de responsabilidades hacia el cargo directivo y la falta de apoyo de profesionales. Los directores manifiestan que los decretos ofrecen una pseudoautonomía ya que en los temas más relevantes la autonomía está limitada.

Las expectativas del nuevo decreto (Decreto de definición de perfil y provisión de puestos de trabajo docente, conocido popularmente como el "decreto de plantillas") que tienen los directores son positivas. La mayor expectación está en poder escoger el 50\% de las plantillas de los docentes y promover una estabilidad a los docentes que permita así mejorar la implicación del profesorado en el centro y a su vez mejorar los resultados académicos del alumnado.

\subsubsection{Estilos de dirección y de liderazgo escolar}

El tercer objetivo de la investigación trata de identificar los diferentes modelos de dirección escolar y liderazgo que desarrollan los directores de la zona.

A partir de la autopercepción de los directores encuestados y sus respuestas estadísticamente significativas del cuestionario se describen los diferentes estilos directivos basados en: la gestión, el liderazgo y la coordinación.

A continuación, vamos a describir las características de cada estilo directivo.

Empezamos con el estilo gestor, un estilo de dirección basado en la gestión del centro. El $46 \%$ de los directores de este estudio se identifican con este estilo. Se trata de un estilo asociado al género femenino ya que el $50 \%$ del total de mujeres se identifican en él frente el $36 \%$ del total de hombres. 
Los directores de este estilo no le dan tanta importancia a la formación continua. Son los directores que puntúan más alto el estado actual del estrés que conlleva el cargo directivo y los que más comunican las jornadas no trabajadas cuando el personal del centro ejerce el derecho a huelga.

En relación a las actuaciones para mantener el compromiso de la comunidad educativa, ofrecen las máximas facilidades de comunicación y destinan un buen porcentaje del tiempo de dirección a la atención personalizada. Autoevalúan su ejercicio de dirección y examinan los diferentes temas que afectan a la escuela.

Por otro lado, el estilo de liderazgo se basa en la noción del director como líder del centro. El 30\% de los directores de esta investigación se identifican con este estilo. Se trata de un estilo asociado al género masculino ya que el $41 \%$ del total de hombres se identifican en este modelo frente al $25 \%$ del total de mujeres.

Los directores de este estilo son los que más importancia le dan a la formación continua por lo que son los directores que más formación reciben durante el mandato. Consideran que el componente más relevante para su cargo directivo es el carisma.

Los directores de este estilo puntúan más alto la situación actual de la representación institucional y la gestión de recursos del centro.

Las actuaciones directivas que más realizan son la promoción de las actividades del centro en el exterior y evalúan y controlan las actividades y sus responsables. Se sienten apoyados y con la confianza de la comunidad educativa. Se trata del el estilo de dirección que más orientan, dirigen y supervisan las actividades del centro. Es el estilo directivo que más realiza la función normativa de "dirección pedagógica y liderazgo"

En relación a las actuaciones para mantener el compromiso de la comunidad educativa sus actuaciones se centran en la acción comunicativa. Es decir, mantener las redes y estrategias de comunicación e información. Proponen actividades para la mejora de manera constante, trabajan en equipo, reflexionan y realizan evaluaciones internas al inicio y al final del curso.

Los componentes que más satisfacción les otorgan son la libertad y autonomía en la toma de decisiones. 
El estilo coordinador se basa en la noción del director como coordinador principal del centro. El 17\% de los directores de este estudio se identifican con este estilo. Este estilo no se observa ninguna preferencia en función del género. El 17\% del total de mujeres y el $18 \%$ del total de los hombres se identifican con él.

Los directores de este estilo son los que menos formación durante el cargo reciben, en comparación con los otros estilos de dirección.

Es el estilo que la dirección escolar más consulta al equipo de profesorado en la toma de decisiones del centro. Las actuaciones que realizan para mantener el compromiso de la comunidad educativa se basan en la comunicación. Se interesan en conocer las familias y a los alumnos. Presiden y dinamizan los órganos de gobierno, participación y de gestión del centro.

Por último, el estilo autoritario se basa en mandar sobre los otros miembros del centro. El director autoritario es aquel que toma las decisiones en solitario, sin consultar a ningún miembro del equipo. Remarca la jerarquía y utiliza el poder de su cargo directivo. Destacar que ningún director de nuestro estudio se identifica con este estilo basado exclusivamente en mandar.

A continuación, se presenta un resumen que recoge los rasgos más característicos de los estilos directivos de los directores de nuestra zona: 
Tabla 124: Rasgos característicos de los estilos de dirección

\begin{tabular}{|c|c|c|}
\hline Estilo gestor & Estilo coordinador & Estilo liderazgo \\
\hline Modelo basado en la gestión & $\begin{array}{l}\text { Modelo basado en la } \\
\text { coordinación }\end{array}$ & Modelo basado en el liderazgo \\
\hline $\begin{array}{l}79 \% \text { de los directores reciben } \\
\text { formación continua }\end{array}$ & $\begin{array}{l}68 \% \text { de los directores reciben } \\
\text { formación continua }\end{array}$ & $\begin{array}{l}\text { 94\% de los directores reciben } \\
\text { formación continua }\end{array}$ \\
\hline $\begin{array}{r}\text { Tan sólo entre el } 20 \% \text { y el } 27 \% \\
\text { consideran el carism }\end{array}$ & los directores de estos estilos & $\begin{array}{c}\text { El } 47 \% \text { de los directores } \\
\text { consideran el carisma relevante } \\
\text { para el cargo }\end{array}$ \\
\hline $\begin{array}{l}\text { Son los directores que puntúan } \\
\text { más alto estado actual del } \\
\text { estrés que conlleva el cargo }\end{array}$ & \multicolumn{2}{|c|}{$\begin{array}{l}\text { Los directores que dicen liderar en comparación con los que dicen } \\
\text { coordinar puntúan más alto la situación actual de la representación } \\
\text { institucional }(4,29 \text { versus } 3,71) \text { y la gestión de recursos del centro }\end{array}$} \\
\hline
\end{tabular}
$(4,21$ versus 3,67$)$

Tan sólo entre el $17 \%$ y el $27 \%$ de los directores de estos estilos dicen sentir el apoyo y la confianza de la comunidad educativa.

Tan sólo entre el $18 \%$ y el $20 \%$ de los directores de estos estilos promueven las actividades del centro en el exterior

Tan sólo un $35 \%$ de los directores de este estilo dicen consultar al profesorado en la toma de decisiones
El 54\% de los directores dicen consultar al profesorado en la toma de decisiones
Son los estilos directivos que menos evalúan y controlan las actividades y sus responsables

Son los estilos directivos que menos orientan, dirigen y supervisan las actividades del centro
El 53\% de los directores dicen sentir siempre el apoyo y la confianza de la comunidad educativa

El $42 \%$ de los directores promueven las actividades del centro en el exterior

Tan sólo un $34 \%$ de los directores de este estilo dicen consultar al profesorado en la toma de decisiones.

Es el estilo directivo que más evalúan y controlan las actividades y sus responsables Es el estilo directivo que más orientan, dirigen y supervisan las actividades del centro
Es el estilo directivo que más comunican las jornadas no trabajadas cuando el personal del centro ejerce el derecho a huelga

Son los estilos directivos que menos realizan la función normativa de "dirección pedagógica y liderazgo"

Son los estilos directivos que menos satisfacción les produce tener libertad y autonomía.
Son los estilos directivos que menos comunican las jornadas no trabajadas cuando el personal del centro ejerce el derecho a huelga

\section{Las actuaciones que realizan para mantener el compromiso de la comunidad educativa son:}

- Fomentar una atención personalizada

- Realizar una autoevaluación de su ejercicio

- Examinar los diferentes temas que afectan a la escuela
Es el estilo directivo que más realizan la función normativa de “dirección pedagógica y liderazgo"

Es el estilo directivo que más satisfacción les produce tener libertad y autonomía.

$$
\text { escuela }
$$

- Conocer las familias y a los alumnos

- Presidir y dinamizar los órganos de gobierno

- Participar y gestionar el centro
- Mantener las redes y estrategias de comunicación e información

- Proponer actividades para la mejora

- Trabajar en equipo

- Reflexionar sobre las evaluaciones internas 


\subsubsection{Acciones para potenciar el liderazgo y el éxito escolar}

El cuarto objetivo, proponer líneas de mejora del liderazgo para el éxito escolar. En este apartado se presenta las consideraciones dirigidas a los diferentes agentes implicados en la dirección escolar en los centros de educación primaria.

\section{Consideraciones a la Administración Educativa:}

La Administración Educativa es, en general, quien recibe más críticas desde todos los sectores. A continuación presentamos algunas consideraciones:

- Definir explícitamente las funciones del director. Actualmente el director actúa como representante, policía, bombero, mediador, equilibrista económico, profesor, etc. que limitan las horas de dirección reales desde la perspectiva de un liderazgo pedagógico como propone la propia Administración educativa.

- Definir la autonomía real que tienen los directores en su centro educativo. No son sólo representantes de la Administración ni aplicadores de las decisiones políticas, sino que, en definitiva, son los responsables del centro educativo. Deben disponer de autonomía real para tomar decisiones sobre el funcionamiento de su centro escolar, aunque se establezcan las vías necesarias de rendición de cuentas en todos los sentidos.

- Revisar el modo de acceso al cargo directivo. Actualmente se accede a través de un concurso de méritos pero en el $90 \%$ de los casos sólo se presenta un único candidato. Es decir, el acceso al puesto se basa en un modelo competitivo pero sin competencia real, lo que denota un bajo atractivo para los profesores.

- Establecer un sistema de incentivación para los directores. Se ha demostrado que la incentivación económica no es atractiva ni un motivo para los directores quieran acceder al cargo. Nos cuestionamos la ética de la compensación económica por parte de la Administración para promover los cargos directivos, ya que no pensamos que sea la mejor compensación que los directores puedan recibir. 
No queremos directores ambiciosos (económicamente) queremos directores inquietos, ambiciosos culturalmente y con altas expectativas, que crean en la educación y trabajen para conseguir entre todos una escuela mejor. Por ese motivo, los incentivos que proponemos estén relacionados con las necesidades de los propios centros, que podrían ir desde un incremento en el presupuesto con partidas concretas, dotación de materiales, estabilidad de plantillas, etc.

- Considerar el acceso al cargo como una oportunidad de renovación para el centro escolar. Potenciar a los nuevos profesionales que se han formado y están motivados para ejercer el cargo. Evitar que las candidaturas se tripliquen y se promueva una acomodación en el puesto que como consecuencia ralenticen las innovaciones en los centros.

- Rediseñar los programas de formación directiva. La formación debe ser más dinámica y adaptadas a las necesidades reales de los directores. Actualmente existen programas de formación generales basados en la legislación y en los aspectos más legislativos y normativos del cargo. En cambio, se potencian poco las formaciones que den respuesta a las necesidades formativas y no formativas que manifiestan tener los directores. Es decir, programas de formación específica y adaptable a las necesidades y a los contextos educativos.

- Considerar ampliar los destinatarios de la formación. La formación debe ser abierta y no exclusiva al cargo directivo si queremos fomentar un liderazgo distribuido en las direcciones escolares. Las formaciones sobre liderazgo escolar no deben ser exclusivas y centradas en el cargo directivo, sino deben ser abiertas para los diferentes profesionales del centro.

- Facilitar la colaboración con las Universidades en trabajos de investigación, lo que demanda un reconocimiento profesional a los docentes implicados. 


\section{Consideraciones a las universidades:}

- Revisar los planes de estudio de educación, planteando la necesidad de incluir competencias directivas $y$ de liderazgo en la formación inicial del profesorado. Si bien es cierto que no todos los docentes serán directores, sí que todos pueden serlo, y todos deben ejercer un cierto liderazgo en su ámbito de actuación empezando por el aula.

- Reivindicar que la formación directiva sea responsabilidad de la Universidad y esté coordinada desde las Facultades con la finalidad de homogenizar las características de las formaciones (número de horas, contenido, evaluación, etc.).

- Potenciar proyectos de investigación e innovación en el ámbito escolar que favorezcan la mejora educativa.

\section{Consideraciones a los centros educativos:}

- Trabajar conjuntamente con otros centros educativos de la zona. Compartir recursos y sumar capacidades. Analizar conjuntamente las necesidades del entorno y dar respuesta conjunta. Los planteamientos que enmarcan los planes de entorno deben ser potenciados dotándolos de recursos profesionales y económicos.

- Replantear los canales de información de los centros con las familias. Potenciar una comunicación más activa y cercana con las familias a partir de las TIC y las redes sociales más populares (Twitter y Facebook).

- Establecer un sistema de trabajo colaborativo con la comunidad educativa de manera que se asegure una línea de actuación común y coherente. Deben hacer partícipes reales del proyecto educativo, no sólo a profesores y personal del centro, sino también a alumnos, padres y entidades culturales y sociales del entorno del centro. 
- Apoyar y colaborar con los AMPAS creando proyectos conjuntos donde se compartan objetivos y responsabilidades entre todos los sectores de la comunidad educativa.

Consideraciones a los equipos directivos:

- Plantear un seguimiento posterior de las actividades. Analizar qué repercusión tienen en el desarrollo profesional del docente y en el aprendizaje del alumnado. Entender la evaluación y la autoevaluación como mecanismos de mejora.

- Entender la necesidad de la formación permanente y de su desarrollo profesional como una característica propia de la profesión.

- Fomentar la implicación de la comunidad educativa en el centro facilitando la participación en distintas actividades. Mostrarse abiertos y flexibles confiriendo confianza y seguridad.

- Potenciar un liderazgo distribuido entre los profesionales del centro educativo lo que conlleva tener altas expectativas de las capacidades del profesorado. 


\subsection{Limitaciones del estudio y futuras líneas de investigación}

Esta investigación, pese a sus limitaciones, nos ofrece pistas para conocer el perfil y necesidades de los directores escolares de nuestros centros de educación primaria. Algunas de las limitaciones presentadas en el estudio están relacionadas con:

- La fundamentación teórica en la que se inscribe la investigación es muy amplia con temas clave de especial transcendencia como el impacto del liderazgo en el éxito escolar, el papel del director en los centros escolares actuales. La mayor parte de estos temas son procesos complejos que no tienen un final delimitado y se encuentra actualmente en pleno debate, esto ha complicado la estructuración del marco teórico.

El marco legal educativo se ha ido modificando en los últimos meses. Al inicio de este estudio (diciembre 2013) entraba en vigor la nueva ley educativa (LOMCE) acompañada de duras críticas e incertidumbre. Esta ley no se aplicaría hasta el curso escolar 2014/2015. En 2014, en Cataluña, se aprueba el Decreto por el cual se regulan los procedimientos para definir el perfil y la provisión de los puestos de trabajo de los docentes. En definitiva, todo ello contribuye a generar un marco cambiante y complejo, pero a la vez novedoso y con expectativas en mejorar.

- El estar realizado sólo desde la perspectiva del director permite profundizar en cómo viven y sienten los directores, el ejercicio de la dirección, aunque limita la visión de la realidad de la dirección escolar. Sería deseable que las encuestas futuras incluyeran al resto del equipo directivo (jefe de estudios, secretario) además de los docentes. Para poder analizar la situación y visión del liderazgo desde otra perspectiva profesional.

En estudios posteriores debería contemplarse un tratamiento de datos más amplio aplicando estudios específicos de las direcciones escolares de los centros rurales, de los centros concertados-privados y centros de alta complejidad. De hecho, esta tesis está vinculada a una investigación más amplia que analiza la dirección escolar y el liderazgo desde una perspectiva mixta (cuantitativa y cualitativa). 
UNIVERSITAT ROVIRA I VIRGILI

TE TARRAGONA

Marta Camarero Figuerola

BIBLIO GRAFIA

ANÁLISIS DEL DESEMPEÑO DE LA FIGURA DIRECTIVA EN CENTROS DE EDUCACIÓN

IA 
Ainscow, M. ., Hopkins, D. ., Soutworth, G. ., \& West, M. (2001). Hacia escuelas eficaces para todos. Madrid: Narcea.

Ainscow, M., \& West, M. (2008). Mejorar las escuelas urbanas. Liderazgo y colaboración. Madrid: Narcea.

Álvarez, E., \& Pérez, R. (2011). Liderazgo directivo en los centros educativos de Asturias. Bordon, 3(3), 23-42.

Álvarez, M. (1998). El liderazgo de la calidad total. Madrid: Editorial Escuela Española.

Álvarez, M. (2006a). La escuela pública también tiene derecho a una dirección profesional: avances en supervisión educativa. Revista de La Asociación de Inspectores de Educación de España., 4. Retrieved from http://www.adide.org/revista/index.php?option=com_content\&task=view\&id=94\& Itemid $=65$

Álvarez, M. (2006b). La misma dirección para una nueva escuela. Organización $Y$ Gestión Educativa, 14, 30-35.

Álvarez, M. (2010a). La dirección escolar que tenemos, la dirección escolar que necesitamos. Participación Educativa, 5, 83-92.

Álvarez, M. (2010b). Liderazgo compartido. Madrid: Wolters Kluwer.

Álvarez, M. (2013). Dirección y liderazgo. In Libro Blanco de la educación FUHEM. Retrieved from http://libroblanco.fuhem.es/wpcontent/uploads/2013/12/Direccion_y_liderazgo_FUHEM.pdf

Anderson, S. (2010). Educational Leadership: Keys for a Better School. Psicoperspectivas, 9, 34-52.

Antúnez, S. (2000a). Claves para la organización de centros escolares. Barcelona: ICEHorsoi.

Antúnez, S. (2000b). La acción directiva en las instituciones escolares. Barcelona: Horsori Editorial.

Antúnez, S. (2011). ¿Qué tiene de particulpar dirigir un centro escolar? consecuencias para la formación de directores. Revista de La Asociación de Inspectores de Educación de España., 14, 1-7.

Antúnez, S. (2012). Una brújula para la dirección escolar. Orientaciones para la mejora. México: SM Ediciones.

Antúnez, S., \& Gairín, J. (2006). La organización académica del alumnado. In La Organización escolar: práctica y fundamentos (pp. 113-140). Barcelona: Graó. 
Apple, M. W., \& Beane, J. A. (1997). Escuelas democráticas. Madrid: Morata. Cuarta Edición (2005).

Aramendi, P., Buján, K., Oyarzabal, J. R., \& Sola, J. C. (2008). El acceso a la dirección escolar en las comunidades autónomas: un estudio comparado. Revista de Investigación Educativa, 26, 445-462.

Aramendi, P., Teixidó, J., \& Bernal, J. L. (2009). Evaluación del acceso a la dirección escolar en los centros públicos del País Vasco. Revista de Educación, 11, 119. 136.

Argos, J., \& Esquerra, M. P. (2014). Liderazgo y educación. Santander: Ediciones PubliCan.

Armstrong, D. (2010). Rites of Passage: Coercion, compliance and complicity in the socialization of new vice-principals. Teachers College Record, 111(12), 1-21.

AXIA. (2015). Asociación de directores de educación pública de Cataluña. Retrieved from www.axia.cat

Ballester, L., Nadal, A., \& Amer, J. (2014). Métodos y técnicas de investigación educativa. Palma: $178 \mathrm{Col} \cdot$ lecció Materials Didàctics.

Barrios, C., Camarero, M., Tierno, J. M., \& Iranzo, P. (2015). Modelos y funciones de dirección escolar en España: el caso de Tarragona. RIE. Revista Iberoamericana de Educación.

Barrios, C., Iranzo, P., \& Tierno, J. (2013). Avances teórico-prácticos y legislativos en la profesionalización de la dirección escolar en España. El caso de Cataluña. Profesorado. Revista de Currículum Y Formación Del Professorado, 17, 371-387.

Bass, B. M. (2000). El futuro del liderazgo en las organizaciones que aprenden. In Liderazgo y organizaciones que aprenden. Bilbao: ICE Universidad de Deusto Mensajero.

Batanaz, L. (2005). El acceso a la dirección escolar: problemas y propuestas. Revista Española de Pedagogia, 232, 443-470.

Bazarra, L., \& Casanova, O. (2013). Directivos de Escuelas Inteligentes. Madrid: Ediciones SM.

Bazarra, S. (2012). ¿Por qué es necesario el liderazgo en los centros escolares? Madrid: ArcixFormación.

Bécue, M., Lebart, L., \& Rajadell, N. (1992). El análisis estadístico de datos textuales: la lectura según los escolares de enseñanza primaria. Anurario de Psicología, 55, 7-22. 
Beltrán de Tena, R., Bolívar, A., Rodríguez Conde, M. J., Rodriguez Diéguez, J. L., \& Sánchez Sánchez, S. (2004). Evaluación de la función directiva en los centros docentessostenidos con fondos públicos. Enseñanza, 22, 35-76.

Bennis, W. (1994). Convertirse en líder. EUA: Perseus Publishing.

Bennis, W., \& Nanus, B. (2001). Líderes estrategias para un liderazgo eficaz. Barcelona: Paidós.

Bernal, J. L. (2006). La formación de directivos en ejercicio. In Congreso Interuniversitario de Organización de Instituciones Educativas. Oviedo: Universidad de Oviedo.

Best, J. W. (1982). Cómo investigar en educación. Madrid: Morata. Novena Edición.

Bisquerra, R. (2004). Metodologia de la investigación educativa. Madrid: La Muralla.

Blase, J., \& Kirby, P. C. (2013). Estrategias para una dirección escolar eficaz. Cómo motivar, inspirar y liderar. Madrid: Narcea.

Bolívar, A. (2000). El liderazgo compartido según Peter Senge. In Liderazgo y organizaciones que aprenden. III Congreso Internacional sobre Dirección de Centros Educativos (pp. 459-471). ICE: Universidad de Deusto. Bilbao: Ediciones Mensajero.

Bolívar, A. (2010). ¿Cómo un liderazgo pedagógico y distribuido mejora los logros académicos? Magis, Revista Internacional de Investigación En Educación., 3, 79106.

Bolívar, A. (2011a). Aprender a liderar líderes. Competencias para un liderazgo directivo que promueva el liderazgo docente. Educar, 47/2, 253-275.

Bolívar, A. (2011b). La situación de la dirección en la actualidad. Luces y sombras. Comparativa de las distintas comunidades. Organización Y Gestión Educativa, 2, 9-12.

Bolívar, A., \& Bolívar, R. (2013). Construir la capacidad de mejora escolar: liderazgo distribuido en una comunidad profesional de aprendizaje.Educ@rnos, 10, 11-34.

Bolívar, A., López, J., \& Murillo, F. J. (2013). Liderazgo en las instituciones educativas. Una revisión de líneas de investigación. Revista Fuentes, 14, 15-60.

Bolívar, A., \& San Fabián, J. L. (2013). La LOMCE, ¿una nueva ley para mejorar la calidad educativa? Organización Y Gestión Educativa, 1, 7-11.

Bonals, J. (2007). El trabajo en equipo del profesorado. Barcelona: Graó.

Bradshaw, J. (1972). The concept of social need. New Society, 30, 640-643. 
Caballero, J. (2003). La necesidad de formación de los directores escolares en la Comunidad Autonoma de Andalucía. Revista Electrónica Interuniversitaria de Formación Del Profesorado., 6. Retrieved from http://www.aufop.org/publica/reifp/03v6n1.asp

Campo, A. (2010). Herramientas para directivos escolares. Madrid: Wolters Kluwer.

Cano, E., \& Gradaïlla, A. (2012). Els directors opinen. Grup de debat sobre la formació per a la funció directiva. Fòrum. Revista d'Organització I Gestió Educativa, 27, $21-25$.

Cantón, I. (2013). Antecedentes, selección, formación y calidad de los directores escolares. Participación Educativa, 3, 165-173.

Cantón, I., \& Arias, A. R. (2008). La dirección y el liderazgo: aceptación, conflicto y calidad. Revista de Educación, 345, 229-254.

Chavarria, X. (2013). Formación y profesionalización de docentes y gestores educativos: políticas y prácticas. Organización Y Gestión Educativa, 2, 23-28.

CINIIE., \& Instituto de la Mujer. (2012). Mujeres en cargos de representación del sistema educativo. Madrid: Instituto de la Mujer.

Cohen, L., \& Manion, L. (2002). Métodos de investigación educativa. Madrid: Editorial la Muralla.

Colás, M., \& Buendía, L. (1998). Investigación educativa (3ª ed). Sevilla: Alfar.

Comisión Europea/EACEA/Eurydice. (2013). Cifras clave del profesorado y la dirección de centros educativos en Europa. Edición 2013. Informe de Eurydice. Luxemburgo: Oficina de Publicaciones de la Unión Europea.

Conde, A., \& García-Carmona, M. (2013). El liderazgo ético en las instituciones educativas como criterio de eficacia organizativa. In Líderes al servicio de la sociedad: liderazgo en entorno internacionales. Editorial Universidad de Granada.

Coronel, J. M. (1998). Gestionar no es liderar: reflexiones sobre el concepto de liderazgo y sus repercusiones en una gestión democrática de los centros. Investigación En La Escuela, 34, 37-47.

Coronel, J. M., Carrasco, M. J., \& Moreno, E. (2012). Superando obstáculos y dificultades: un estudio multicaso sobre directoras escolares, políticas de liderazgo y gestión para la mejora. Revista de Educación, 357, 557-559.

Cuadrado, I. (2011). Liderazgo y discriminación femenina. In Liderazgo: hecho y ficción. Visiones actuales. Madrid: Alianza Editorial.

Cuevas, M. M., Díaz, F., \& Hidalgo, V. (2008). Liderazgo de los directores y calidad de la educación. Un estudio del perfil de los directivos en un contexto pluricultural. 
Profesorado. Revista de Currículum Y Formación Del Professorado, 12. Retrieved from http://www.ugr.es/ recfpro/rev122COL3.pdf

Darder, P. (2001). Experimentació sobre la coordinació de centres d'educació infantil $i$ primària amb centres d'educació secundària. Informe final. Barcelona: Associació de mestres Rosa Sensat.

Day, C. (2014). Sustaining the turnaround: What capacity means in practice? REICE. Revista Iberoamericana Sobre Calidad, Eficacia Y Cambio En Educación., 12, 920 .

Day, C., \& et al., (2009). The impact of School Leadership on Pupil Outcomes. Final Report. University of Nottingham.

Day, C., \& Bakioglu, A. (1996). Development and disechantment in the professional lives of headteachers. In Teachers' professional lives (pp. 205-227). Londres: Routledge Falmer.

Day, C., Sammons, P., Harris, A., Hopkins, D., Leithwood, K., Gu, Q., \& Brown, E. (2010). Ten Strong Claims for Successful School Leadership in English Schools. Londres: National College for Leadership of Schools and Childrens Services (NCSL).

De Puelles, M. (2008). Las grandes leyes educativas de los últimos doscientos años. CEE Participación Educativa, 7, 7-15.

Díez, E. (coord. ). (2004). La cultura de género en las organizaciones escolares: motivaciones y obstáculos de acceso de la mujer a los puestos de dirección. Instituto de La Mujer, Madrid.

Dyson, A. (2008) Más allá de las puertas de la escuela: contexto, desventajas y "escuelas urbanas", en M.Ainscow \& M, West, Mejorar las escuelas. Liderazgo y colaboración. Madrid: Santillana.

Donoso, S., Benavides, N., Cancino, V., Castro, M., \& López, L. (2012). Análisi crítico de las políticas de formación de directivos escolares en Chile. Revista Brasileira de Educaçao, 17, 133 - 240.

Egido, I. (1995). La evolución de la enseñanza primaria en España: organización de la etapa y programa de estudio. Revista de Tendencias Pedagógicas, 1, 75-86.

Elmore, R. (2010). Mejorando la escuela desde la sala de clases. Santiago de Chile: Fundación Chile.

Escamilla, S. (2006). El director escolar: necesidades de formación para un desempeño profesional. Universidad Autónoma de Barcelona.

Escudero, J. M. (2009). Buenas prácticas y programas extraordinarios de atención al alumnado en riesgo de exclusión educativa. Profesorado. Revista de Currículum $Y$ 
Formación Del Profesorado, 13. Retrieved from http://www.ugr.es/local/recfpro/revl33ART4.pdf

Escudero, J. M. (2013). La reforma de la LOMCE no es la que necesitamos. Organización Y Gestión Educativa, 4, 18-21.

Estruch, J. (2002a). Dirección profesional y calidad educativa. Barcelona: Praxis.

Estruch, J. (2002b). Hacia la profesionalización de la dirección de centros escolares. Revista de Educación, 329, 77-90.

Europea/EACEA/Eurydice, C. (2013). Cifras clave del profesorado y la dirección de centros educativos en Europa. Edicion 2013. Informe de Eurydice, Luxemburgo.

Evans, E. (2015). Interacción entre inteligencia emocional y estilos de liderazgo en directivos de instituciones educativas. Universitat de València.

Fernández, L. (2005). ¿Cuáles son las técnicas de recogida de información? Secció de Recerca. Institut de Ciències de l'Educació. Universitat de Barcelona.

Fernández, M. L. (2006). La formación inicial para la dirección. In J. Teixidó, P.Aramendi, M.L. Fernández y J.L. Bernal, Simposio sobre el acceso y formación para la dirección escolar. CIOIE.

Ferreres, V., \& González-Soto, A.P. (Editores). Evaluación para la mejora de los centros docentes. Madrid: Praxis.

Frías Navarro, D. (2014). Alfa de Cronbach y consistencia interna de los ítems de un instrumento de medida. Retrieved from http://www.uv.es/ friasnav/AlfaCronbach.pdf

Fullan, M. (2002). Liderar en una cultura de cambio. Barcelona: Octaedro.

Fundació Jaume Bofill. (2015). Com millorar el relleu de les direccions dels centres educatius? Barcelona. Retrieved from http://www.fbofill.cat/agenda/com-millorarel-relleu-de-les-direccions-dels-centres-educatius

Gairín, J. (2011). El alumnado. In M. Lorenzo (Coord.) Organización y gestión de centros y contextos educativos( pp.99-138). Madrid: Editorial Universitas.

Gairín, J., \& et al. (1995). Estudio de las necesidades de formación de los equipos directivos de los centros educativos. Madrid: MEC-CIDE.

Gámez, R. L., Soria, R., \& López-Portillo, C. (2006). Organizaciones y políticas públicas: una mirada desde el noroeste. México: Once Ríos Editores.

Gan, F. (1997). La comunicación interna. In J. Tejada \& V. Giménez (coord.) Formación de formadores. Escenario Institucional (pp. 135-182). Madrid: Thomson. 
García Olalla, A., Poblete, M., \& Vila, A. (2006). La función directiva: un problema sin resolver. Tres decadas de formación, investigación y acción. Revista de Educación, $8,13-34$.

García-Carmona, M., \& Conde, A. (2013). Liderazgo y calidad en las organizaciones educativas. In J.M González-González \& C.M. García-Guiu (Coord.) Líderes al servicio de la sociedad: liderazgo en entorno internacionales (pp. 93-103). Editorial Universidad de Granada.

García-Carreño, I., \& Olmo, M. (2013). Enfoques actuales de liderazgo y estilos de dirección escolar: Revisión teórica. In Investigación e Innovación Educativa al Servicio de Instituciones y Comunidades Globales, Plurales y Diversas: Actas del XVI Congreso Nacional // II Internacional Modelos de Investigación Educativa de la Asociación Interuniversitaria de Investigación Peda (pp. 1143-1151). Alicante.

García-Garduño, J. M., Slater, C., \& López-Gorosave, G. (2010). El director escolar novel de primaria: Problemas y retos que enfrenta en su primer año. Revista Mexicana de Investigación Educativa (RMIE), 15, 1051-1073.

García-Garduño, J. M., Slater, C., \& López-Gorosave, G. (2011). El director escolar novel: Estado de la investigación y enfoques teóricos. REICE. Revista Iberoamericana Sobre Calidad, Eficacia Y Cambio En Educación., 9, 31-50.

García-Llamas, J. L., González-Galán, M. A., \& Ballesteros, B. (2001). Introducción a la investigación en educación. Madrid: Universidad Nacional de Educación a Distancia.

Generalitat de Catalunya. (1988). Decret 195/1988, de 27 de juliol, sobre la constitució de zones escolars rurals per a centres públics d'ensenyament primari. Diari Oficial de La Generalitat de Catalunya, DFGC.

Generalitat de Catalunya. (2009). Llei d'Educació de Catalunya (LEC).DOGC, 5422, de 16.VII.2009, 56589-56682.

Generalitat de Catalunya. (2010a). Decret 102/2010 d'autonomia dels centres educatius. DOGC, 5686, de 5.X.2010, 61485-61519.

Generalitat de Catalunya. (2010b). Decret 155/2010 de la direcció dels centres educatius públics i del personal directiu professional docent. DOGC, 5753, de 11.XI.2010, 82840-82863.

Generalitat de Catalunya. (2012). A favor de l'èxit escolar. Pla per a la reducció del fracàs escolar a Catalunya 2012-2018. Retrieved from http://www20.gencat.cat/docs/Educacio/Home/Departament/Linies_estrategiques/ Ofensiva_de_pais_favor_exit_escolar/ExitEscolar.pdf

Generalitat de Catalunya. (2013). Formació inicial en direcció de centres docents públics. Retrieved from http://eapc.gencat.cat/ca/formacio/formacio_directiva/curs_direccio_centres_docen ts/ 
Generalitat de Catalunya. (2014a). Decret 39/2014 Pel qual es regulen els procediments per definir el perfil i la provisió dels llocs de treball docents. DOG, 6591, de 27.III.2014, 1-25.

Generalitat de Catalunya. (2014b). Resolució ENS/906/2014 del director general de professorat i de personal de centres públics, per la qual es fa pública, amb caràcter provisional, la relació de centres educatius classificats com de màxima complexitat. Retrieved from: http://portaldogc.gencat.cat/utilsEADOP/PDF/6613/1352400.pdf

Generalitat de Catalunya. (2015). Decret 29/2015 de modificació del Decret 155/2010, de 2 de novembre, de la direcció dels centres educatius públics i del personal directiu professional docent. DOGC, 6824, de 3.III.2015, 1-12.

Generalitat de Catalunya. (2015). Serveis Territorials d'Ensenyament a Tarragona.

Retrieved from http://sac.gencat.cat/sacgencat/AppJava/organisme_fitxa.jsp?codi=1754

George, D. ., \& Mallerty, P. (2003). SPSS for Windows step by step: a simple guide and reference. 11.0 Update. Boston: Allyn \& Bacon.

Gimeno, J. (coord. ) (1995). La dirección de centros docentes: análisis de tareas. Madrid: Ministerio de Educación y Ciencia.

Goleman, D. (2012). Liderazgo. El poder de la inteligencia emocional. Barcelona: Ediciones B.

Goleman, D., Boyatzis, R., \& McKee, A. (2010). El líder resonante crea más. Barcelona: DEBOLS!LLO.

Gómez Delgado, A. (2011). La descentralización de la formación inicial para la dirección escolar en España. Profesorado. Revista de Currículum Y Formación Del Professorado, 15, 199-217.

Gómez Delgado, A. (2012). Mejor formación, mejor dirección, mejor escuela. Contextos Educativos, 15, 61-78.

Gómez-Hurtado, I. (2011). Dirección escolar y atención a la diversidad: rutas para el desarrollo de una escuela para todos. Universidad de Huelva.

Gómez-Hurtado, I. (2012). Una dirección escolar para la inclusión escolar. Perspectiva Educacional, 51(2), 21-45.

González, A. M. (2015). Dirección escolar existosa en España. Un estudio de casos. Universidad Autónoma de Madrid.

Gros, B., Fernández-Salinero, C., Martínez, M., \& Roca, E. (2013). El liderazgo educativo en el contexto del centro escolar. In XXXII Seminario Interuniversitario de teoría de la educación. Liderazgo y Educación. Santander. Retrieved from http://www.site.unican.es/Ponencia 3.pdf 
Hall, G. (2013). Evaluating change processes: Assessing extent of implementation (constructs, methods and implications). Journal of Educational Administration, 51, 264-289.

Hallinger, P., \& Heck, R. (2011). Conceptual and methodological issues in studying school leadership effects as a reciprocal process. School Effectiveness Ans School Improvement, 22, 149-173.

Hargreaves, A., \& Fink, D. (2008). El liderazgo sostenible: 7 principios para el liderazgo en centros educativos innovadores. Madrid: Morata.

Haslam, A., Reicher, S., \& Platow, M. (2011). El liderazgo como gestión de la identidad social. In Liderazgo: hecho y ficción. Visiones actuales (pp. 77-116). Madrid: Alianza Editorial.

Helga, S. (2014). Educational leadership and market values: A study of school principals in Iceland. Educational Management Administration \& Leadership, 42, 83-103.

Heck, R., \& Hallinger, P. (2010). Testing a longitudinal model of distributed leadership effects on school improvement. The Leadership Quartely, 21, 867-885.

Hernández, F. (1995). Bases metodológicas de la investigación educativa. Barcelona: PPU.

Hersey, P., \& Blanchard, K. (1993). La administración y el comportamiento humano. México: Pearson.

Hopkins, D., \& Highman, R. (2007). System leadership: mapping the landscape. Retrieved from http://www.davidhopkins.co.uk/articles/systemleadership.pdf

Horn, A. (2013). Liderazgo Escolar en Chile y su influencia en los resultados de aprendizaje. Universidad Autonoma de Madrid.

Howley, A., Adrianaivo, S., \& Perry, J. (2005). The pain outweighs the gain: Why teacher don't want to become principals. Teachers College Record, 107(4), 757782.

Institut de estadística de Catalunya, (2015). Indicadors Estadístics de l'ensenyament. Retrieved from http://www.idescat.cat/tema/educa

International Association for the Evaluation of Educational Achievement. (2011). TIMSS 2011: Trends in International Mathematics and Science Study. Boston Collage.

Iranzo, P., Barrios, C., Tierno, J., \& Camarero, M. (2014). Liderar o getionar: desempeño de la dirección escolar en Tarragona. In XIII Congreso Internacional de Formación del Profesorado. AUFOP. Santander. 
Iranzo, P., Tierno, J., \& Barrios, C. (2014). Autoevaluación institucional y dirección de centros inclusivos. Teoría de La Educación. Revista Interuniversitaria, 26(2), 229257.

Jiménez, B., \& Tejada, J. (1997). Procesos y métodos de investigación. In J. Tejada \& V. Giménez (Coord.) Formación de Formadores. Escenario Institucional (pp. 543630). Madrid: Thomson.

Jiménez-González, J.M., González-Soto, A.P., \& Fandos, M. (1997). La programación en el proceso enseñanza-aprendizaje. In J. Tejada \& Giménez, V. (Coord.) Formación de Formadores. Escenario Aula (pp.209- 210). Madrid: Thomson.

Kaparou, M., \& Bush, T. (2007). Invisible barriers: the career progress of women secondary school principals in Greece. Compare: A Journal of Comparative and International Education, 37(2), 221-237.

Kaufmann, A. (1997). Liderazgo transformador y formación continua. Revista Española de Investigaciones Sociológicas, 77-78, 163-184.

Kerlinger, F. (1975). Investigación del compartamiento: técnicas y metodología. Méxito: Nueva Editorial Interamericana.

Kirkpatrick, D., \& Kirkpatrick, J. (2007). Evaluación de acciones formativas. Los cuatro niveles. Barcelona: Ediciones Gestión 2000.

Koetting, J. (1984). Foundations of naturalistic inquiry: developing atheory base for understanding individual interpretations of reality. Dallas: Association for Educational Communications and Technology.

Kotter, J. (1990). El factor liderazgo. Madrid: Ediciones Díaz Santos S.A.

Kotter, J. (2000). Que hacen los líderes. Barcelona: Gestión 2000.

Krichesky, G. J., \& Murillo, F. J. (2011). Las Comunidades Profesionales de Aprendizaje. Una estrategia de mejora para una nueva concepción de escuela. REICE. Revista Iberoamericana Sobre Calidad, Eficacia Y Cambio En Educación., 9(1), 65-83.

Latorre, A., del Rincón, D., \& Arnal, J. (2003). Bases metodológicas de la investigación educativa. Barcelona: Ediciones Experiencia.

Leithwood, K. (2009). ¿Cómo liderar nuestras escuelas? Aportes desde la investigación. Chile: Salesianos Impresores.

Leithwood, K., Harris, A., \& Hopkins, D. (2008). Seven strong claims about successful school leadership. School Leadership and Managment, 28, 27-42.

Leithwood, K., Patten, S., \& Jantzi, D. (2010). Testing a conception of how leadership influences student learning. Educational Administration Quarterly, 46, 671-706. 
López, J., \& Lavié, J. M. (2010). Liderazgo para sostener procesos de innovación en la escuela. Profesorado. Revista de Currículum Y Formación Del Professorado, 14, $1,71-92$.

Lorente, Á. (2012). La influencia del género en la dirección de los centros docentes. Organización Y Gestión Educativa, 2, 5-10.

Lorenzo, M. (2012). Las comunidades de liderazgo de centros educativos. Educar, 48, 9-22.

Lumby, J. (2013). Distributed Leadership: The uses and abuses of power. Educational Management Administration \& Leadership, 41, 581-597.

Martínez, F. (2002). El cuestionario. Un instrumento para la investigación en las ciencias sociales. Barcelona: Laertes Psicopedagogía.

Martínez, M., Badia, J., \& Jolonch, A. (Coord.) (2013). Lideratge per a l'aprenentatge. Estudis de cas a Catalunya. Barcelona: Fundació Jaume Bofill.

Maureira, O., Moforte, C., \& Gonzálvez, G. (2014). Más liderazgo distribuido y menos directivo. Nuevas perspectivas para caracterizar procesos de influencia en los centros escolares. Perfiles Educativos, 146, 134-153.

May, H.; Huff, J. \& Goldring, E. (2012). A longitudinal study of principals' activities and student performance. School Effectiveness and School Improvement, 23, 417439.

McMillan, J., \& Schumacher, S. (2007). Investigación educativa. Madrid: Pearson educación, S. A.

MEC (Ministerio de Educación y Ciencia). (1967). Decreto 193/1967, de 2 de febrero, por el que se aprueba el texto refundido de la Ley de Enseñanza Primaria. BOE, 37.

MEC (Ministerio de Educación y Ciencia). (1985). Ley Orgánica reguladora del Derecho de Educación. (LODE). Boletín Oficial Del Estado, 159(04.07.1985), 2101-21022.

MEC (Ministerio de Educación y Ciencia). (1995). Ley orgánica de la Participación, la Evaluación y el Gobierno de los Centros Docentes. ( LOPEGCD). Boletín Oficial Del Estado, 278(21.11.1995), 33651-33665.

MECD (Ministerio de Educación Cultura y Deporte). (2004). Evolución del sistema educativo español. Retrieved from http://uom.uib.cat/digitalAssets/202/202199_6.pdf

MECD (Ministerio de Educación Cultura y Deporte). (2013). Ley Orgánica para la Mejora de la Calidad Educativa. (LOMCE). BOE, 295(10.12.2013), 97858-97921.

MECD (Ministerio de Educación Cultura y Deporte). (2014). Real Decreto 894/2014, de 17 de ocubtre, por el que se desarrollan las caracteristicas el curso de formación 
sobre el desarrollo de la función directiva. Retrieved from http://www.boe.es/buscar/doc.php?id=BOE-A-2013-12886

Medina, Á. (2011). Sentir-se acompanyats en les tasques de direcció. Guix d'Infantil, $63,9-13$.

Meza, D. (2014). Liderazgo universitario: factores que determinan el estilo de liderazgo en directores de escuelas y departamentos académicos en universidades costarricenses. Universitat de València.

Molero, F. (2011). Liderazgo transformacional y carismático. In F. Molero \& J.F. Morales (Coord.) Liderazgo: hecho y ficción. Visiones actuales (pp. 77-144). Madrid: Alianza Editorial.

Molinar, M., \& Velázquez, L. (2005). Liderazgo en la labor docente. Madrid: Editorial Trillas.

Montero, A. (2008). El acceso a la dirección en el sistema educativo español. Dificultades para la definición de un modelo. Revista de Educación, 347, 275-298.

Montero, A. (2010). Dirección profesional y selección de directores en el sistema educativo español. Revista Española de Pedagogía, 247, 417-435.

Mulford, B. (2006). Leadership and quality secondary education. Profesorado. Revista de Currículum Y Formación Del Profesorado, 10(1). Retrieved from http://www.ugr.es/local/recfpro/Rev101-ART2.pdf

Mulford, B., \& Silins, H. (2009). Revised models and conceptualization of successful school principalship in Tasmania. In Successful school principalship in Tasmania (pp. 157-183). Launceston, Tasmania: Faculty of education: University of Tasmania.

Murillo, F. J. (2006). Una dirección escolar para el cambio: el liderazgo transformacional al liderazgo distribuido. REICE. Revista Iberoamericana Sobre Calidad, Eficacia y Cambio En Educación, 4, 11-24.

Murillo, F. J., \& Hernández-Castilla, R. (2015). Liderazgo para el aprendizaje: ¿Qué tareas de los directores y directoras escolares son las que más inciden en el aprendizaje de los estudiantes? RELIEVE - Revista Electrónica de Investigación Y Evaluación Educativa, 21(1). doi:10.7203/relieve.21.1.5015

Naicker, S.\& Mestry, R. (2013). Teachers's reflections on distributive leadership in public primary schools in Soweto. South African Journal of Education, 33, 1-15.

OCDE. (2005). The Definition and Selection of Key Competencies. Executive Summary. París: OCDE.

OCDE. (2008). Improving School Leadership.Education and training Policy.Vol 1, Policy and Practice. Retrieved from http://www.oecd.org/edu/school/44374937.pdf 
OCDE. (2009). Creating Effective Teaching and Learning Environments First Results from TALIS. París.

Padilla, M. T. (2008a). El acceso a al dirección escolar de las profesoras de educación infantil y primaria: barreras y oportunidades. Bordón, 3(7), 67-83.

Padilla, M. T. (2008b). Opiniones y experiencias en el desempeño de la dirección escolar de las mujeres directoras en Andalucía. Revista Electronica de Investigación Y Evaluación Educativa (RELIEVE), 14(1), 1-27.

Palomares, A. (2011). Asociaciones de madre y padres (AMPAS) y participación comunitaria. In M. Lorenzo (coord.) Organización y gestión de centros y contextos educativos (pp. 171-201). Madrid: Editorial Universitas.

Palomero, E. (2013). LiderArte. Todas las claves para dirigir y motivar a tu equipo. Barcelona: Gestión 2000.

Palomo, M. T. (2008). Liderazgo y motivación de equipos de trabajo. Madrid: ESIC EDITORIAL.

Parkay, F. W., \& Hall, G. E. (1992). Becoming a principal: The challenges of beginning leadership. Boston: Allyn and Bacon.

Pascual, R., Villa, A., \& Auzmend, E. (1993). El liderazgo transformacional en los centros docentes: un estudio en las Comunidades Autónomas del País Vasco y Castila - León. Bilbao: Ed. Mensajero.

Pereda, S., Berrocal, F., \& López, M. (2002). Gestión de recursos humanos y gestión del conocimiento. Dirreción Y Organización, 28, 43-54.

Poblete, M. ., \& García Olalla, A. (2003). Perfil directivo de competencias para la gestión del cambio en centros educativos. Barcelona.

Pont, B. (2008). Los directores de escuela deben centrarse en la mejora de los resultados escolares. In Organizaciones educativas al servicio de la sociedad (pp. 50-81). Bilbao: Wolters Kluwer.

Pont, B., Nusche, D., \& Moorman, H. (2009). Mejorar de el liderazgo escolar. volumen 1: política y práctica. OCDE.

Puig, J. M., Martín, X., Escardíbul, S., \& Novella, A. (2000). Cómo fomentar la participación en las escuelas. Propuestas de actividades. Barcelona: Graó.

RAE. (n.d) Real Académia Española. Retrieved from http://www.rae.es/

Rajadell, N. (2001). Los procesos formativos en el aula: estrategias de enseñanzaaprendizaje. In F. Sepulveda \& N. Rajadell, Didáctica General para Psicopedagogos (pp. 465-525). Madrid: Eds. de la UNED. 
Rajadell, N. (2002). La importancia de las estrategias docentes para la resolución de conflictos en el aula. Revista Electrónica Interuniversitaria de Formación Del Profesorado, 5(3). Retrieved from http://web.archive.org/web/20041206093520/www.aufop.org/publica/reifp/articulo .asp?pid=210\&docid $=1016$

Ramos, M. A. (2005). Mujeres y liderazgo: Una nueva forma de dirigir. Valencia: Universidad de Valencia.

Robbins, S. (1996). Administración teoría y práctica. México: Prentice Hall.

Robinson, V. (2010). From instructional leadership to leadership capabilities: empirical findings and methodological challenges. Leadership and Policy in Schools, 9(1), $1-26$.

Robinson, S. (2011). Primary headteachers: new leadership roles inside and outside the school. Educational Management Administration \& Leadership, 39, 63-83.

Rodríguez, G. (2011). Funciones y rasgos del liderazgo pedagógico en los centros de enseñanza. Educación Y Educadores, 14(2), 253-267.

Rodríguez Pulido, J., Rodríguez Fernández, A. J., Artíles, J., Aguiar, M. V., \& Alemán, J. (2013). El acceso a la dirección escolar: dificultades y necesidades. Educar, 49, $105-125$.

Rodríguez-Sabiote, C., García-Mino, F., Garcia-Vacas, I., \& Álvarez-Rodríguez, J. (2013). La problemática de la función directiva en primaria desde posiciones encontradas. Los directores frente al profesorado. Profesorado. Revista de Currículum y Formación Del Professorado, 17, 421-440.

Royo, M. (2012). Formar directors? Revista d'Organització I Gestió Educativa, 27, 710 .

Ruiz, M. (2013). Liderazgo y responsabilidad educativa: el necesario liderazgo de directores y profesores en la educación. Revista Fuentes, 14, 85-104.

Sammons, P., \& Bakkum, L. (2011). Effective Schools, Equity and Teacher Effectiveness: A Review to the Literature. Profesorado. Revista de Currículum Y Formación Del Profesorado, 15. Retrieved from http://www.ugr.es/recfpro/rev153ART2.pdf

Sánchez-Moreno, M. . (2009). Mujeres dirigentes en la universidad. Las texturas del liderato. Zaragoza: Prensas universitarias.

Sánchez-Moreno, M. ., \& Hernández, R. (2014). Otros tiempos, nuevas visiones de liderazgo educativo. REICE. Revista Iberoamericana Sobre Calidad, Eficacia $Y$ Cambio En Educación., 12, 334-359.

Santos, M. A. (2000). Dirección escolar educativa e innovación educativa. Revista de Educación, 2, 61-76. 
Santos, M. A. (2015). Las feromonas de la manzana. El valor educativo de la dirección escolar. Barcelona: Graó.

Sarramona, J. (2010). La llei d'educació de catalunya. dimensió política i oportunitat pedagògica. Revista Catalana de Pedagogia, 7, 349-361.

Sartre, J. P. (1963). Crítica de la razón dialética. Buenos Aires: Editorial Losada.

Shatzer, R., Caldarella, P., Hallam, P., \& Brown, B. (2014). Comparing the effects of instructional and transformational leadership on student achievement: implications for practice. Educational Management Administration \& Leadership, 42, 445-459.

Silva, P. (2012). La formació de directors i directores: què ens aporta 1 'experiència? Fòrum. Revista d'Organització I Gestió Educativa, 27, 4-6.

Southword, G. (2004). El liderazgo de la escuela primaria en su contexto. Diferencias de liderazgo de las escuelas pequeñas, medianas y grandes. Londres- New York: Routledge Falmer.

Spillane, J. (2012). Distributed leadership. San Francisco: Jossey-Bass.

Sun, J., \& Leithwood, K. (2012). Transformational school leadership effects on student achievement. Journal of Leadership and Policy in Schools, 11, 418-451.

Teixidó, J. (2000). El acceso a la dirección de un centro público. In Liderazgo y organizaciones que aprenden.

Teixidó, J. (2007a). Competencias para el ejercicio de la dirección escolar. In XVIII Jornadas Estatales del Fórum Europeo de Administradores de la Educación. Retrieved from http://www.joanteixido.org/doc/comp_direct/Jornadas_Toledo.pdf

Teixidó, J. (2007b). El acceso a la dirección escolar: de la LODE a la LOE. Participación Educativa, 5, 39-48.

Teixidó, J. (2010). Hacia un cambio de modelo en la dirección escolar. Luces y sombras en un camino tortuoso. In Organizar y dirigir en la complejidad. Instituciones educativas en evolución (pp. 85-97). Madrid: Wolters Kluwer.

Teixidó, J. (2011). Lapiceros: un modelo de formación de directivos escolares. Organización Y Gestión Educativa, 2, 20-24. Retrieved from http://www.joanteixido.org/doc/form_dir/lapiceros.pdf

Teixidó, J., Aramendi, P., Fernández, M. L., \& Bernal, J. L. (2006). Acceso y formación para la dirección escolar. In Congreso Interuniversitario de Organización de Instituciones Educativas (CIOIE). Retrieved from www.joanteixido.org/doc/accesdireccio/CIOIE_simposio.pdf

Teixidó, J., \& Bofill, J. (2007). Aires nuevos en la dirección escolar. Organización Y Gestión Educativa, 1, 9-12. 
Tejada, J. (1997). El proceso de investigación científica. Barcelona: La Caixa.

Tejada, J. (2009). Competencias docentes. Profesorado. Revista de Currículum Y Formación Del Profesorado, 13(2). Retrieved from https://www.ugr.es/ recfpro/rev132COL2.pdf

Tejada, J. (2013). Profesionalización docente en la Univrsidad: implicaciones desde la formación. Revista de Universidad Y Sociedad Del Conocimiento, 10(1), 170-184.

Tejada, J., Navío, A., Ferrández, E., Mas, O., Ruíz, C., Jurado, P., \& Burgos, A. (2009). Estrategias de innovación en la Formación para el trabajo. In $V$ Congreso Internacional de Formación para el trabajo. Madrid: Tornapunta.

Tejero, C., \& Fernández, M. . (2007). (Des-)Igualdad de género y dirección escolar. Docencia E Investigación: Revista de La Escuela Universitaria de Magisterio de Toledo. Retrieved from http://www.uclm.es/varios/revistas/docenciaeinvestigacion/pdf/numero7/Carlos_T ejero.doc.

Tejero, C., \& Fernández, M. J. (2010). Estrés laboral y dirección escolar. escala de medición y jerarquía de estresores. Bordon, 62(4), 123-137.

Ten Bruggente, G., Luyten, H., Scheerens, J., \& Sleegers, P. (2012). Modeling the influence of school leaders on student Achievement: how can school leaders make a difference? Educational Administration Quarterly, 48, 699-732.

Thoonen, E., Sleegers, P., Oorts, F., Peetsma, T., \& Geiisel, F. (2011). How to improve teaching practices: the role of teacher motivation, organizational factors, and leadership practices. Educational Administration Quarterly, 47, 496-536.

Torreblanca, J. (2010). La LODE. $25^{\circ}$ aniversario de la promulgación de una ley. CEE Participación Educativa, 14, 18-28.

Torres, J. (2010). La justicia curricular. El caballo de Troya de la cultura escolar. Madrid: Morata.

Turnbull, K., Mann, J., \& Creasy, J. (2007). Leaders as Lead Learners: A Case Example of Facilitating Collaborative Leadership Learning for School Leaders. Management Learning, 38(1), 79-94.

Valle Aparicio, E. (2013). Profesionalización de la dirección escolar: claves de un debate. Participación Educativa, 2(2), 51-59.

Valle, J. M., \& Martínez, C. (2010). La dirección de centros escolares en Europa en perspectiva comparada ¿De los modelos tradicionales a un "meta-modelo" supranacional? Revista Latinoamericana de Educación Comparada, 1, 55-68.

Vázquez Recio, R. M. (2002). La dirección de centros y sus metáforas: Símbolo, acción y ética. Estudio de un caso. Retrieved from http://rodin.uca.es:80/xmlui/handle/10498/14715 
Vázquez Toledo, S., \& Bernal, J. L. (2008). Necesidades formativas del director: análisis de la formación inicial en la comunidad Autónoma de Aragón. In Organizaciones educativas al servicio de la sociedad.

Vilalta, D. (2013). LOMCE: que no ens aixequin la camisa! Aula de Intantil, 72, 6-7.

Villa, A., Escotet, M. A., \& Goñi, J. J. (2007). Modelo de innovación de la educación superior. ICE: Universidad de Deusto. Bilbao: Mensajero.

Villa, A., \& Gairín, J. (1996). Funcionamiento de los equipos directivos. Análisis y reflexión a partir de una investigación empírica. Dirección Participativa $Y$ Evaluación de Centros. Actas Del II Congreso Internacional Sobre Dirección de Centros Docentes, Bilbao., ICE de la , 489-556.

Villa, A., \& García Olalla, A. (2003). El procedimiento de acceso a la dirección. Reflexiones y propuestas para el debate. Organización Y Gestión Educativa, 2, 4 14.

Villa, A., \& Poblete, M. (2007). Aprendizaje basado en competencias. Una propuesta para la evaluación de las competencias genéricas. Bilbao: Mensajero.

Viñao, A. (2000). Organización y gestión de centros educativos ante el siglo XXI. Organización Y Gestión Educativa, 1, 21-28.

Viñao, A. (2004). La Dirección Escolar: un análisis genealógico-cultural. Educaçâo, 2(54), 367-415.

Waite, D., \& Nelson, S. (2005). Una revisión del liderazgo educativo. Revista Española de Pedagogia, 232, 389-406.

Waters, T., Marzano, R., \& McNulty, B. (2003). Balanced Leadership: What 30 years of Research Tells us about the effect of leadership on student achievement.

(McREL, Ed.). Denver.

Weber, M. (1947). The Theory of Social and Economic Organization. New York: Parsons.

Weber, M. (1970). Economia y sociedad. Madrid: S.L Fondo de cultura economia de España.

Weindling, D. (1999). Stages of headship. In Educational management: Redefining theory, policy and practice (pp. 90-102). London: Sage.

Woycikowska, C., De clerq, B., Luc, J., Pfander-Meny, L., \& Pinard, A. (2008). Cómo dirigir un centro educativo. Guía para asumir las funciones de director. Barcelona: Graó. 
DIRECCIÓN ESCOLAR Y LIDERAZGO:

PRIMARIA DE TARRAGONA Marta Camarero Figuerola

ANEXOS

ANÁLISIS DEL DESEMPEÑO DE LA FIGURA DIRECTIVA EN CENTROS DE EDUCACIÓN 


\section{Anexo 1: Competencias directivas básicas}

La selección y definición de las competencias directivas utilizadas en el cuestionario de nuestra investigación están basadas en la publicación de Teixidó (2007b: 24-26).

\section{Adaptación al cambio}

Autogestión

Autonomía

Compromiso ético

Comunicación

Control
emocional

Desarrollo personal

Desarrollo profesional de colaboradores Energía

Fortaleza interior
Anticipa las necesidades, prevé los riesgos y genera respuestas. Comunica su visión acerca de la estrategia ante lo imprevisto y busca el compromiso de los colaboradores. Modifica la propia conducta para alcanzar determinados objetivos cuando surgen dificultades. Es versátil. Imagina situaciones, escenarios, procesos y estructuras originales.

Planifica el uso del tiempo. Establece prioridades, programa actividades, prevé imprevistos. Ejecuta con disciplina lo previsto. Delimita el tiempo profesional y el personal. Controla el estrés, etc.

Muestra suficiencia en las tareas a realizar; sin necesidad de supervisión. Decide y lleva a cabo las cuestiones que son de su competencia, sin dejarse condicionar por intervenciones o interferencias externas que puedan condicionar su resolución. Se muestra confiado en su mismo.

Se siente comprometido con los objetivos del centro. Desarrolla su trabajo consecuentemente con los valores morales y las buenas costumbres. Evalúa las repercusiones que se derivan del ejercicio de la función directiva desde una perspectiva ética. Respeta los derechos de las personas. Cumple con los compromisos contraídos, tanto los profesionales como los personales.

Se dirige a otras personas y se integra en un grupo de manera efectiva. Formula preguntas u observaciones dirigidas al meollo de la cuestión. Se comunica con claridad y precisión. Alienta el intercambio de informaciones e ideas. Muestra interés por las personas. Mantiene informadas a las personas que pueden verse afectadas por una decisión. Es hábil explicando las razones que le han llevado a tomar una decisión. Es sensible a los consejos y puntos de vista de los demás.

Tiene dominio de sí mismo. Mantiene controladas las propias emociones. Evita reacciones negativas ante provocaciones, oposición y hostilidad. Es resistente al trabajo en condiciones de estrés.

Analiza críticamente su comportamiento. Es consciente de sus fortalezas y reconoce sus debilidades. Selecciona y asiste a acciones de formación adecuadas a sus necesidades. Se plantea retos de mejora profesional. Se plantea y ensaya nuevos comportamientos ante situaciones de dificultad. Piensa y actúa con sentido común.

Contribuye al desarrollo profesional y personal de los miembros del equipo directivo y del claustro. Ayuda los colaboradores a identificar sus puntos débiles y a plantearse retos de mejora. Asesora y anima a sus colaboradores. Actúa de manera proactiva. Marca el ritmo de los acontecimientos mediante acciones concretas, no sólo palabras. Capacidad para modificar las rutinas de la organización. Capacidad para trabajar duro en situaciones cambiantes, con interlocutores diversos, en jornadas laborales prolongadas.

Se muestra sereno en circunstancias adversas. Justifica o explica los problemas, los fracasos o los acontecimientos negativos. Es firme y constante en los propósitos. Comunica las intenciones y los sentimientos de manera abierta, noble. Actúa de manera coherente con lo que piensa y declara. Es honesto incluso en negociaciones difíciles con agentes externos. En sensato, moderado en la aplicación de la normativa. Transmite credibilidad. 


\begin{tabular}{|c|c|}
\hline Liderazgo & $\begin{array}{l}\text { Influye en las personas para conducir al grupo hacia un determinado fin. } \\
\text { Comunica de forma convincente visión de futuro. Transmite entusiasmo e } \\
\text { ilusión. Motiva a las personas a comprometerse en proyectos. Inspira } \\
\text { confianza y confía en el equipo directico. Ampara al profesorado ante } \\
\text { situaciones de abuso. Se constituye en modelo y referente para los demás. } \\
\text { Delega responsabilidades. }\end{array}$ \\
\hline Organización & $\begin{array}{l}\text { Establece claramente los objetivos. Delimita funciones, tareas y } \\
\text { responsabilidades aprovechando los valores de las personas. Asigna los } \\
\text { recursos necesarios para realizar el trabajo. Vela por la coordinación entre } \\
\text { las diversas unidades: ciclos, departamentos, comisiones... }\end{array}$ \\
\hline $\begin{array}{l}\text { Orientación al } \\
\text { aprendizaje de } \\
\text { los alumnos }\end{array}$ & $\begin{array}{l}\text { Pone énfasis en el aprendizaje de los alumnos como factor determinante en } \\
\text { la toma de las decisiones. Planifica la actividad del centro en función de las } \\
\text { actividades de enseñanza-aprendizaje. Encamina las actuaciones al logro de } \\
\text { la mejora educativa. Fomenta el análisis en profundidad de los resultados } \\
\text { escolares. Procura conocer y contribuir a la resolución de los problemas de } \\
\text { las familias y de los alumnos. }\end{array}$ \\
\hline Partic & $\begin{array}{l}\text { Fomenta la participación de los diversos segmentos de la Comunidad } \\
\text { Educativa. Plantea abiertamente los conflictos para optimizar la calidad de } \\
\text { las decisiones tomadas buscando el compromiso de las partes. Considera y } \\
\text { es respetuoso con los argumentos e intereses de las partes. }\end{array}$ \\
\hline $\begin{array}{c}\text { Relaciones } \\
\text { interpersonales }\end{array}$ & $\begin{array}{l}\text { Desarrolla y mantiene una amplia red de relaciones con personas cuya } \\
\text { cooperación es necesaria, tanto en el interior del centro (profesorado, } \\
\text { alumnado, PAS) como en el exterior (familias, administraciones, sindicatos, } \\
\text { entidades sociales,...). }\end{array}$ \\
\hline $\begin{array}{l}\text { Resolución de } \\
\text { problemas }\end{array}$ & $\begin{array}{l}\text { Identifica las dificultades (tanto externas como de la propia organización) } \\
\text { clave de una situación compleja. Recaba y contrasta información. Analiza y } \\
\text { pondera las diversas alternativas. Elabora y propone estrategias de actuación } \\
\text { oportunas en el tiempo. No se siente vulnerable cuando le toca afrontar } \\
\text { situaciones difíciles. }\end{array}$ \\
\hline $\begin{array}{l}\text { Trabajo en } \\
\text { equipo }\end{array}$ & $\begin{array}{l}\text { Fomenta la comunicación, la colaboración y la confianza mutua entre los } \\
\text { miembros del equipo directivo y del equipo docente. Crea ambiente de } \\
\text { trabajo amistoso. Plantea el trabajo individual en función de su contribución } \\
\text { al logro de un objetivo común. Resuelve los conflictos que se crean dentro } \\
\text { del equipo. Comparte los resultados con los demás. Fortalece el espíritu y } \\
\text { genera adhesión al equipo. }\end{array}$ \\
\hline
\end{tabular}




\section{Anexo 2: Cuestionario directores}

\section{Introducción:}

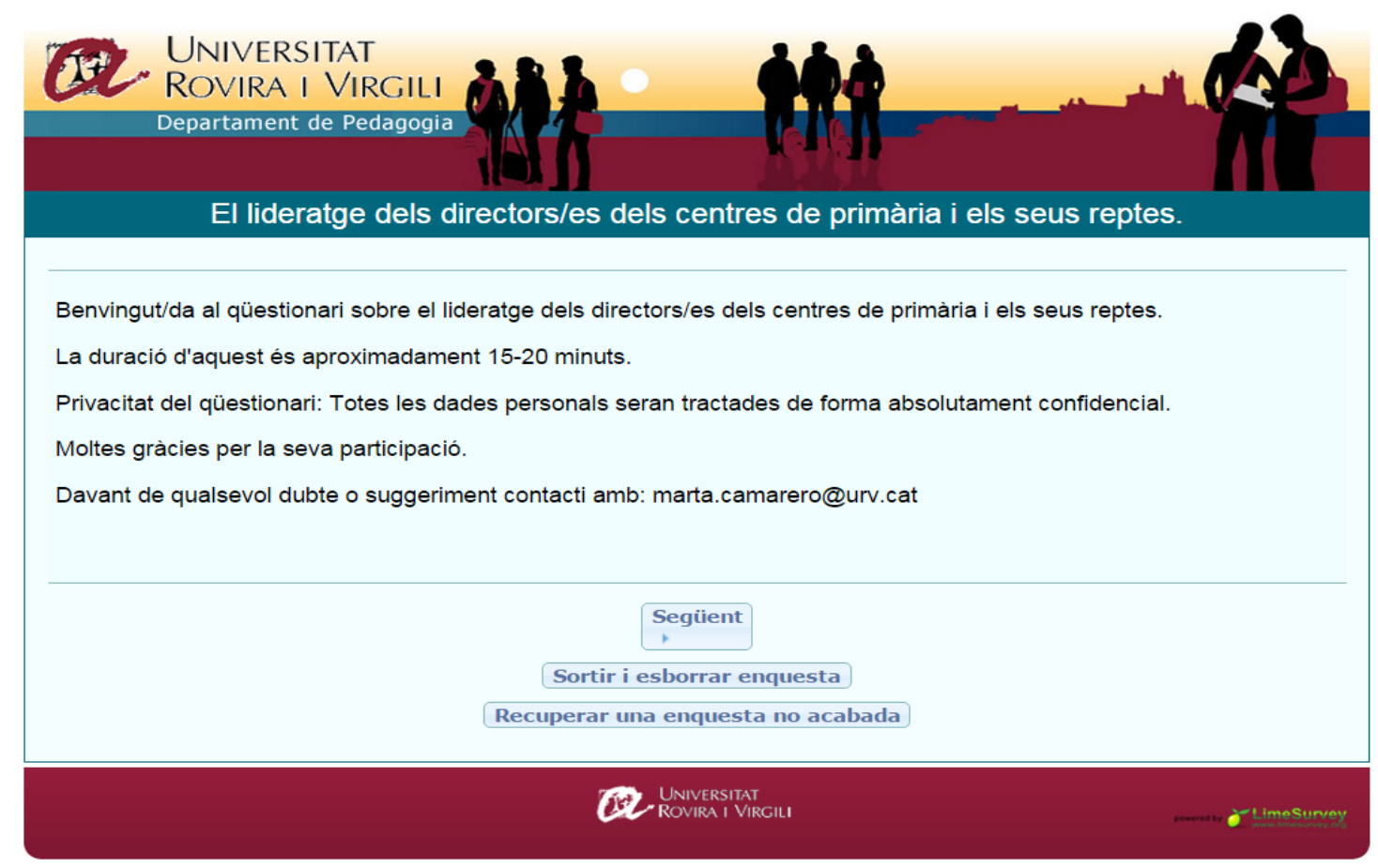

Datos del centro:

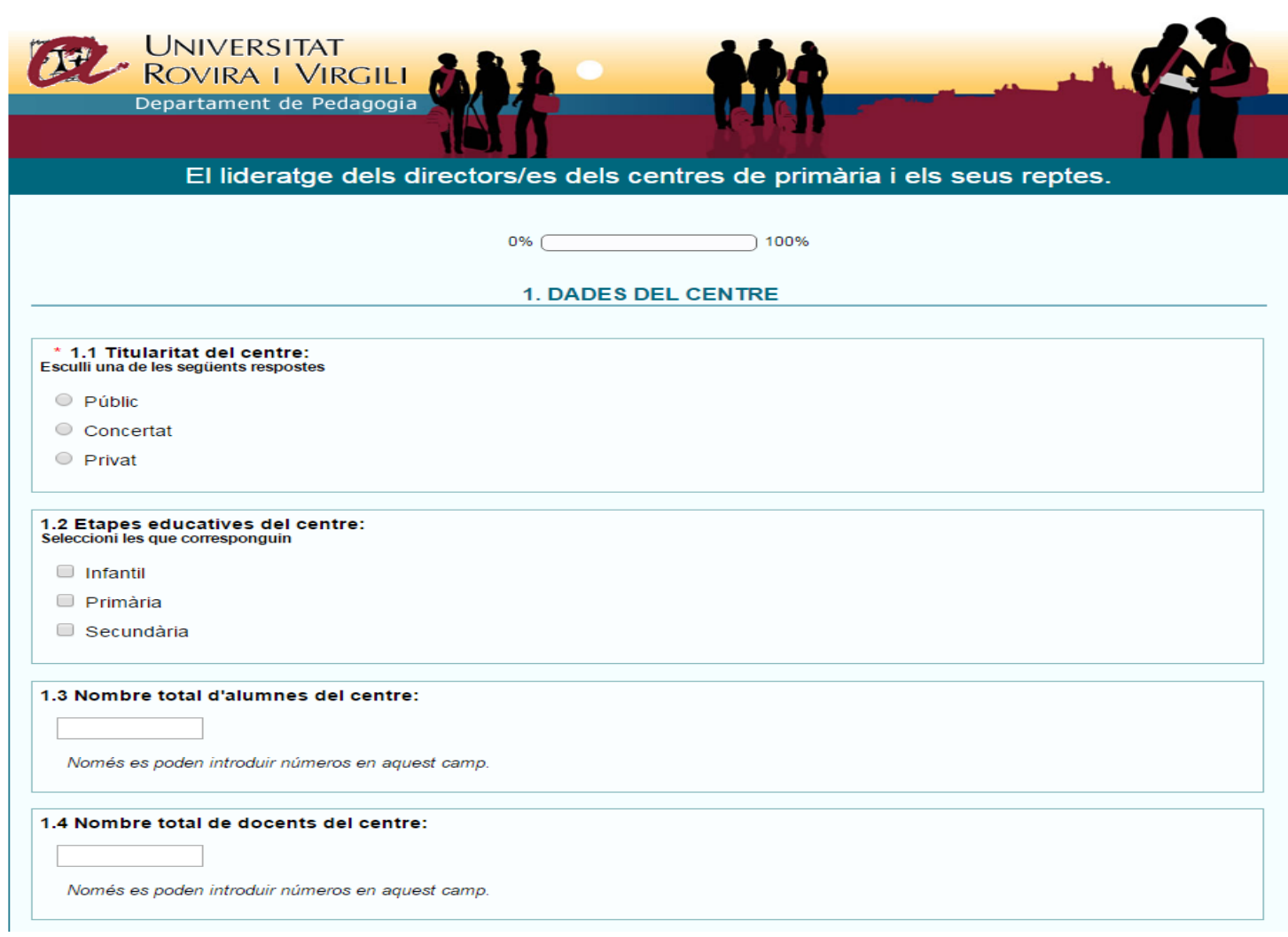




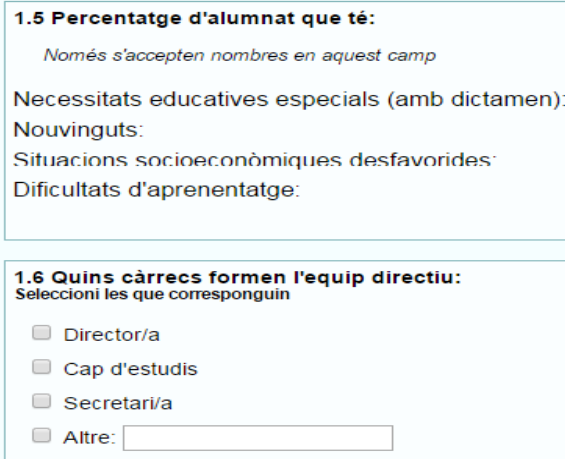

Necessitats educatives especials (amb dictamen)

Nouvinguts:

Situacions sociner.onòmiques desfavorides

Dificultats d'aprenentatge:

$\square$ Director/a

$\square$ Cap d'estudis

$\square$ Secretari/a

$\square$ Altre:

1.7 En funció al curs anterior, quins són els resultats globals per cicle:

Cicle inicial

Cicle mitjà

Cicle superior

Promociona i supera adequadament $(\%)$

No promociona (\%)

Promociona tot i que no supera $(\%)$

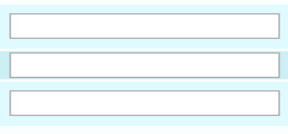

\section{Anterior} Següent

Sortir i esborrar enquesta

Continuar més tard

Datos directores:

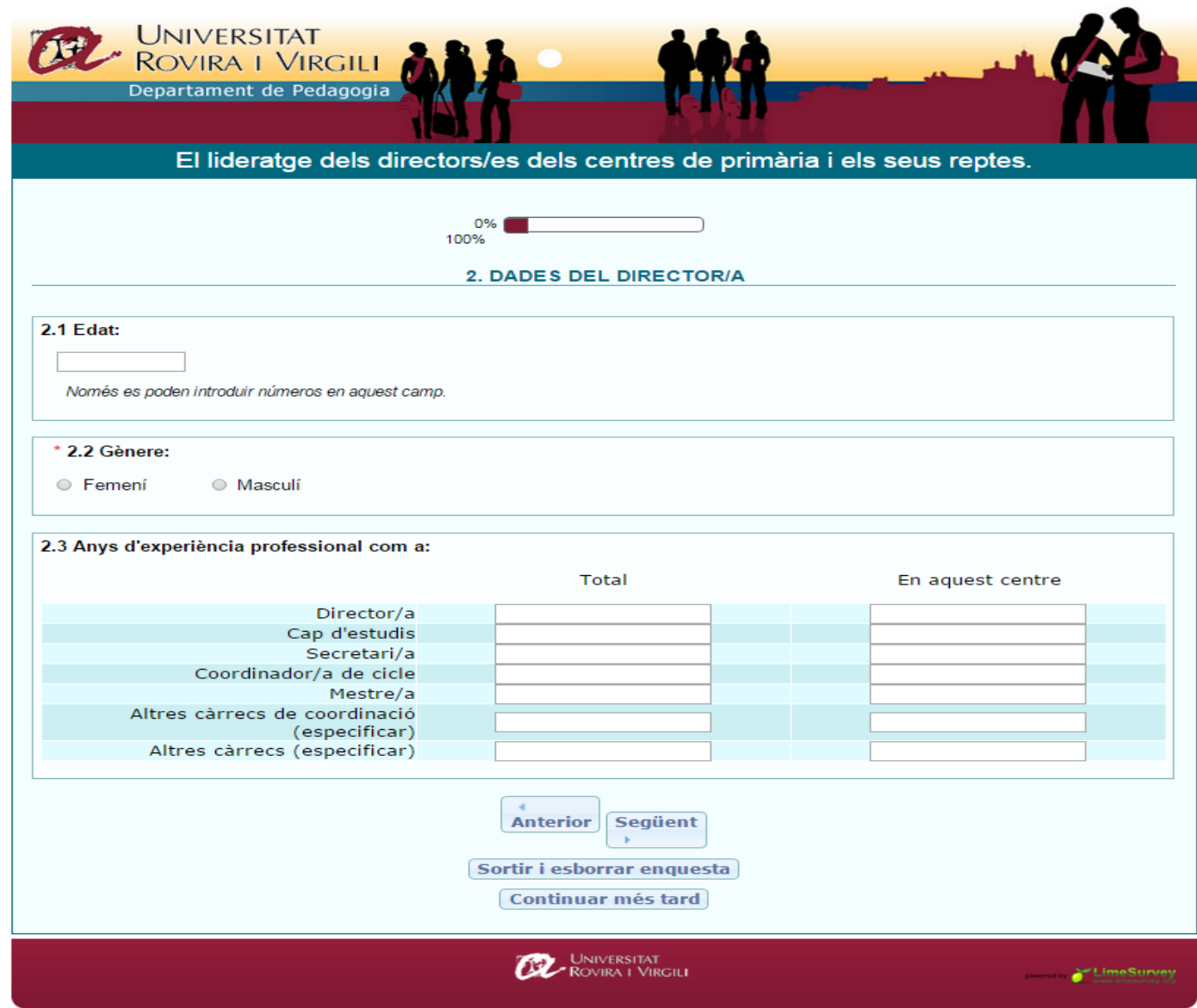


Acceso al cargo:

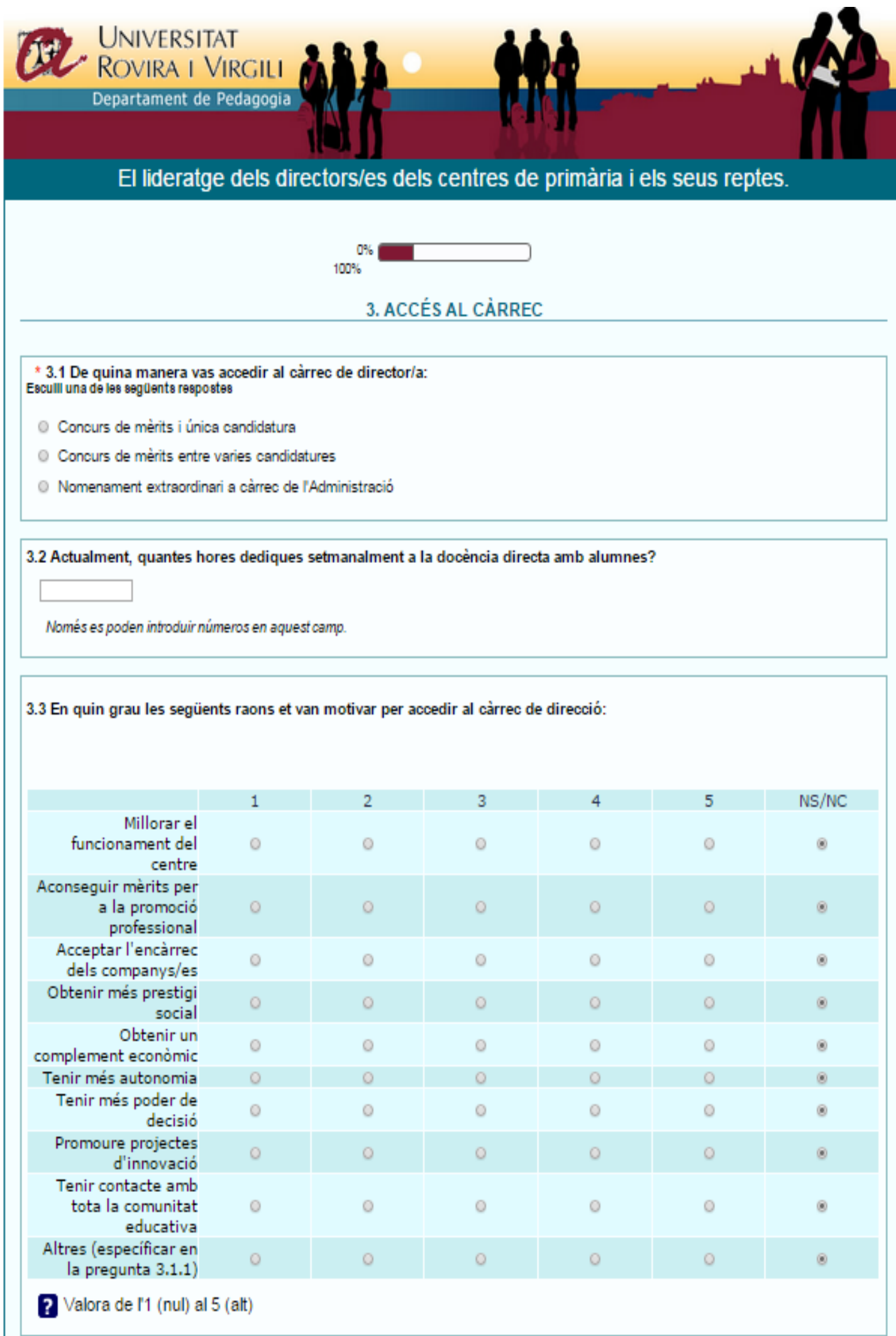

3.3.1 Si s'escau, altres raons que et van motivar per accedir al càrrec de direcció: 
Formación directiva:

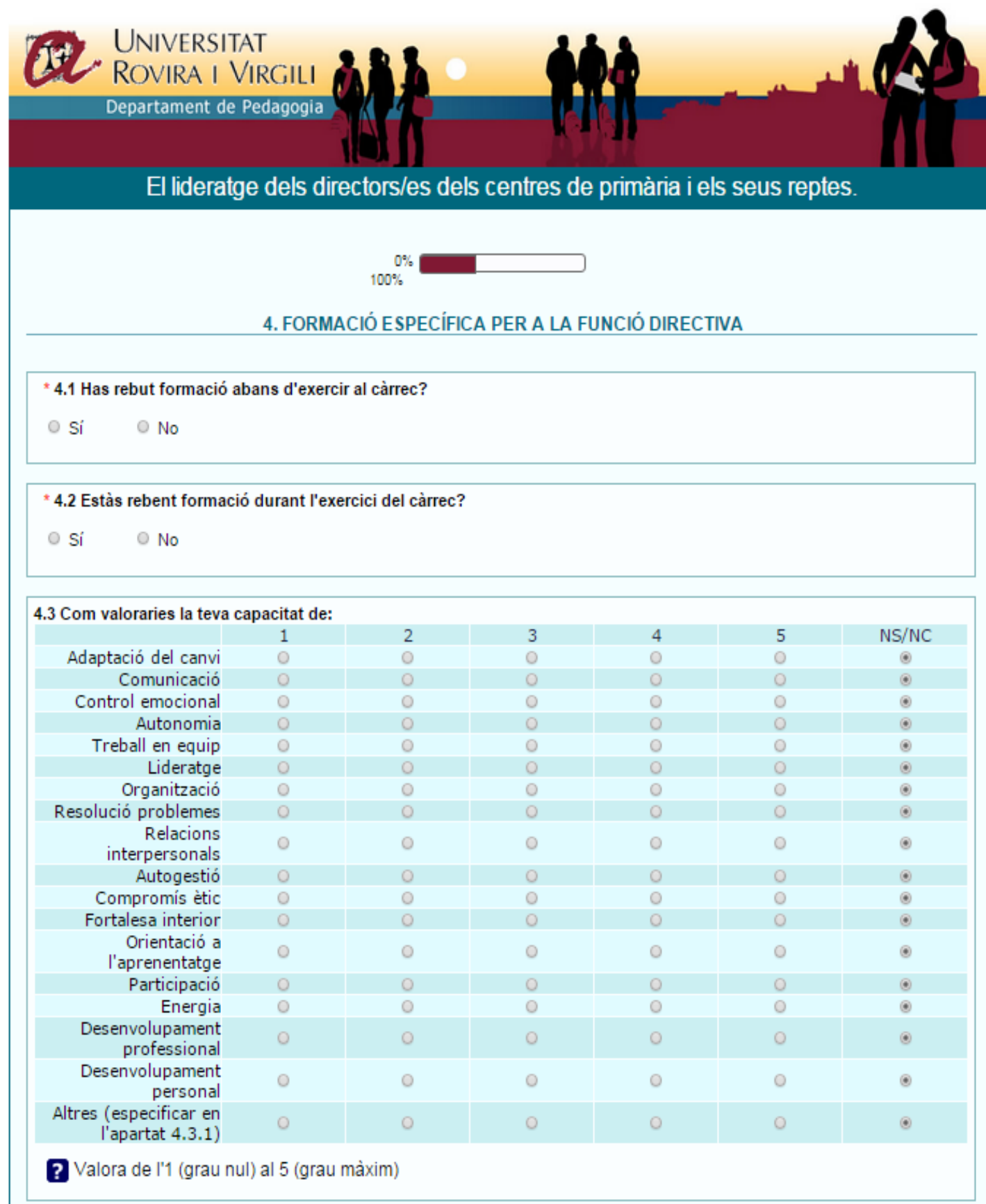

4.3.1 Si s'escau, altres capacitats:

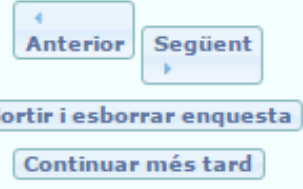




\section{Ejercicio del cargo:}

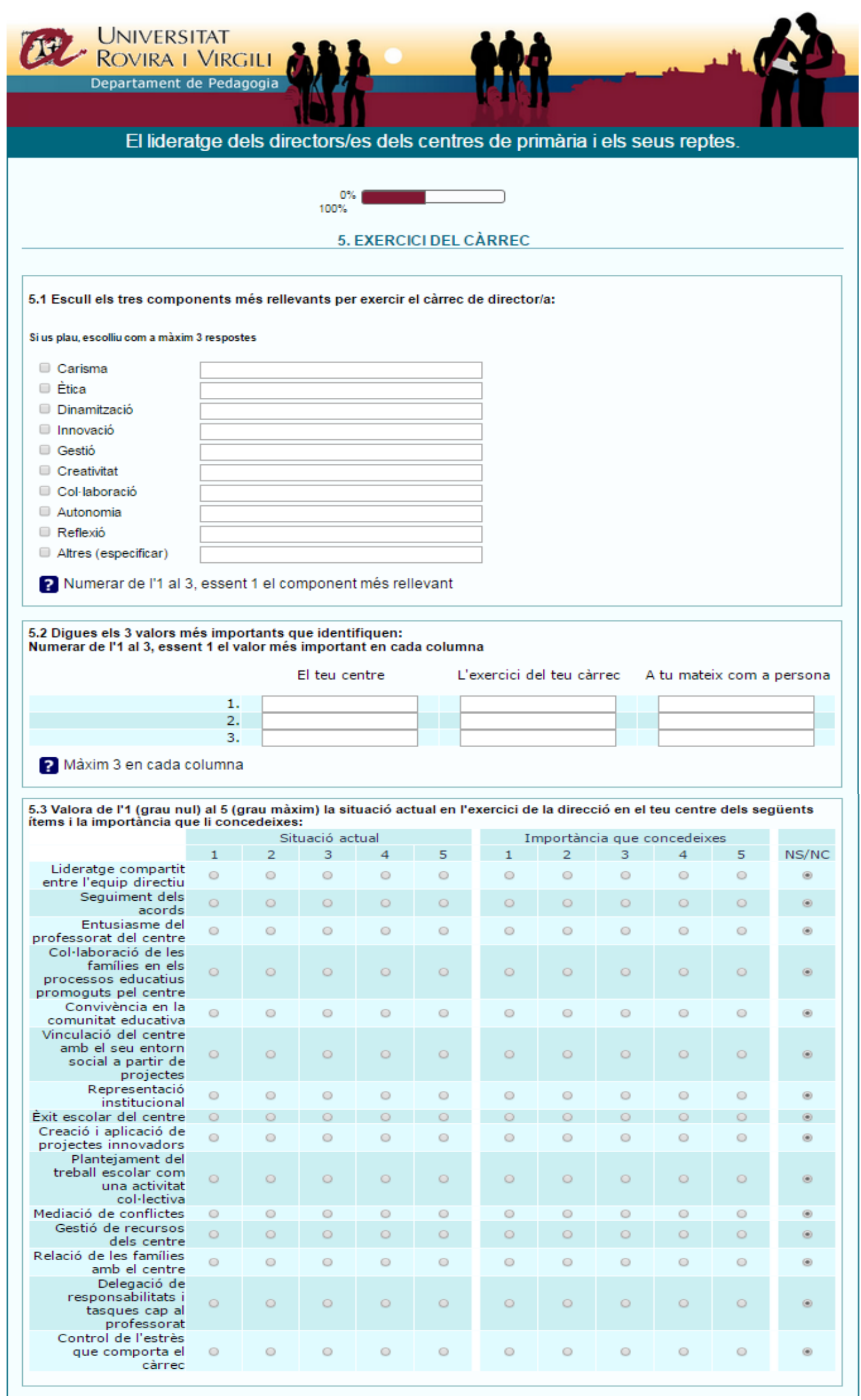




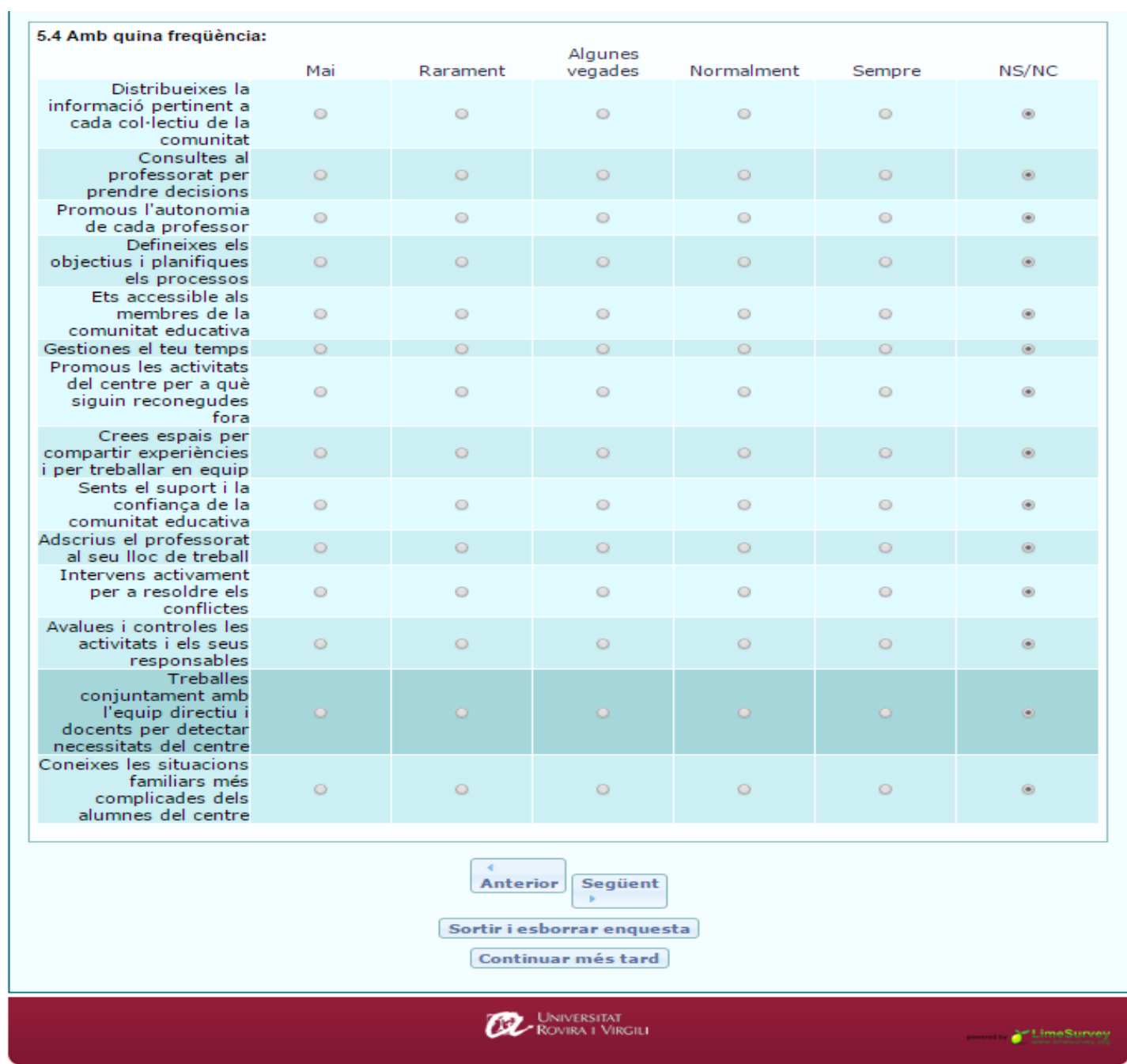

Modelo de dirección:

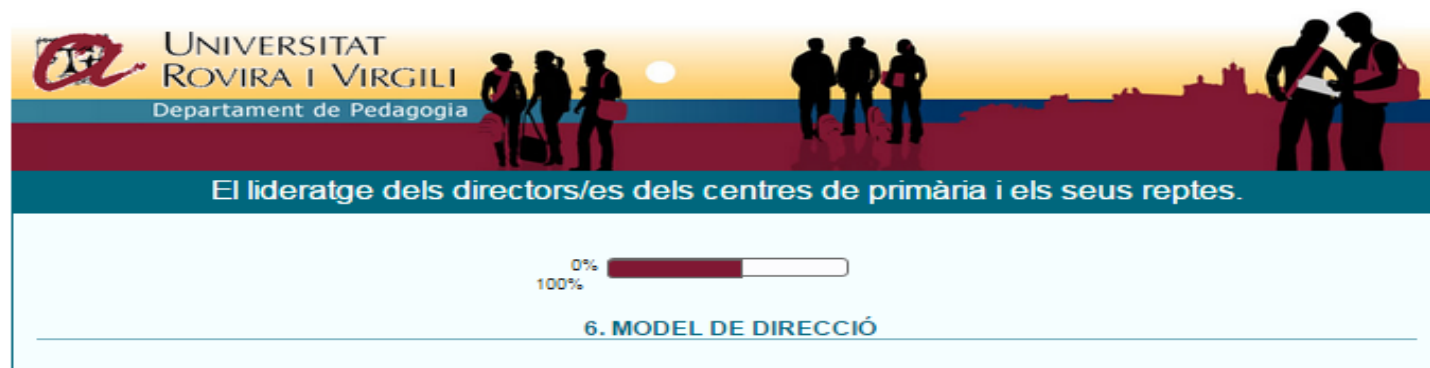

6.1 En quin grau consideres que fas les següents funcions i quina és la seva dificultat:

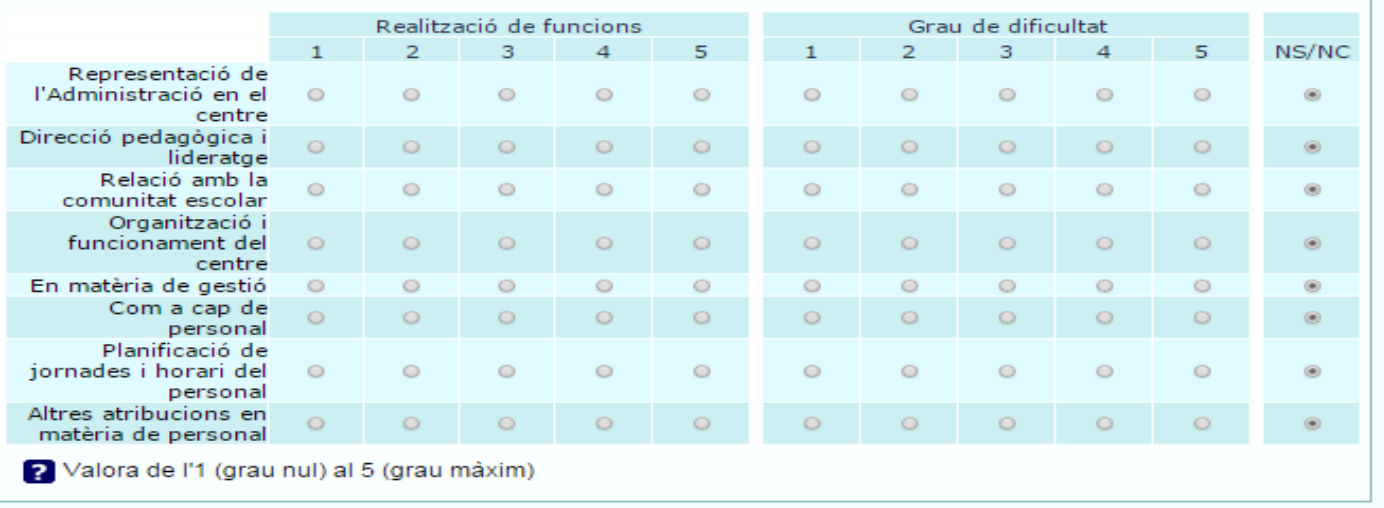




\begin{tabular}{|c|c|c|c|c|c|c|}
\hline 6.2 En quina freqüència c & deres & $\begin{array}{l}\text { litzes les seg } \\
\text { Rarament }\end{array}$ & $\begin{array}{l}\text { ts actuacion } \\
\text { Algunes } \\
\text { vegades }\end{array}$ & Normalment & Sempre & $\mathrm{NS} / \mathrm{NC}$ \\
\hline $\begin{array}{l}\text { Mantens una xarxa de } \\
\text { relacions, tant en el } \\
\text { centre com en l'entorn }\end{array}$ & 0 & $\circ$ & $\circ$ & $\circ$ & $\circ$ & • \\
\hline $\begin{array}{l}\text { Presideixes el consell } \\
\text { escolar, el claustre de } \\
\text { professorat i els actes } \\
\text { acadèmics del centre }\end{array}$ & 0 & $\circ$ & $\circ$ & 0 & $\circ$ & c \\
\hline $\begin{array}{r}\text { Orientes, dirigeixes i } \\
\text { supervises les } \\
\text { activitats del centre }\end{array}$ & $\circ$ & $\circ$ & $\circ$ & 0 & $\circ$ & • \\
\hline $\begin{array}{r}\text { Impulses la } \\
\text { coordinació del } \\
\text { projecte educatiu del } \\
\text { centre amb els altres } \\
\text { centres }\end{array}$ & $\circ$ & $\circ$ & $\circ$ & 0 & $\circ$ & • \\
\hline $\begin{array}{r}\text { Garanteixes els drets i } \\
\text { deures de tots els } \\
\text { membres de la } \\
\text { comunitat escolar }\end{array}$ & $\circ$ & $\circ$ & $\circ$ & $\circ$ & $\circ$ & - \\
\hline $\begin{array}{r}\text { Estableixes canals de } \\
\text { relació amb les } \\
\text { associacions de mares } \\
\text { i pares d'alumnes }\end{array}$ & $\circ$ & $\circ$ & 0 & 0 & 0 & c \\
\hline $\begin{array}{r}\text { Impulses l'establiment } \\
\text { de normes } \\
\text { d'organització i } \\
\text { funcionament del } \\
\text { centre }\end{array}$ & 0 & $\circ$ & $\circ$ & $\circ$ & $\circ$ & - \\
\hline $\begin{array}{r}\text { Proposes la } \\
\text { programació general } \\
\text { anual del centre }\end{array}$ & $\circ$ & $\circ$ & 0 & 0 & $\circ$ & c \\
\hline $\begin{array}{r}\text { Gestiones les despeses } \\
i \text { els pagaments } \\
\text { d'acord amb el } \\
\text { pressupost aprovat }\end{array}$ & $\circ$ & $\circ$ & $\circ$ & $\circ$ & $\circ$ & • \\
\hline $\begin{array}{r}\text { Lideres el personal del } \\
\text { centre per garantir que } \\
\text { compleixen llurs } \\
\text { funcions }\end{array}$ & 0 & $\circ$ & $\circ$ & 0 & $\circ$ & $\bullet$ \\
\hline $\begin{array}{r}\text { Assignes al professorat } \\
\text { del centre altres } \\
\text { responsabilitats de } \\
\text { gestió i coordinació } \\
\text { docent }\end{array}$ & $\circ$ & $\circ$ & $\circ$ & 0 & $\circ$ & • \\
\hline $\begin{array}{r}\text { Fomentes la } \\
\text { participació del } \\
\text { professorat en } \\
\text { activitats de formació } \\
\text { permanent }\end{array}$ & 0 & $\circ$ & $\circ$ & 0 & 0 & $\bullet$ \\
\hline $\begin{array}{r}\text { Resols les faltes } \\
\text { d'assistencia i de } \\
\text { puntualitat no } \\
\text { justificades de tot el } \\
\text { personal del centre }\end{array}$ & $\circ$ & $\circ$ & $\circ$ & $\circ$ & $\circ$ & c \\
\hline $\begin{array}{r}\text { Comuniques les } \\
\text { jornades no } \\
\text { treballades quan el } \\
\text { personal del centre } \\
\text { exerceix dret de vaga }\end{array}$ & $\circ$ & $\circ$ & 0 & 0 & 0 & c \\
\hline $\begin{array}{r}\text { Sanciones les faltes } \\
\text { d'acord amb la } \\
\text { normativa disciplinària } \\
\text { vigent }\end{array}$ & $\circ$ & $\circ$ & $\circ$ & $\circ$ & $\circ$ & • \\
\hline $\begin{array}{r}\text { Formules la proposta } \\
\text { d'incoació d'expedient } \\
\text { disciplinari per faltes } \\
\text { greus del personal }\end{array}$ & 0 & $\circ$ & 0 & $\circ$ & $\circ$ & • \\
\hline
\end{tabular}




\begin{tabular}{|c|c|c|c|c|c|c|}
\hline \multicolumn{7}{|c|}{ 6.3 Valora de l'1 (molt baix) al 5 (molt alt) com consideres que és el grau de compromís de: } \\
\hline & 1 & 2 & 3 & 4 & 5 & $\mathrm{NS} / \mathrm{NC}$ \\
\hline $\begin{array}{r}\text { Del teu càrrec amb el } \\
\text { funcionament del } \\
\text { centre }\end{array}$ & 0 & 0 & $\circ$ & 0 & $\circ$ & • \\
\hline $\begin{array}{l}\text { Del teu càrrec amb la } \\
\text { comunitat educativa }\end{array}$ & 0 & 0 & 0 & 0 & 0 & $\bullet$ \\
\hline $\begin{array}{r}\text { Del professorat amb } \\
\text { l'èxit escolar }\end{array}$ & 0 & $\circ$ & 0 & $\circ$ & 0 & - \\
\hline $\begin{array}{r}\text { Del professorat amb } \\
\text { els projectes del } \\
\text { centre i comunitat }\end{array}$ & 0 & $\circ$ & 0 & $\circ$ & 0 & • \\
\hline $\begin{array}{r}\text { Del professorat amb la } \\
\text { família }\end{array}$ & 0 & 0 & $\circ$ & 0 & $\circ$ & • \\
\hline $\begin{array}{r}\text { De les famílies amb els } \\
\text { projectes del centre i } \\
\text { comunitat }\end{array}$ & 0 & 0 & 0 & 0 & 0 & $\bullet$ \\
\hline $\begin{array}{r}\text { De les families amb els } \\
\text { resultats dels seus } \\
\text { fills/es }\end{array}$ & 0 & ० & 0 & 0 & 0 & $\bullet$ \\
\hline $\begin{array}{r}\text { De l'alumnat amb els } \\
\text { seus resultats }\end{array}$ & 0 & 0 & 0 & 0 & 0 & $\bullet$ \\
\hline $\begin{array}{r}\text { De l'alumnat amb els } \\
\text { projectes del centre i } \\
\text { comunitat }\end{array}$ & 0 & 0 & 0 & 0 & 0 & $\bullet$ \\
\hline
\end{tabular}

6.4 En els casos anteriors en què hagis puntuat de l'1 al 2: Quines accions potenciaries per millorar-ho?

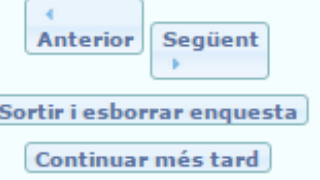


Satisfacción del cargo:

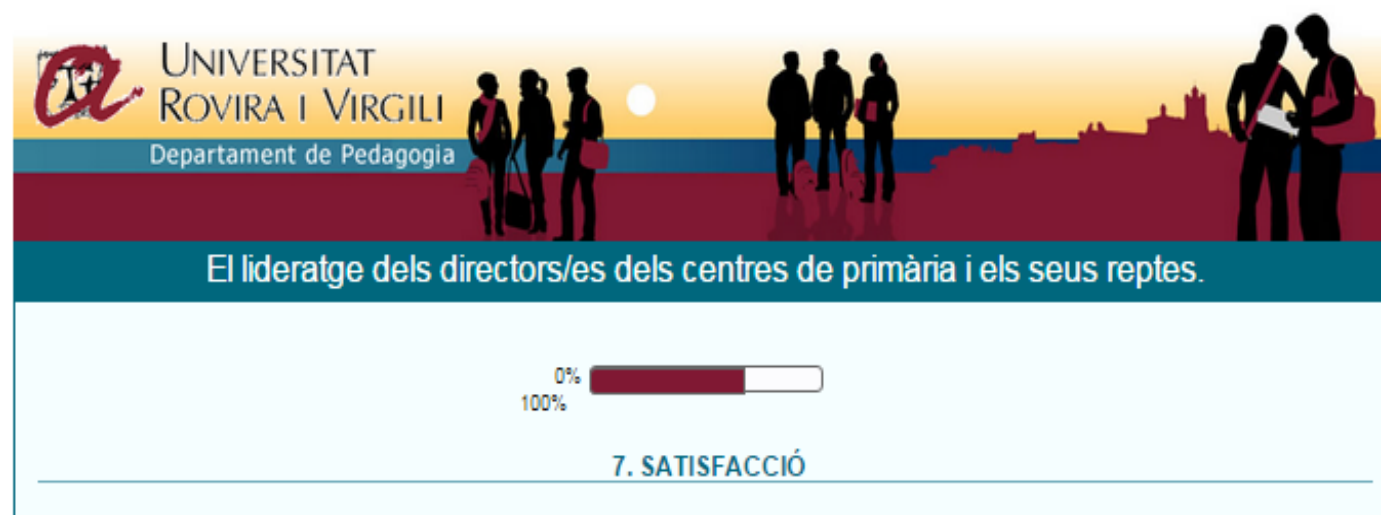

7.1 Valora el grau de satisfacció que et proporcionen els següents aspectes:

\begin{tabular}{|c|c|c|c|c|c|c|}
\hline & 1 & 2 & 3 & 4 & 5 & NS/NC \\
\hline $\begin{array}{r}\text { La implicació de l'equip } \\
\text { docent en el } \\
\text { funcionament del } \\
\text { centre }\end{array}$ & 0 & 0 & 0 & 0 & 0 & • \\
\hline $\begin{array}{l}\text { Les tasques realitzades } \\
\text { per l'equip directiu }\end{array}$ & 0 & 0 & 0 & 0 & 0 & • \\
\hline $\begin{array}{l}\text { La utilitat del projecte } \\
\text { educatiu per definir els } \\
\text { valors del centre }\end{array}$ & 0 & 0 & 0 & 0 & 0 & • \\
\hline $\begin{array}{r}\text { La participació i } \\
\text { col-laboració dels } \\
\text { alumnes en els } \\
\text { projectes del centre }\end{array}$ & 0 & 0 & 0 & 0 & 0 & • \\
\hline $\begin{array}{r}\text { Les oportunitats per } \\
\text { crear projectes } \\
\text { innovadors i creatius }\end{array}$ & 0 & 0 & 0 & 0 & 0 & $\bullet$ \\
\hline $\begin{array}{r}\text { El reconeixement } \\
\text { social que reps com a } \\
\text { director/a }\end{array}$ & 0 & 0 & 0 & 0 & 0 & $\bullet$ \\
\hline $\begin{array}{r}\text { Les relacions dels } \\
\text { membres del centre } \\
\text { amb els pares/mares } \\
\text { dels alumnes }\end{array}$ & 0 & 0 & 0 & 0 & 0 & • \\
\hline $\begin{array}{l}\text { Els procediments per } \\
\text { gestionar els recursos }\end{array}$ & 0 & 0 & 0 & 0 & 0 & $\bullet$ \\
\hline $\begin{array}{r}\text { La disposició dels } \\
\text { docents per trobar } \\
\text { espais de treball } \\
\text { conjunts }\end{array}$ & 0 & 0 & 0 & 0 & 0 & • \\
\hline $\begin{array}{r}\text { El recolzament de } \\
\text { I'Administració en la } \\
\text { teva tasca de } \\
\text { director/a }\end{array}$ & 0 & 0 & 0 & 0 & 0 & $\bullet$ \\
\hline $\begin{array}{r}\text { La coordinació i } \\
\text { cooperació amb } \\
\text { l'entorn social del } \\
\text { centre (associacions, } \\
\text { escoles..) }\end{array}$ & 0 & 0 & 0 & 0 & 0 & • \\
\hline $\begin{array}{l}\text { La relació dels docents } \\
\text { amb l'equip directiu }\end{array}$ & 0 & 0 & 0 & 0 & 0 & $\bullet$ \\
\hline $\begin{array}{r}\text { El grau de compliment } \\
\text { dels acords }\end{array}$ & 0 & 0 & 0 & 0 & 0 & • \\
\hline $\begin{array}{l}\text { La competència docent } \\
\text { del professorat }\end{array}$ & 0 & 0 & 0 & 0 & 0 & • \\
\hline $\begin{array}{l}\text { La llibertat i autonomia } \\
\text { per prendre decisions }\end{array}$ & 0 & 0 & 0 & 0 & 0 & $\bullet$ \\
\hline
\end{tabular}




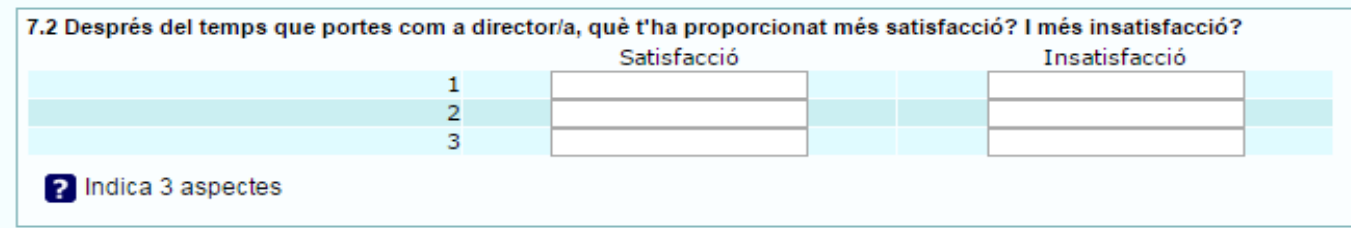

7.3 En quin sentit han canviat les teves motivacions des del començament d'accedir al càrrec fins ara?

$$
\begin{array}{|l}
\text { Anterior Següent } \\
\text { Sortir i esborrar enquesta } \\
\text { Continuar més tard }
\end{array}
$$

Resultados:

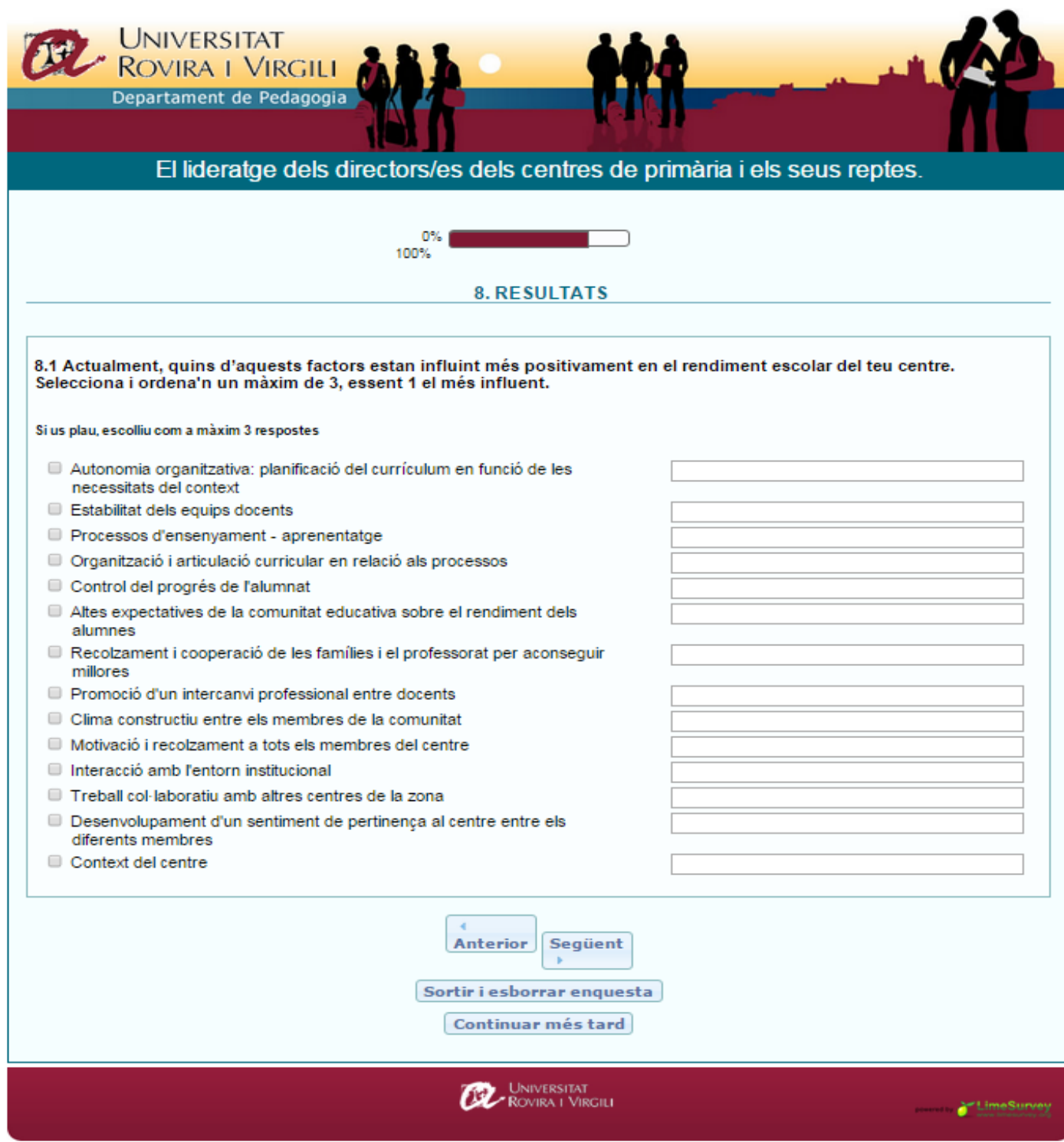


Para finalizar:

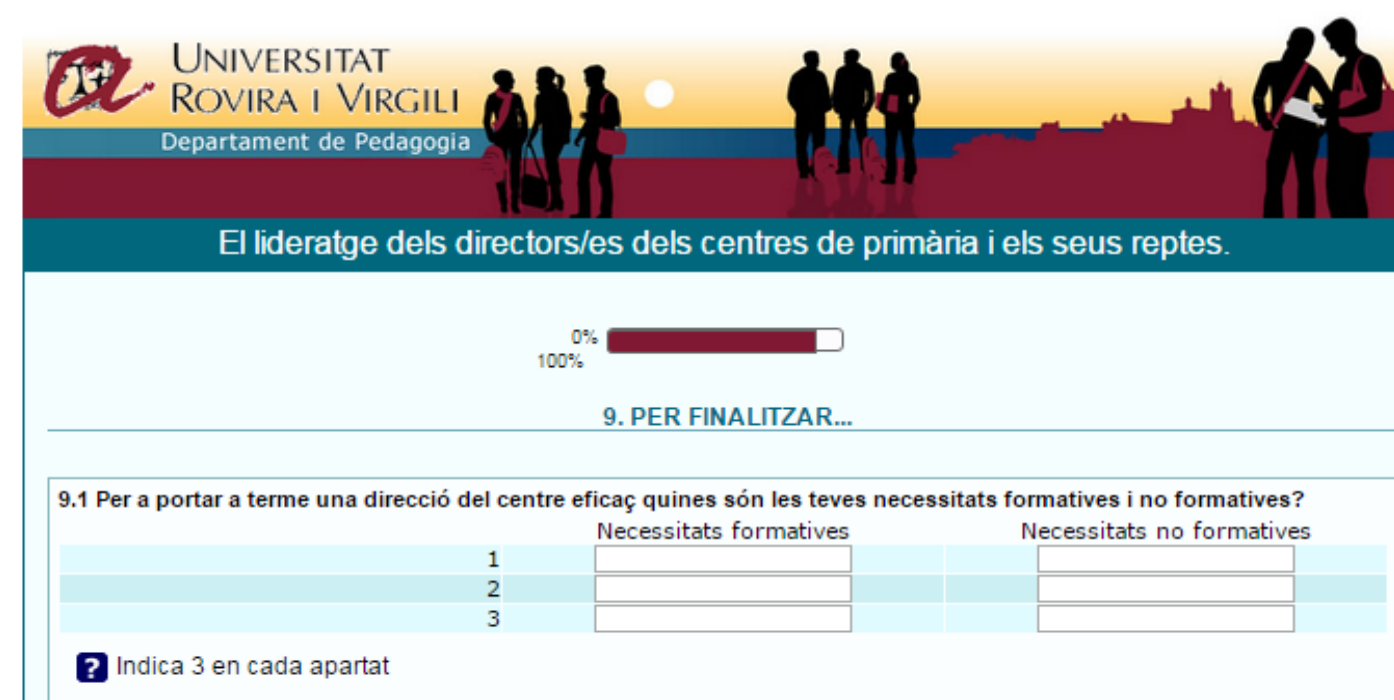

9.2 Assenyala els aspectes facilitadors i obstaculitzadors que han tingut els Decrets d'Autonomia i de Direcció en el teu exercici de director/a:

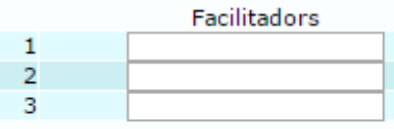

Indica 3 en cada apartat

9.3 Què esperes del nou Decret de Plantilles?

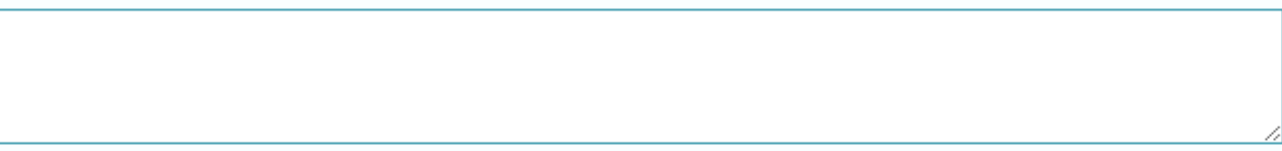

9.4 Quines són les característiques personals més importants pel càrrec de director/a i com les has après?

Esculli una de les següents respostes
Coordines
Manes
Lideres
Gestiones
Altre:

? Marca una única opció

$$
\text { Anterior Enviar }
$$

Sortir i esborrar enquesta

Continuar més tard 